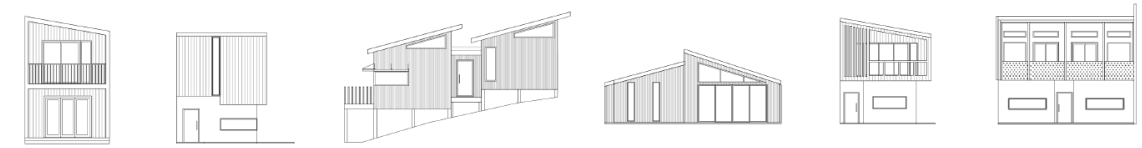

NEXT GENERATION ARCHITECT

Terian Kate Le Compte 


\title{
NEXT GENERATION ARCHITECT
}

\author{
Terian Kate Le Compte
}

A 120 point thesis submitted to the School of Architecture and Design, Victoria University of Wellington, in fulfilment of the requirements for the degree of Master of Architecture Professional.

Victoria University of Wellington 
Acknowledgements

I would like to thank the support of my supervisor Mark Southcombe, for his endless support, motivation and guidance throughout the past year. I am forever grateful for the invaluable knowledge you have shared.

To my friends for your constant encouragement and making the last 5 years in Wellington unforgettable.

And finally, Mum and Dad thank you for your continuous support and encouragement over the last 5 years, none of this would have been possible without you. 


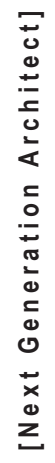


How can architects work with value to optimise design? 


\section{Abstract}

The stereotype of an architect is expensive, with minimal consideration and awareness towards cost and budget. This is damaging the reputation of the profession. This thesis will look at the Next Generation Architect who combines both design and construction to understand the cost implications from the start to the completion of the project. A Next Generation Architect works with an innovative approach that is more affordable to how they currently practice. They design houses that are both economical and retain a strong design quality, through the value of the aesthetics, materials and living conditions. An effective architect should be able to design, mindful of costs, along with the implications involved and actively manage the costs, based on design decisions made.

This research will commence by exploring tactics of affordability, housing economics, and costing and design tactics, to portray exemplars of affordable housing. Elements will be costed with data from QV costbuilder implemented through the use of Building information modeling (BIM) through Revit. The architectural value will explore the use of materials, living conditions, economics, and lifecycle to optimise the design. A series of precedents will be analysed to gain an understanding of the techniques of affordable methods used within New Zealand's construction industry.

This thesis aims to provide architecturally designed and preliminarily costed affordable architectural products. Through a series of architecturally designed standalone houses that explore affordability, and tested through the use of architecture as a product across four sites, displaying different site conditions of the Wellington region.

This thesis will portray efficient, economic building and design techniques and cost monitoring while retaining a strong architectural quality.

The aim is to convey the contemporary role of a Next Generation Architect who works accurately with value. Who is mindful of costs and designs economically, without compromising the quality of an architecturally designed product. 
Growing up around the construction industry, it has exposed me to several builders and their negative perspectives towards architects, and their ability to work towards a budget. In several conversations, I have heard tradespeople say architects can not design affordably. Their focus is predominantly on the bespoke quality rather than cost. This made me wonder how architecture could be practiced differently, giving architects the potential to achieve a more affordable design.

New Zealand's housing market is becoming increasingly more unaffordable, especially for those aspiring to be first-time homeowners. Land prices are a contributor to this strain. As standalone housing is the preferred type of housing for New Zealanders, it needs to be affordable. This can be achieved by monitoring design decisions made by an architect.

Scope

This research is limited to four sites within the Wellington region. Typical materials and construction methods investigated consist of standard timber framing, concrete and a hybrid combination. The value of affordability is calculated through an in-depth first cost estimate, considering the build-up of individual dwellings core elements, using relevant cost data for the Wellington region. Affordability will be further explored through basic lifecycle costing reviewing maintenance requirements and the lifespan of selected materials. 


\section{Contents}

ACKNOWLEDGEMENTS i

ABSTRACT IV

MOTIVATION \& SCOPE V V

CONTENTS Vi

01 INTRODUCTION

$\begin{array}{ll}\text { Methodology } & 04\end{array}$

02 ARCHITECTURE PROFESSION 07

Costing and Architecture Diagrams 12

03 INITIAL DESIGN 14

$\begin{array}{lr}\text { Case studies, Tactics of Affordability } & 16\end{array}$

$\begin{array}{ll}\text { Site } & 20\end{array}$

Initial Design 28

Sketch Design Cost Estimate $\quad 30$

$\begin{array}{ll}\text { Reflection } & 35\end{array}$

04 EXPLORING AFFORDABILITY 36

Design \& Build Packages, New Zealand 38

Case studies, Tactics of Affordability $\quad 44$

Site Arrangement- Wellington City Council BRP 47

Form Development $\quad 52$

Sun Shading $\quad 54$

Design Development $\quad 55$

$\begin{array}{ll}\text { Testing Affordability } & 61\end{array}$

$\begin{array}{ll}\text { First Cost Estimates } & 67\end{array}$

Findings and Reflection $\quad 72$ 
The History of the Pattern Book 76

$\begin{array}{ll}\text { Architecture as Product Case Studies } & 77\end{array}$

A Series of House Designs 90

Design Development 102

$\begin{array}{ll}\text { The Pattern Book } & 104\end{array}$

First Cost Estimates + BIM 130

Findings and Reflection 136

06 NEXT GENERATION ARCHITECT 139

New Zealand Architectural Homes 141

Economic Exemplars 143

$\begin{array}{ll}\text { Standard Detailing } & 147\end{array}$

Lifecycle and Economic Material Studies 150

The Dwellings 162

First Cost and Lifecycle Estimates 188

Findings and Reflection 196

$\begin{array}{ll} & 198\end{array}$

Next Generation Architect 203

\begin{tabular}{ll}
\hline BIBLIOGRAPHY & 204
\end{tabular}

$\begin{array}{ll}\text { LIST OF FIGURES } & 208\end{array}$

APPENDIX 1: Library of Costs 211

APPENDIX 2: Design Phase 3 Costing Breakdown 219

APPENDIX 3: Design Phase 4 Costing Breakdown 230 
$\bar{J}$
0
0
0
0
0
0
0
0
0
0
0
0
0
0
0
$x$
0
0
$z$ 
\begin{tabular}{l}
$z$ \\
$z$ \\
$x$ \\
$x$ \\
0 \\
0 \\
0 \\
0 \\
0 \\
0 \\
0 \\
0 \\
0 \\
$D$ \\
$D$ \\
0 \\
0 \\
\hline 0 \\
0 \\
0 \\
$\Xi$
\end{tabular}

$\frac{01}{\text { Introduction }}$ 
"Affordable housing of the 1940s and 1950s - the single detached dwelling funded by the state for rent or purchase has become an iconic part of New Zealand's heritage."

Bierre, Howden-Chapman \& Early,2013,p.7

"Just because it's small in floor area doesn't mean it should be lacking in beauty, design, rigour or comfort.... Whether it's material wastage, human error or altered timelines, everything has a cumulative cost implication."

Foster, 2015 p.29 
New Zealand's housing market is currently facing problems considered similar to those of the past, although these problems are faced with additional challenges. These include; widening income inequalities. An increasing number of people both live and work in urban areas, where there is a short supply of quality affordable houses to rent and buy in (Bierre, Howden-Chapman \& Early, 2013). The average New Zealand house costs approximately 8.8 times the annual wage which has dropped slightly from the previous 9.2. This figure sat at 3.0 during the early 1990's (Chatson, 2019).

The contributing factors to the strain on affordable housing in New Zealand are land prices in conjunction with council fees, consents, infrastructure and preparation (Beveridge, 2016). Due to these constraints, home ownership rates have declined from 78\% in 1986 to 63.2\% in March 2019 (Church, 2019).

Historically New Zealand's existing housing stock was made up primarily of threebedroom standalone houses on large properties, typically referred to as the "quarter acre lot". The traditional characteristics of standalone housing is a timber framed weatherboard home, derived from the 1930's which is seen as cost effective in terms of construction and maintenance costs (Bierre et al., 2013). New Zealanders enjoy standalone housing, as it is part of the suburban lifestyle, with there being little incentive for the detached housing market changing to medium density. (Beveridge, 2016)

Many New Zealanders dream of home ownership, as it symbolises success within our New Zealand culture. Eaqub and Eaqub (2015) state: “Owning one's own home has been a rite of passage for generations of New Zealanders. Home ownership has long offered financial security and played a central role in our national identity" (p.7). As New Zealanders we should have access to high quality affordable housing. This is needed to cater for aspiring homeowners, at a cost that doesn't involve sacrificing increasingly large amounts of their incomes to do so. Quality housing shouldn't be compromised by short term cost considerations of a cheaper build. Choosing a sustainable build that has a larger upfront cost, reduces the consequences related to health, schooling, productivity and over all wellbeing (Bierre et al., 2013).

Stereotypically architects are known as being expensive with minimal consideration and awareness towards cost and budget. Effective architects should be able to design mindful of costs. Understanding what is feasible within a project from the beginning, and directing clients into correct decisions. Architectural services do come at a price, however, what people forget is that this fee is only a small proportion of the construction cost, with the cost of an architect outweighing the added value of a project. The NZIA (2017) states, "You engage an architect to maximise the possibilities of your brief and make the most of your budget." (p.7). But how come so many projects do come in over budget? Too often compromises have to be made for cost cutbacks. Which creates reworks for the architect, and additional time to a project. This is damaging the reputation of an architect.

This research is framed by the question:

How can architects work with value to optimise design? 


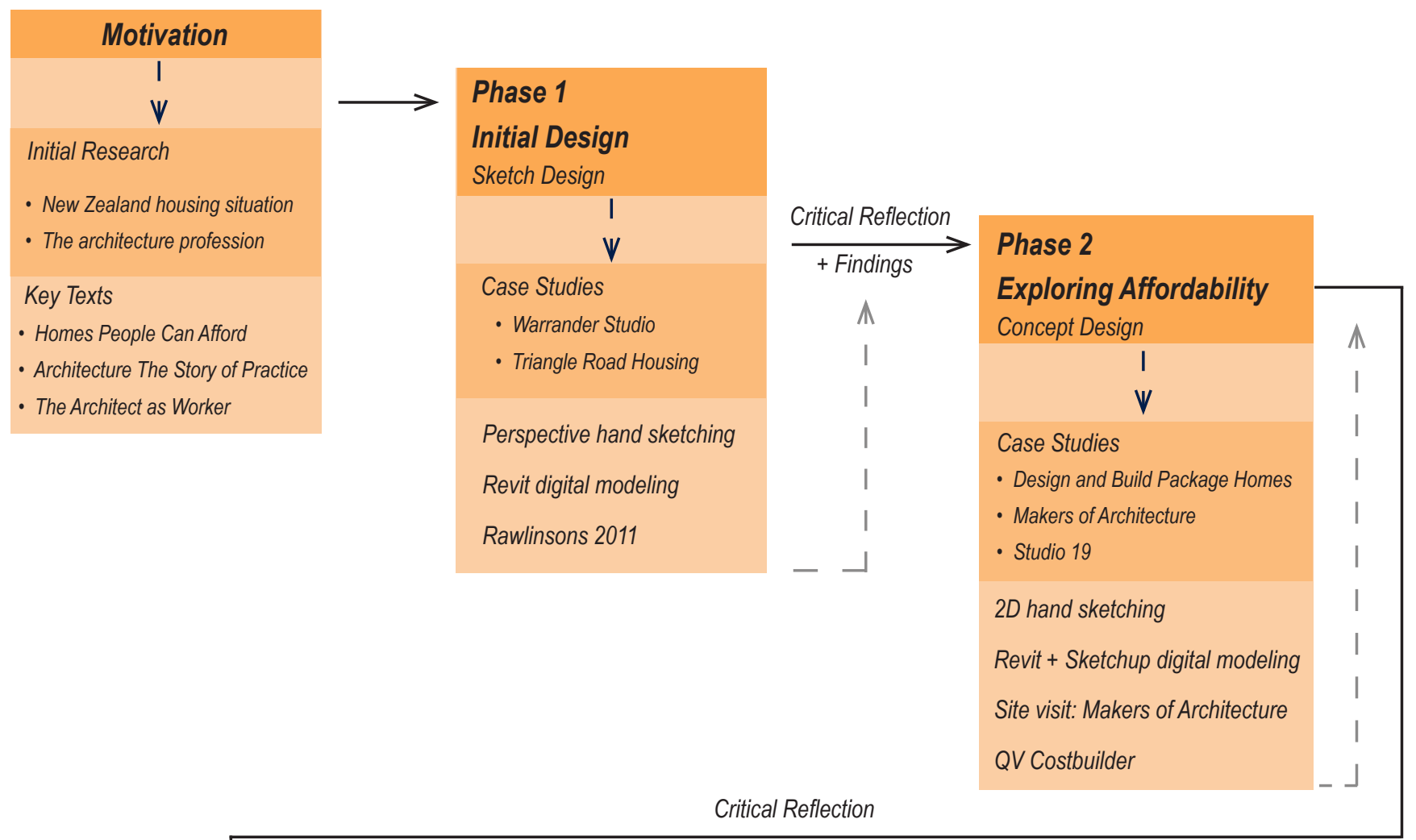

+ Findings

Phase 3
Architecture as Product
Developed Design
Case Studies
- Snug Homes
- iPad
- Australian Project Housing
Perspective hand sketching
Physical Modeling
Revit Digital Modeling
BIM + Revit
QV Costbuilder
The pattern book
Key Texts
- Designer Suburbs: Architects and
Affordable Homes in Australia
- Max Rosenfeld: Identity and

Phase 4

Next Generation Architect

Final Design

I
V

Case Studies

- Te Modular

- Madras St Duplex

- The Wedge House

- Eames House

Site visit: Monastra QS Consultants

Lifecycle Analysis

Revit Digital Modeling

$B I M+$ Revit

QV Costbuilder

Key Texts

- BRANZ material lifecycle reports

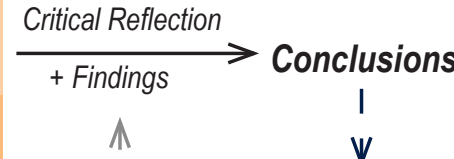

Next Generation Architect 
This research implements the methodology of design-led research. This allows designs to contain both iterative and reflective processes. The methodology of design research is seen through Jane Rendell's approach, used throughout; "instead of posing research questions and then finding answers, in much design research the process operates through generative modes, producing works at the outset that maybe reflected upon later" (Rendell, 2013, p.117).

Questions are raised throughout design process; this is perceived within Perry Kupler's design approach. "When working on a project, I raise specific questions about the sequence of design decisions - some questions matter now, some matter later; perhaps some matter now and later or never. In this constantly shifting terrain, I tailor visualisation techniques and design methods to explore a fit between what is being worked on, when it is being worked on, and how it is being worked on" (Kupler, 2003, p.59).

An investigation into key precedents and literature is introduced at the beginning of each design phase influencing new pathways for design. This provides an understanding into design principles surrounding value within the design, through economics, construction, materials, technology and how this has been successful in the past. The four design phases involve rigorous design tests and iterations to reach a final design. Key tools aiding this process include BIM through the use of Revit, QV costbuilder database and designing both physically and digitally. Designs are tested across four sites within the Wellington region to ensure designs are adaptable to several site conditions; considering orientation and site gradient. A reflective process occurs at the end of each design phase. Reflecting on the strengths and weaknesses of the findings, allowing for a framework to be set surrounding further development in the following design phases. 


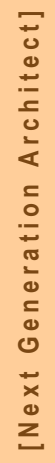


02

Architectural Profession 


\section{The Architecture Profession}

Architects are engaged to maximise their client's brief and budget. However, stereotypes of the profession are breaking the trust between clients surrounding their awareness towards cost. To restore their reputation, architects need to work with an innovative approach, that is more affordable to how they currently practice.

Cost blowouts are a common occurrence within home building in New Zealand, although these cost implications can be minimised. Moller from Grand Designs New Zealand could only cite two projects that have met budget, with the majority of houses coming in over budget. Cost blowouts occur for various reasons, that are not always within the architect's control. These include material cost escalations, changes to local regulations and delays to building due to concerns about the plans. Moller (2019) suggests "building a house is much more complex than most people realise. There can be multiple reasons for cost blowouts" (as cited in Hawkes, 2019). Architects need to ensure clients expectations are realistic for their budget, and exactly what is included within the price and the implications of any remaining costs.

Architects' services alone do not produce the product many other professionals such as engineers, quantity surveyors and trades people intervene with the design and construction of the project. Cuff (1992) an architectural theorist states, "architectural products may become functionally superior to non-architectural ones... a building may be considered valuable to its owners, to its inhabitants, to real estate speculators, or to its locale, but it is specific to its site and programme." (P.32). Architectural design holds value unlike houses by developers do,. Bespoke and site-specific design clearly distinguishes architects from developer's cookie cutter projects, however can be seen as a target for wealthy clients and not the average person.

Architecture is a changing profession that has moved from hand drafting into the digital age and is moving into advanced technology such as BIM, virtual reality and digital fabrication. Deamer (2015) discusses architecture as a profession, with the tasks and daily lives of an architect in practice. Unlike traditional architecture, today's technology allows architects to be stretched geographically with communication directed through email, video conferencing and BIM. Deamer (2015) states, "Architecture and subcontractors are turning into a network working together, rather than traditionally separate roles in a chain" (p.xxviii). This allows collaboration across disciplines as a whole process. 
"Expensive architects and their expensive schemes"

(London Deputy Mayor, 2013)

"Designers work to the best interest of the design, and not necessarily to the budget"

(Building Performance, 2016)

"So often homeowners commence work with an architect with a firm budget... they get it costed by a builder, and it's 1.5 times, or double, or triple their budget."

(Shead, 2015)

"Code of Professional Conduct hearings regularly hear complaints of architects failing to work to budget."

(RIBA, 2018 ) 
In architecture school we are taught to be aspirational designers considering the aesthetics rather than the cost implications involved with design. We gain minimal understanding of the costs of materials, construction techniques, and average floor area costs. This can come as a shock moving into practice.

The NZIA Agreement for Architects Services is a contract between the client and architect, protecting both parties from unforeseen circumstances. This agreement establishes the budget, location, programme and architects fee. Each stage contains inputs, tasks and deliverables that all parties must agree on with tasks appropriately delegated seen in figure 1.02. Costing sections are referred to a quantity surveyor for accurate estimates in the concept design, developed design and detailed design phases (NZIA, 2018). The architect is only in charge of the costing when the budget is established. They rely on a separate consultant to gain cost information, requiring additional fees. This is referred to as the number of consultants and trades people who 'clip the ticket', adding additional costs to the overall project.

Monastra (personal conversation, October 12, 2019) indicated through a personal conversation, a quantity surveyors' perspective of the diverse range of architects and tactic's, surrounding awareness of value within a design project. Every architect displays different strengths. Some are good designers, others good administrators, while some are good at both. Generally, architects that are good administrators tend to be more conscious of cost. Architects must interpret their clients to understand their wants, needs and budget. The architect may have to educate them from the start of the project, if they are being over ambitious, which many clients can be, due to a lack of knowledge. Quantity surveyors typically give houses one cost estimate, unless they are over budget and these estimates become more accurate as a project proceeds such as at the tender documentation stage. 
This image has been removed by the author of this thesis for copyright reasons.

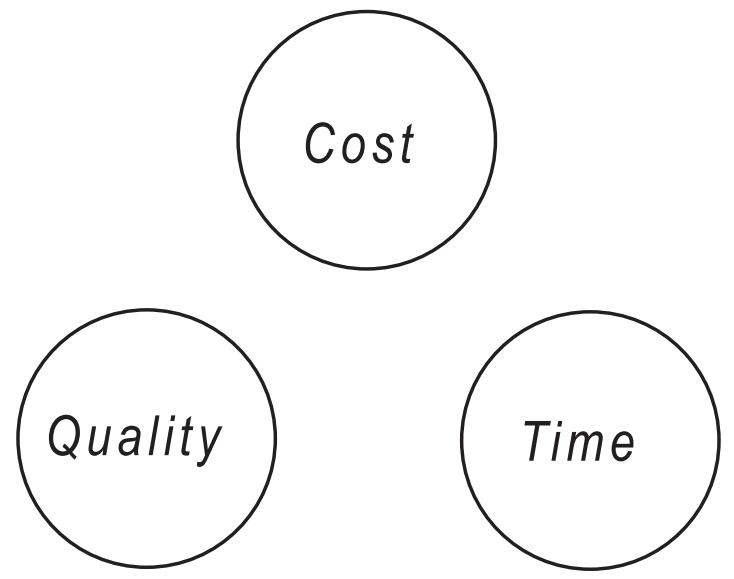

Figure 1.03 Cost, Quality and Time Diagram

Typically two aspects are selected with a compromise in one aspect. Quality is generally prioritised by architects. To ensure at least two of these are met, a project must be carefully planned to stay on track, by minimising significant changes (Hawkes, 2019). 


\section{Typical Architect's Process}

\section{Costing phase diagram}

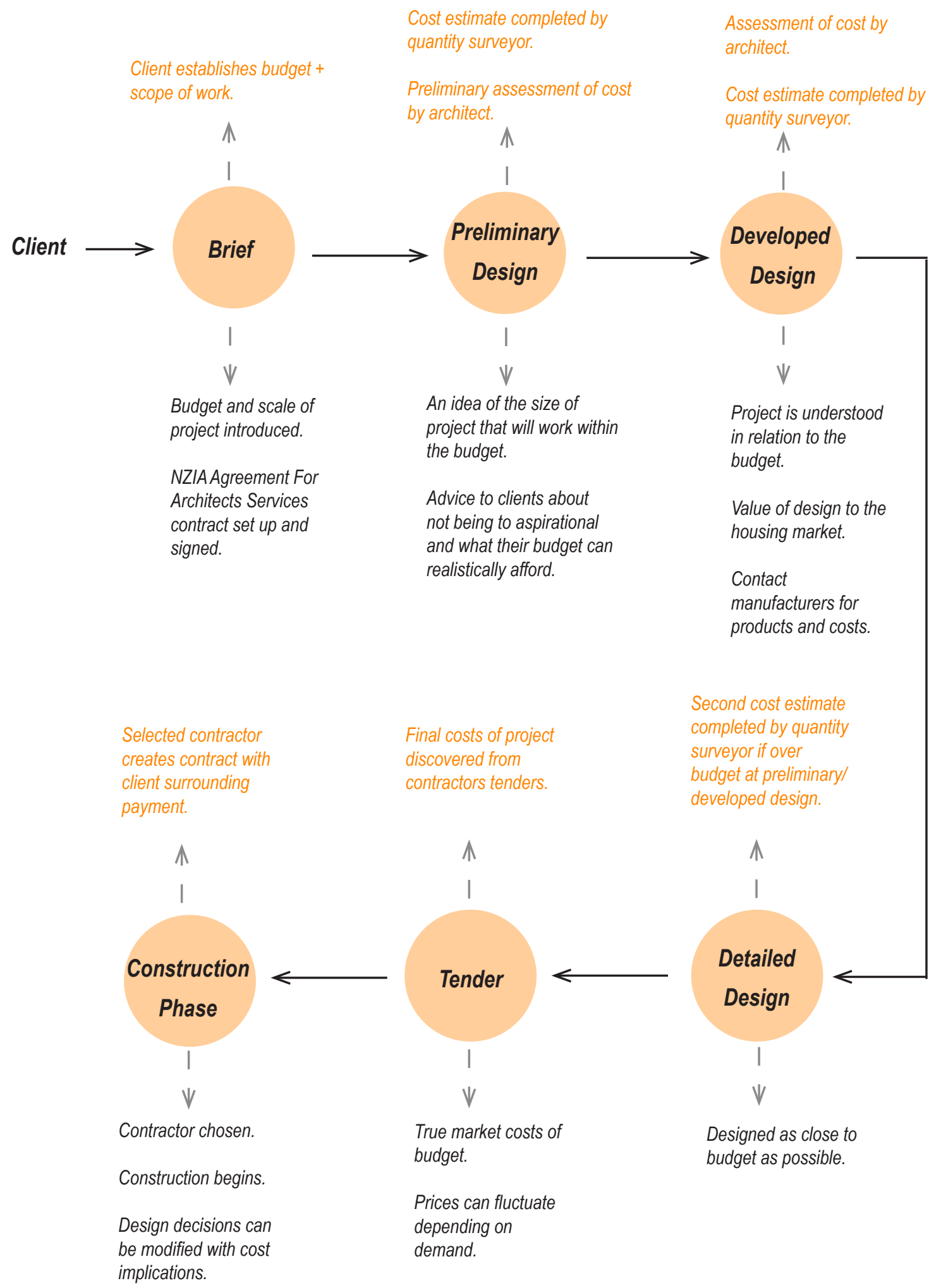

Figure 1.04 Typical architect's design process costing phase diagram 


\section{Next Generation Architect's Process}

Costing phase diagram

BIM costing set up by architect.

Cost Libraries utilised, manufactures

contacted and relevant databases used.

BIM costing by architect.

Client establishes budget +

scope of work.

Working alongside a quantity surveyor/

builder/ fabricator for cost estimates.

Inhouse or external QS to

review cost estimates.

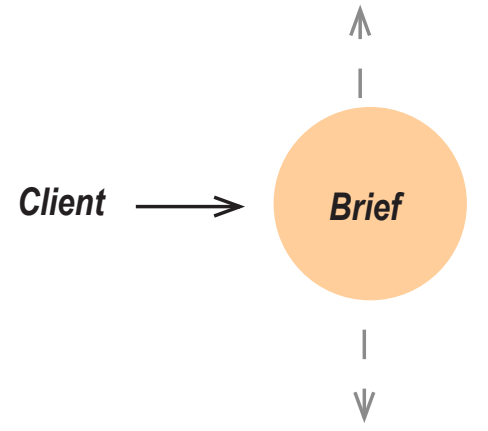

Budget and scale of project introduced

Advice to clients aspirations and what their budget can realistically afford.

NZIA Agreement For Architects Services contract set up and signed.
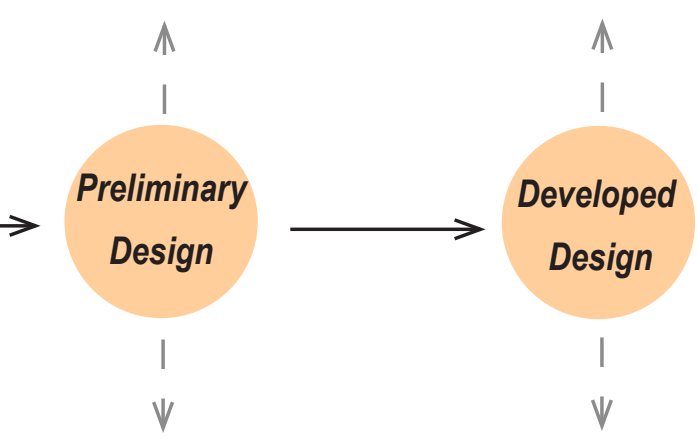

An idea of the size of project that will work within the budget.

Knowldge of value through cost, material and construction techniques.

Costs of elements tracked through BIM

BIM costing updated.

\section{Material properties and lifecycle} value understood when selected.

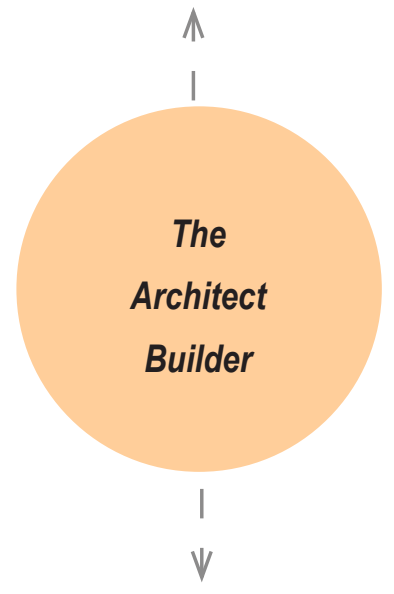

Final costs should be similar to estimated costs.

Constructed by fabricator or one selected building company who has been apart of the project from the start.

Design and contruction processes kept as one phase instead of two.
Detailed cost estimate completed through BIM by architect and overlooked by a QS and builder/ fabricator.

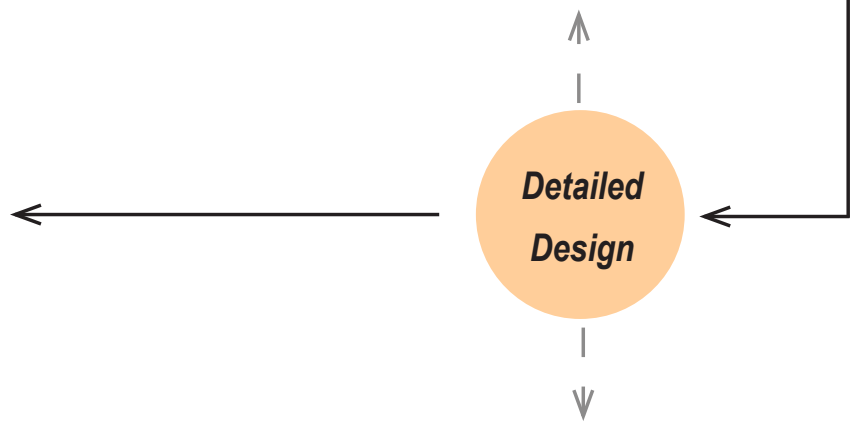

Cost implications understood and designed to meet budget.

Standard construction details minimal use of bespoke detailing. Libraries of costing and details utilised.

Material properties, value and lifecycle analysed.

Designed above minimum insulation codes.

BIM file collaborated across disciplines. 
Design Phase One investigates

economic precedents, site selection,

plot arrangements and the conceptual

design of a single dwelling testing

initial tactics of affordability. 


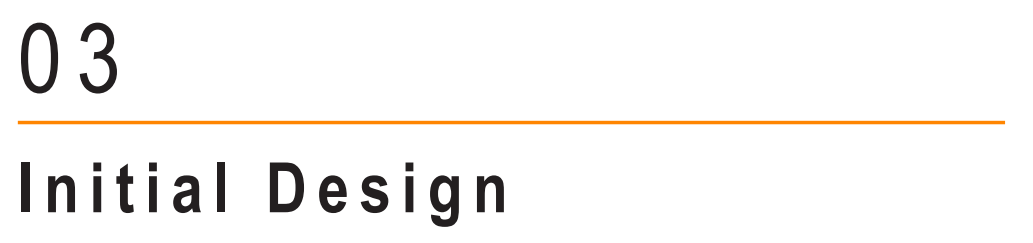




\section{Warrander Studio}

Tactics of Affordability

Warrander Studio, designed by Makers of Architecture, is a small-scale project located in Governors Bay, Christchurch. The studio uses new construction methods, including the use of CLT XLam panels made off site. The prefabricated nature reduces both construction waste and time, enabling the studio structure to be constructed on site within 3 days. This project was digitally designed and fabricated through the use of BIM, allowing for precise costing and CNC technologies (Foster, 2015).

- $\quad$ Total build cost only $=\$ 130,000$

- Additional Site Costs $=\$ 25,000$

Tactics of affordability:

- Prefabricated CLT Panels to reduce overall construction time to two months.

- Exposed material finishes.

- Small floor area which maximises the potential of each space.

- No wasted spaces, with storage areas maximised within the design.

- Open plan kitchen, dining and living.

- The use of BIM allowing for precise costing in the design phase.

- The use of polycarbonate instead of a larger glazed window in the stair well. 
This image has been removed by the author of this thesis for copyright reasons.

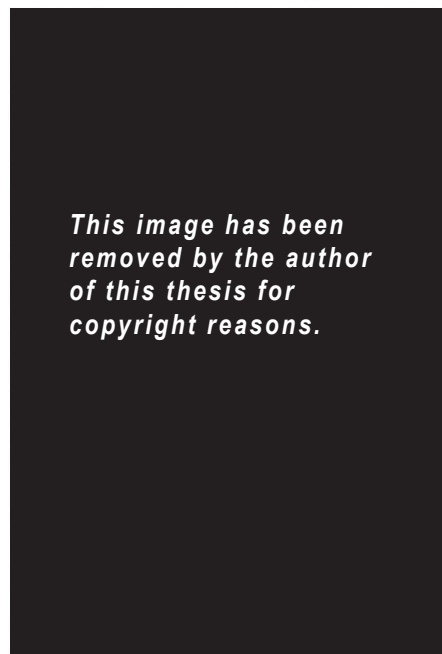

Figure 1.07 Interior Materiality

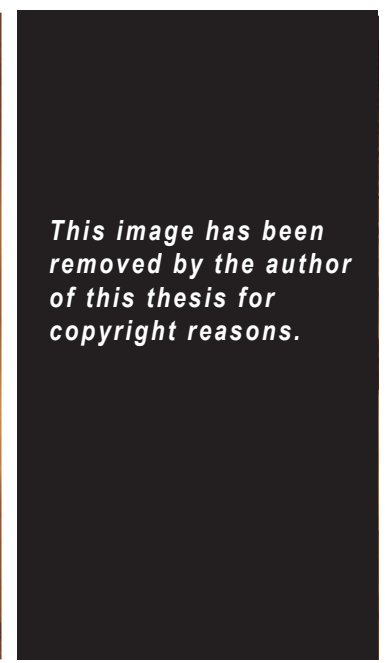

Figure 1.08 Clever Storage

This image has been removed by the author of this thesis for copyright reasons.

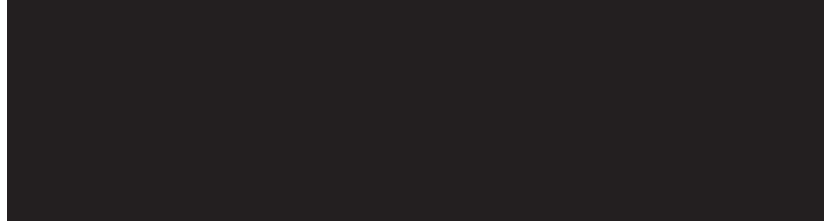

Figure 1.09 Warrander Studio Exterior

Figure 1.06 Warrander Studio Exterior

$2 \longdiv { \square } 1 \stackrel { \coprod ^ { 0 } } { \square }$
This image has been removed by the author of this thesis for copyright reasons.
This image has been removed by the author of this thesis for copyright reasons.

Figure 1.11 Level One

Figure 1.10 Ground Floor 


\section{Triangle Road Community Housing}

Tactics of Affordability

Stratchan Group Architects have an enthusiasm for fast, affordable and energy efficient construction, implemented within the design for the Triangle Road Community Housing Scheme. Located in Massey, Auckland, the development contains a mixture of ten terraced homes containing two, three- and four-bedroom arrangements. The approach towards the design explored the planning, materiality and construction methods to provide the greatest value both economically and in terms of meeting the social and lifestyle needs of the occupants (Strachan Group Architects, n.d.).

Tactics of Affordability:

- Dual housing.

- Precast concrete shared walls.

- Concrete ground floors for thermal mass.

- Cross laminated timber mid floor.

- Structurally insulated roof panels.

- All insulation is at least 50\% above NZBC requirements.

- Standard glazed window and door joinery.

- Walls and floors with raw finish, and sealed or white washed to finish.

- Open plan living, dining and kitchen.

- Strong emphasis on passive solar architecture: solar gain, thermal mass and ventilation.

- Solar gain maximised by window orientation to the north.

(Smith, n.d.) 
This image has been removed by the author of this thesis for copyright reasons.

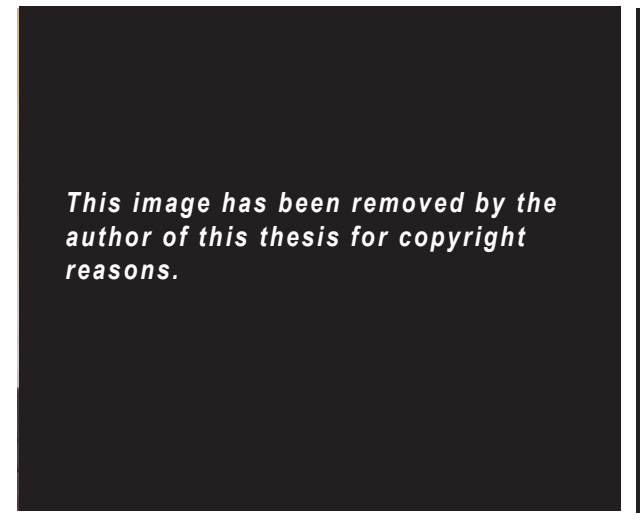

Figure 1.13 Living and Kitchen Materiality

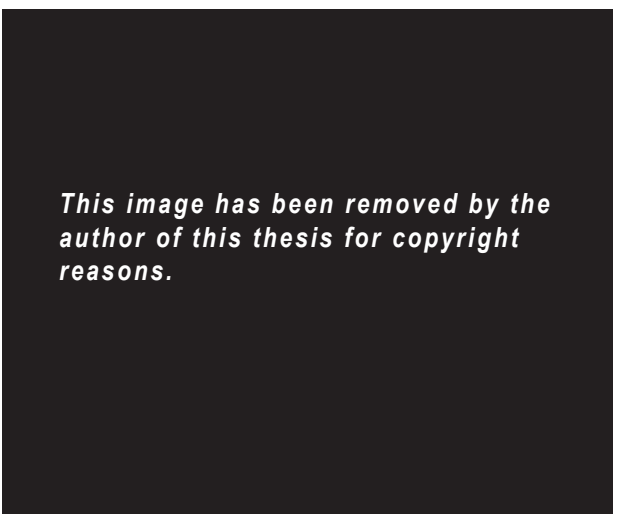

Figure 1.14 Stair Panelling 


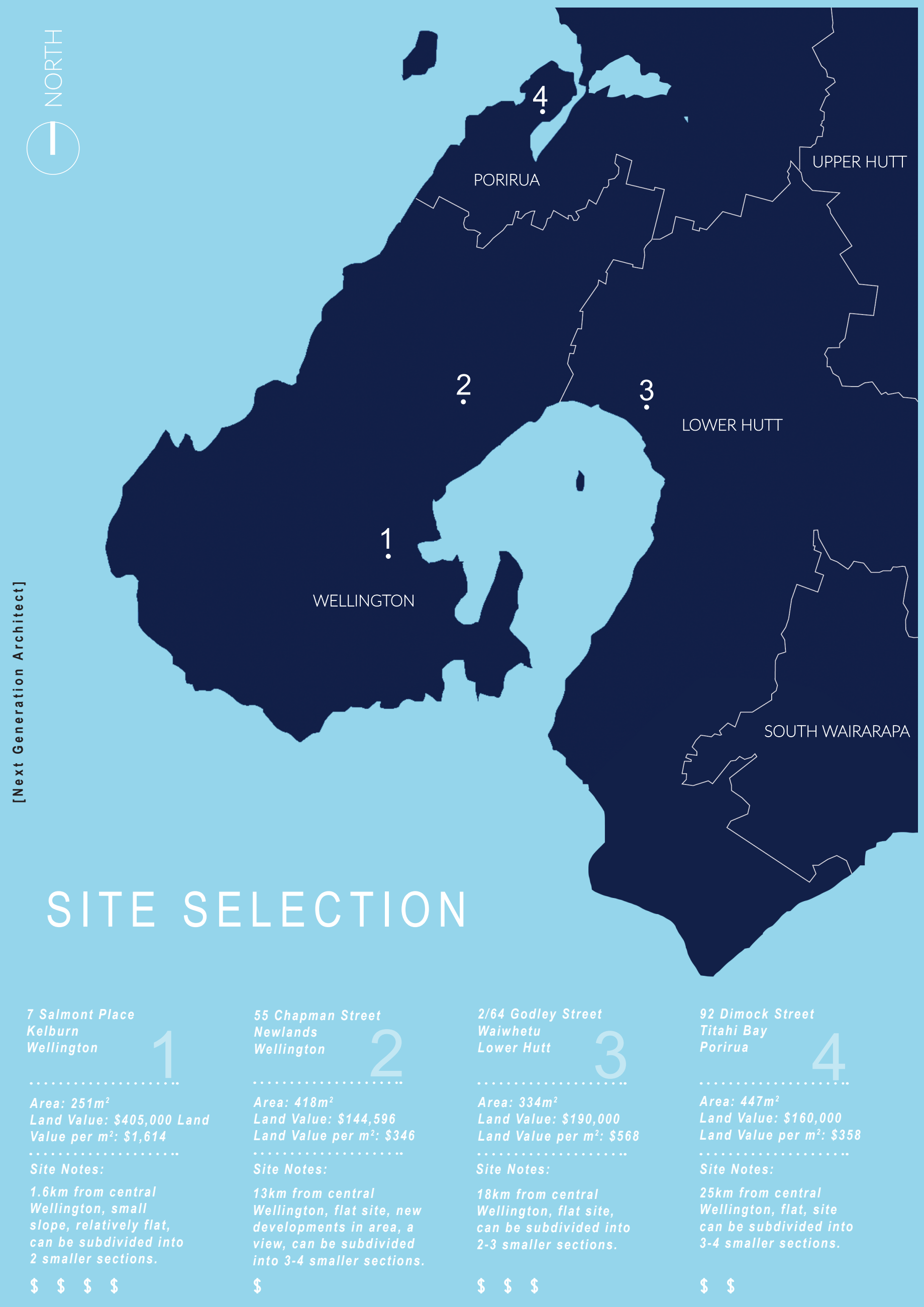

Figure 1.15 Wellington Region Site Selection 


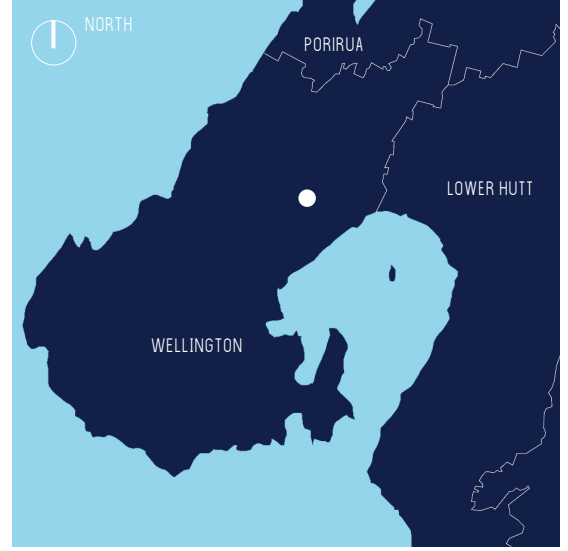

Figure 1.16 Region View

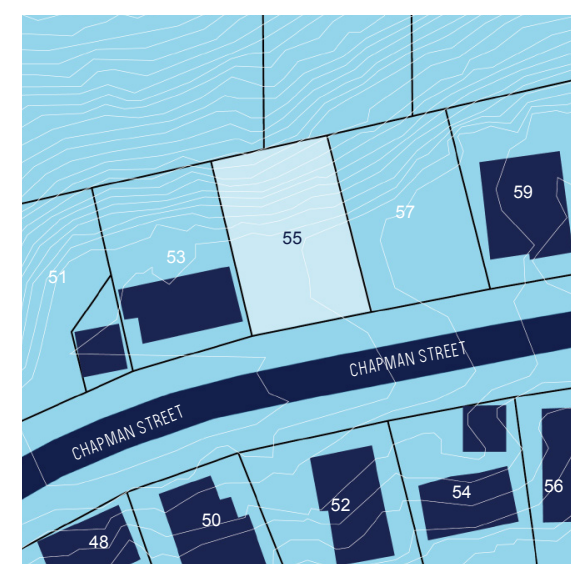

Figure 1.17 Chapman Street Site

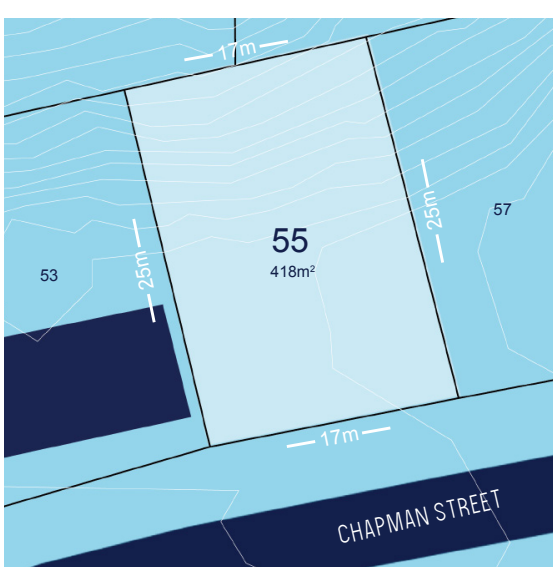

Figure 1.18 Selected Site

[ 55 CHAPMAN STREET, NEWLANDS ]

\section{Site Selection}

\section{Wellington Region Analysis}

The selected site is located at 55 Chapman Street, Newlands. A Wellington site has been selected due to the increasing house and land values of the region. The average house value has increased $44.6 \%$ while land value has increased $77 \%$ over the past three years (Manch, 2018). This site has been selected from an analysis of 4 empty sites across the Wellington region (Figure 1.15), selecting the most economical site by comparing costs of land per $\mathrm{m}^{2}$. The site will be subdivided to densify the plot, providing land that is created to be more affordable to those that aspire home ownership.

55 Chapman Street is a $418 \mathrm{~m}^{2}$ plot. The land on the street side is fairly flat and falls away with a sharp gradient at the back of the plot. Located in Newlands, the site is relatively close to public transport, Johnsonville shopping area, local schools, parks and State Highway One (Figures 1.19 and 1.20). 


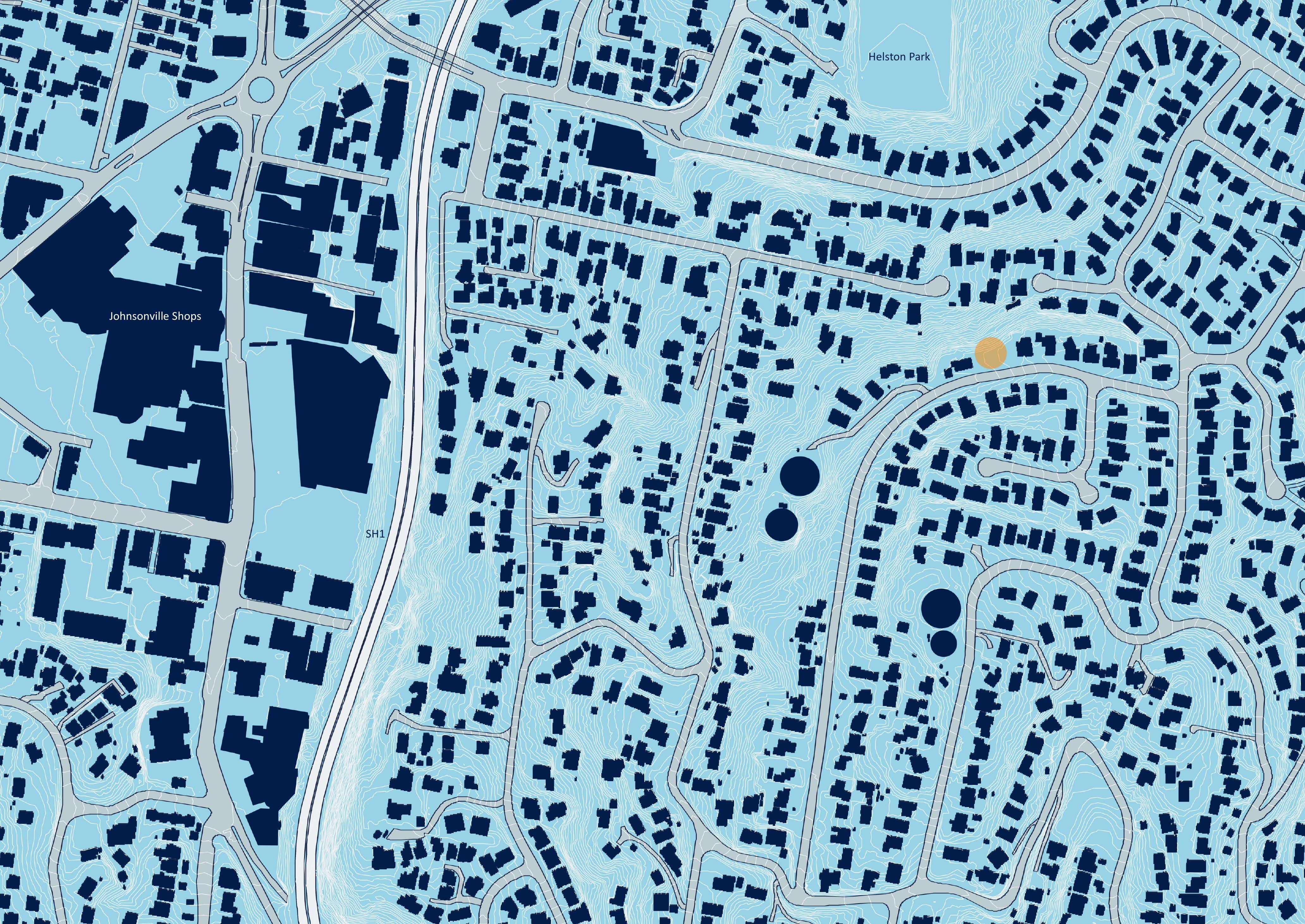




\section{Site Context Map}

Zoomed Out Neighbourhood Map

Figure 1.19 Site context map zoomed ou 


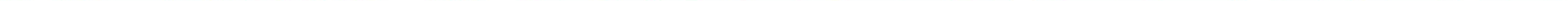


Site Context Map

Zoomed Neighbourhood Map

Figure 1.20 Site context map zoomed in 


\section{Site images}

55 Chapman Street

Newlands

Wellington

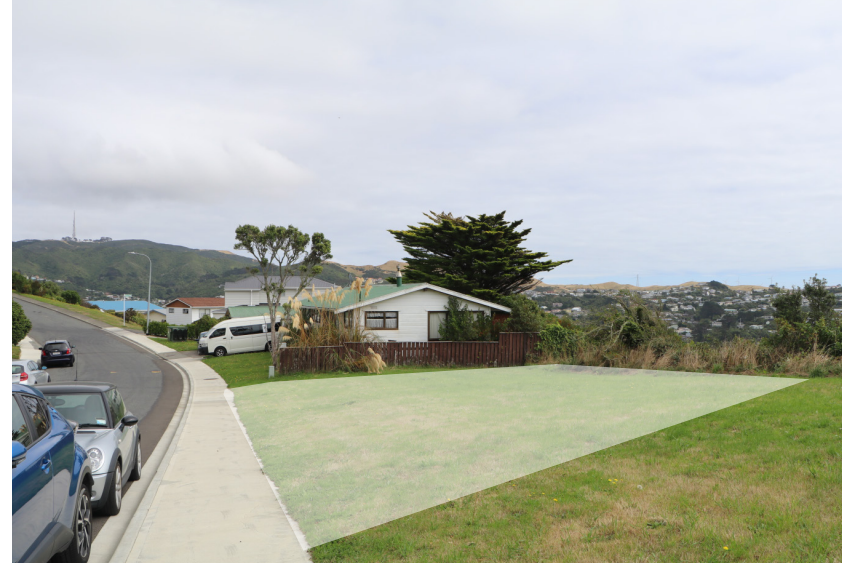

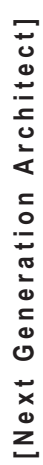

Figure 1.2155 and 56 Chapman Street empty plots looking west

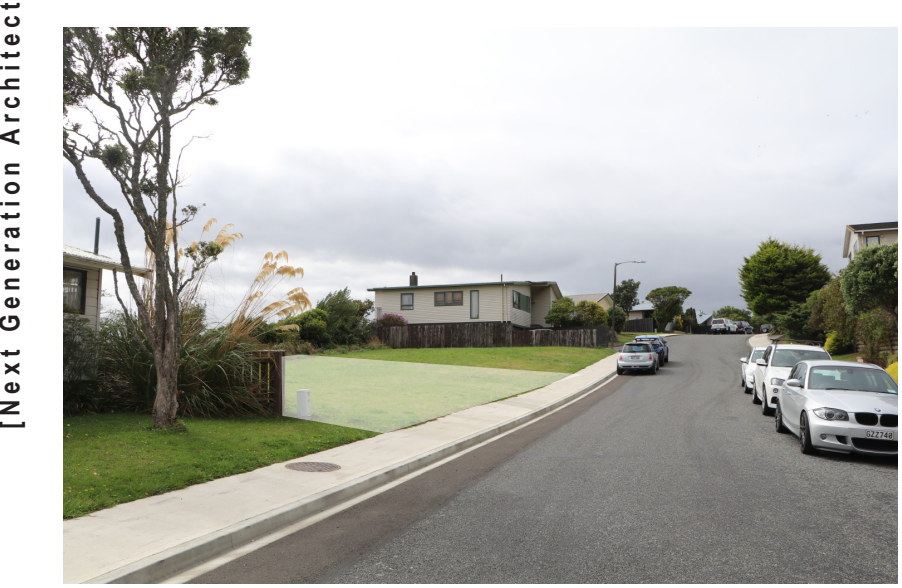

Figure 1.2355 and 56 Chapman Street empty plots looking east

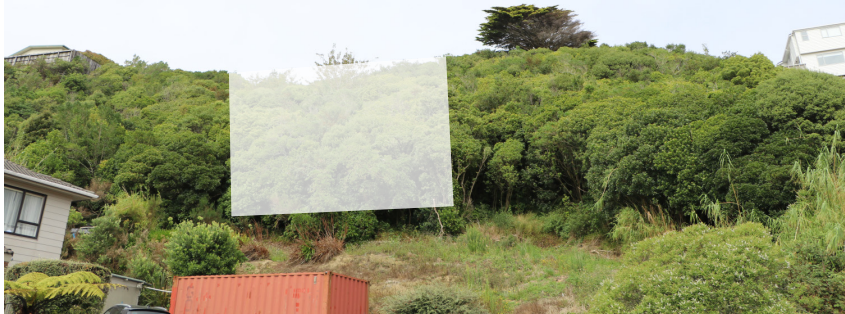

Figure 1.22 View looking up at site from Burgess Road

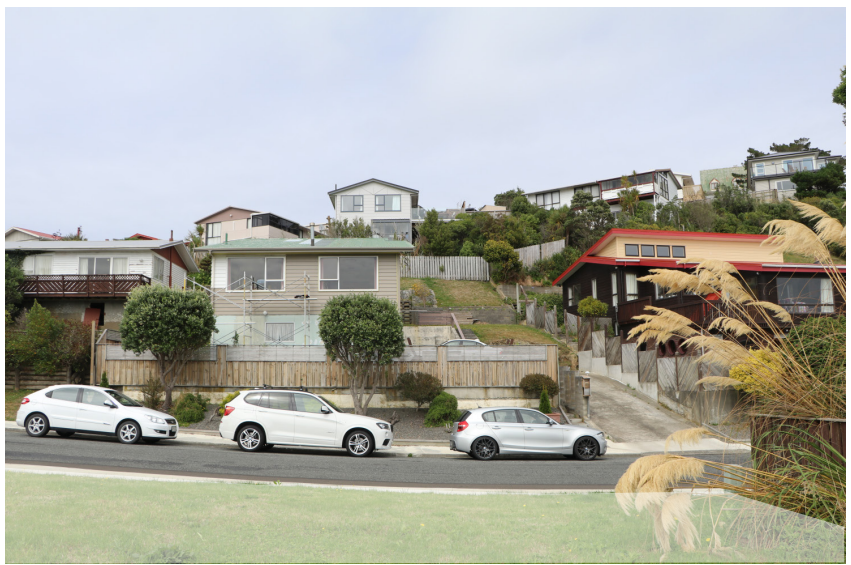

Figure 1.24 Neighbouring properties

Figure 1.25 View from site 
Densifying the plot allows for the cost of land to be divided across several homeowners. The cost of land in New Zealand is a key contributor to the strain on homeownership. Plots are larger than the average homeowner needs to accommodate one dwelling; subdividing sites reduces the strain of land cost. The test includes two options of subdividing the plot. Option A has 3 plots seen in figure 1.26, Option B has 4 plots seen in figure 1.27. Option A has larger sections accommodating dwellings with larger floor areas or green spaces. Option B is the most economical choice accommodating 4 houses on the plot. Two houses sited on the flat part of the site and two houses sited on the sloped part.

- $\quad$ Land price per $\mathrm{m}^{2}=\$ 346$

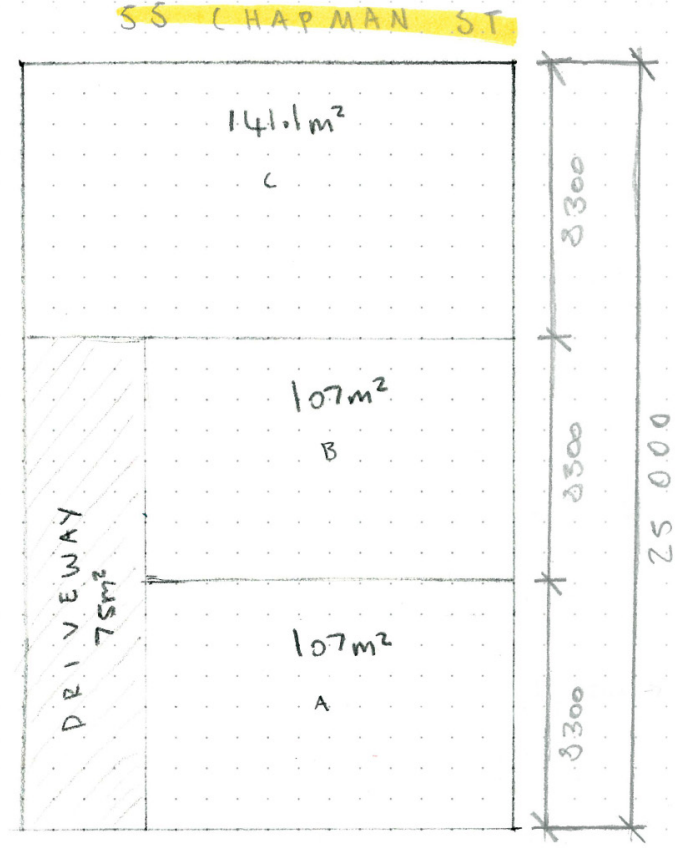

Plot economics including right of way costs:

Plots A \& $B=\$ 46,000$

$20 \%$ Deposit $=\$ 9200$

Plot $\mathrm{D}=\$ 57,500$

$20 \%$ Deposit $=\$ 11,500$

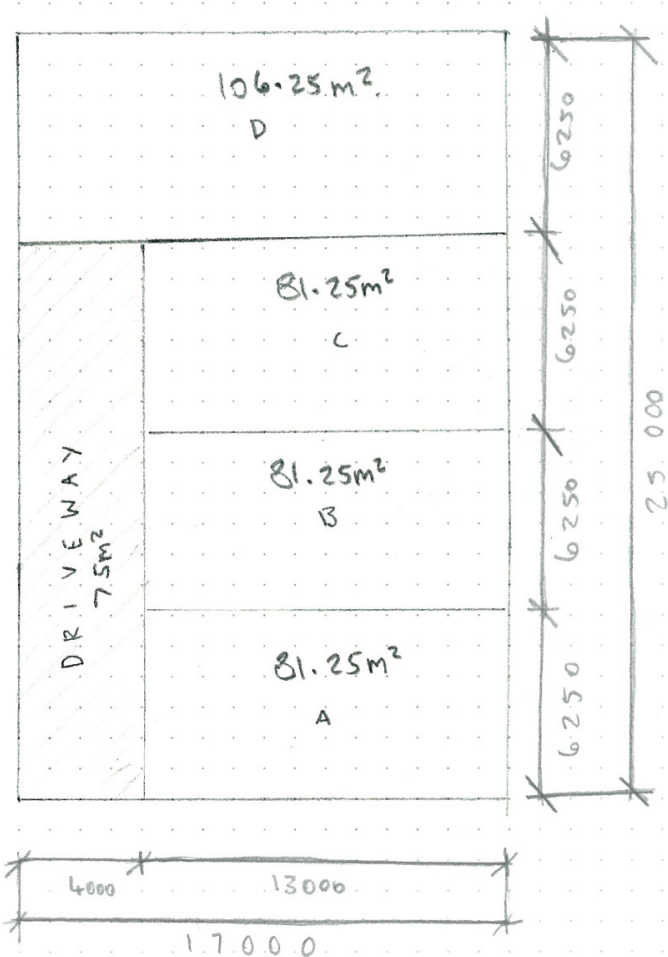

Plot economics including right of way costs:

Plots $A, B$ \& $C=\$ 34,600$

$20 \%$ Deposit $=\$ 8650$

Plot $\mathrm{D}=\$ 43,250$

$20 \%$ Deposit $=\$ 9,200$ 


\section{Initial Design}

Housing Typology 1.1

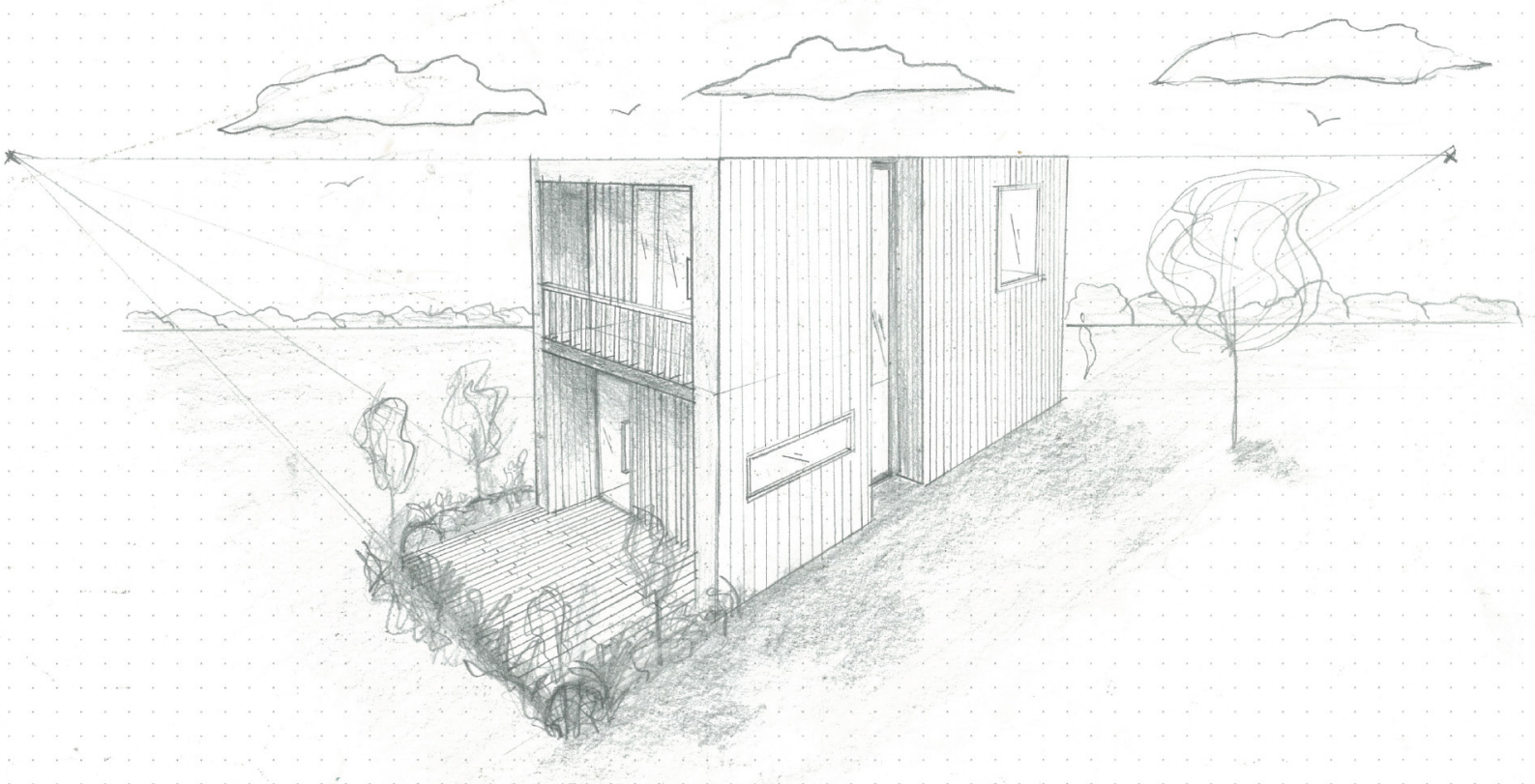

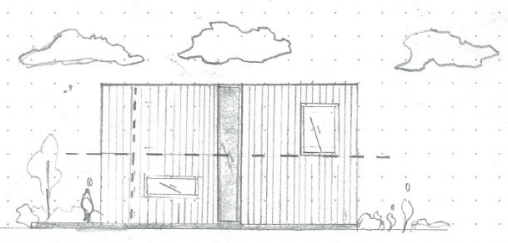

SIDE ELEVATION

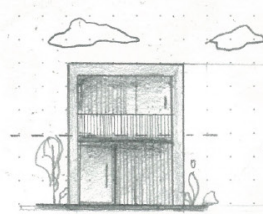

Front ElEvation

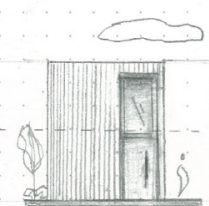

Back elevation

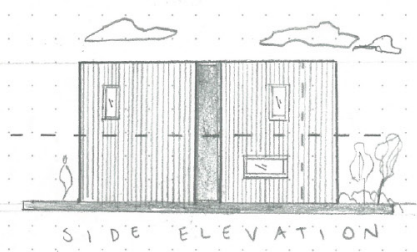

Figure 1.28 Conceptual drawing for 55 Chapman Street site

The initial sketch design investigates a first glance at economical design, implementing design principles extracted from precedent analysis including: modular form, small footprint, and a two storey dwelling reducing land coverage. A recess on the north and south faces breaks up the modular form, applying an architectural aesthetic to the dwelling. 
Floor Plan

Housing Typology 1.1

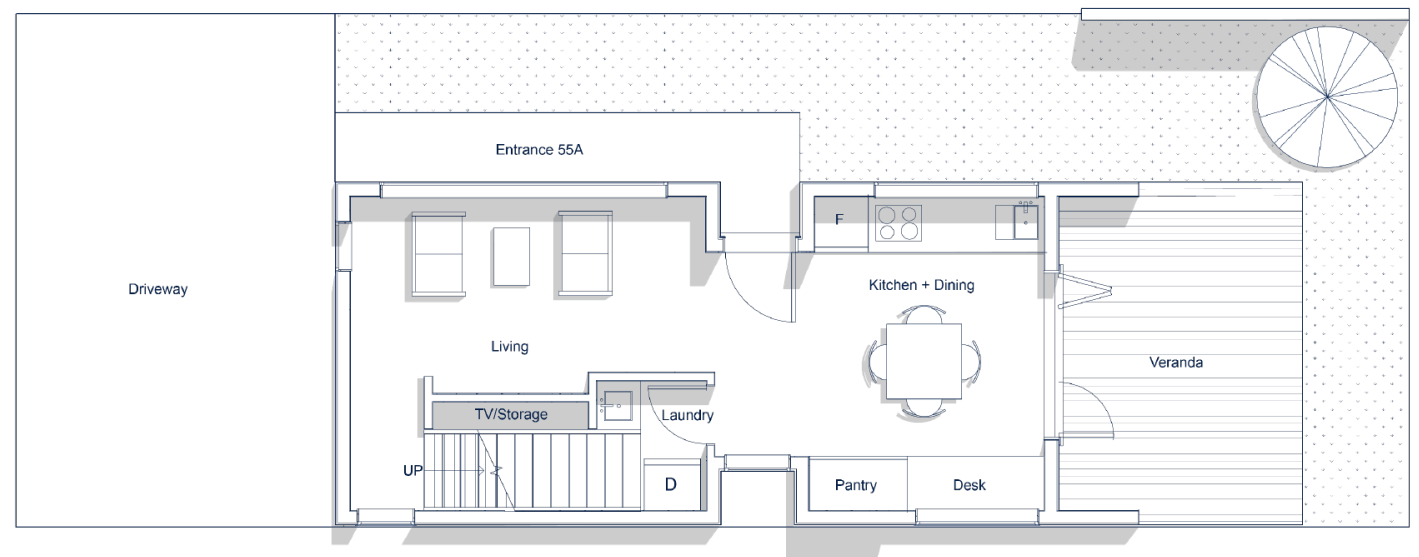

Figure 1.29 Ground Floor Plan

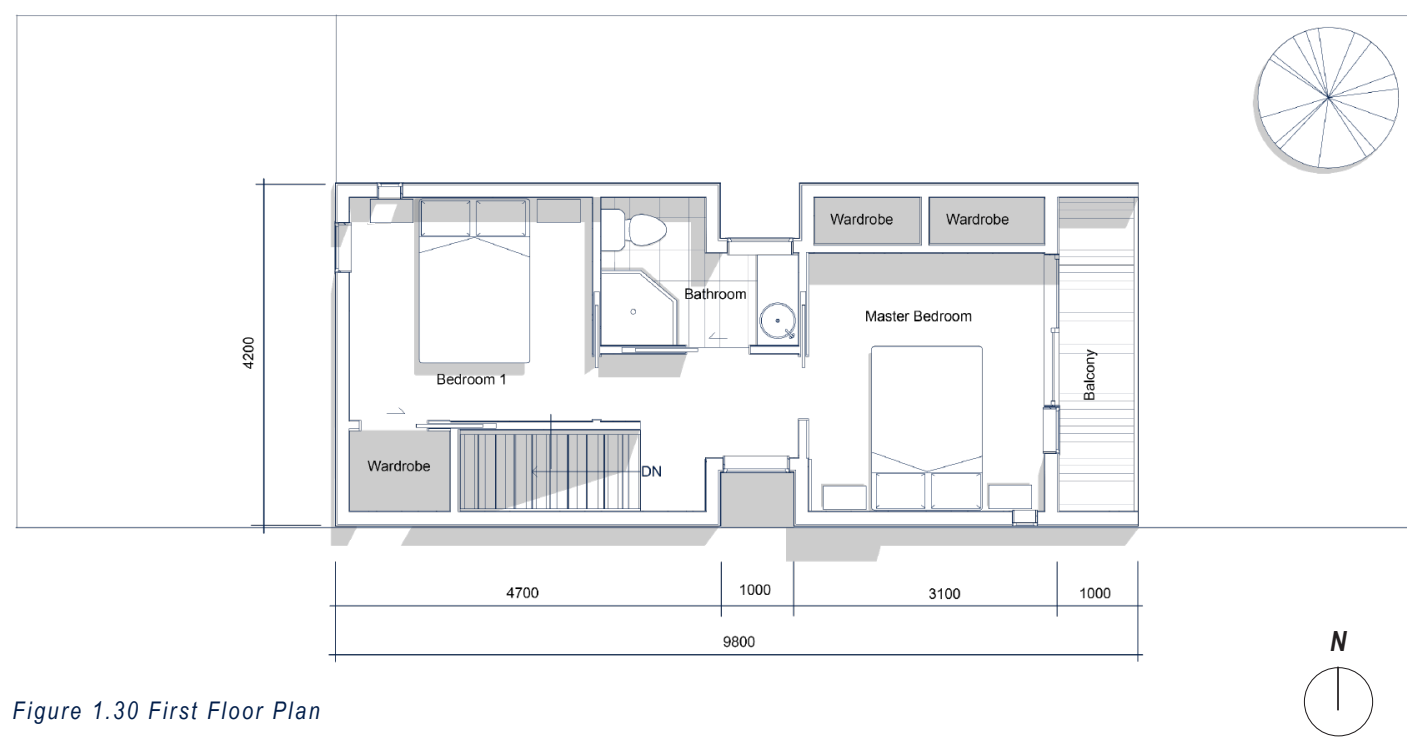

The first iteration of the floor plan consists of a $68 \mathrm{~m}^{2}$ floor area, containing two bedrooms, one bathroom, and an open plan living, kitchen and dining area. To make sure an economical approach was taken towards the value of the dwelling, the floor plan is maximised by only containing necessary spaces, resulting in less material usage and a reduced floor area. 


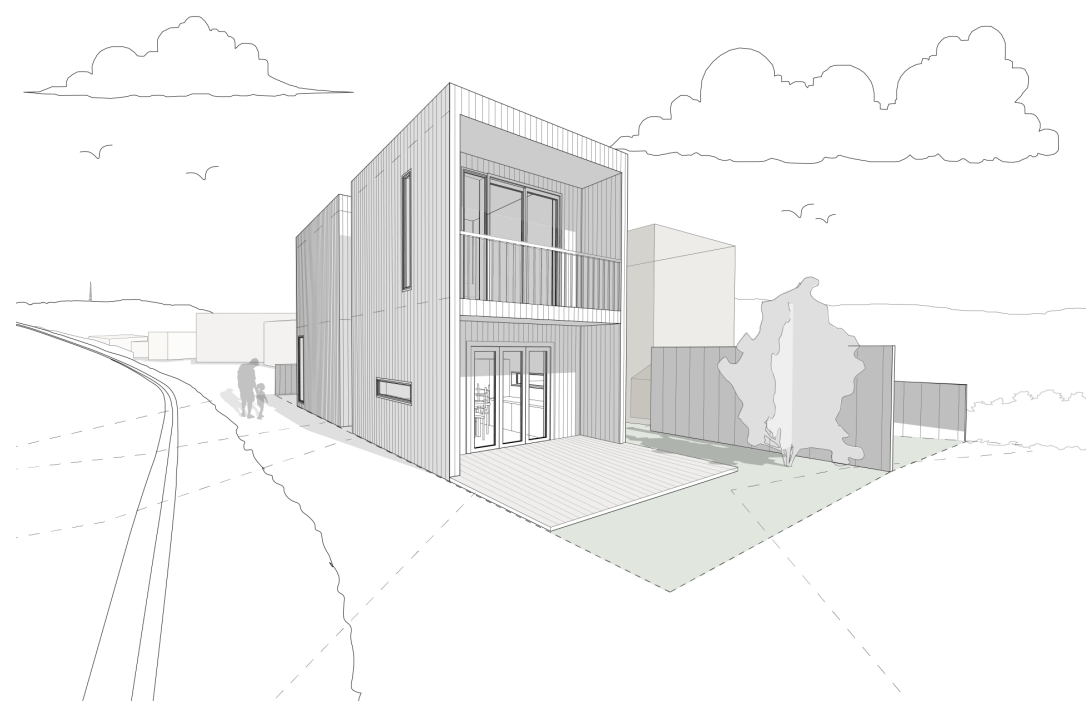

Figure 1.31 South west exterior view at sketch phase design pause

\title{
Sketch Design Cost Estimate
}

\author{
First Cost Estimate
}

Typically, architects will gain a first cost estimate from a quantity surveyor at the end of the sketch design phase to ensure the project is feasible. A first cost estimate was given to the initial design as an introduction into building economics and the implications on the design. Rawlinson's 2011 Costing Handbook facilitated the first cost estimate. It contains information surrounding building materials and products with elemental costs available for the site, plumbing, and electrical services. A spreadsheet (figure 1.32) was used as a tool to contain relevant cost information with areas of material calculated from Revit. The elements costed include; windows, doors, walls, roof, floors, insulation, joinery, elemental, professional fees and land. The first cost estimate for the $68 \mathrm{~m}^{2}$ dwelling is $\$ 237,000$ GST inclusive. This figure will become more accurate as the design progresses with materials and internal fixtures finalised. A finding from completing the cost estimate, was the cost of the butyl membrane roof, which costs considerably more than a standard Coloursteel corrugated iron roof. It was not possible to use corrugated iron for the flat roof designed because of the minimum slope required. 
First Cost Estimate

Excel Breakdown

Figure 1.32 Housing Typology 1.1 Excel Costing Breakdown

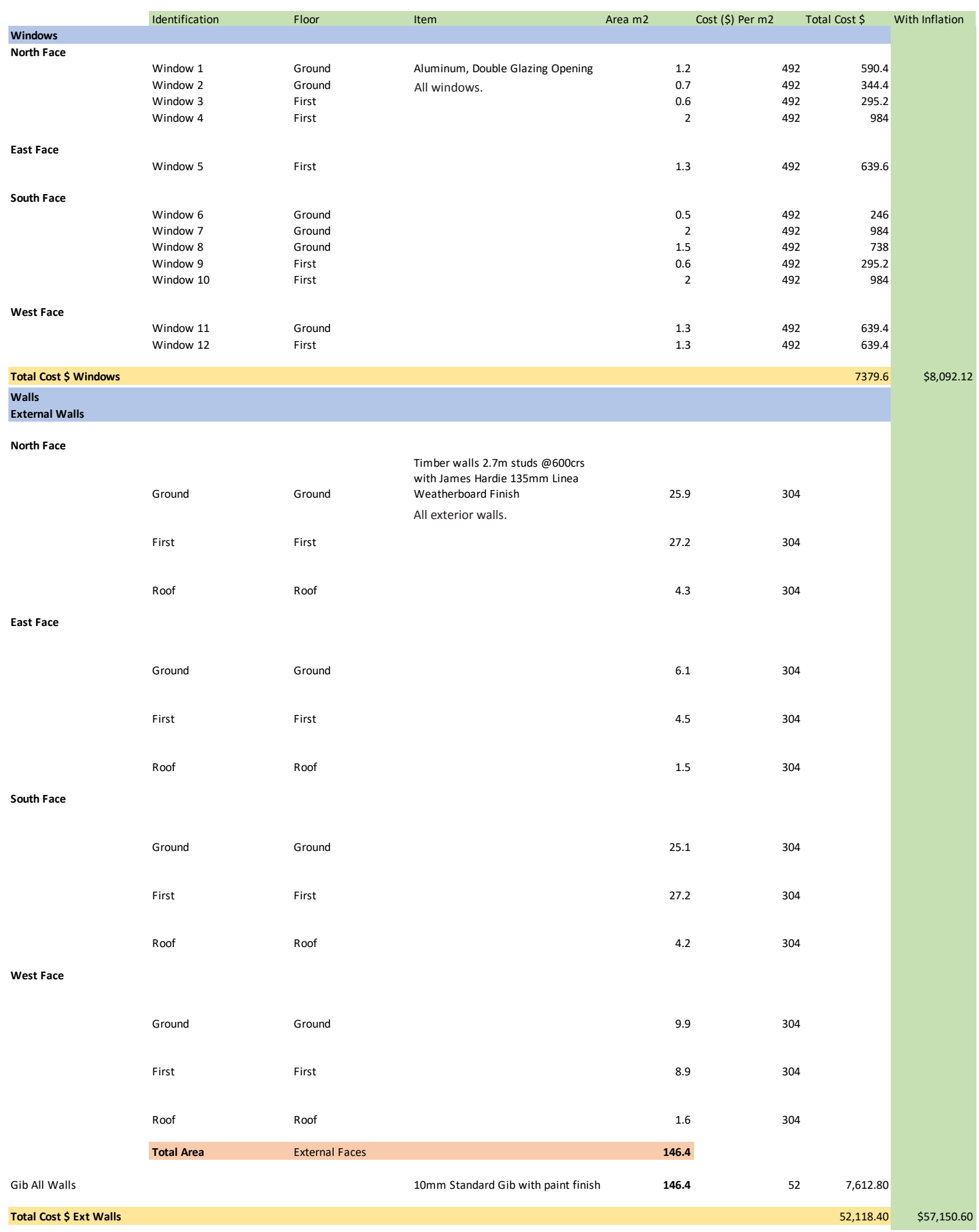




\begin{tabular}{|c|c|c|c|c|c|c|c|}
\hline Doors & & & & & & & \\
\hline External & & & & & & & \\
\hline North Face & & & & & & & \\
\hline & Door 1 & Ground & Normal Glazed & $860 \times 2030$ & 1800 & 1800 & \\
\hline East Face & & & & & & & \\
\hline & Door 2 & Ground & Bifold & $2100 \times 1980$ & 2800 & 2800 & \\
\hline & Door 3 & First & Sliding Glazed & $1850 \times 2400$ & 1500 & 1500 & \\
\hline Internal & & & & & & & \\
\hline & Door 4 & Ground & Normal & $710 \times 1980$ & $170+55$ & 225 & \\
\hline & Door 5 & First & Cavity Slider & $760 \times 1980$ & $460+80+110$ & 650 & \\
\hline & Door 6 & First & Cavity Slider & $760 \times 1980$ & & 650 & \\
\hline & Door 7 & First & Cavity Slider & $760 \times 1980$ & & 650 & \\
\hline & Door 8 & First & Cavity Slider & $760 \times 1980$ & & 650 & \\
\hline & Door 9 & First & WD Door & $1200 \times 1980$ & & 150 & \\
\hline & Door 10 & First & WD Door & $1200 \times 1980$ & & 150 & \\
\hline Total Cost \$ Doors & & & & & & 9225 & $\$ 10,116$ \\
\hline Internal Walls & & & & & & & \\
\hline Ground Floor & & & & & & & \\
\hline & Int Wall 1 & & $\begin{array}{l}90 \times 45 \text { Framing, GIB lining both } \\
\text { sides, with painted finish }\end{array}$ & 1.5 & 135 & & \\
\hline & - & & All interior walls. & 1.5 & 年 & & \\
\hline & Int Wall 2 & & & 4.6 & 135 & & \\
\hline & Int Wall 3 & & & 1.4 & 135 & & \\
\hline & Int Wall 4 & & & 3.8 & 135 & & \\
\hline & Int Wall 5 & & & 0.7 & 135 & & \\
\hline & Total Area & Ground & & 12 & & 1620 & \\
\hline First Floor & & & & & & & \\
\hline & Int Wall 6 & & & 1.5 & 135 & & \\
\hline & Int Wall 7 & & & 6 & 135 & & \\
\hline & Int Wall 8 & & & 5.7 & 135 & & \\
\hline & Int Wall 9 & & & 4.2 & 135 & & \\
\hline & Int Wall 10 & & & 5.1 & 135 & & \\
\hline & Int Wall 11 & & & 3.1 & 135 & & \\
\hline & Int Wall 12 & & & 1.5 & 135 & & \\
\hline & Total Area & First & & 27.1 & & $3,658.50$ & \\
\hline & GIB Aqualine Area & First & & 19.2 & 60 & 1,152 & \\
\hline & Total Area & All INT Walls & & 39.1 & & & \\
\hline Total Cost INT Walls & & & & & & 5,135 & $\$ 5,630.80$ \\
\hline Insulation & & & & & & & \\
\hline Exterior Walls & EXT Wall Insualtion & Ground and First & Pink Batts 2.2 Fitted between studs & 146.4 & 12.2 & 1,786 & \\
\hline Interior Walls & INT Wall Insulation & Ground and First & Pink Batts 2.2 Fitted between studs & 39.1 & 12.2 & 477.00 & \\
\hline Floor Insulation & Timber Flooring & First & Pink Batts 1.6 Snug Floor & 30 & 17.1 & 513 & \\
\hline Total Insualtion Cost & & & & & & 2776 & $\$ 3,044.03$ \\
\hline Flooring & & & & & & & \\
\hline First Floor + Ceiling & & & $\begin{array}{l}20 \mathrm{~mm} \text { Pynefloor GT Particle Board } \\
\text { on SG8 Timber Framing; } 250 \times 50\end{array}$ & & & & \\
\hline Ground & Timber Framed Flooring & First & Joists span of 4.3m @ @450 crs & 30 & 117 & 3510 & $\$ 3,848.90$ \\
\hline Slab & Slab + Foundations & Ground & Concrete Slab & 35 & 220 & 7,700 & $\$ 7,700$ \\
\hline Decking & Timber Deck & Ground & Timber Framing & 40.8 & 11.1 & 453 & $\$ 496.74$ \\
\hline Decking & Timber Deck & Ground & Pine Timber Topping & 12 & 57 & 684 & $\$ 750.04$ \\
\hline & & & $\begin{array}{l}20 \mathrm{~mm} \text { Pynefloor GT Particle Board } \\
\text { on SG8 Timber Framing; } 250 \times 50\end{array}$ & & & & \\
\hline Balcony & Timber Balcony & First & Joists span of $4.3 \mathrm{~m} @ 450$ crs & 3 & 117 & 351 & $\$ 384.89$ \\
\hline Balcony & Timber Balcony & First & Pine Timber Topping & 3 & 57 & 171 & $\$ 187.51$ \\
\hline Entrance & Concrete Paving & Ground & Concrete Slab & 5 & 220 & 1100 & $\$ 1,206.21$ \\
\hline Total Flooring Cost & & & & & & 13968.88 & \\
\hline Ceiling Battens & Timber Battens & Ground & 70x20mm timber battens @600crs & $60 \mathrm{~m}$ total & 5.5 & 330 & $\$ 361.86$ \\
\hline Ceiling Battens & Timber Battens & First & 70x20mm timber battens @600crs & $60 \mathrm{~m}$ total & 5.5 & 330 & $\$ 361.86$ \\
\hline Ceiling Ground Floor & Gib board & Ground & Gib with paint finish & 30 & 42.4 & 1,272 & $\$ 1,394.82$ \\
\hline Ceiling First Floor & Gib Board & First & Gib with paint finish & 35 & 42.4 & 1,484 & $\$ 1,627.28$ \\
\hline Total Ceiling Cost & & & & & & 3,416 & \\
\hline
\end{tabular}




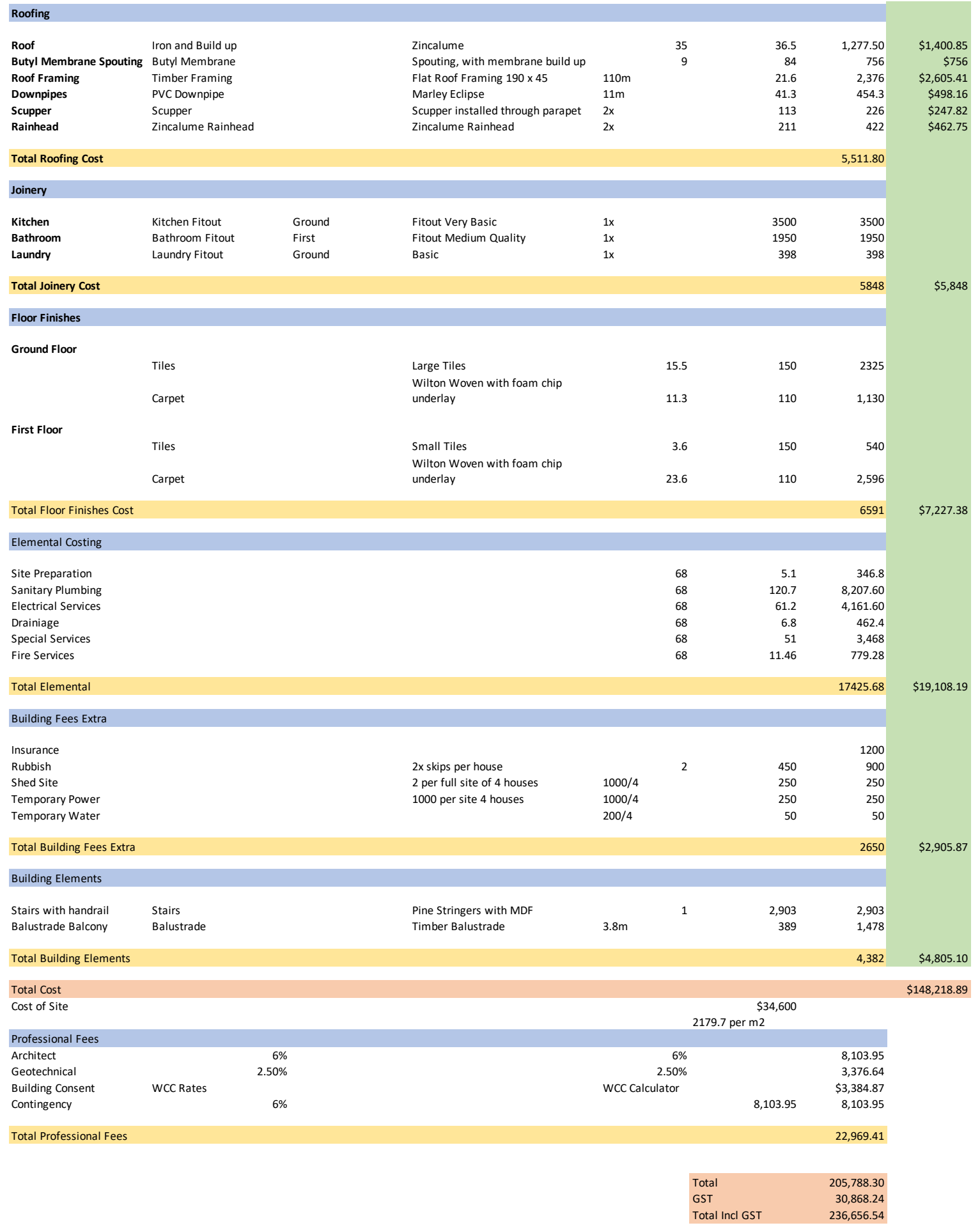




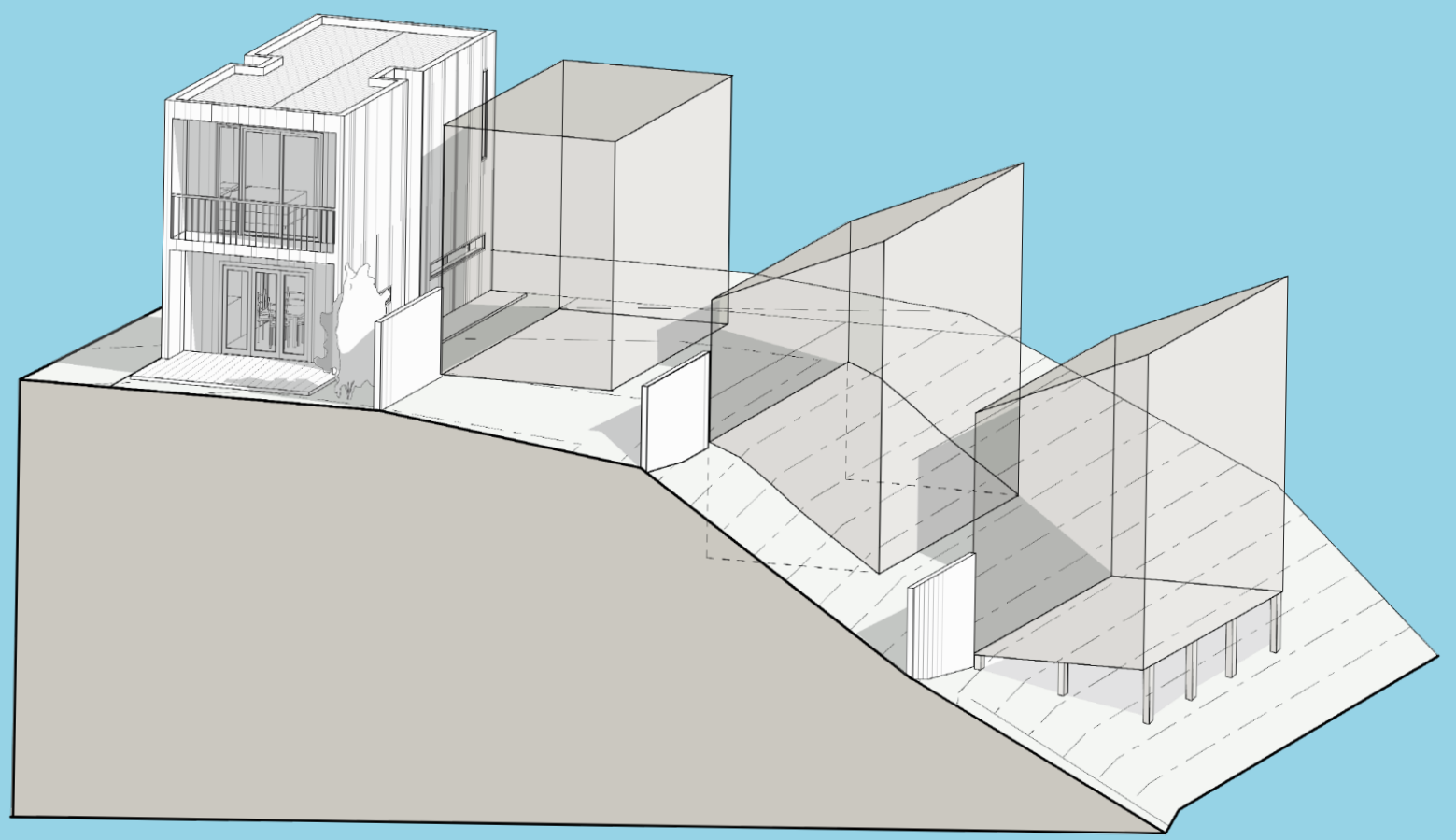

Figure 1.33 Conceptual design of the 55 Chapman Street plot

The plot has been densified to accommodate four dwellings. The conceptual design of the plot illustrates potential forms and foundation types to be considered moving into the developed design phase. 

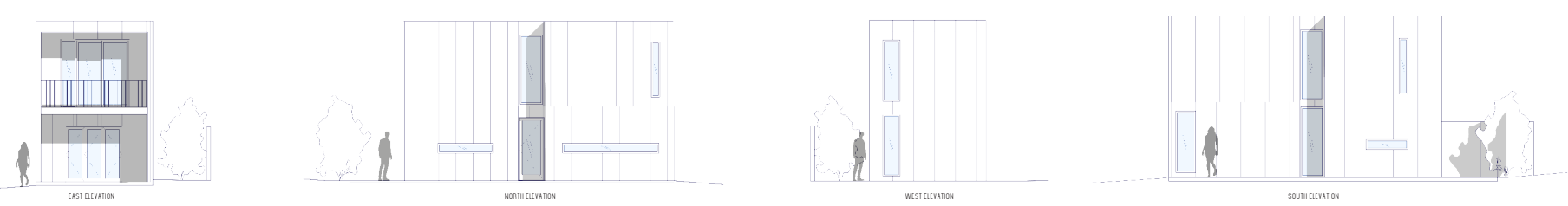

Figure 1.34 Elevations of conceptual design

Findings and Reflection

Initial Design

Phase One involved the design of a single housing typology that investigates affordability. Value was investigated through economic design and construction processes, which enabled an understanding towards the concept of the project's value. These processes involved standardisation of windows, doors and floor heights, and maximising the floor area, by removing unnecessary spaces. The first design is a $68 \mathrm{~m}^{2}$ two-bedroom home, containing one bathroom and an open plan ground floor containing the kitchen, dining and living spaces. Rawlinson's 2011 Costing Handbook was used to gain an understanding of the basic elemental costs; but, this source is from 2011 so did not give a correct estimate of the first cost of this house in 2019. Moving forward, the QV costbuilder database will be used, to gain a more accurate first cost. The QV database updates regularly with the latest construction data from the industry.

The considerations to make moving forward, are the council restrictions on-site and how these will affect the design and site arrangement. The northern face of the design requires further development, ensuring the windows are large enough to let in an acceptable amount of sunlight, ensuring a good quality of living. A quality criteria needs to be established around living conditions and materials usage. How can this be made more affordable and have a good quality of living? Introducing dual housing would allow for further cost reductions. The flat membrane roof needs development to accommodate for a standard roofing build up, which will save costs on the roof itself and the spouting.

\section{Next Generation Architect}

The architectural services of a Next Generation Architect will involve the task of educating clients; on tactics of affordability and the implications of cost estimates from the sketch design phase. 
Design Phase Two explores tactics of affordability. It will introduce new precedents, council restraints, dual housing and comparison sites to gain an understanding of how architects can control costs within a project. 
04

Exploring Affordability 
This image has been removed by the author of this thesis for copyright reasons.

Figure 2.01 Build Smart prefabricated home PLB68

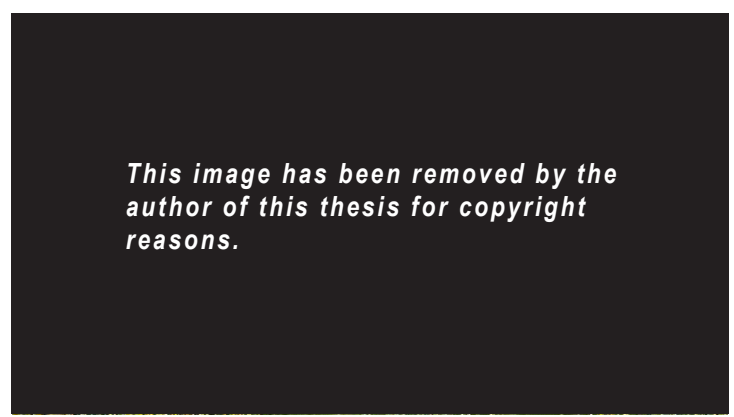

Figure 2.02 Lockwood Home, Vacationer.

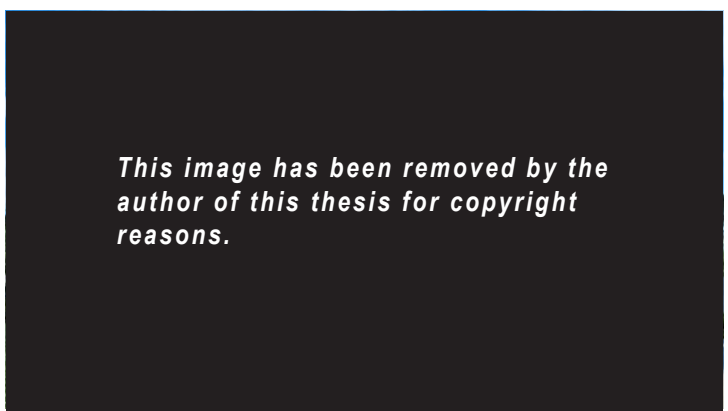

Figure 2.03 Stonewood Homes, Avon.

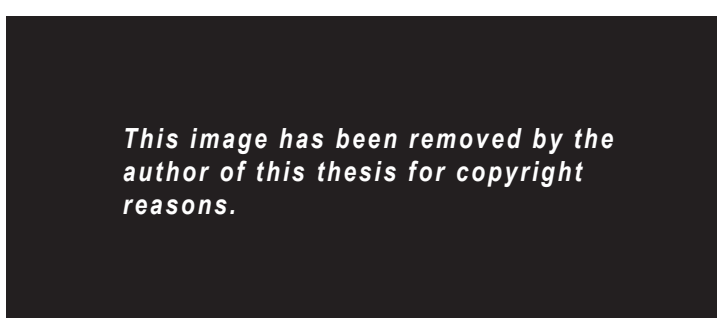

Figure 2.04 A1 Homes EH127

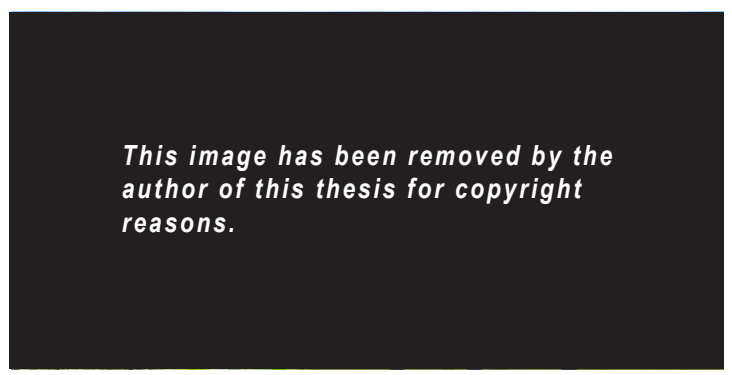

Figure 2.05 Design Builders Plan 1705
This image has been removed by the author of this thesis for copyright reasons.

Figure 2.06 A1 Homes BH136

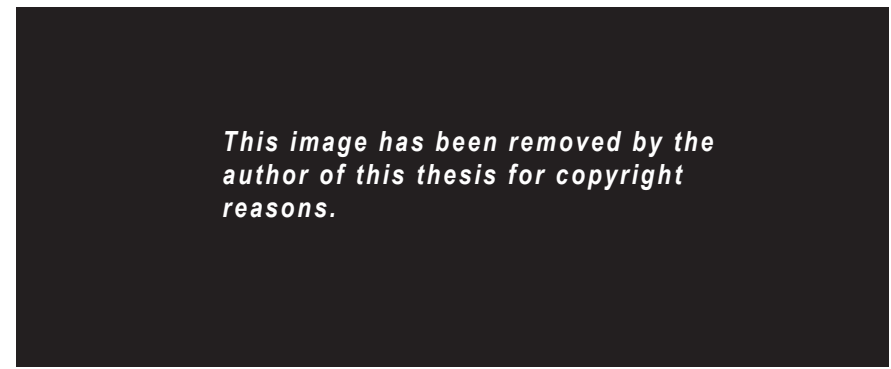

Figure 2.07 A1 Homes BH84 transportable home

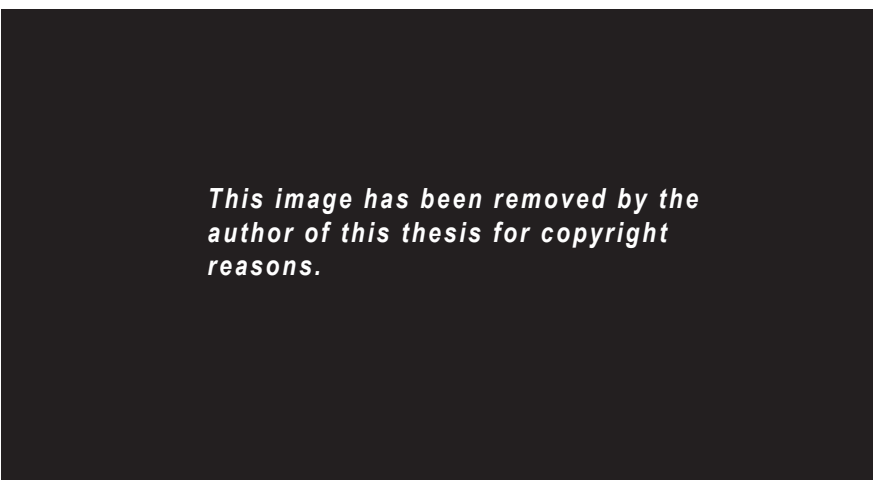

Figure 2.08 Keith Hay Homes, Raglan

This image has been removed by the author of this thesis for copyright reasons.

Figure 2.09 Design Builders Plan BH84

This image has been removed by the author of this thesis for copyright reasons.

Figure 2.10 Design Builders Plan 18004 
Design and build package homes make up a large proportion of New Zealand's overall housing stock. The popularity of these homes in the housing market led to this analysis. Analysed features include the location, floors, the number of rooms, room types, open plan, materials, roof, overall costs and costs per $\mathrm{m}^{2}$. This data collection and analysed was aided by the use of an excel spreadsheet. Conclusions include the common use of similar materials, these are weatherboards, in particular, James Hardie and colour steel. QV costbuilder displays these two materials are the cheapest per $\mathrm{m}^{2}$. Houses use standardised rectangular windows and doors, repeated throughout the design. The analysis of construction methods and their cost implications show $90 \%$ of houses use standard timber framing.

The average area of the package homes analysed is $149 \mathrm{~m}^{2}$ with prices ranging between $\$ 250,000$ and $\$ 500,000$. Prefabricated houses are cheaper, although the floor areas are smaller. An interesting finding was the number of houses with a garage. This was lower than expected with half the houses not containing a garage. We can see this as a tactic of affordability to reduce the overall build area. Monastra (personal conversation, October 12,2019 ) indicated through a personal conversation, that package homes use small windows for economical purposes. Aesthetically they look disproportionate to the surface area but glazing is approximately twice the cost of an exterior wall per $\mathrm{m}^{2}$. The homes contain gable or hipped roofs, as they are the most economical to build. The hipped roofs can look unusual such as figure 2.04 this is the result of a plan based design.

The positives of the developer home:

- Cater for a range of budgets and housing types.

- Family orientated homes with several bedrooms.

- Come as packages: house and land or just the house.

- Catalogue housing and show homes that are viewed as a product.

- Mass production; to create more affordable homes.

- Houses only allow minimal changes to the finishes, keeping the homes on a budget.

- Work with standardised construction details and elements.

The negatives of the developer home:

- They design houses for flat sites that are north facing; there is no consideration for hill sites.

- Not designed to be site-specific unlike an architecturally designed home.

- Poor aesthetics.

- Basic level of internal planning, there are no special elements.

- Mass-produced designs that can end up with minimal individualisation for clients.

- The typical package home doesn't consider sustainable or passive solar features. 


\section{Design and Build Package Homes}

Analysis of 15 Package Homes

Figure 2.11 Package home analysis

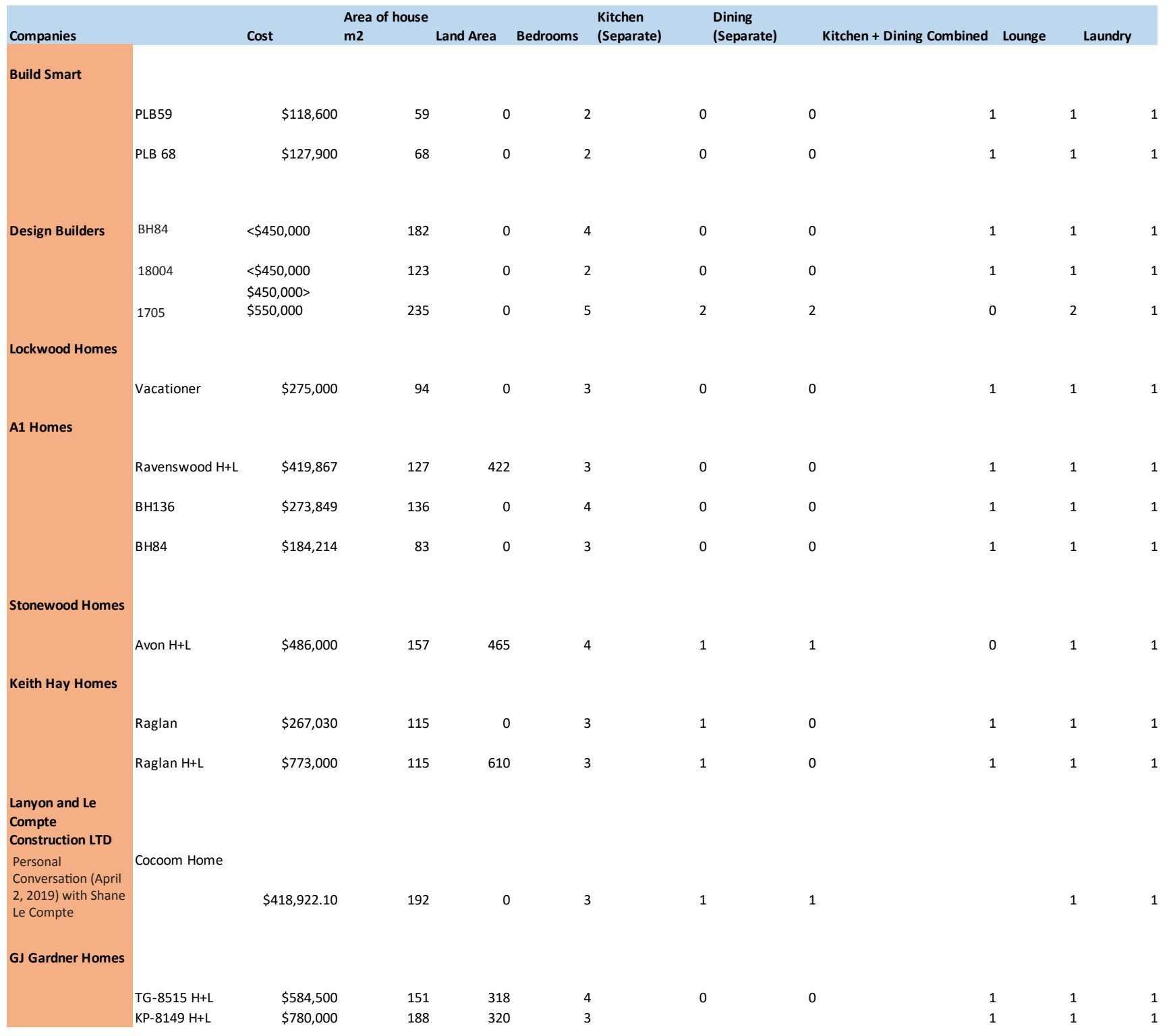




\begin{tabular}{|c|c|c|c|c|c|c|c|c|c|c|c|}
\hline Bathroom & Separate Toilet & t Garage & Location & Levels & & Cost per $\mathrm{m} 2$ & Building Technique & Exterior Materials & Roof Material & Roof Type & Transportable \\
\hline 1 & 1 & 0 & 0 North Island & & 1 & $2,010.20$ & Prefabricated & Weatherboard + Iron & Iron & Mono-pitched & Yes \\
\hline 1 & 1 & 0 & 0 North Island & & 1 & 1880.9 & Prefabricated & Weatherboard + Iron & Iron & Gable & Yes \\
\hline 1 & 2 & $12 \mathrm{Car}$ & Nation Wide & & 1 & $2,472.50$ & NZS3604 & Weatherboard & Iron & Mono-pitched & No \\
\hline 1 & 1 & $01 \mathrm{Car}$ & Nation Wide & & 1 & $3,658.50$ & NZS3604 & Weatherboard & & Flat & No \\
\hline 1 & 3 & $02 \mathrm{Car}$ & Nation Wide & & 2 & $2,340.40$ & NZS3604 & Weatherboard & Iron & Mono-pitched & No \\
\hline 1 & 1 & 0 & 0 Rotorua & & 1 & $2,925.50$ & Lockwood & Weatherboard & Iron & Mono-pitched & Yes \\
\hline 1 & 1 & $11 \mathrm{Car}$ & Canterbury & & 1 & 994.9 & NZS3604 & Weatherboard & Iron & Hipped & No \\
\hline 1 & 2 & 1 & 0 Wellington & & 2 & 2,013 & NZS3604 & $\begin{array}{l}\text { Weatherboard + Titan } \\
\text { Board }\end{array}$ & Iron & Mono-pitched & No \\
\hline 1 & 1 & 0 & 0 Wellington & & 1 & 2,219 & NZS3604 & Weatherboard & Iron & Mono-pitched & Yes \\
\hline 1 & 2 & $02 \mathrm{Car}$ & Canterbury & & 1 & 1,045 & NZS3604 & Weatherboard + Brick & Tile & Gable + Hipped & No \\
\hline & & & & & & & & Weatherboard + Titan & & & \\
\hline 1 & 2 & 0 & 0 West Auckland & & 1 & 2,322 & NZS3604 & Board & Iron & Monopitched & Yes \\
\hline 1 & 2 & 0 & 0 Helensville & & 1 & 1,267 & NZS3604 & Board & Iron & Monopitched & Yes \\
\hline 1 & 2 & $12 \mathrm{Car}$ & Christchurch & & 1 & $2,181.90$ & Precast Concrete Panels & Precast Concrete & Iron & Gable & No \\
\hline 1 & 2 & $01 \mathrm{Car}$ & Tauranga & & 1 & 1,838 & NZS3604 & $\begin{array}{l}\text { Brick Masonry + } \\
\text { Weatherboard }\end{array}$ & Tile & Hipned +Gable & No \\
\hline 1 & 2 & $11 \mathrm{Car}$ & Elsdon- Porirua & & 2 & 2437.5 & NZS3604 & Weatherboard & Iron & Hipped & No \\
\hline
\end{tabular}


This image has been removed by the author of this thesis for copyright reasons.
This image has been removed by the author of this thesis for copyright reasons.

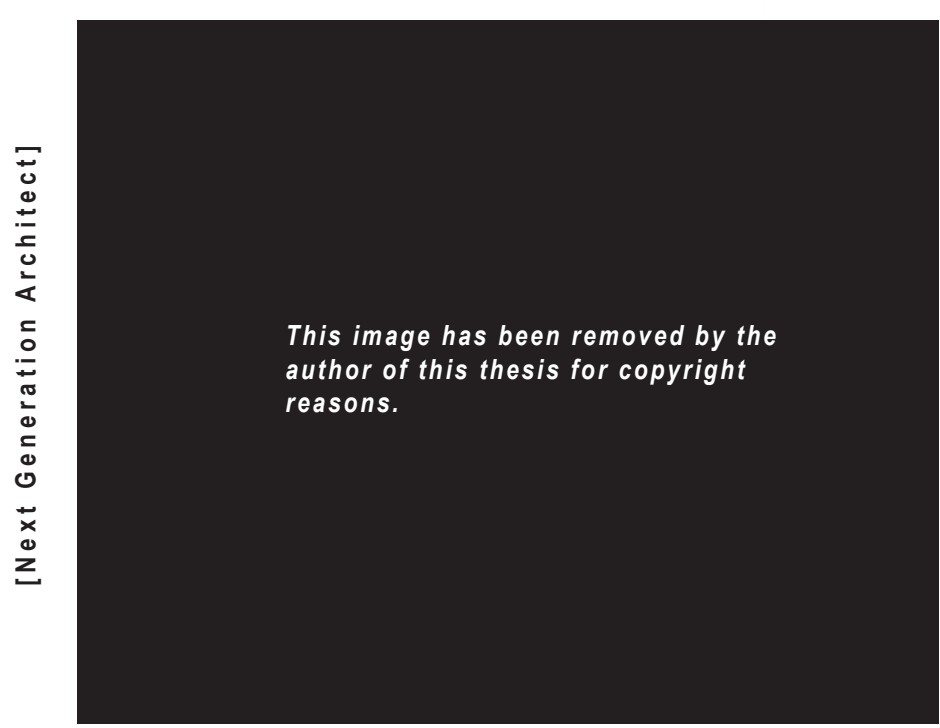

Figure 2.14 A1 Homes BH136, ground floor.

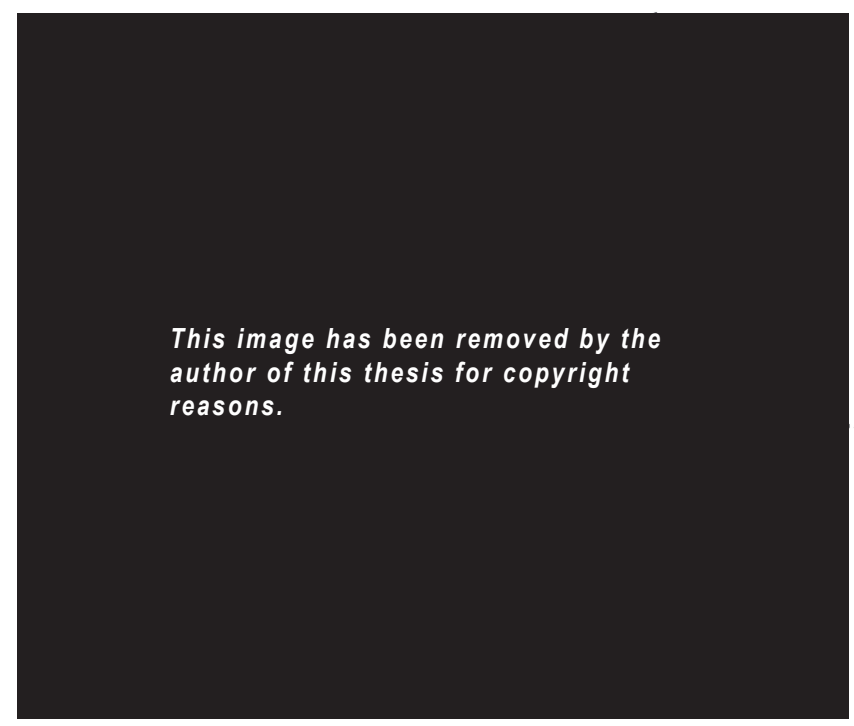

Figure 2.15 A1 Homes BH136, first floor

This image has been removed by the author of this thesis for copyright reasons. 
This image has been removed by the author of this thesis for copyright reasons.
This image has been removed by the author of this thesis for copyright reasons.

Figure 2.19 Lockwood Vacationer plan.

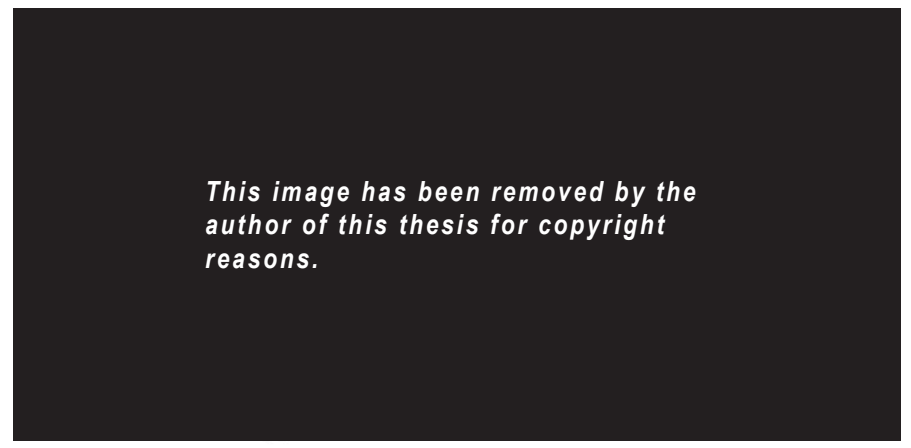

KEY:

PUBLIC SPACES

PRIVATE SPACES

CIRCULATION

ADDITIONAL SPACES

Figure 2.18 A1 Homes EH127 plan

\section{Design and Build Packages}

Floor Plan Analysis

The floor plan analysis included five developer homes looking into four functions; public and private spaces, circulation and additional spaces.

The findings include:

- Open plan kitchen, dining and living.

- Distinct divide between public and private spaces.

- Regular forms.

- Separate toilets and bathrooms.

- Storage spaces.

- Entrances through the living room or corridor.

- Divide between houses that have garages and those that do not. 


\section{Makers of Architecture}

Designing + Fabricating

Makers of Architecture, work inversely to the characteristics of a traditional architecture practice. Makers consider the design and build process as a whole, instead of the traditional process of two individual stages, as seen through the typical architect. Designing and fabricating projects, Makers have both an architecture and building sector to their business. This allows these two processes to work seamlessly as a whole.

Makers, hold the intentions to be an architectural company that builds, tests and develops efficient design and construction techniques. Makers Fabrication facilitates the intentions, providing a digital manufacturing and prefabrication facility both for their designs and the wider architectural community. (Melbourne-Hayward, 2017)

"We want to see architectural design perform to enhance people's lives, and we want this to become more attainable and flexible."

(Melbourne-Hayward, 2017)

Makers, are an example of the upcoming generation of the architectural profession engaging with advanced technology: prefabrication and the use of BIM. Assessing precise costing information through the design process with a correlation to the sizing and placement of the CNC panels, used in their designs. This allows for the development of an efficient method of designing and building quality custom prefabricated architectural projects, to suit individual client's needs. 


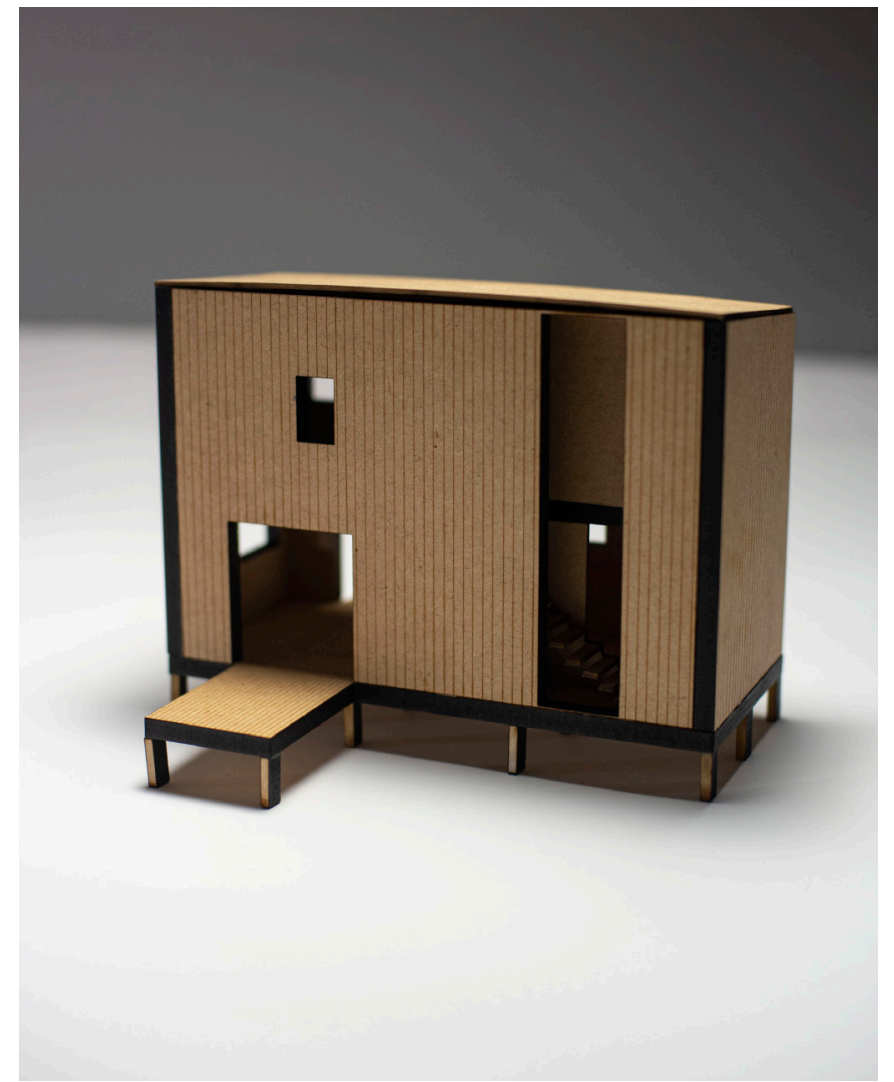

Figure 2.20 Warrander Studio model front elevation

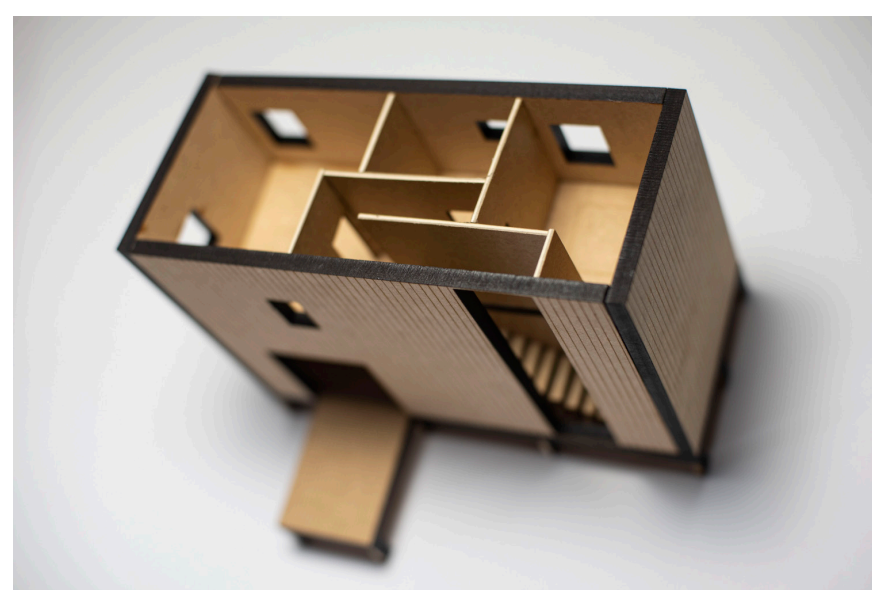

Figure 2.22 Interior of Warrander Studio model

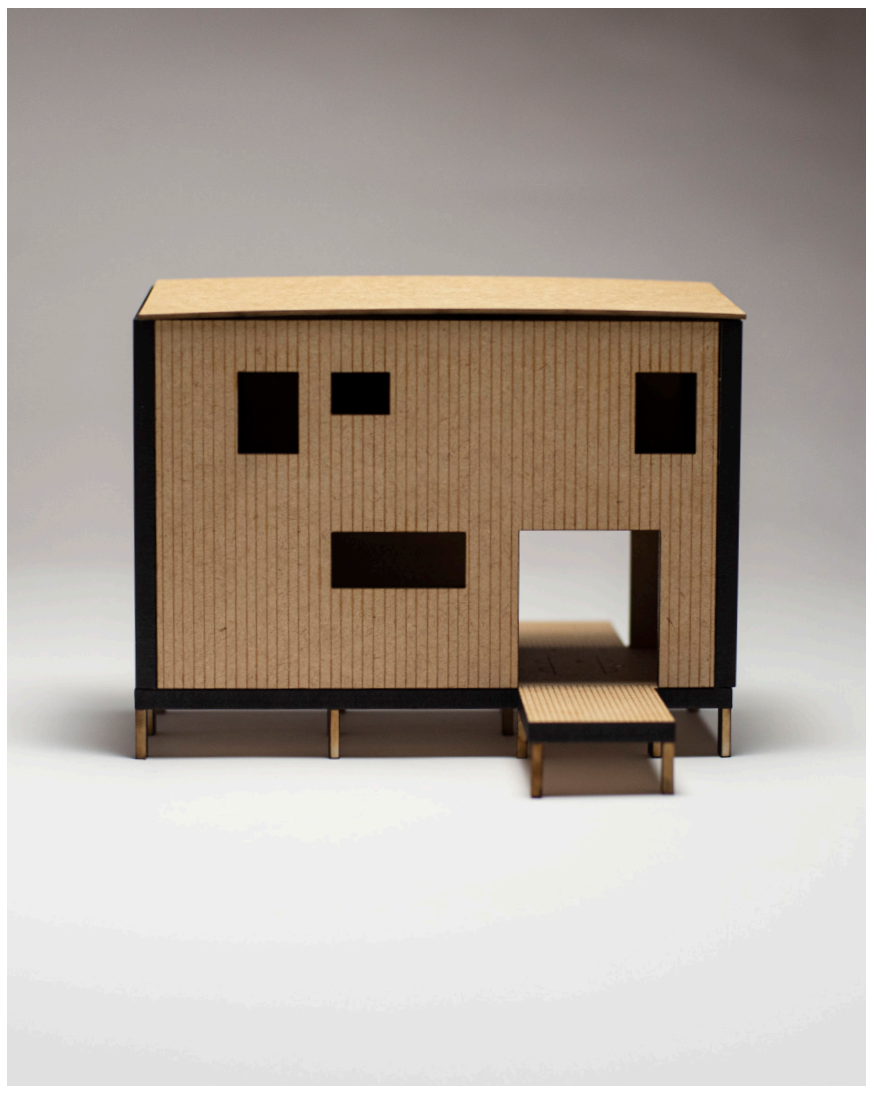

2
2
0
$\times$
0
0
0
0
0
0
0
0
0
0
0
1
7
0
5
7
0
0
0
0

Figure 2.21 Warrander Studio model back elevation

\section{WARRANDER STUDIO}

Modelling Exercise

The Warrander studio was modelled as a key precedent. This modelling exercise aimed to allow an understanding of the spaces, spatial configuration and composition of the house. The findings from this exercise are the thickness of CLT walls vs standard and internal walls. While understanding the spatial layout with the floor plan etched onto each level and the minimal slope to the roof visualised as if it is flat. 


\section{Studio 19}

Tactics of Affordability

The Studio 19 Bach located in the Coromandel was designed by 16 third year students at Unitec, in collaboration with architects, David Stratchan and Marshall Cook. The project gave students an opportunity to learn practical skills such as timber design and construction, working collaboratively and working to a small budget. The total budget for the two bedroom dwelling was $\$ 120,000$, with a total footprint of $100 \mathrm{~m}^{2}$; a $75 \mathrm{~m}^{2}$ interior and $25 \mathrm{~m}^{2}$ of decking. The dwelling is clad with board and batten plywood, with plywood ceilings and walls in the interior. High thermal performance is achieved by the envelope penetrated by a slatted timber breezeway; a key architectural element of the dwelling. (Strachan Group Architects, n.d.)

Tactics of Affordability:

- Prefabricated design that was trucked to site.

- Designed and constructed by students; significant reduction in professional fees.

- Clip on decking and pergolas that were prefabricated offsite.

- Thermal performance: cross ventilation, timber slated breezeway.

- High levels of insulation.

- Working with site contours.

- Structurally insulated panelled roof.

This image has been removed by the author of this thesis for copyright reasons.

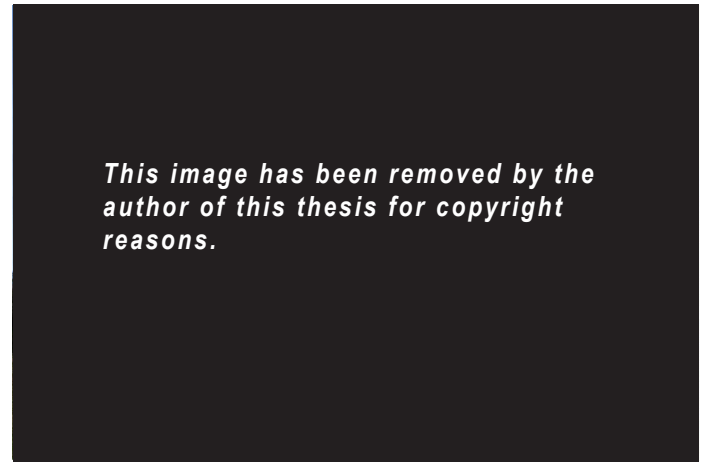

Figure 2.23 Studio 19 Exterior

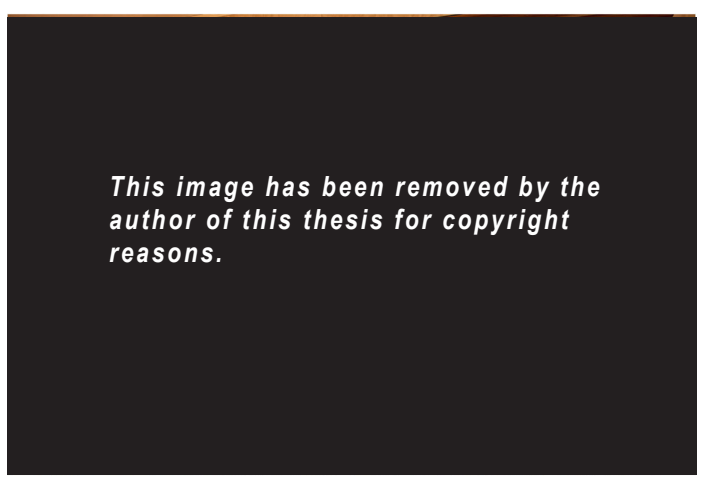

Figure 2.25 Timber interior

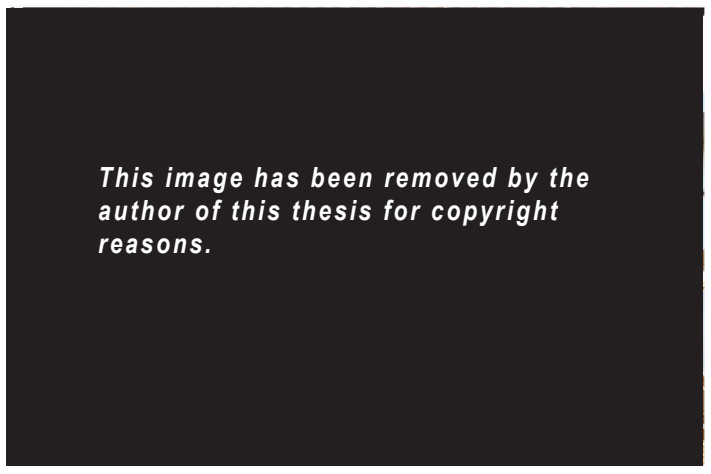

Figure 2.24 Studio Exterior Materiality

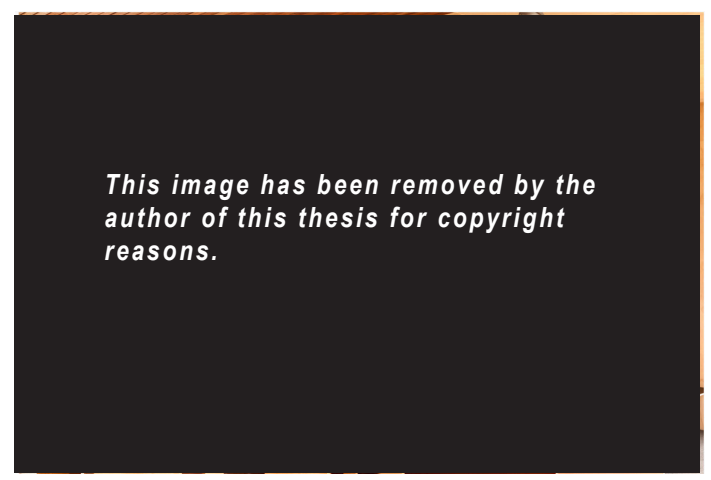

Figure 2.26 Double usage furniture 


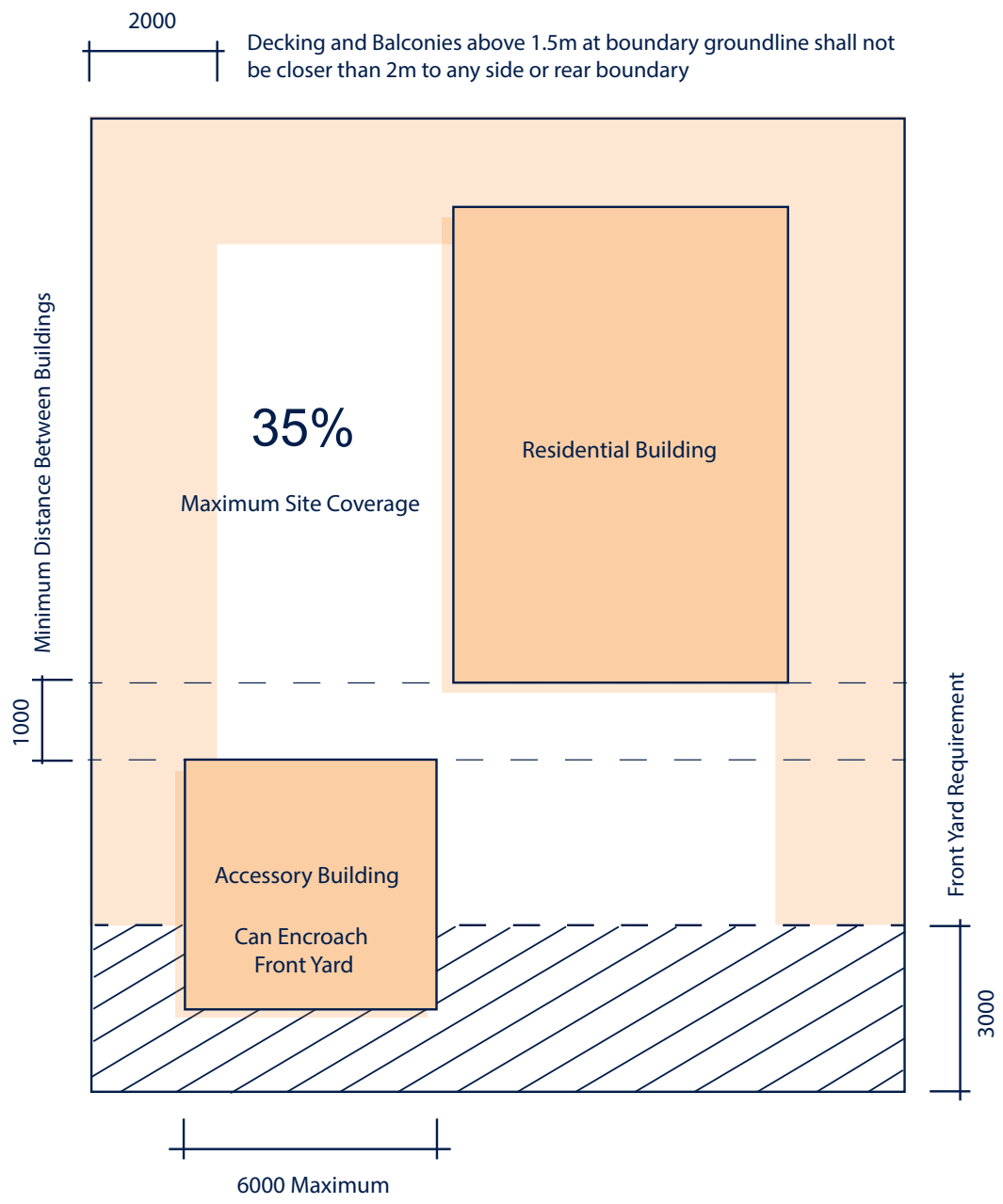

Figure 2.27 Outer Residential Zoning District Plan Requirements Diagram

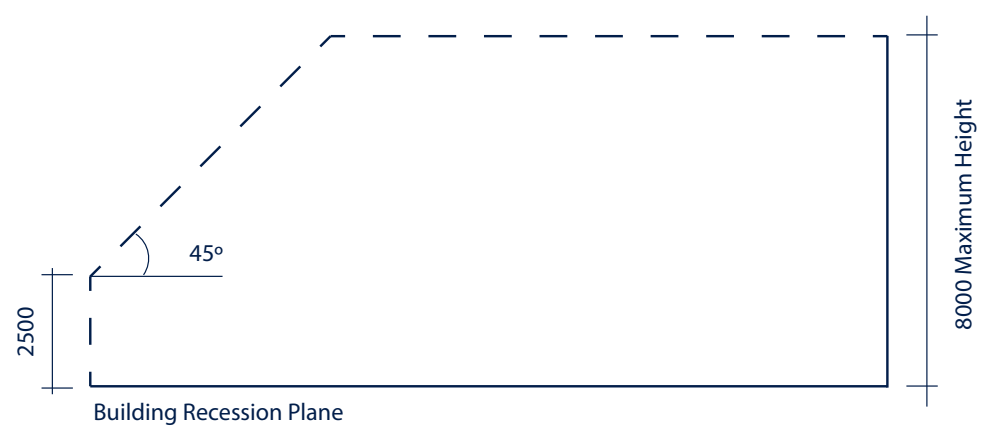

Figure 2.28 Building Recession Plane Requirements

The Wellington Region District Plan in accordance to Wellington City Council (2009) regulations is diagrammed in figures 2.27 and 2.28 for outer residential zoning. An architect has no control over the building envelope. Working within these restrictions ensures a design does not require additional costs of applying for a resource consent. 
Figure 2.2955 Chapman Street Plan Implementing the District Plan

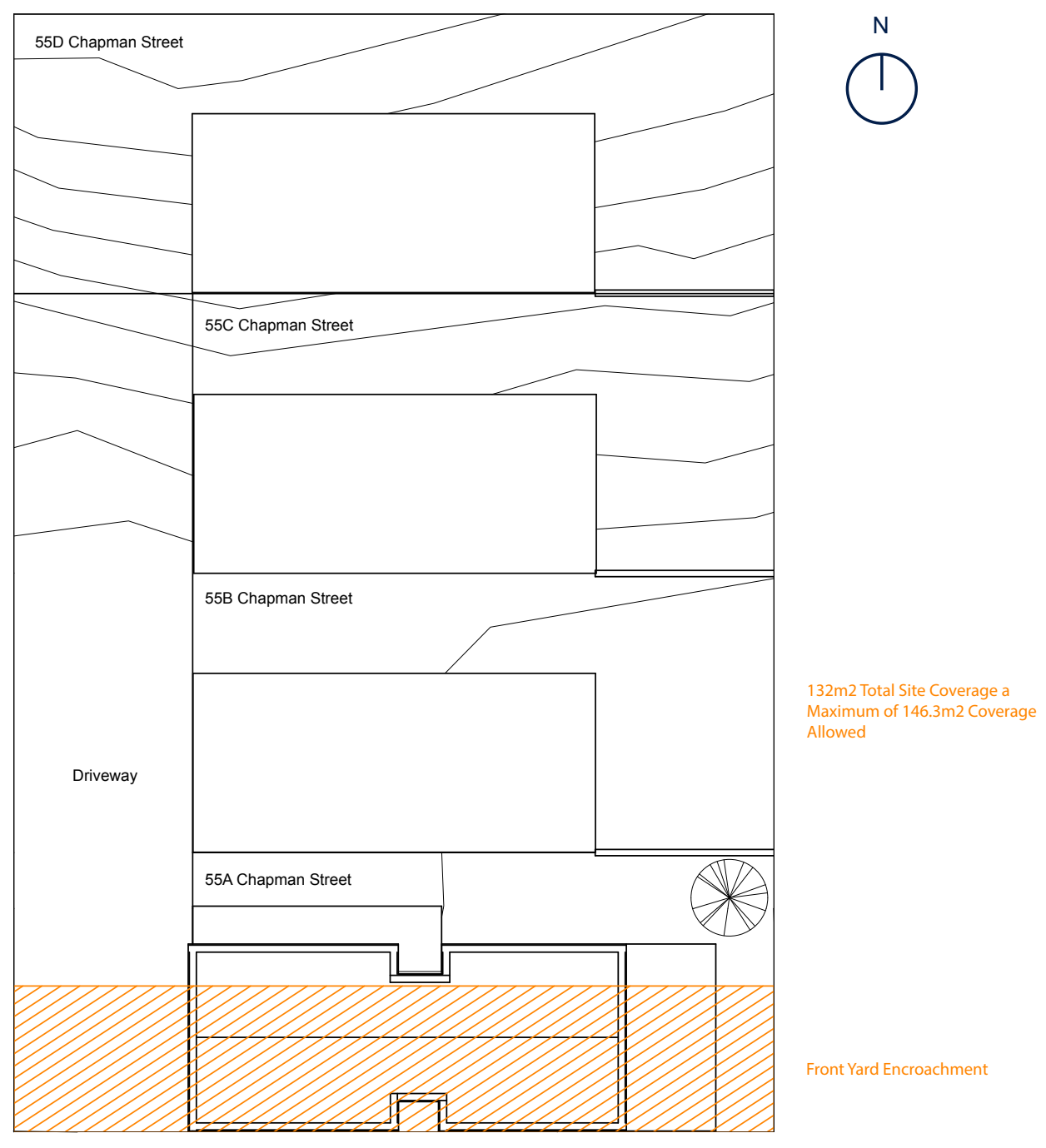

55 Chapman Street Site Plan

Figure 2.30 55 Chapman Street West elevation interation on the building envelope

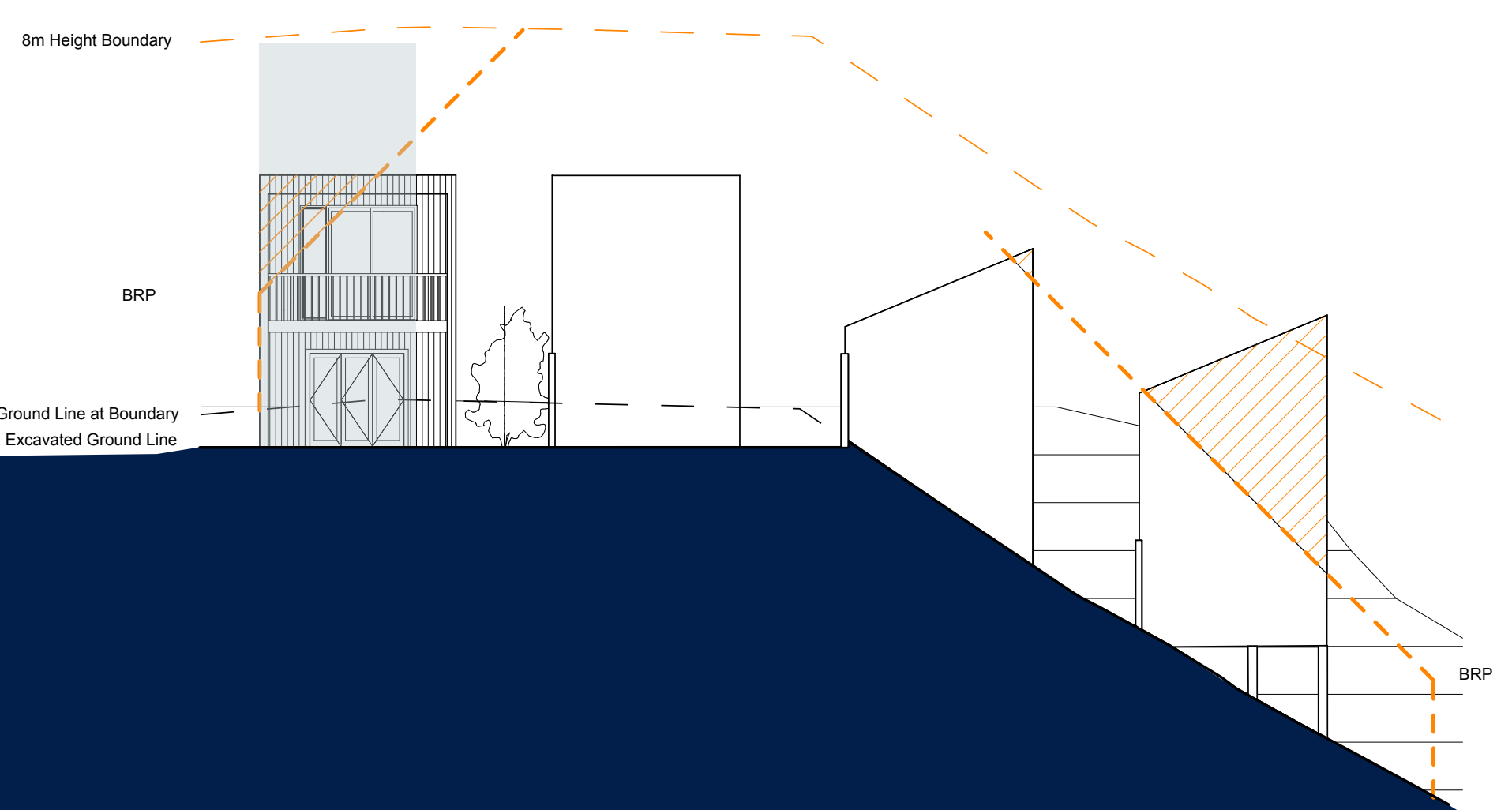




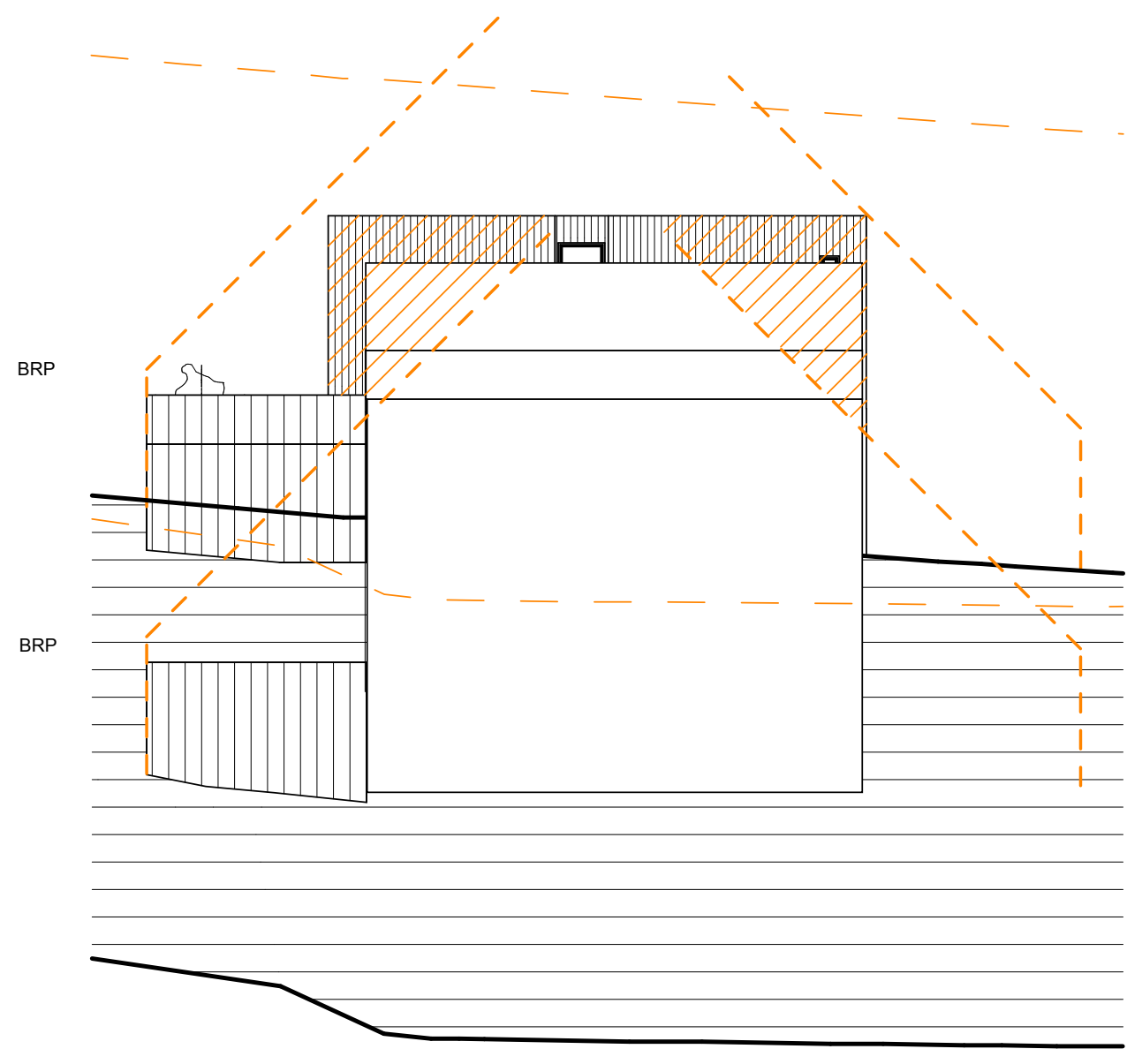

8m Height Boundary

BRP

Ground Line at Boundary $8 \mathrm{~m}$ Height Boundary

BRP

Figure 2.3155 Chapman Street North elevation interation on the building envelope

Figure 2.3255 Chapman Street South elevation interation on the building envelope

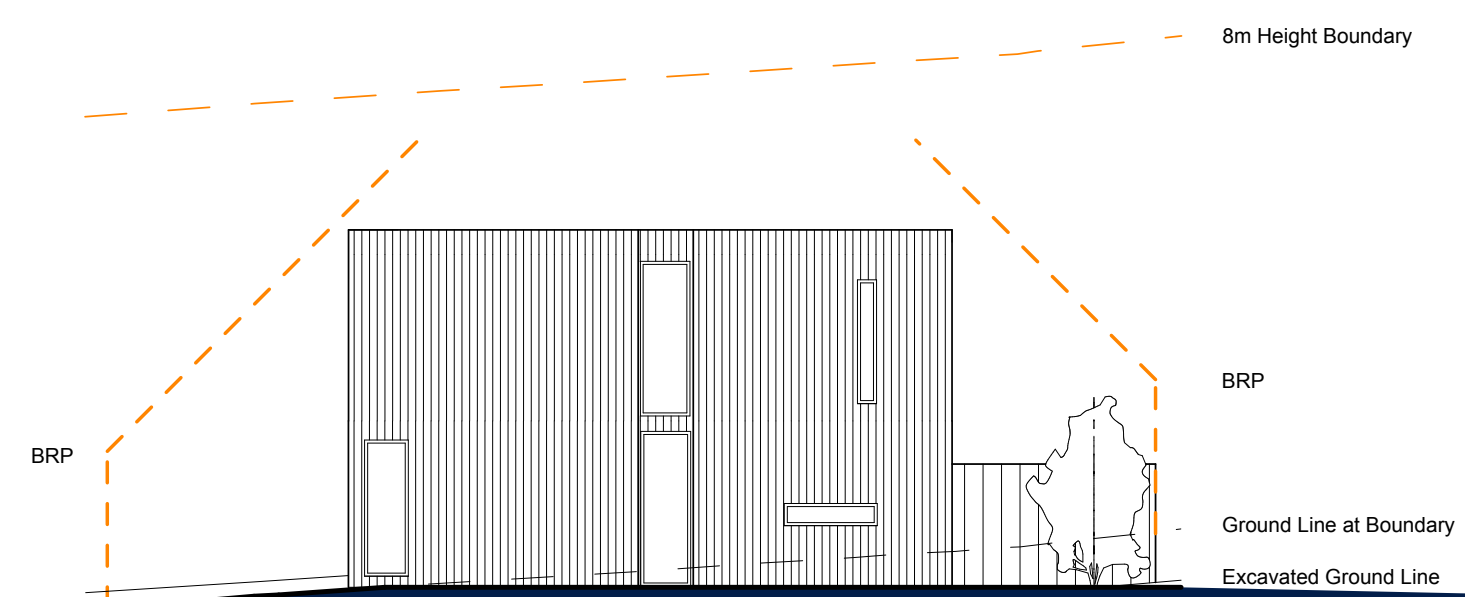




\title{
The District Plan
}

\author{
Implemented on Site
}

The district plan is applied to the plot arrangement showing areas of encroachment requiring amendment seen in figures 2.29 - 2.32. Figure 2.29 shows plot $A$ encroaches the front yard requirement, solved by reducing the number of plots to 3 . Figures $2.30-2.32$ illustrate the encroachments within the building envelope. Issues occur surrounding the connection between the hill and the building envelope. This includes the requirement of excavation or a low height dwelling to sit below the 45-degree angle. Housing typology 1.1 will sit within the building envelope for all elevations when behind the front yard requirement.

\section{Site Arrangement}

Accomodating The District Plan

Three different site arrangements are iterated, exploring access and plot arrangement and accommodating for district plan requirements. The site is reduced to three plots due to the district plan requirements (figure 2.33). Figures 2.34 and 2.35 rotate the site arrangement to allow plots $B$ and $C$ to gain a larger building height. This is explored in section as well as plan, showing the interaction with the building envelope.

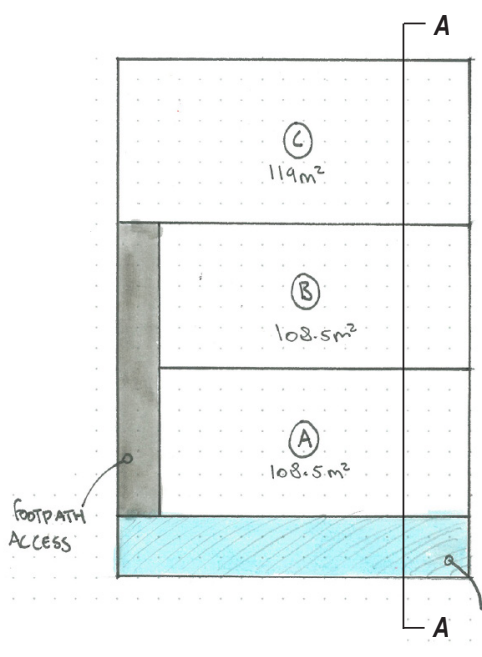

Figure 2.33 Plot Arrangement A

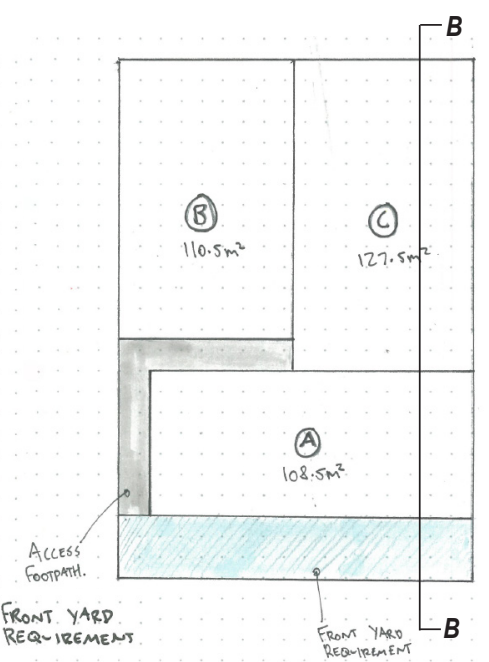

Figure 2.34 Plot Arrangement B

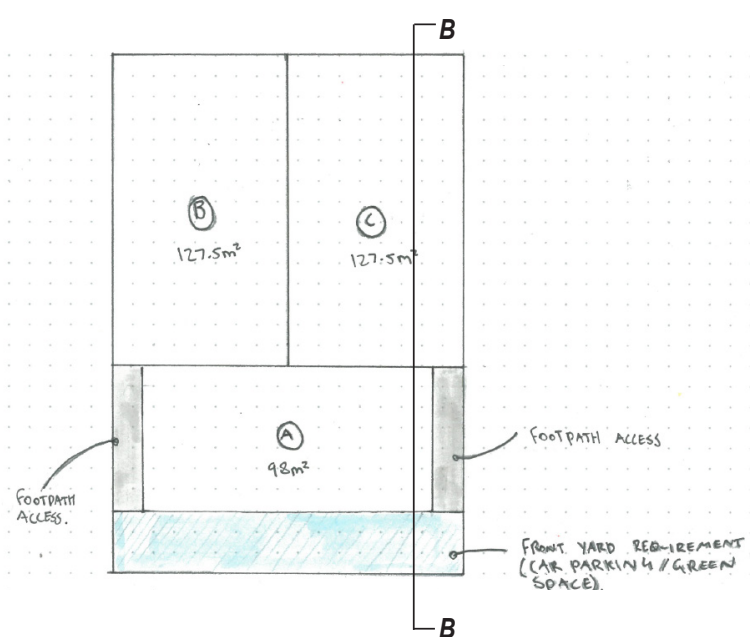

Figure 2.35 Plot Arrangement C 

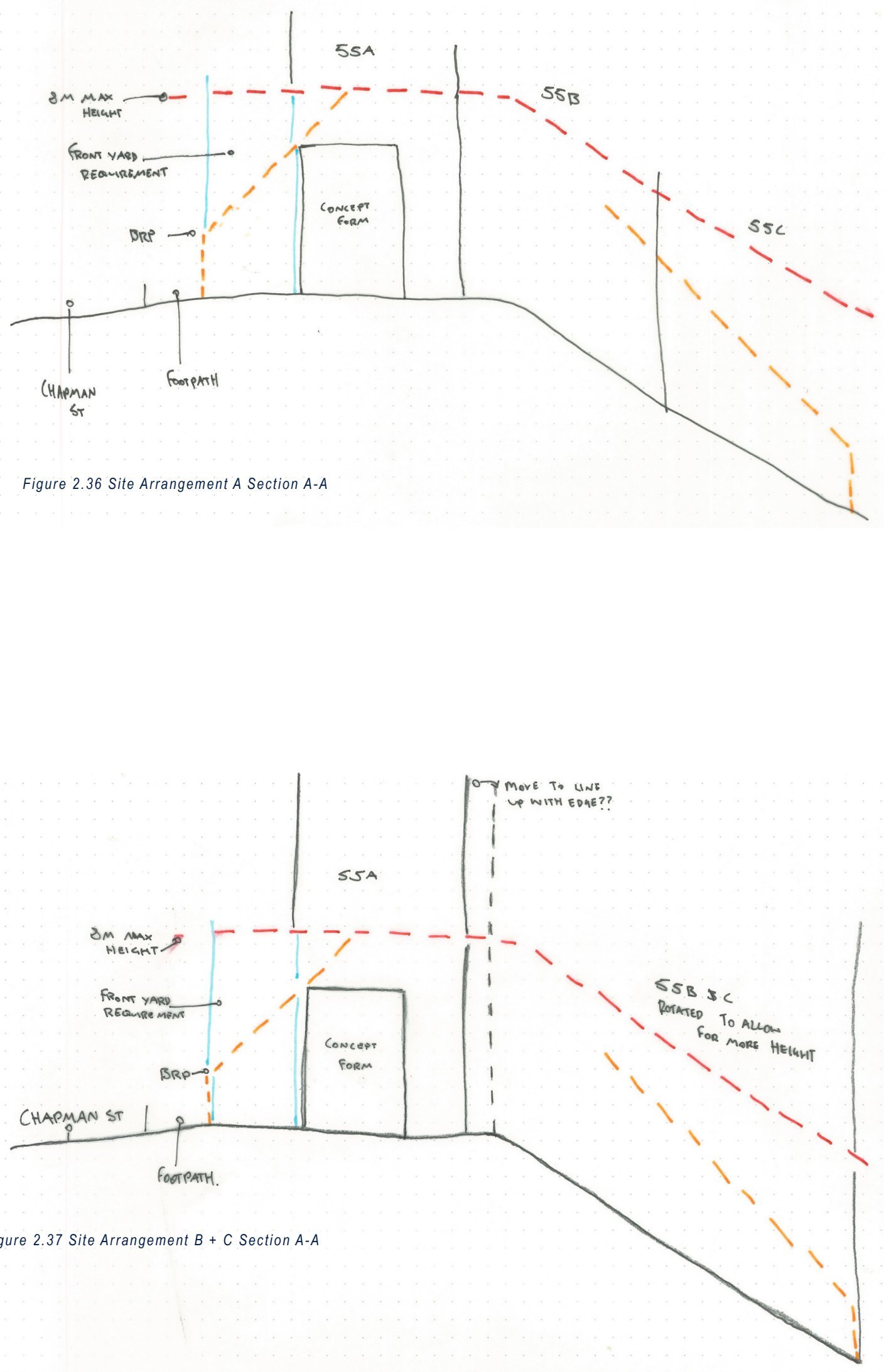


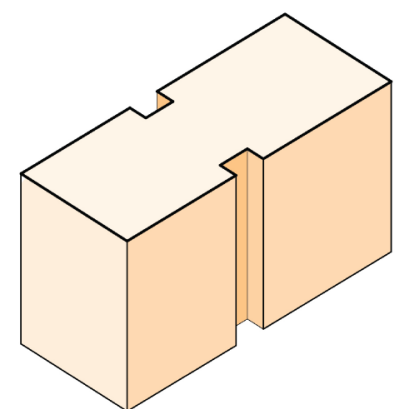

Floor Plan Form

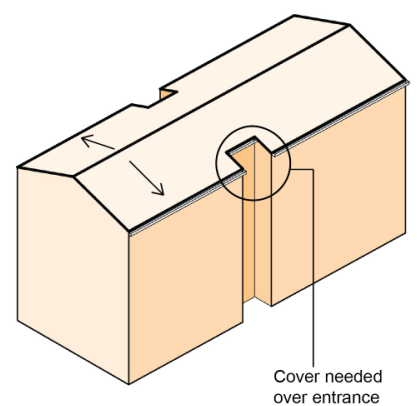

Form Development Series and Guttering Location

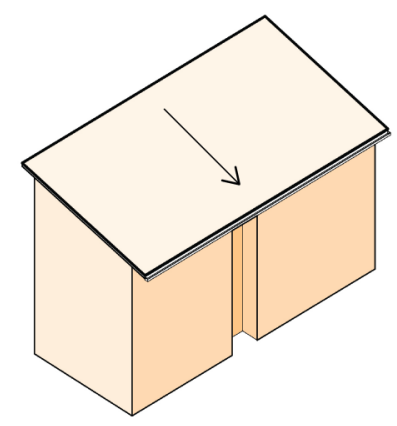

Monopitched Roof with Overhang $\longleftrightarrow$

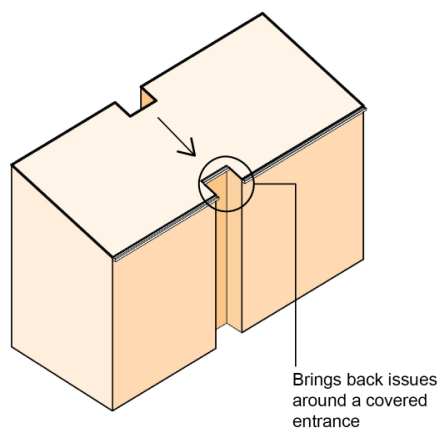

Cut outs added and overhangs removed

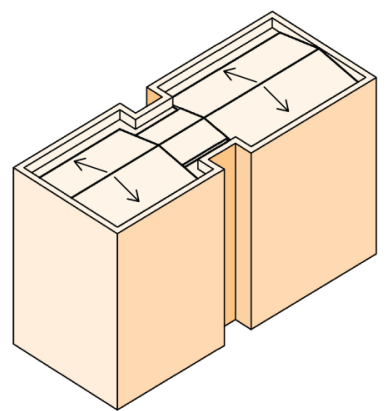

Internal Guttering Option 1 Conceptual Form

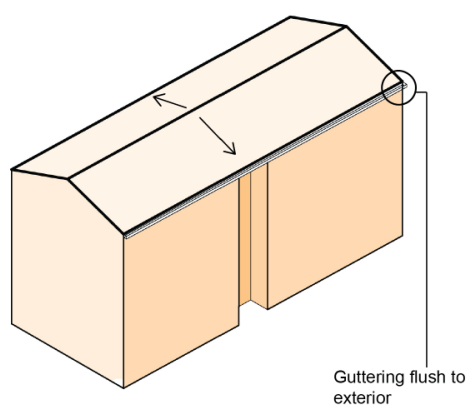

Simplified with Cutouts Removed

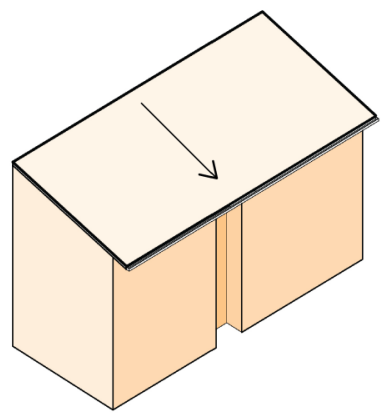

Overhang One Side Only $\longrightarrow$

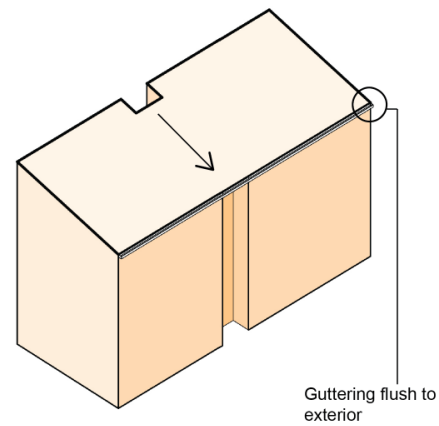

One Cut Out Removed

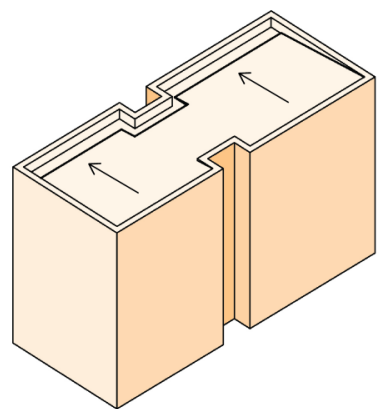

Internal Guttering Option 2 Conceptual Form

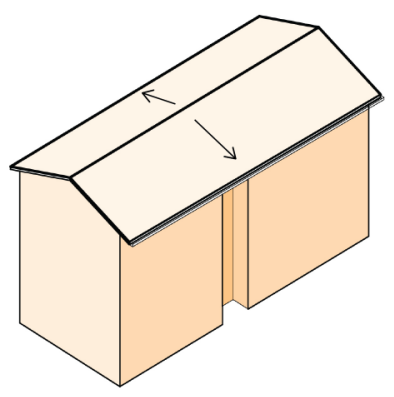

Overhang Added $\longleftrightarrow$

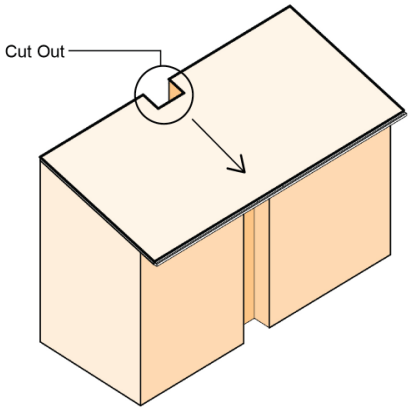

Overhang One Side Only

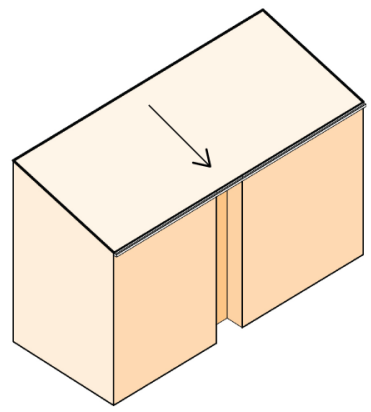

Simplified for Economical Reasons

Figure 2.38 A series of roofing developments for housing typology 1.1 

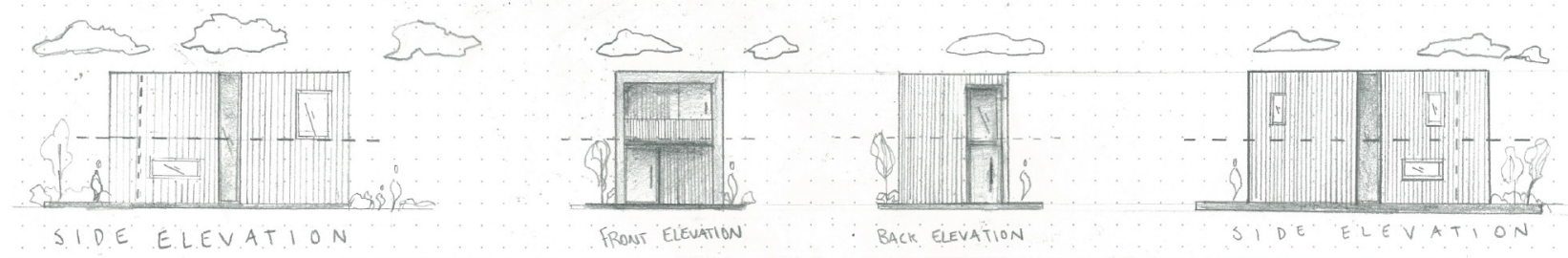

Figure 2.39 Original flat roof of typology 1.1
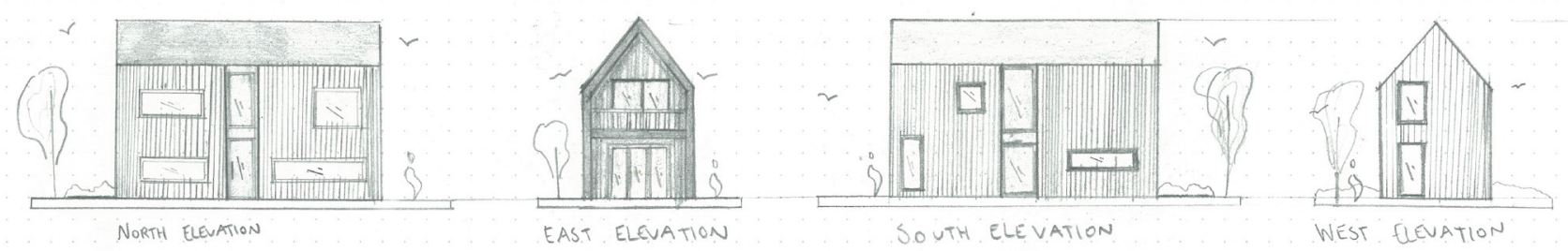

Figure 2.40 Gable roof form exploration of typology 1.1

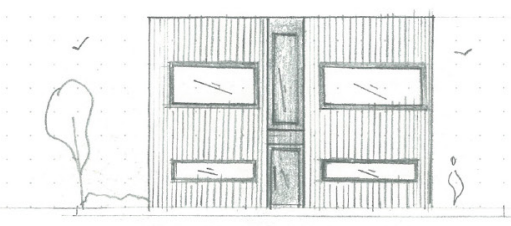

NORTH ELEUATION

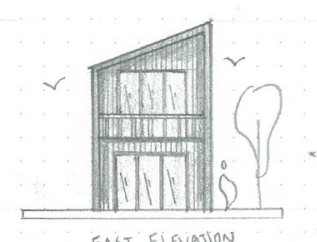

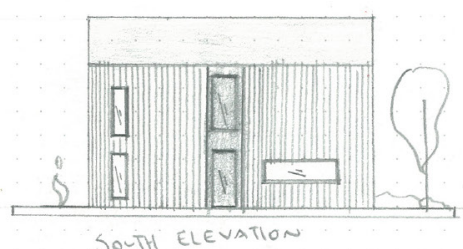

SOUTH ELEVATION

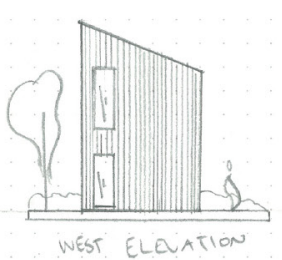

Figure 2.41 Monopitched form exploration of typology 1.1

Form Development

Housing Typology 1.1

This series of design iterations aims to explore design variations of the roof; through aesthetic appeal and economic reasoning. Sketchup has been used as a tool to mass the basic form of the house and to quickly change iterations shown in figure 2.38 . The iterations started with a flat roof, however economically the build-up for this type of roof is considerably more than a standard roof. Iterations explore overhangs, guttering placement, cut outs and simplification of the overall form. Digitally massing the overall external envelope and form is developed through a series of sketches. These sketches are focusing on the form and predominantly the northern face, which required a larger glazed area. 


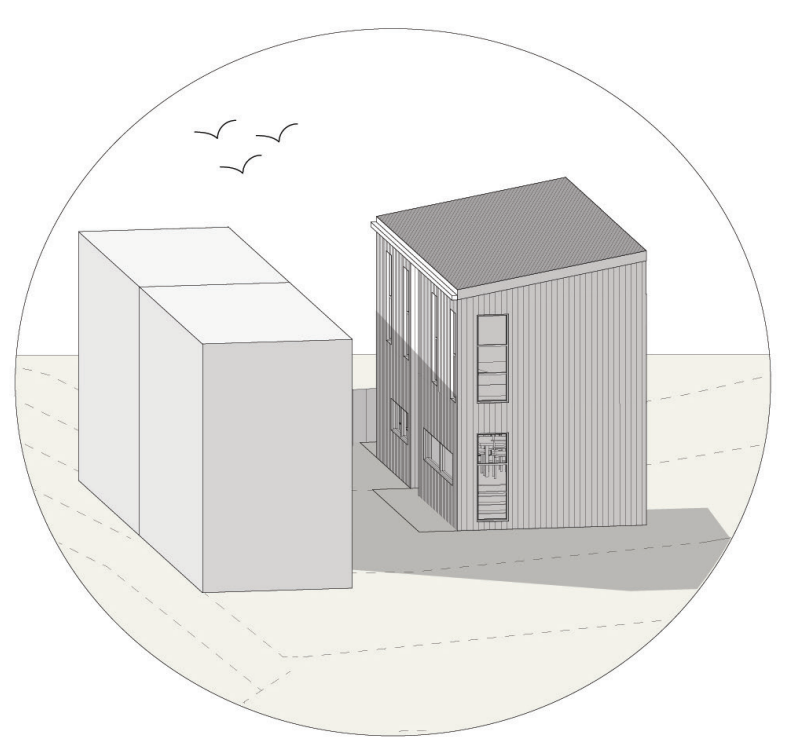

Figure 2.43 Two storied house shading onto plot A

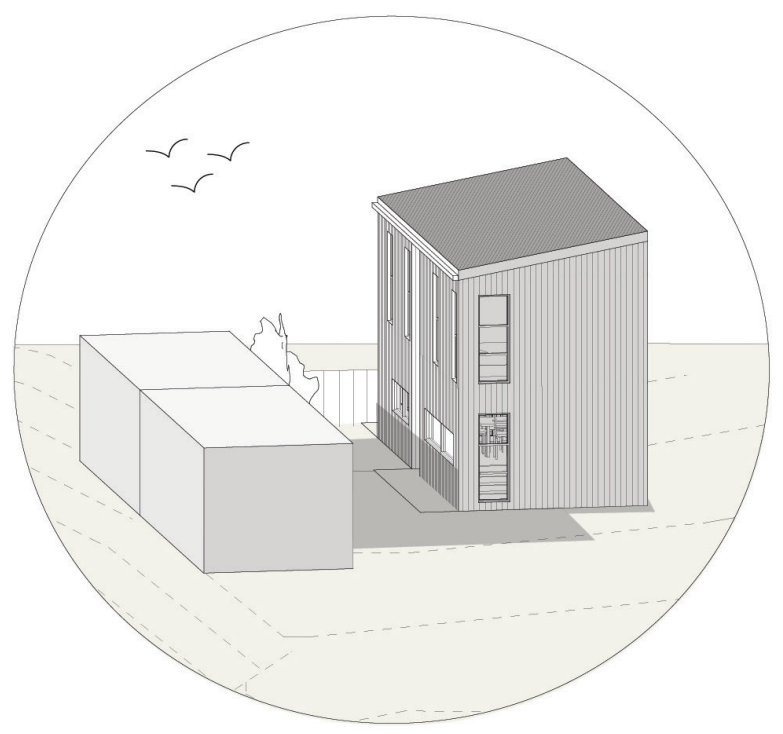

Figure 2.42 Single storied house shading onto plot $A$

\section{Sunshading Analysis}

Sun shading is an issue shown in figure 2.41 when a two storey house, allowed by the building envelope, is placed in front of plot A. All northern sun is blocked out on the ground floor, where the living areas are located, thus decreasing the value of the quality of living in this house. In comparison a single storey house shown in figure 2.42 reduces the impact of shadowing on plot $A$, allowing northern sun to enter. The quality of living involves, allowing a substantial amount of sunlight into all houses on the site, which reduces energy costs and considers the wellbeing of occupants. 


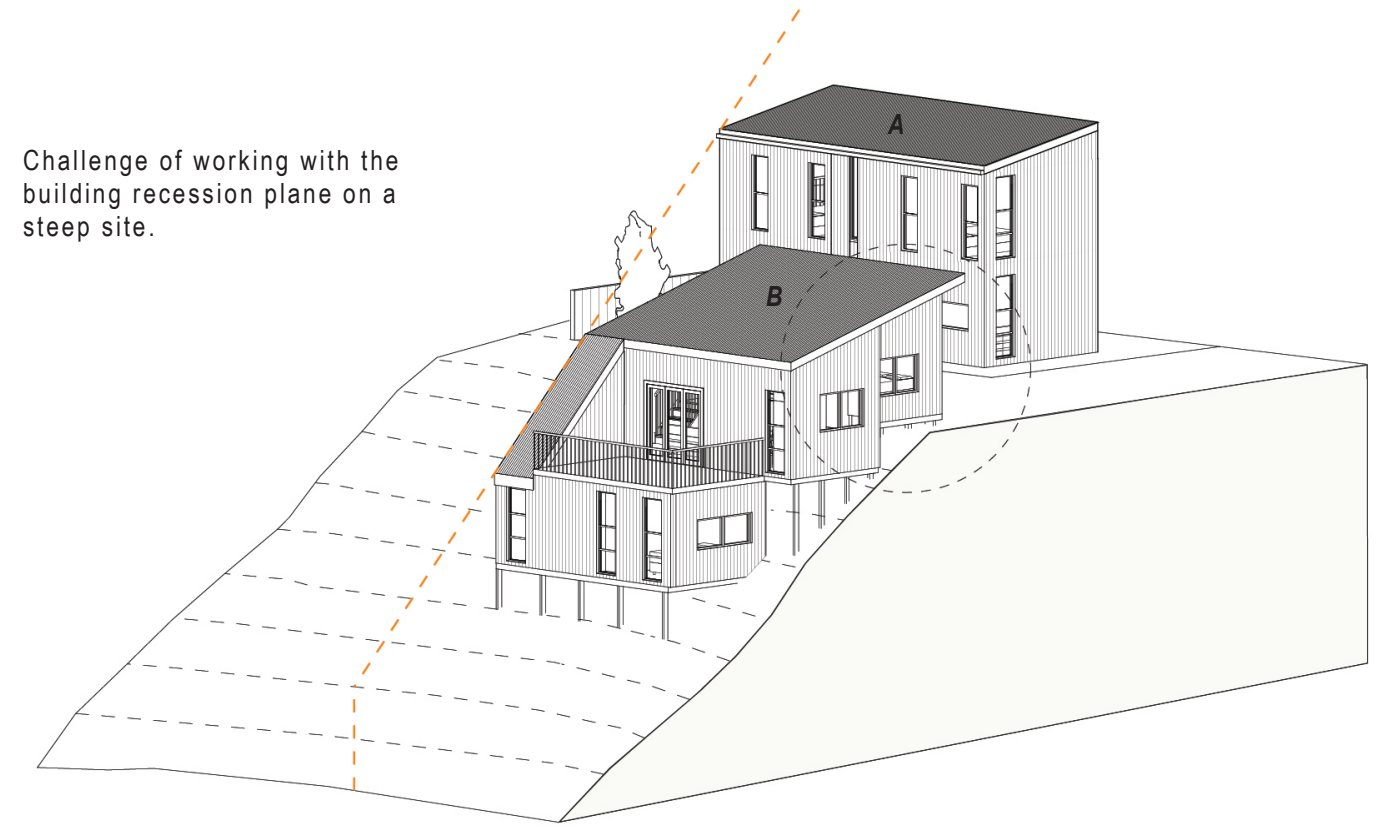

Figure 2.44 Final Site Iteration 2.1.2

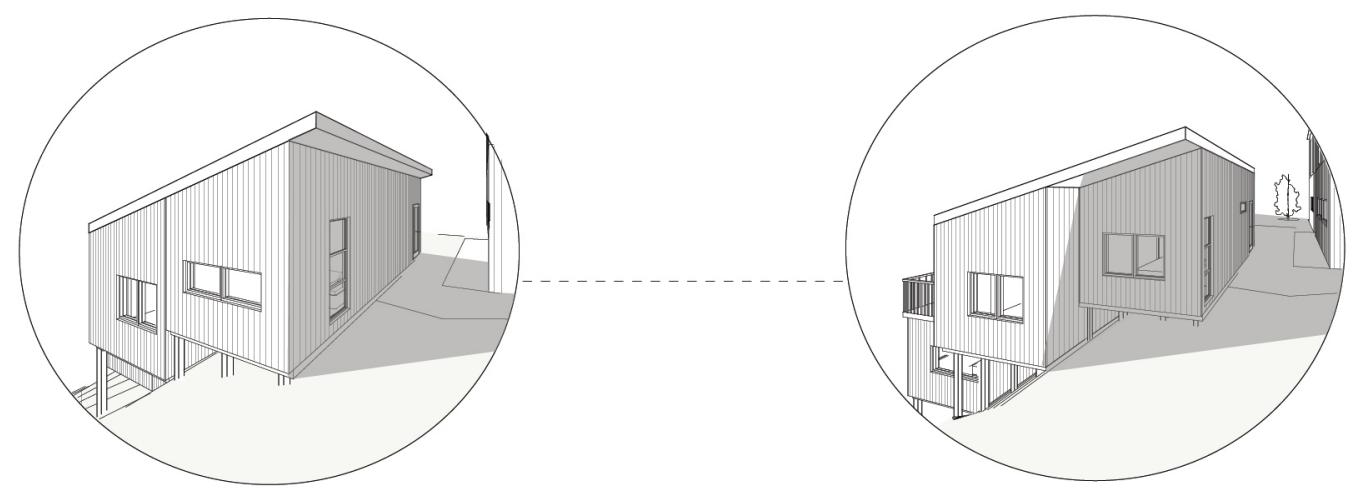

Figure 2.45 Iteration 2.1.1 South Face

Figure 2.46 Iteration 2.1.2 South Face
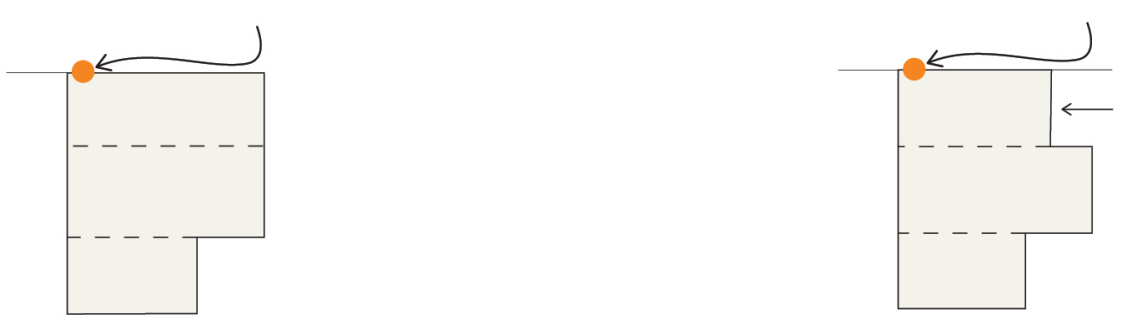

\section{Design Development}

Iteration set 2.1 faced the challenge of working with the building recession plane on a steep hill site. Iteration 2.1.1 started with a basic form placed on the boundary of plot A. Modular forms have been used to reduce the complexity, allowing for a faster build time. Figure $2.45 \& 2.44$ show the entrance points of the house and arrangement of the modules. Iteration 2.1.2 has an offset added with a roof overhang. There are privacy issues with the entrance shown in figure 2.45 running along the side of plot $A$. 
Roof form developed to allow natural light from the north into the south module

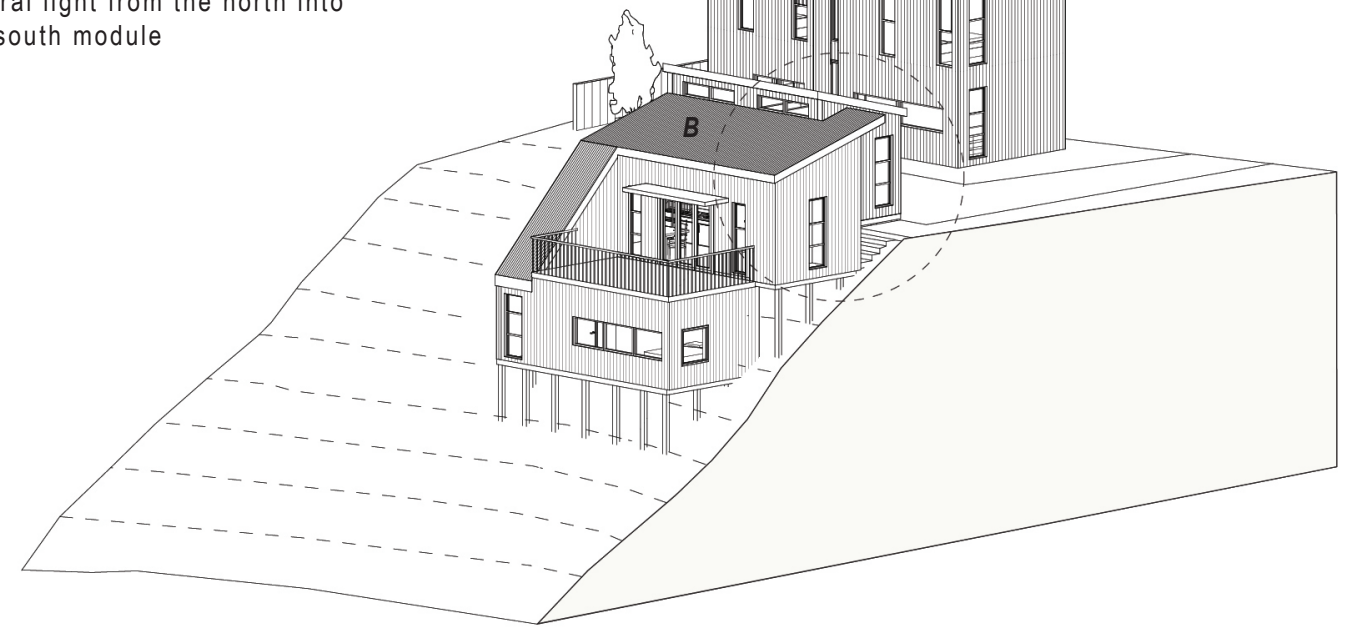

Figure 2.47 Final site Iteration 2.2.2

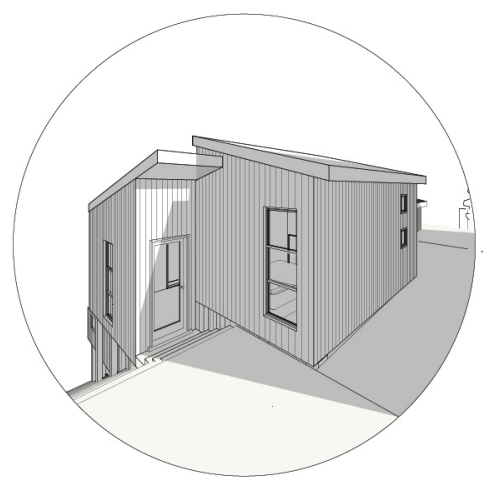

Figure 2.48 Iteration 2.2.1 New entrance with stairs and rain shelter

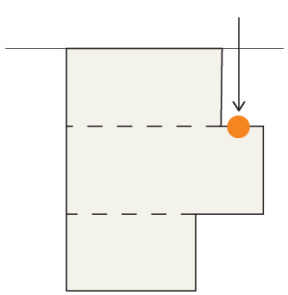

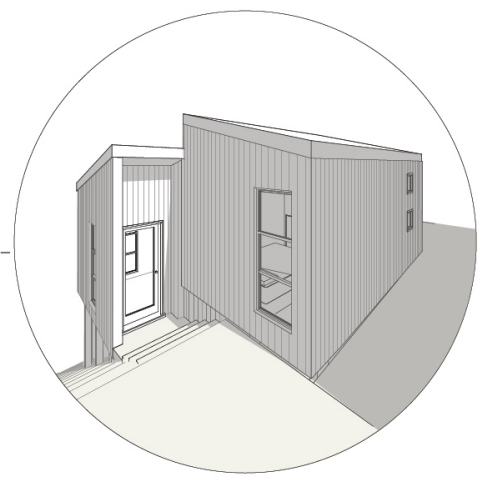

Figure 2.49 Iteration 2.2.2 developed entrance, creating an entrance way

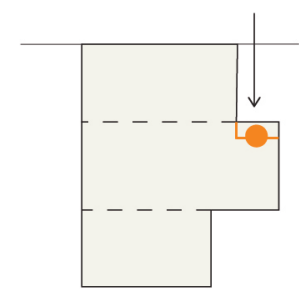

\section{Design Development}

Iteration set 2.2 develops the roof form to allow natural light from the north into the southern module. The entrance in iteration 2.2.1 has been moved, with stairs added, to create an entrance, seen from the pathway on site. Iteration 2.2.2 develops the entrance further with a pushback of the wall, allowing for a landing at the bottom of the steps. The roof form is simplified to create a regular form for construction.

Iteration 2.3.1 explores dual housing. This is an economic decision to share one exterior wall keeping costs at a minimum. Although there are issues around the aesthetic appeal of this arrangement.

In iteration 2.4.1 house $\mathrm{C}$ is pushed forward for aesthetic purposes to break up the design, although it still shares the same exterior wall. Iteration 2.4.1 is Phase Two's design pause. There are economic issues around house $\mathrm{C}$. This is due to the large amount of excavation and construction of retaining walls because of the contours on one side of the site being slightly steeper. 


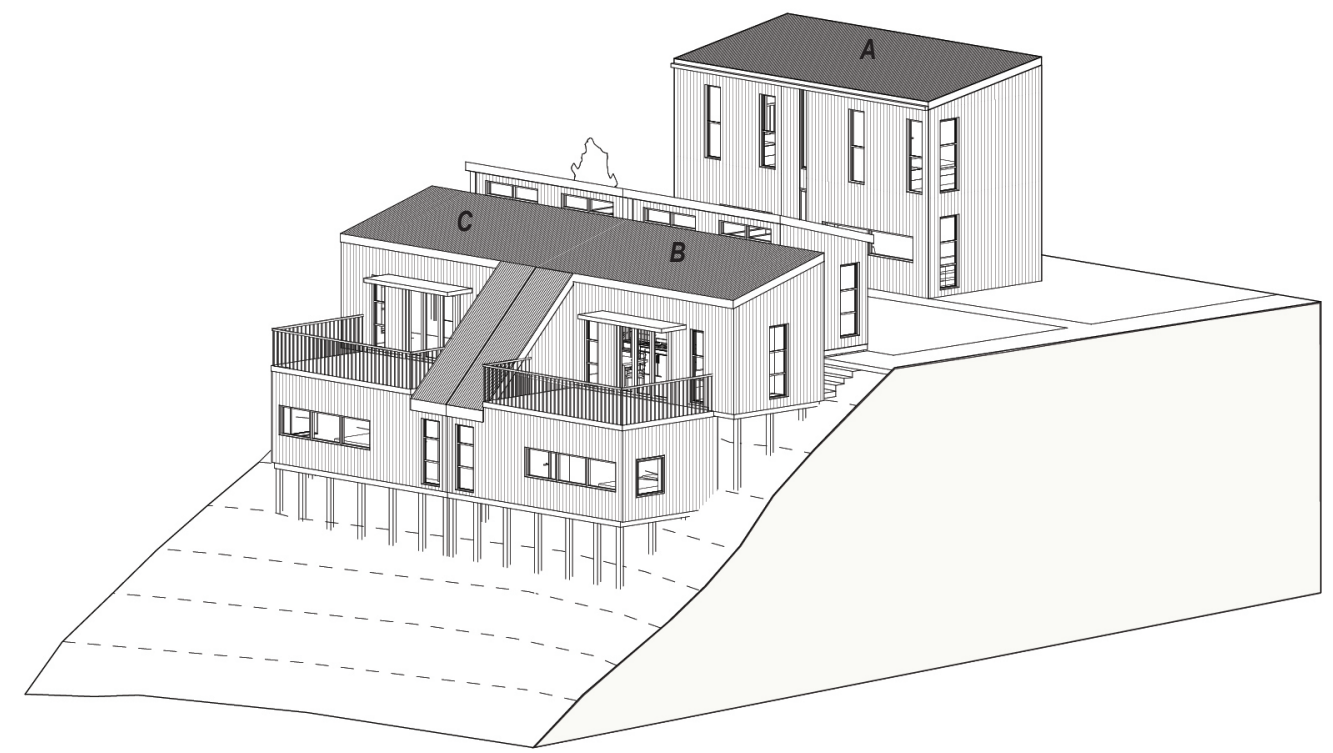

Figure 2.50 Iteration 2.3.1
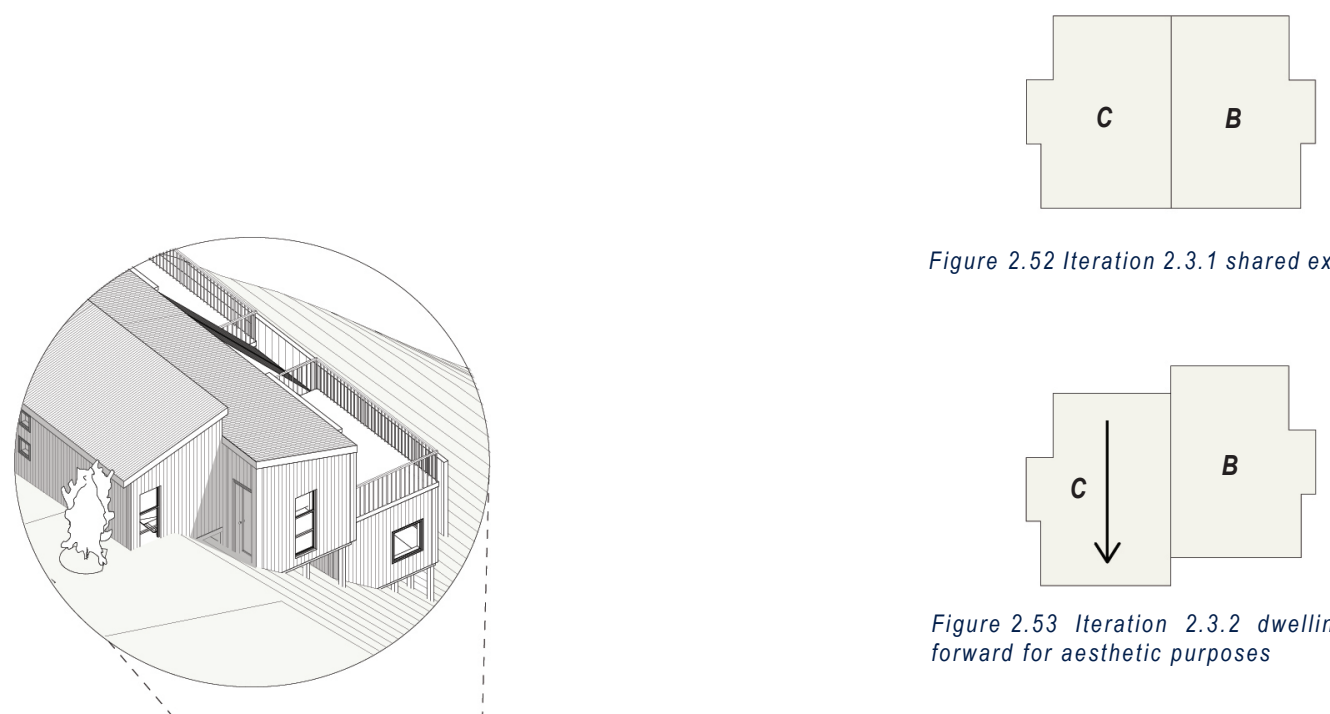

Figure 2.52 Iteration 2.3.1 shared external wall

Figure 2.54 Iteration 2.3.2 House $C$ excavation and retaining wall requirements.

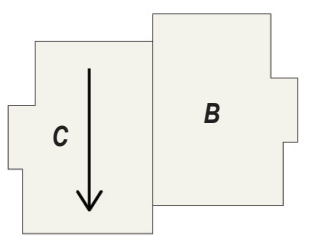

Figure 2.53 Iteration 2.3.2 dwelling C pushed forward for aesthetic purposes

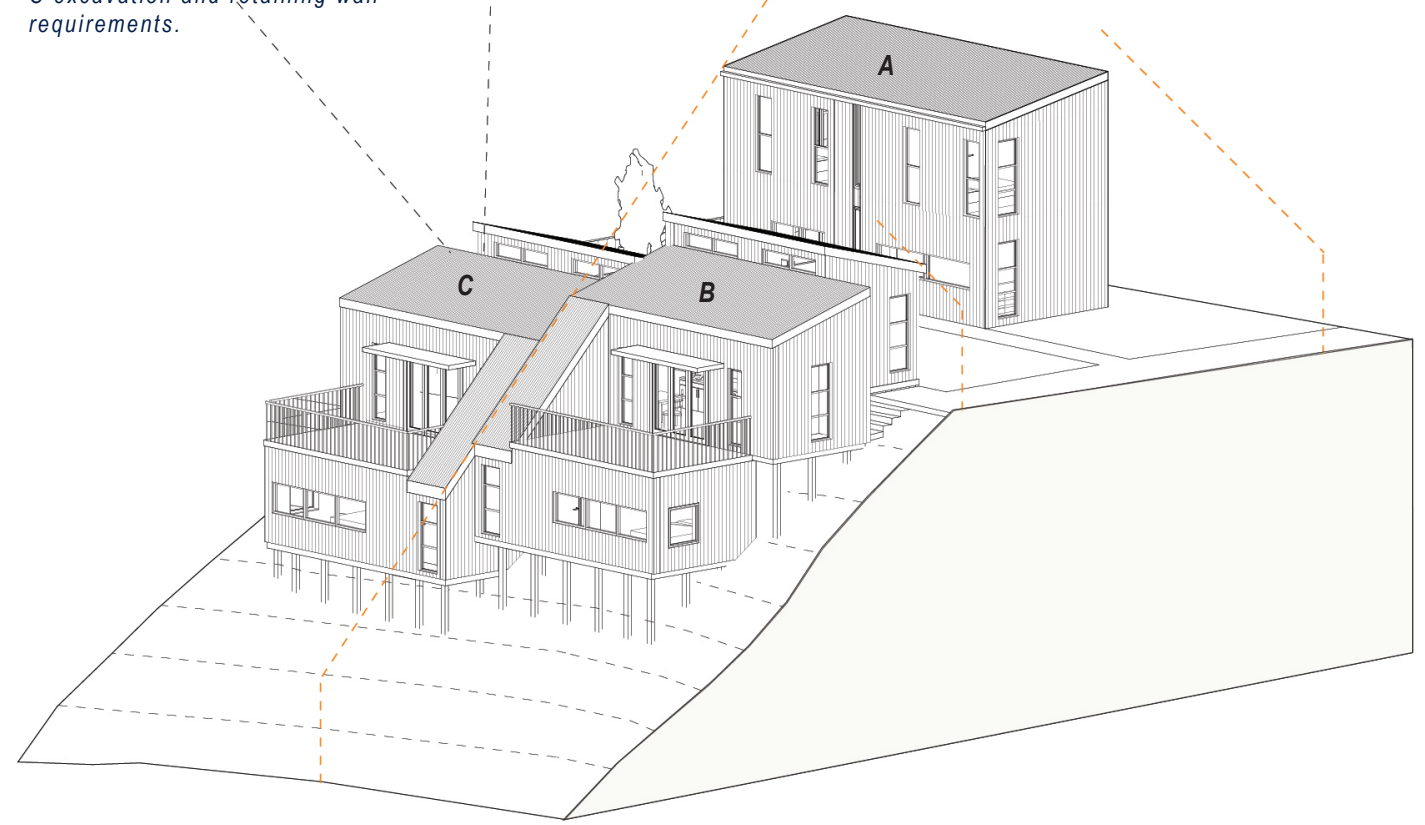




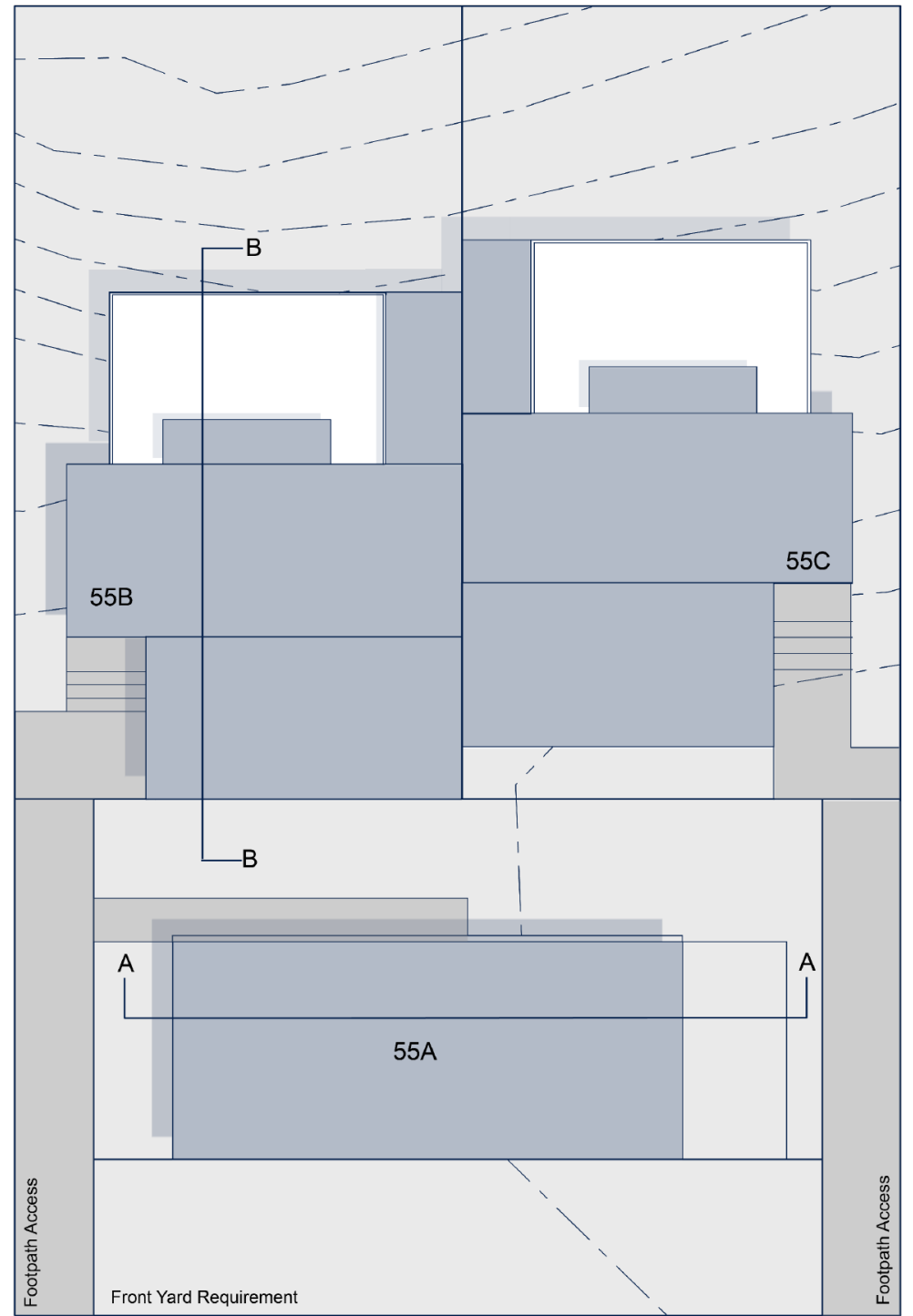

Figure 2.5555 Chapman Street Site Plan

\section{Site Plan}

55 Chapman street consists of three dwellings and two different housing typologies. The site contains two footpath access points. This is to ensure all dwellings have a level of privacy. The front yard requirement is green space for all dwellings at this conceptual phase. 


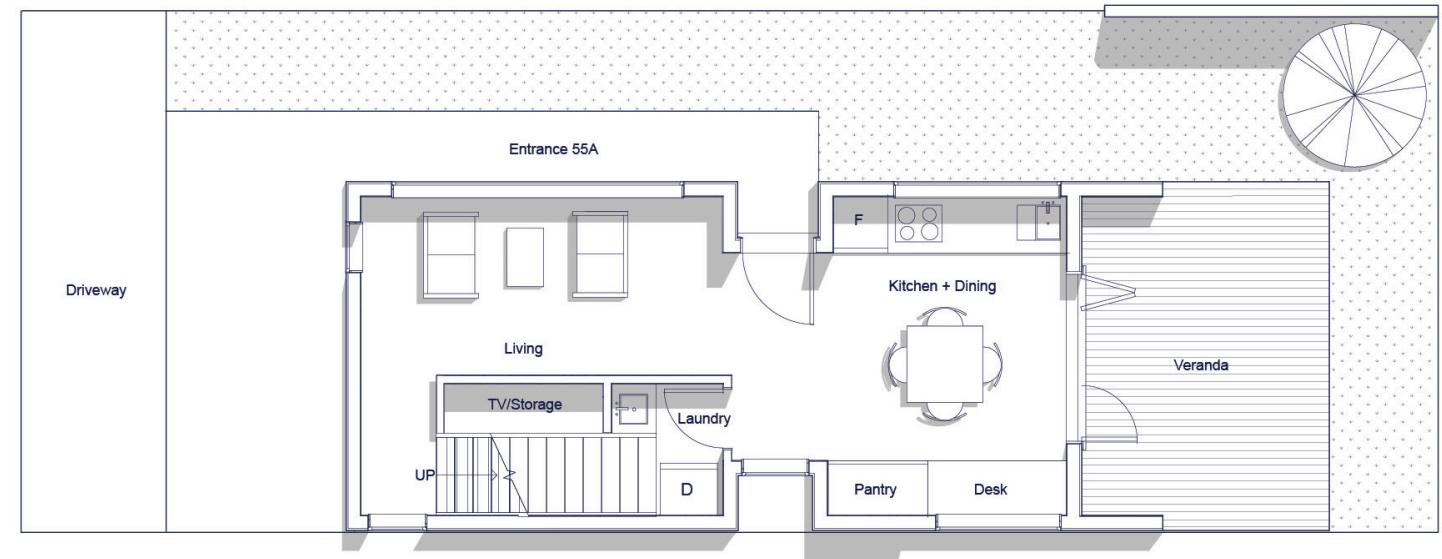

Figure 2.56 Typology 1.1 ground floor

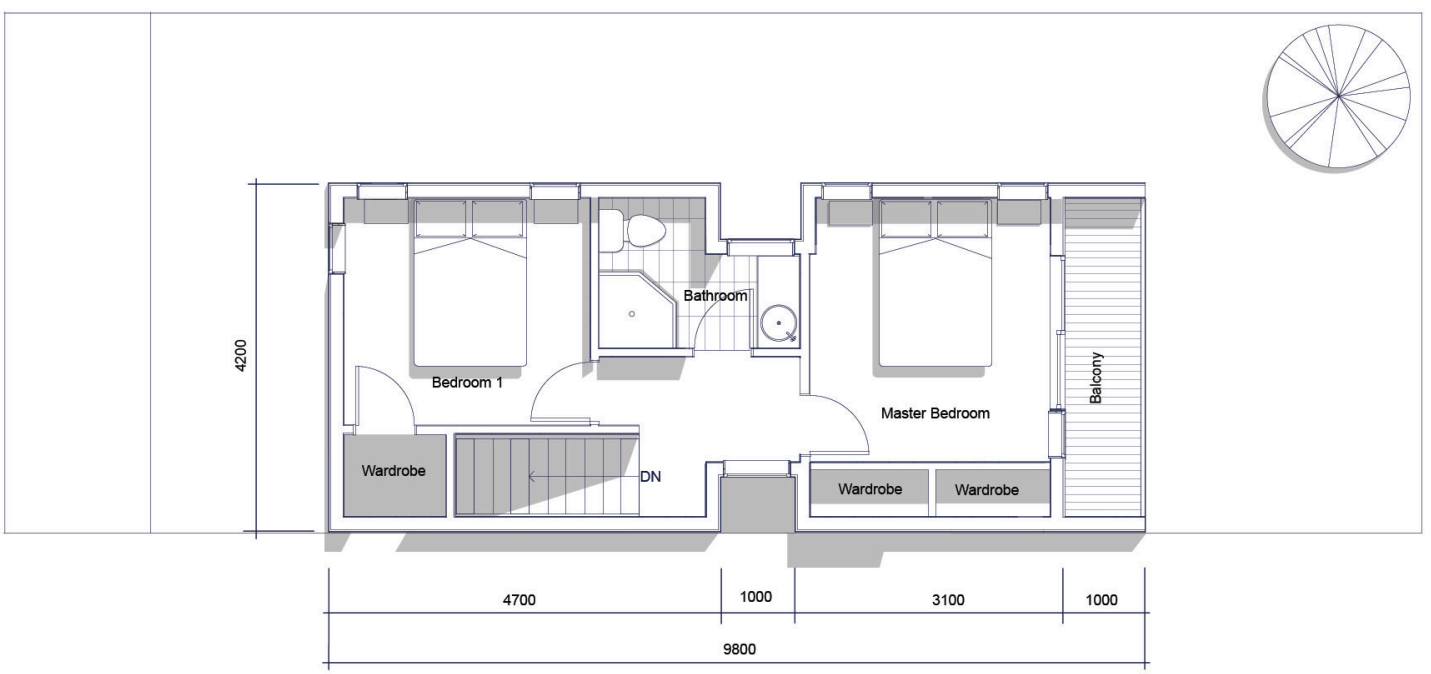

Figure 2.57 Typology 1.1 first floor

Housing typology 1.1 is a $68 \mathrm{~m}^{2}$ home that consists of two bedrooms, one bathroom and open plan living, dining and kitchen. There are strong connections to the outdoors allowing for spaces to feel spacious. Housing typologies 1.1 and 2 are both timber framed houses that follow NZS3604. Typology 1 consists of a concrete slab that holds thermomass properties, whereas housing typology 2.1.4 consists of a timber floor due to the connection of the timber piles.

Eames answer to a modern house is open plan living with multi-purpose rooms that are divided between public and private spaces. Living spaces have stand out creative details and sliding doors link interior and exterior spaces (Dejtiar, 2019). This design tactic has been impleted throughout both dwellings. 
Housing Typology 2.4.1

Floor Plan

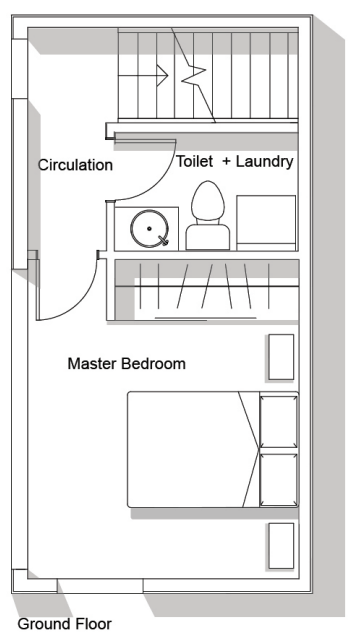

$N \in$

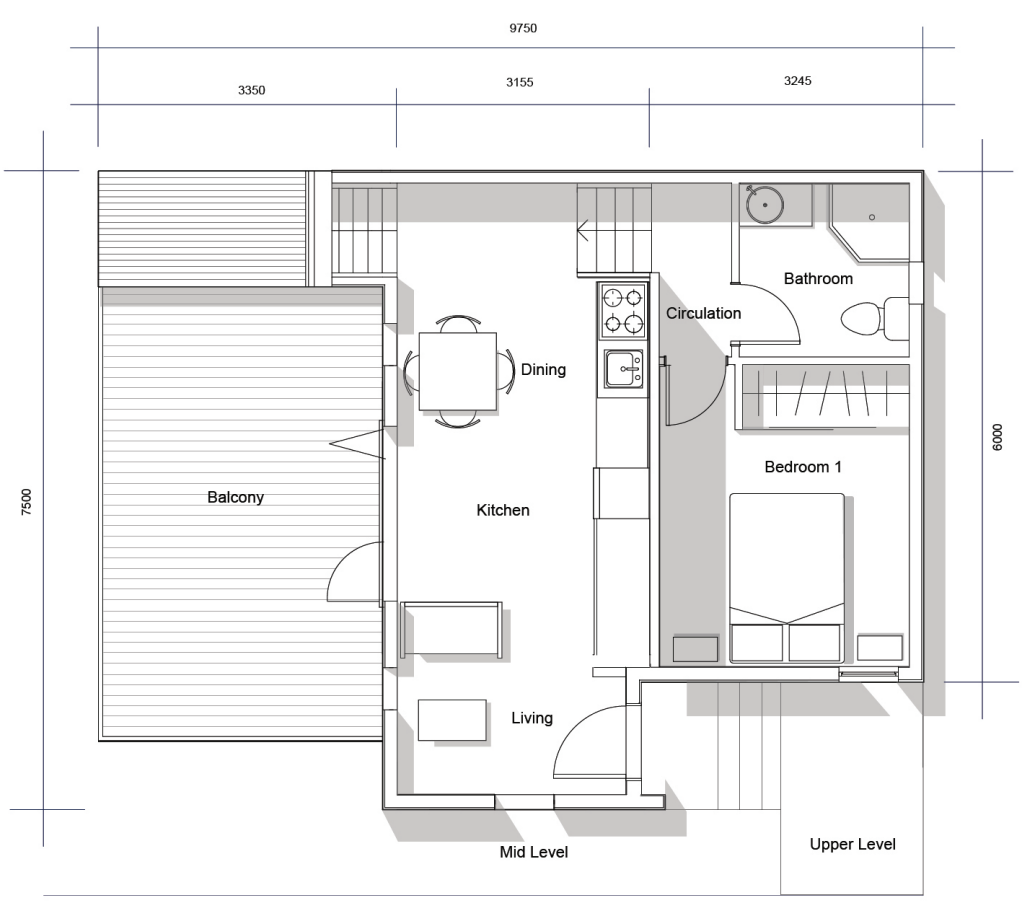

Figure 2.58 Typology 2.4.1 floor plan

Housing typology 2.4 .1 is a $68 \mathrm{~m}^{2}$ split-level home. It integrates with the contours on site, to minimise excavation costs. The house is located on timber piles. This typology consists of 2 bedrooms, 2 bathrooms and an open plan living, dining and kitchen. Housing typology 2 is used for plots B and C. 


\section{Visualising The Site}

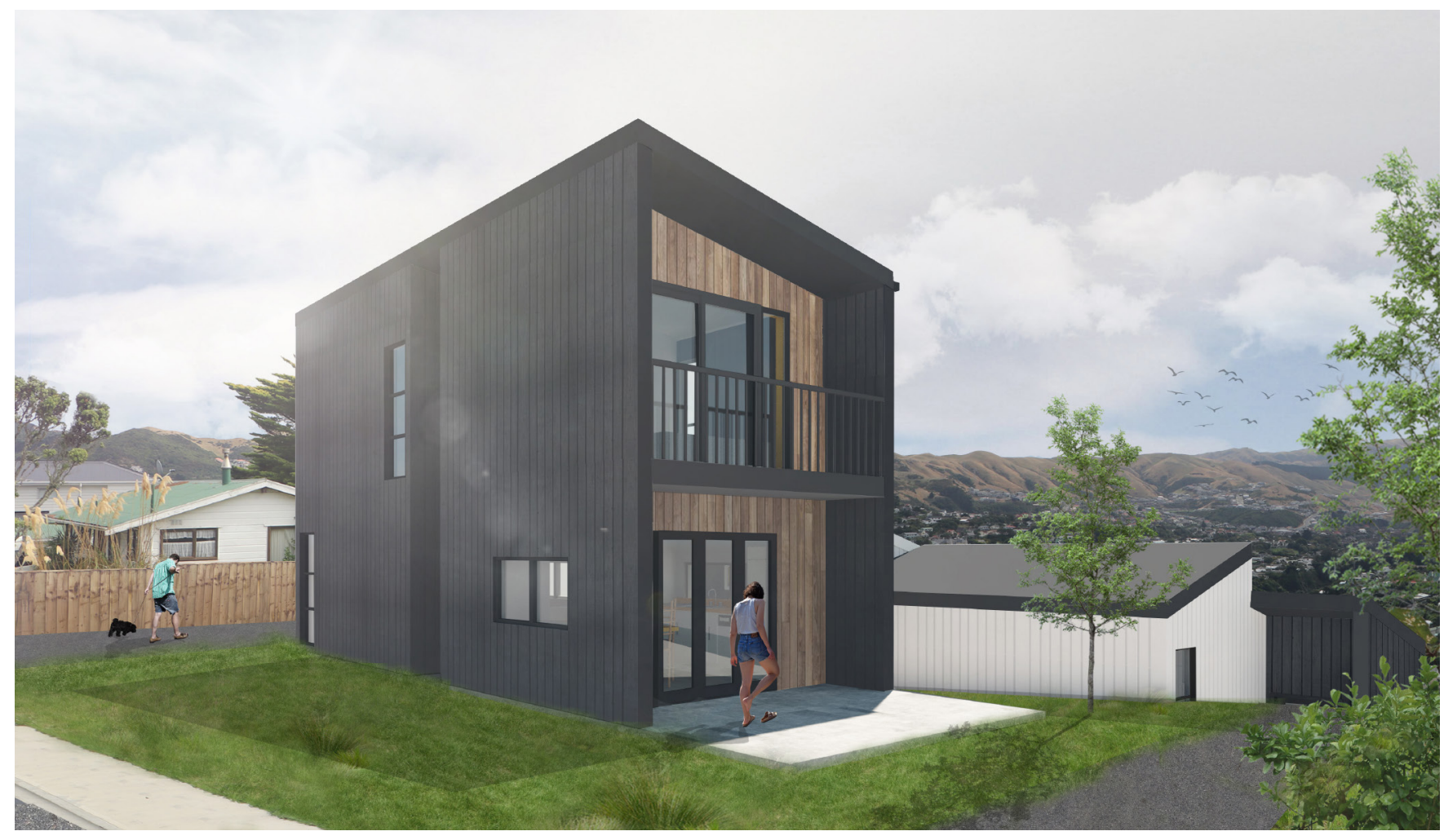

Figure 2.5955 Chapman Street Site Realistic Render of Plot A

Figure 2.60 compares the first cost estimates across the 3 plots. Plot A is slightly smaller than plots $B$ and $C$ which are identical. Dwelling 1.1 is considerably cheaper than houses 2.4.1 with approximately a $\$ 120,000$ cost difference. Plot $C$ is the least economical with an extra $\$ 15,383$ spent on excavation and retaining walls. 


\section{Chapman Street, Newlands, Wellington}

Land Value $=\$ 144,596$

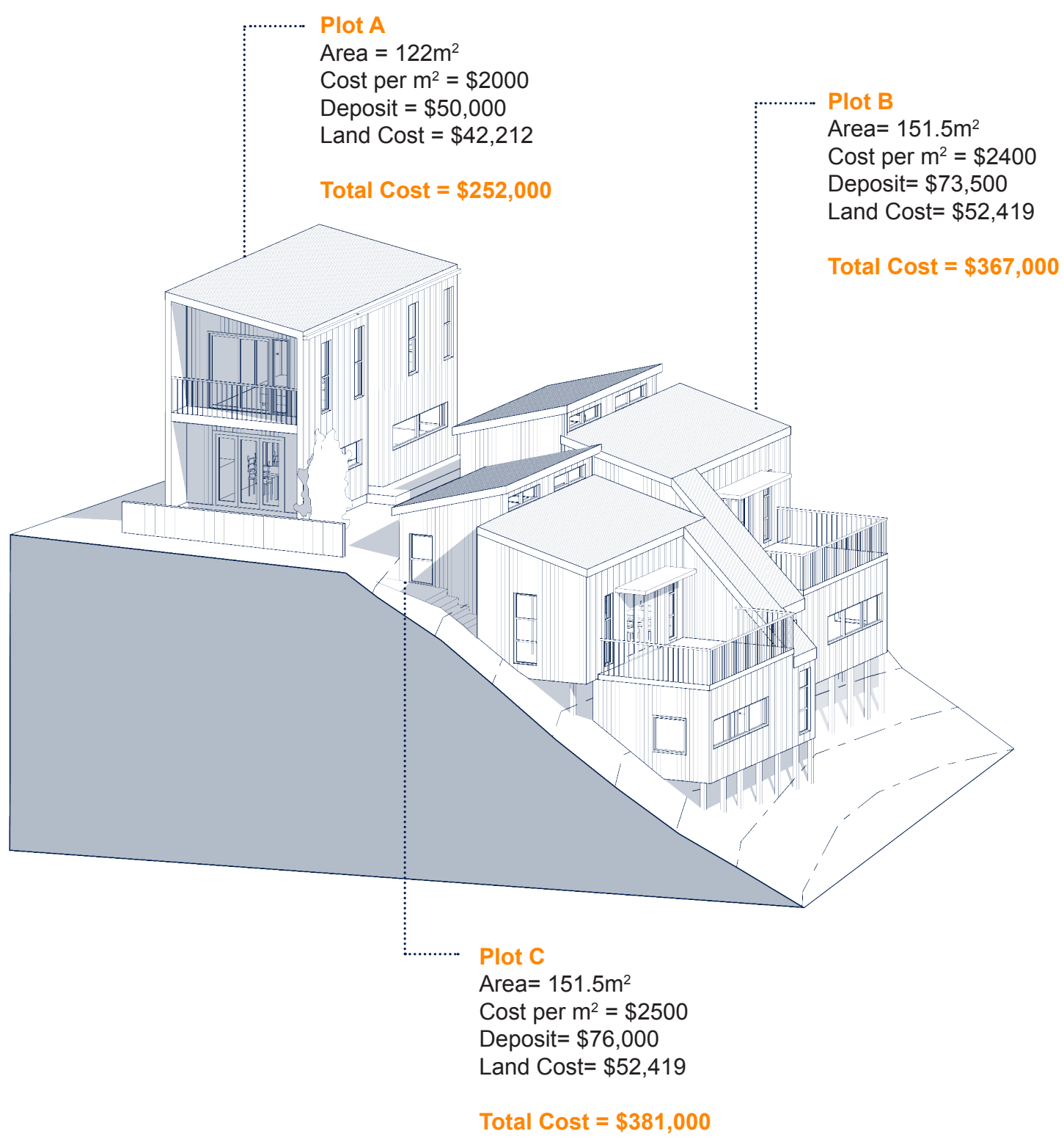

Retaining Walls + Excavation Cost $=\$ 14,000$

Total Cost $=\$ 1,000,000$

Figure 2.60 55 Chapman Street site costing 


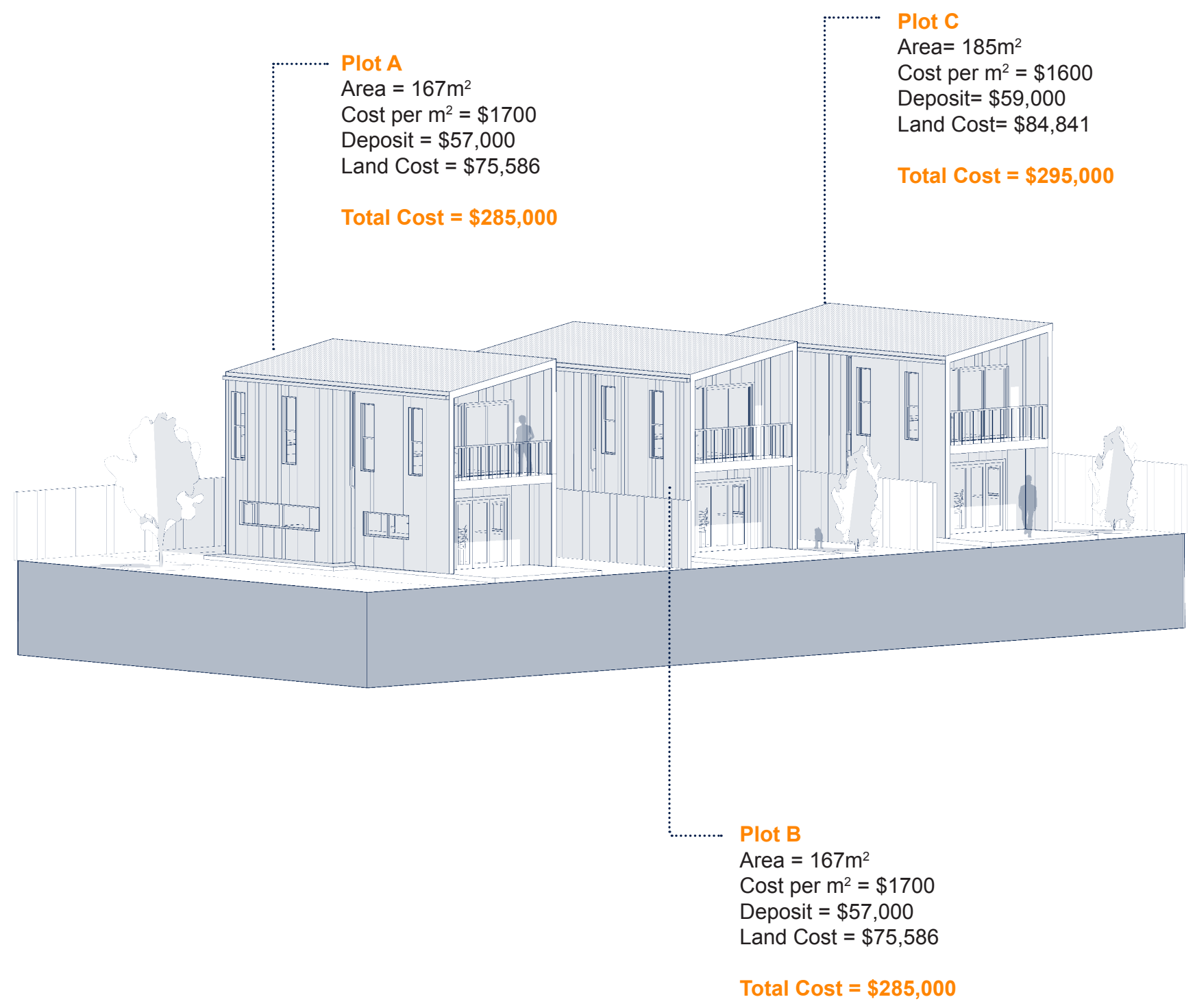

\begin{tabular}{l}
2 \\
0 \\
0 \\
$x$ \\
0 \\
0 \\
0 \\
0 \\
0 \\
0 \\
0 \\
0 \\
0 \\
0 \\
0 \\
0 \\
0 \\
5 \\
7 \\
0 \\
0 \\
$\Xi$ \\
\hline
\end{tabular}

$\$ 135,000$ Cheaper to build on this site

Total Cost $=\$ 865,000$

Figure 2.61 Whites East Road site costing 


\section{$105+107$ Whites East Road}

Proposed Site 2

The second proposed site is located at 105 and 107 Whites East Road, Lower Hutt. This site has been introduced as a comparative site to the site in Newlands and looks at understanding the economics and building envelope implications of building on a sloped site versus a relatively flat site. Two empty plots located next to each other have been selected to create an accurate comparison between land area and overall site dimensions. Although this site cost $\$ 93,404$ more than Chapman Street, when housing typology 1.1 is duplicated across the site, the cost difference between the two sites including the land and houses is $\$ 135,000$ based on a first cost estimate using the QV Costbuilder database.

Figure 2.61 gives a cost break down of the Lower Hutt site. New plots $A$ and $B$ are identical whereas plot $C$ is slightly larger. The same housing typology has been duplicated across the 3 plots, as the original design on the Chapman Street site.

The district plan works significantly better with the Lower Hutt site. The site arrangement complies with the building envelope and front yard requirements. The yard space for each dwelling is also usable space, unlike Chapman street where plot A contains the only dwelling with a usable outdoor space due to the steep gradient of the site. There is a small encroachment on the 2 higher ends of the mono pitched roof however this complies with the district plan as roof ends may penetrate the building recession plane by no more than a third of its height. 


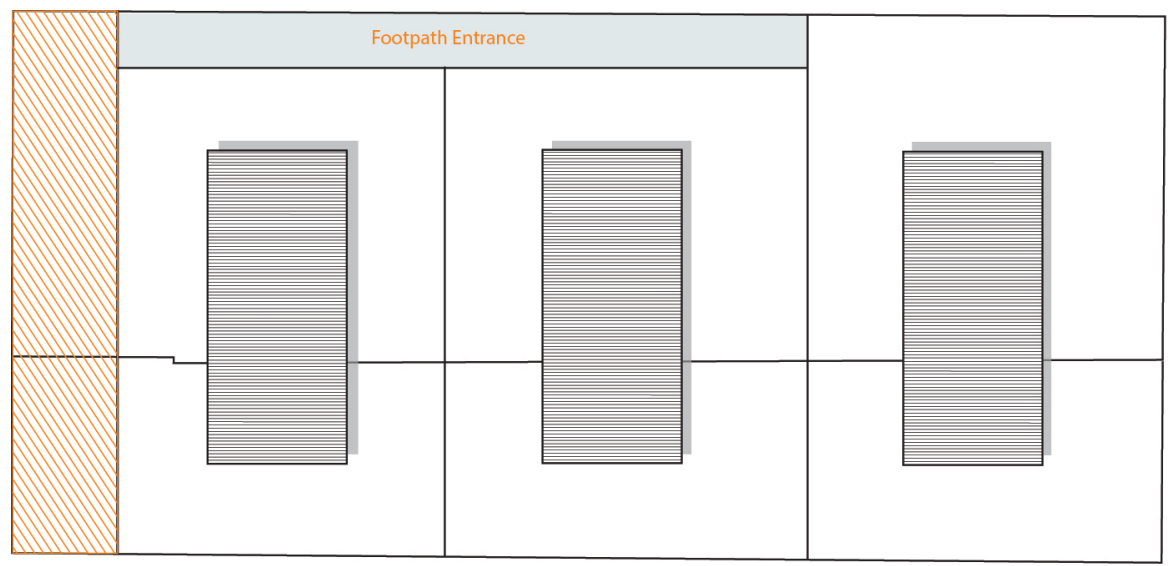

Front Yard Encroachment

Carparking Allocation

Figure 2.62 White East Road site plan

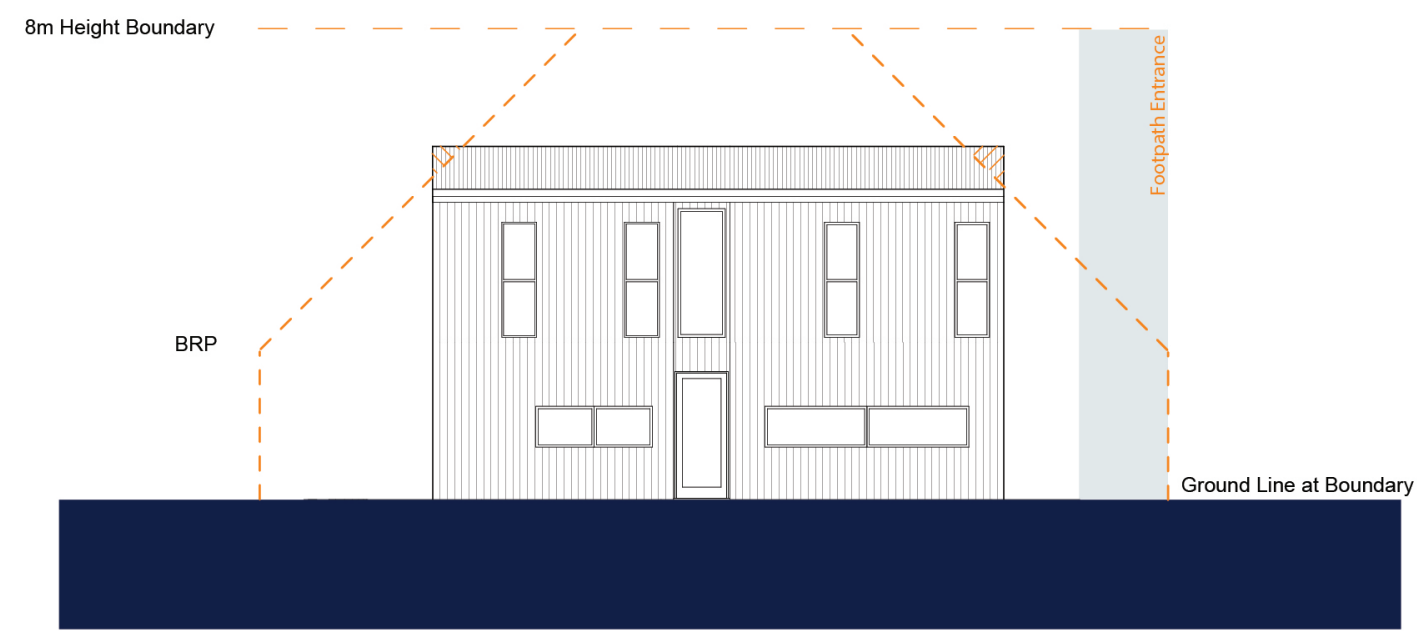

Figure 2.63 BRP North elevation

Figure 2.64 BRP West elevation
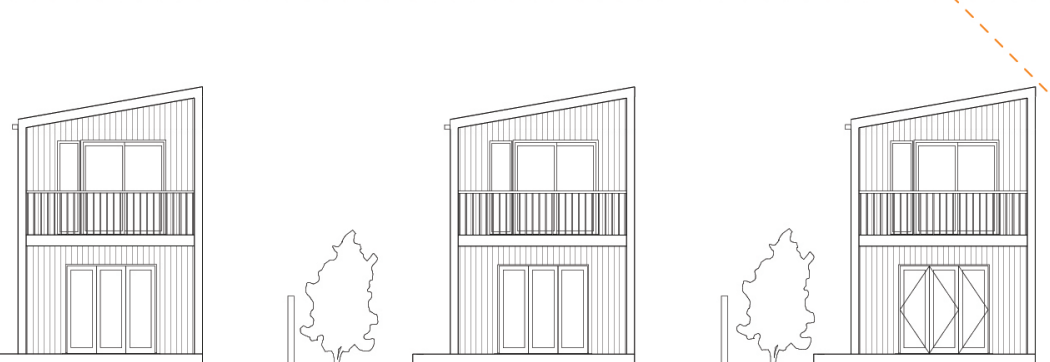


\section{Testing Affordabilty}

\section{Affordability in Context}

An architect does not have a specified group of clients. Anyone can approach an architect, whether they are looking for a new build or renovation. An architect's client can be any of the following: first time home owners, families, middle aged couples, singles and elderly people. As an architect always works to a budget, New Zealand housing prices were investigated to set an affordable budget for the housing typologies designed to be tested against. According to Interest New Zealand, the current median house price is $\$ 607,500$ with lower quartile house prices sitting at $\$ 437,500$. This figure is higher in Wellington with the median house price sitting at $\$ 640,000$ and lower quartile houses at $\$ 505,000$ (Chatson, 2019). Kiwi Build caps their house prices of 3 bedrooms or more at $\$ 550,000$ within the Wellington region, with any dwelling below 3 bedrooms capped at $\$ 500,000$ (KiwiBuild, 2019). First time home owners within the Wellington region can afford a deposit of $\$ 78,000$ whereas young families or those higher up the ladder have larger budgets, assuming they have sold their previous home (Chatson, 2019). The housing typologies designed are considered affordable if the first cost estimate is below $\$ 500,000$. 


\section{First Cost Estimate}

QV Costbuilder + Excel

The QV costbuilder database is a tool used for a first cost estimate for all housing typologies. This tool has been used to gain an understanding of the cost implications per $\mathrm{m}^{2}$ of the housing typologies. Costing is broken down into the following categories; elemental costs, specific materials fittings, fixtures and joinery. The first cost estimate includes a mixture of elemental costing for electrical, plumbing, drainage and site works along with specific material costing, working alongside current market prices in New Zealand. The data base includes all labour costs involved for all elements (Quotable Value Limited, 2019). Excel spreadsheets (figures 2.65 and 2.66) were used as a tool to calculate relevant cost information with areas of material calculated from selecting elements within the Revit model. The excel spreadsheets give a full breakdown of the first cost estimate, Housing typology 4.2.1 is broken down in the Chapman street estimate and typology 1.1 is broken down in the Whites East Road cost estimate. All dwellings are below the $\$ 500,000$ budget. There are a number of elements not costed which will have cost implications including: landscaping, interior fixtures, special hardware and lighting, overheads and margins. The interiors are at a conceptual stage. Additional costs will be added with specified material selection. 


\section{First Cost Estimate Typology 2.4.1}

\section{Chapman Street Hill Site}

Figure 2.65 Cost estimate spreadsheet Typology 2.4 .1

\begin{tabular}{|c|c|c|c|c|c|}
\hline \multirow{2}{*}{$\begin{array}{l}\text { Identificatior Floor } \\
\text { Windows / Aluminium Joinery }\end{array}$} & \multirow[t]{2}{*}{ Dimension } & \multirow[t]{2}{*}{ Item Description } & \multirow[t]{2}{*}{ Area $\mathrm{m} 2$} & \multicolumn{2}{|c|}{ Cost (\$) per I Total Cost \$ } \\
\hline & & & & & \\
\hline \multicolumn{6}{|l|}{ Ground Floor } \\
\hline W01 & $2000 \times 700$ & Aluminium double glazed, residential quality & 1.4 & 556 & 778.4 \\
\hline W02 & $2000 \times 700$ & All windows. & 1.4 & 556 & 778.4 \\
\hline W03 & $1000 \times 1000$ & & 1 & 556 & 556 \\
\hline w04 & $500 \times 500$ & & 0.25 & 556 & 139 \\
\hline W05 & $500 \times 500$ & & 0.25 & 556 & 139 \\
\hline w06 & $400 \times 2000$ & & 0.8 & 556 & 444.8 \\
\hline W07 & $400 \times 2000$ & & 0.8 & 556 & 444.8 \\
\hline w08 & $2000 \times 500$ & & 1 & 556 & 556 \\
\hline w09 & $200 \times 500$ & & 0.1 & 556 & 55.6 \\
\hline W10 & $800 \times 3500$ & & 2.8 & 556 & 1556.8 \\
\hline W11 & $1800 \times 700$ & & 1.26 & 556 & 700.56 \\
\hline Bifold & $1980 \times 2000$ & Glazed Bifold Door External & $1 x$ & 2800 & 2800 \\
\hline Front Door & $860 \times 2030$ & Glazed Front Door External & $1 x$ & 1740 & 1740 \\
\hline
\end{tabular}

Total Cost Windows/ Aluminium Joinery

Doors

$\begin{array}{llllrr}\text { D01 } & 710 \times 1980 & \text { Timber Hollowcore, standard flush door with paint finish } & 1.4 & 254 & 254 \\ \text { D02 } & 710 \times 1980 & \text { All interior doors. } & 1.4 & 254 & 254 \\ \text { D03 } & & 1.4 & 254 & 254 \\ \text { D04 } & 710 \times 1980 & & 1.4 & 254 & 254 \\ \text { WD Door 1 } & 710 \times 1980 & & 1 \times & & 150 \\ \text { WD Door 2 } & & \text { Wardrobe Door } & \text { Wardrobe Door } & 1 \times & \end{array}$

Total Cost Doors $\quad 1316$

Walls

External Walls + Insulation

Fire walls + acoustic + framing

$34 \quad 194 \quad 6596$

Linea weatherboards, timber framing build up, insualtion, Gib

48492.8

Total Cost Exterior Walls

ing

$\begin{array}{rrr}99 & 423.2 & 41896.8 \\ & 48492.8\end{array}$

48492.8 Internal Walls

\begin{tabular}{|c|c|c|c|c|}
\hline & Stanadrd Gib + Timber Framing & 150.4 & 172 & 25868.8 \\
\hline & Aqualine Gib + Timber Framing & 42.1 & 185 & 7788.5 \\
\hline otal Cost INT Walls & & & & 33657.3 \\
\hline \multicolumn{5}{|l|}{ Flooring + Finishes } \\
\hline pper & Timber Framing build up with subfloor framing + foundations & 19.5 & 270 & 52 \\
\hline nid & All flooring. & 23.3 & 270 & 629 \\
\hline ower & & 22 & 270 & 59 \\
\hline lywood & Flooring build up construction plywood & 64.8 & 80 & 5184 \\
\hline arpet & & 27.2 & 54.3 & 1476.96 \\
\hline imber & Stained timber flooring & 21.6 & 193 & 4168.8 \\
\hline iles & Small format & 7 & 120 & 840 \\
\hline
\end{tabular}

33657.3

\section{Flooring + Finishes}

Upper

Mid

Lower

Plywood

Carpet

Tiles

Tot

Total Flooring Cost

Roofing

Roofing Iron

Build Up

Roof Framing

Roof Framing

Roof Framing

Downpipes

Guttering

Flashings

Ceiling Gib
Zincalume roofing and fixings

Underlay

Rafters Timber

Ceiling Battens

Purlins Timber

PVC

PVC Marley Stormcloud

Aluminium

Gib

$\begin{array}{rrr}56.7 & 23.6 & 1338.12 \\ 56.7 & 4.4 & 249.48 \\ 149 & 35.2 & 5244.8 \\ 126 & 7.5 & 945 \\ 96 & 10.6 & 1017.6 \\ 7.5 & 21.5 & 161.25 \\ 3 & 331 & 993 \\ 60 & 32.1 & 1926 \\ 72.1 & 53 & 3821.3\end{array}$

15696.55

15696.55

Insulation

Interior Walls

Floor Insulation

Roof Insulation

Pink Batts R2.2

Pink Batts Snug Floor R.2

Pink Batts R3.2

Total Insulation Cost 3823.55 


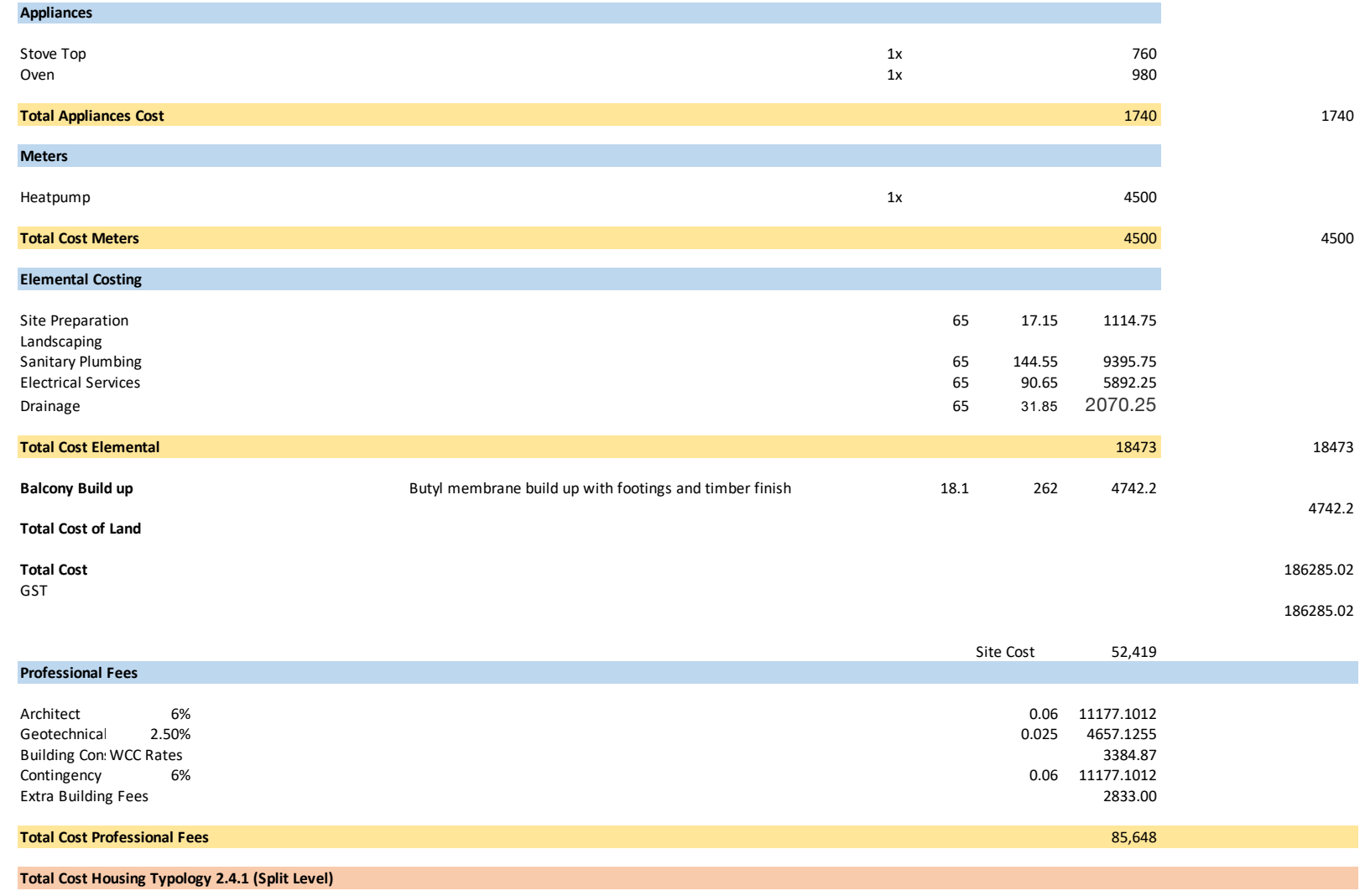

\section{Total Cost Housing Typology 2.4.1 (Split Level)}

\begin{tabular}{lr} 
Total Excl Gst & 271,933 \\
GST & 40789.98269 \\
\hline
\end{tabular}

Excavation + Retaining Walls Plot C

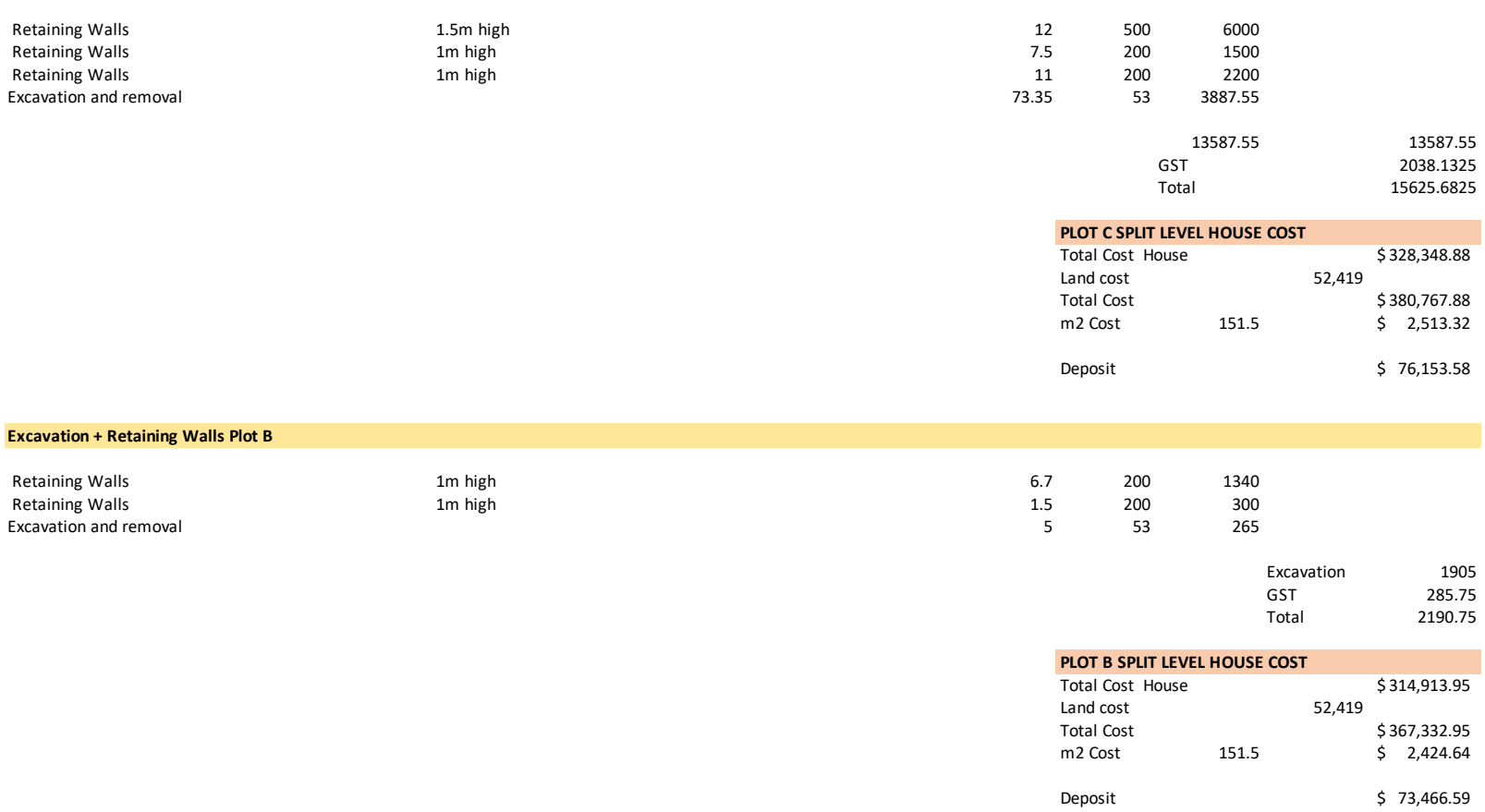

Plot A Housing Typology 1.1 Cost. Full Cost breakdown on 105+ 107 Whites East Road Cost Estimate Sheet

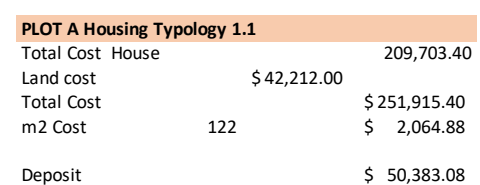


First Cost Estimate Typology 1.1

$105+107$ Whites East Road, Flat Site

Figure 2.66 Cost estimate spreadsheet Typology 1.1

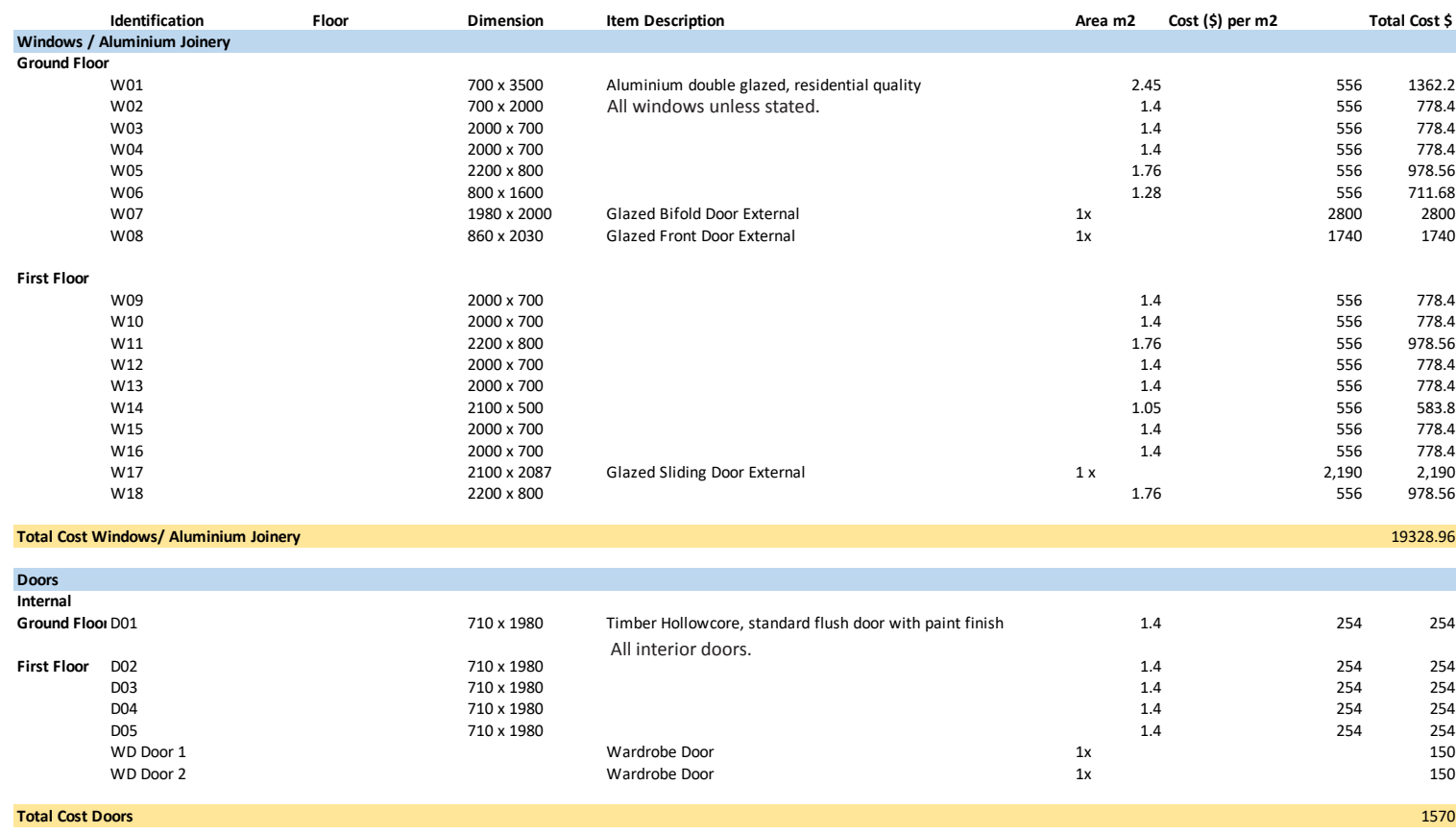

19328.96

Walls
External Walls + Insualtion

North Face

Ground
First

East Face

Linea Weatherboard + timber framing build up + Insulation + Gib $\begin{array}{r}23 \\ \text { All exterior walls. }\end{array} \quad 20.1$

$\begin{array}{ll}\text { East Face } & \\ & \text { Ground } \\ \text { First }\end{array}$

West Face

Ground
First

South Face

Ground
First

6.1
5.6

9.7
9

24.7
30.7

130

Total Cost Exte
Internal Walls

Ground Floor

INT W 1
INT W 2

INT W 3

Joinery Wall/TV

Standard Gib with paint finish + timber framing

All interior walls.

INT W 4

INT W 5

INT W 6

INT $W 7$

INT W 8

INT W 9

INT W 10

INT W 11

0.75
1.7
4.6

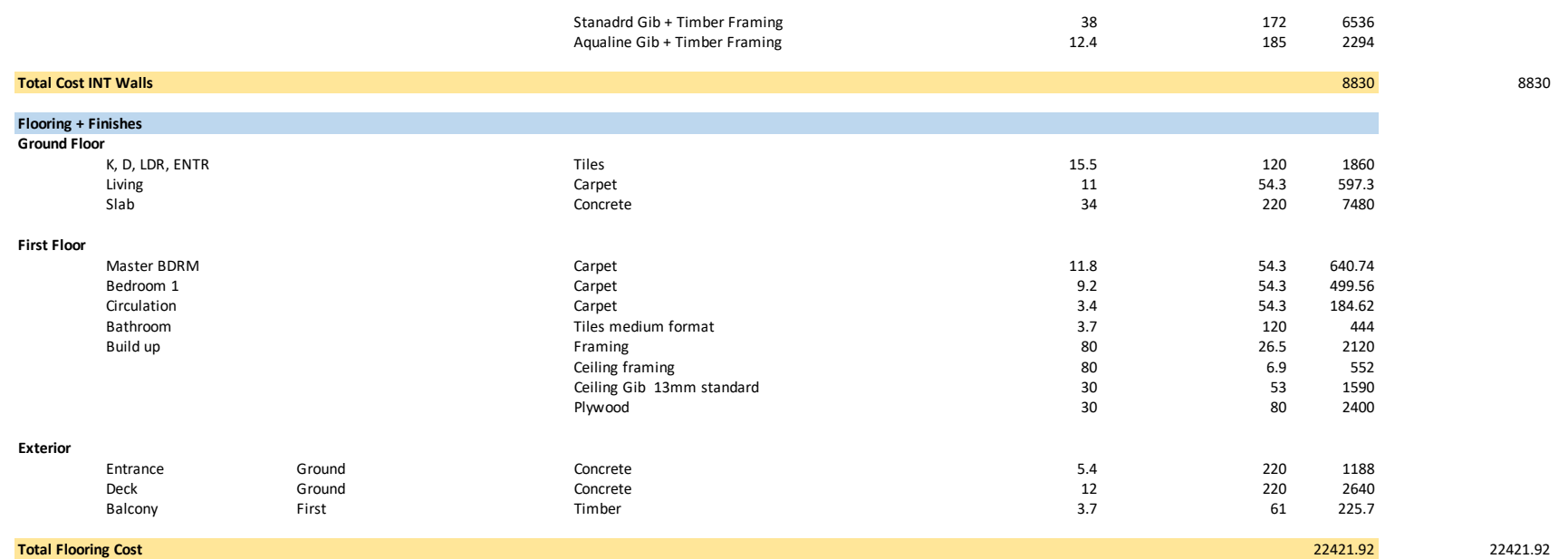




\begin{tabular}{|c|c|c|c|c|c|c|}
\hline \multicolumn{7}{|l|}{ Roofing } \\
\hline Roofing Iron & & Zincalume roofing and fixings & 41.6 & 23.6 & 981.76 & \\
\hline Build Up & & Underlay & 41.6 & 4.4 & 183.04 & \\
\hline Roof Framing & & Rafters Timber & 118.58 & 35.2 & 4174.016 & \\
\hline Roof Framing & & Ceiling Battens & 80 & 7.5 & 600 & \\
\hline Roof Framing & & Purlins Timber & 46 & 10.6 & 487.6 & \\
\hline Downpipes & & PVC & 10.2 & 21.5 & 219.3 & \\
\hline Guttering & & PVC Marley Stormcloud & ( & 331 & 331 & \\
\hline Flashings & & Aluminium & 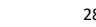 & 32.1 & 898.8 & \\
\hline Ceiling Gib & & Gib & 41. & 53 & 2204.8 & \\
\hline Total Roofing Cost & & & & & 10080.316 & 10080.316 \\
\hline \multicolumn{7}{|l|}{ Insulation } \\
\hline Interior Walls & & Pink Batts R2.2 & 50. & 8.7 & 438.48 & \\
\hline Floor Insulation & & Pink Batts Snug Floor R.2 & 36 & 20.4 & 612 & \\
\hline Roof Insulation & & Pink Batts R3.2 & 41.6 & 11 & 457.6 & \\
\hline Total Insulation Cost & & & & & 1508.08 & 1508.08 \\
\hline \multicolumn{7}{|l|}{ Building Elements } \\
\hline Stair with Handrail & & Stairs Pine stringers mdf treads with handrail & 2.7 & 413 & 1115.1 & \\
\hline Balustrade Balcony & & Square balustrade & 2 & 389 & 1556 & \\
\hline Total Elements Cost & & & & & 2671.1 & 2671.1 \\
\hline \multicolumn{7}{|l|}{ Joinery } \\
\hline Kitchen & & Basic kitchen joinery fitout & $1 \mathrm{x}$ & 3500 & 3500 & \\
\hline Bathroom & & Basic bathroom joinery fitout & $1 x$ & 1950 & 1950 & \\
\hline Laundry & & Basic laundry joinery fitout & $1 \mathrm{x}$ & 398 & 398 & \\
\hline Lounge & & Basic lounge joinery fitout & $1 x$ & 1800 & 1800 & \\
\hline Total Joinery Cost & & & & & 7648 & 7648 \\
\hline \multicolumn{7}{|l|}{ Appliances } \\
\hline Stove Top & & & $1 x$ & & 760 & \\
\hline Oven & & & $1 \mathrm{x}$ & & 980 & \\
\hline Total Appliances Cost & & & & & 1740 & 1740 \\
\hline \multicolumn{7}{|l|}{ Meters } \\
\hline Heatpump & & & $1 x$ & & 4500 & \\
\hline Total Cost Meters & & & & & 4500 & 4500 \\
\hline \multicolumn{7}{|l|}{ Elemental Costing } \\
\hline $\begin{array}{l}\text { Site Preparation } \\
\text { Landscaping }\end{array}$ & & & 68 & 17.15 & 1166.2 & \\
\hline Sanitary Plumbing & & & $6 \varepsilon$ & 144.55 & 9829.4 & \\
\hline Electrical Services & & & 68 & 90.65 & 6164.2 & \\
\hline Drainage & & & 68 & 31.85 & 2165.8 & \\
\hline Total Cost Elemental & & & & & 19325.6 & 19325.6 \\
\hline \multicolumn{7}{|l|}{ Total Cost Hardware } \\
\hline Total Cost & & & & & & 154639.976 \\
\hline & & & & & & 154639.976 \\
\hline \multicolumn{7}{|l|}{ Professional Fees } \\
\hline Architect & $6 \%$ & & 148227.17 & 0.06 & 8893.63 & \\
\hline Geotechnical & $2.50 \%$ & & 148227.17 & 0.025 & 3705.68 & \\
\hline Building Con: WCC Rates & & & & & 3384.87 & \\
\hline Contingency & $6 \%$ & & 148227.17 & 0.06 & 8893.63 & \\
\hline Extra Building Fees & & & & & 2833.00 & \\
\hline \multirow[t]{17}{*}{ Total Professional Fees } & & & & & 27710.81 & 182350.79 \\
\hline & & & & PLOT A \& B & & \\
\hline & & & & Total Cost No Site & 182350.79 & 182,351 \\
\hline & & & & GST & 27352.618 & 27,353 \\
\hline & & & & Total No Site & 209703.40 & $209,703.40$ \\
\hline & & & & Site Cost Plots $A+B=$ & 75,586 & \\
\hline & & & & & & $285,289.40$ \\
\hline & & & & Per m2 & 167 & $1,708.32$ \\
\hline & & & & Deposit & $\$ 57,058$ & \\
\hline & & & & PLOT C & & \\
\hline & & & & Total Cost No Site & 182350.79 & 182,351 \\
\hline & & & & & 27352.618 & 27,353 \\
\hline & & & & Total No Site & 209703.40 & $209,703.40$ \\
\hline & & & & Site Cost Plot C $=$ & 84,841 & \\
\hline & & & & & & $294,544.40$ \\
\hline & & & & Per m2 & 185 & $1,592.13$ \\
\hline & & & & & $\$ 58,909$ & \\
\hline
\end{tabular}




\section{Value within the design:}

\section{What can an architect control surrounding economic value?}

- Dual housing (sharing one or more external walls).

- Standardised features such as stud heights, windows and doors.

- Regular, non-complex forms.

- Standard roofing build up (sloped not flat).

- Working with standard sheet sizes.

- Timber piles on hill sites, build up and not excavate.

- Split levels to work with contours of the site.

- Maximising the floor area.

What are the architectural qualities creating value within the housing typologies?

- Recesses on sides of building and balcony.

- Use of double-glazed windows which cost more but are more efficient for energy savings and heating.

- Thermo mass properties on concrete floor.

- Glazed feature through recess which is composed as 2 large windows.

- Thicker exterior walls for better insulation.

- Designing above minimum codes.

Exceeding the minimum and designing new homes above the absolute minimum requirements of the building code, improves livability, often for a little extra cost, which in the long run pays off in energy consumption and costs (Pringle,2019). 


\section{Findings and Reflections}

Exploring Affordability

The combination of the building envelope and the relationship with the abrupt gradient of the site created restrictions to the architectural outcome of housing typology 2.4.1, the split level. To enhance the architectural outcome on this slope, these restrictions need to be pushed, to allow the architecture to be in control over the building envelope. What is currently not working with this housing typology, is the stair well roof, sloping up with the recession plane. The floor plan has a number of issues. These include the small entrance, being more generous with the living and dining space. Piercing the envelope boundary would allow for a more architectural outcome through both the form, planning and economics with less excavation into the ground. To enhance the architectural outcomes of the houses a playful approach is needed through a series of new conceptual designs. This can be explored through sketching and modelling.

The two housing typologies are currently not well developed as livable spaces. They are designed from the outside in with more input into the exteriors than interiors at this stage. The interiors need to be enhanced, to develop what these houses feel like to live within, showing materials and human interaction. This is also required for the site arrangement and atmosphere, with the two side entrances refined to one main right of way. The front yard needs to be designed incorporating landscaping into the house designs.

Moving forward, parameters are required for the elements and spaces included within the typologies, the client and their budget, quality and cost control and sustainable features. An architect will have a number of clients with different budgets and spatial requirements. This needs to be designed economically, while containing a strong architectural aesthetic and living qualities. The introduction of BIM with QV costbuilder data will speed up the costing process, with relation to how a next generation architect would work.

Next Generation Architect

In the profession a Next Generation Architect will restore the stereotype of an architect having minimal consideration towards cost. This new architect will combine both quality and cost as effective design values with zero compromises on either values. 
Design Phase 3 introduces architecture

as product illustrated through the pattern

book. Four designs are repeated across a

number of test sites within Wellington, to

gain an understanding of the challenges both

aesthetically and economically faced by different

site conditions. 
05

Architecture as Product 


\section{The Pattern Book}

\section{Architectural History}

The 16th century introduced the first version of the architectural pattern book, in the five books of architecture, by Italian architect Serlio. Serlio's early pattern books pushed the boundaries of architecture of the time, giving several classical precedents around the ways, design rules could be used. (Marmor, 1996)

New Zealand's first version of the pattern book was introduced in 1949 by Max Rosenfeld who became known through his publications in the weekly newspaper as the home architect, as people could obtain published house plans for free. Rosenfeld published 13 editions of the New Zealand House, comprising of several house designs available for people to use in the form of a pattern book (Gluckman, 1990). New Zealand's design and build companies contain online databases of housing designs; this idea is seen as a digitalised form of a pattern book.

Australian project housing companies of the 1960s generated their own versions of the pattern book. Seen through a series of housing typologies marketed and designed to buy. What made these companies stand out compared to the typical developer, was the ability to customise the design to suit selected sites. For example Pettit and Sevitt's customisable split-level house to work with the topography of Sydney. These companies involved architects, ensuring that houses were desirable through strong design aesthetics. (Judith O'Callaghan \& Pickett, 2012)

Affordability is explored within a pattern book through the repetition of design removing bespoke architecture. Repeating a product creates a standardised design, that reuses documentation and results in decreased fees for the client. 
Max Rosenfeld

Architectural Influences

1949 marked the beginning of a significant change between New Zealander's and their homes. The government at the time started a policy of subsidising loan interest, encouraging home ownership. Max Rosenfeld introduced innovative concepts which are still used today as if no other methods previously existed. These concepts are seen applied to his house plans that were published in the weekly newspaper. The principles included; prefabricated storage fittings preferable to solid internal walls, prefabricated light timber trusses to replace individual rafters, laundry as a transitional room between indoors and outdoors, and concrete floors on the ground floor to prevent draughts and borer. (Gluckman, 1990)

Rosenfeld analysed the stereotypical New Zealand home before the 1950 s found on a quarter acre section. Coming from Czechoslovakia he believed both the section and the houses were far too big for their inhabitants. He found houses were incorrectly orientated, with living quarters and bedrooms facing the street irrespective to the sun, which can also be seen through the large floor to ceiling windows that served no real purpose. Houses disregarded the sun, influencing lower living conditions and overall health of occupants (Gluckman, 1990). His findings are seen in figure 3.01 of the typical 1950's state housing plan.

Rosenfeld had his own set of design parameters. Which included tailoring houses with living spaces facing the sun. Rectangular designed homes which are desirable for future additions. Reducing building costs, open plan living with the house consisting of three zones including, living spaces (public), bedrooms (private) and passage (circulation). Viewpoints overlooking a garden, with kitchens, laundry and utility rooms to face the shadows. These parameters changed the way New Zealander's designed and built their homes, with Rosenfeld being an influential contributor to New Zealand's modern living (Gluckman, 1990). Rosenfeld's influences can be seen in figure 3.02 of the typical 1970's state housing. 


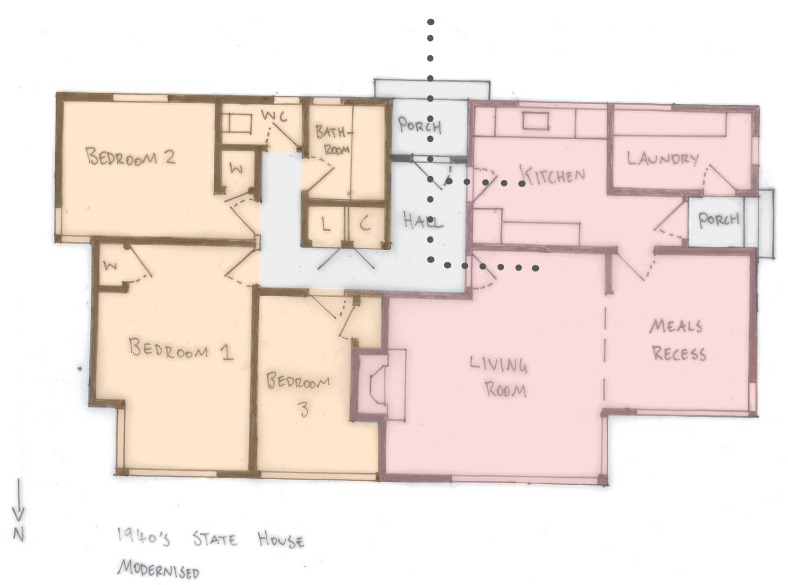

Figure 3.01 Typical 1950's NZ state housing plan

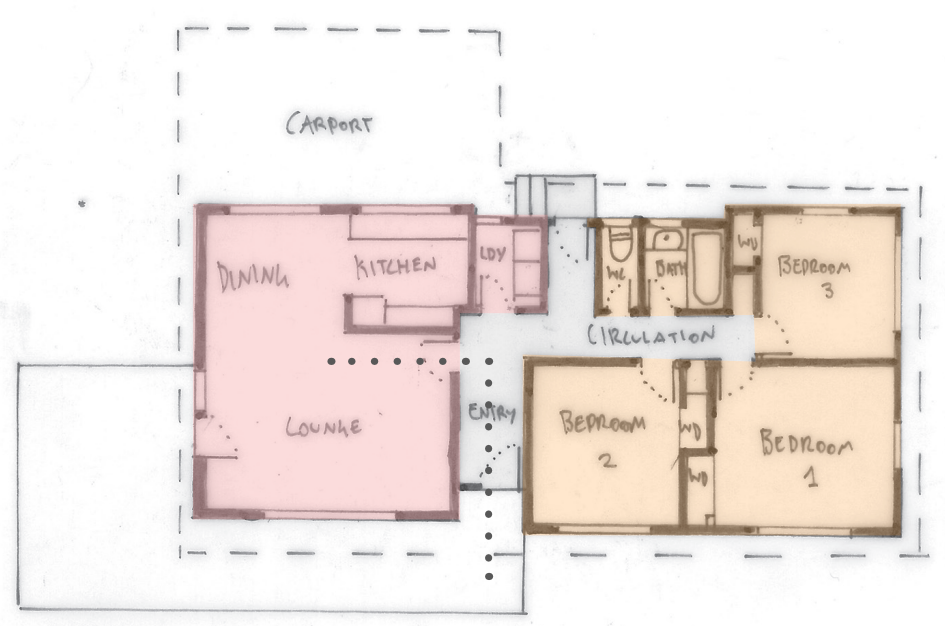

Figure 3.02 Typical 1970's NZ state housing plan

KEY:
PRIVATE SPACES
PUBLIC SPACES
CIRCULATION 
"Rosenfeld can be seen as one of the essential contributors for the modern building practice we find in New Zealand from the 1950's to the 1970's and someone who decisively influenced the way kiwis live today." (Abreue Lima \& Isaacs, 2018) 
This image has been removed by the author of this thesis for copyright reasons.

Figure 3.03 The Terrace House

This image has been removed by the author of this thesis for copyright reasons.

Figure 3.04 Modern housing village

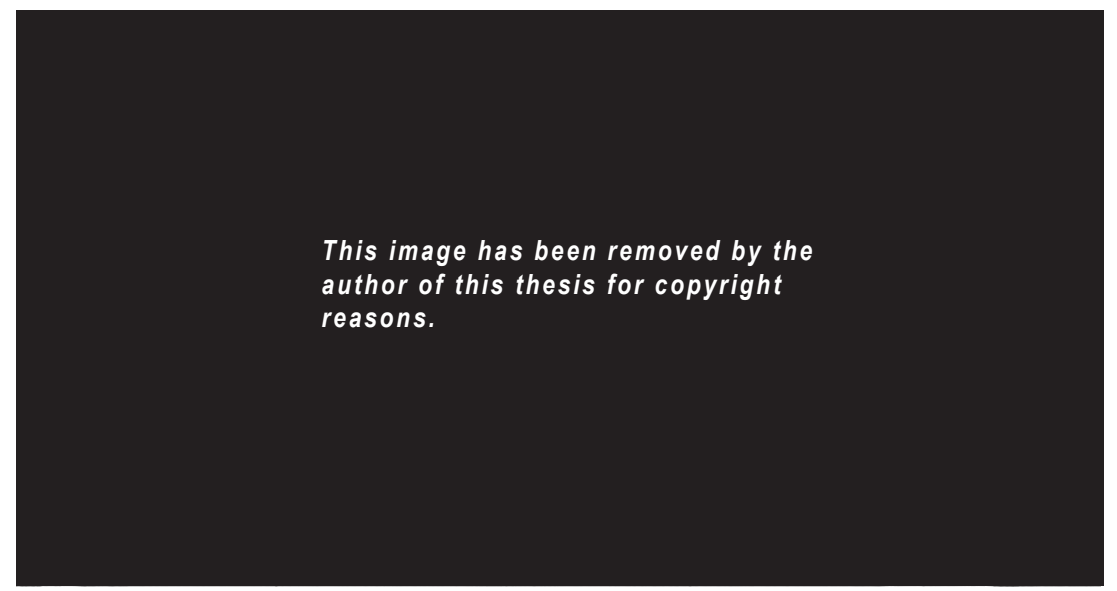

Figure 3.05 Single Dwelling 
Merchant Builders was established in Melbourne in 1965 by three partners Yencken, Ridge and Gunn. All had previous experience within the construction industry. The driver of this project home company, was to break the dull, repetitive suburban housing. By working as a team together, they believed that they could offer more appealing houses, that were appropriate to the Australian landscape and climatic conditions and would fulfill the expectations of the typical family villa. Each of the three partners was responsible for their roles which involved the architect, building processes, contracts and marketing. (Melbourne School of Design, 2015)

"Thus for the first time a genuine architectural circumspection was brought within the financial reach of the average owner.... Among the more notable enterprises was... a firm called Merchant Builders in Melbourne, which offered various designs of the architect Graeme C. Gunn." (Boyd, 1968 as cited in Melbourne School of Design, 2015, p.6)

The first display homes opened in 1966 and consisted of the terrace, courtyard and studio. Initially, people found these houses "too stark and too unusual", compared to the typical villa with its layout and siting. All houses offered several variations, with each house presenting a different typology and site. An integral part of the architecture was the relationship between the house and its site. To ensure this was met, landscaping was included as part of the housing package. Landscaping became an integral part of the design with a visionary move taken to remove the typical fence and backyard. This move integrated houses with their surroundings. It sparked the possibilities of exploring group developments, which could provide the greatest privacy and share other general facilities. (Judith O'Callaghan \& Pickett, 2012)

"Some of our houses went into settings where there was no relationship to the houses around them. Landscaping provided the "clothing" that made that relationship work much better." (Judith O'Callaghan \& Pickett, 2012, p.136)

The houses were designed to be affordable for the average home owner. The value of design and tactics of affordability within design include:

- A strong emphasis on orientation.

- Siting and landscaping.

- Passive energy with north facing living areas.

- Indoor- outdoor connection.

- Minimal interiors that involved minimal materials and colour.

- Catalogue housing in the form of a pattern book. 
This image has been removed by the author of this thesis for copyright reasons.

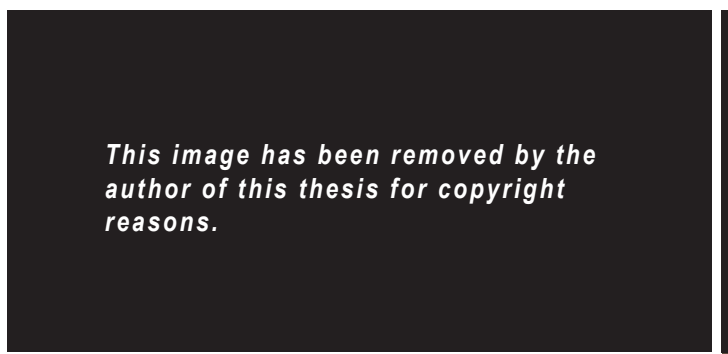

Figure 3.06 The split level

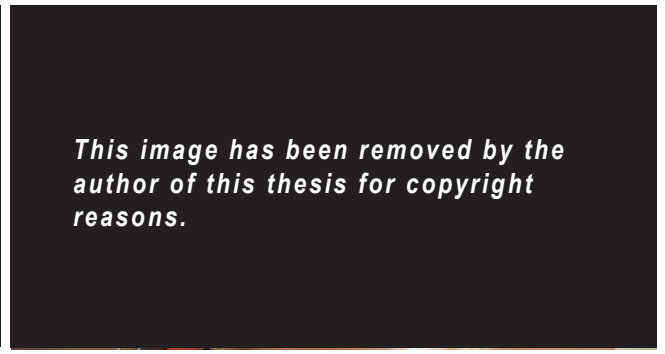

Figure 3.07 Marketing of the interior

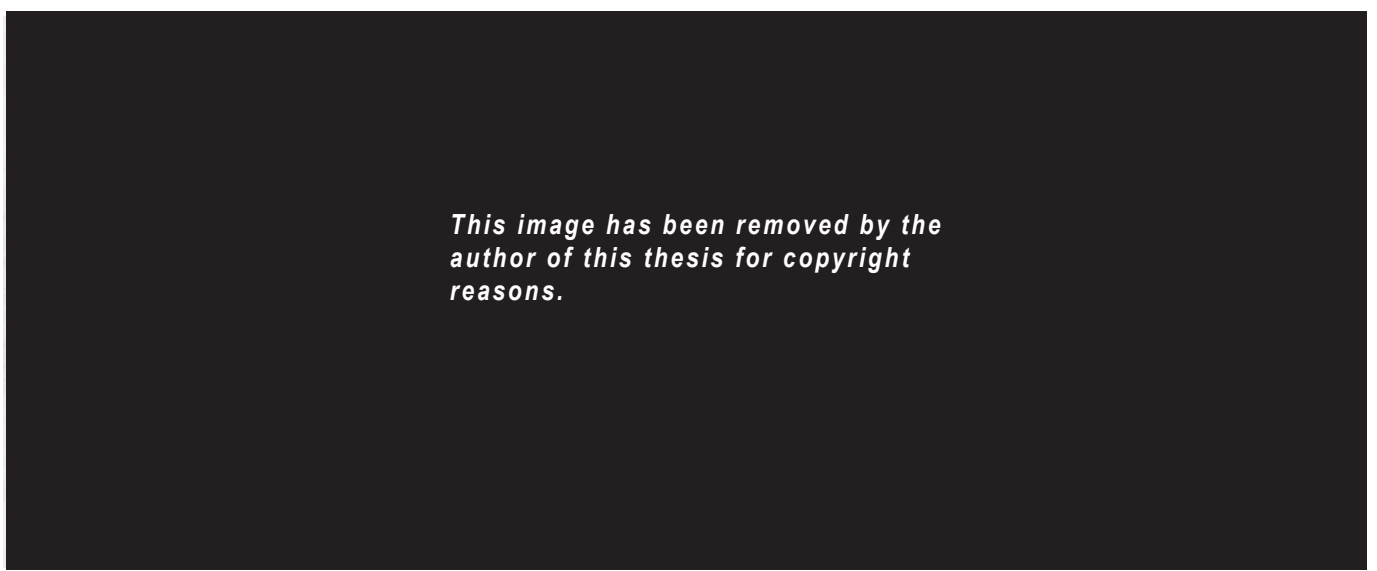

Figure 3.08 Marketing of a dwelling

\section{Pettit and Sevitt}

Sydney, Australia

Known as the most famous and innovative project builders of the 1960s and 1970s in Sydney, Australia was Pettit and Sevitt. They targeted their homes at those who had tried to have a house designed by an architect or those who had not because of the cost implications involved. Like Merchant builders, both partners had earlier experience within the construction industry and valued the aesthetics of the homes, which led to using architects.

The boom period saw Pettit and Sevitt's houses securing over half the project house design awards in New South Wales. Their first display home designed by architects Ken Woolley and Michael Dysart, was the split level that opened in 1961, with a catalogue of house designs expanding over this period. (O'Callaghan, 2017)

Ken Woolley a well-known Sydney architect worked for Pettit and Sevitt for fifteen years. Houses consisted of white brick, exposed timber posts and split levels, that could adapt a standard plan to the rocky terrain. These were the external aesthetics of Woolley along with the clever internal planning. These designs were used in over 3500 houses built in Sydney during the 1960s to 1970s. (Wheeler, 2015) 


\section{MultiProof Consent}

Reducing time and cost

MultiProof Consents allow for standardised designs to be replicated a number of times with minor changes to the overall design. They are targeted at builders and companies who design and build standardised designs and want to gain building consent faster and save clients' money. The parameters of a MultiProof Consent involve the design being for a whole building but doesn't require site specific features such as foundations and drainage. Variations to the design are allowed, as long as approval has been given, allowing for flexibility surrounding site and environmental conditions, as well as providing a number of options to suit specific clients. These including cladding type, window placement and kitchen and bathroom layouts. ( Ministry of Business, Innovation and Employment, 2016)

Positives:

- Beneficial for builders and companies who build standardised designs.

- Lower cost option for clients.

- Flexibility within design as long as there has been pre approval.

- Assures clients they will gain building consent.

- Site specific features can change to comply with the building code.

- Faster process streamlining gaining building consent.

- Have built or intend to build a number of similar designs.

- Relevant to a number of building types including, residential, garages, car ports and sheds.

- Parameter based variations allowed for low risk buildings containing standard detailing.

- Flexible design allowed through the use of modules, layouts and connections can be modified to best suit the client and site.

- Works with the idea of architecture as product.

Negatives:

- The design must have the intention to be built at least 10 times over a 2-year period.

- Still have to apply for building consent for each project.

- Only includes standardised designs that are seen as a product not bespoke design. 


\section{Snug Homes}

Prefab New Zealand

Snug Homes are designed as secondary prefabricated dwellings. Marketed through a catalogue as a form of pattern book illustrating 12 dwellings. Dwellings are prefabricated and transported to site as a whole, or as constructed panels. All dwellings are under $65 \mathrm{~m}^{2}$ meeting Auckland councils' requirements as a minor dwelling. (Prefab NZ, 2018)

Tactics of Affordability:

- Prefabricated, saving time and ensuring a quality build.

- Innovative construction techniques through a panel-based construction, using SIPS and CLT panels.

- Minimal use of external materials with dwellings predominantly clad in Coloursteel or weatherboard which are economic options.

- Dwellings contain sustainable features. Thermal mass and solar panels save energy costs.

- Flexible designs specifically in the Flip dwelling which can be either one story or two.

- Modular design.

- Open plan with minimal circulation.

- Services aligned in plan.

- Pre-consent granted saving clients time, with reuse of drawings.

KEY:

PUBLIC SPACES

PRIVATE SPACES

CIRCULATION

... MOVEMENT
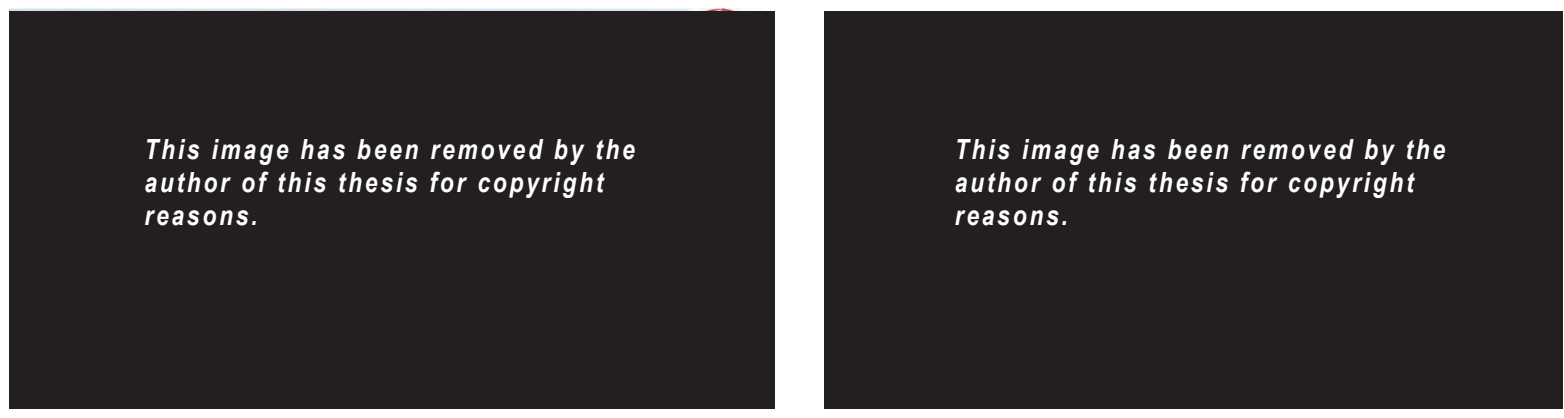

Figure 3.09 Flip dwelling 
This image has been removed by the author of this thesis for copyright reasons.

Figure 3.10 Casabella dwelling

This image has been removed by the author of this thesis for copyright reasons.

This image has been removed by the author of this thesis for copyright reasons.
This image has been removed by the author of this thesis for copyright reasons.
This image has been removed by the author of this thesis for copyright reasons.

Figure 3.12 Whare-iti dwelling 
IPad

Andre Hodgkins

The iPad is an architectural product designed by Andre Hodgkin from Architex New Zealand. The dwelling is designed in modules, as a flexible $50 \mathrm{~m}^{2}$ kitset bach, that can be extended by adding pods to suit clients' needs and budgets. There is a strong emphasis on the marketing through the use of a website (figures 3.13-3.16). The base pod is illustrated with five different material options and ten layout options ranging in price and floor area. A limited material pallet allows clients to have a handful of choices when selecting the product, just as a consumer of everyday products has. The iPad is an economic kitset product with a cost range of $\$ 174,500$ up to $\$ 523,500$, GST and transport exclusive (Hodgkin, n.d.).

The design of the iPad offers a number of layout variations. These are all seen as one storey modules connected by large areas of decking (figure 3.17-3.19). The more pods the more spread-out the dwelling becomes. This works well for clients with large sites, however as the pods are modular they are able to be stacked, creating a number of two storey options to reduce site coverage and work with a number of different orientated sites. The stacking effect is explored through massing (figure 3.20). The two storey massed forms show the potential for a balcony area that can reduce the amount of decking around the dwelling in larger variations, while still providing a flexible design, with circulation added as a module on the side of the existing pod. 
This image has been removed by the author of this thesis for copyright reasons.
This image has been removed by the author of this thesis for copyright reasons.
This image has been removed by the author of this thesis for copyright reasons.

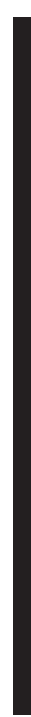

Figure 3.15 Red tongue and grove finish
Figure 3.16 Black finish
This image has been removed by the author of this thesis for copyright reasons. 
This image has been removed by the author of this thesis for copyright reasons.

This image has been removed by the author of this thesis for copyright reasons.

This image has been removed by the author of this thesis for copyright reasons. 

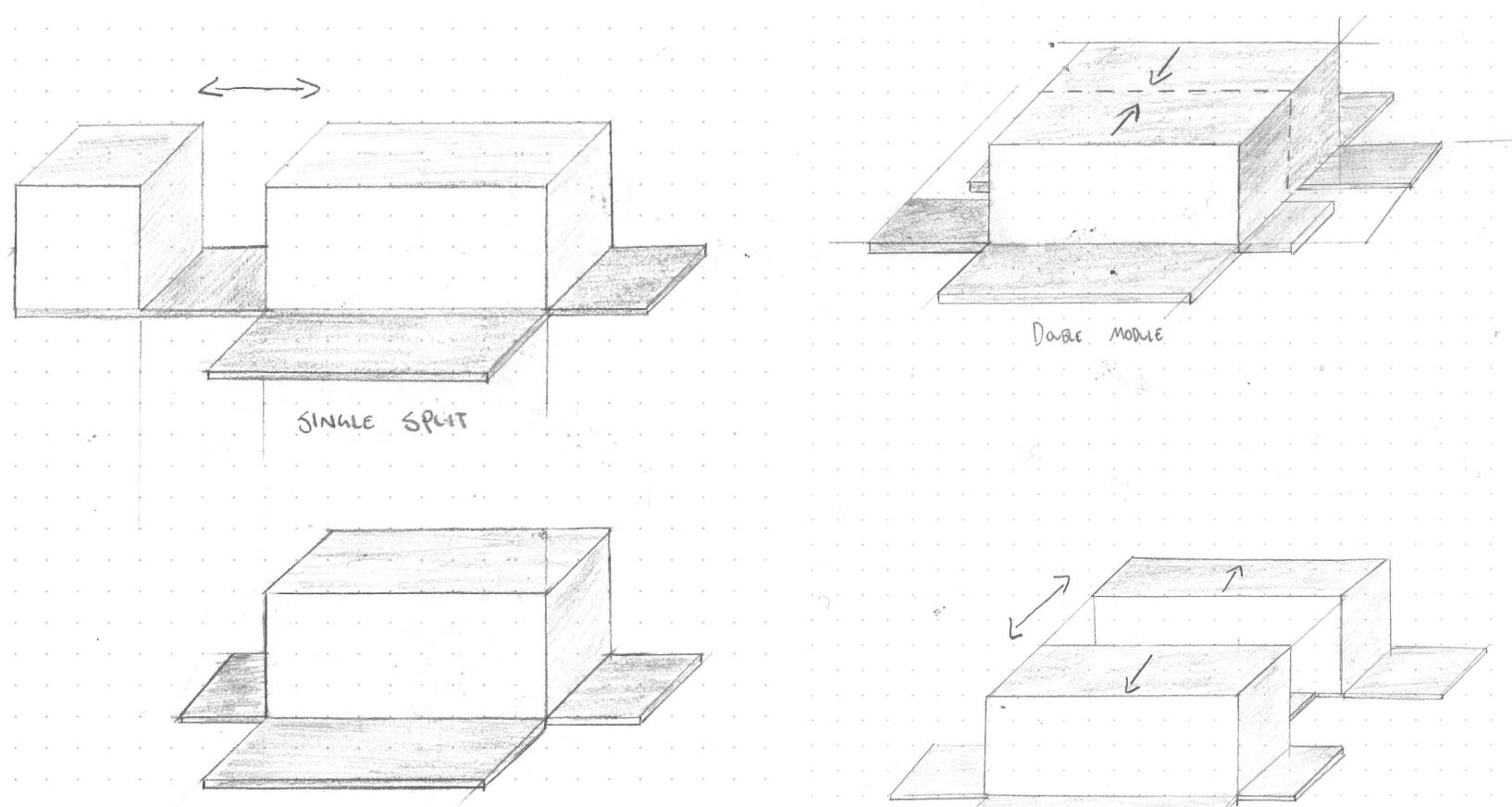

SINGLE MODULE
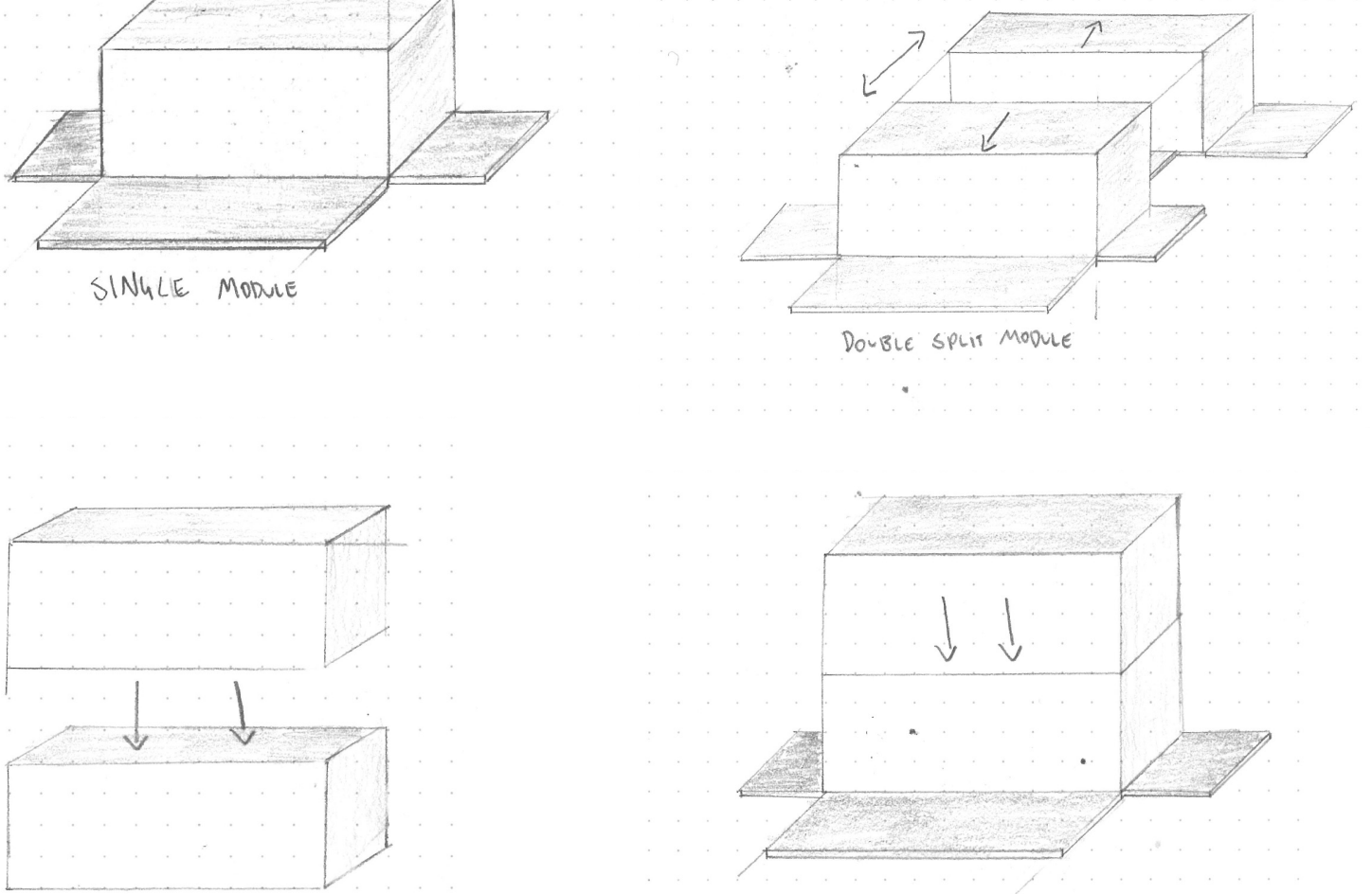

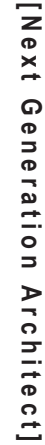

TWO STORT MASSINh

TWO STORY LARLE MOQULE

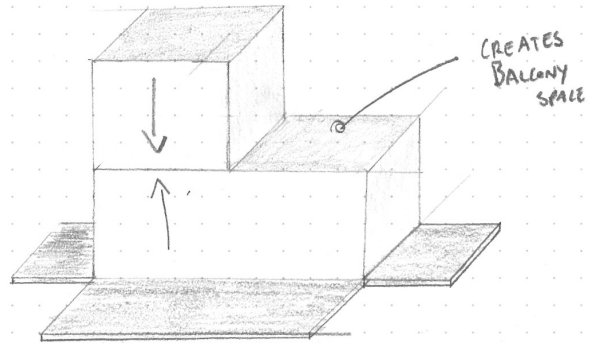

TWo Slory SMAL Mooule

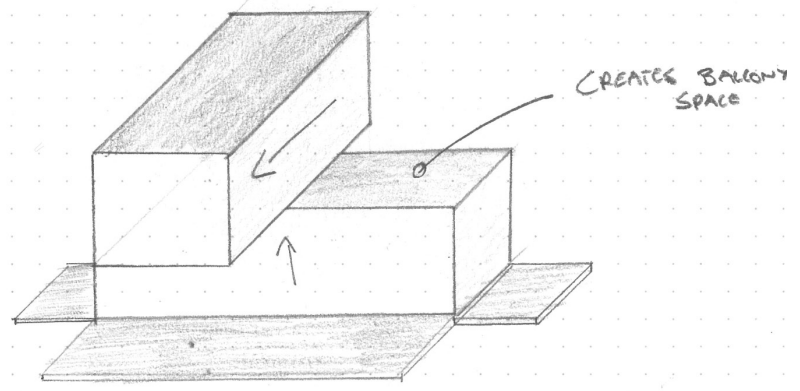

TWO STORY LARGE MODUE 


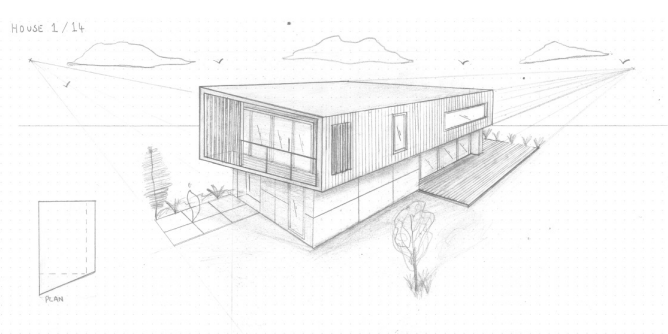

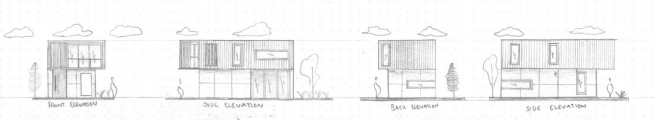
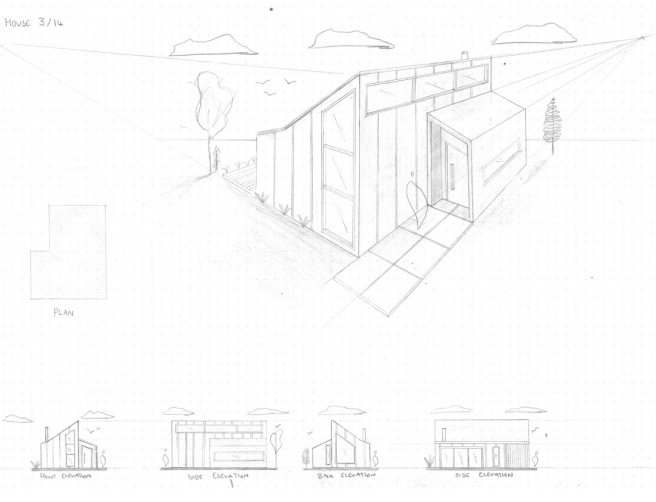

5
0
0
0
0
0
$\vdots$
0
0
0
0
0
0
0
0
0
0
0
0
$z$

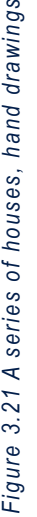
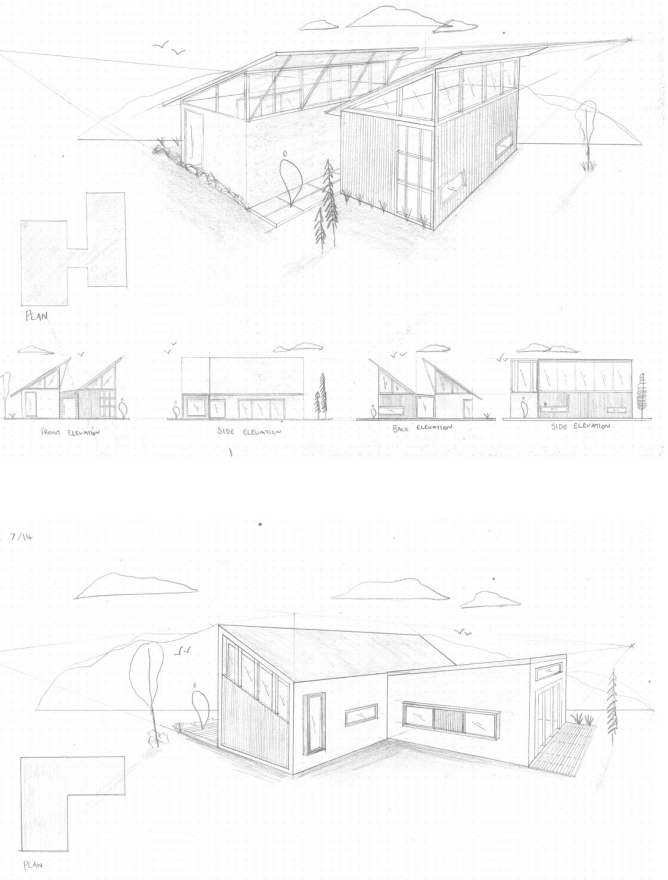

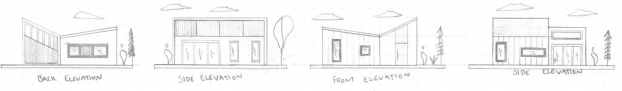
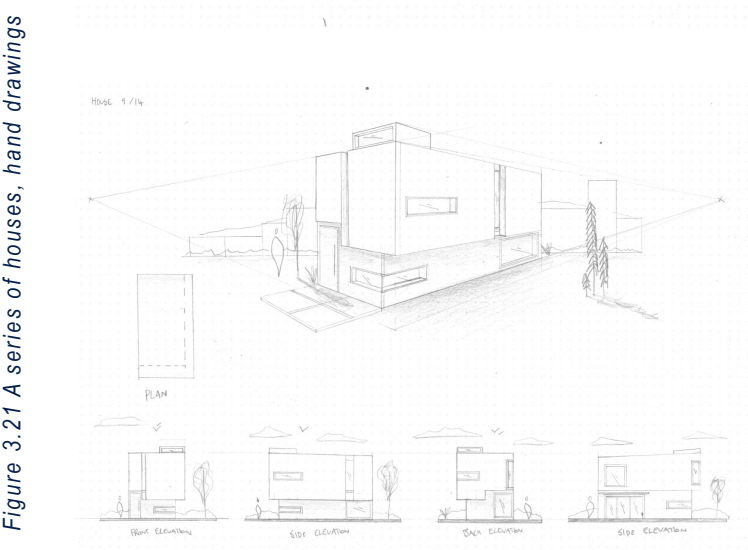

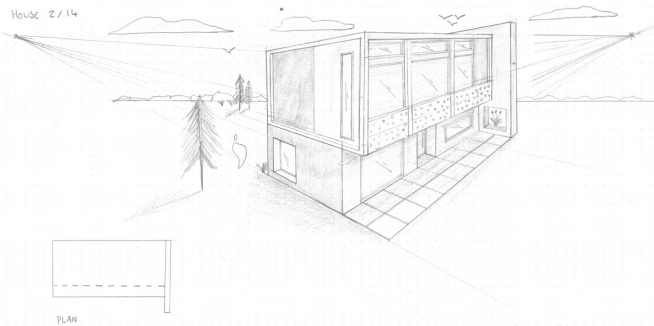

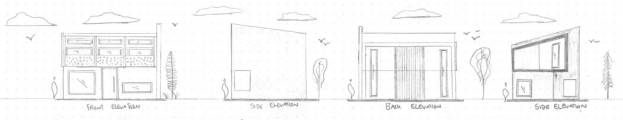

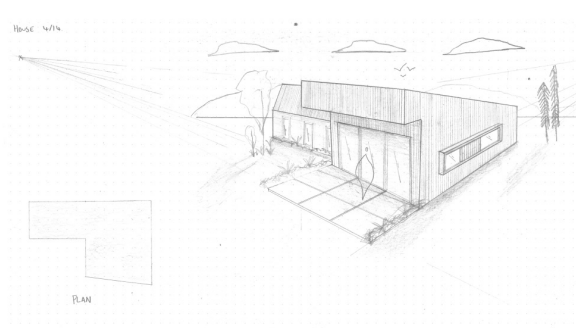

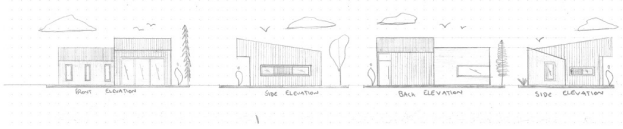

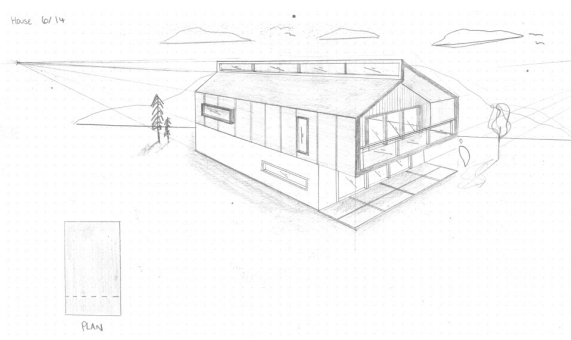

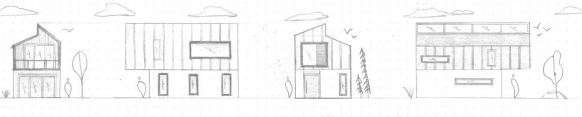
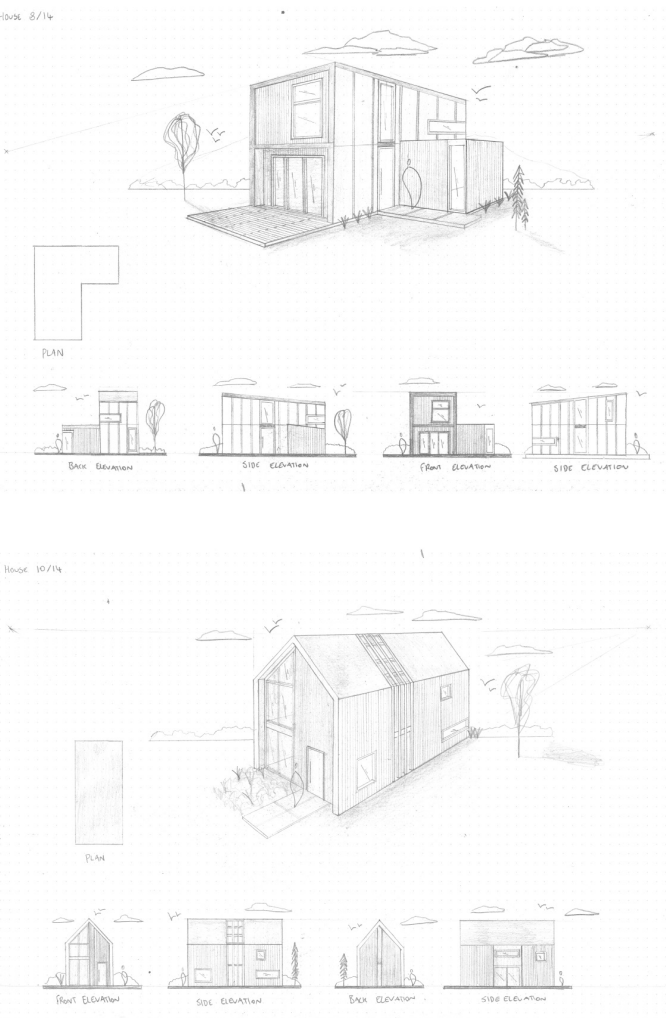
A Series of House Designs

A Two Week Exercise

The aim of this two-week exercise, was to design a series of architecturally designed homes every day over the period, focusing on the aesthetics of the external envelope as well as form. Sketching was the tool used to produce designs, firstly through perspective, followed by 2D elevations drawn to scale. Sketching the conceptual designs allowed for a quick, iterative design process to occur, with materiality and architectural elements added and explored more quickly than digital modelling. A reflection occurred after the design of each house, with drawings annotated and sketched over to improve the overall value of design through form, composition and economic factors.

The design parameters implemented from findings in Design Phases 1 and 2:

- Houses at a minimal size.

- Minimal exterior material pallet.

- Modular forms.

- Standardised windows, doors and forms.

- Indoor-outdoor connection.

- Wall to floor height of 3 metres per floor.

- Base dimensions no larger than 5 by 10 metres. 
Figure 3.22 House 1

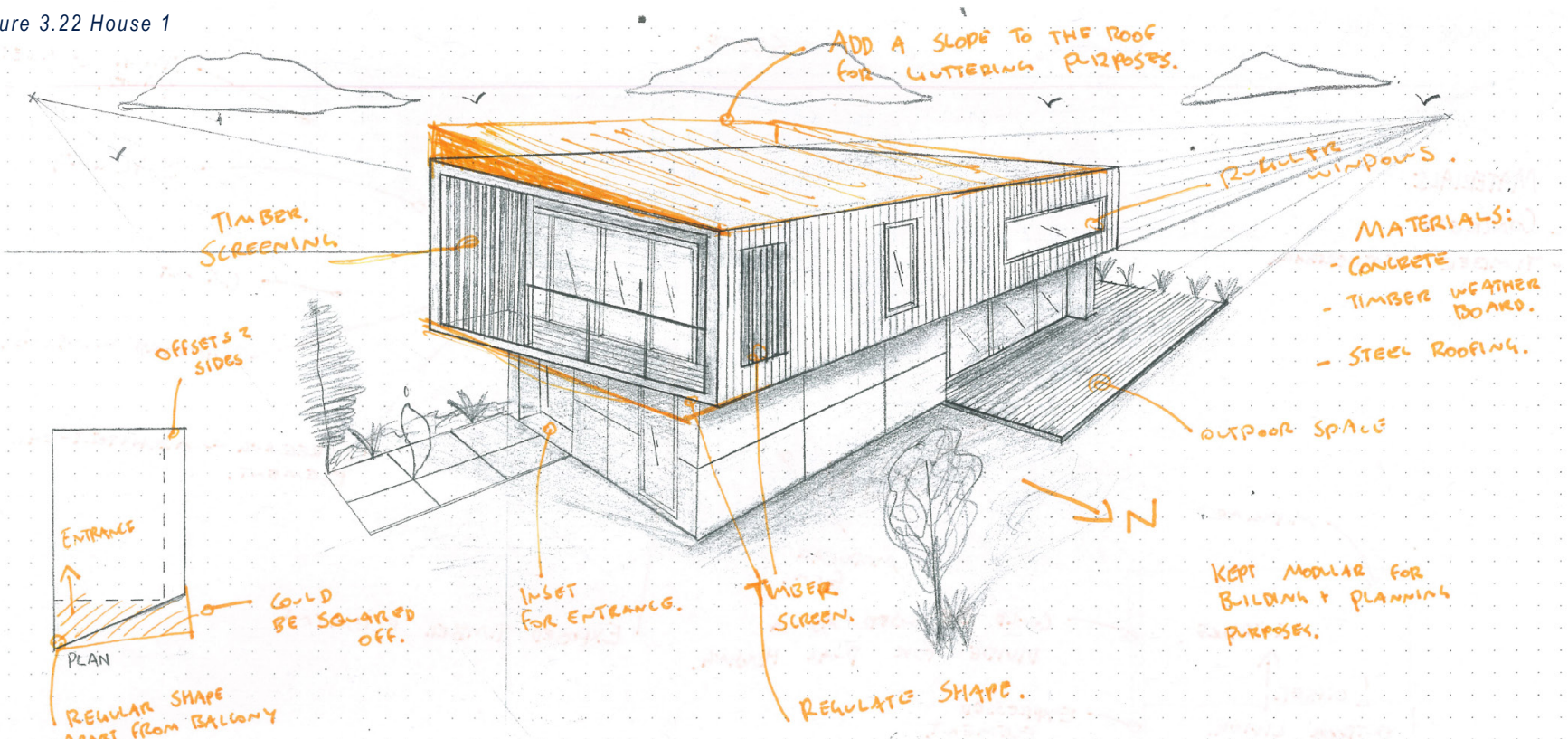

apart Grom Ballony

over hang

is rhis EfACIENT?

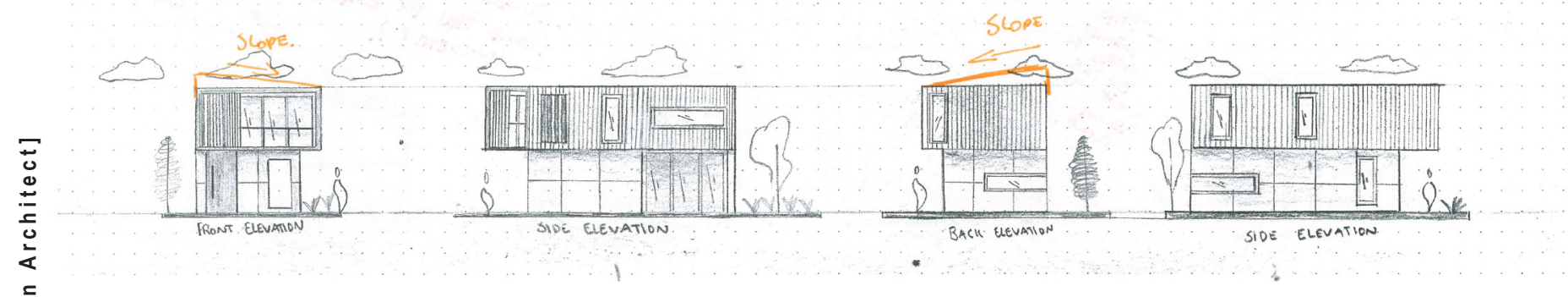

Figure 3.23 House 2

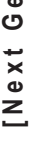

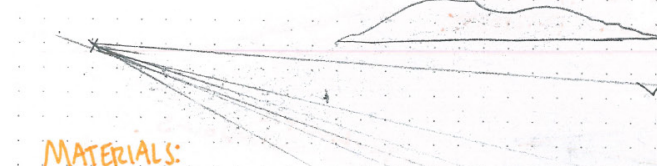

Conncrete

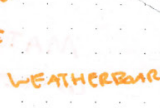

- timiser wentherbana.
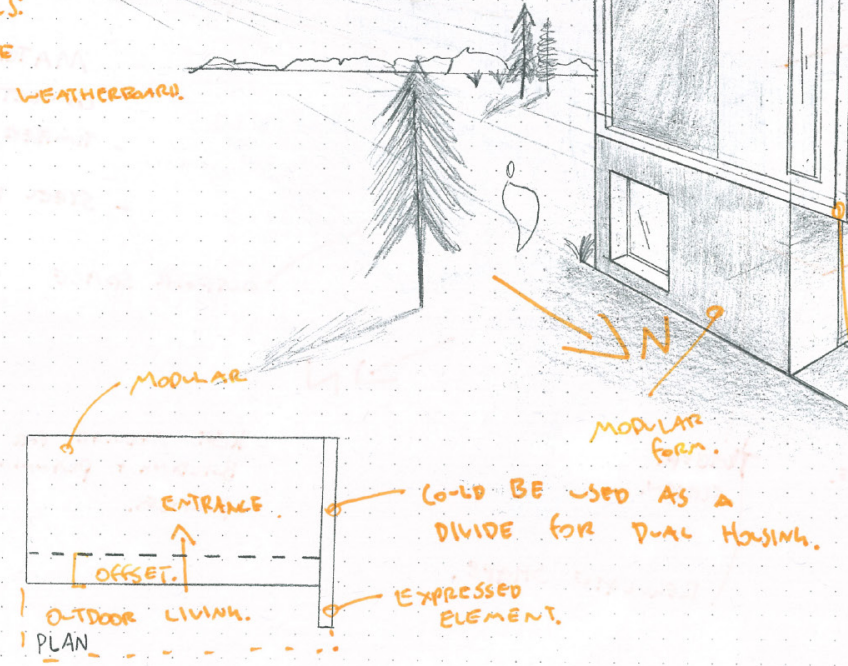

- Dinere

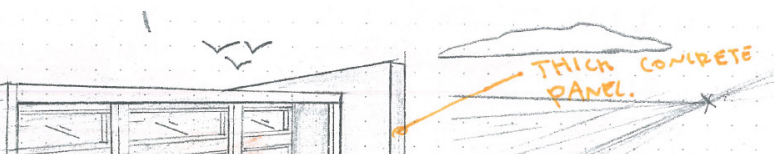

IS THE COT OT

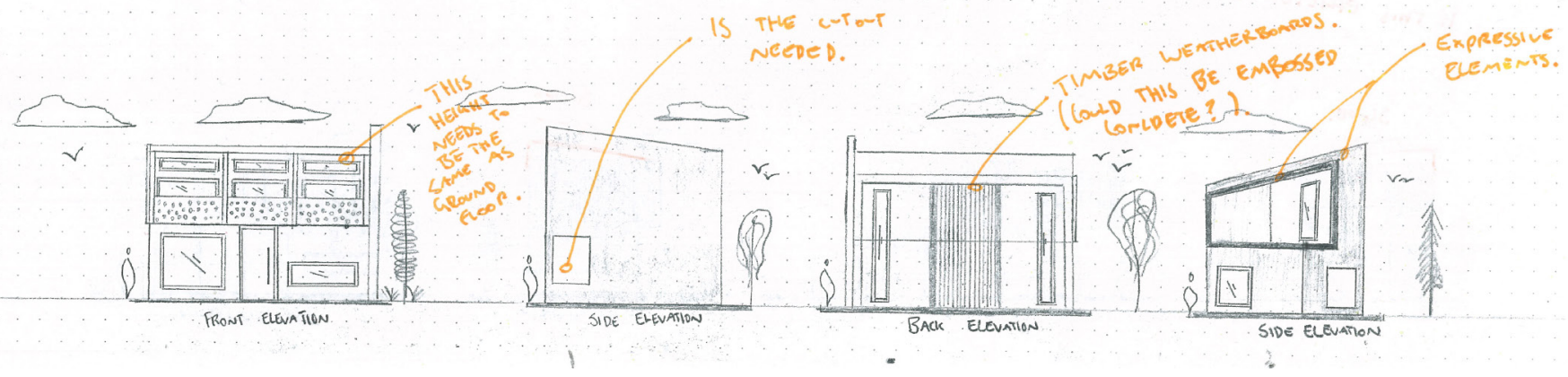


Figure 3.24 House 3

Desilined as a one

BEDRoom HOME:

Matera als:

- Colour steel with folped seam

- preciast concrete.

EnTrance
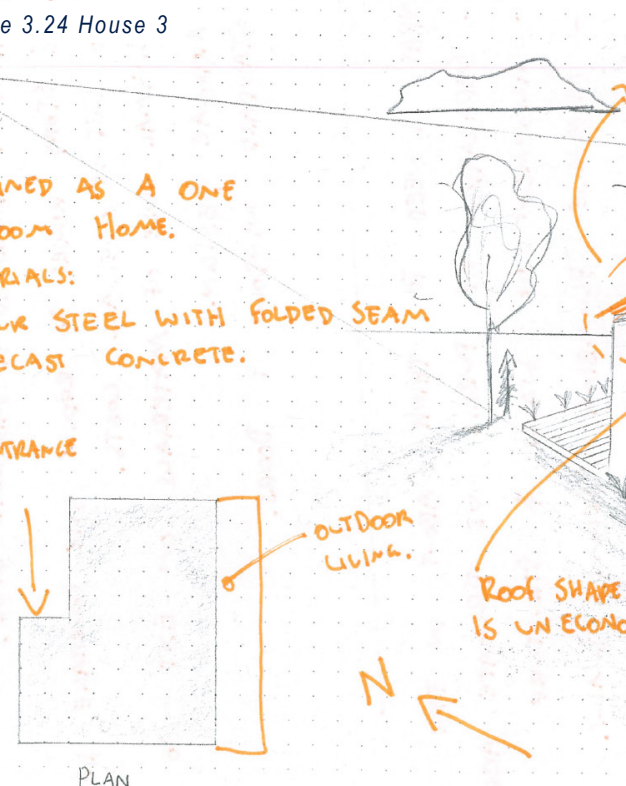

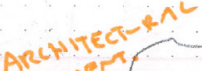

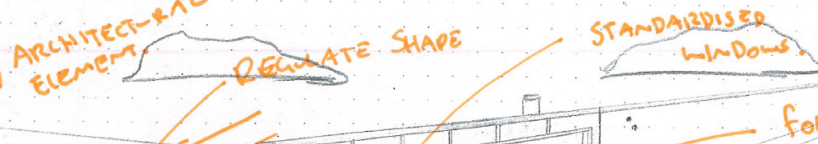

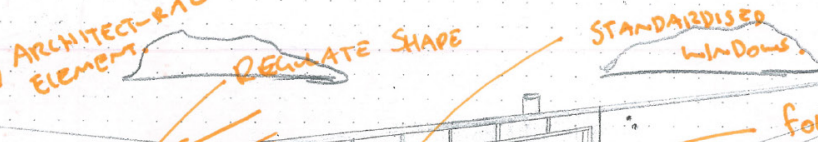

foldeo seta

oueviriser.

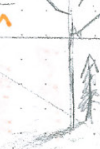

48,1

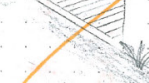

Roof SWANE

is UN ECONOAIL
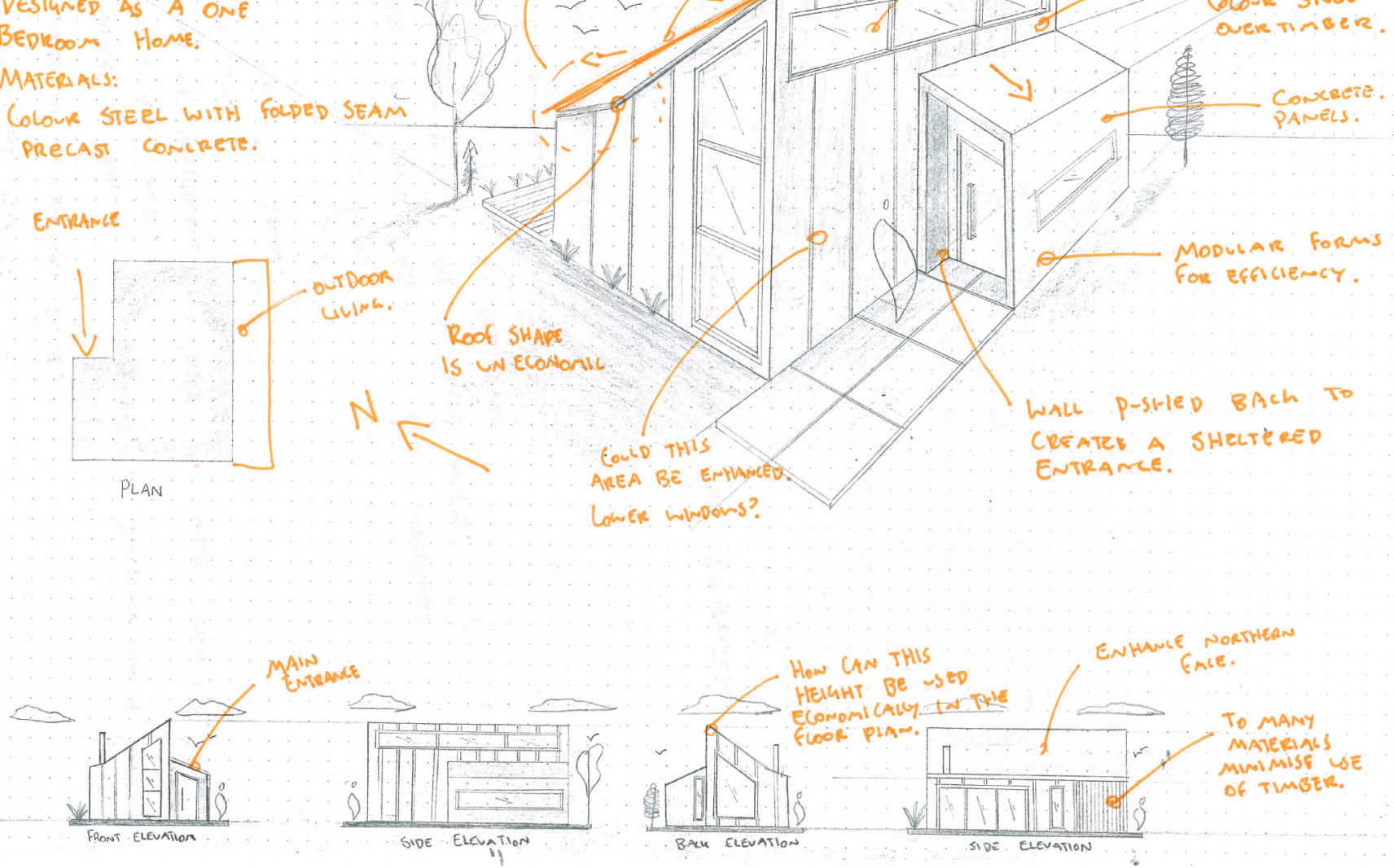

Figure 3.25 House 4

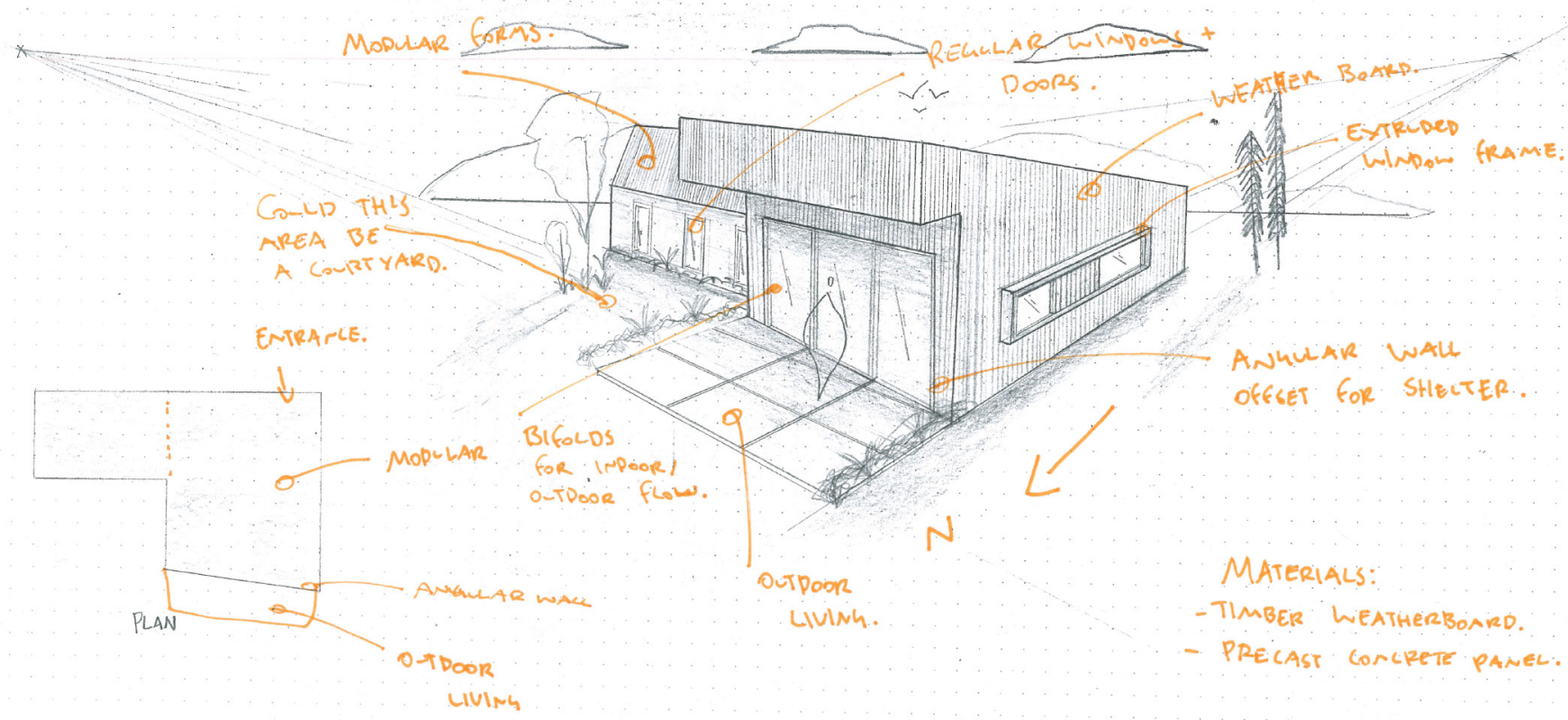

THE. 2 SIDES

LAN THE 2 SIDES OARER
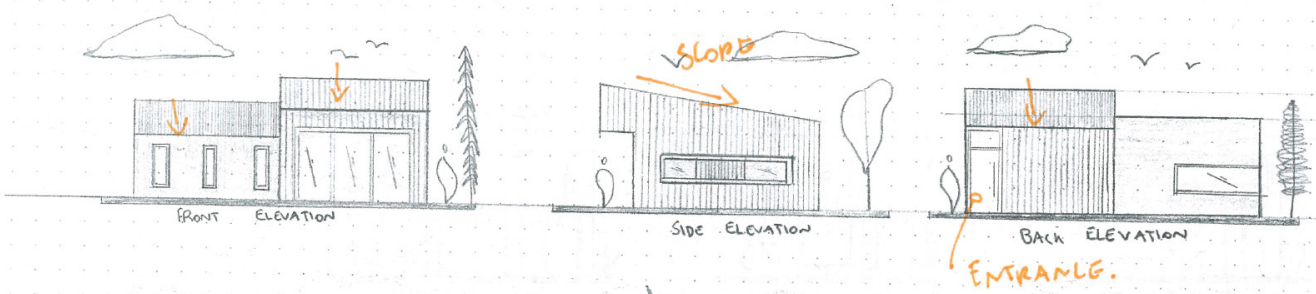

BETIER. 
MATERIALS:

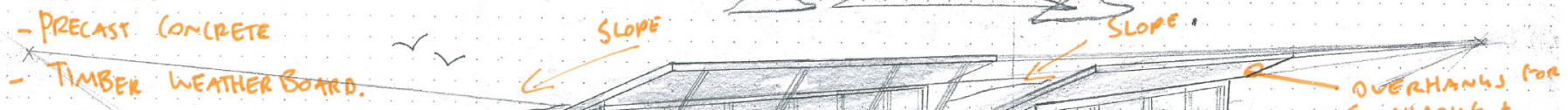
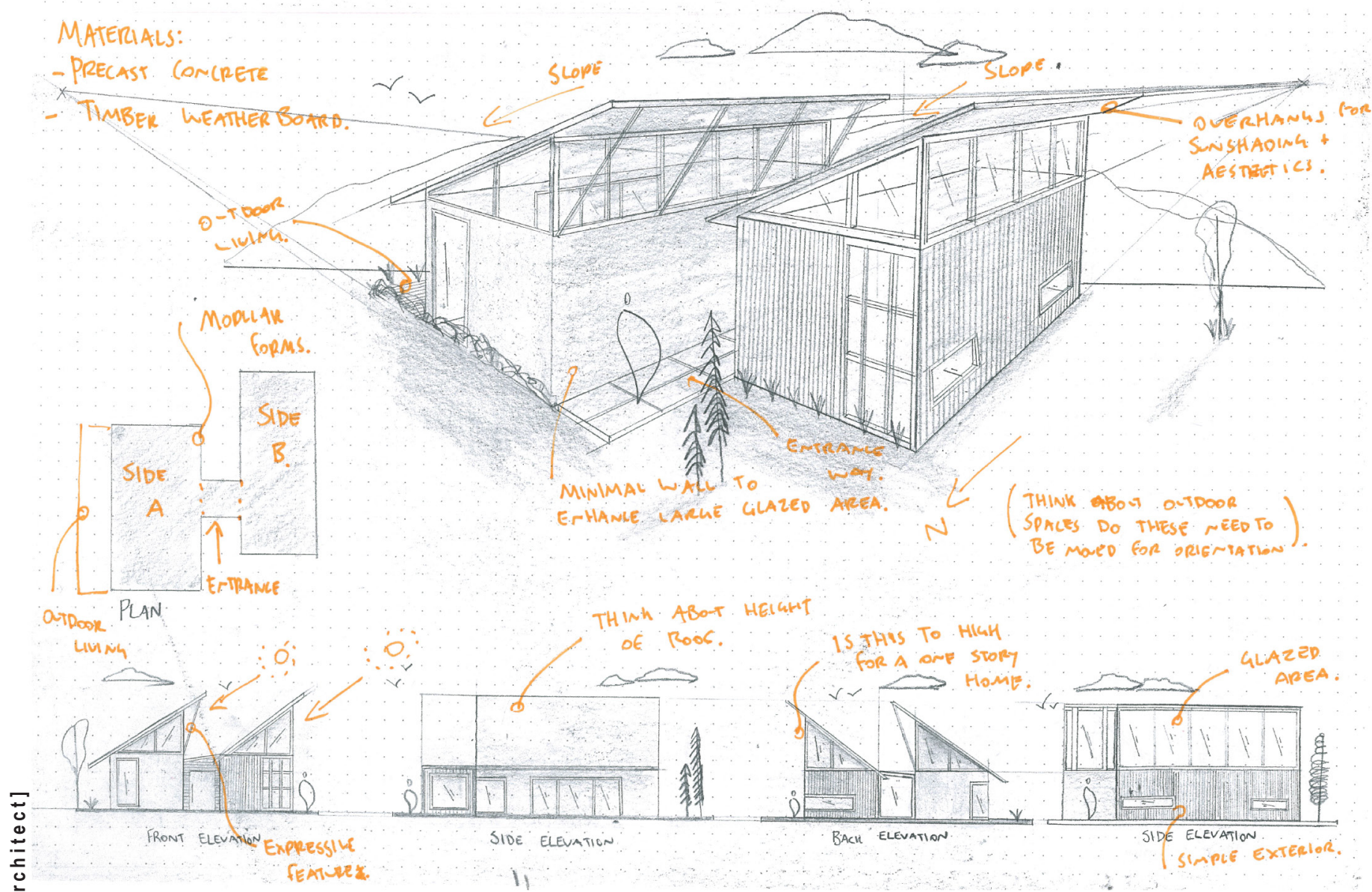

II

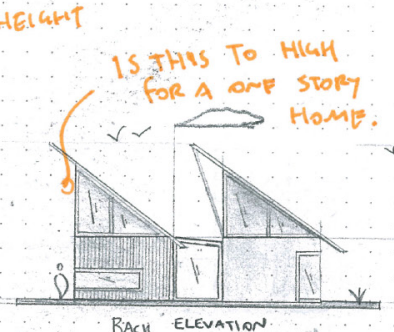

SPALE. DO THESE rEEDTO.

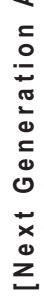

Figure 3.27 House 6

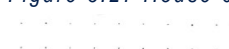

.

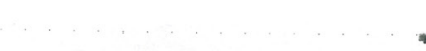

\section{- is trics mary aEP.}
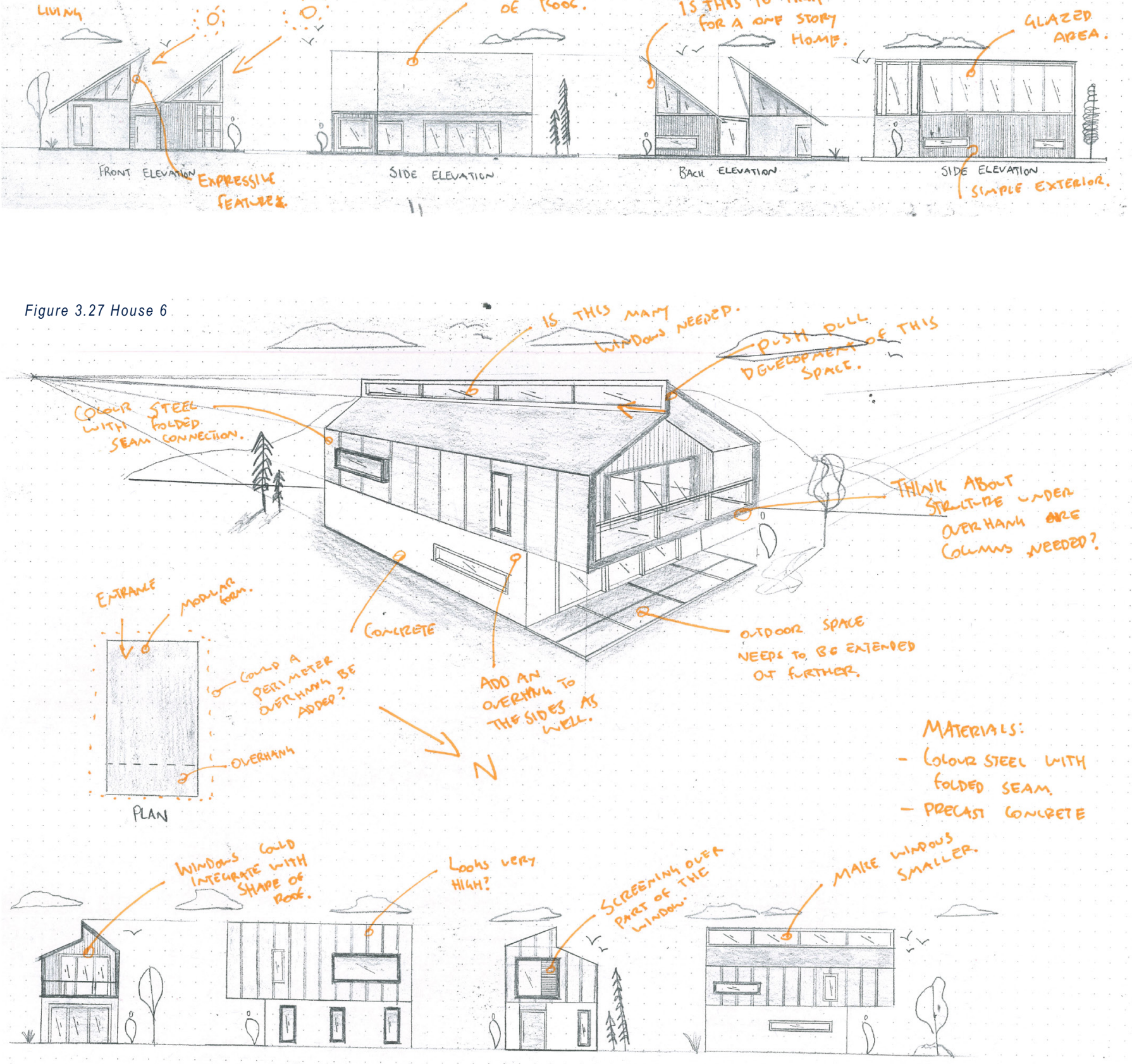


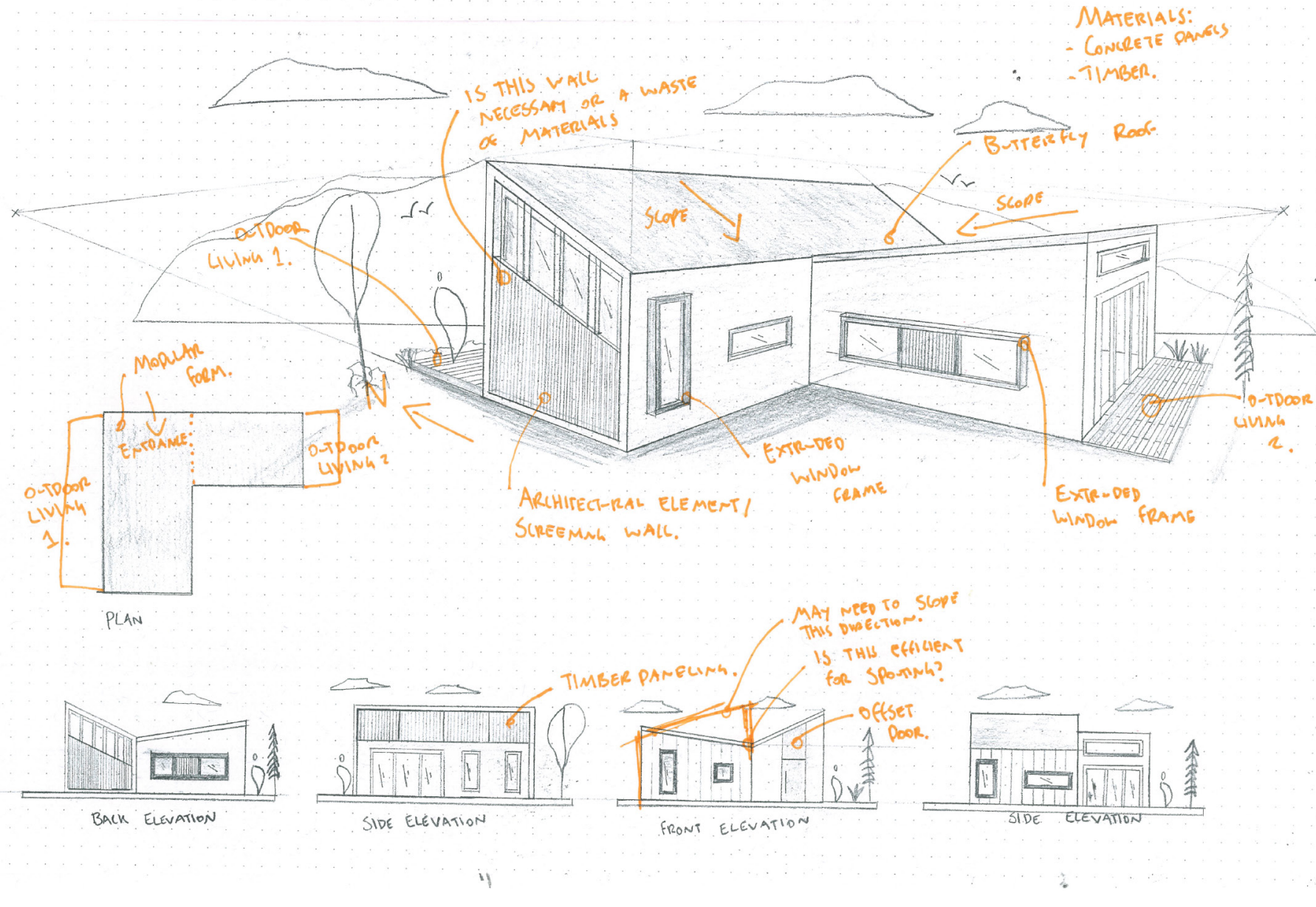

Figure 3.29 House 8

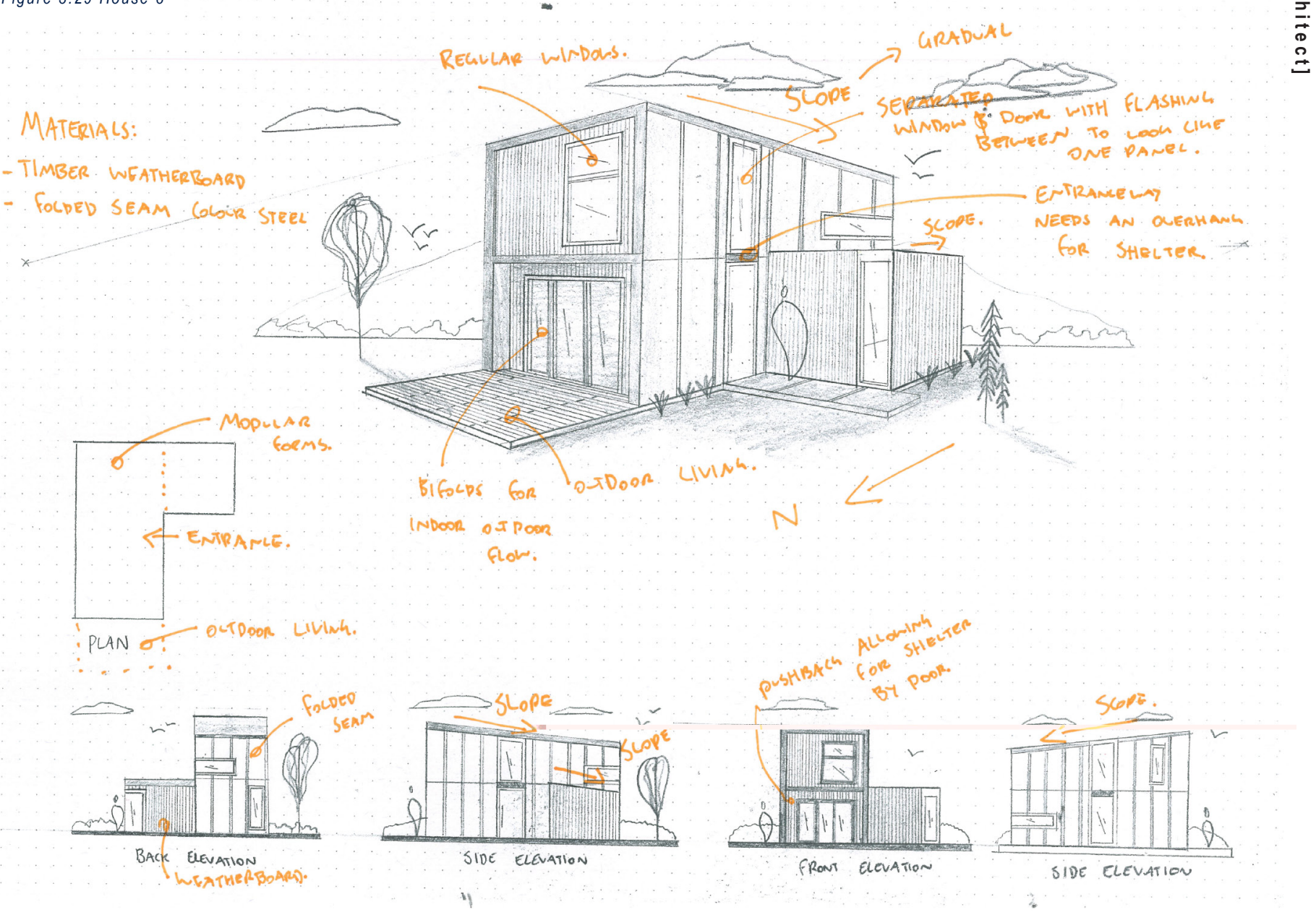


MATERAALS: IS THES NEEDEO?

- Concrete
- Stees Robinla.

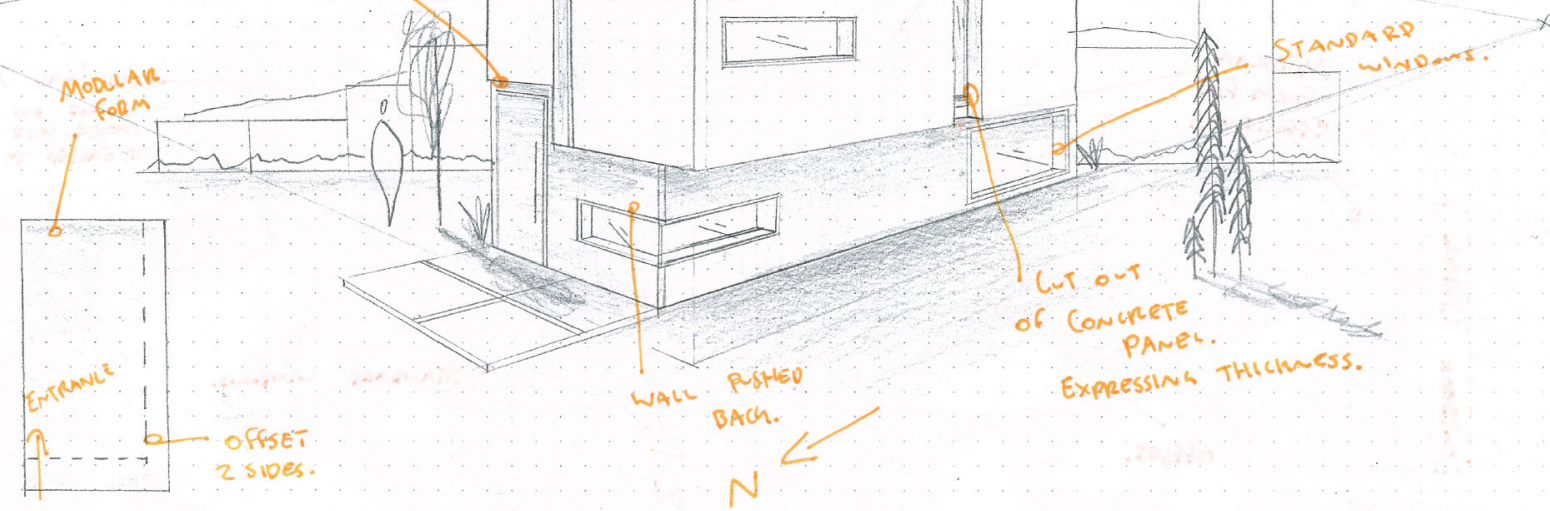

PLAN

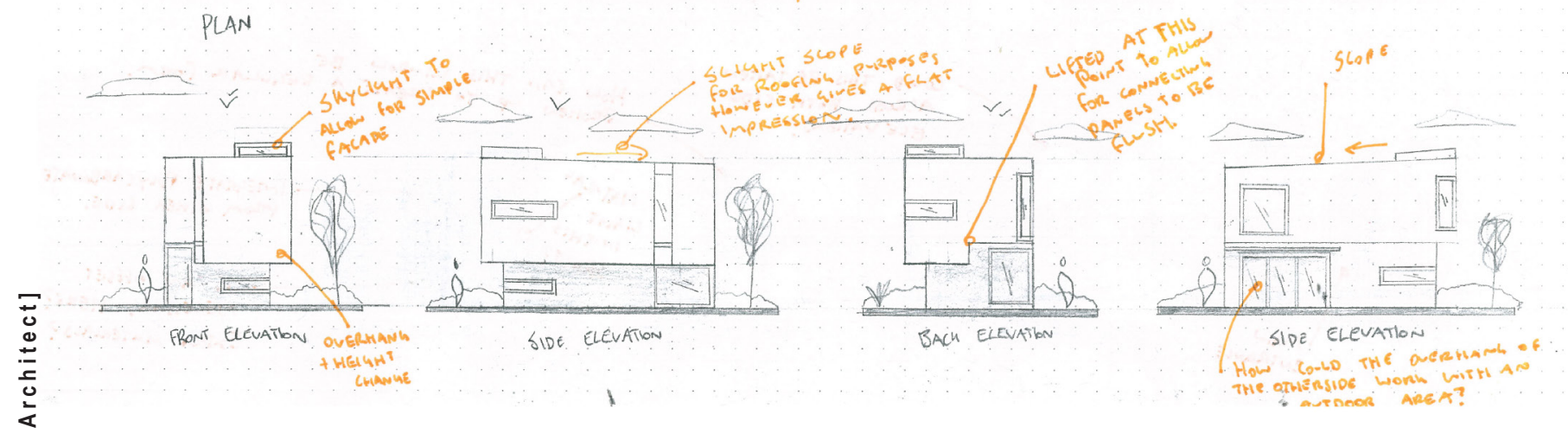

Figure 3.31 House 10

$\underset{\mathbf{x}}{\mathbf{x}}$

timber weatherrisonos

Mron Roofinis.

- Poly carbonate.

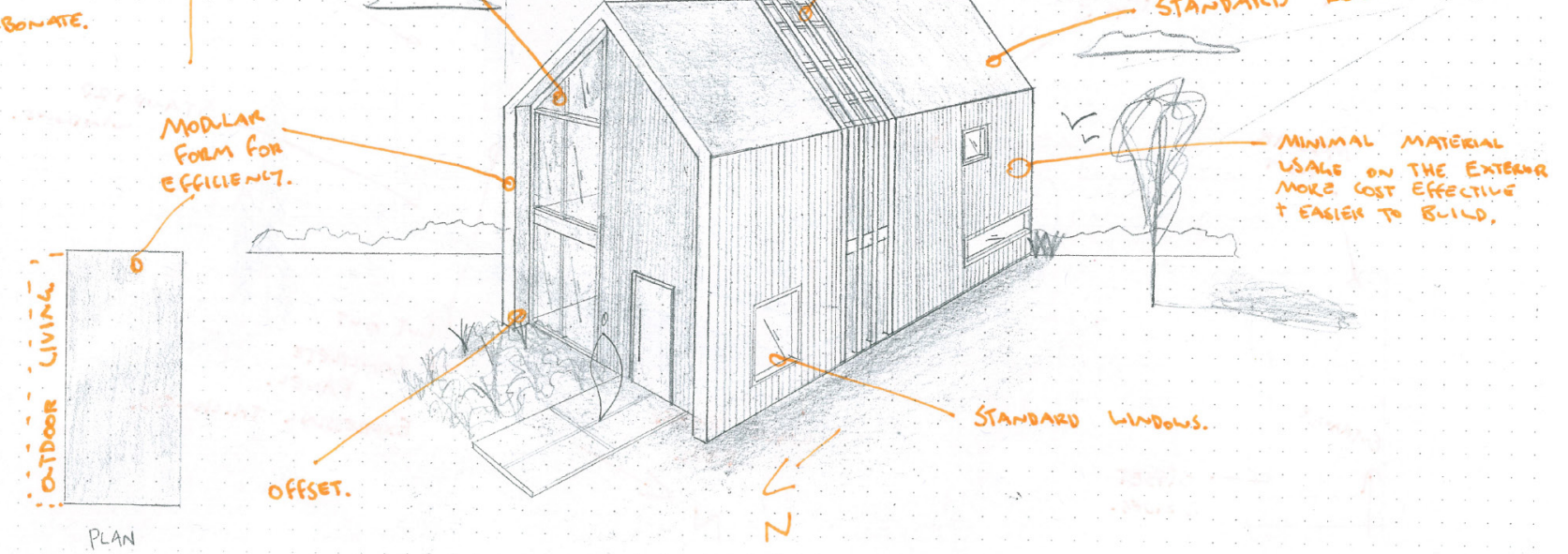

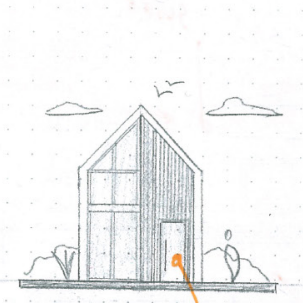

FRONT ELEVATION

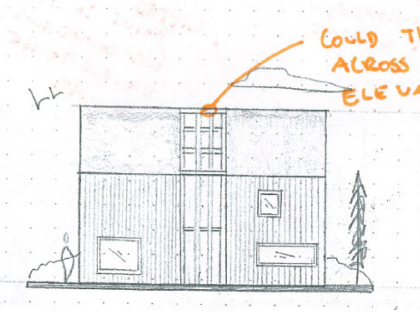

SIDE ELEVATION

THIS BE TAKEN

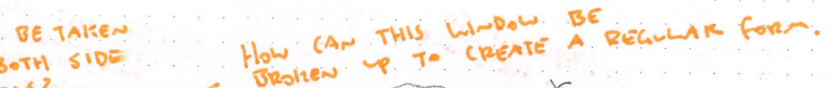
for llame diffusal. - Elonomic cholce.

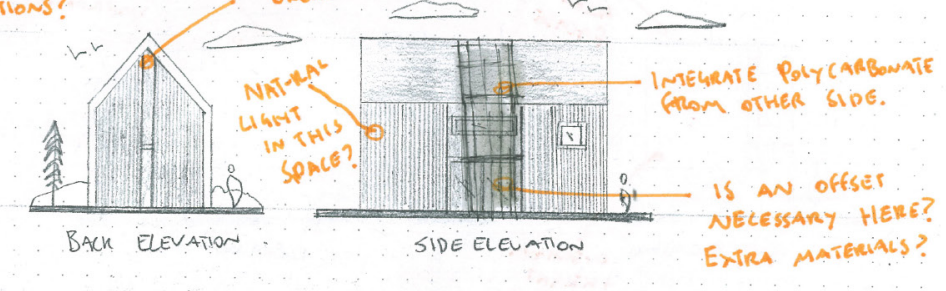




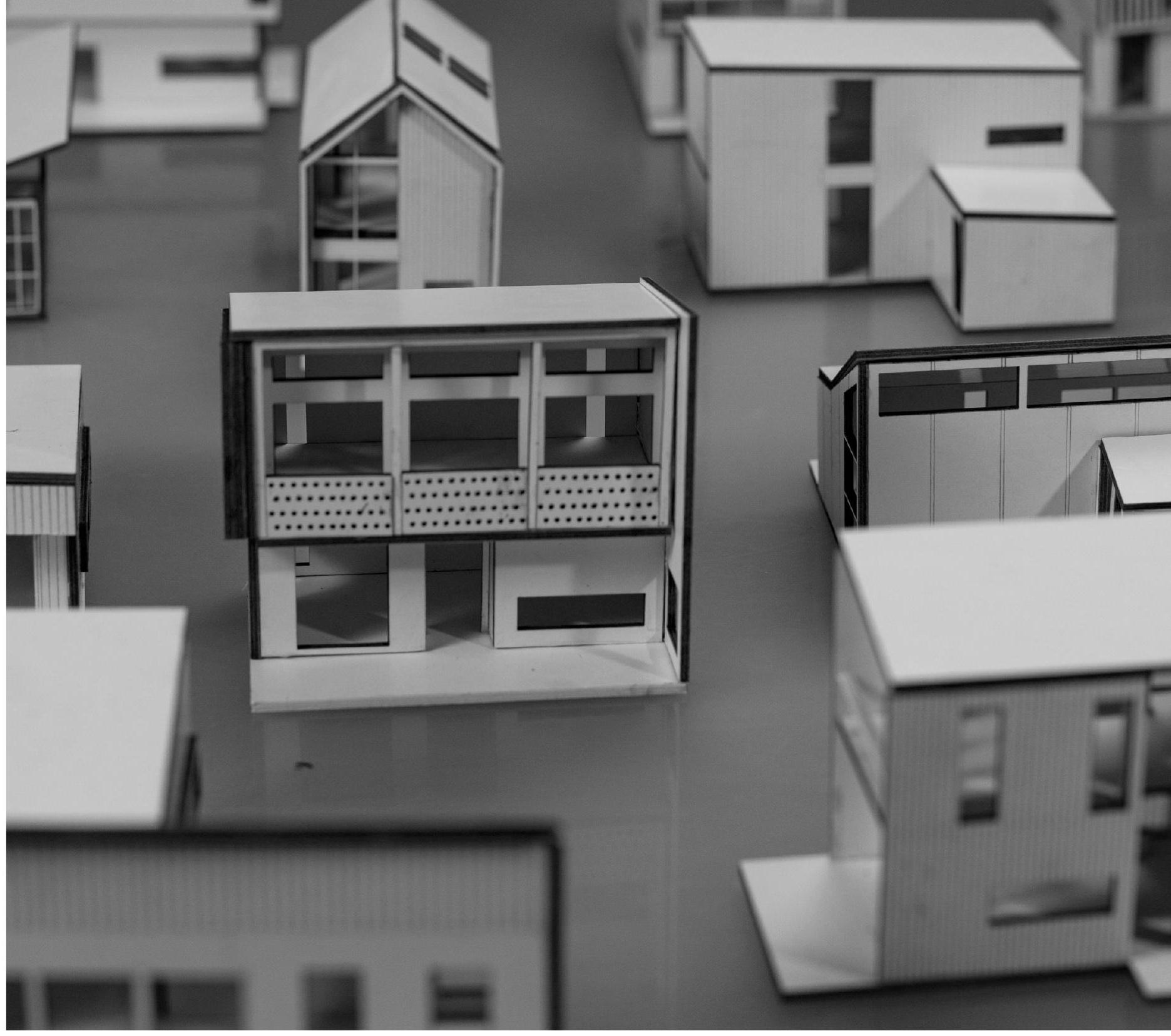

Figure 3.32 A series of models

\section{A Series of House Designs}

Physical Modelling

Physical models have been created for each of the ten housing typologies designed along with housing typology 1.1 from Design Phase Two. Physical modelling has allowed for the houses to be seen as a whole providing a view of the composition of each elevation within a 3D model while remaining in a conceptual phase. Designing through sketching restricts the overall 3D composition as only one perspective view is seen of each house. Scale is explored through the models and the overall construction of the form, highlighting problematic areas and places for further development. 

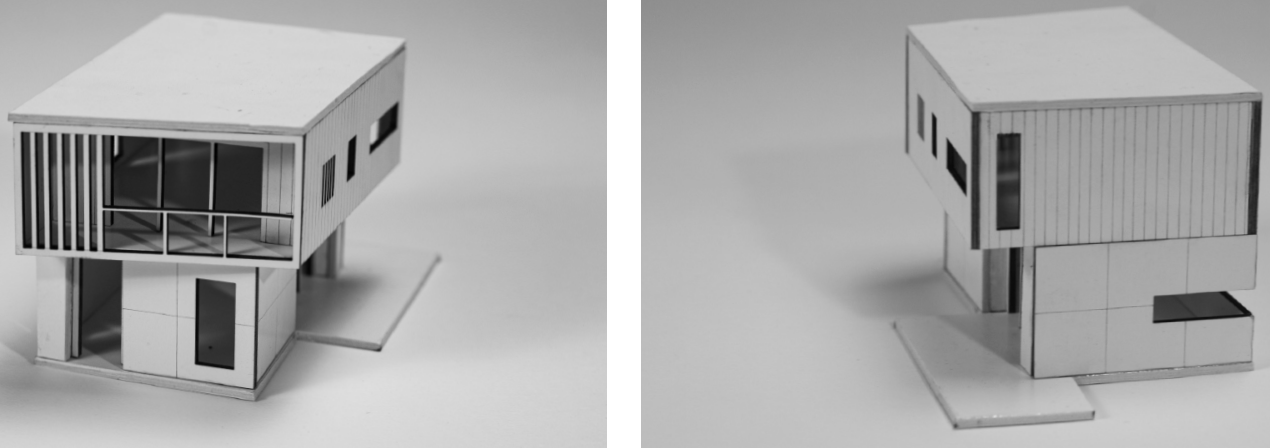

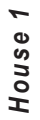

Figure 3.34 House 2
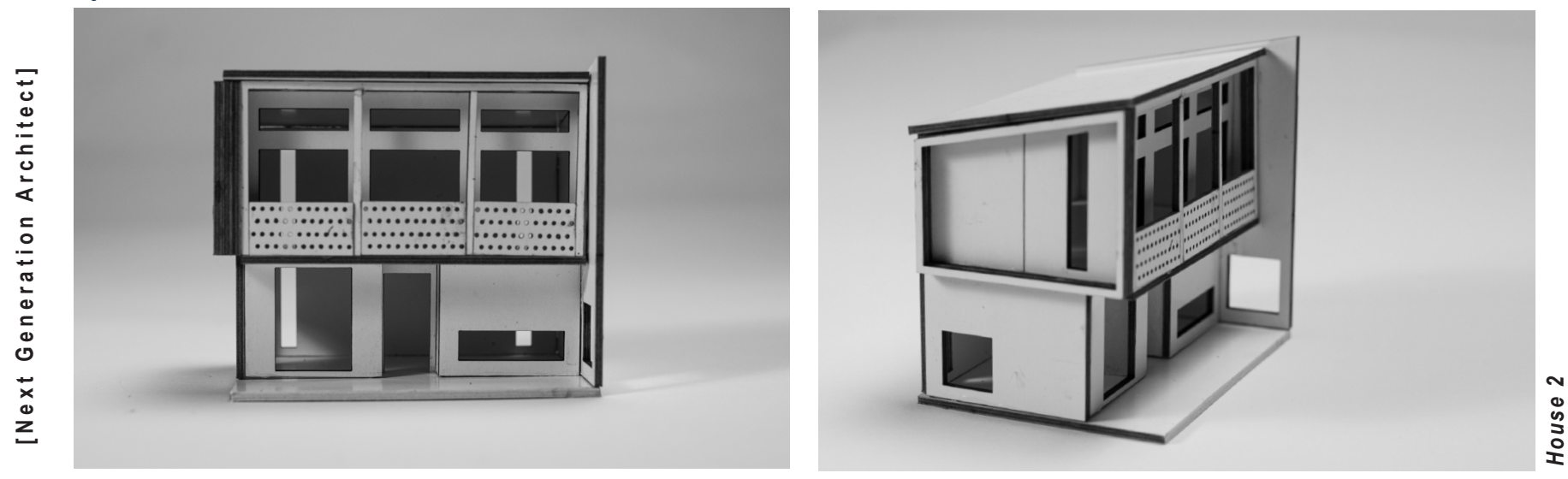

Figure 3.35 House 3
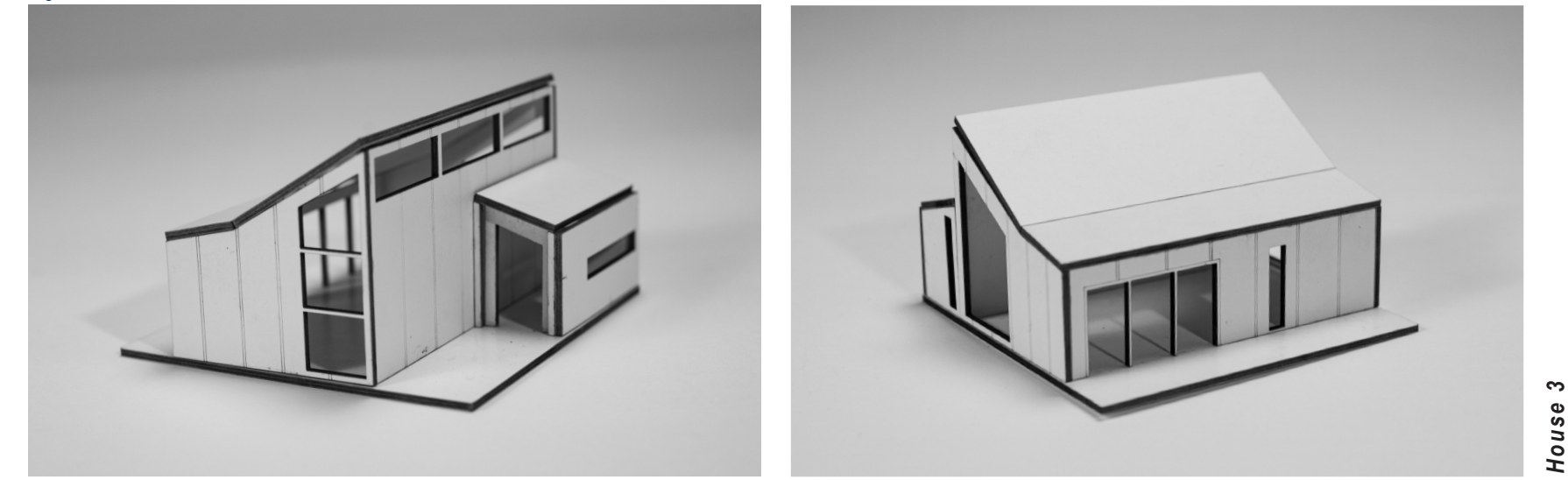

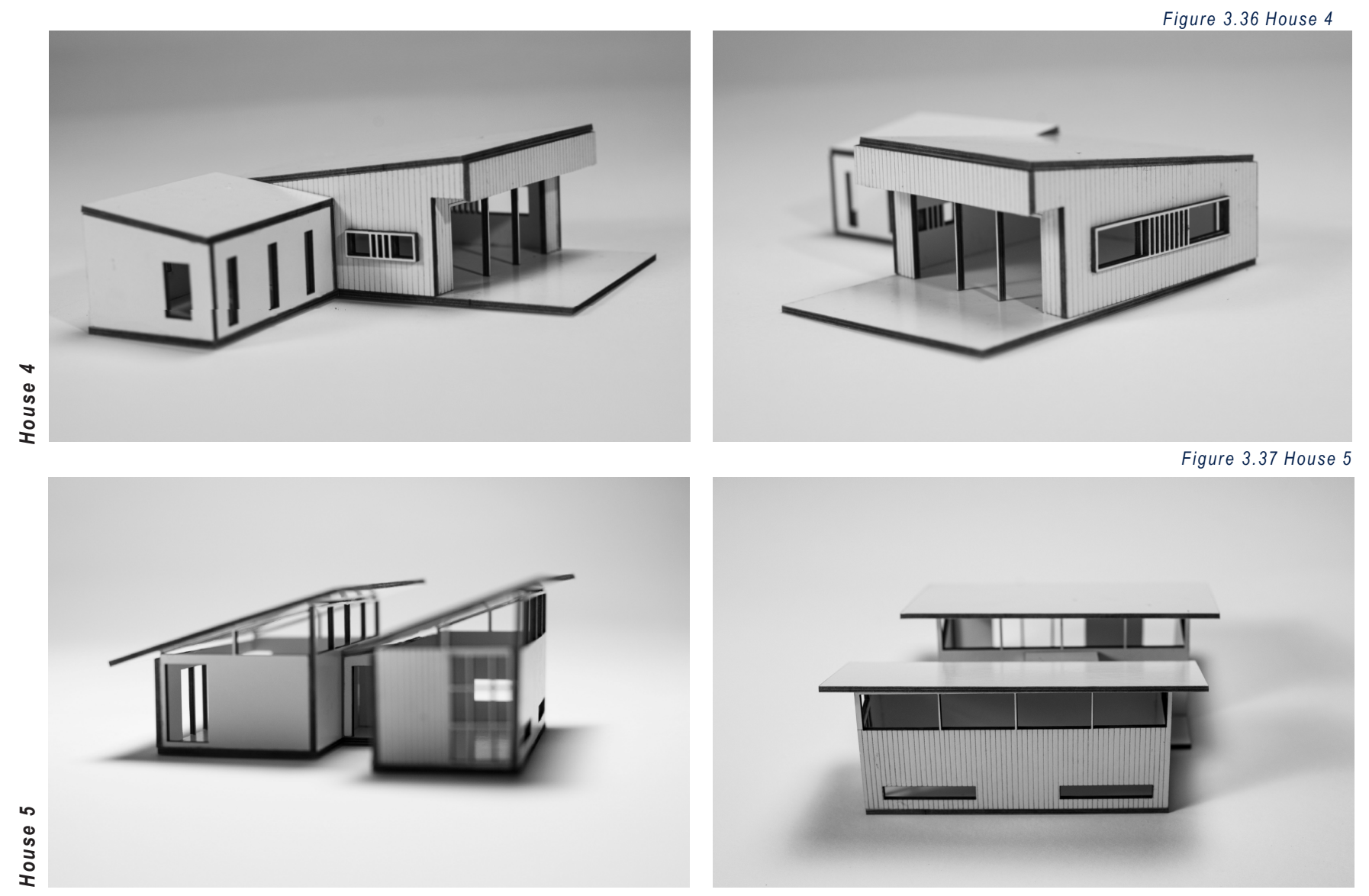

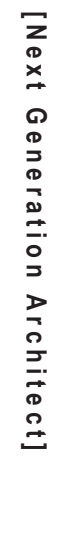

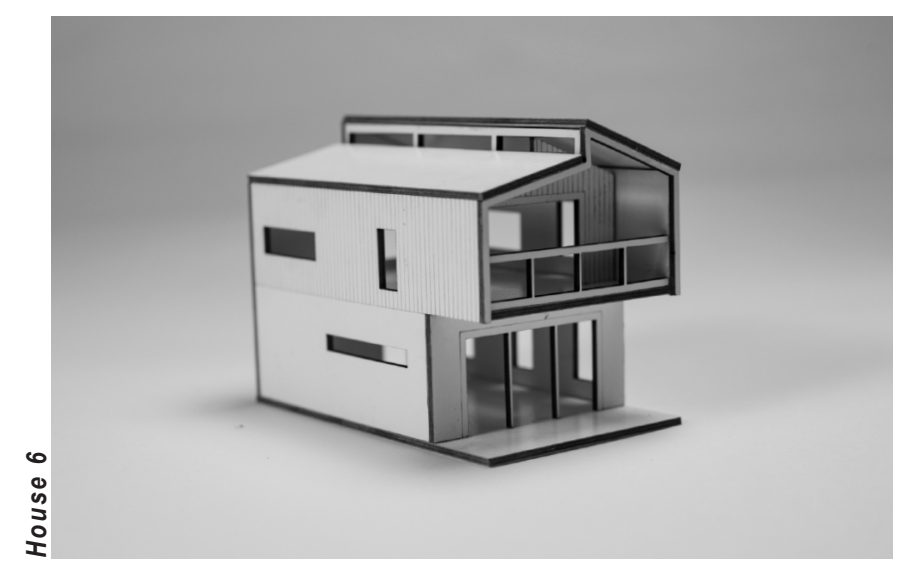

Figure 3.38 House 6

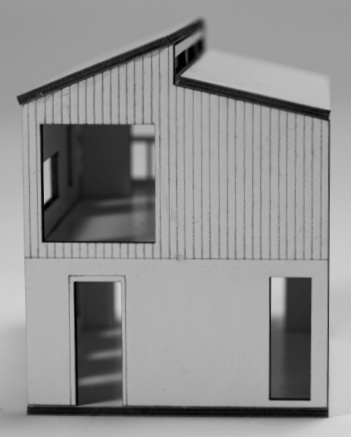



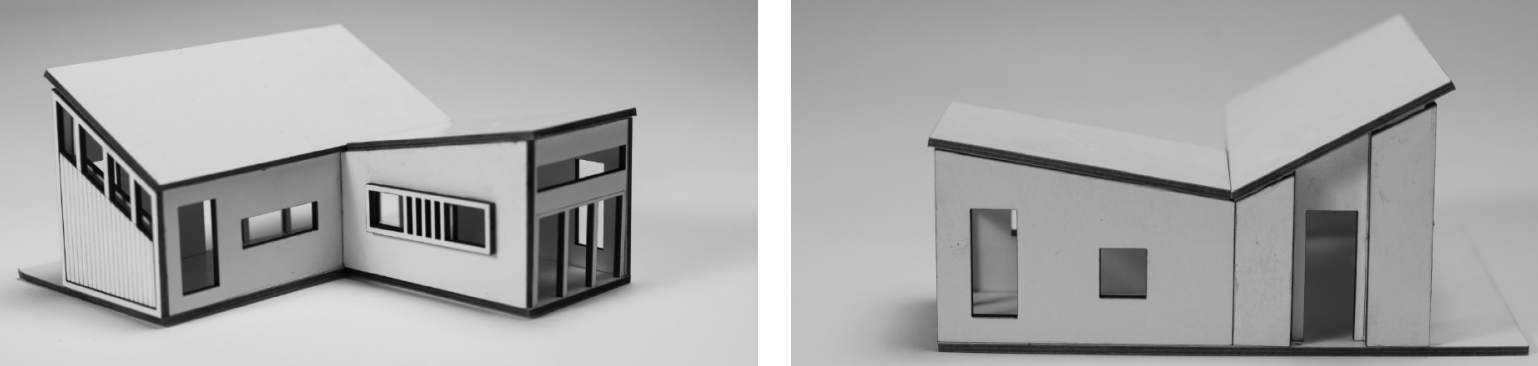

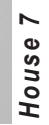

Figure 3.40 House 8
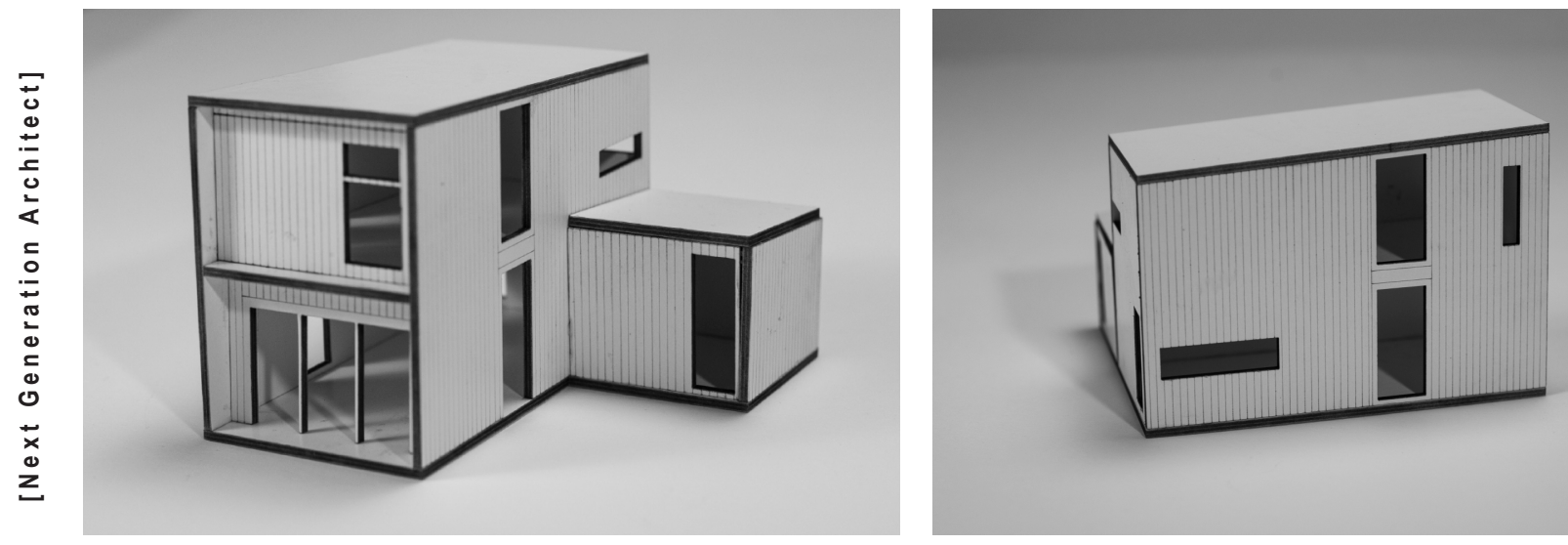

Figure 3.41 House 9
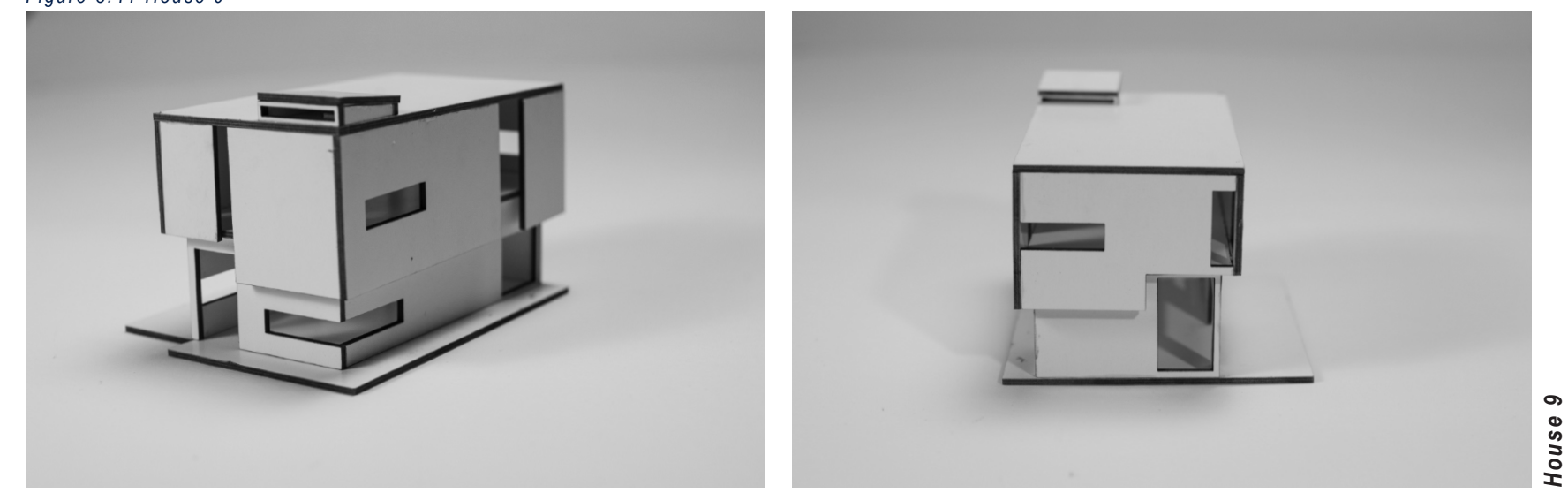

$\infty$
0
s
0
1 

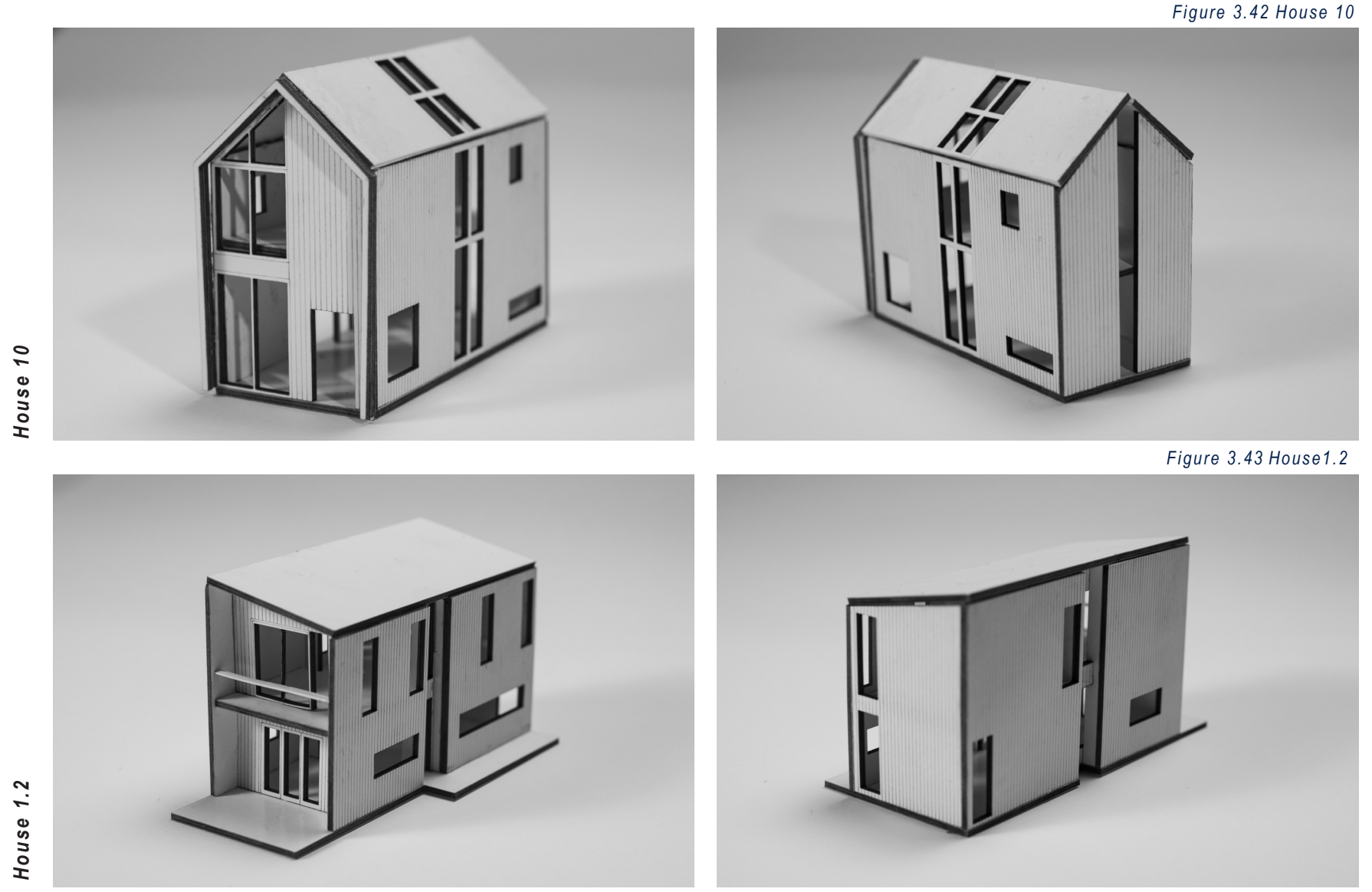

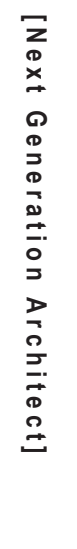
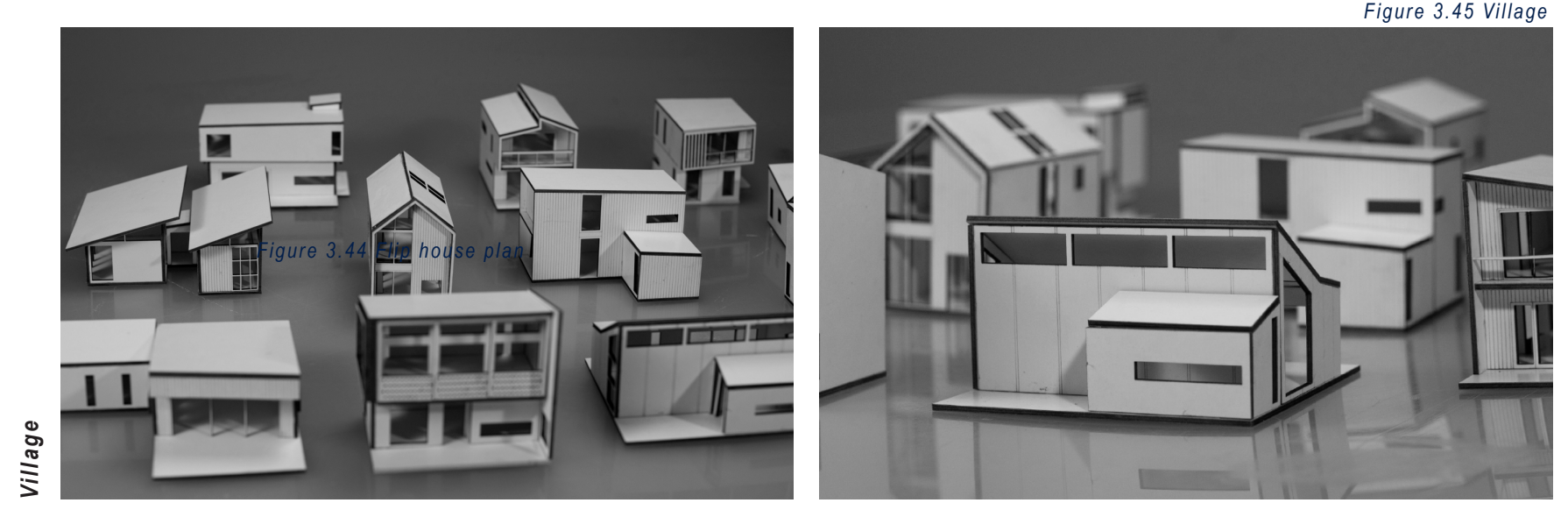
Development Process

Digitalising Designs

The overhang on typology 3.2 (previously house 9) was adjusted to be on one short and one long face, allowing for shelter at the entrance and partial shelter over the outdoor living space. Consideration into dual housing influenced the faces with an overhang. The skylight structure was removed, as this additional element is not needed on the base design. The windows and the location of the outdoor living space have been adjusted to suit the planning and north facing areas.

The planning and footprint of house 3.3 (previously house 2) had a number of variations to the planning, including 3 bedroom and two 2 bedroom options, however, the 3 bedroom option had a large floor area which was pushing the boundaries of the design parameters set. The challenge with this design was the balcony facade working with internal walls. To solve planning issues, an additional panel was added to create a grid of four instead of three.

The analysis of house 3.4 (previously house 1) in the sketch design phase highlighted the issues of the flat roof and irregular form of the balcony. The first modelled iteration regulated the form and added a slope to the roof, however regulating the form took the architectural qualities away from the house, the irregular shape was reintroduced. The entrance consists of a cutaway to create an entrance porch sheltered by the floor above; this was absent through the physical modelling. 
Typology 3.2

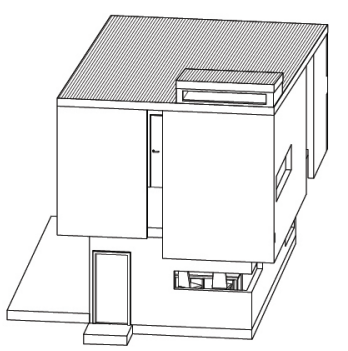

Concept Model
Aligned

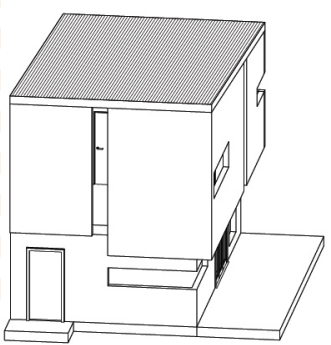

Developed Model

Figure 3.46 Typology 3.2 developments

Typology 3.3

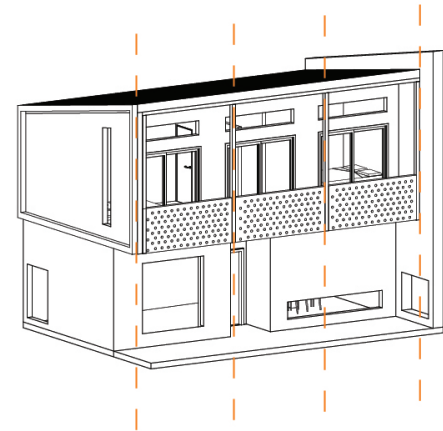

Concept Model. Original grid

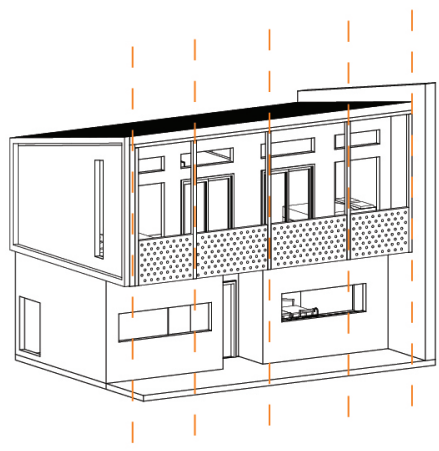

Concept Model. New grid

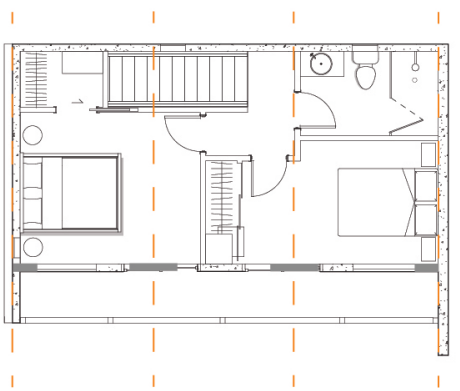

Original grid on floor plan

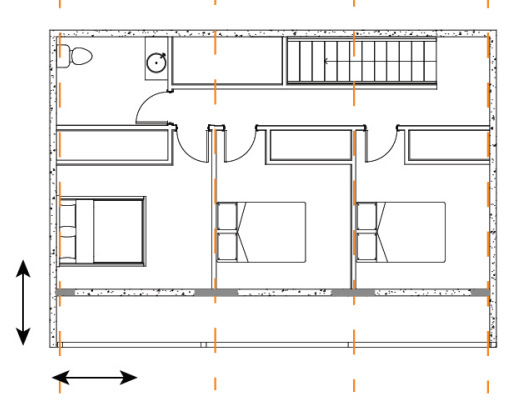

Original grid on expanded plan

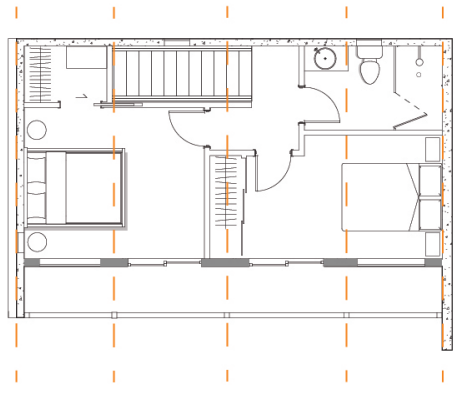

New grid on floor plan

Figure 3.48 Typology 3.3 developments

Typology 3.4

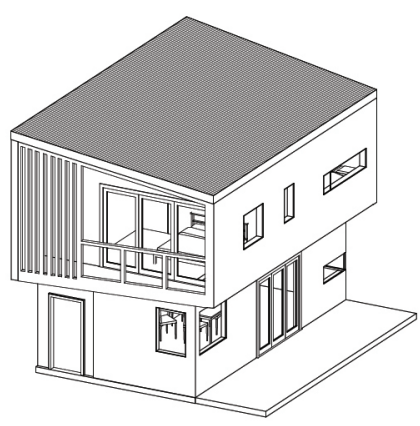

Concept Model

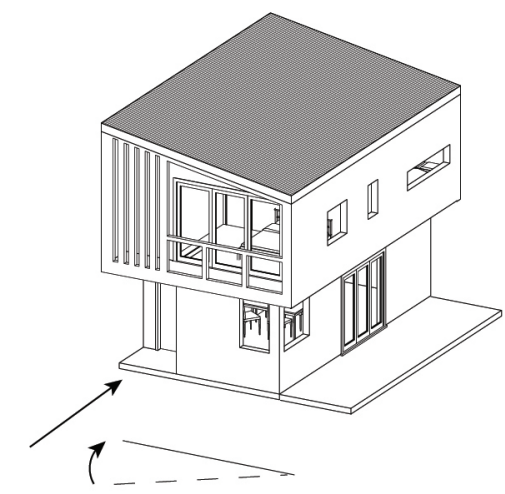

Entrance pushed back + angle removed.

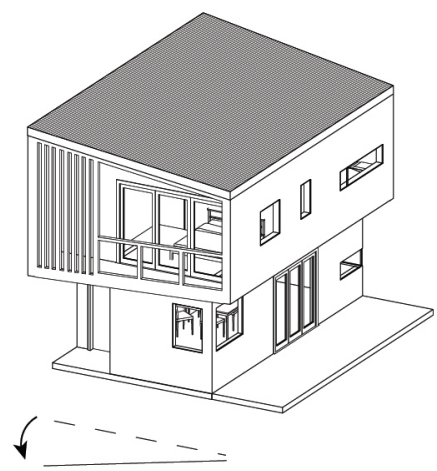

Angle added 


\section{The Pattern Book}

The Two Storey Series

The first iteration of the pattern book involves the design of four housing typologies, with each typology consisting of several variations to suit individual site conditions and housing types. The four typologies selected include houses 1, 2 and 9 from the series of house designs exercise and house 1.1 from Phase Two. Each typology and its variation has been preliminarily costed with cost data from the QV costbuilder database; these costs are a first cost only and don't include the cost of the land. 


\section{The Design of The Pattern Book}

What is included?

The pattern book consists of four sites across the Wellington Region located in Newlands, Lower Hutt, Wilton and Island Bay (figure 3.49). The aim of selecting several sites across Wellington ensures the testing and adaption of housing typologies across several site conditions such as connection to topography, orientation, foundations and types of housing.

Architects' design bespoke projects for their clients that consider unique designs and a range of site conditions. Conclusions drawn from the analysis of developer driven housing developments, summarises houses are designed for flat sites that are north facing. Therefore it is fundamental that the pattern book created for this thesis exhibits several variations of the housing typologies with the mindset of an architect.

The four sites selected include north and south facing sites and west and east sloping sites prevalent to Wellington.

- Site A at 55 Chapman Street, Newlands: North facing views, across both flat and sloped topography.

- Site B at $105+107$ Whites East Road, Lower Hutt: South facing flat site with a northern street entrance.

- Site $\mathrm{C}$ at 35 Worcester Street, Wilton: West sloping site.

- Site D at 1/43A Wye Street, Island Bay: East sloping Site.

Design parameters were set to ensure all designs met a specific criteria, targeted at aesthetics and economics. The parameters consist of the following:

- Modular forms.

- Standardisation of windows, doors, sheet sizes and construction techniques.

- Separation of public and private spaces.

- Maximised floor areas with two storey dwellings reducing site coverage.

- Minimal materials (no more than two exterior materials).

- Site specific.

- Costs below $\$ 500,000$. 


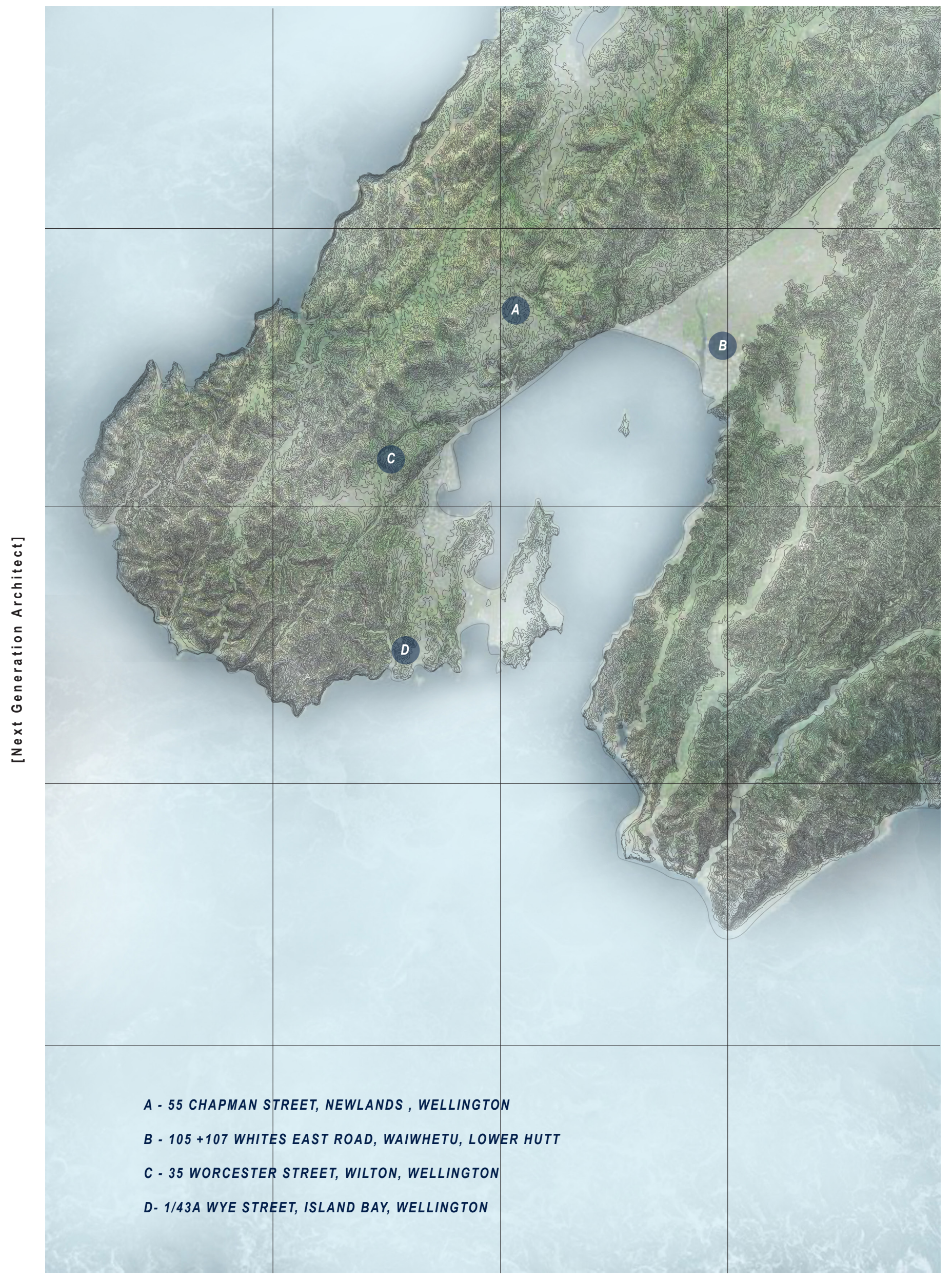

Figure 3.49 Map showing locations of 4 test sites across the Wellington Region 


\section{Test Sites}

A. NEWLANDS

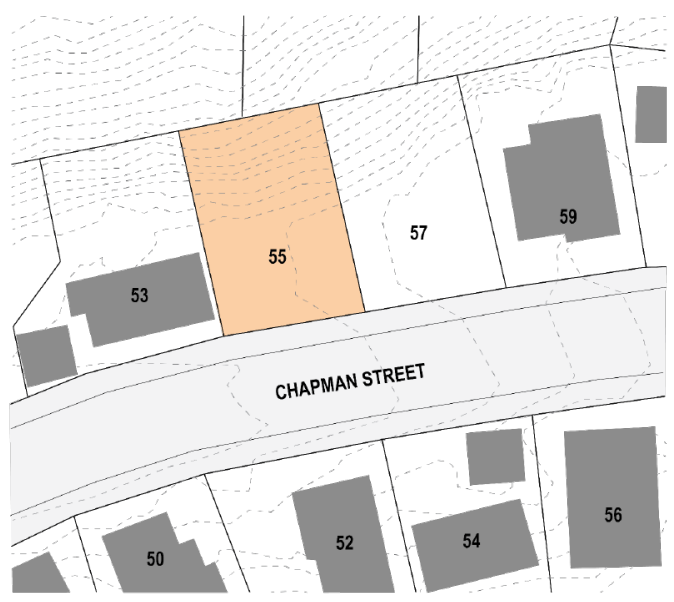

Land value: $\$ 144,596$

Site Area: $418 M^{2}$

Site Conditions: North facing, flat + sloped

Figure 3.50 Test site A map

\section{WILTON}

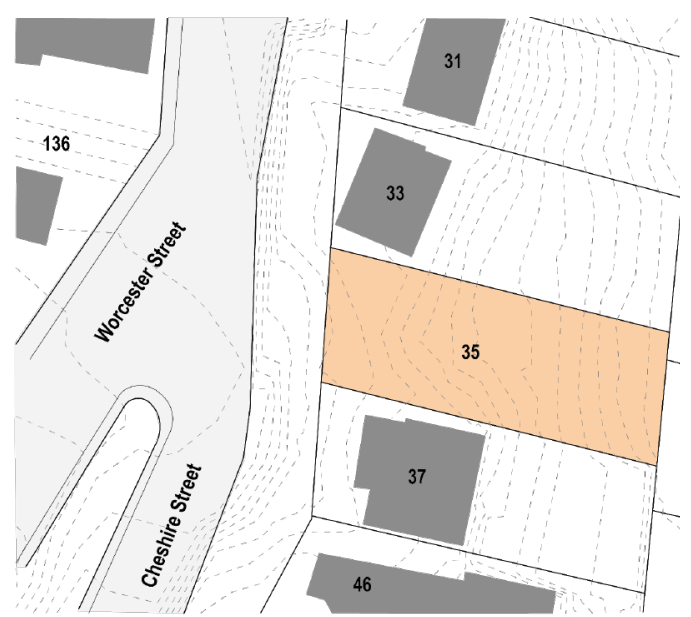

Land value: $\$ 320,000$

Site Area: $519 \mathrm{M}^{2}$

Site Conditions: West slope

Figure 3.52 Test site $C$ map
B. LOWER HUTT

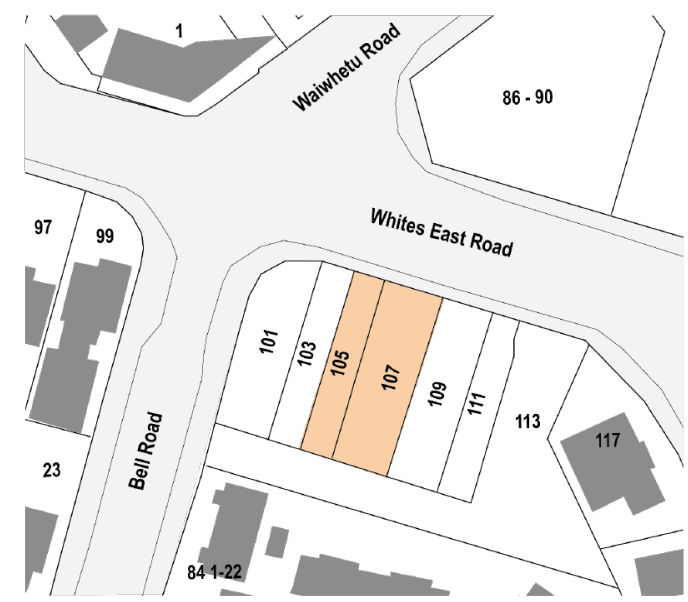

Land value: $\$ 238,000$

Site Area: $519 \mathrm{M}^{2}$

Site Conditions: South facing views, flat

Figure 3.51 Test site B map

\section{ISLAND BAY}

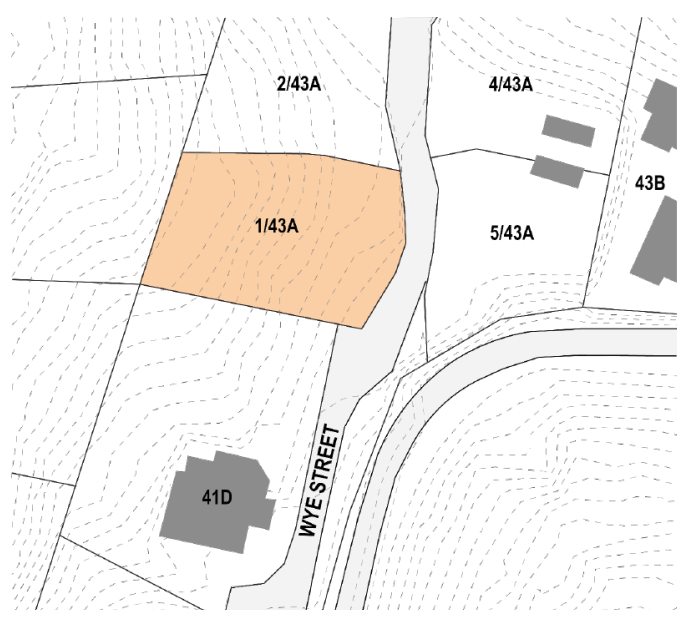

Land value: $\$ 400,000$

Site Area: $550 \mathrm{M}^{2}$

Site Conditions: East slope

Figure 3.53 Test site D map 
House 3.1

$68 m^{2}$

5
0
0
0
0
0
$\frac{1}{4}$
5
0
0
0
0
0
0
0
5
0
0
$z$

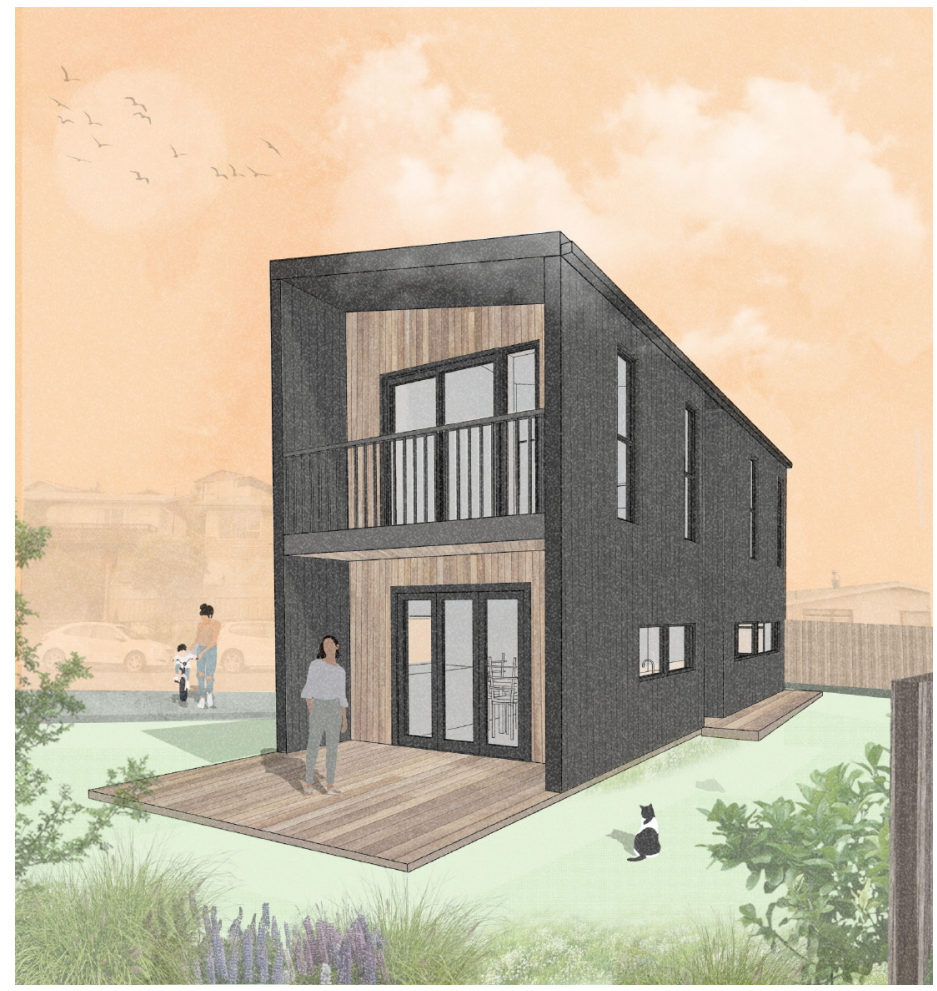

Figure 3.54 House 3.1.1 and 3.1.2 Exterior Aesthetic

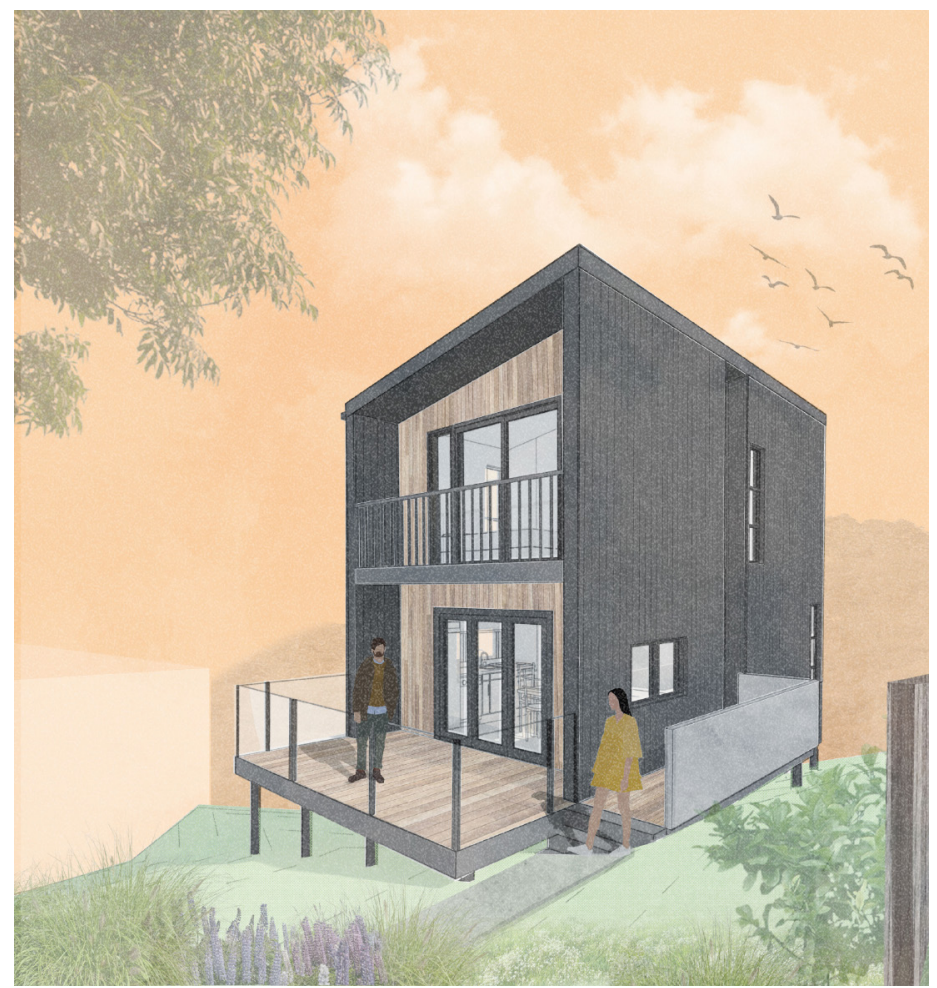

Figure 3.55 House 3.1.3 Exterior Aesthetic 


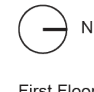

First Floor

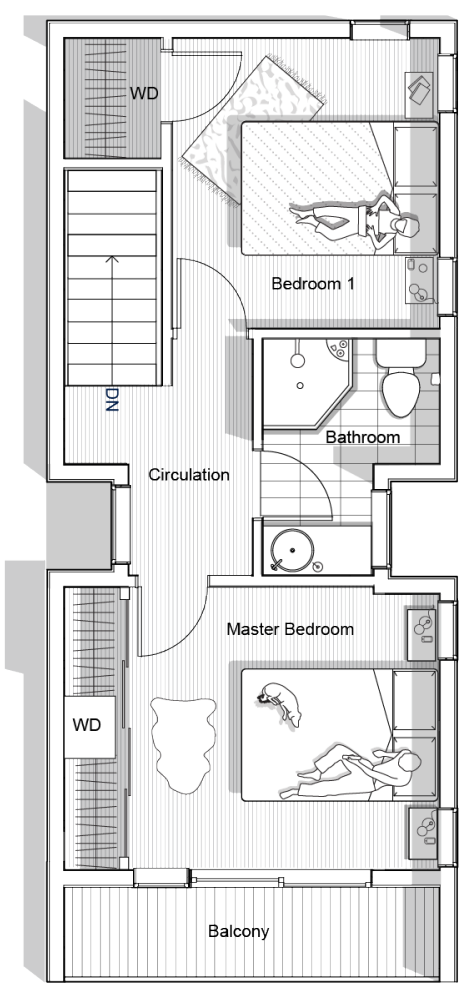

First Cost $=\$ 243,000$

Cost per $m^{2}=\$ 3600$

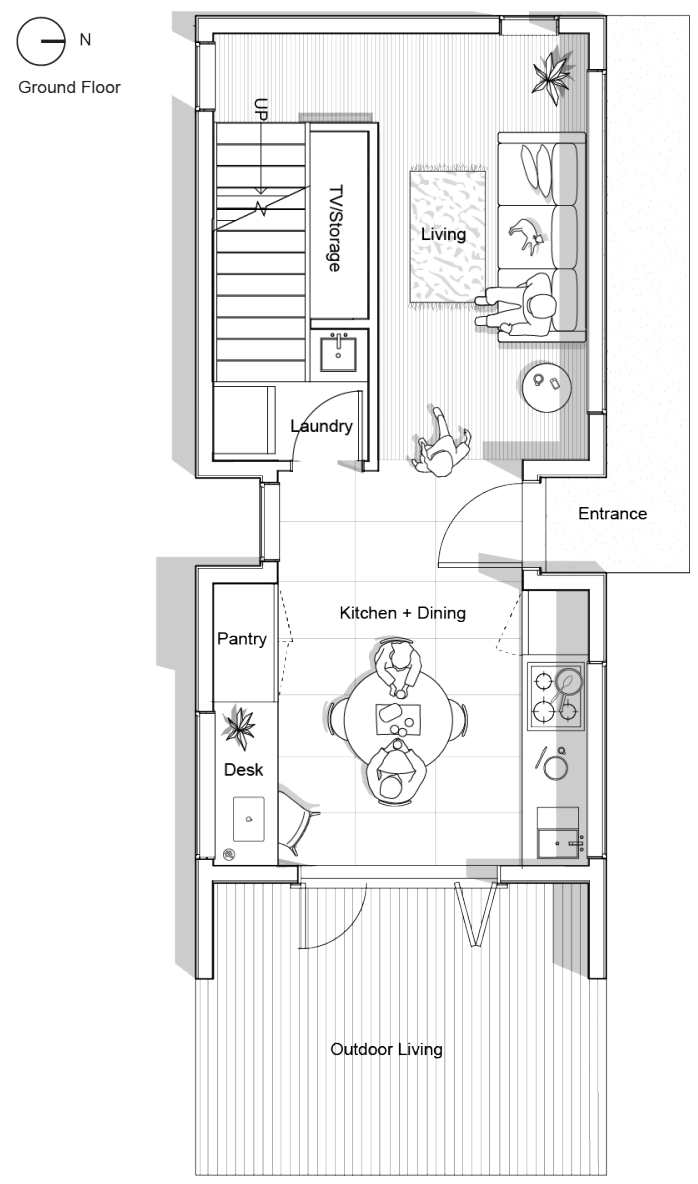

House 3.1 is a 2 bedroom 1 bathroom home at $68 \mathrm{~m}^{2}$. All variations of this house consist of light timber framed construction with weatherboard. Variations to the typology are tested across 3 sites.

- $\quad 3.1 .1$ tested on site $A$.

- $\quad 3.1 .2$ is reflected for site B with a north-facing street frontage.

- 3.1.3 uses timber piles and contains a reflected entrance and raised walkway to suit the conditions of site $D$. 


\section{1 .2}

Figure 3.57 Typology 3.1 .2 reflected plan
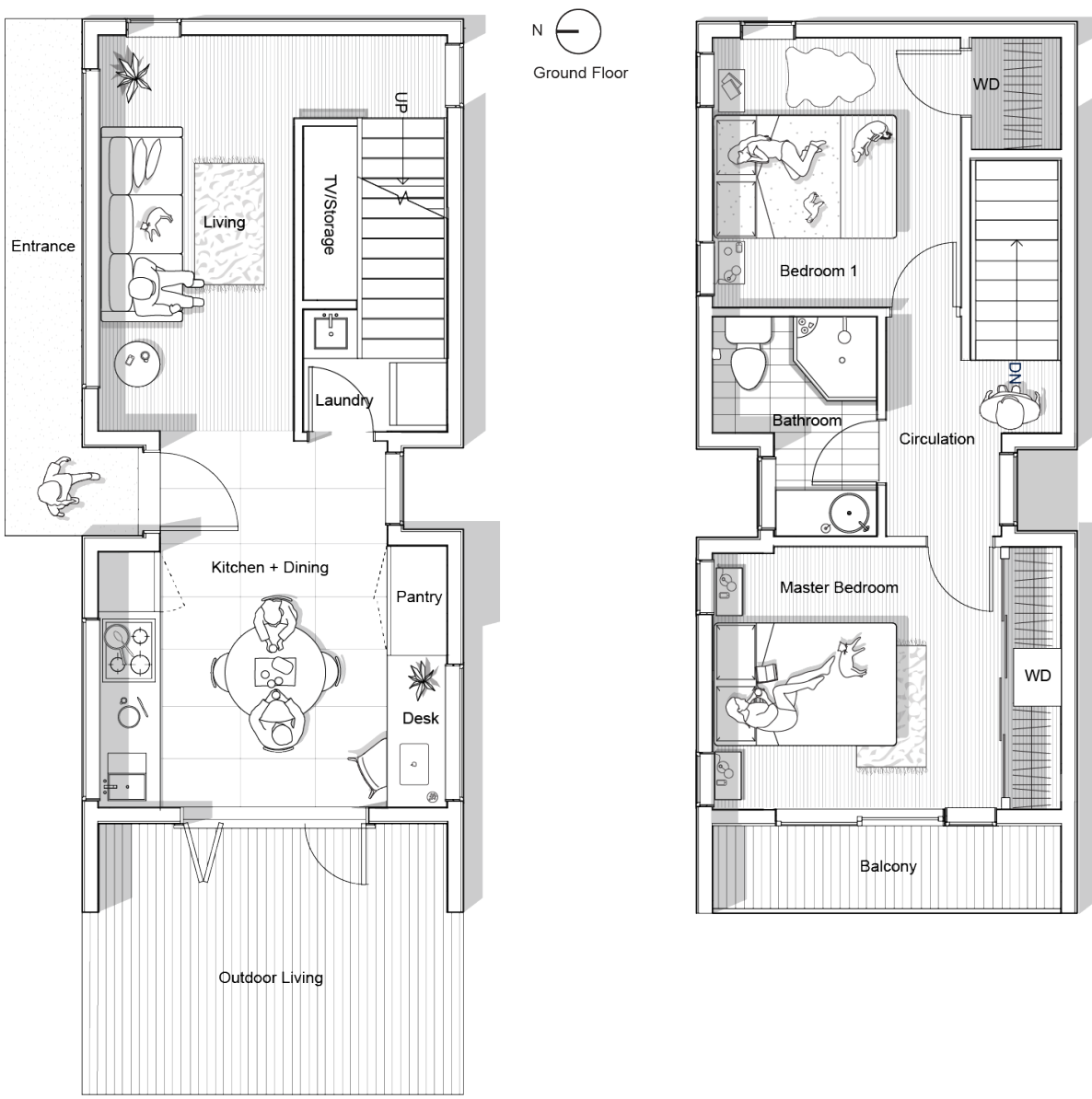

$N \in$

First Floor

First Cost $=\$ 243,000$

Cost per $m^{2}=\$ 3600$ 
3.1.3

Figure 3.58 Typology 3.1.3 east sloping site plan
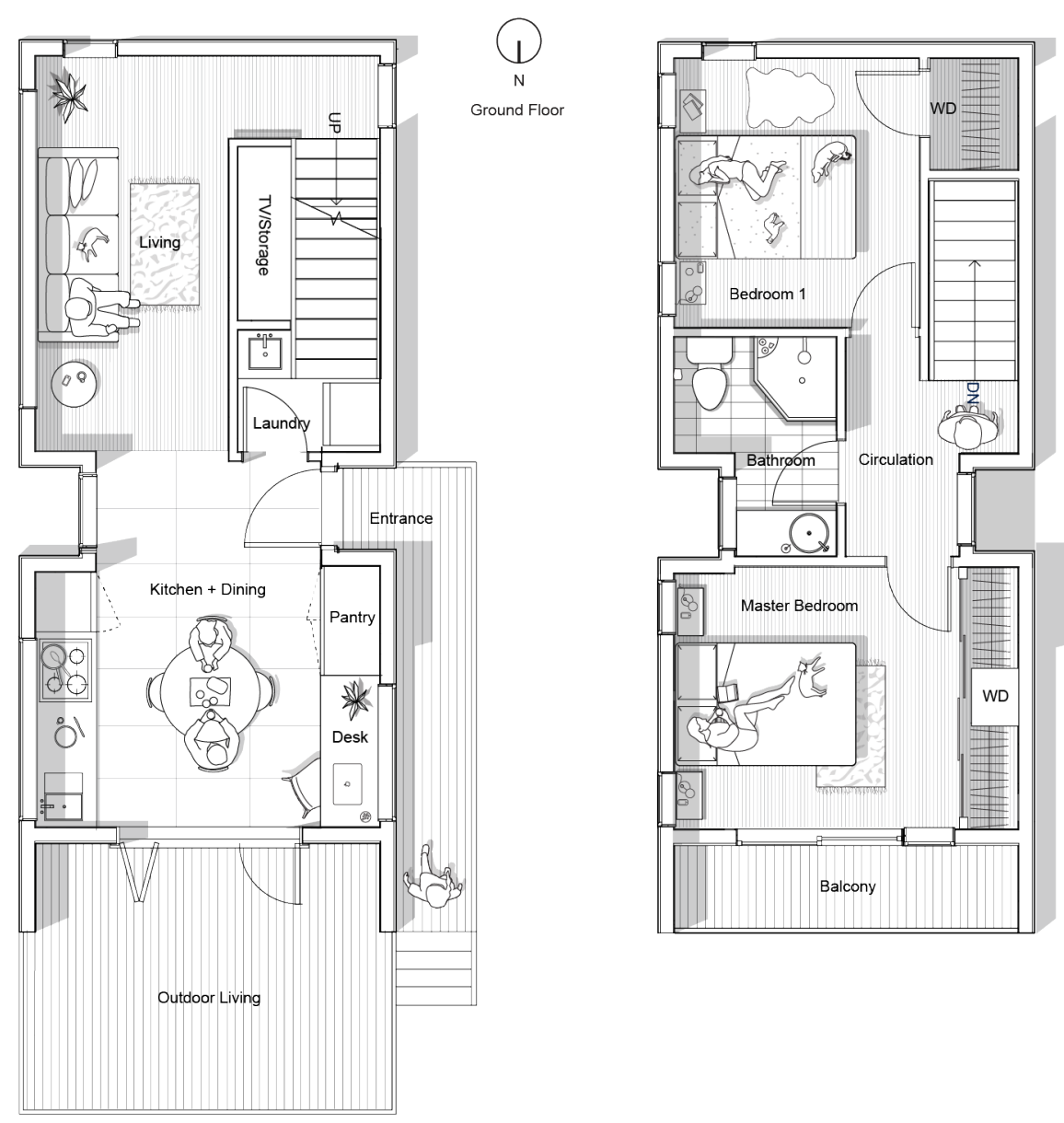

$Q_{N}$ First Floor

First Cost $=\$ 258,000$

Cost per $m^{2}=\$ 3800$ 
House 3.2

$93 m^{2}$

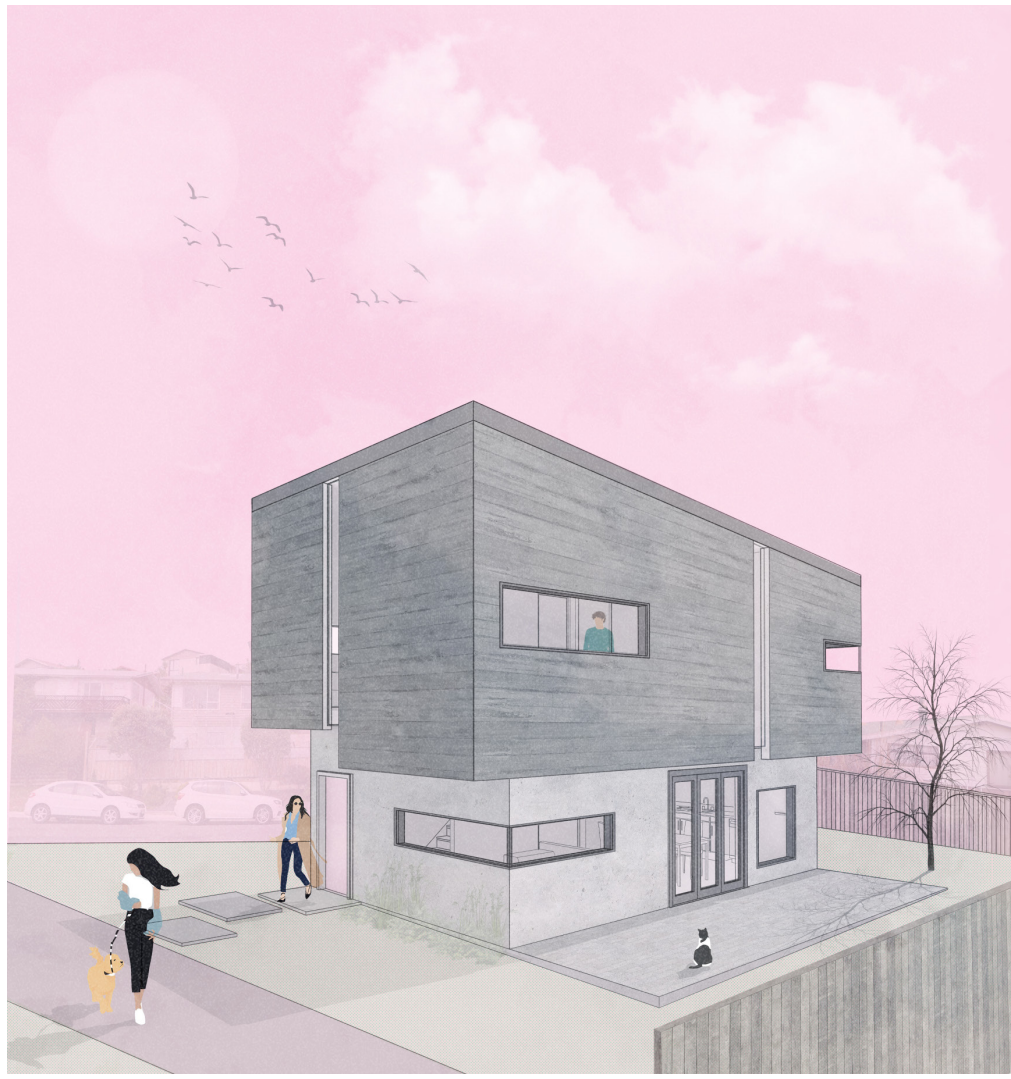

Figure 3.59 Typologies 3.2.1 and 3.2.2 Exterior Aesthetic

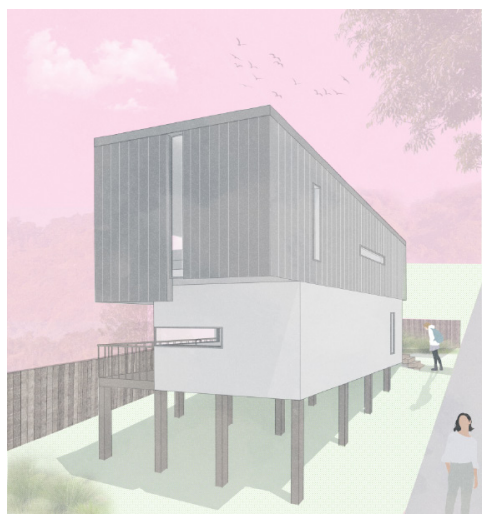

Figure 3.60 Typology 3.2.3 Exterior

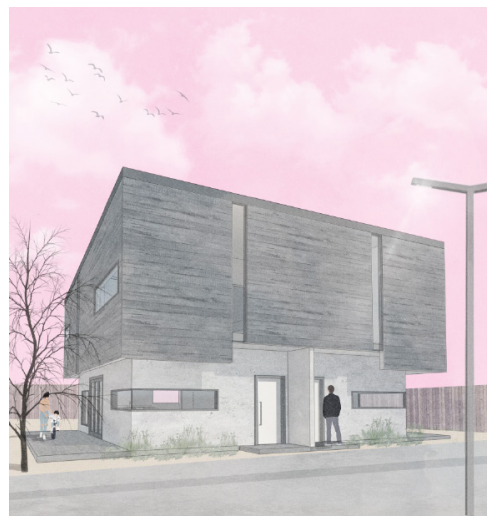

Figure 3.62 Typology 3.2.5 Exterior

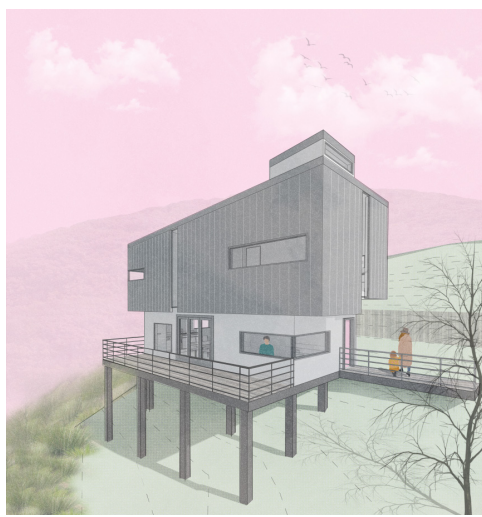

Figure 3.61 Typology 3.2.4 Exterior

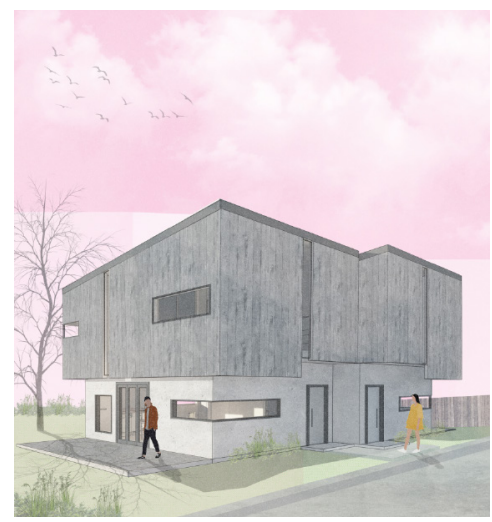

Figure 3.63 Typology 3.2.6 Exterior 

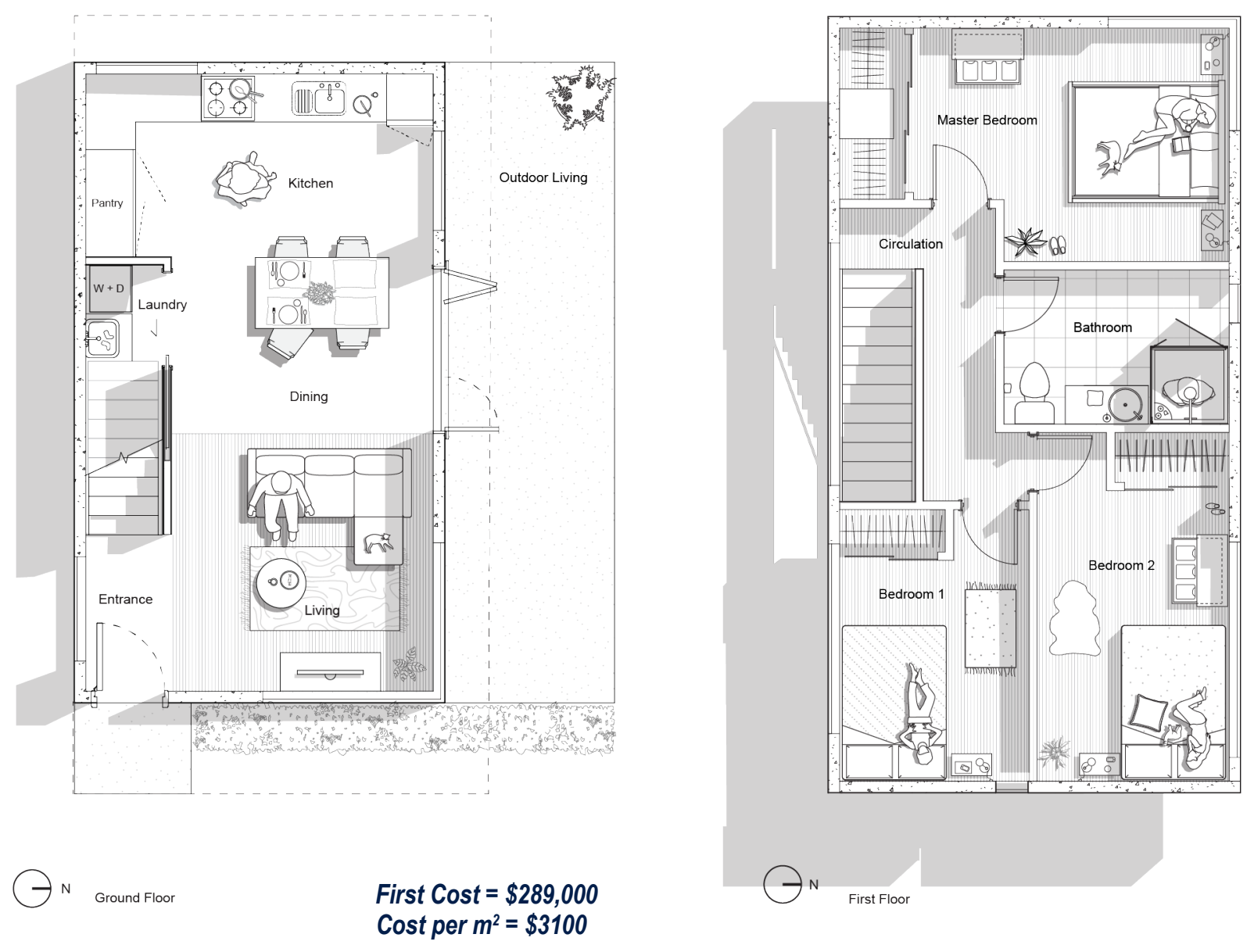

House 3.2 is a 3 bedroom 1 bathroom home at $93 \mathrm{~m}^{2}$ per dwelling with the dual houses at a total of $186 \mathrm{~m} 2$. The design for this house contained six variations across the four test sites. Houses 3.2.3 and 3.2.4 consists of timber-framed construction to reduce costs on engineering for the hill sites. Both are clad with weatherboard and titan board. The remaining houses are constructed of concrete.

- House 3.2.1 and 3.2.2 reflect each other for north-facing site $A$ and south-facing site B.

- House 3.2.3 is modified, allowing the main entrance to be at the back of the house where it meets the land on site C. Upstairs is modified, moving a bedroom and the bathroom to accomodate the new entrance.

- House 3.2.4 is orientated for the living spaces to face east on site D. A skylight is added for additional lighting into bedrooms on the northern face.

- Two dual houses are tested on site B to assess economic and aesthetic implications of sliding one dwelling forward as seen in houses 2.2.5 and 2.2.6. 
Figure 3.65 Typology 3.2.2 Reflected Plan

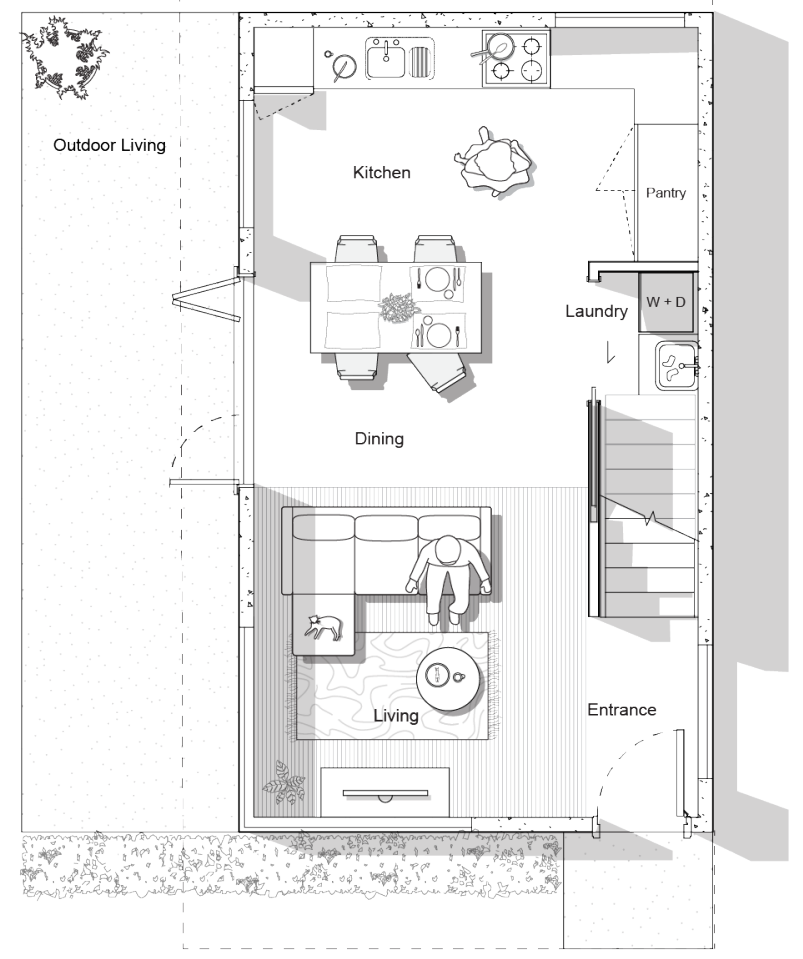

$N \in$ Ground Floor

First Cost $=\$ 289,000$

Cost per $m^{2}=\$ 3100$

Figure 3.66 Typology 3.2.3 west facing plan

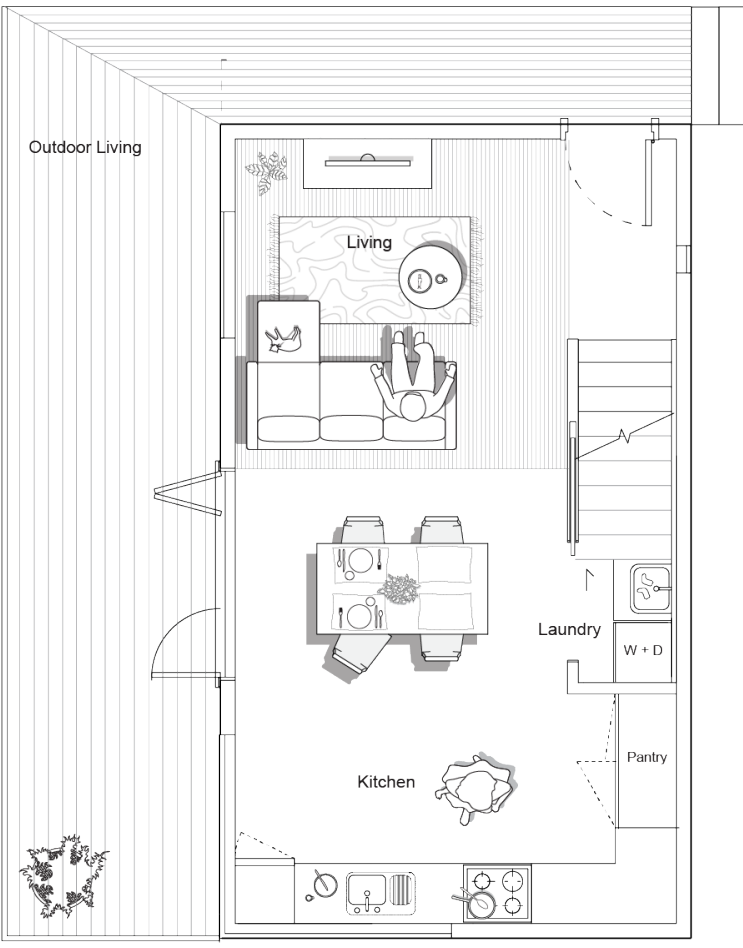

(1)

N Ground Floor

First Cost $=\$ 248,000$

Cost per $m^{2}=\$ 3000$
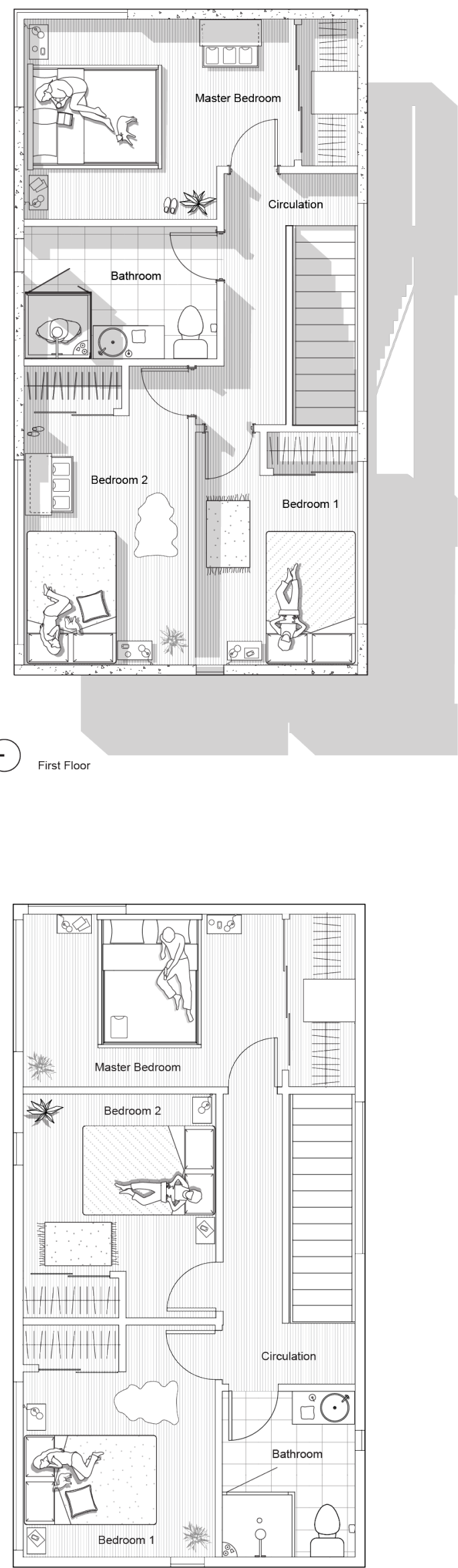

(1) 
Figure 3.67 Typology 3.2.4 East facing plan

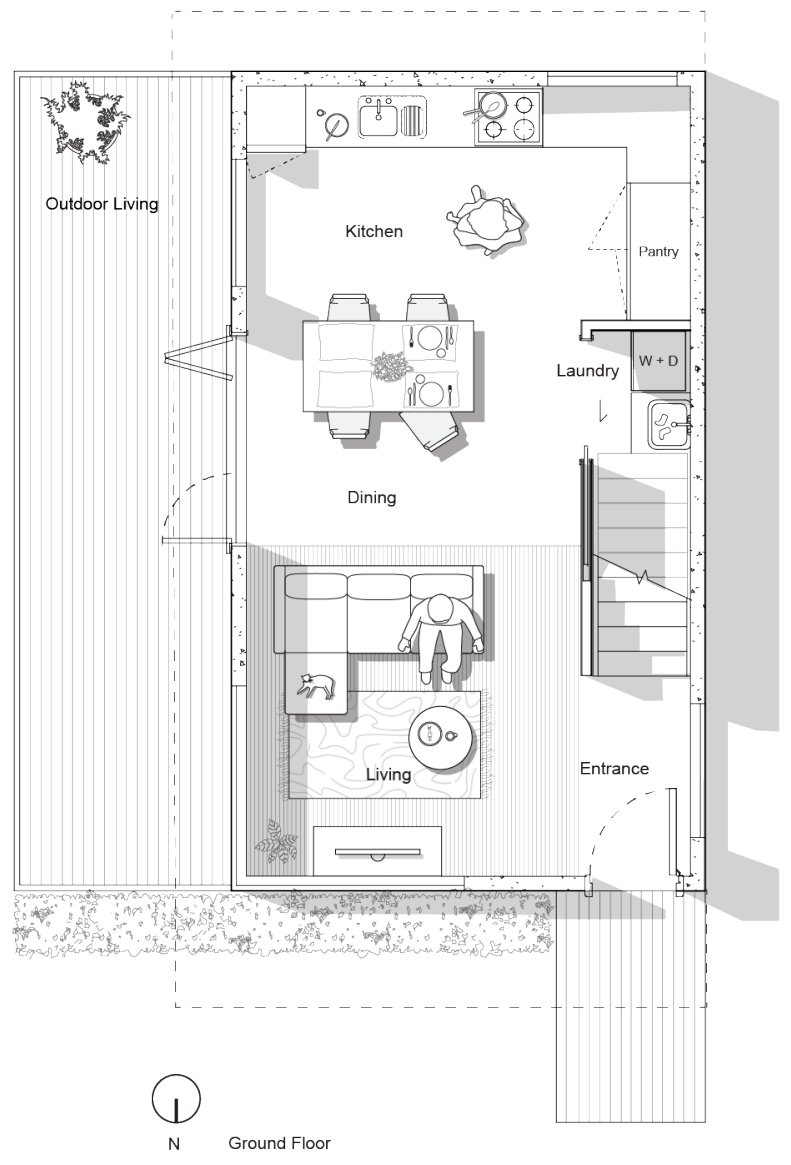

First Cost $=\$ 249,000$

Cost per $m^{2}=\$ 3100$

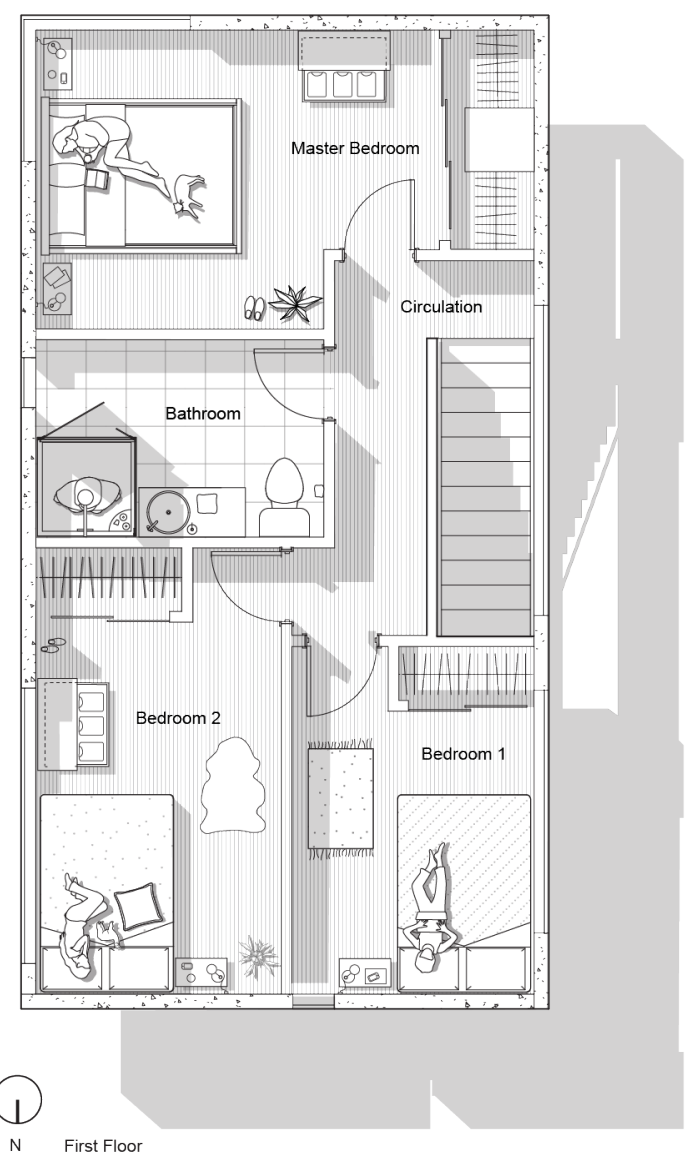

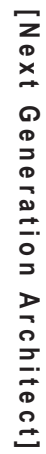




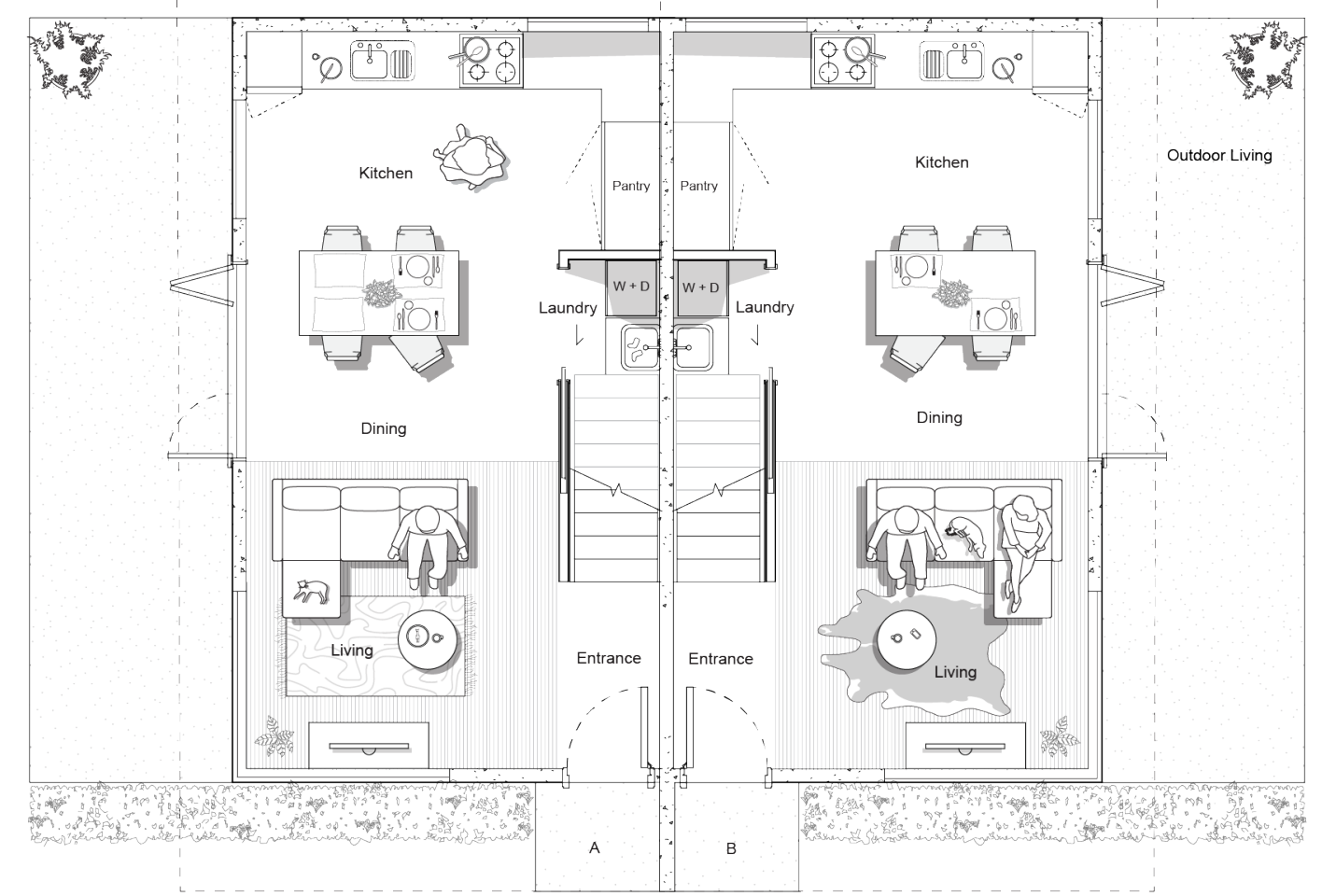

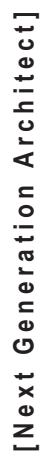

Q

N Ground Floor

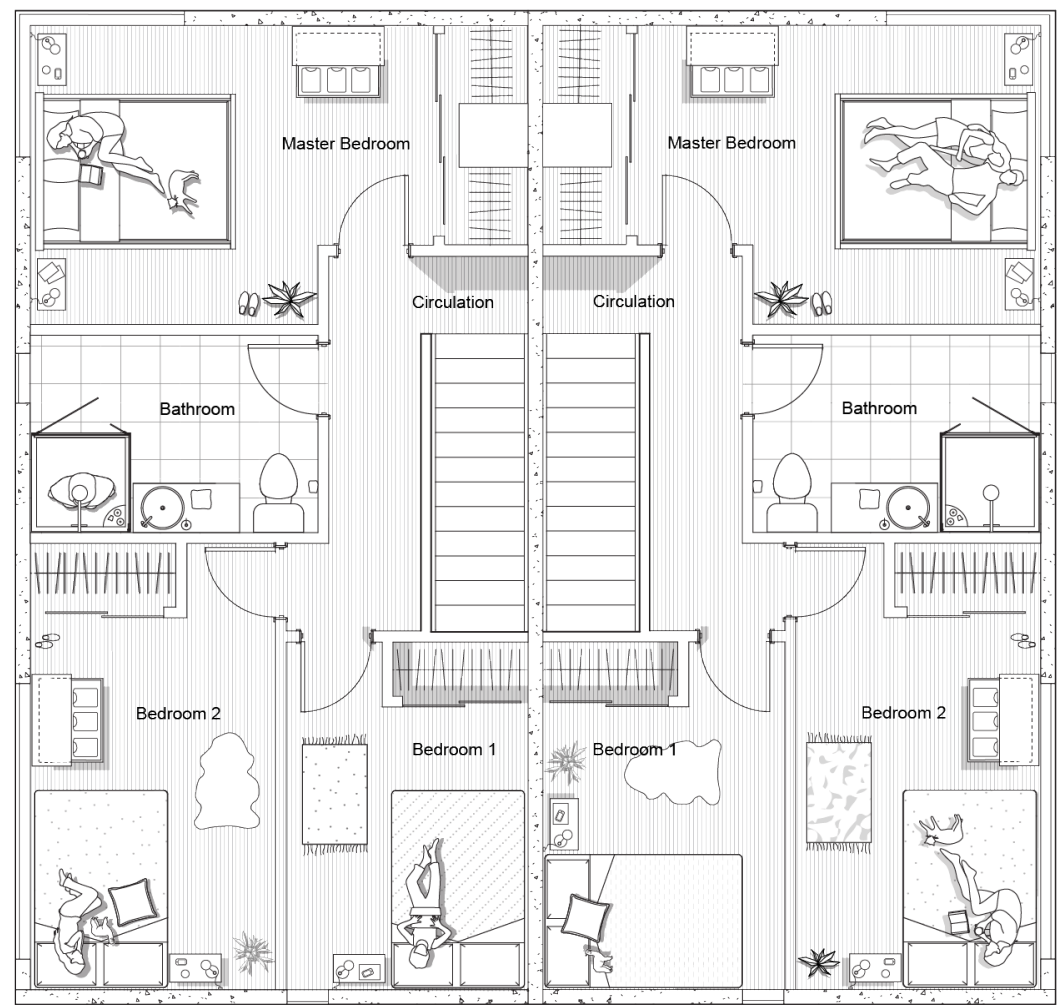

$\bigoplus_{\text {First Floor }}$ 

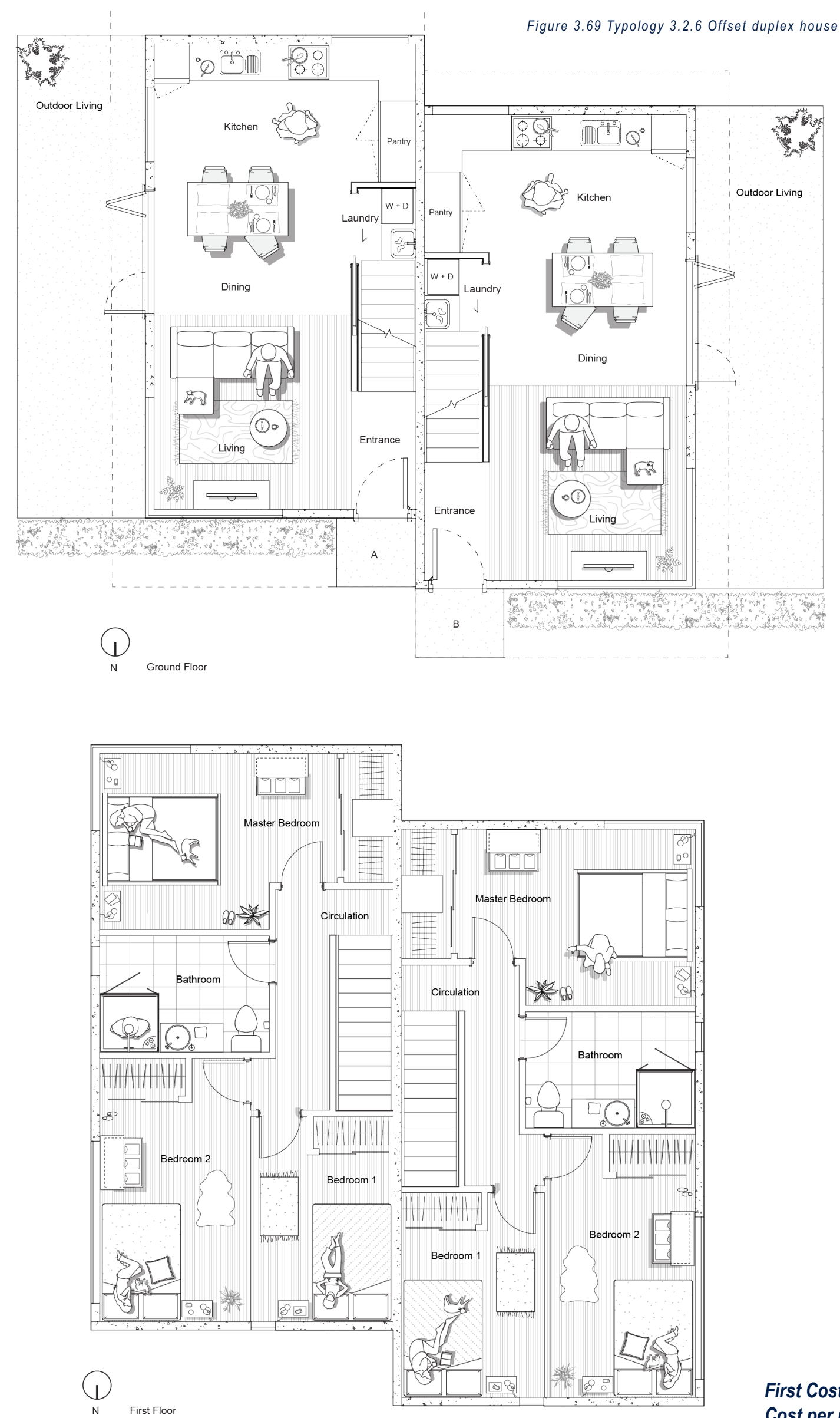


\section{House 3.3}

$82 m^{2}$

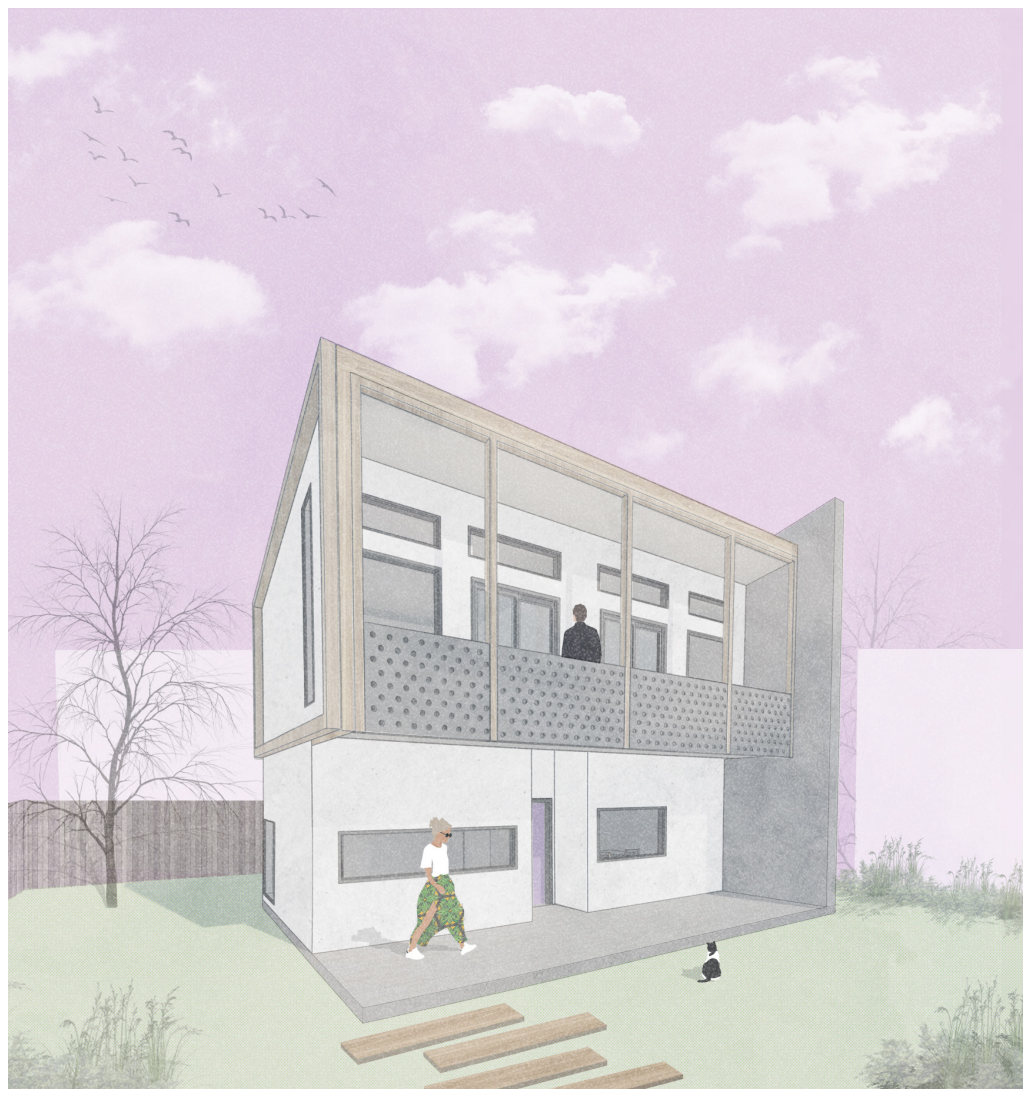

Figure 3.70 Typology 3.4.1 Flat site variation
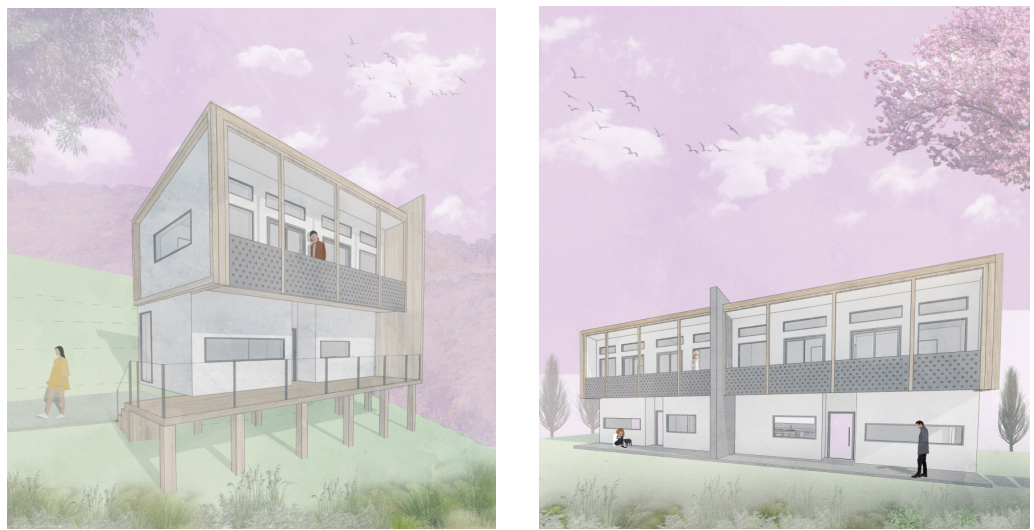

Figure 3.71 Typology 3.4.2 hill site variation

Figure 3.72 Typology 3.4.3 duplex variation 
Figure 3.73 Typology 3.3.1 Plan

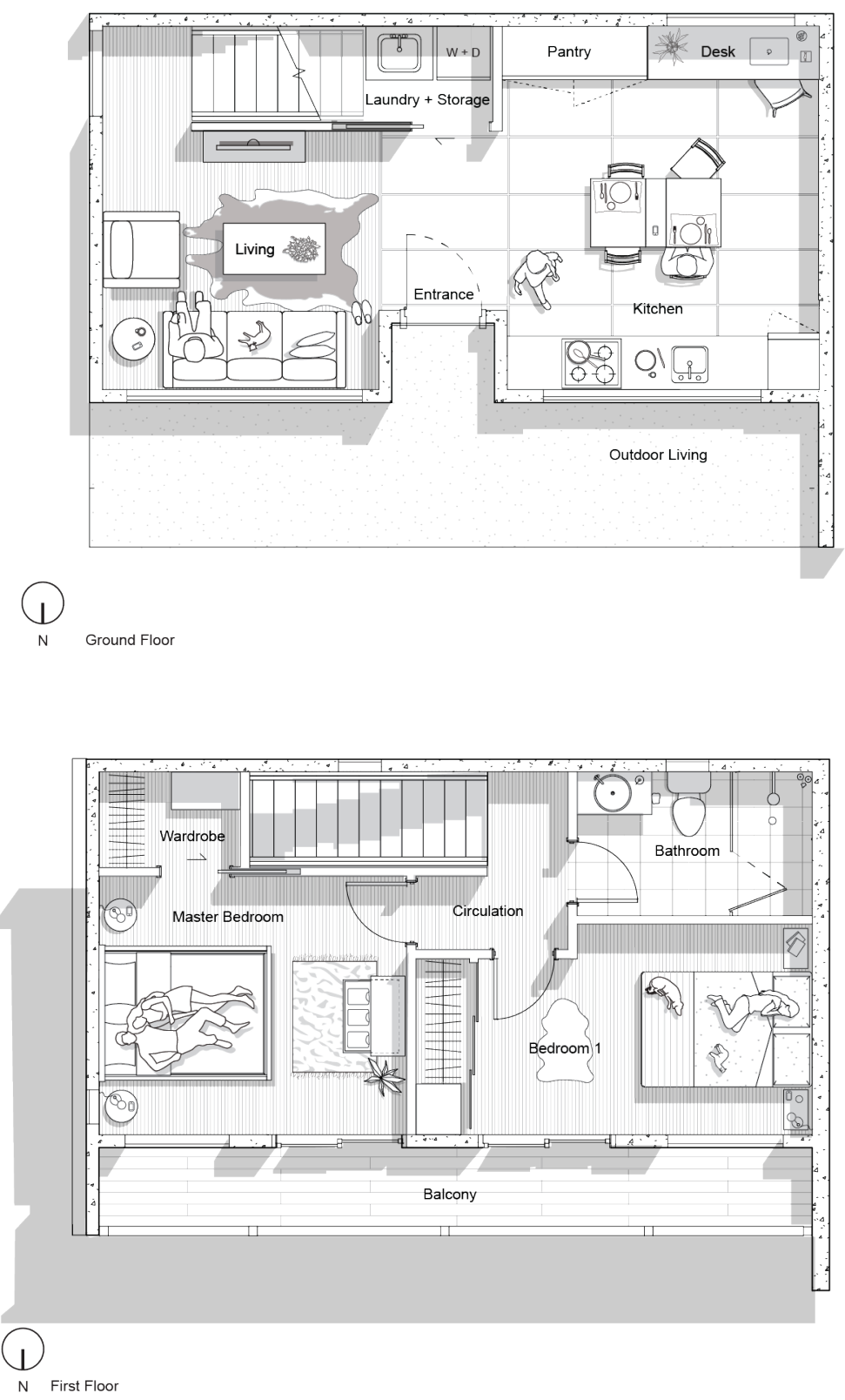

First Cost $=\$ 265,000$

Cost per $m^{2}=\$ 3200$

House 3.3 is a 2 bedroom 1 bathroom home at $82 \mathrm{~m}^{2}$ per dwelling with the dual houses at a total of $164 \mathrm{~m}^{2}$. This house is designed for a northern street frontage and due to this has been tested on-site B for variations 3.3.1 and 3.3.3, constructed of concrete. The architectural elements of house 3.4 are the large panel which if orientated correctly can be used as a windshield for prevailing winds. Balcony panelling and timbers are another feature. House 3.3.2 is modified for site $C$ to be west facing allowing for the afternoon sun to enter living areas and bedrooms, while the north face is modified allowing for larger windows than in variations 3.3.1 and 3.3.3. This house is constructed of light timber framing and clad with titan board to save costs and allow for timber piles on the hill site. 


\subsection{2}

Figure 3.74 Typology 3.2.1 plan for site C

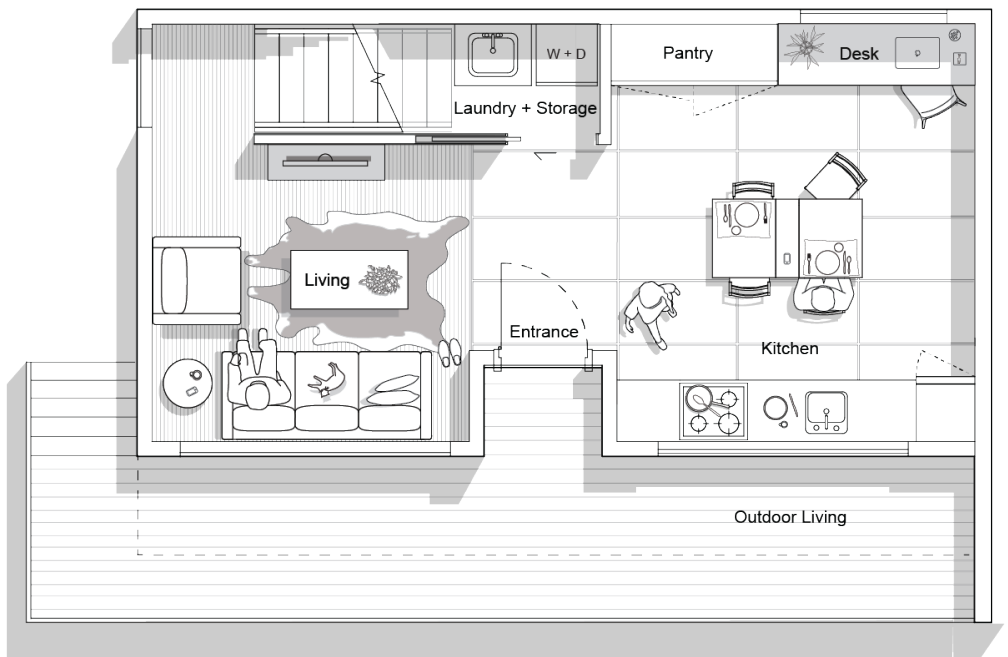

$N \subseteq$ Ground Floor

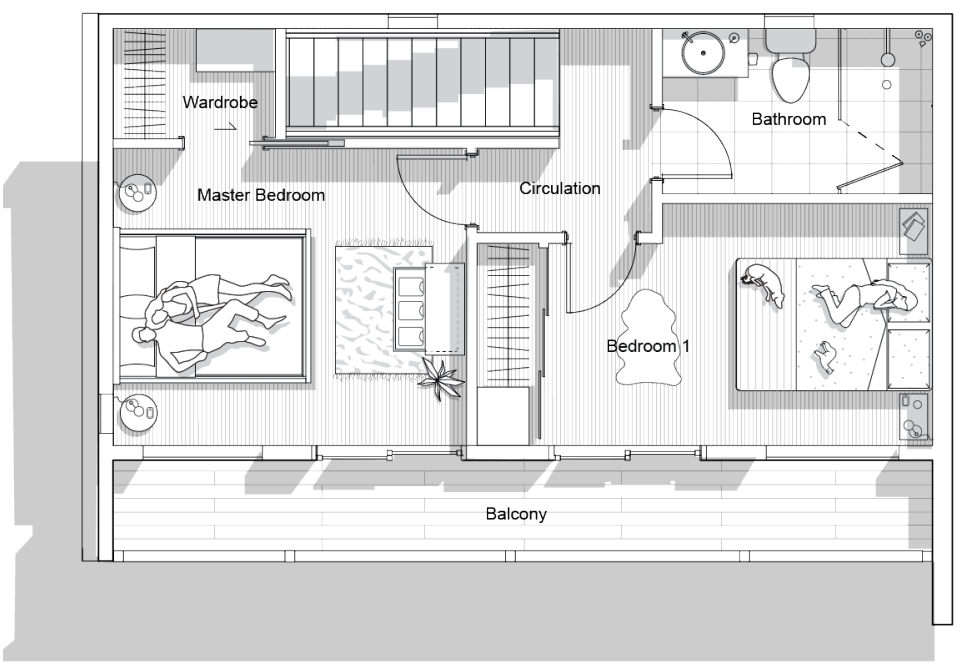

$N \bigoplus$ First Floor 

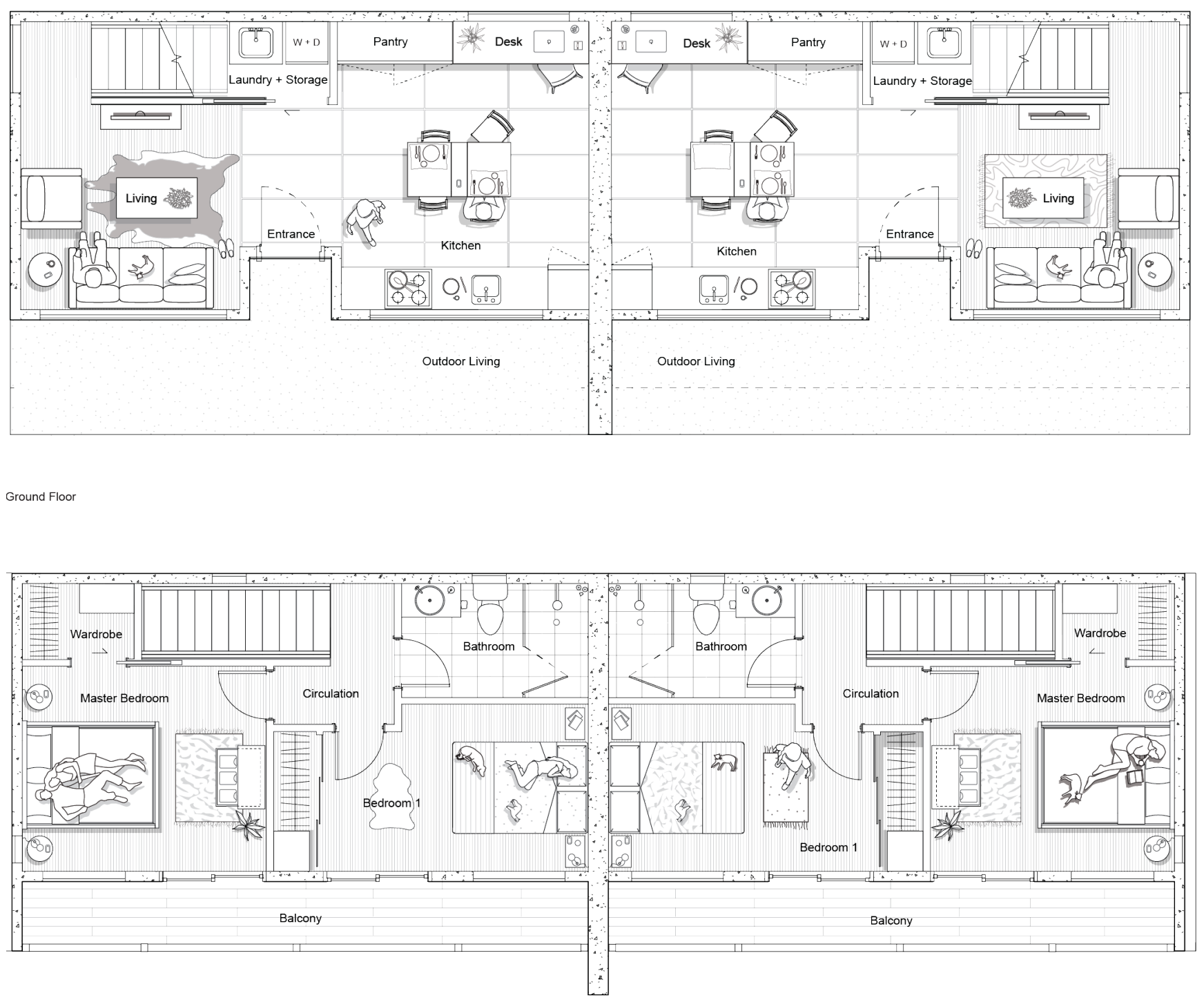

First Floor 


\section{House 3.4}

$68 \mathrm{~m} 2$

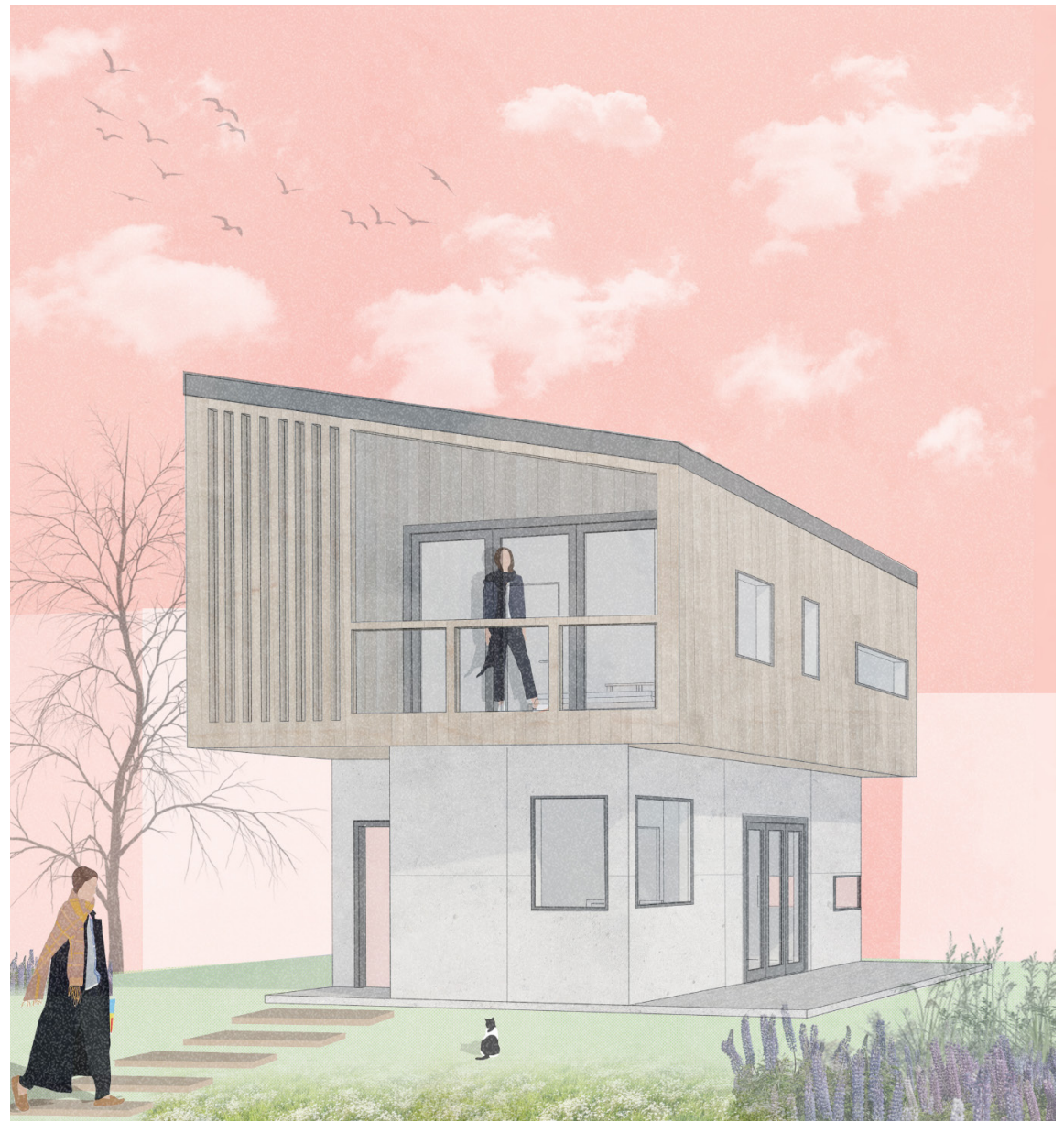

Figure 3.76 Typology 3.4.1 Exterior
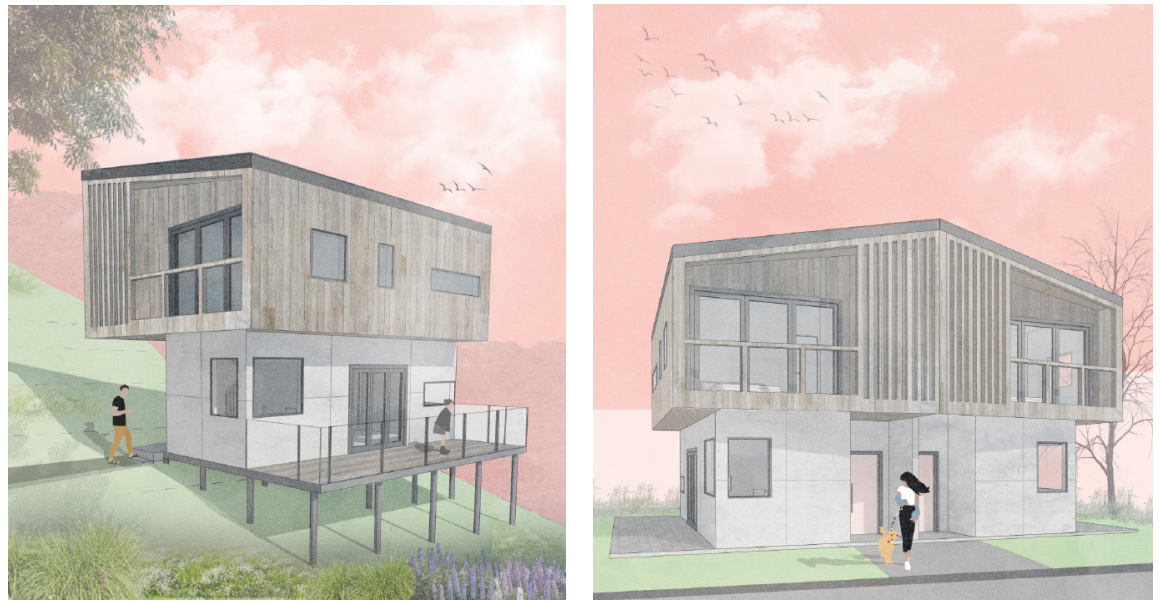

Figure 3.77 Typology 3.4.2 Exterior

Figure 3.78 Typology 3.4.3 Exterior 

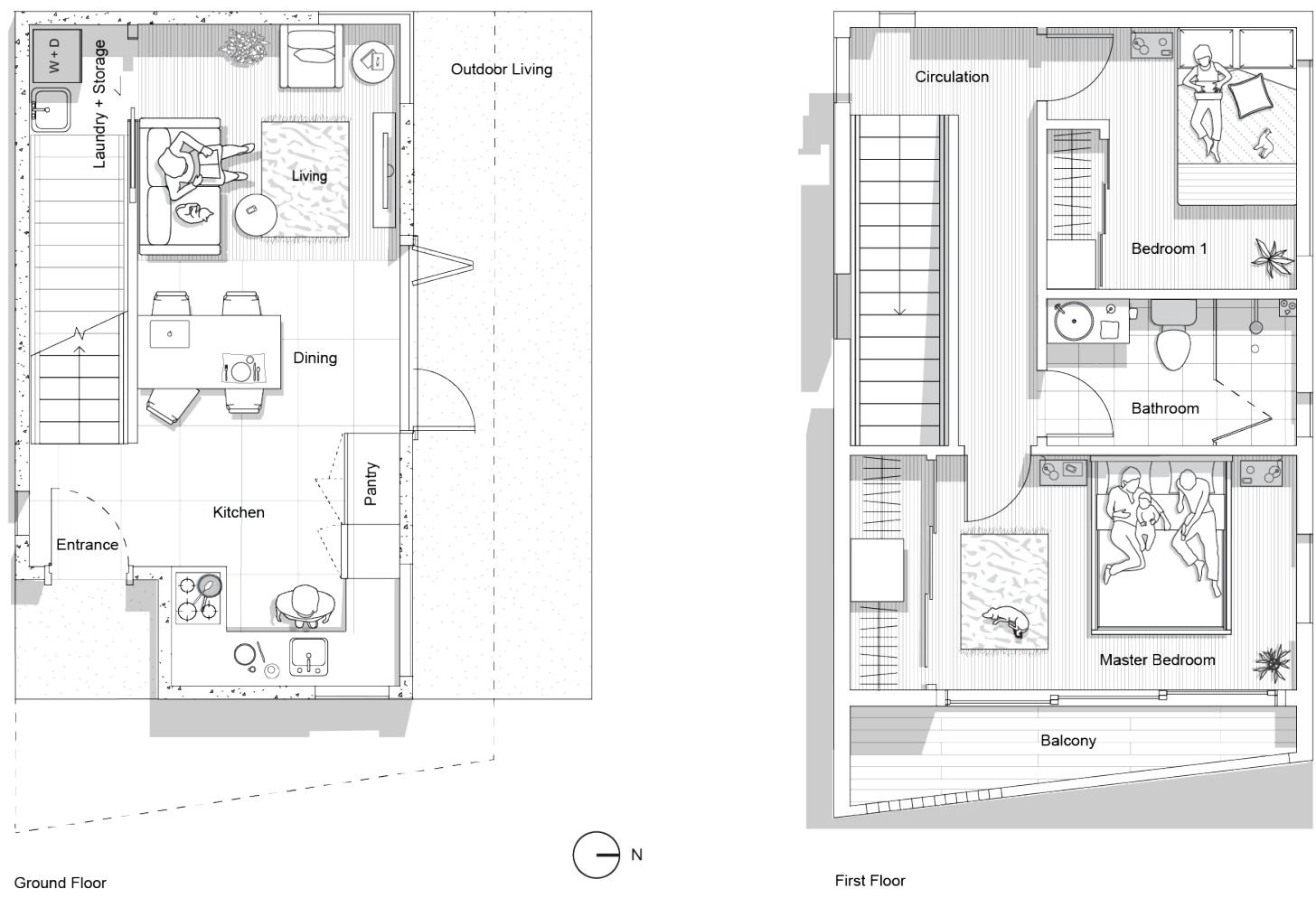

First Floor

House 3.4 is a 2 bedroom 1 bathroom home at $80 \mathrm{~m}^{2}$ per dwelling with the dual houses at a total of $160 \mathrm{~m}^{2}$. The architectural elements include the overhang of level 1 , the panelling on the balcony and irregular angled form of the balcony space. This house is designed for a northern street frontage and due to this, has been tested on site $B$ for variations 3.4.1 and 3.4.3. These variations consist of a mixture of precast concrete construction on the ground floor and light timber framing clad in weatherboard on level 1. Variation 3.4.2 is placed on timber piles for site $\mathrm{C}$ and is constructed of timber framing clad in titan board and weatherboard. The site orientation allows the afternoon sun to enter the living spaces, with the balcony facing north. 


\section{4 .2}

Figure 3.80 Typology 3.4 .2 plan

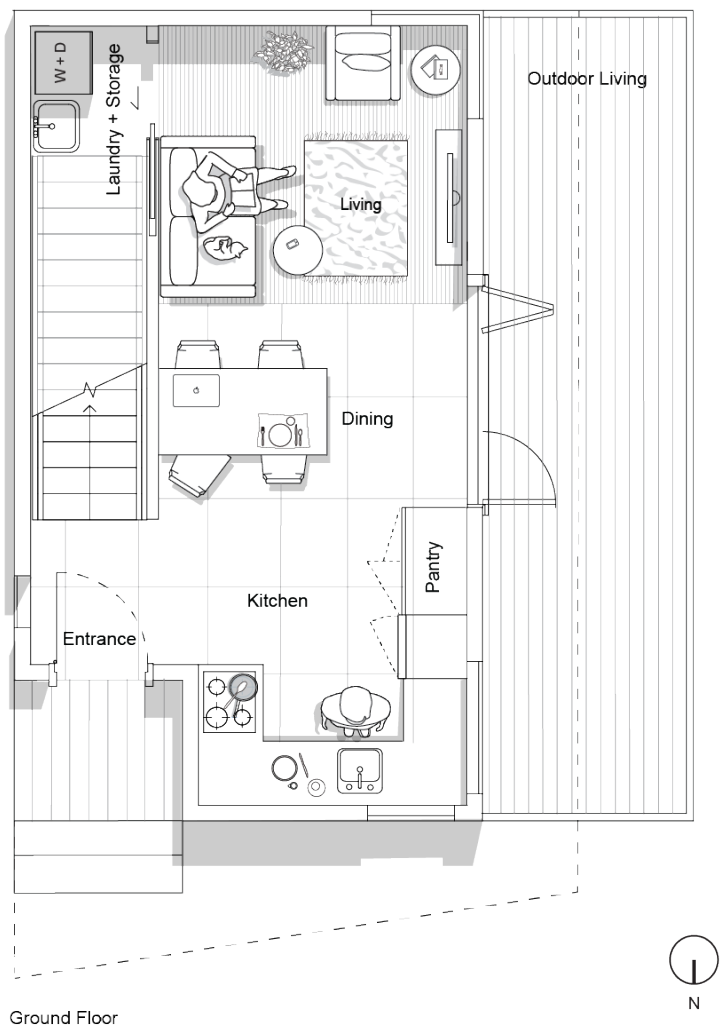

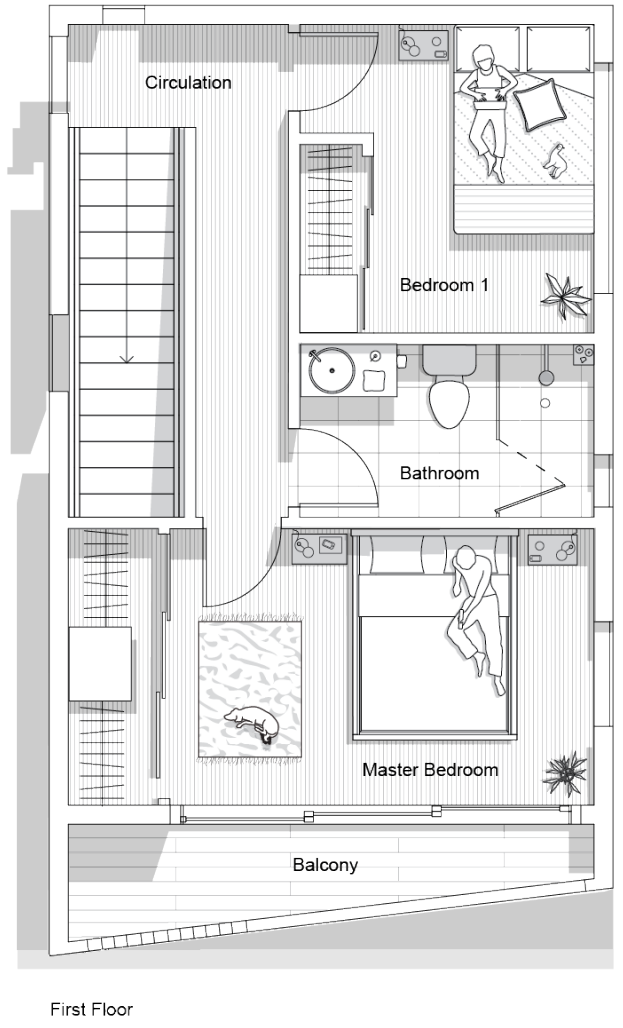

First Cost $=\$ 263,336$

Cost per $m^{2}=\$ 3300$ 
Figure 3.81 Typology 3.4.3 duplex housing plan
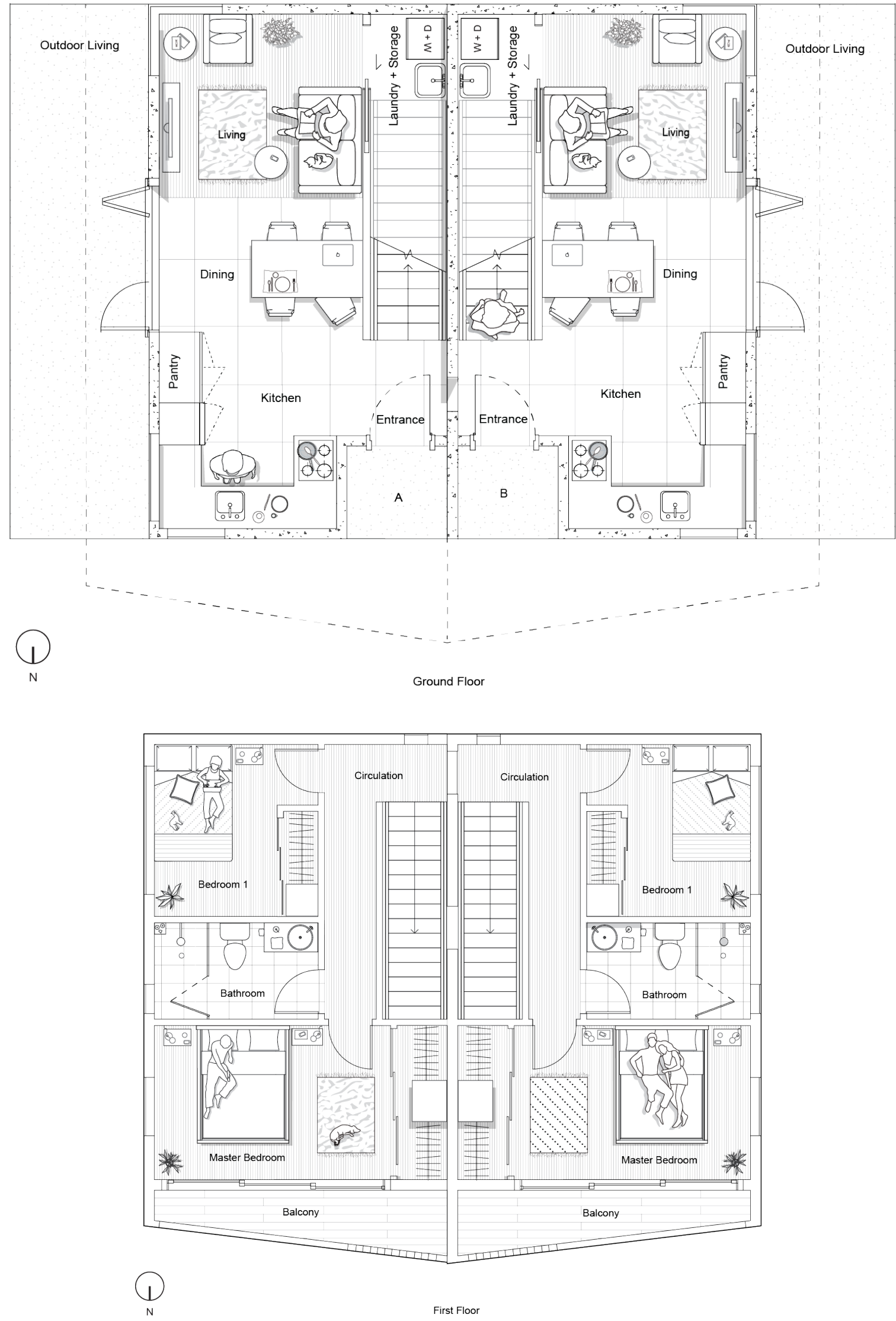


\title{
The Pattern Book
}

\author{
In Print Form
}

Figure 3.82 The pattern book in print form
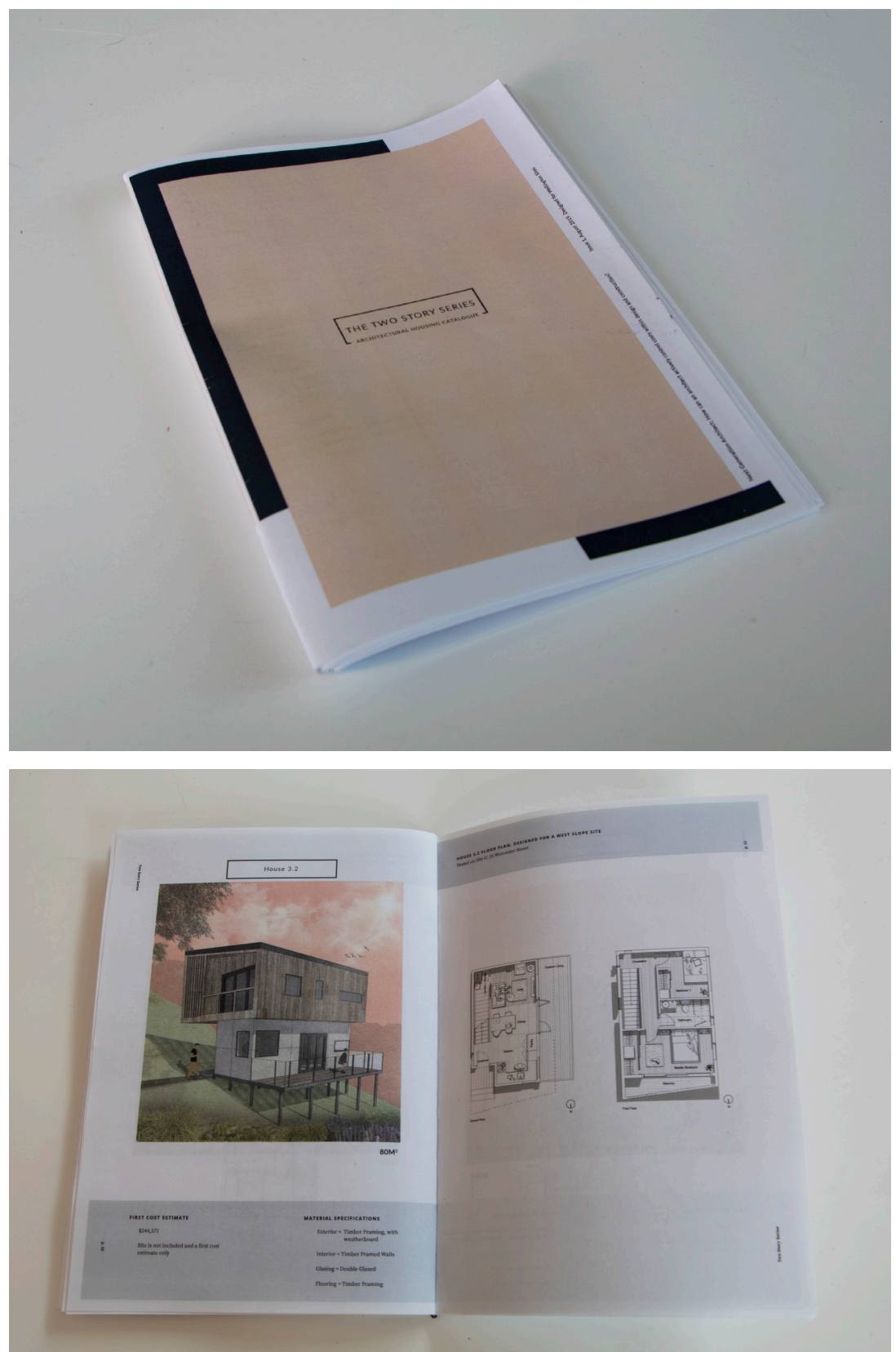

The pattern book was designed as a design tool in the form of a booklet derived from the findings of architectural pattern books. The book portrays the design, components and cost estimate of the individual housing typologies. 
Figure 3.83 Pages from the printed pattern book
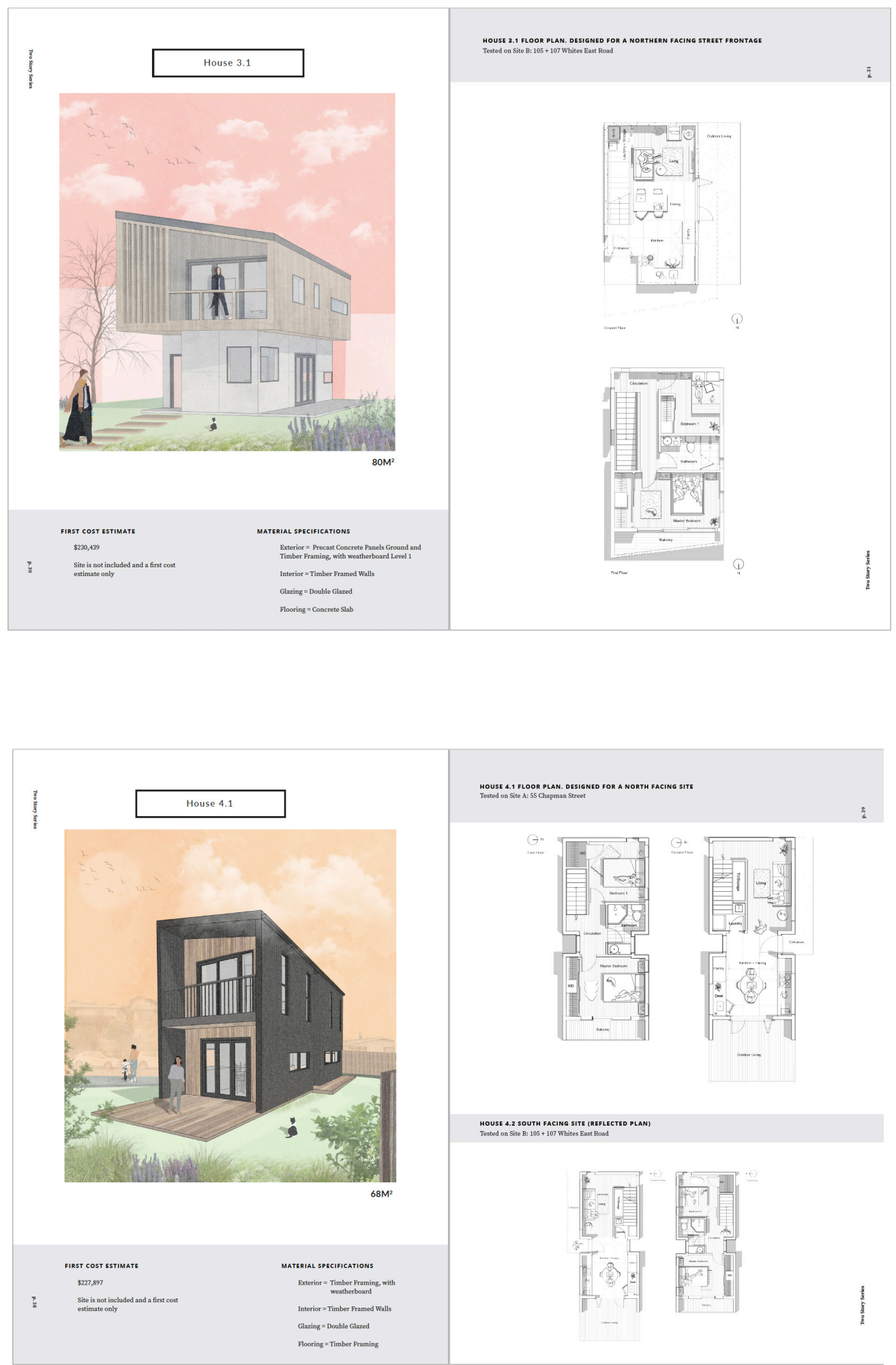


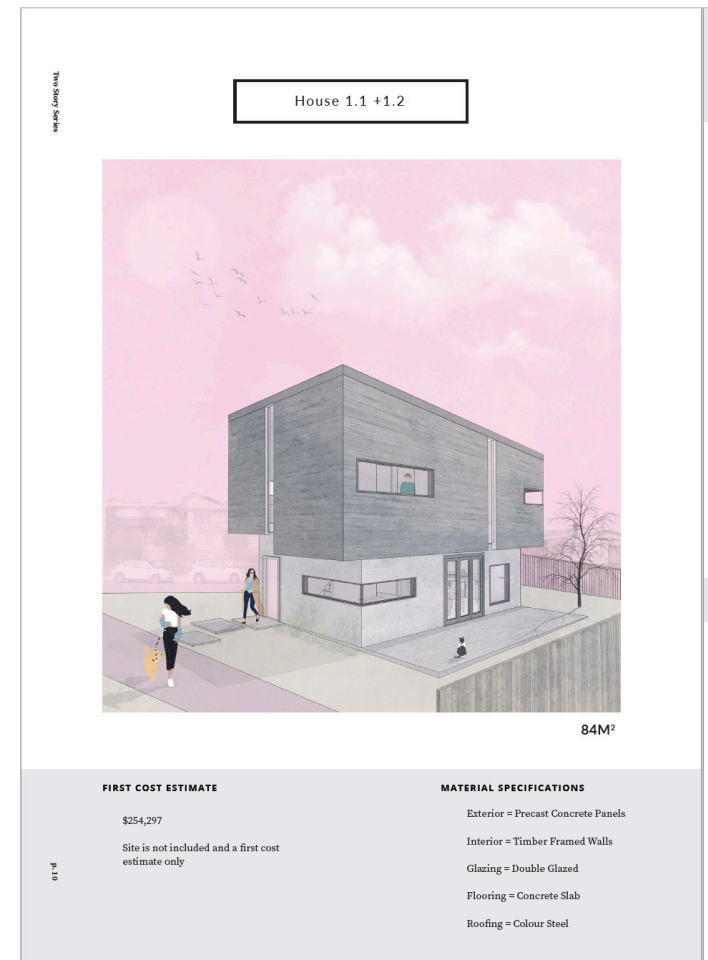

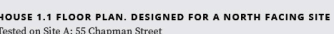
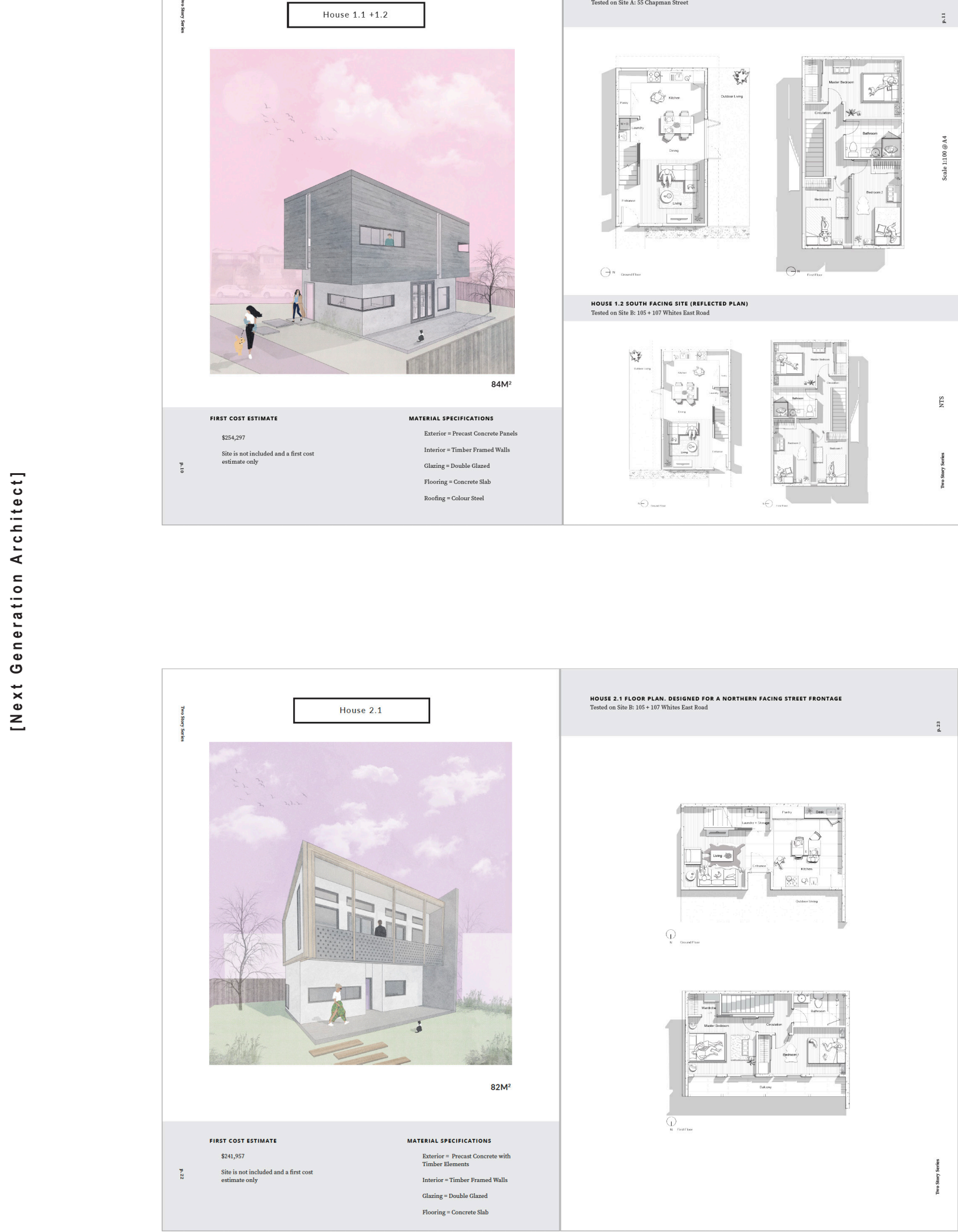
Building Information Modelling

Building information modelling (BIM) is an intellectual 3D model-based process that gives professionals within the construction industry insight to tools needed to plan efficient projects, including the design, construction, management of infrastructure. BIM objects are data rich in the form of a 5D model that contains geometric information, cost, R-value and energy. Collaboration across disciplines such as architecture, structural and mechanical engineering is a key component to BIM. Collaboration is known to have a number of benefits to the documentation and coordination of a project, reducing the number of mistakes before projects are constructed which is critical to large scale projects (Levy \& Ouellette, 2019). Levy \& Ouellette (2019) states, "BIM gives the designer opportunities to make richer design decisions" (p.8). Decisions can be applied when knowledge surrounding elements and their implications are understood within a design such as cost, which ultimately improves the overall building process.

In the Netherlands, small-scale housing developments used BIM to achieve affordable housing goals. Sebastian (2010) states, "decisions made during the design phase on average affect $70 \%$ of the lifecycle cost of the building" (p.106). BIM allowed for design changes to be made at the early stages, reducing cost of reworks. Through a series of design experiments conducted with the BIM model, it was found BIM impacted on cost reduction and enabled quality design improvement. In turn highlighting the effectiveness of implementing such models.

Advantages:

- Collaboration within a workplace and cross discipline.

- Improved design and planning decisions.

- Data available to the 3D model.

- Mistakes can be picked up before the construction phase with fewer reworks required.

- Accurate cost calculations across all elements and families.

Disadvantages:

- Lack of knowledge within the profession to maximise the use of BIM.

- Cost of software.

- Incompatibility of software with cross disciplines. 


\section{Costing}

$B I M+R E V I T$

The objective of costing through the use of BIM in Revit allowed for a quick and accurate first cost estimate while understanding the cost implications based on design decisions made. BIM proved to be significantly faster and easier to cost through, than the previous use of a spreadsheet. Elements costed through BIM include floors, roof, walls, windows and doors seen in figure 3.83. Additional elements are applied in a spreadsheet. Figure 3.84 illustrates an example spreadsheet of the breakdown of typology 3.1, this process is repeated across all typologies (cost breakdowns are located in appendix 2). A cost library (located in the appendix) was established with data from the QV database to ensure accuracy.

Additional components added to spreadsheets

\section{Additional Components:}

- Floor Coverings

- Guttering and Downpipes

- Stairs

- Balustrades

- Joinery for Kitchen, Bathroom and Laundry

- Basic Appliances (Oven + Stove Top)

- Heatpump

\section{Elemental:}

- Site Works

- Plumbing + Drainage

- Electrical

Professional Fees:

- Architect

- Geotechnical

- Building Consent

- Contingency

- Engineer

- Additional Building Fees 


\section{The Costing Process}

$B I M+R E V I T$

The process of costing through Revit is as follows:

1. Adding cost data to each element e.g. walls. This requires having all relevant cost information from the $\mathrm{QV}$ database per $\mathrm{m}^{2}$. The cost of timber walls includes timber costs, insulation, external cladding, gib and paint finishes.

2. Elements individualised by appropriately naming each element, with appropriate cost data added.

3. Individual cost schedules set up for each elemental group. This involves selecting the family type, area and cost. From here the formula for the total cost was applied to give the total of each schedule set up. This automatically updates when elements are changed allowing for costs to be tracked instantly.

Overall the use of BIM through Revit is a useful tool that has allowed for an accurate and efficient costing process, that can be used from the conceptual form, into the final iteration.

Figure 3.84 Revit schedules costing process

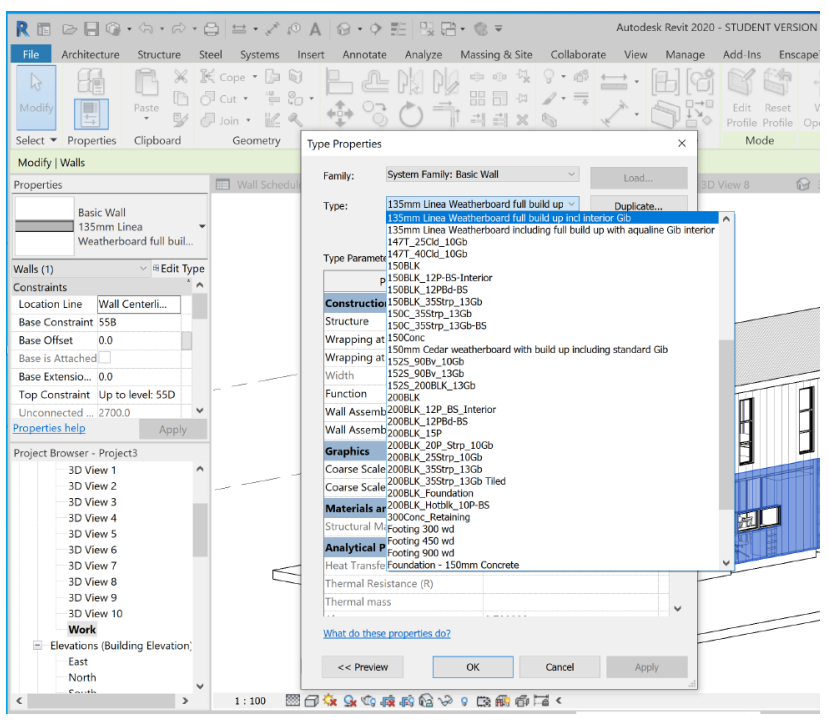

1. Family Type named and selected

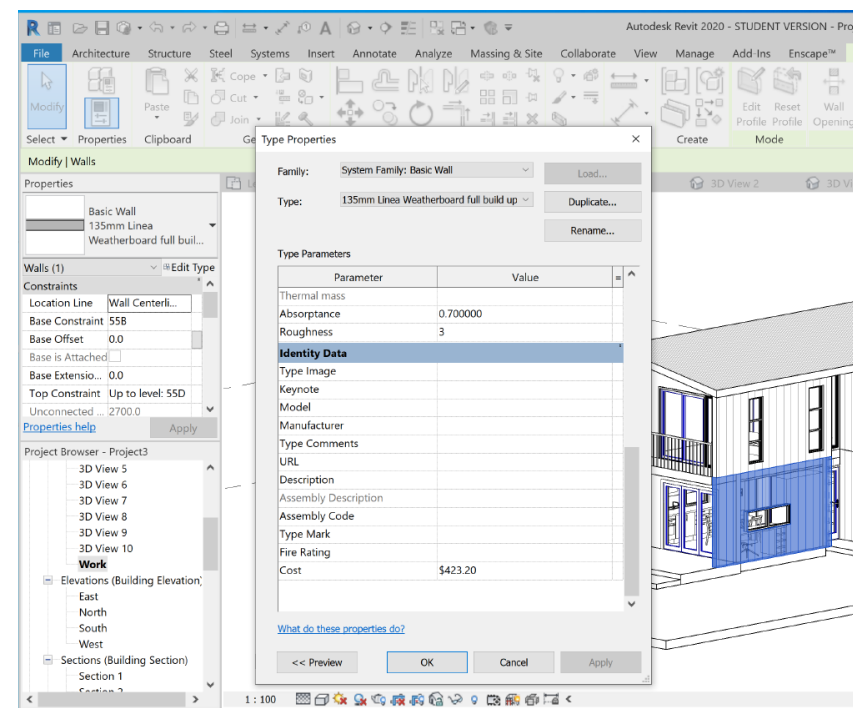

2. Costs added to wall element 


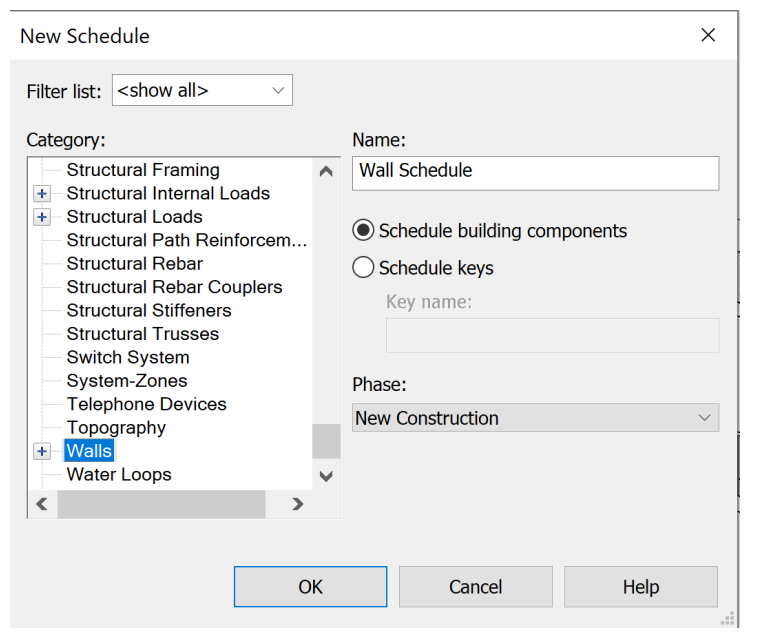

\section{Wall schedule set up}

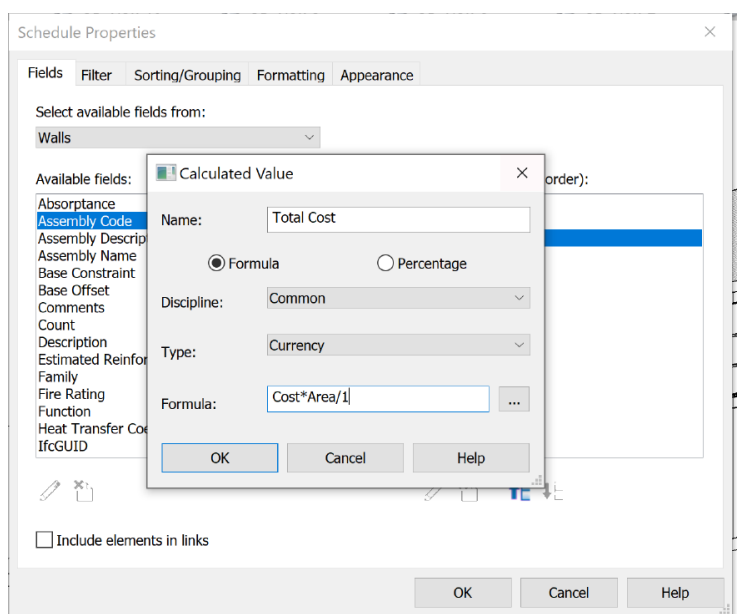

5. Formula added to calculate total cost

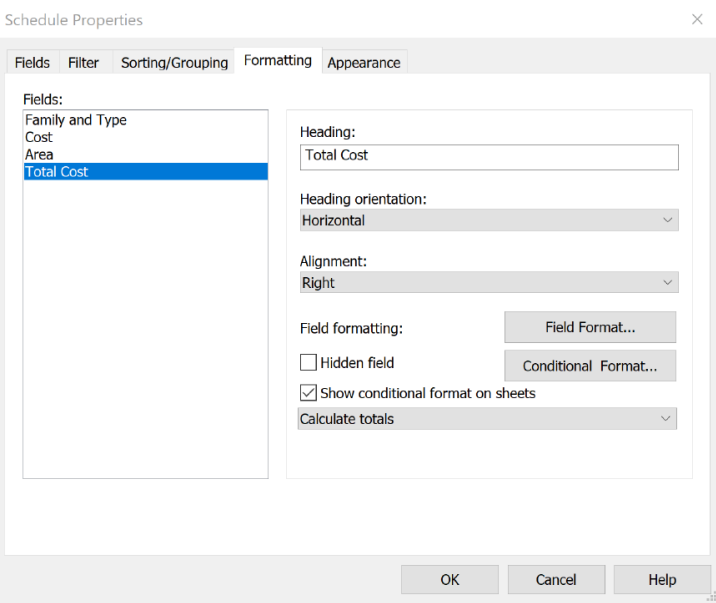

\section{Formatting the total cost to be calculated}

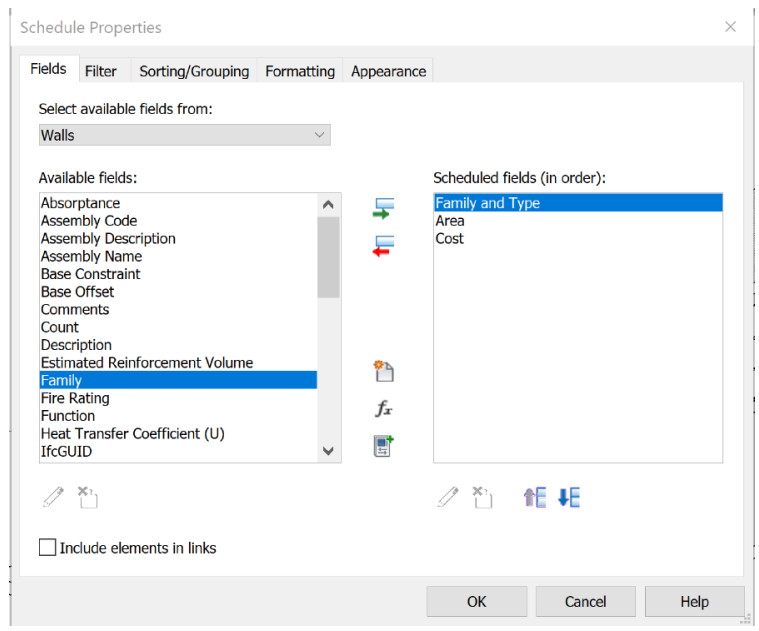

\section{Properties selected}

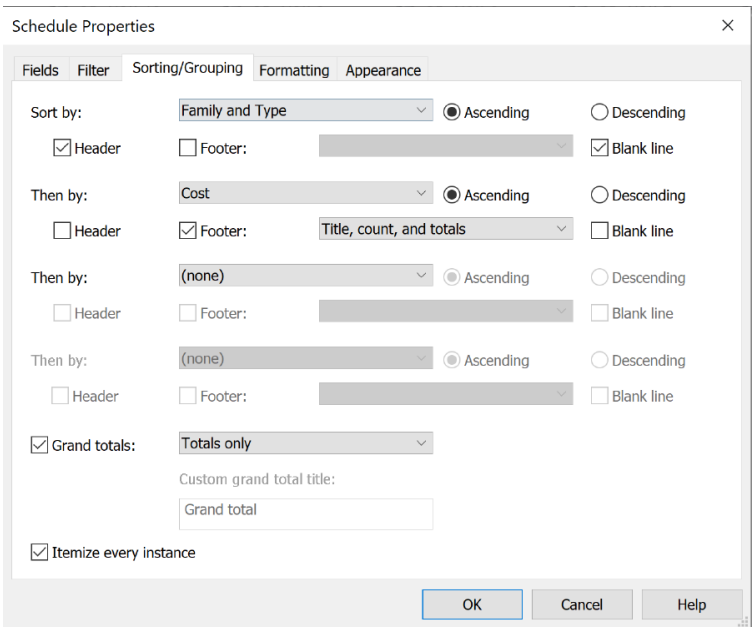

\section{Schedule layout grouped and total costs calculated}

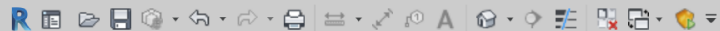
File Architecture Structure Steel Systems Insert Annotate Analyze Massing \&S

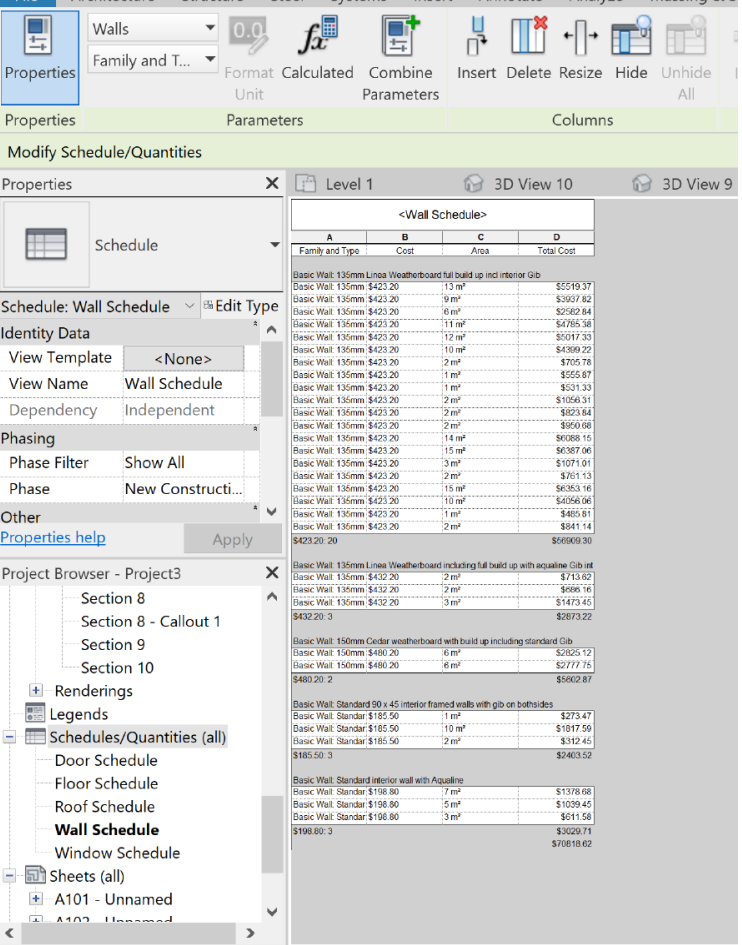

8. Final wall schedule 


\begin{tabular}{|c|c|c|c|}
\hline \multicolumn{4}{|c|}{$<$ Wall Schedule $>$} \\
\hline A & B & C & $\mathbf{D}$ \\
\hline Family and Type & Area & Cost & Total Cost \\
\hline \multicolumn{4}{|c|}{ Basic Wall: 90T_10Gb-BS } \\
\hline Basic Wall: 90T_10 & $4 \mathrm{~m}^{2}$ & 185.50 & 706.03 \\
\hline Basic Wall: 90T_10 & $3 \mathrm{~m}^{2}$ & 185.50 & 488.16 \\
\hline Basic Wall: 90T_10 & $6 \mathrm{~m}^{2}$ & 185.50 & 1204.43 \\
\hline Basic Wall: 90T_10 & $6 \mathrm{~m}^{2}$ & 185.50 & 1071.57 \\
\hline Basic Wall: 90T_10 & $2 \mathrm{~m}^{2}$ & 185.50 & 395.37 \\
\hline Basic Wall: 90T_10 & $2 \mathrm{~m}^{2}$ & 185.50 & 313.59 \\
\hline Basic Wall: 90T_10 & $1 \mathrm{~m}^{2}$ & 185.50 & 263.60 \\
\hline Basic Wall: 90T_10 & $1 \mathrm{~m}^{2}$ & 185.50 & 138.25 \\
\hline Basic Wall: 90T_10 & $5 \mathrm{~m}^{2}$ & 185.50 & 858.10 \\
\hline Basic Wall: 90T_10 & $9 \mathrm{~m}^{2}$ & 185.50 & 1606.61 \\
\hline Basic Wall: 90T_10 & $1 \mathrm{~m}^{2}$ & 185.50 & 243.53 \\
\hline \multicolumn{4}{|c|}{ Basic Wall: Aqualine with Timber } \\
\hline Basic Wall: Aqualine & $5 \mathrm{~m}^{2}$ & 198.80 & 1071.60 \\
\hline Basic Wall: Aqualine & $5 \mathrm{~m}^{2}$ & 198.80 & 1080.42 \\
\hline \multicolumn{4}{|c|}{ Basic Wall: Cedar Weatherboard + Interior } \\
\hline Basic Wall: Cedar & $6 \mathrm{~m}^{2}$ & 480.20 & 2941.16 \\
\hline Basic Wall: Cedar & $4 \mathrm{~m}^{2}$ & 480.20 & 2013.61 \\
\hline Basic Wall: Cedar & $1 \mathrm{~m}^{2}$ & 480.20 & 675.98 \\
\hline \multicolumn{4}{|c|}{ Basic Wall: Linea Weatherboard + Interior } \\
\hline Basic Wall: Linea W & $10 \mathrm{~m}^{2}$ & 423.20 & 4121.75 \\
\hline Basic Wall: Linea W & $8 \mathrm{~m}^{2}$ & 423.20 & 3192.79 \\
\hline Basic Wall: Linea W & $9 \mathrm{~m}^{2}$ & 423.20 & 3770.33 \\
\hline Basic Wall: Linea W & $10 \mathrm{~m}^{2}$ & 423.20 & 4050.57 \\
\hline Basic Wall: Linea W & $10 \mathrm{~m}^{2}$ & 423.20 & 4127.77 \\
\hline Basic Wall: Linea W & $10 \mathrm{~m}^{2}$ & 423.20 & 4194.04 \\
\hline Basic Wall: Linea W & $2 \mathrm{~m}^{2}$ & 423.20 & 675.17 \\
\hline Basic Wall: Linea W & $1 \mathrm{~m}^{2}$ & 423.20 & 563.92 \\
\hline Basic Wall: Linea W & $1 \mathrm{~m}^{2}$ & 423.20 & 563.92 \\
\hline Basic Wall: Linea W & $2 \mathrm{~m}^{2}$ & 423.20 & 750.72 \\
\hline Basic Wall: Linea W & $2 \mathrm{~m}^{2}$ & 423.20 & 679.87 \\
\hline Basic Wall: Linea W & $2 \mathrm{~m}^{2}$ & 423.20 & 750.72 \\
\hline Basic Wall: Linea W & $10 \mathrm{~m}^{2}$ & 423.20 & 4374.14 \\
\hline Basic Wall: Linea W & $10 \mathrm{~m}^{2}$ & 423.20 & 4192.89 \\
\hline Basic Wall: Linea W & $2 \mathrm{~m}^{2}$ & 423.20 & 667.31 \\
\hline Basic Wall: Linea W & $1 \mathrm{~m}^{2}$ & 423.20 & 330.22 \\
\hline Basic Wall: Linea W & $10 \mathrm{~m}^{2}$ & 423.20 & 4270.93 \\
\hline Basic Wall: Linea W & $1 \mathrm{~m}^{2}$ & 423.20 & 596.33 \\
\hline Basic Wall: Linea W & $1 \mathrm{~m}^{2}$ & 423.20 & 501.26 \\
\hline Basic Wall: Linea W & $8 \mathrm{~m}^{2}$ & 423.20 & 3293.38 \\
\hline Basic Wall: Linea W & $1 \mathrm{~m}^{2}$ & 423.20 & 501.26 \\
\hline Basic Wall: Linea W & $1 \mathrm{~m}^{2}$ & 423.20 & 482.45 \\
\hline Basic Wall: Linea W & $2 \mathrm{~m}^{2}$ & 423.20 & 650.19 \\
\hline Basic Wall: Linea W & $3 \mathrm{~m}^{2}$ & 423.20 & 1405.68 \\
\hline Basic Wall: Linea W & $3 \mathrm{~m}^{2}$ & 423.20 & 1310.72 \\
\hline Basic Wall: Linea W & $0 \mathrm{~m}^{2}$ & 423.20 & 56.09 \\
\hline Basic Wall: Linea W & $0 \mathrm{~m}^{2}$ & 423.20 & 26.20 \\
\hline Basic Wall: Linea W & $0 \mathrm{~m}^{2}$ & 423.20 & 73.65 \\
\hline Basic Wall: Linea W & $0 \mathrm{~m}^{2}$ & 423.20 & 17.03 \\
\hline Basic Wall: Linea W & $0 \mathrm{~m}^{2}$ & 423.20 & 58.85 \\
\hline Basic Wall: Linea W & $0 \mathrm{~m}^{2}$ & 423.20 & 179.63 \\
\hline Basic Wall: Linea W & $1 \mathrm{~m}^{2}$ & 423.20 & 284.40 \\
\hline Basic Wall: Linea W & $0 \mathrm{~m}^{2}$ & 423.20 & 135.33 \\
\hline
\end{tabular}

\begin{tabular}{||l|c|c|c|}
\multicolumn{4}{||l|}{ <Roof Schedule> } \\
\hline \multicolumn{1}{||l|}{ A } & B & C & D \\
\hline Family and Type & Area & Cost & Total Cost \\
\hline \multicolumn{3}{|l|}{} & \\
\hline Basic Roof: Colour Steel Roof + Timber + ceiling & $\$ 10696.11$ \\
\hline Basic Roof: Colour & $42 \mathrm{~m}^{2}$ & 257.00 & $\$ 10696.11$ \\
\hline Grand total: 1 & &
\end{tabular}

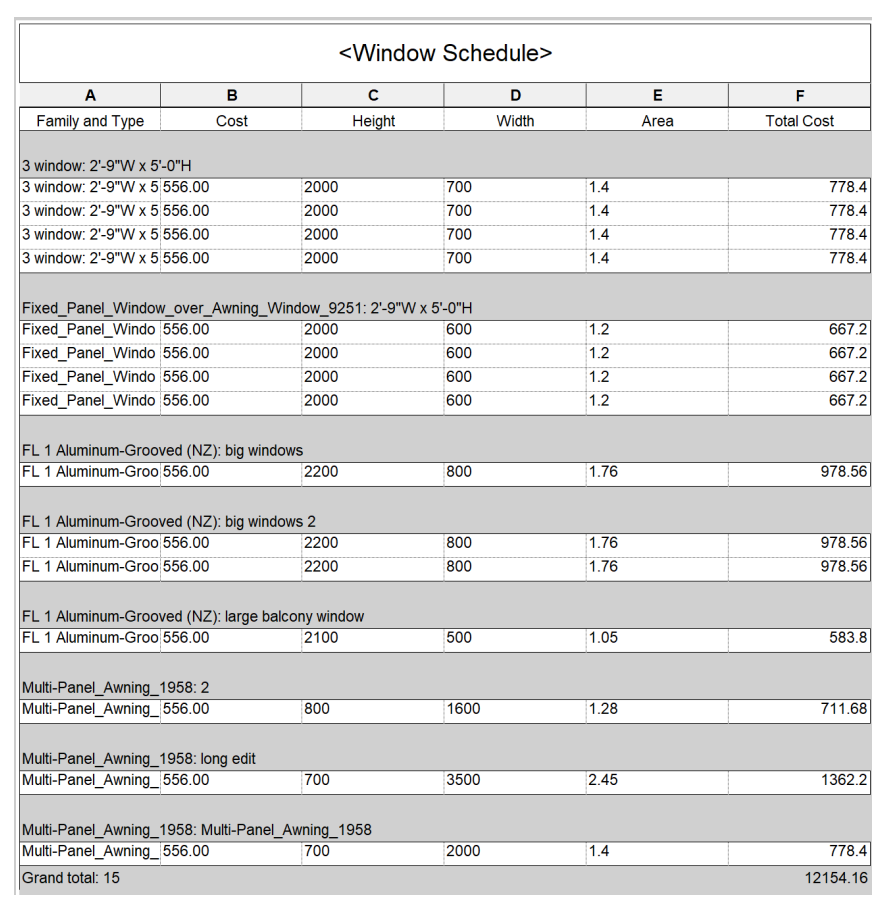

$<$ Floor Schedule>

\begin{tabular}{|c|c|c|c|}
\hline A & B & C & D \\
\hline Family and Type & Area & Cost & Total Cost \\
\hline \multicolumn{4}{|c|}{ Floor: Concrete Slab } \\
\hline Floor: Concrete SI & $4 \mathrm{~m}^{2}$ & 150.00 & $\$ 550.65$ \\
\hline Floor: Concrete SI & $35 \mathrm{~m}^{2}$ & 150.00 & $\$ 5184.68$ \\
\hline \multicolumn{4}{|c|}{ Floor: Timber Decking } \\
\hline Floor: Timber Deck & $13 \mathrm{~m}^{2}$ & 170.00 & $\$ 2171.92$ \\
\hline Floor: Timber Deck & $5 \mathrm{~m}^{2}$ & 170.00 & $\$ 926.55$ \\
\hline \multicolumn{4}{|c|}{ Floor: Timber Mid Floor + Ceiling } \\
\hline Floor: Timber Mid & $29 \mathrm{~m}^{2}$ & 280.00 & $\$ 8238.56$ \\
\hline Grand total: 5 & & & $\$ 17072.36$ \\
\hline
\end{tabular}

\begin{tabular}{|c|c|c|}
\hline \multicolumn{3}{|c|}{$<$ Door Schedule $>$} \\
\hline A & B & C \\
\hline Family and Type & Cost & Total Cost \\
\hline \multicolumn{3}{|c|}{ Ext Bifold3-1Lite(NZ): $2100 \times 1980$} \\
\hline \multicolumn{2}{|c|}{ Ext Bifold3-1Lite(N 2571.00} & 2571.00 \\
\hline \multicolumn{3}{|c|}{ Ext Single In-Timber-1Lite (NZ): Front Door Glazed } \\
\hline \multicolumn{2}{|c|}{ Ext Single In-Timbe 2040.00} & 2040.00 \\
\hline \multicolumn{3}{|c|}{ Exterior_Sliding_Door_3843: 6'-0"W. x 7'-0"H. } \\
\hline \multicolumn{2}{|c|}{ Exterior_Sliding_D 2571.00} & 2571.00 \\
\hline \multicolumn{3}{|c|}{ Int Single-Flush (NZ): $710 \times 1980$} \\
\hline \multicolumn{2}{|c|}{ Int Single-Flush (N 254.00} & 254.00 \\
\hline \multicolumn{2}{|c|}{ Int Single-Flush (N 254.00} & 254.00 \\
\hline \multicolumn{2}{|c|}{ Int Single-Flush (N 254.00} & 254.00 \\
\hline \multicolumn{2}{|c|}{ Int Single-Flush (N 254.00} & 254.00 \\
\hline \multicolumn{2}{|c|}{ Int Single-Flush (N 254.00} & 254.00 \\
\hline \multicolumn{2}{|l|}{ Grand total: 8} & 8452.00 \\
\hline
\end{tabular}


Figure 3.86 Excel breakdown typology 3.1

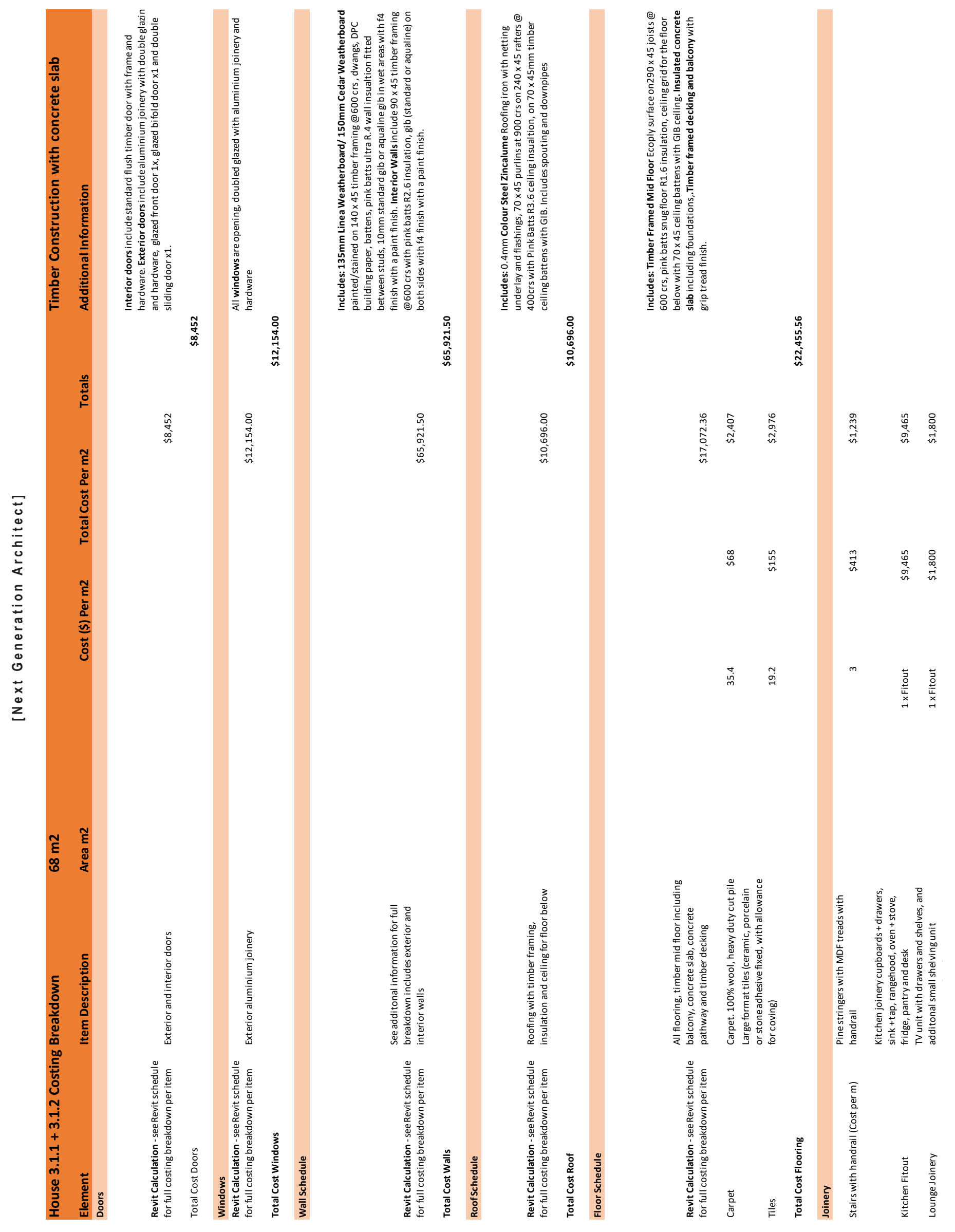




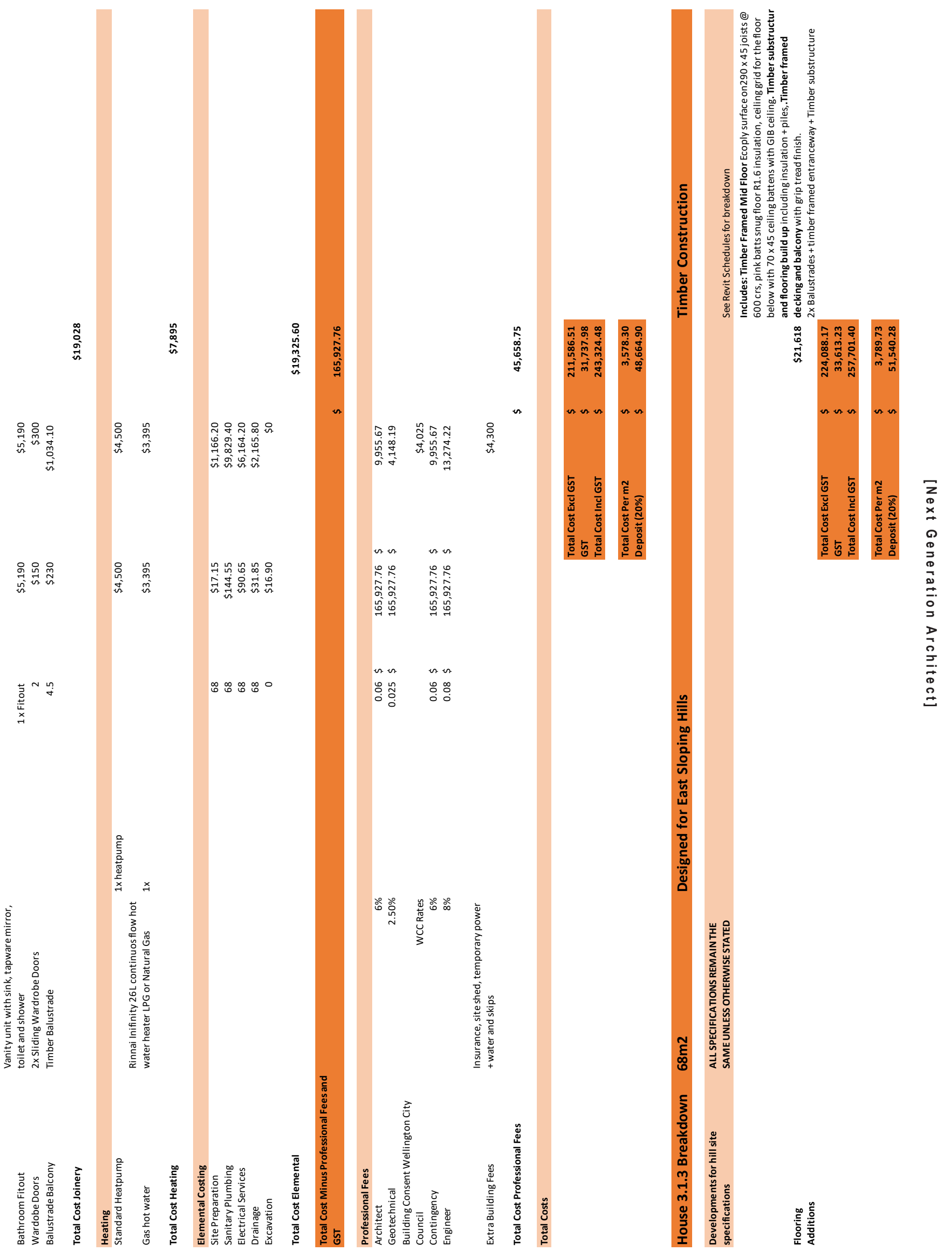




\section{Findings from the Pattern Book}

How can an architect design more accurartely with value?

Materiality and Costing:

- Houses on flat sites are cheaper to build than those on hill sites. A contributor to this is the cost of the timber substructure that is approximately $\$ 120$ more per $\mathrm{m} 2$ than an insulated concrete slab, which all houses contain on the flat test sites.

- Hill sites cost more to build on. In a personal conversation with a QS it is advised engineering and excavation is researched first.

- It is approximately $\$ 200$ cheaper per $\mathrm{m}^{2}$ for duplex houses.

- Housing typology 1.1 has the highest costs per $\mathrm{m}^{2}$. Even though it has the smallest floor area. What makes this typology cost more is the cost of the build-up of the kitchen and bathroom and joinery throughout the house - all elements are needed. It just has less floor area to be shared across.

- The most economic houses are timber framed with weatherboard, the construction of the hybrid house is more economical than full concrete construction. All houses have a timber framed roofs. The hybrid has a timber framed mid floor.

- Concrete mid floor costs more than a timber framed floor.

Findings from the pattern book:

- Repetition of design.

- Architecture as product that works with site specific conditions just as an architect would for bespoke architecture.

- Optimised and efficient planning.

- The use of BIM as a costing tool to observe implications of design decisions.

- The use of dual housing to reduce costs that would include site in a built situation.

- Light timber framing on hill sites to reduce engineering costs.

- Building on timber piles to reduce the need for excavation.

- Working with sheet sizes.

- Simple regular forms.

- No repetition of service areas. 


\section{Findings + Reflection}

The Next Steps

The pattern book allowed for a successful comparison of four housing typologies and their relationship to different site conditions. This has allowed for a distinguishable difference between the choices an architect would make specific to site compared to a developer who would only show one variation of each house. The use of BIM through Revit was a successful tool to cost all houses minimising mistakes made for a first cost estimate. The current weaknesses include the interiors of the houses where there is currently no understanding to what these look like and how you live within the interior from a human perspective. Introducing the lifecycle of materials will show stronger links to the differences between this thesis and developers homes.

Creating a unique product creates the branding of the pattern book houses. This was seen through project homes in Australia where Pettit and Sevitt and Merchant builders both marketed and branded their companies through unique processes, grasping clients attention. "Individualism served as an early form of product identification, or 'branding', offering the consumers of products or services the potential for their own self-realisation and individualisation through the act of consumption" (O'Callaghan, 2017, p.142). The pattern book requires further development enhancing individualisation and desirability through the form of a product. This can be achieved through revisiting the planning of the spaces and enhancing the overall desirability to live within them. In addition it has also be achieved by reconsidering interior layouts to consider viewpoints and how spaces can be used for more than one function or arrangement, as well as including architectural elements that will enhance the aesthetics and functions of a space. Reconsidering the connection between the indoors and outdoors through external spaces and landscaping, which the designs currently lack, will tie the overall experience of the home together.

Where to next?

- Improve desirability and branding of homes.

- Undertaking lifecycle analysis of materials.

- Development of the pattern book, introducing single level houses and a split level option.

- Designing interiors from a occupants perspective.

Next Generation Architect

A next generation architect will be approachable for all types of clients and will utilise time, cost and quality through the use of innovative tools such as BIM and pattern books. In addition they will produce architectural products, creating libraries of designs, drawings and costs. 


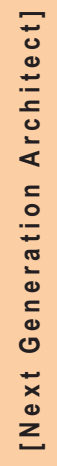


06

Next Generation Architect 
Chapter 5 investigated the Next Generation Architect. An architect who understands cost implications of materials, standard construction techniques and the impact of their lifecycle. This chapter introduces two new housing typologies and explores the habitation of all housing typologies. 
The interiors of the dwellings in Design Phase Three contained weaknesses surrounding inhabitation and architectural elements of the interiors. Design Phase Four explores the interiors through materiality, habitation and architectural elements, exhibiting the dwellings as architectural products. A precedent analysis exercise was undertaken using Home magazine, investigating architecturally designed homes in New Zealand. Elements from this analysis were adopted to influence a versatile and homely habitation.

Findings:

- Smart storage through recesses, joinery and furniture.

- The application of shelving and paneling as architectural elements.

- Level changes to break up open plan spaces.

- Efficient layouts optimising floor area.

- Material usage and selection on both the interior and exterior, for aethetic purposes.

- Effective easy care landscaping.

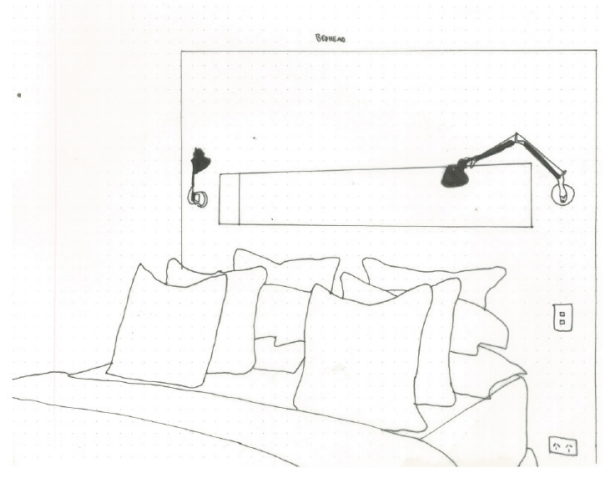

Figure 4.01 Recessed bedhead design reducing the area used to the side of the bed

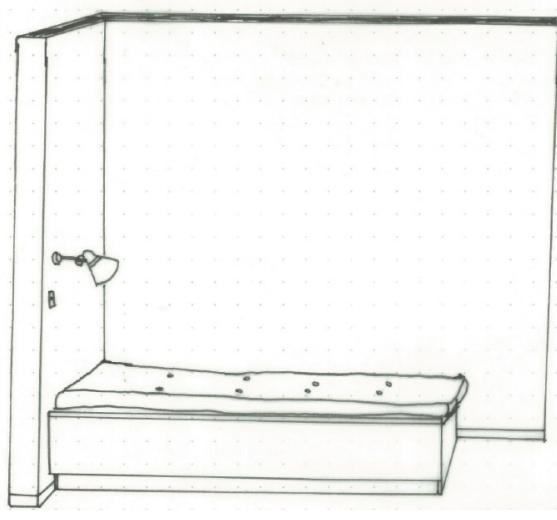

Figure 4.02 Built in daybed joinery with swab and electrical fittings

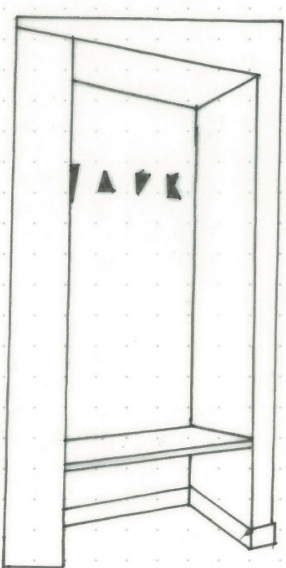

Figure 4.03 Storage recessed into wall with hooks and a shelf

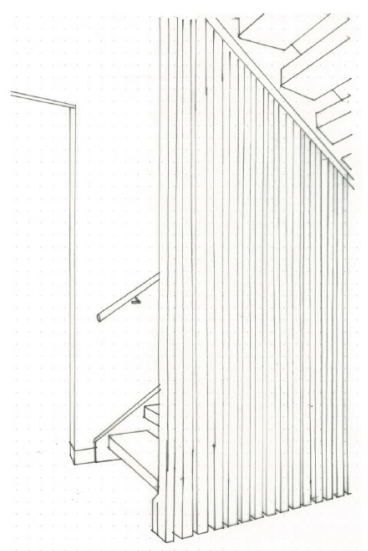

Figure 4.04 Timber panelling used as railing for the stairs

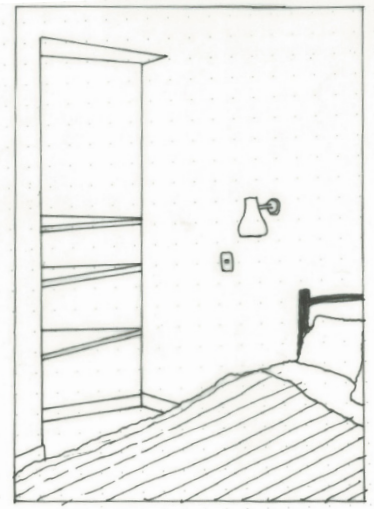

Figure 4.05 Shelving recessed into wall with bed lamp 


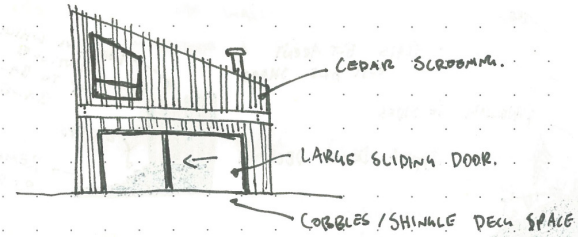

Figure 4.06 Exterior materiality

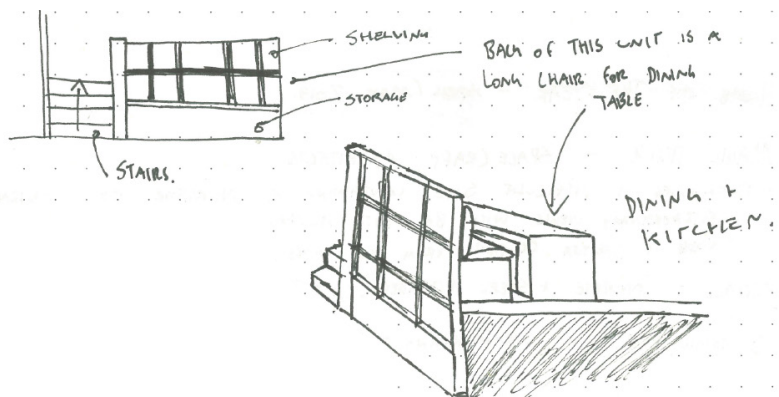

Figure 4.08 Double usage furniture and space divider

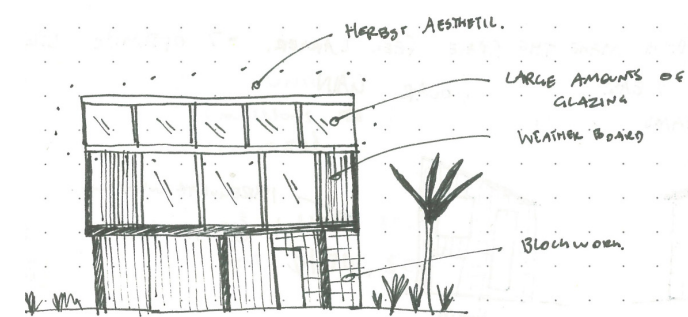

Figure 4.07 Herbst Architects Aesthetic

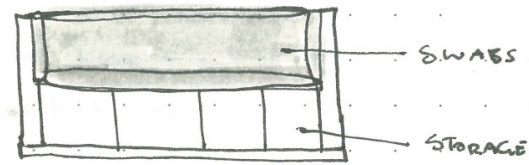

Figure 4.09 Furniture containing storage

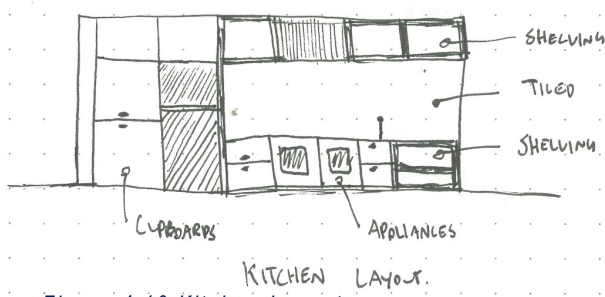

Figure 4.10 Kitchen Layout

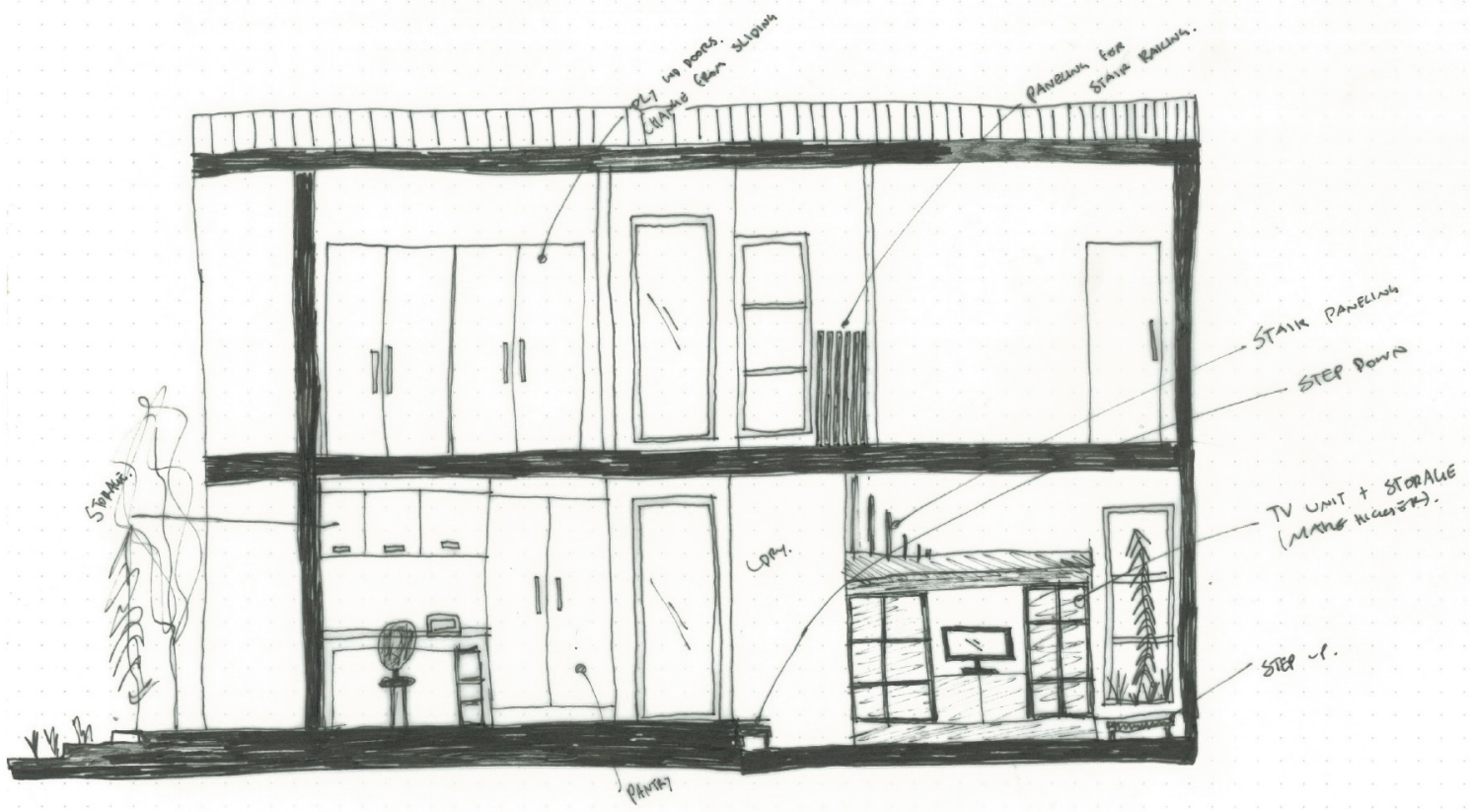

Figure 4.11 Finidngs applied to house 3.1 .1 in a development sketch 
Te Modular

Herbst Architects

Herbst Architects concept for the design of the Te Modular bach arose from a number of people requesting a bespoke bach design within a small budget. Targeted at reducing building costs, through a package design, and containing detailed drawings and specifications at a set price. Additional fees are required for site consultation and the processing of consents (Foster, 2015). Te Modular can be seen as a successful architectural product, with the first Te Modular bach being built in 2013 on Great Barrier Island and the second in 2015 at the same beach (figure 4.12 and 4.13).

"Our thinking was not so much in terms of a kitset, but a bach that is adaptable enough to suit most sites that we design and detail extensively, down to the furniture... We can then repeat this allowing us to significantly reduce the cost to the client of professional fees" (Bucknell, n.d.)

Tactics of affordability:

- Standardisation of built elements.

- Architecture as product: creating a model that can be repeated across a number of sites.

- A flexible pod layout. Modified to suit specific client and site requirements.

- Repeatable drawings reducing an architect's professional fees, as these are spread across a number of builds.

- Controlled floor area providing only the essentials.

- Reducing material usage by enclosing half the structure.

- Specifically designed furniture containing storage.

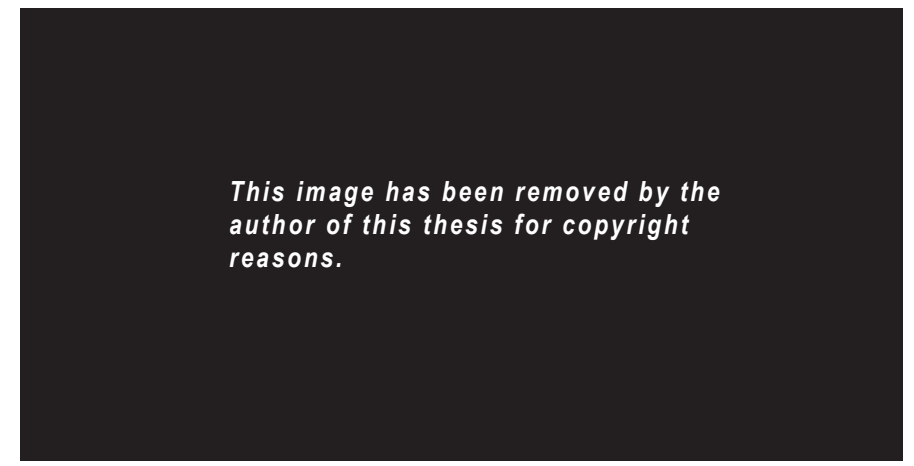

Figure 4.12 First Te Modular bach on Great Barrier Island

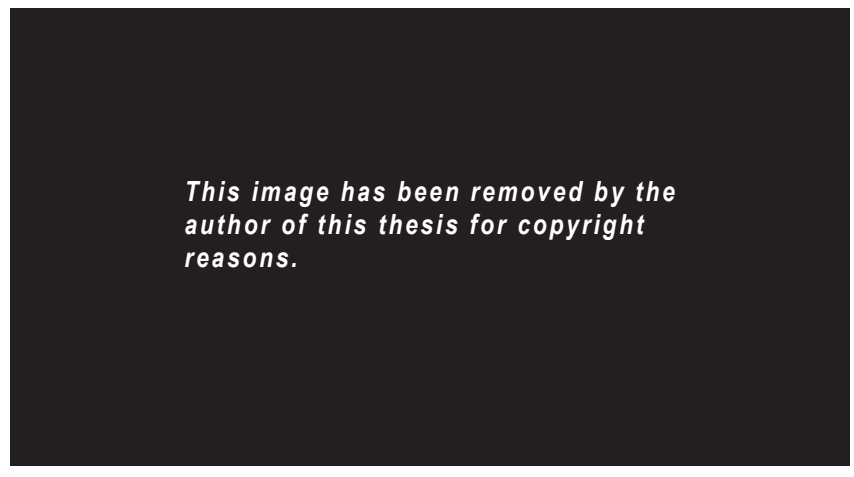

Figure 4.13 Second bach on Great Barrier Island with a different external colour pallet 


\section{Madras Street Duplex}

\section{Coll Architecture}

The Madras Street duplex designed by Coll Architecture is located in Christchurch. The two units are reflected, sharing a common wall with a floor area of $74 \mathrm{~m} 2$ each. Coll designed with the interest of cost efficiency, and wanted to demonstrate that new homes can be warm, dry, low maintenance, efficient to run and built for no more than the average sized architecturally designed home. This is achieved through the consideration of every element within the dwelling. (Foster, 2019)

"By building a house small and design dense, the money saved can be spent on quality. The maths isn't complicated- if you half the size you get twice the quality and overall price." (Foster, 2019, p.99)

Tactics of affordability:

- Duplex dwelling with costs split.

- Shared services wall between the two dwellings.

- Future proofing the building.

- Strategic material usage with minimal use of cor-ten steel on the street frontage

- Open plan.

- CLT structure.

- Minimal material pallet.

- Strong indoor-outdoor flow, allowing for living areas to feel larger.

Economics:

- Land: $\$ 215,000$.

- Build: $\$ 361,000$ per house $\left(\$ 4878\right.$ per $\left.\mathrm{m}^{2}\right), \$ 722,000$ in total.

- Landscaping: $\$ 57,000$.

- Fees and Compliance: $\$ 47,000$.

- Total for whole dwelling: $\$ 1,041,000$, Per unit: $\$ 520,500$.
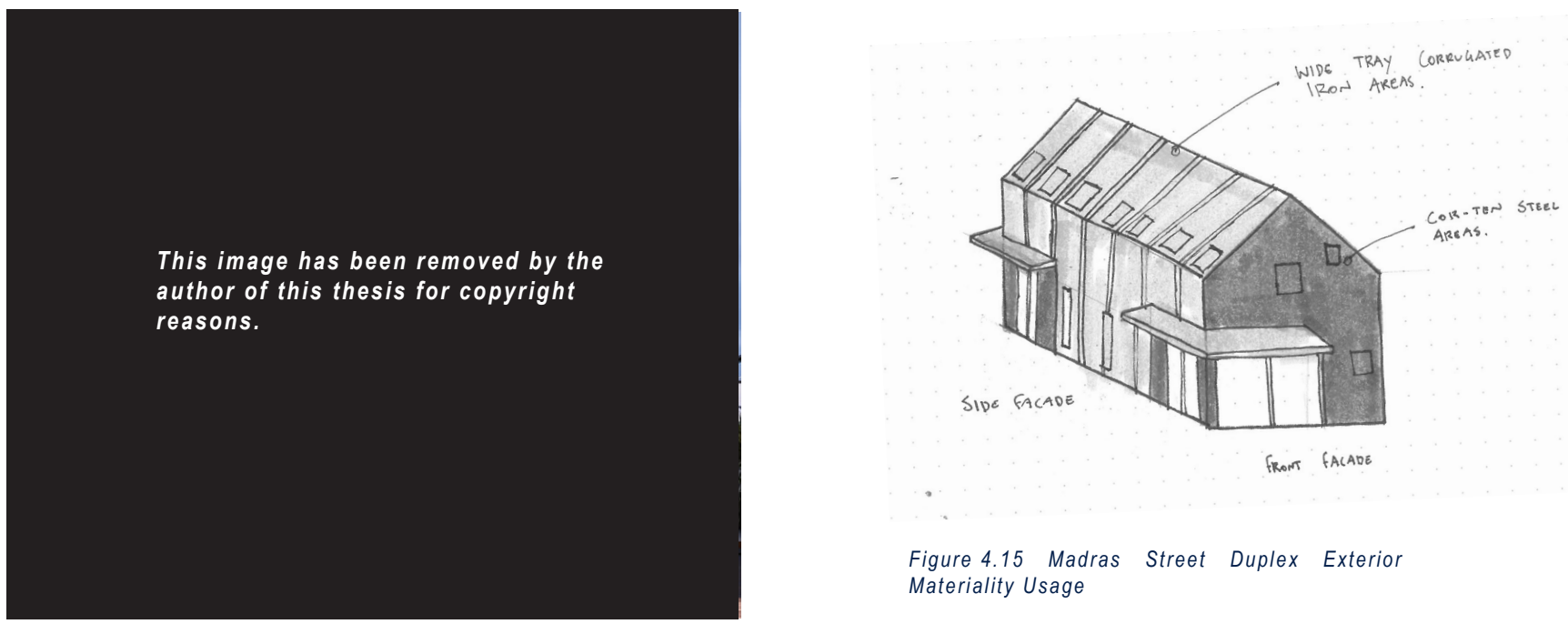

Figure 4.15 Madras Street Duplex Exterior Materiality Usage

Figure 4.14 Madras Street Duplex Cor-ten Steel Street Frontage 


\section{The Wedge House}

Grand Designs New Zealand

The Wanaka Wedge House is a $240 \mathrm{~m}^{2}$ home, portrayed as an architectural product. The clients came across the bold design on the internet. Although the house was not designed for the New Zealand climate. It was originally designed but never built for a site on the east coast of the United States by architect Jeff Day. The house was adapted to suit the climatic and environmental conditions and building regulations of New Zealand. (Hawkes, 2019)

Positives:

- Architecture as product with plans available for purchase online.

- Adaptable design to suit sites located across the globe.

- Prefabricated construction processes; SIPS, CLT and standard timber framing.

Negatives:

- Expensive. An estimated cost of $\$ 995,000$.

- Project came in overbudget by a $15 \%$, total build was $\$ 1.137$ million, $\$ 4740$ per $\mathrm{m}^{2}$.

- Irregular windows.

- Irregular design took 18 months to gain council approval.

This image has been removed by the author of this thesis for copyright reasons.

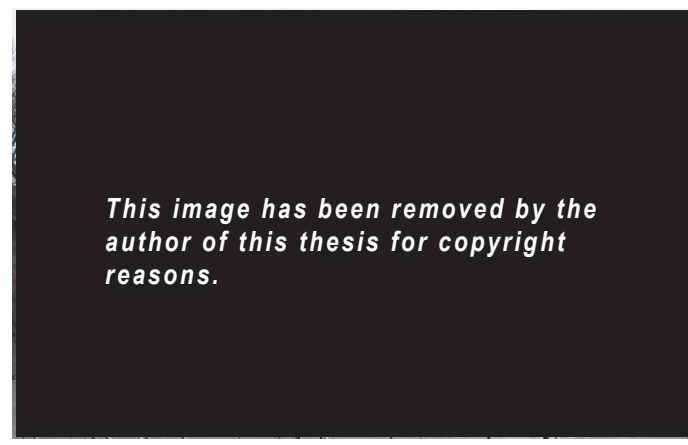

Figure 4.16 Original design and materiality of the Wedge house located in the USA.

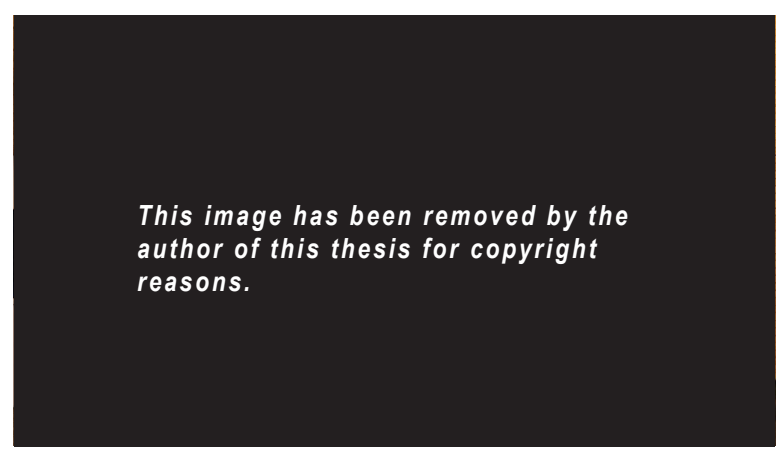

Figure 4.17 Wanaka Wedge House tongue and grove ceiling

This image has been removed by the author of this thesis for copyright reasons.

Figure 4.18 Wanaka Wedge House situated within the landscape, flipped from the original design 


\section{Eames House}

\section{Case Study House}

The case study house program was initiated in 1945 by John Entenza of the Arts and Architecture Magazine in Los Angeles. It Involved the design of 36 housing prototypes over 21 years, with 8 architects commissioned. Prototypes were designed to be economic, experimental, and easy to build. The modern home was defined through the program which has internationally influenced residential architecture by established new materials and methods (Steele, 2002).

Case study house number 8 known as the Eames house designed by Charles and Ray Eames was identified as one of the first experimental dwellings. It experimented with planning, structure and the integration of industrial materials and techniques into architecture (McCoy, 1977).

Tactics of Affordability:

- Minimal complexity

- Standardised construction techniques:

- Windows at a width of 3'4

- Coloured panels on the external envelope integrating with the structural grid

- Simple steel framing involving 2-inch $\mathrm{H}$ columns

- 12- inch open web steel beams (Perez, 2010)
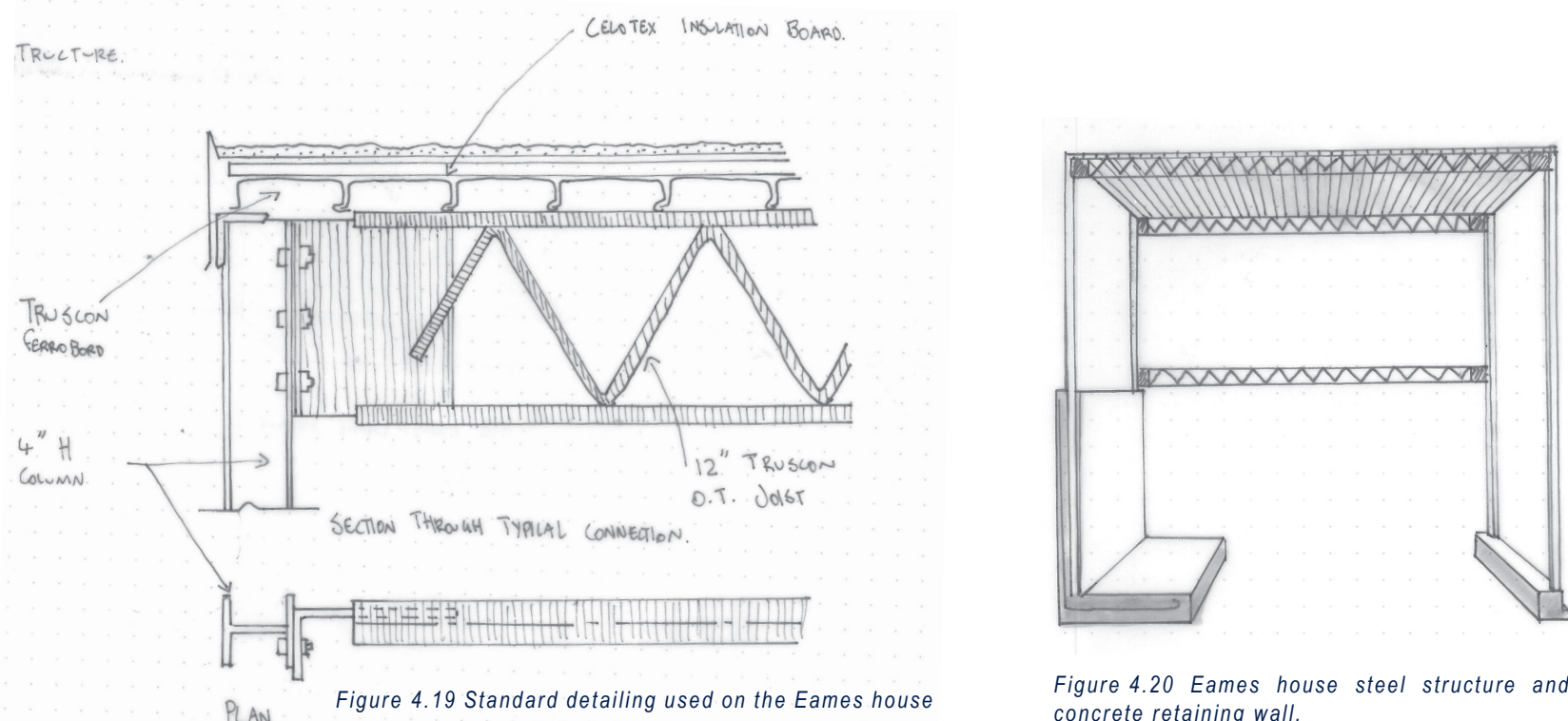

Figure 4.20 Eames house steel structure and concrete retaining wall.

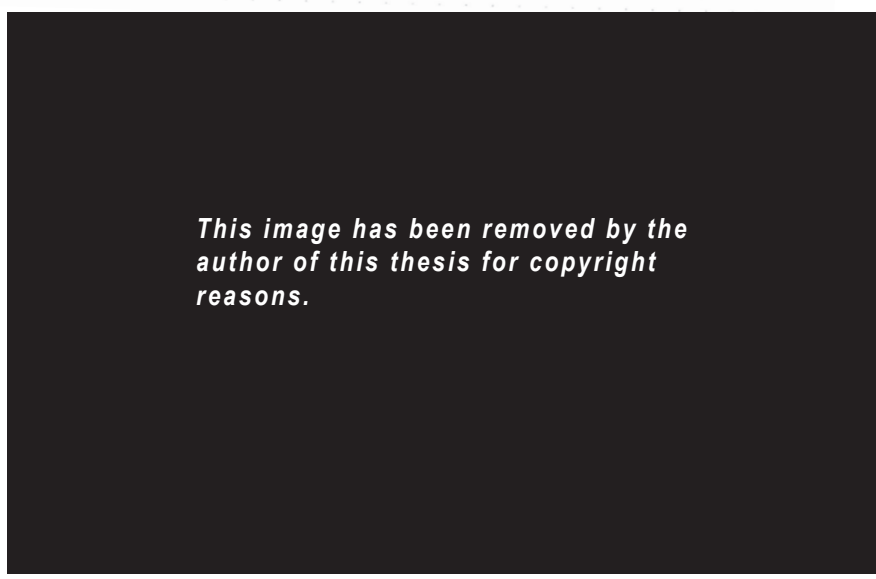

Figure 4.21 Exterior of the Eames house exposing the structure. 


\section{Standard Detailing}

Construction of Dwellings

Minimising the complexity of the construction of a dwelling allows for an economic outcome. This is achieved through the use of standard detailing. Standard detailing allows for a straightforward construction process, with builders and other trades people having a strong knowledge of how the dwelling is constructed. It means an efficient and economic outcome, where the architect does not have to supervise each individual area being constructed. This also comes into account within the council consent process to meet building code compliance. A dwelling containing standard detailing is more likely to be understood and ticked off as meeting compliance, compared to a dwelling with complex irregular detailing. (Building Performance, 2016).

Using standard details across projects allows for architects to create libraries of details. This saves architects time, which in the long run is more economical. Libraries of details can be created, so only minimal changes are needed for each project, rather than reinventing details. Bespoke details should be kept to a minimum, with standard detailing substituted into the detailing where applicable.

Standard detailing is used throughout all housing typologies designed. Posi-struts are substituted as a standardised replacement providing an economical method for larger spans, for areas of timber framing not meeting standard timber sizes. The majority of windows for all dwellings are regulated, apart from the minimal use of irregular shaped windows in typologies 4.5 and 4.6 for architectural intentions. Irregular shaped or windows requiring structural elements costs approximately $30 \%$ more per $\mathrm{m}^{2}$ than standard glazing (QV Cost builder). All housing typologies contain typical cladding options with a small material pallet of weatherboard, Coloursteel, titan board or precast concrete panels. Roofing is consistent with the use of Coloursteel over light timber framing. 


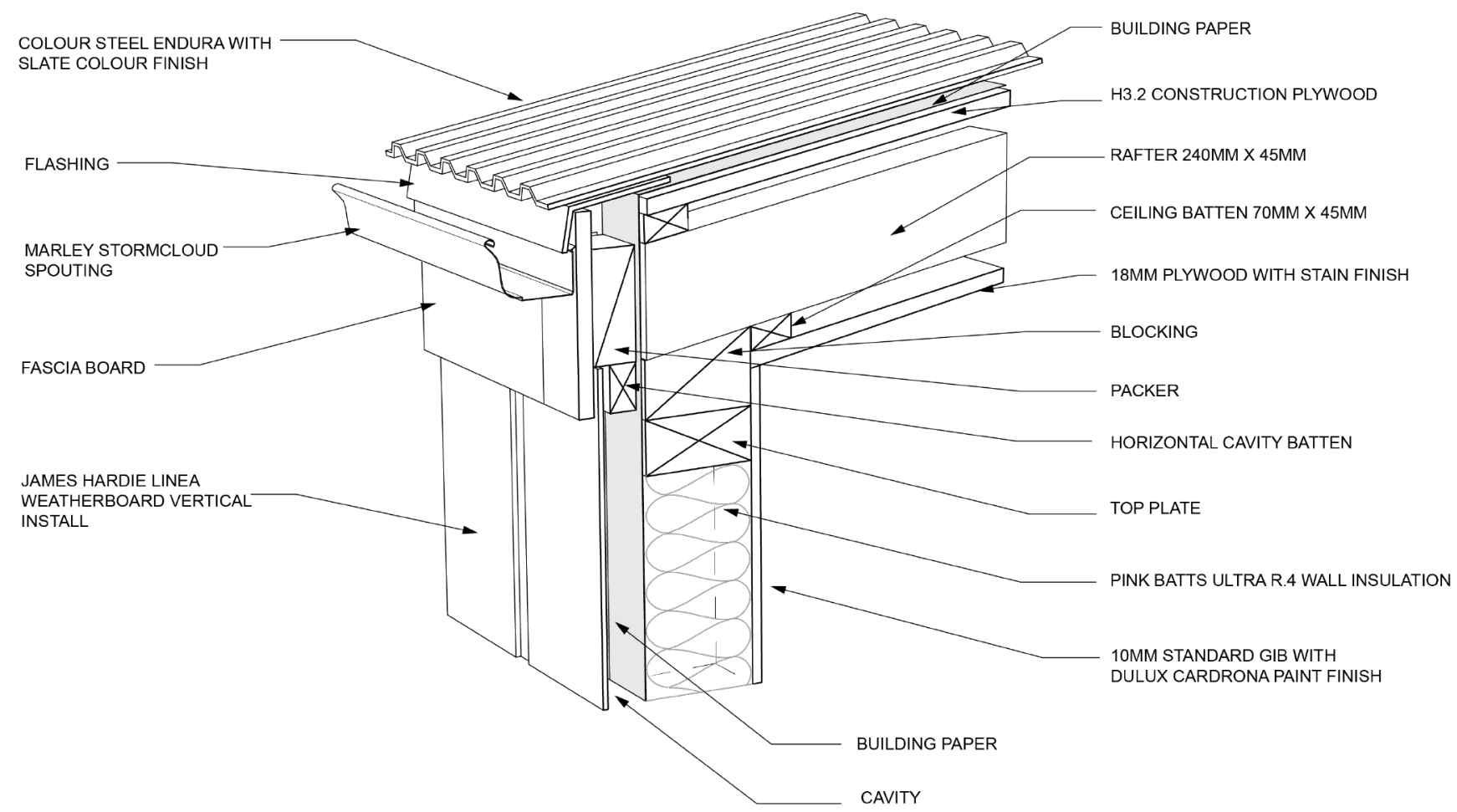

Figure 4.22 Standard Roof to External Wall Cladding Detail

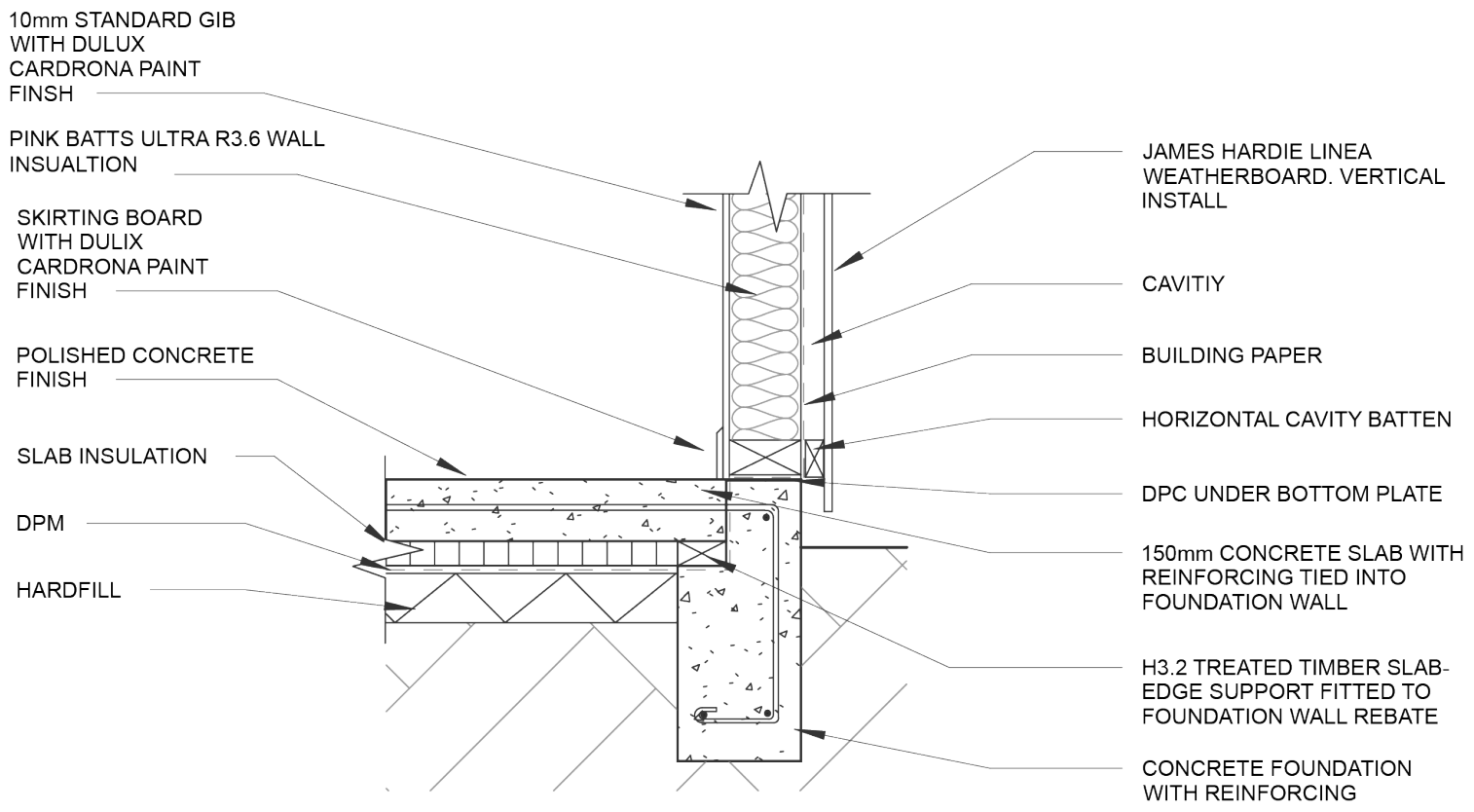

Figure 4.23 Standard insulated concrete slab and foundation detail 


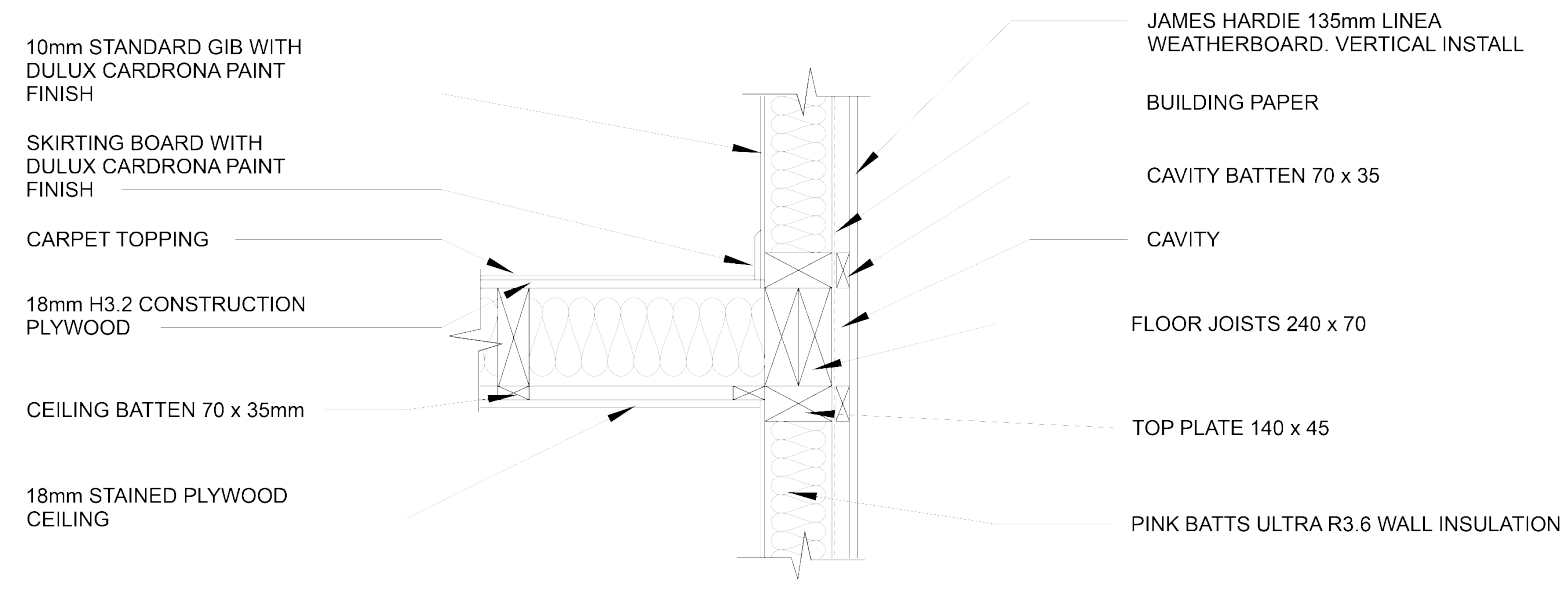

Figure 4.24 Standard timber midfloor to external wall detail

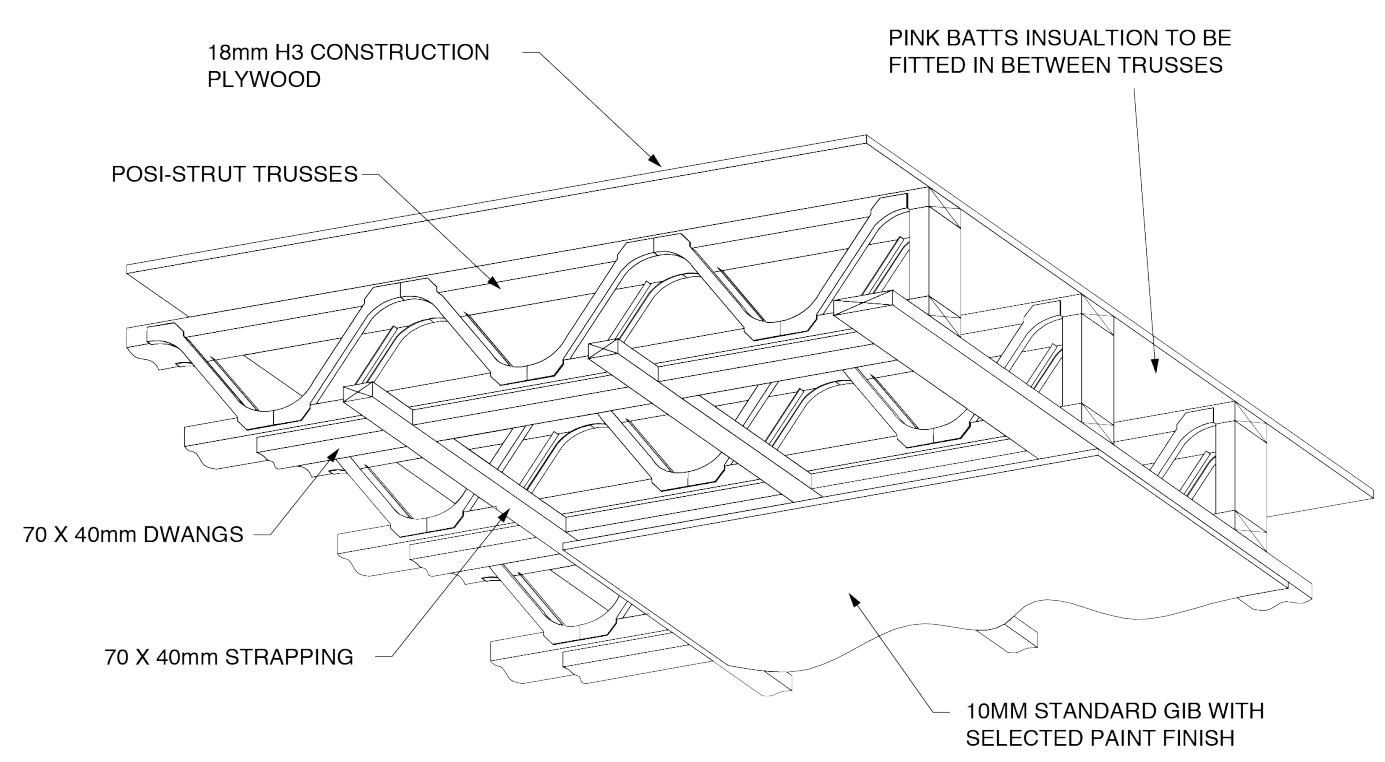

Figure 4.25 Standrad Posi-Strut floor framing detail 


\section{Material Analysis}

Overall Costs and Lifespan

Figure 4.26 Average lifespan of exterior wall claddings

\section{Average Lifespan of Exterior Wall Claddings}

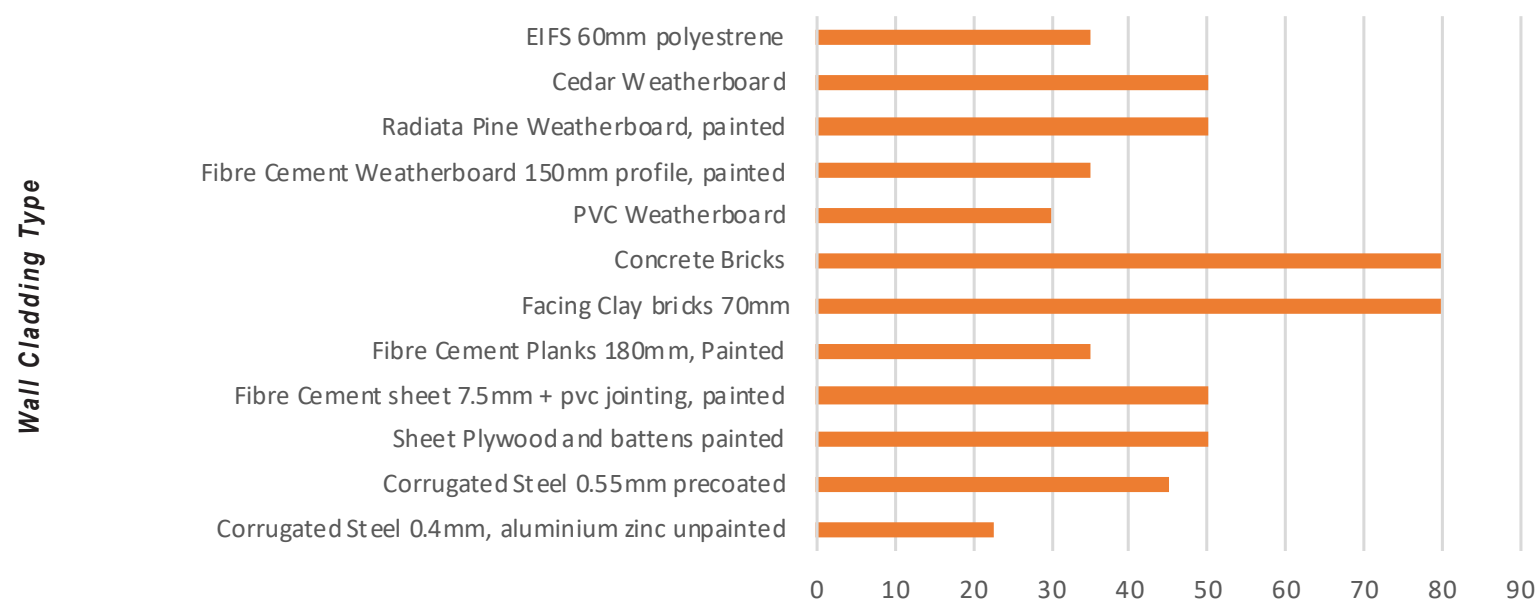

Figure 4.27 Average cost of exterior wall claddings

\section{Average Cost of Exterior Wall Claddings}

EIFS $60 \mathrm{~mm}$ polyestrene

Cedar weatherboard

Radiata Pine Weatherboard, painted Fibre Cement Weatherboard $150 \mathrm{~mm}$ profile, painted

PVC Weatherboard

Concrete Bricks

Facing Clay bricks $70 \mathrm{~mm}$

Fibre Cement Planks 180mm, Painted

Fibre Cement sheet $7.5 \mathrm{~mm}+$ pvc jointing, painted Sheet Plywood and battens painted

Corrugated Steel $0.55 \mathrm{~mm}$ precoated

Corrugated St eel $0.4 \mathrm{~mm}$, aluminium zinc unpainted

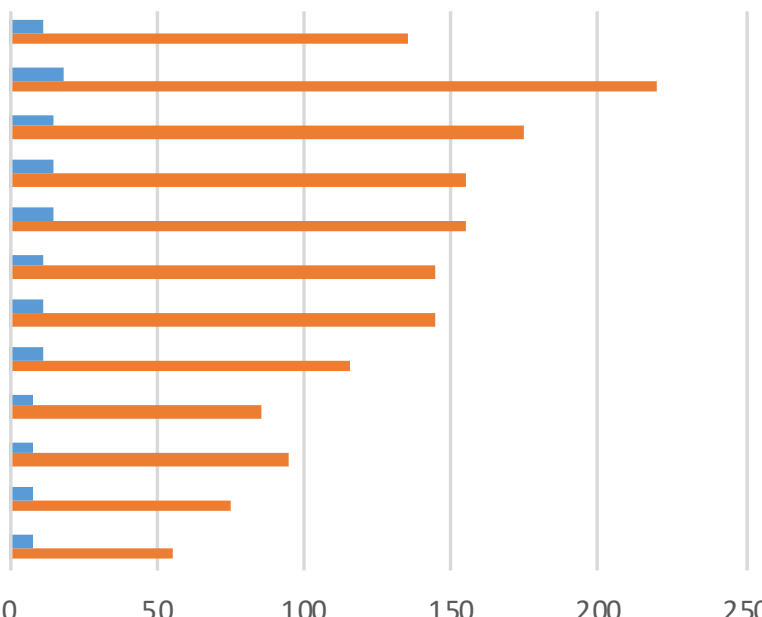

- Lifetime Cost Per m2/year $\quad$ Initial Cost Per m2 
Figure 4.28 Average lifespan of roof claddings

\section{Average Lifespan of Roof Claddings}

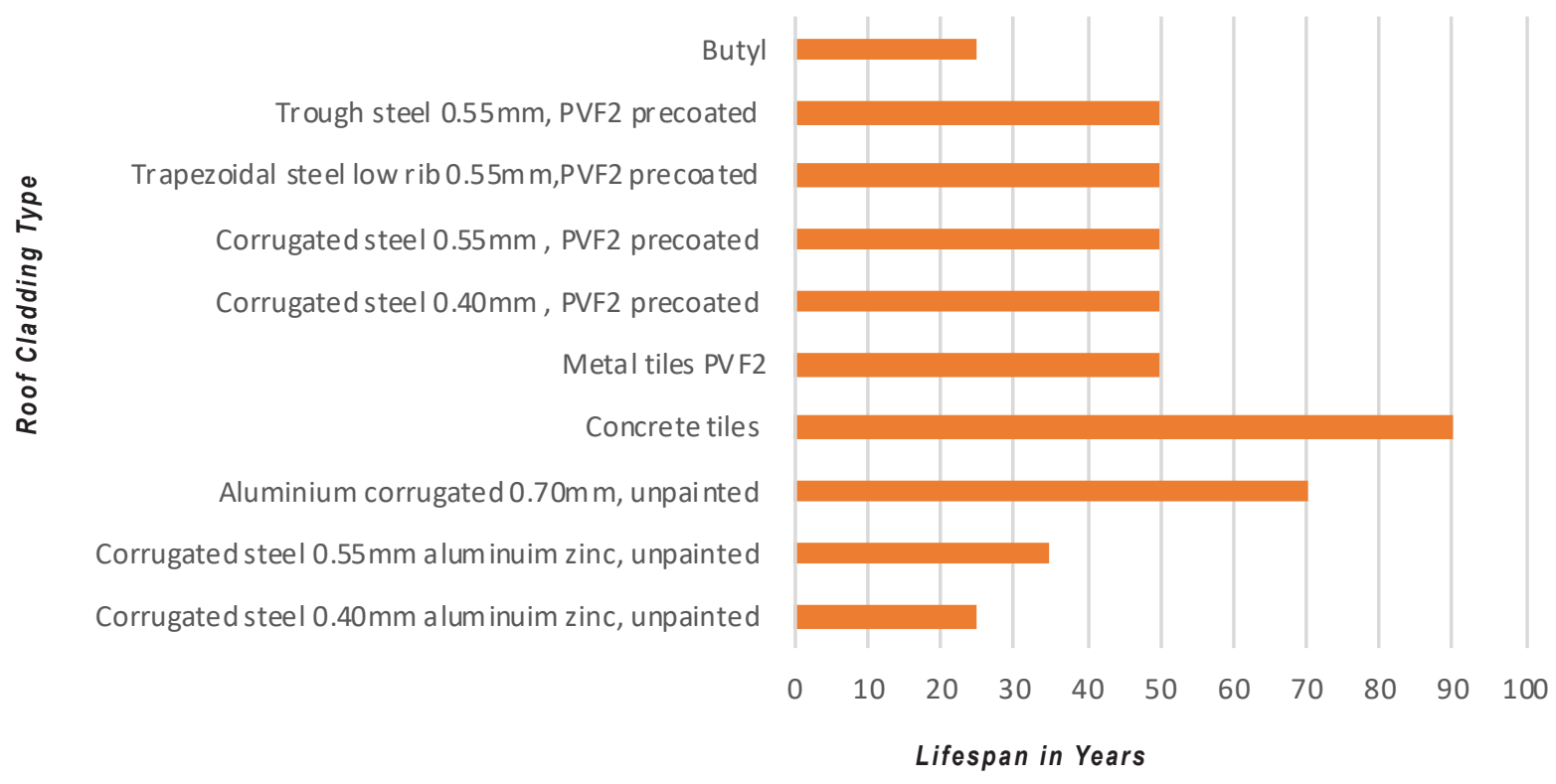

Figure 4.29 Average cost of roof claddings

\section{Average Cost of Roof Claddings}

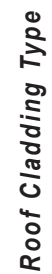

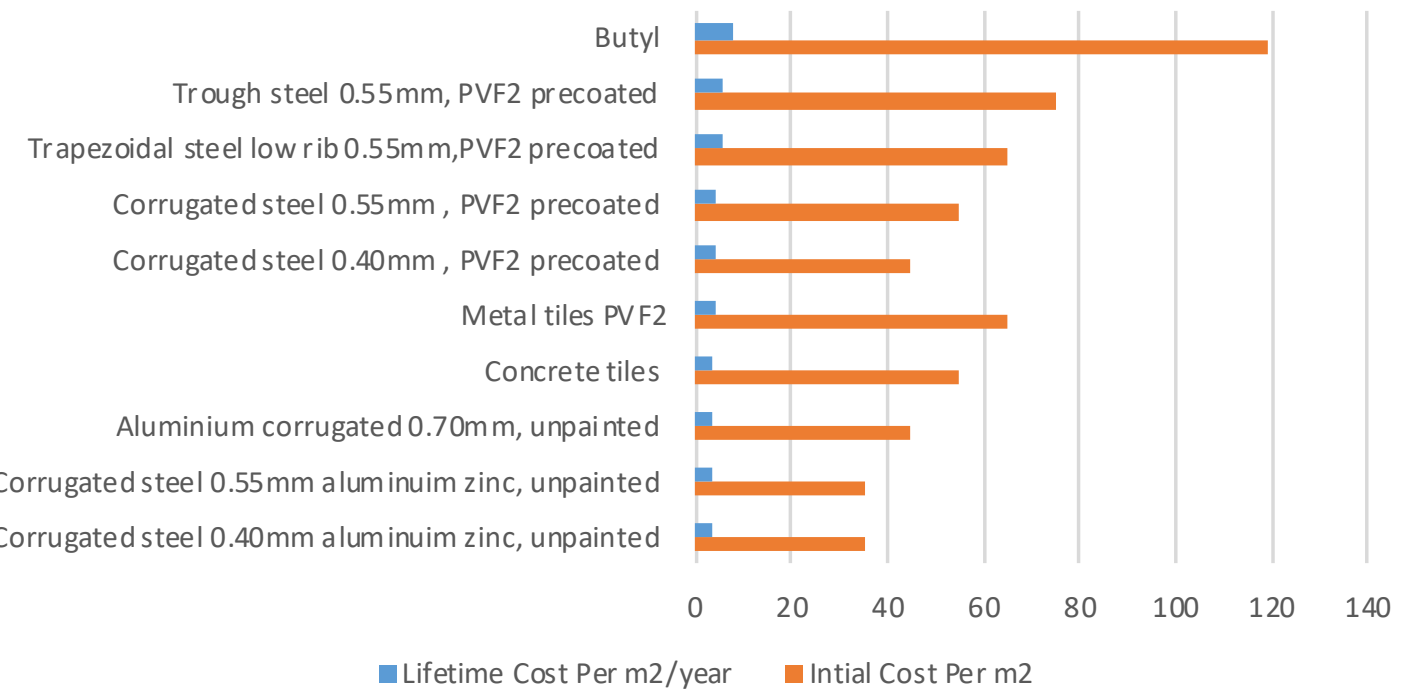

Cost in Dollars (\$) 


\section{Material Analysis}

Overall Costs and Lifespan

Figure 4.30 Selected exterior wall cladding lifecycle costing using QV database.

\section{Selected Exterior Wall Cladding Lifecycle Costing}

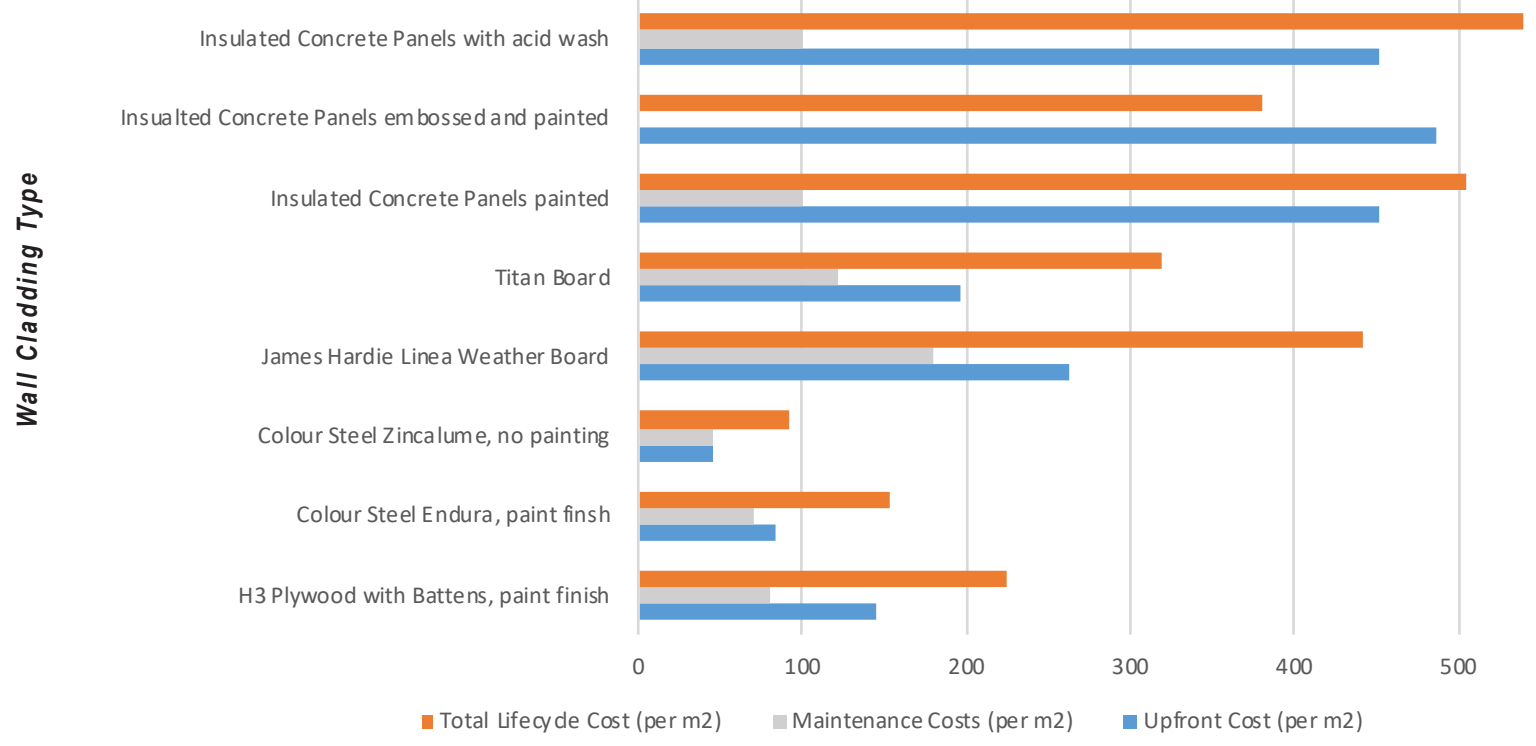

Cost in Dollars (\$)

Figure 4.31 Selected wall cladding lifespans

\section{Selected Exterior Wall Cladding Lifespan}

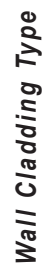

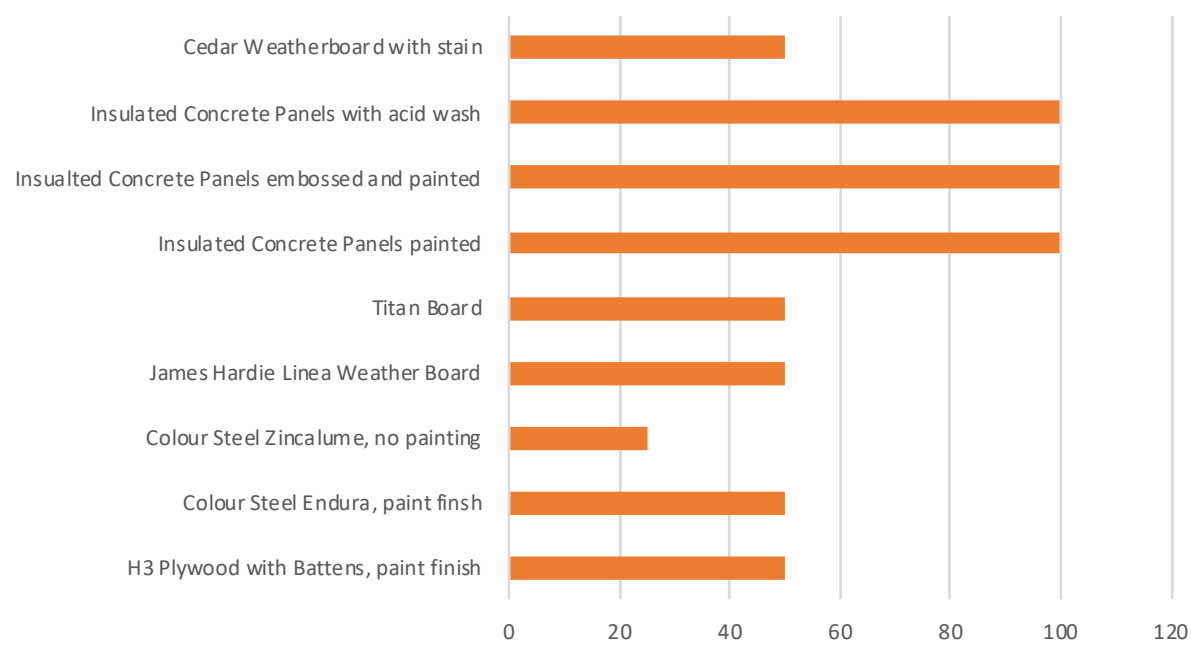


Figure 4.32 Selected roof cladding lifespan

\section{Selected Roof Cladding Lifespan}

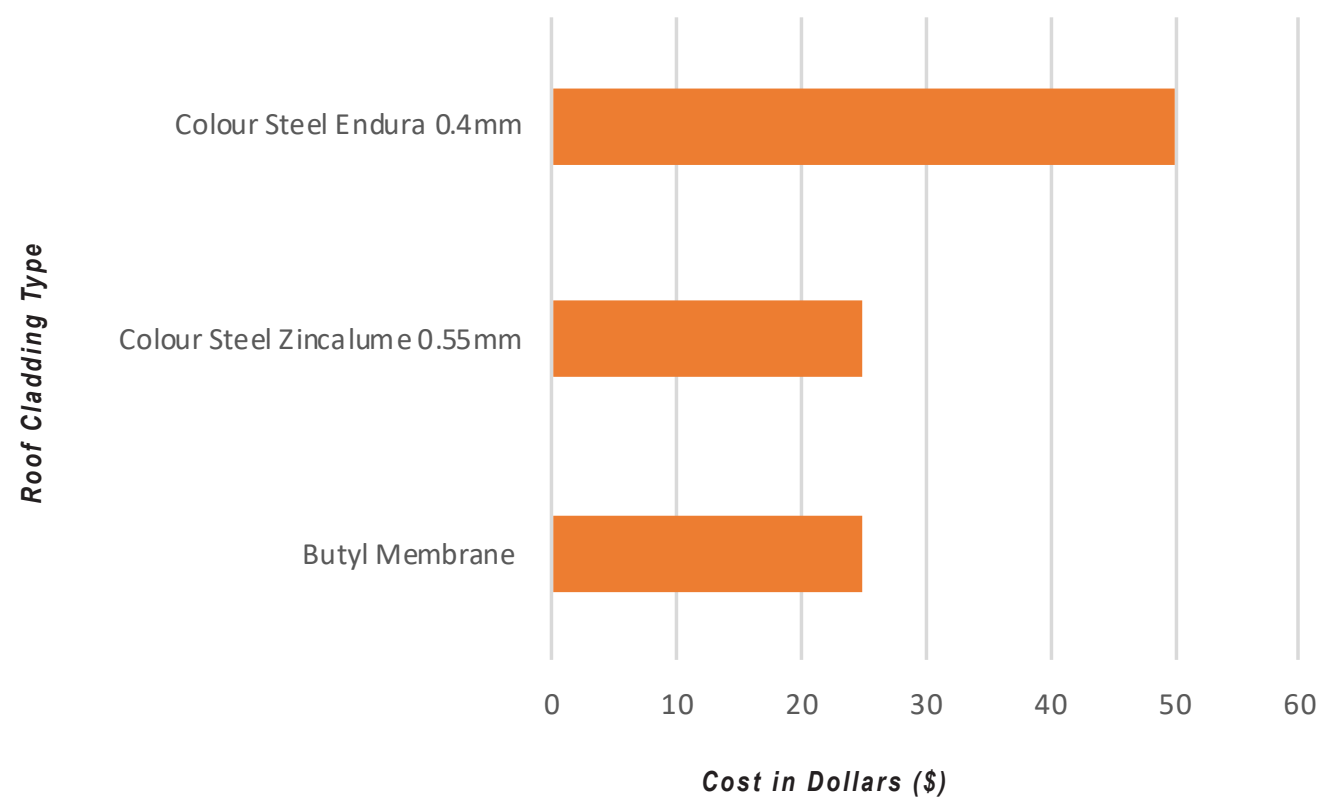

Figure 4.33 Selected roof cladding lifecycle costing

\section{Selected Roof Cladding Lifecycle Costing}

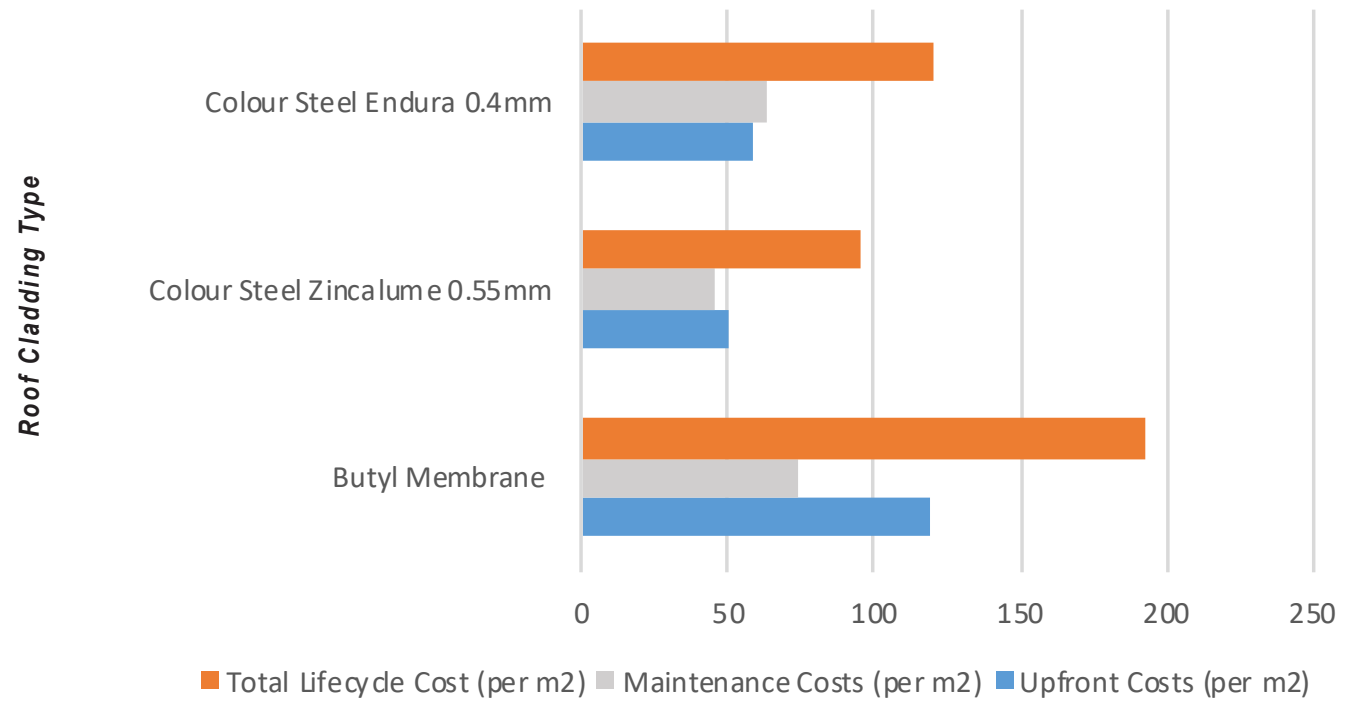

Cost in Dollars $(\$$ 


\section{Material Analysis}

Overall Costs and Lifespan

New Zealand's Building Code clause B2 requires all building materials to meet a durability requirement. These requirements include three levels of durability, lasting no less than 5,15 or 50 years. No product should deteriorate before 5 years, with structural elements requiring a durability of 50 years (Ministry of Business, Innovation and Employment, 2019). B2 was used to make assumptions for the lifecycle costs and life spans involved with materials used within the housing typologies designed. All designs analyse costs over a 50-year life span, implemented within the material analysis graphs. Aluminium and timber joinery require replacement at 35 years and PVC at 22 years (Howard, Burgess, \& Lim, 2007). It is crucial a next generation architect can comprehend the full value of the materials they select.

The first four graphs in figures 4.26 - 4.29 apply data from BRANZ in Fung (2010), BRANZ data in Page (2015) and Brudson (2017), for the average lifespan and costs of exterior wall and roof cladding in normal climatic conditions. This set of data informs the next set of graphs (figures 4.30 - 4.33) where selected and potential materials used within designs, are analysed using manufacturers lifespans and costing from QV cost database.

Findings:

- Unpainted steel, Zincalume is the cheapest material for both wall and roof claddings, and has the lowest lifespan of 25 years. Zincalume was used in previous design phases however will now be substituted with precoated Colour Steel Endura.

- Precoated corrugated steel such as Endura is the most economical material overall, followed by painted plywood and batten cladding.

- Weatherboards contain high maintenance costs; repainting is required every 10 years.

- Butyl roofing has a low lifespan of 25 years and has the highest overall costs. Upfront costs are twice those of steel roofing.

- Most materials have a minimum lifespan of 50 years

- The longest lasting materials are clay, concrete bricks and tiles at 70 years, Precast concrete is the longest lasting with lifespans up to 100 years.

- Manufacturers specifications state Linea weather board and Colour Steel will require its first repaint after $15-18$ years then every 10 years after.

- Staining a product requires high levels of maintenace; staining is required every 5 years. 
"Decisions are usually not made soley on cost. Appearance is also important to the owner. The more expensive, longer-lasting products usually maintain their appearance better than cheaper materials." (Page, 2015, p. 72) 
House 4.1

Interior Materials and Cost Implications

\section{Interior Option 1}

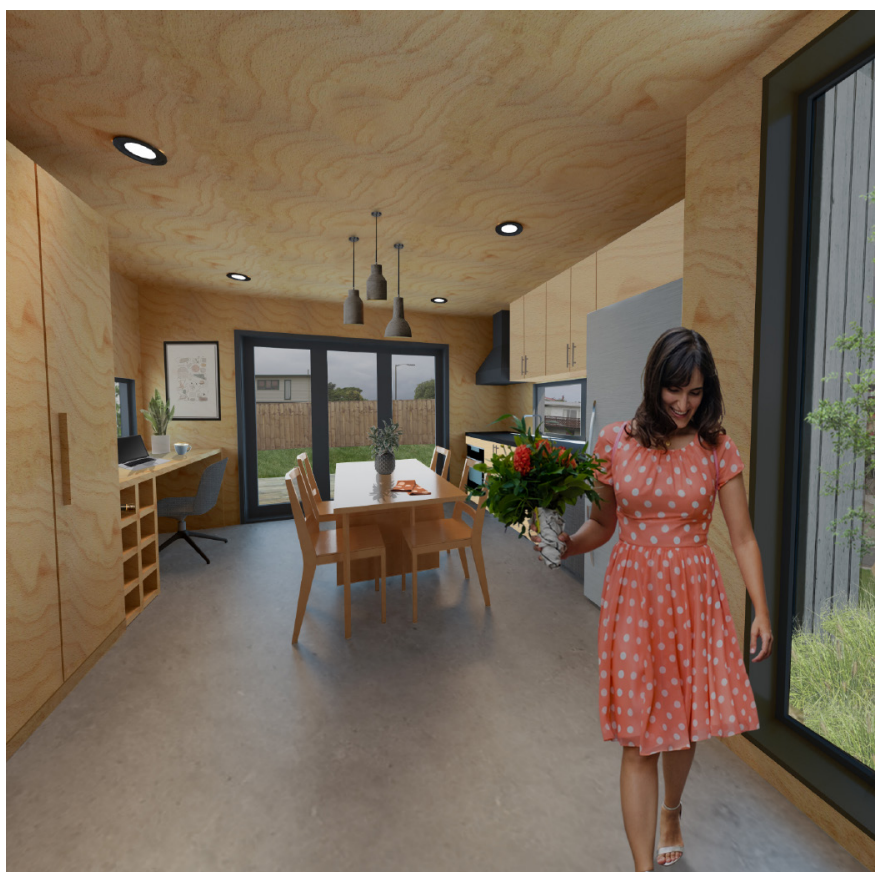

Figure 4.34 Full raw plywood interior with polished concrete flooring.

\section{Interior Option 2}

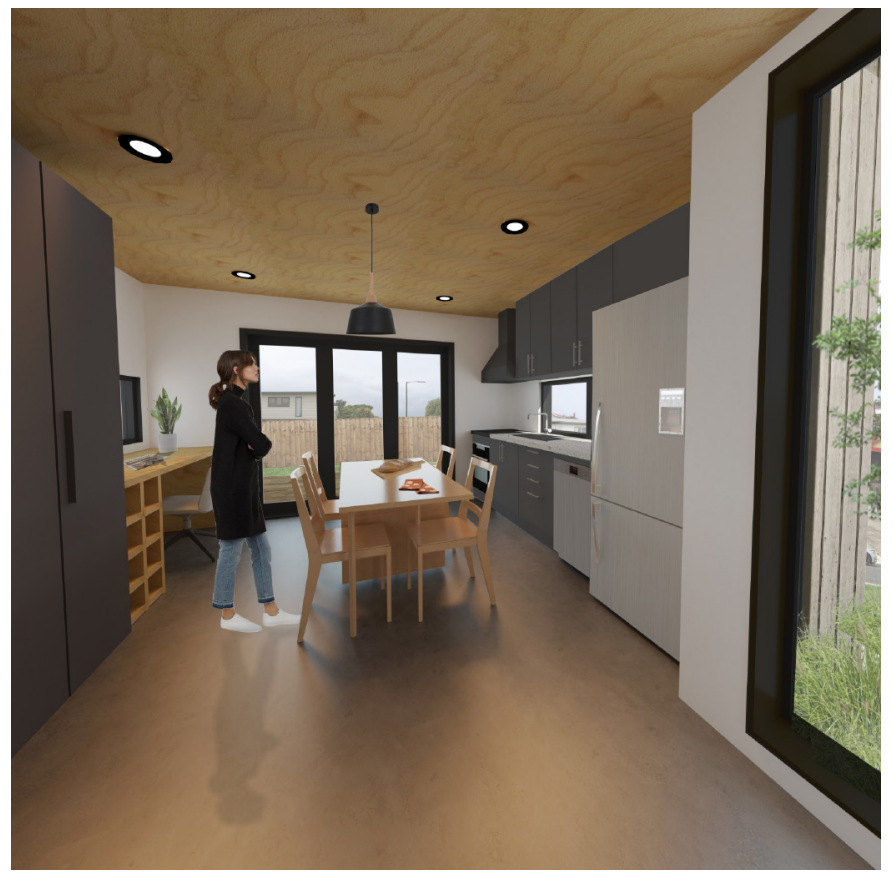

Figure 4.35 Hybrid plywood and gib interior with polished concrete flooring

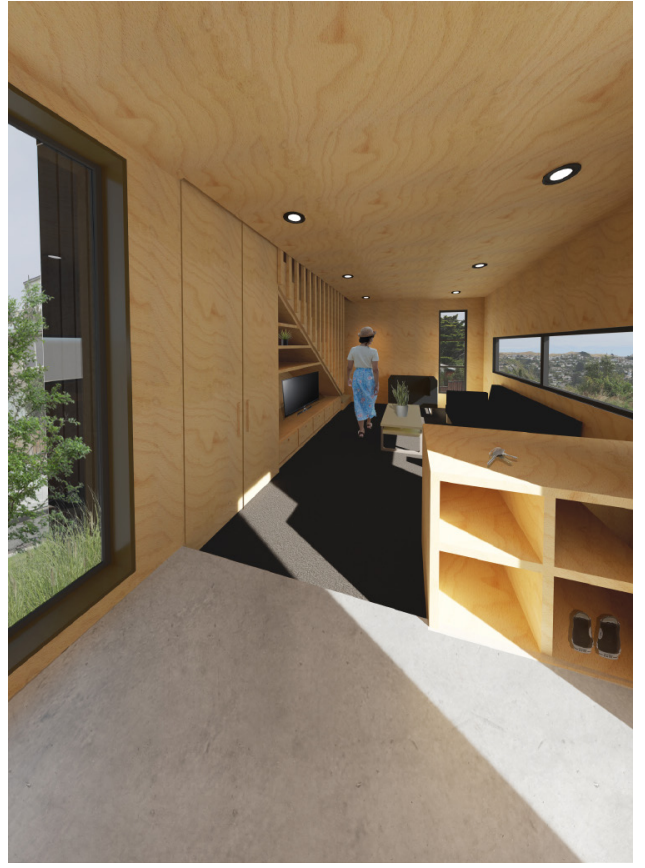

Cost per $\mathrm{m}^{2}=\$ 315.80$

Total cost $=\$ 11,020.80$

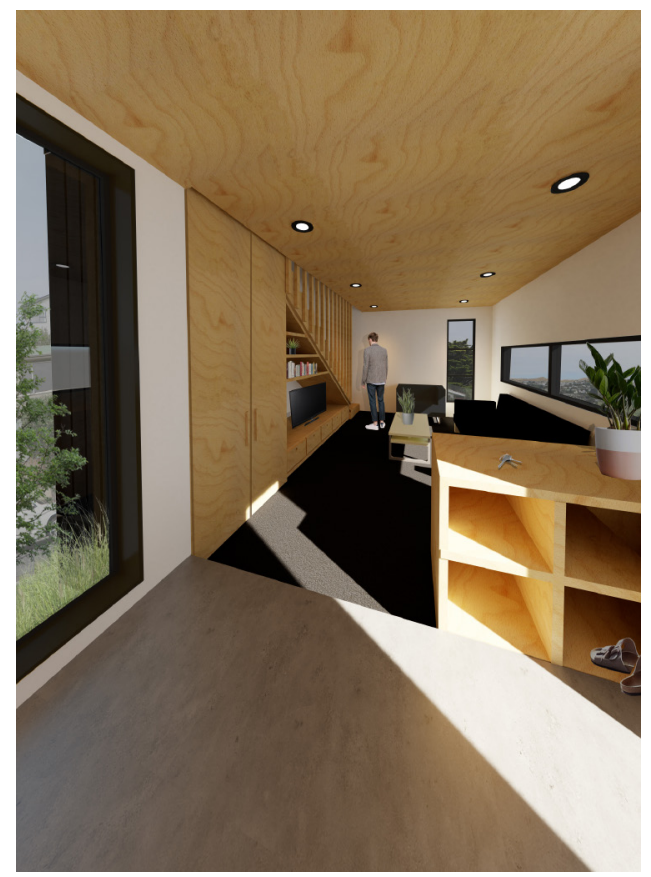

Total cost per $\mathrm{m}^{2}=\$ 298.90$

Total cost $=\$ 10,623.90$ 


\section{Interior Option 3}

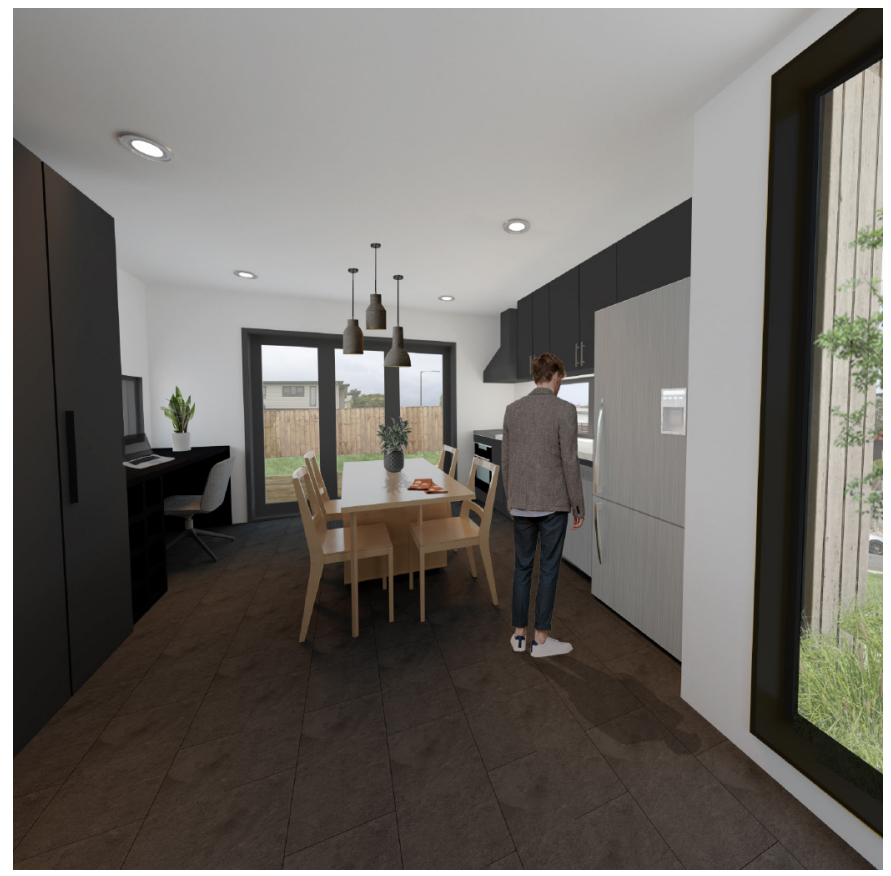

Figure 4.36 Gib interior with tiled flooring

\section{Interior Option 4}

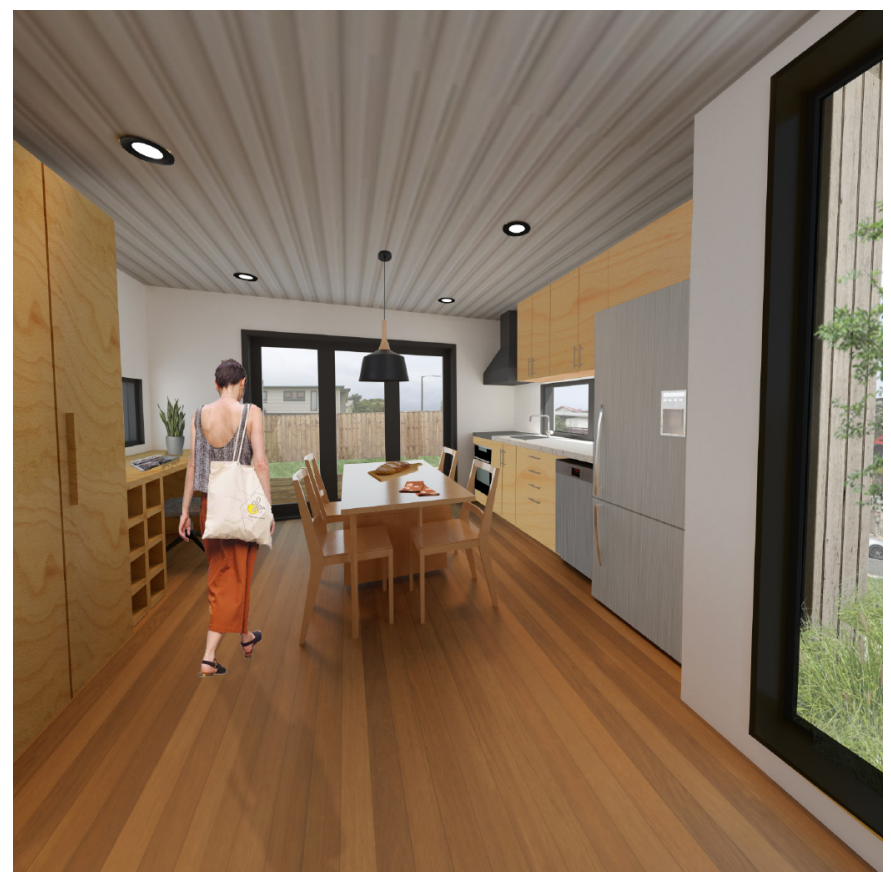

Figure 4.37 Hybrid Gib and Zincalume interior with timber flooring.

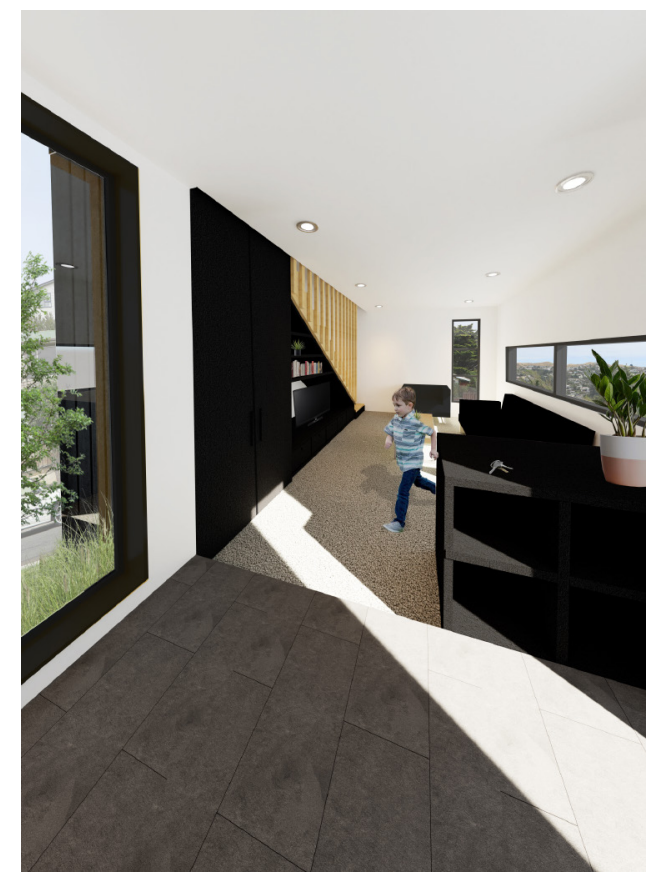

Total cost per $\mathrm{m}^{2}=\$ 333$

Total cost $=\$ 10,765$

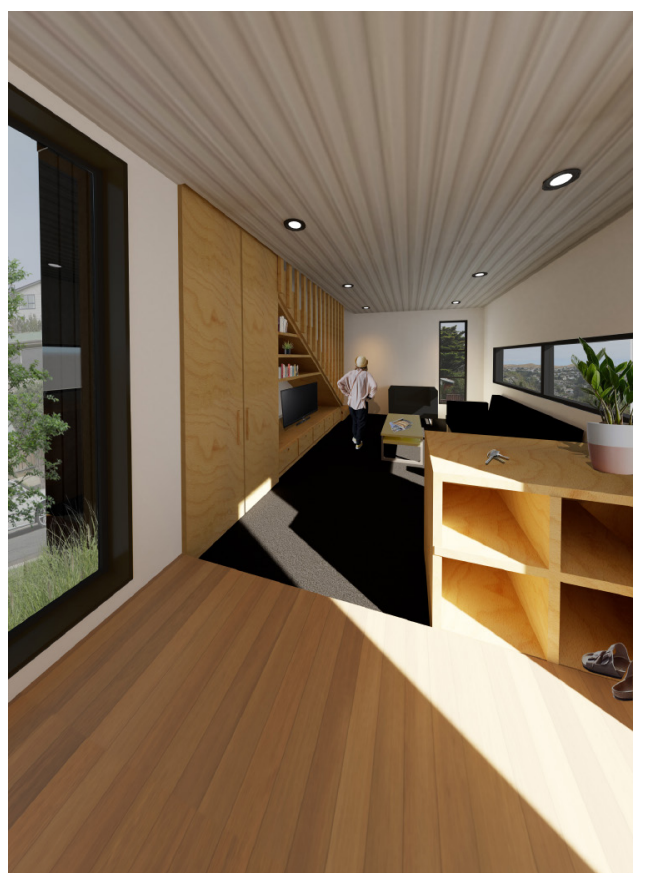

Total cost per $\mathrm{m}^{2}=\$ 332.10$

Total cost $=\$ 10,591 \cdot 10$ 


\section{House 4.1.1}

Interior Materials and Cost Implications

The aim of this exercise was to gain an understanding of aesthetic appeal and cost implications within the ground floor of house 4.1. The exercise explored four different variations in the kitchen and living spaces including; Option 1 a full plywood interior with a polished concrete floor, Option 2 hybrid plywood and gib interior with a polished concrete floor, option 3 gib interior with tiled flooring and a gib. Option 4 Zincalume hybrid with timber flooring. A material change of carpet is used in the living are, indicating a space and level change. All costing was estimated through the use of BIM through Revit.

Findings:

- Tiled and timber flooring costs more than polished concrete. Timber is the highest cost out of the three

- Exposed concrete holds thermal mass properties for passive solar architecture

- Plywood as an interior lining costs more than gib stopped and finished

- Zincalume is the cheapest option for a ceiling finish

- Allowing for a small pallet of interior fitouts to choose from, ensures the house is seen as an architectural product that caters to a range of clients and their preferred aethetics.

Overall there is a very small price difference between Option 2,3 and 4. The reason Option 1 is the most expensive is the use of plywood on both the floors and walls instead of a hybrid combination. 


\section{Exterior Materials and Cost Implications}

House 4.1.1

\section{Exterior Option 1}

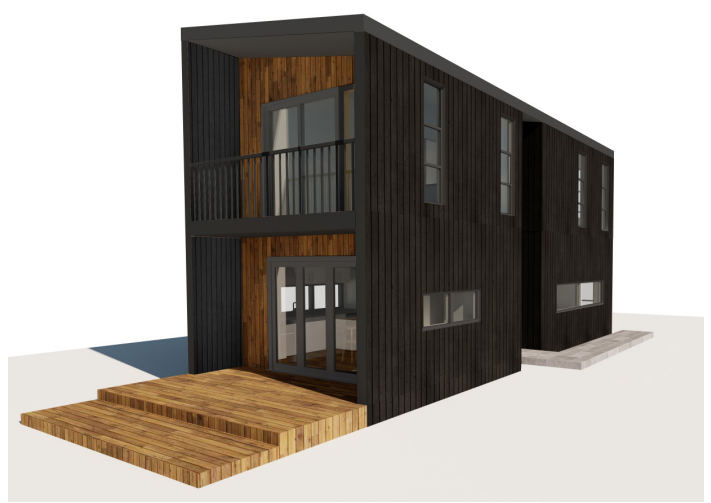

$\$ 62,048$

$\$ 27,007$

$\$ 89,055$

Maintenance Requirements:

- 4 repaints on Linea Weatherboard, $\$ 45$ per $\mathrm{m}^{2}$

- 9 cedar restains, $\$ 28.40$ per $\mathrm{m}^{2}$

Figure 4.38 Linea weatherboard and cedar

\section{Exterior Option 2}

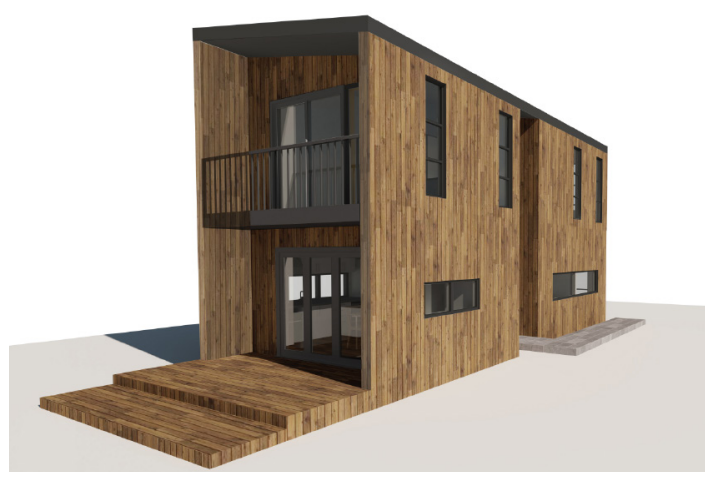

$\$ 69,629$

$\$ 37,062$

$\$ 106,691$

Maintenance Requirements:

- 9 cedar restains, $\$ 28.40$ per $\mathrm{m}^{2}$

Figure 4.39 Cedar weatherboard 


\section{Exterior Option 3}

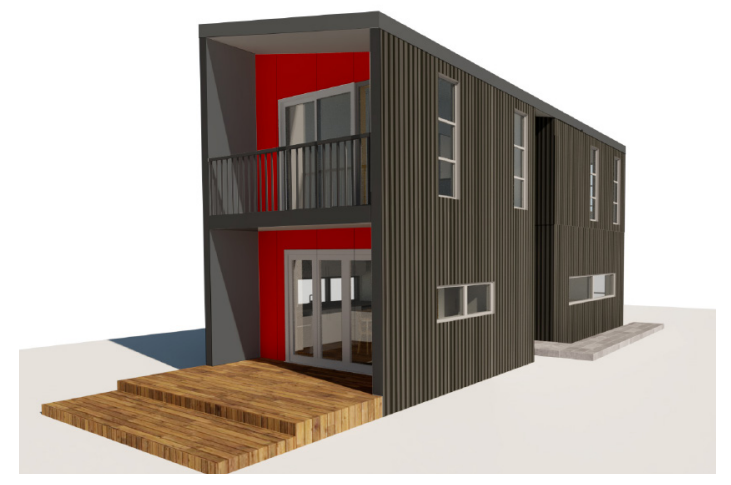

$\$ 39,192$

$\$ 11,251$

$\$ 50,443$

Maintenance Requirements:

- 3 repaints of Coloursteel, $\$ 20.90$ per $\mathrm{m}^{2}$

- 4 repaints of Titan Facade Panel, $\$ 45$ per $\mathrm{m}^{2}$

Figure 4.40 Colour Steel and Titan Board

\section{Exterior Option 4}

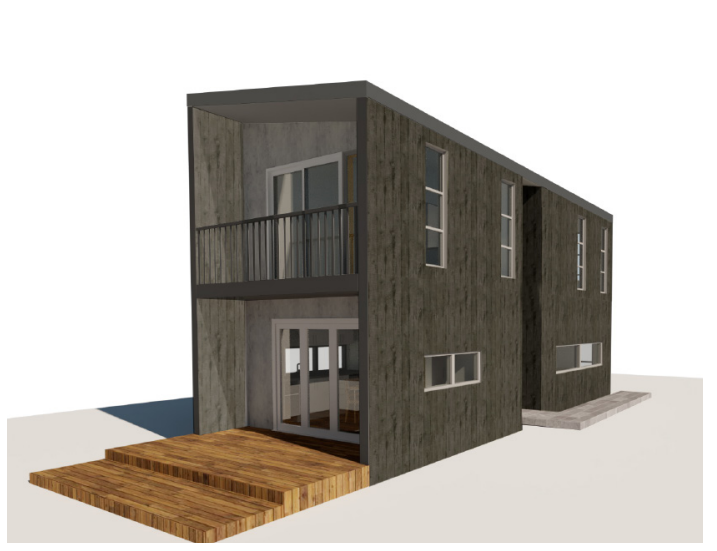

Figure 4.41 Embossed and painted insulated concrete

\section{Exterior Option 5}

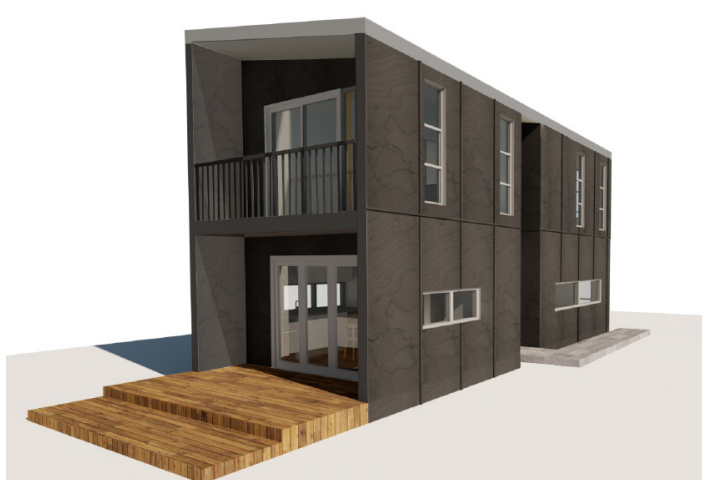

$\$ 45,472$

$\$ 24,012$

$\$ 69,484$

Maintenance Requirements:

- 9 restains on plywood, $\$ 18.40$ per $\mathrm{m}^{2}$

Figure 4.42 Board and batten plywood 


\section{Exterior Materials and Cost Implications}

House 4.1.1

This rendering exercise was aimed at understanding the value of the cost implications and aesthetics of five cladding options on house 4.1. Architectural products typically have a number of cladding options per design for clients to select. Cost implications are understood through the upfront costs, lifecycle costs including repainting or staining over 50 years, and finally the combined cost. All products selected for this exercise have a life span of at least 50 years.

Findings:

- Full cedar cladding is the most expensive and requires a higher level of maintenance, with staining required every 5 years.

- Embossed insulated concrete panels have the highest upfront costs, however, have lower maintenance costs and requirements with a longer lifespan than all materials tested.

- Reducing the area of cedar to $12 \mathrm{~m}^{2}$ has significantly reduced costs by $\$ 7000$ with the use of Linea Weatherboard on the remaining external wall area.

- Plywood with battens is the second most economical option however requires twice the maintenance with staining required every 5 years. Painting the plywood would halve the maintenance requirements; to 10 years, although gives a different aesthetic.

- Coloursteel is the most economical cladding, requiring minimal maintenance. A $12 \mathrm{~m}^{2}$ area of Titan Facade Panel is used for aesthetic purposes. 


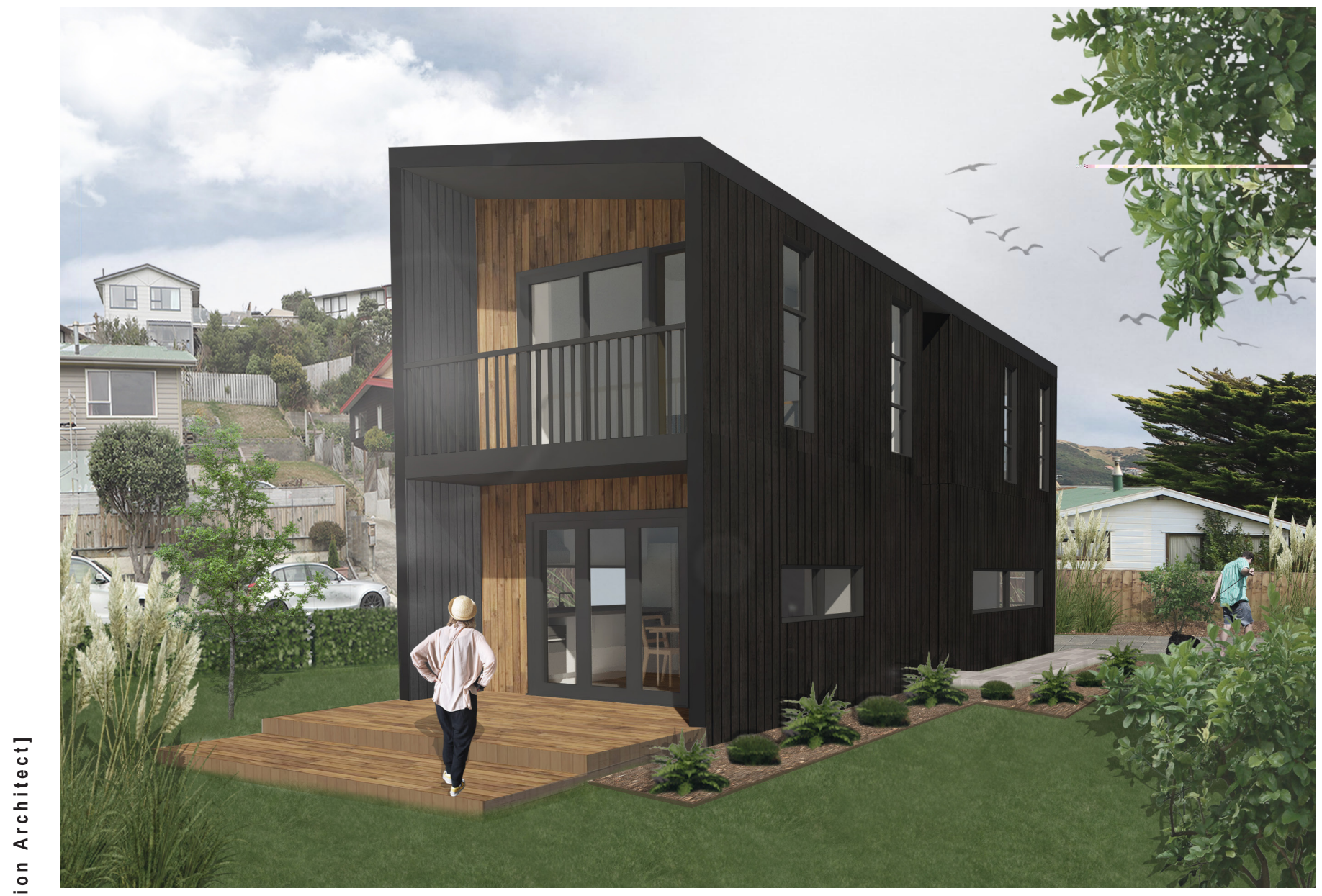

Figure 4.43 House 4.1 Exterior

\section{House 4.1}

House 4.1.1 consists of a timber framed construction according to NZS3604 and is a 2 bedroom 1 bathroom home. The weaknesses in the plan for House 3.1.1 in Phase 3 Included: habitation within the living space, stair tread heights and landscaping.

Developments:

- Laundry located under the stair cavity to create more floor space.

- Joinery designed for the stairs including storage, shelving and timber panelling.

- Joinery in bedrooms.

- Floor area increased allowing all spaces to function ergonomically and efficiently.

- Step down into the living room module to break spaces up.

- Basic landscaping.

- Stair tread issue resolved with curving stairs and a new landing. 


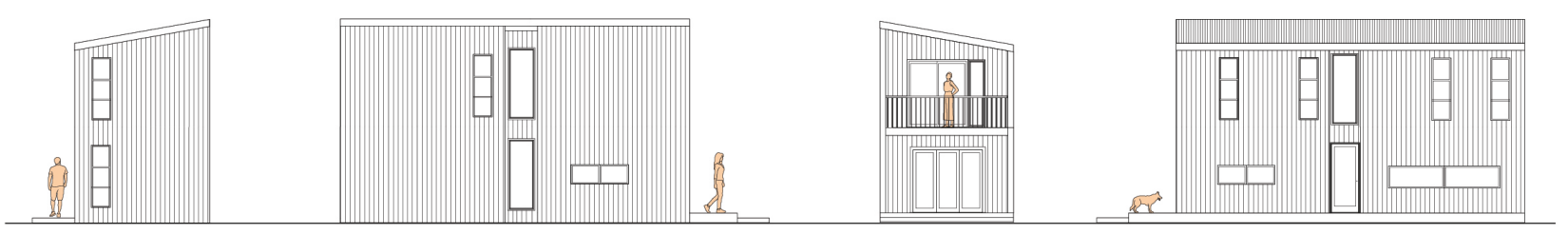

Figure 4.44 Elevations

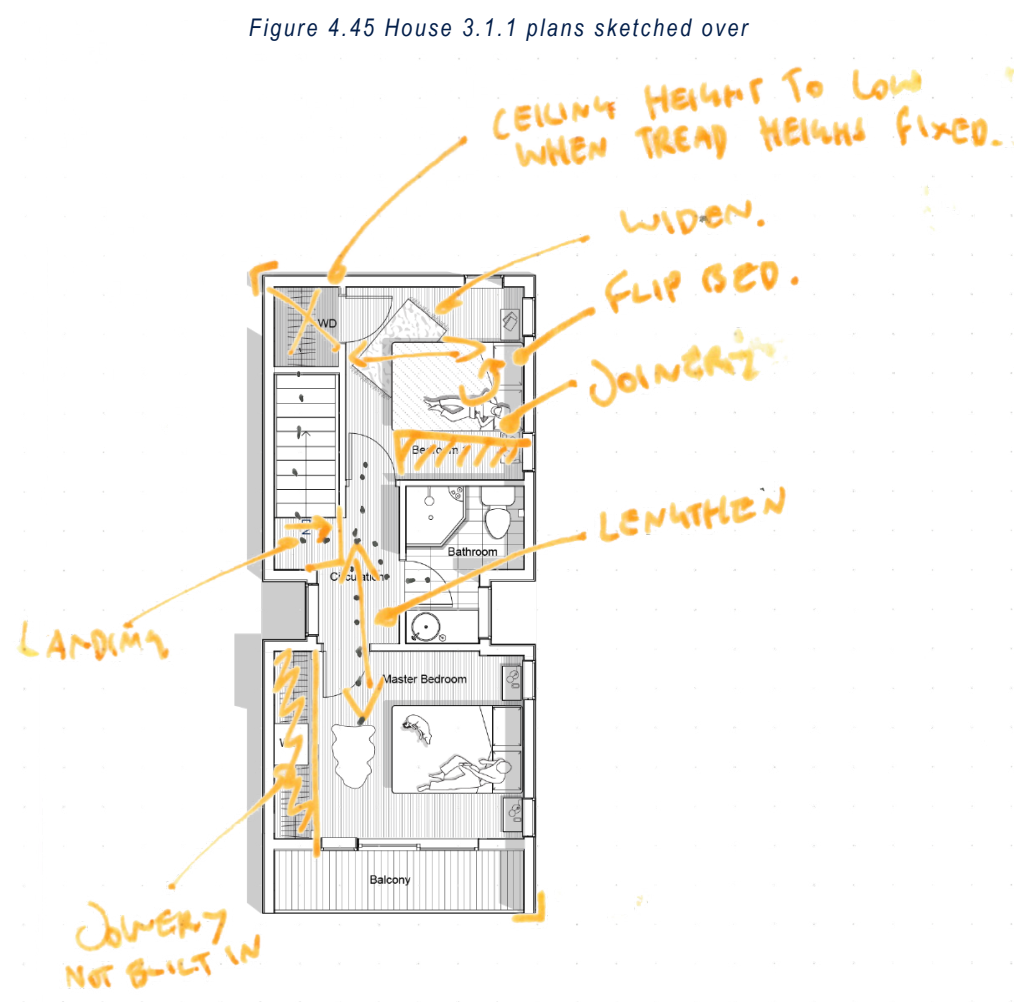

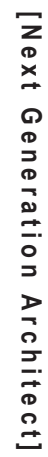

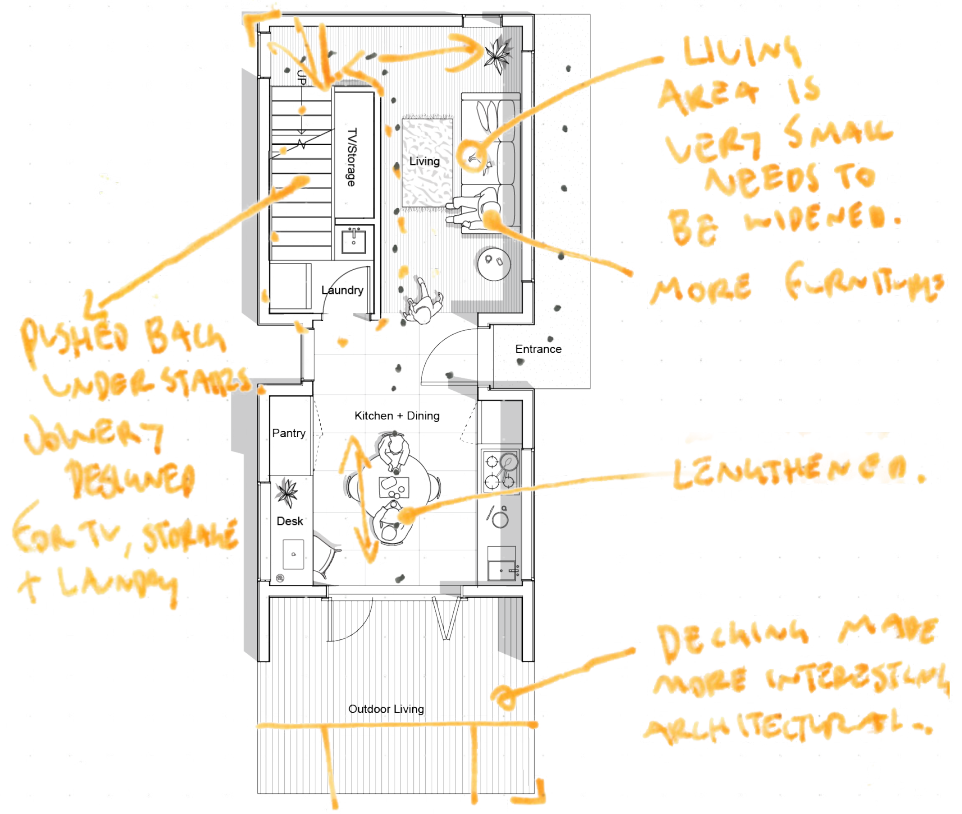

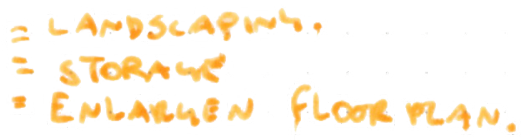


House 4.1

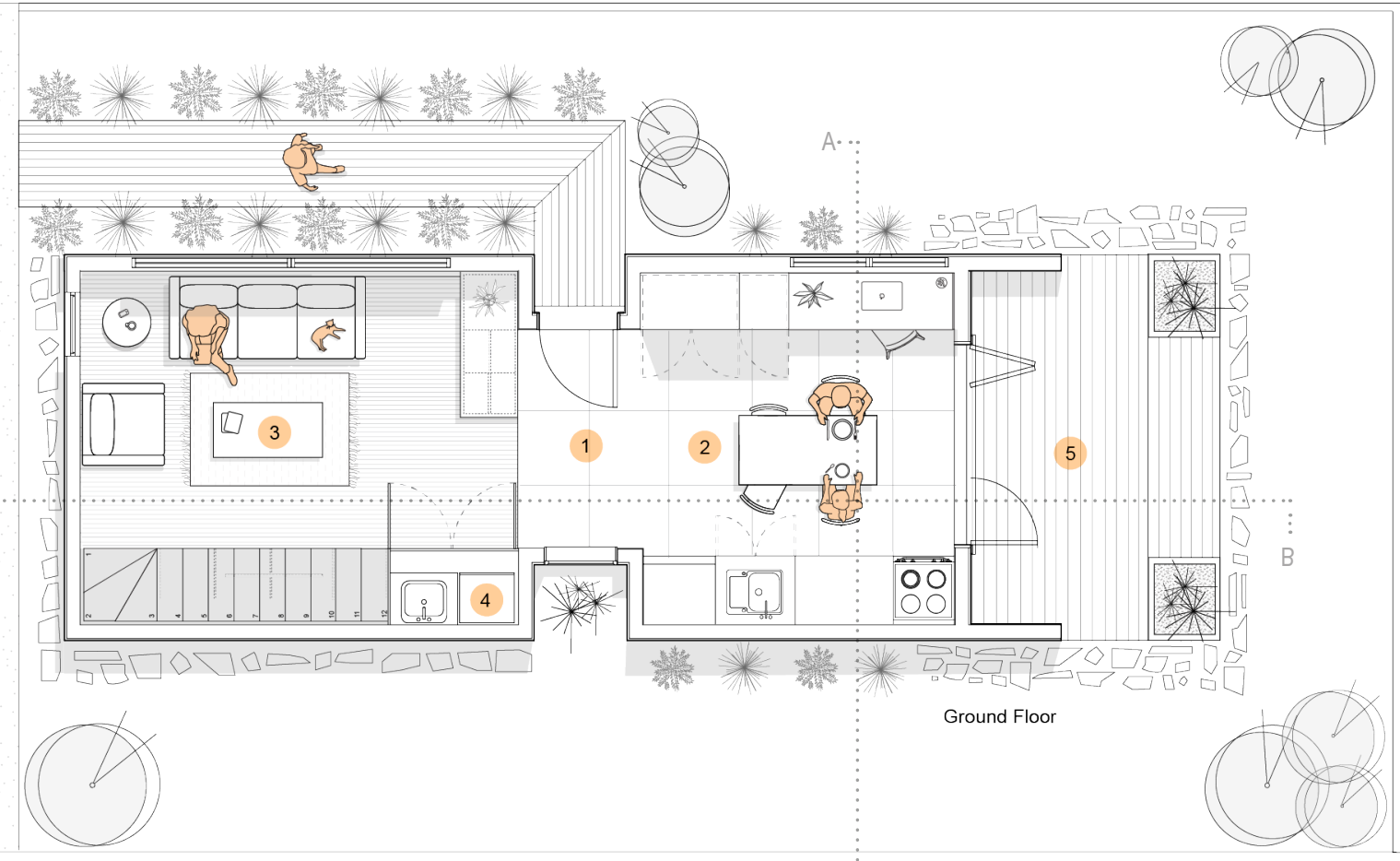

Figure 4.46 Ground Floor Plan

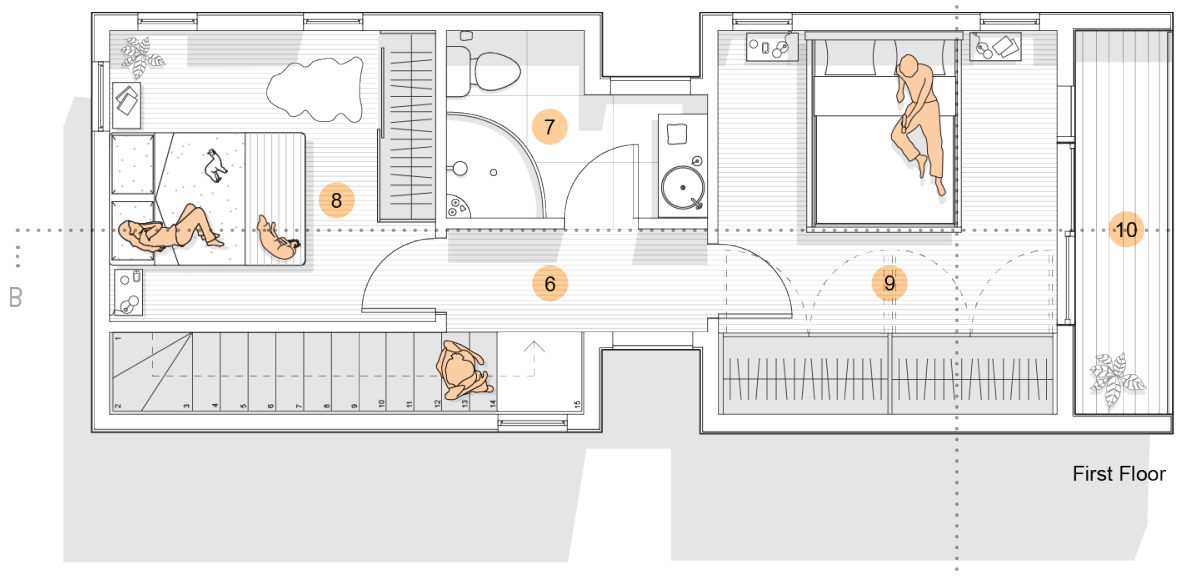




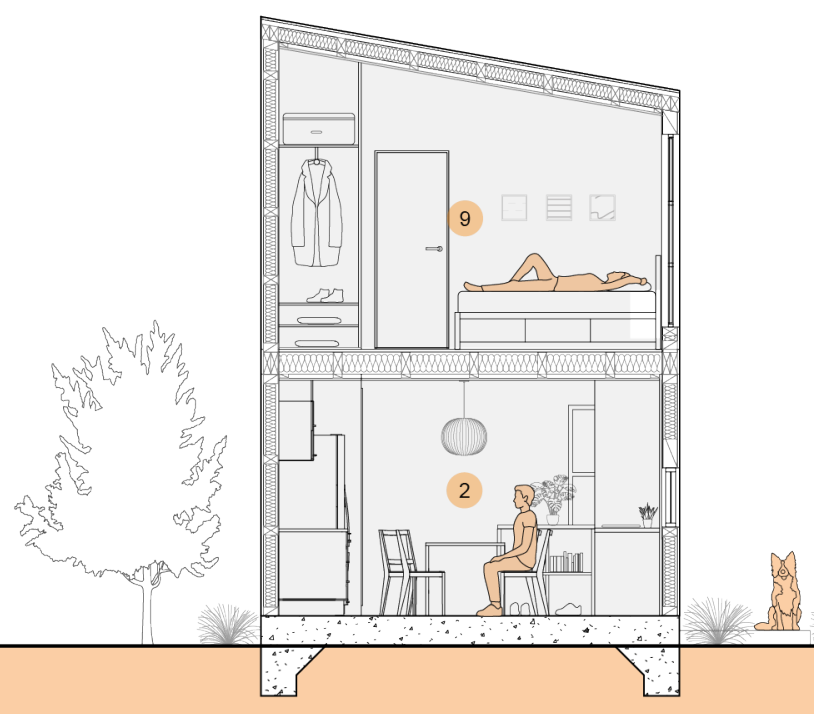

Figure 4.48 Section $A-A$

\begin{tabular}{l}
$z$ \\
0 \\
0 \\
$x$ \\
0 \\
0 \\
0 \\
0 \\
0 \\
0 \\
0 \\
\hline 0 \\
0 \\
$D$ \\
0 \\
0 \\
$D$ \\
0 \\
0 \\
$\Xi$
\end{tabular} 
$93 m^{2}$

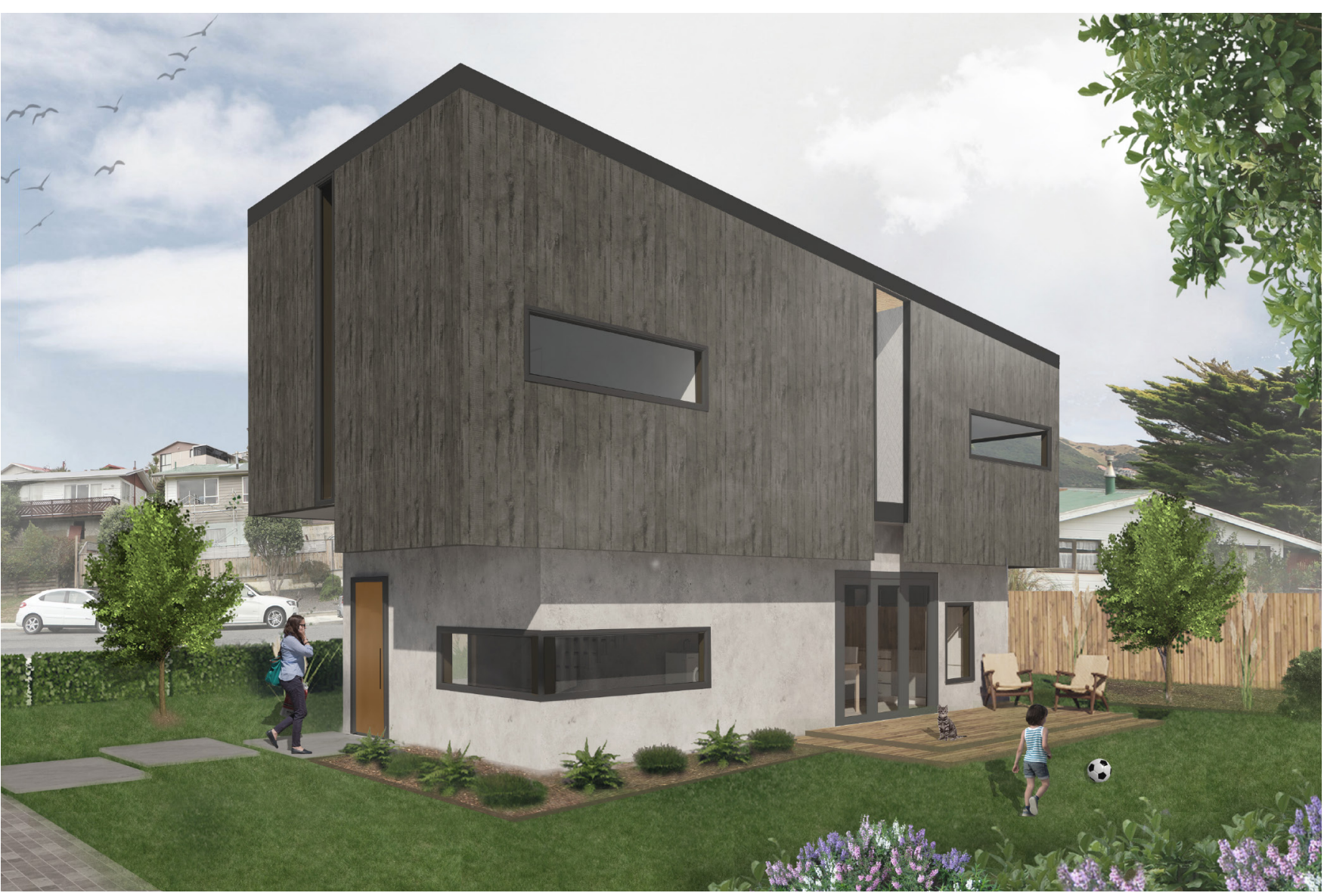

Figure 4.50 House 4.2 Exterior

\section{House 4.2}

House 4.2 is a 3 bedroom 1 bathroom home, designed with a concrete construction and a light roof framed with Posi-Struts. Achieving longer spans than typical timber framing. The floor plan has been rearranged and the purpose designed furniture creates an efficient use of space.

Developments:

- The circulation space on first floor doubles as a storage and study area.

- Expanded floor area ensuring functionality.

- Plumbing walls aligned with the bathroom moved to the south-west corner.

- Bedrooms located along the northern wall.

- Laundry and storage spaces located under the stairs.

- Joinery behind the bed in the master bedroom allowing more space next to the bed.

- Stair joinery with panelling duplicated from house 4.1.

- Purpose designed couch to fit the living area with additional storage at the base.

- Shelving unit used as a divide between living and dining spaces. 

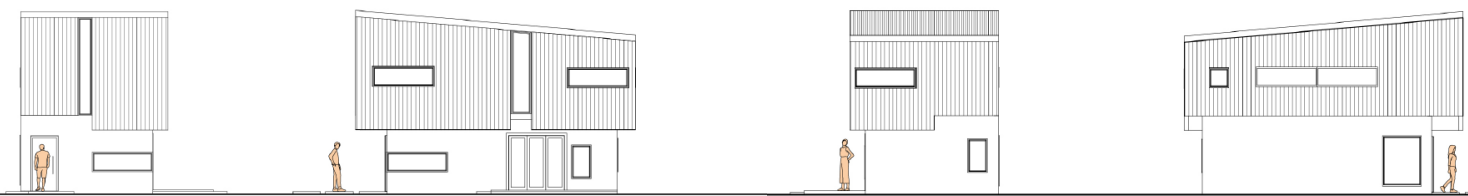

Figure 4.52 Elevations

Figure 4.51 House 3.2.1 plans sketched over
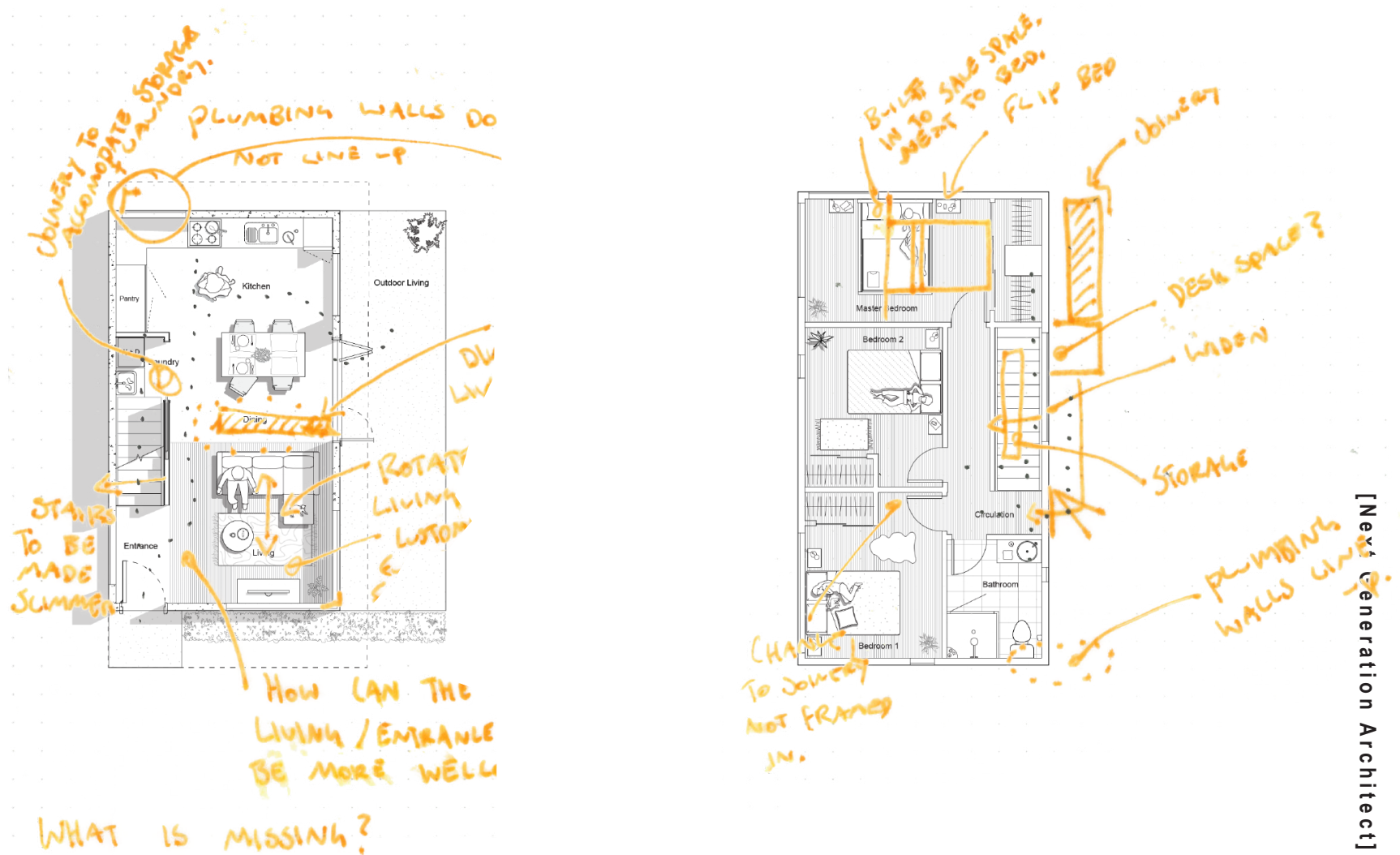

WHAT IS MISSINH?

- Dasn space

- Storane

$\rightarrow$ LINE UP PLOMBING WALLS.

- LANPSLAPING.

- Fiy mistare in stairs.

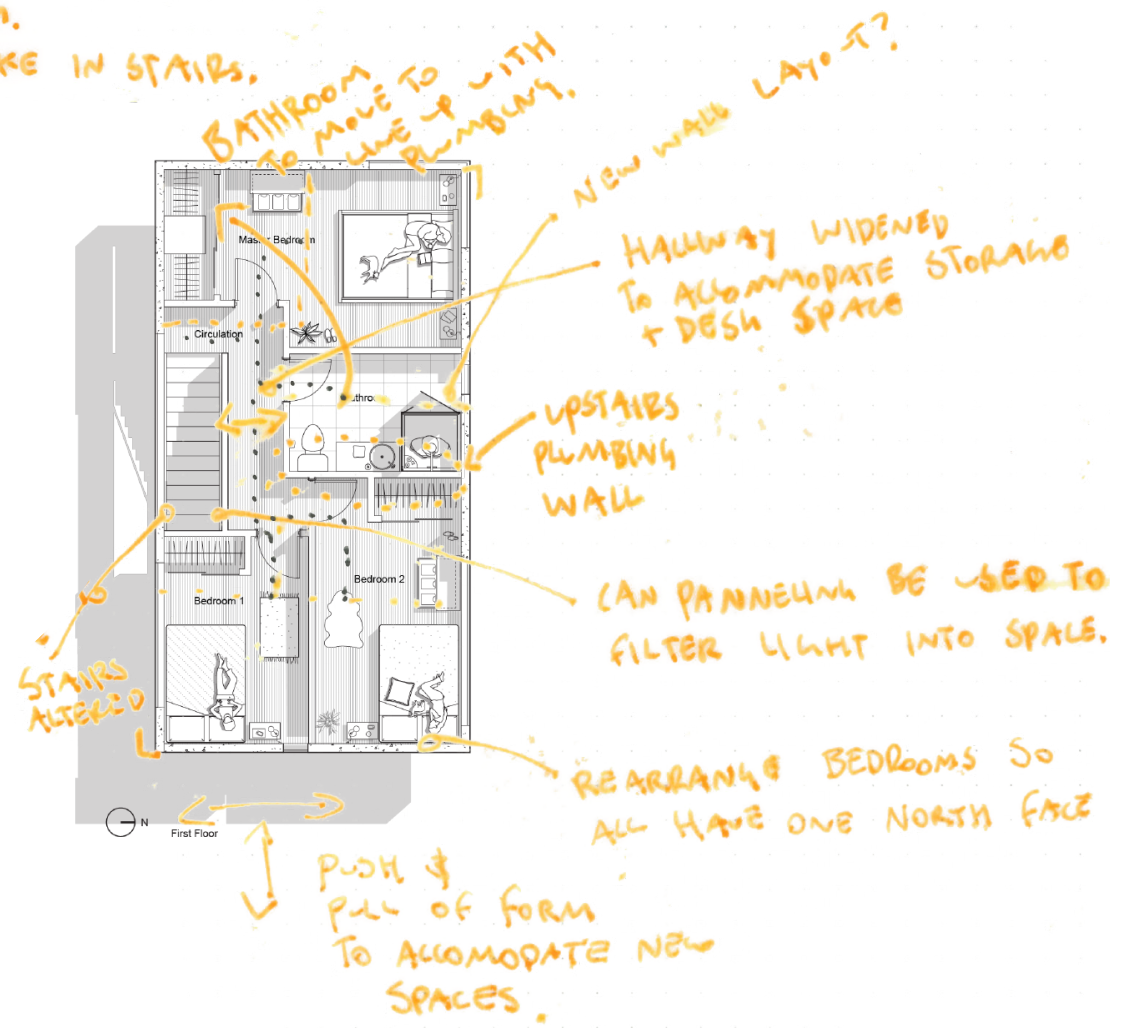




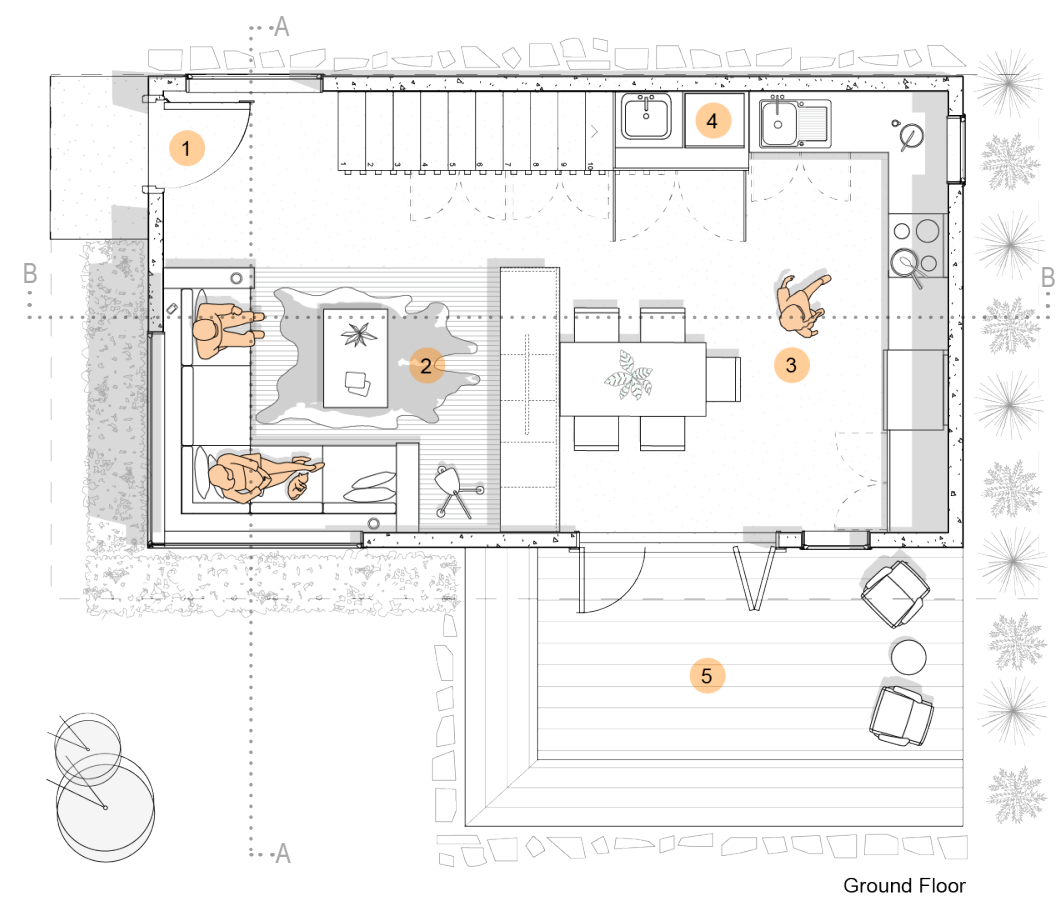

Figure 4.53 Ground Floor

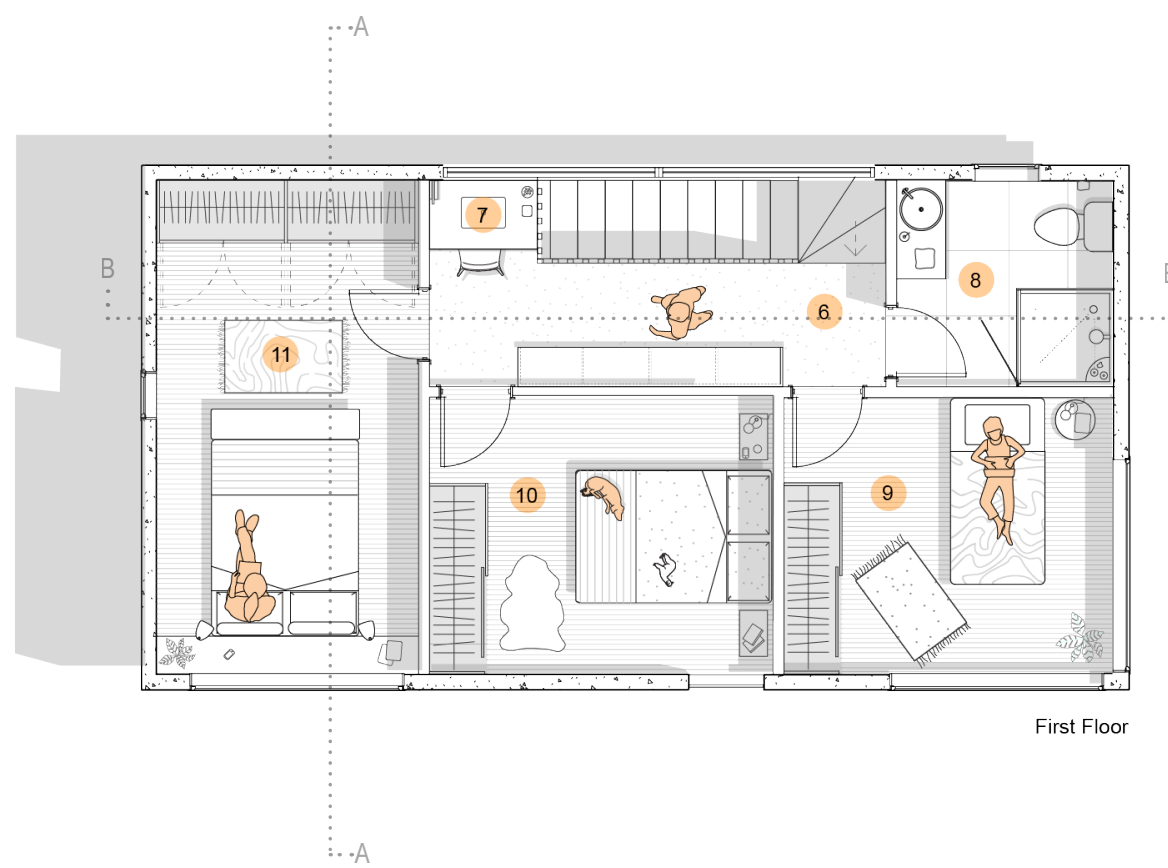

Figure 4.54 First floor

Key:

1. Entrance

2. Kitchen + Dining

3. Living

4. Laundry

5. Outdoor Living

6. Circulation

7. Study Area

8. Bathroom

9. Bedroom 1

10. Bedroom 2

11. Master Bedroom 


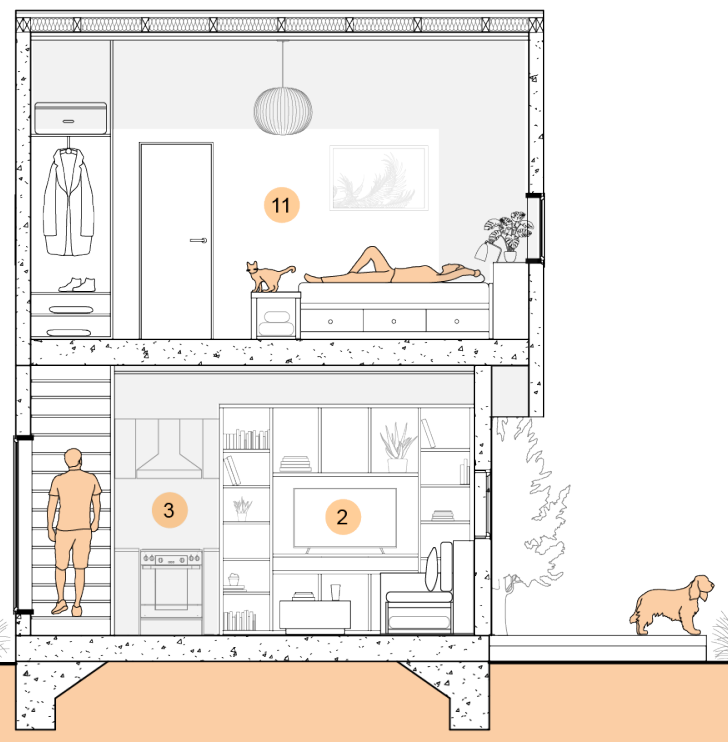

Figure 4.55 Section $A-A$

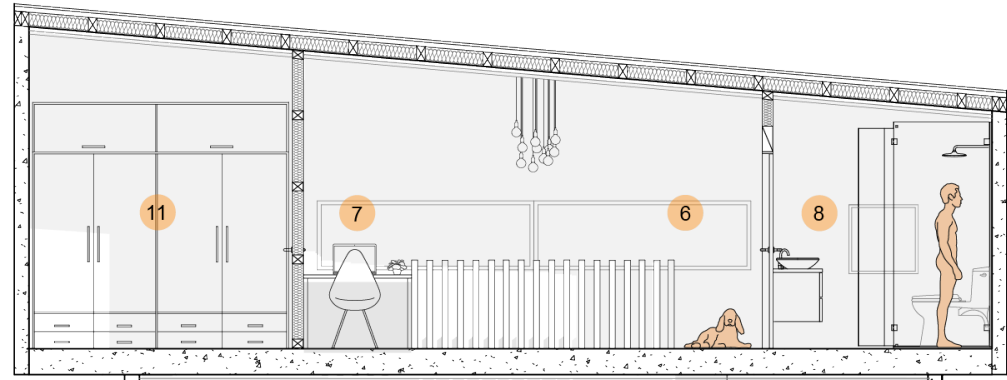




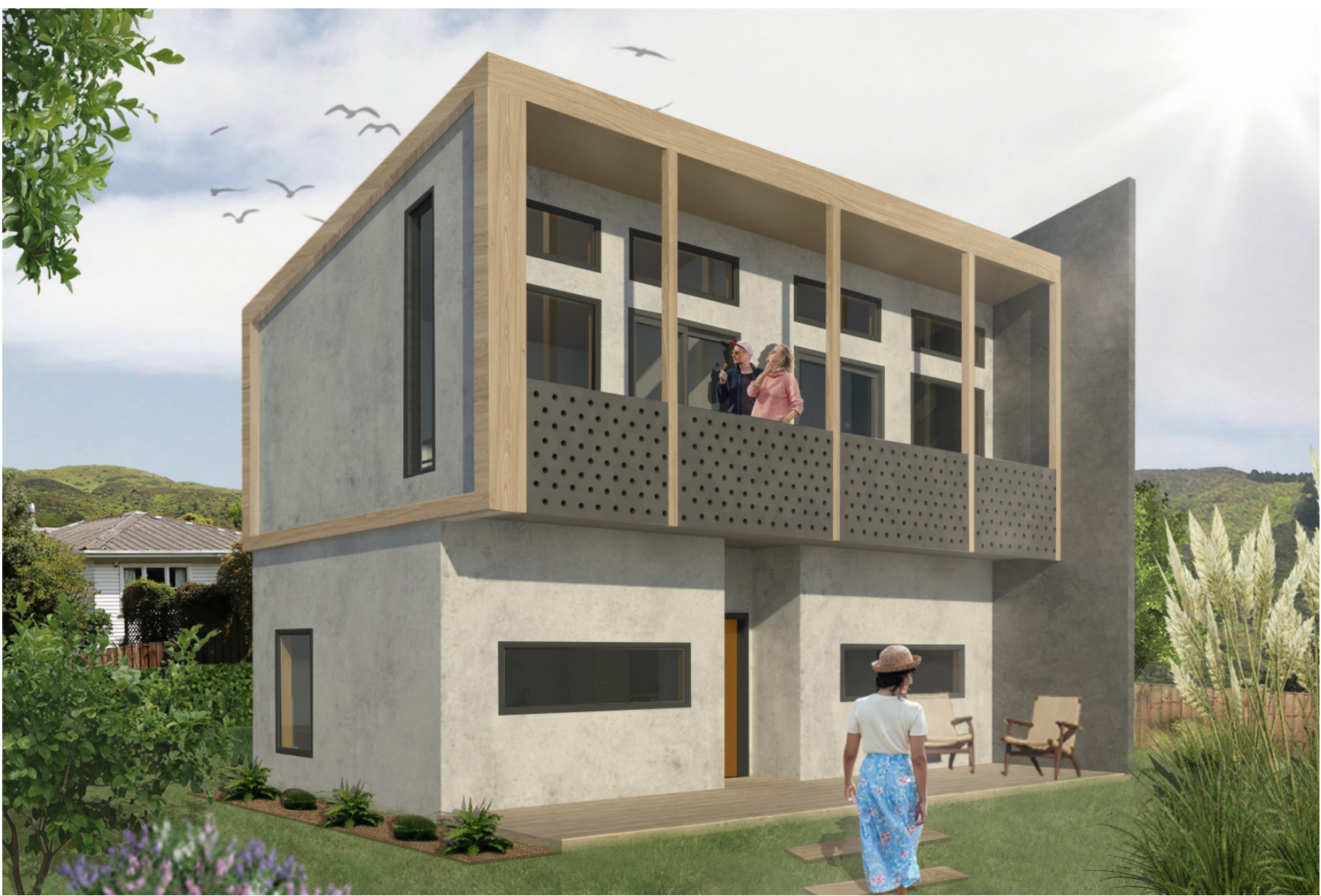

Figure 4.57 House 4.3 Exterior

\section{House 4.3}

House 4.3 contains 2 bedrooms and 1 bathroom and is constructed of precast concrete panels with a light Posi-strut framed roof. The initial floor plan contained weaknesses with the size of the living area and balcony. These were extended to create comfortable spaces.

Developments:

- Seed design of stair joinery replicated with perforated steel panelling reflected from the exterior, allowing space under stairs to be utilised as storage.

- Daybed, desk and additional bench and storage in kitchen.

- Balcony widened to allow comfortable habitation with furniture.

- Widened living area and kitchen.

- Stair tread amended and first floor rearranged to accommodate stair height.

- Joinery designed in bedrooms. 


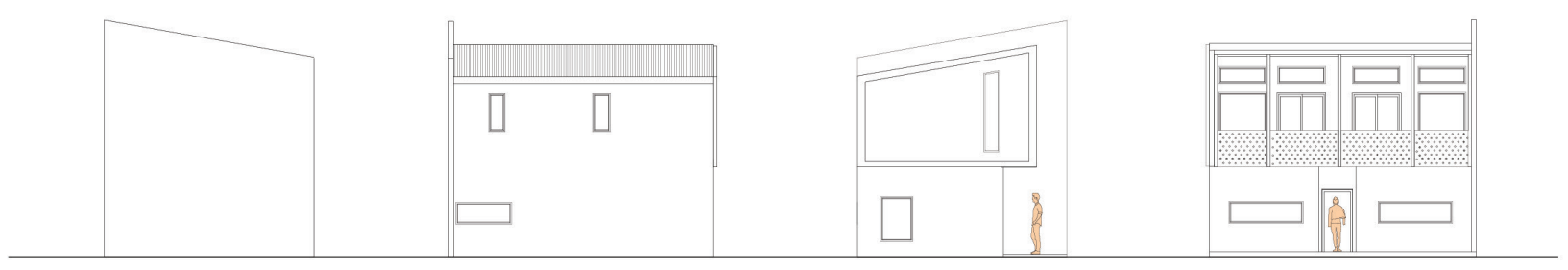

Figure 4.58 Elevations

Figure 4.59 House 3.3.1 plans sketched over

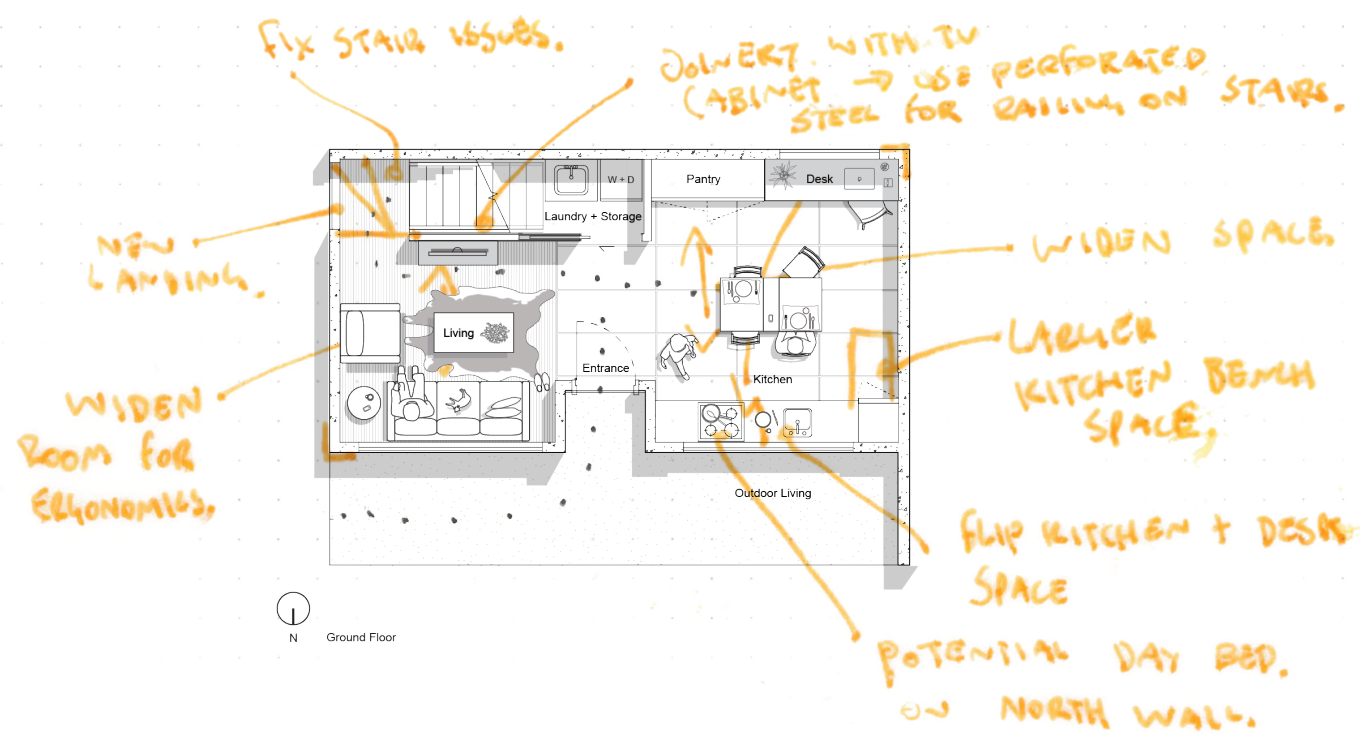

\begin{tabular}{l}
$z$ \\
0 \\
$x$ \\
0 \\
0 \\
0 \\
0 \\
0 \\
0 \\
0 \\
0 \\
0 \\
0 \\
$D$ \\
0 \\
0 \\
\hline \\
\hline 0 \\
0 \\
0
\end{tabular}

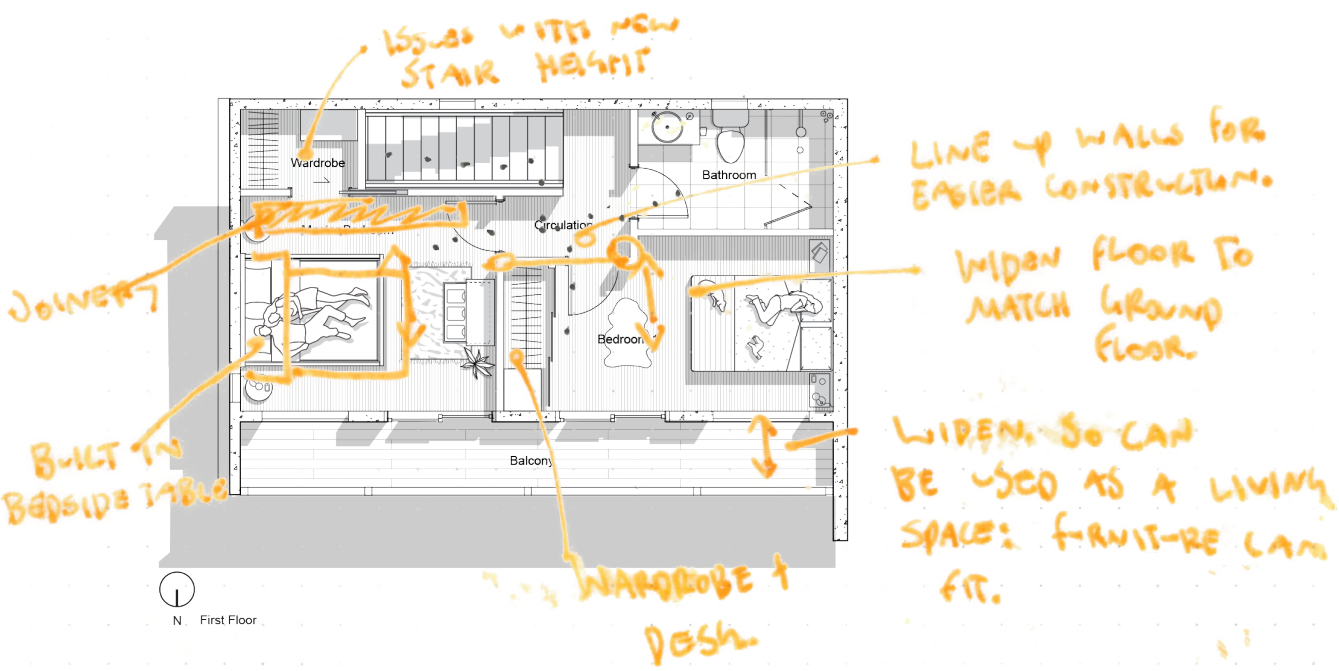


House 4.3

Plans + Sections
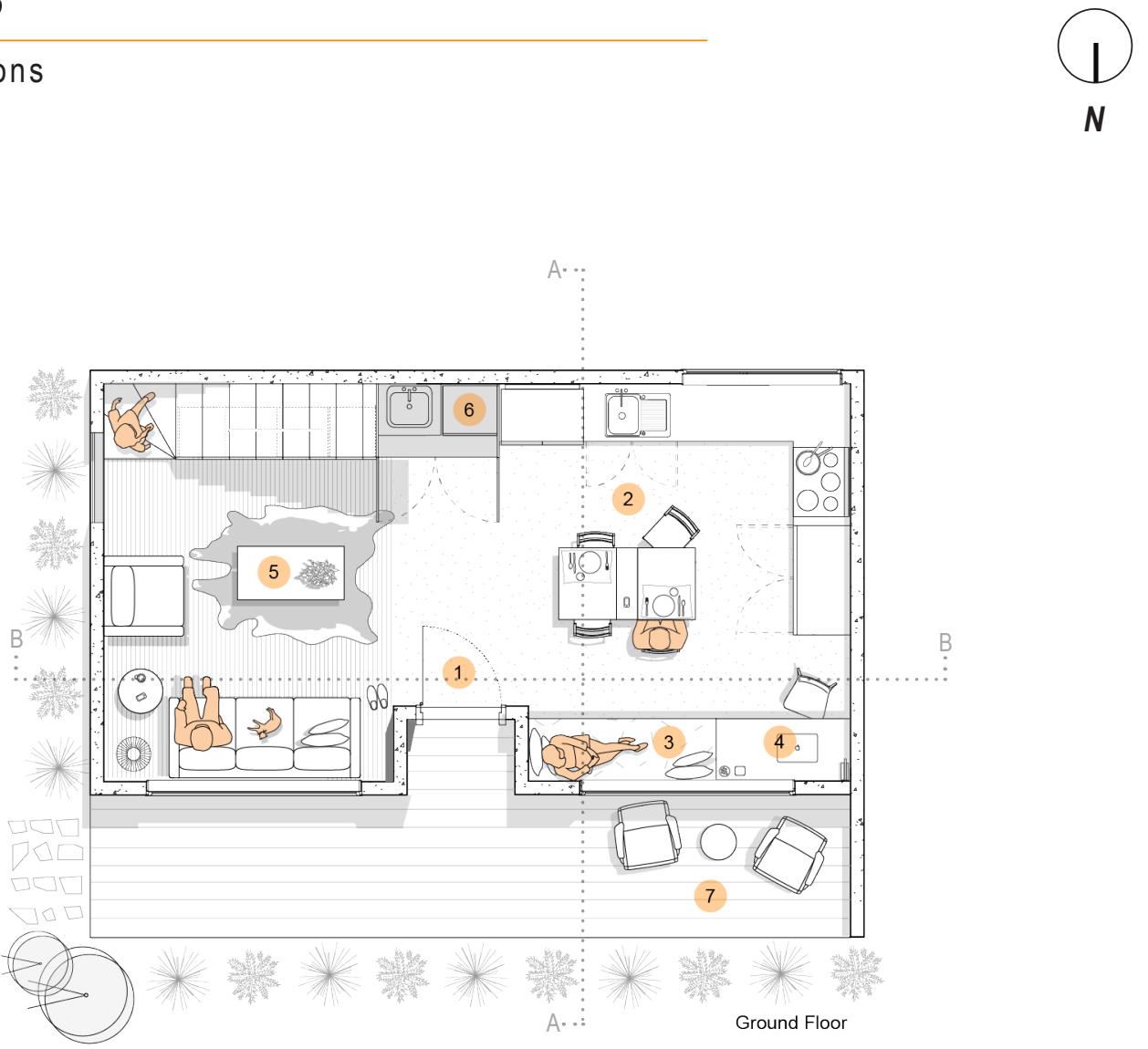

Figure 4.60 Ground Floor

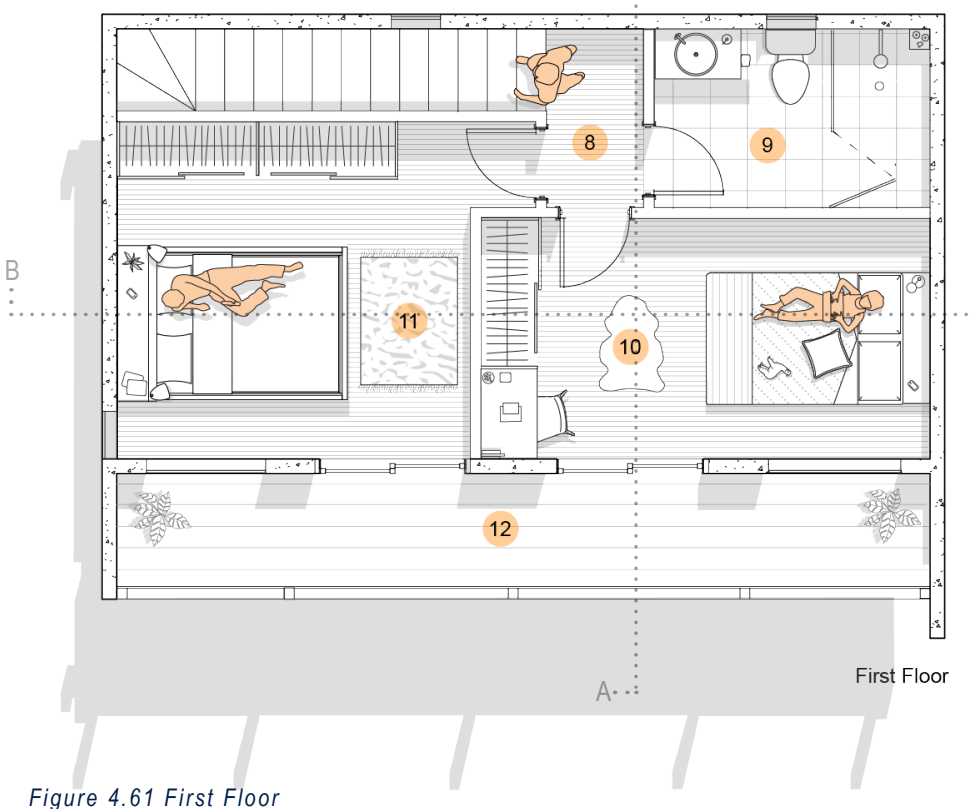

Key:

1. Entrance

2. Kitchen + Dining

3. Daybed

4. Desk

5. Living

6. Laundry

7. Outdoor Living

8. Circulation

9. Bathroom

10. Bedroom 1

11. Master Bedroom

12. Balcony 
Figure 4.62 Section A-A

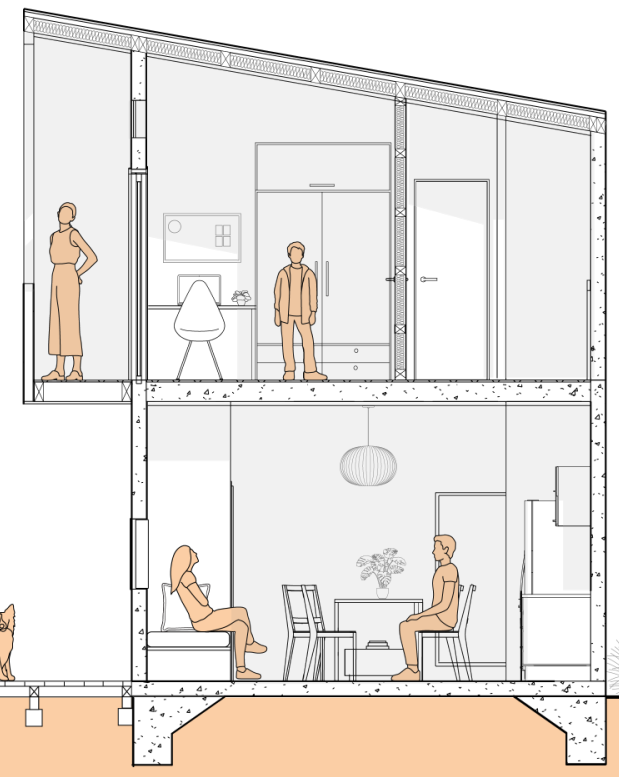




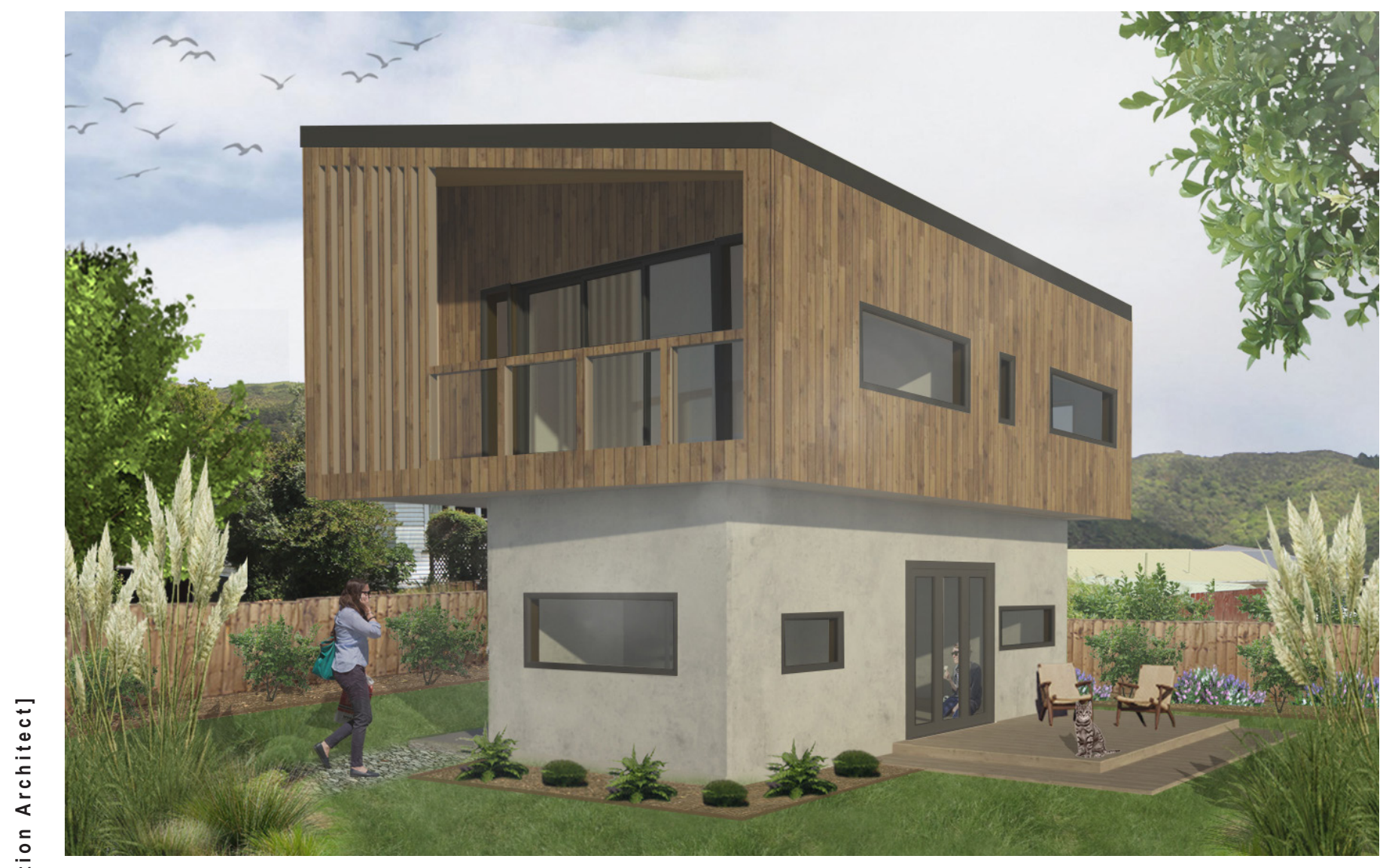

Figure 4.64 House 4.4 Exterior

\section{House 4.4}

House 4.4 contains a hybrid construction of timber and concrete, with 2 bedrooms and 1 bathroom. The dwelling has adopted a similar layout to house 4.2 on the first floor, with the same master bedroom layout and desk located in the circulation space. The initial floor plan did not contain enough storage and additional width was needed on the ground floor plan.

- A larger balcony, that is user friendly and can now contain furniture.

- Seed joinery for TV storage, stairs and laundry. Space under the stairs is now utilised as storage.

- Specific designed $L$ shaped couch to fit the space, containing additional storage at the base. 


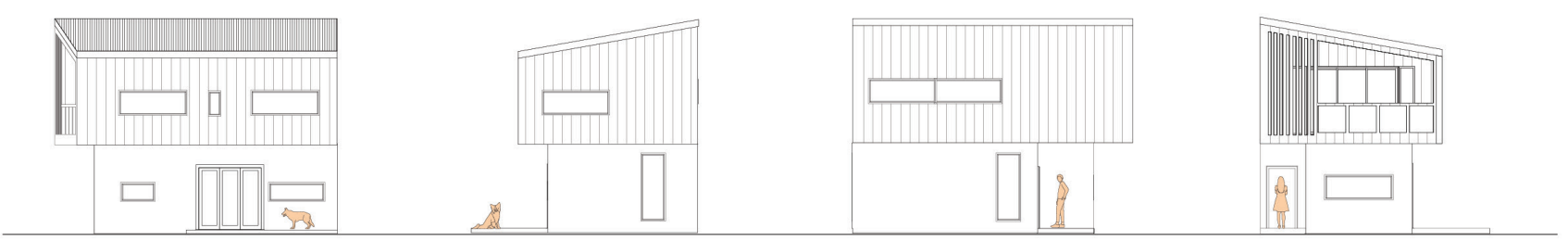

Figure 4.65 Elevations

Figure 4.66 House 3.4.1 plans sketched over

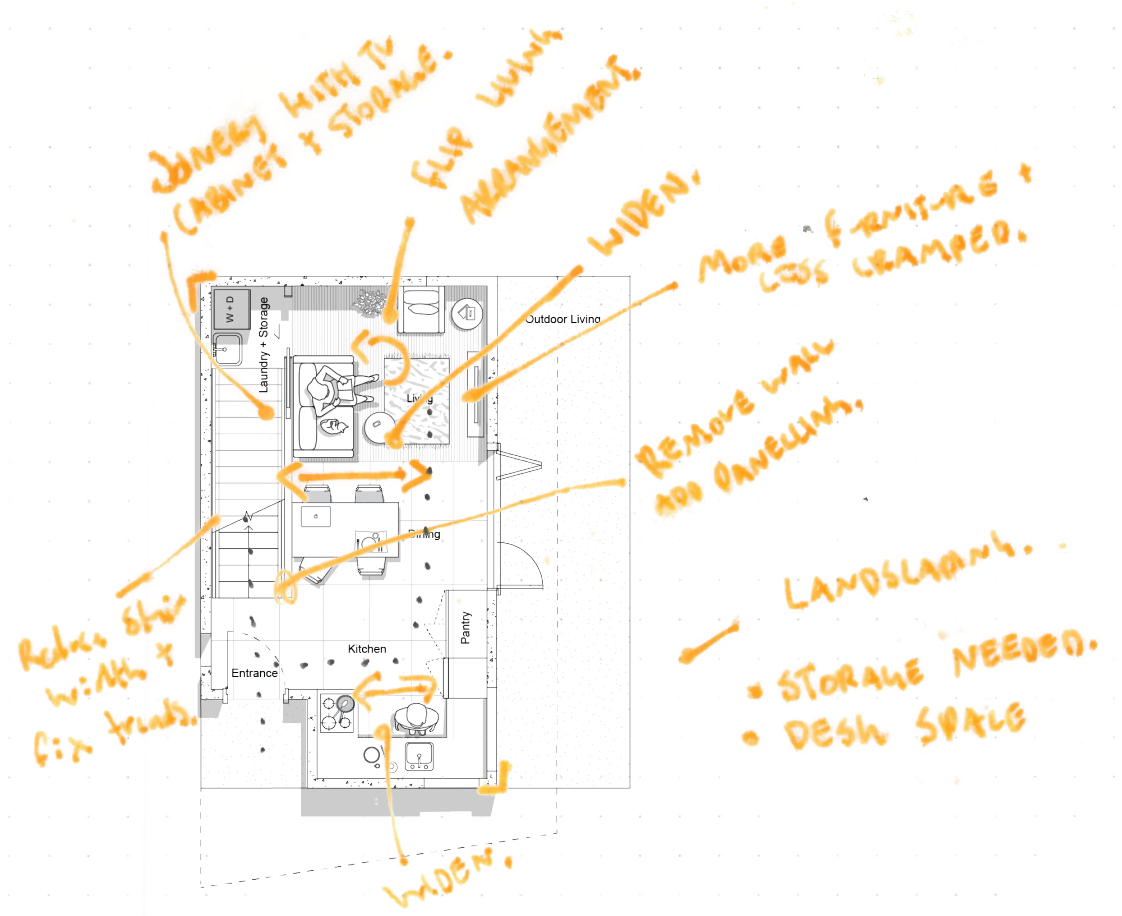

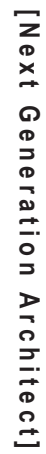

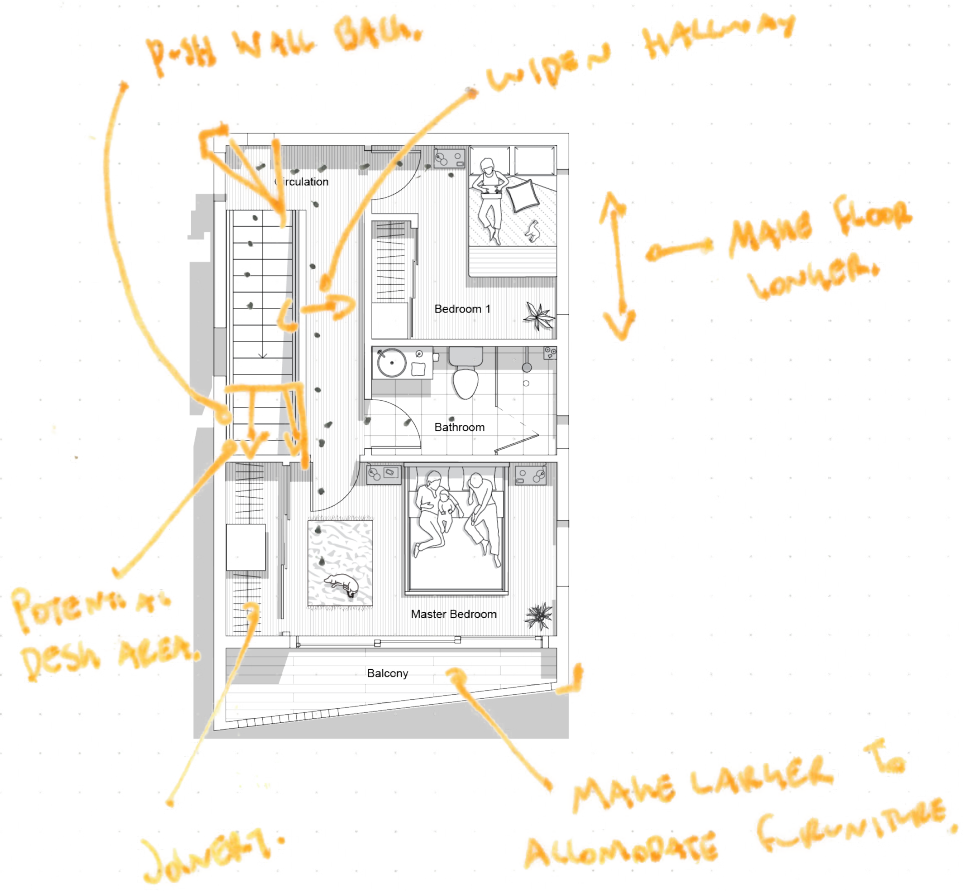


House 4.4

Plans + Sections

$1^{N}$

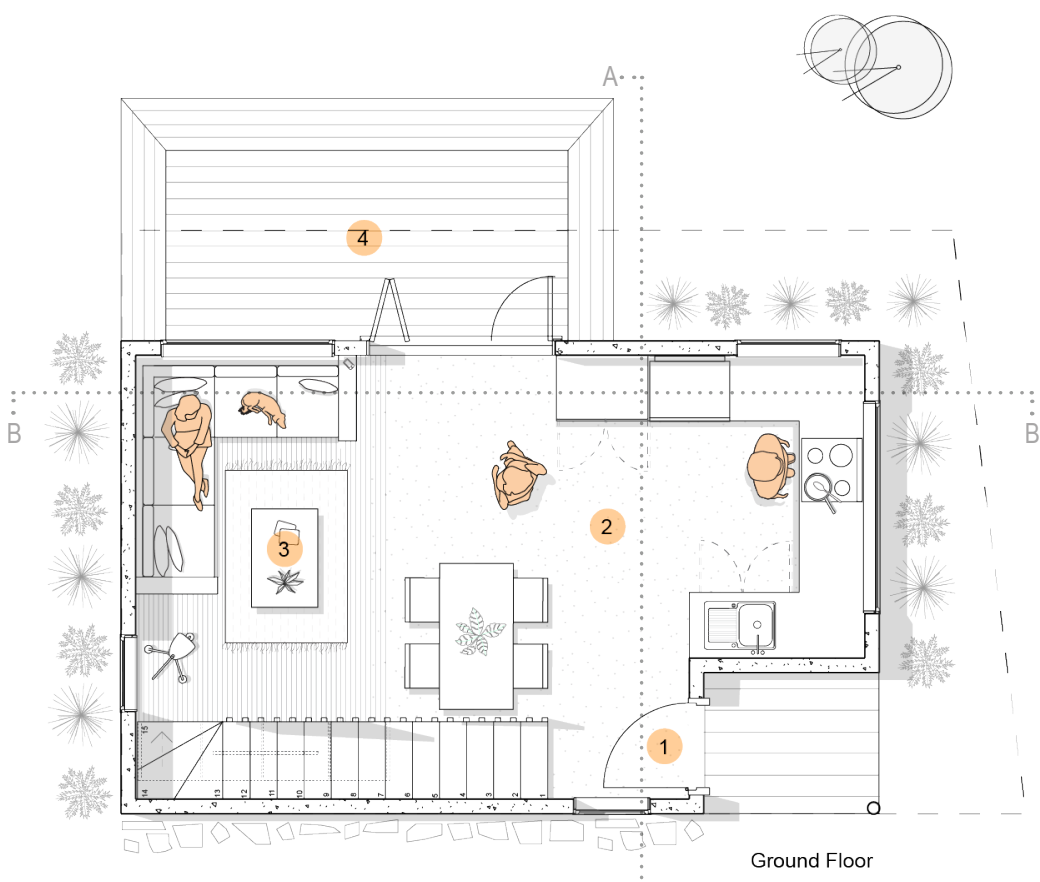

Figure 4.67 Ground floor

First Floor 


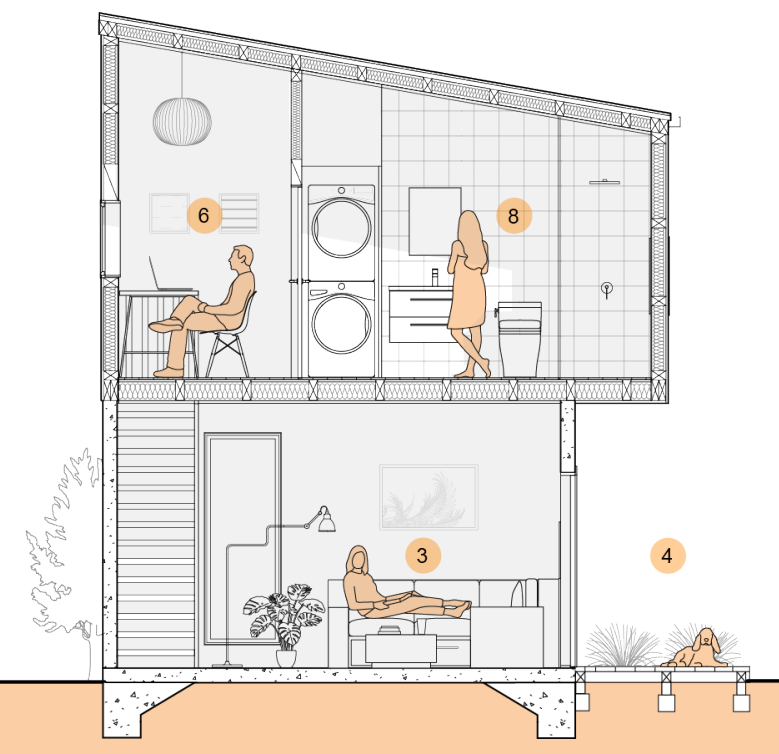

Figure 4.69 Section A-A

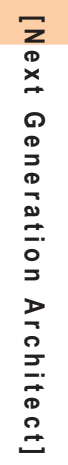

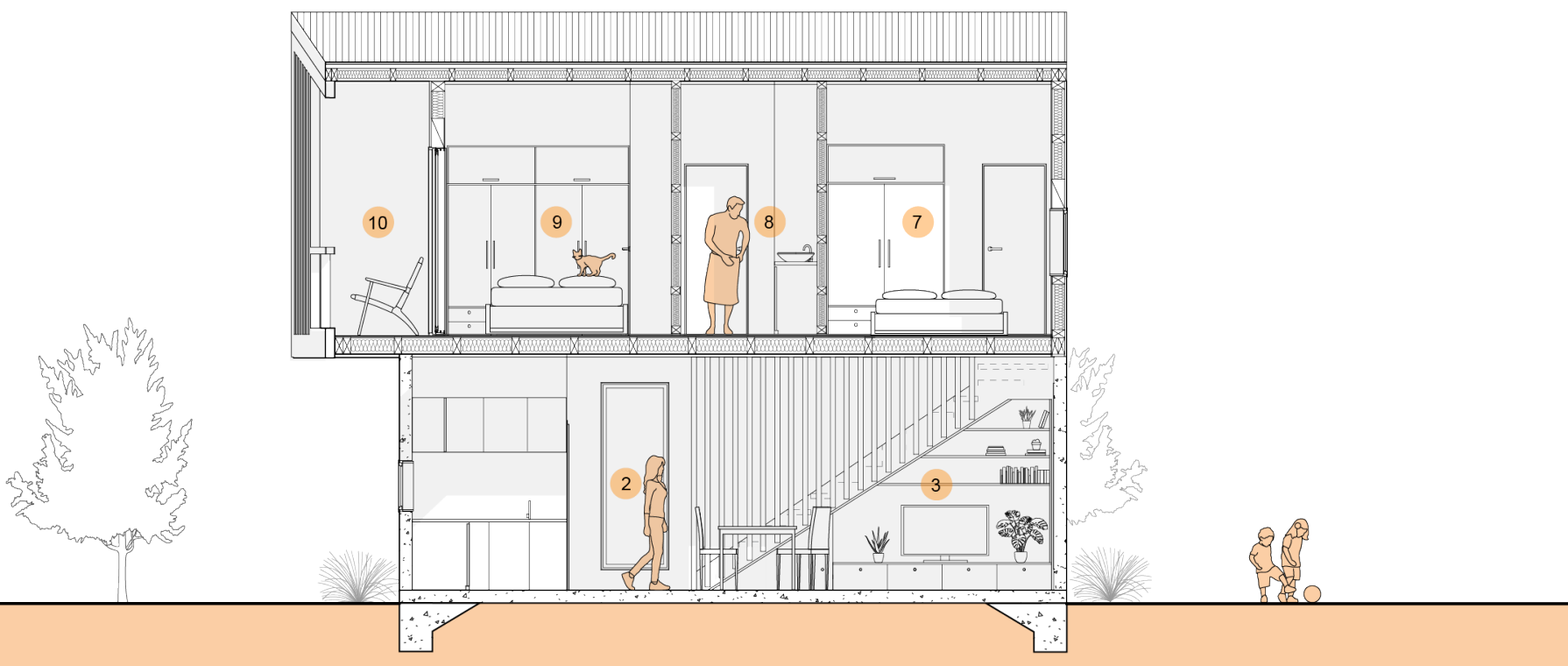


$58 m^{2}$

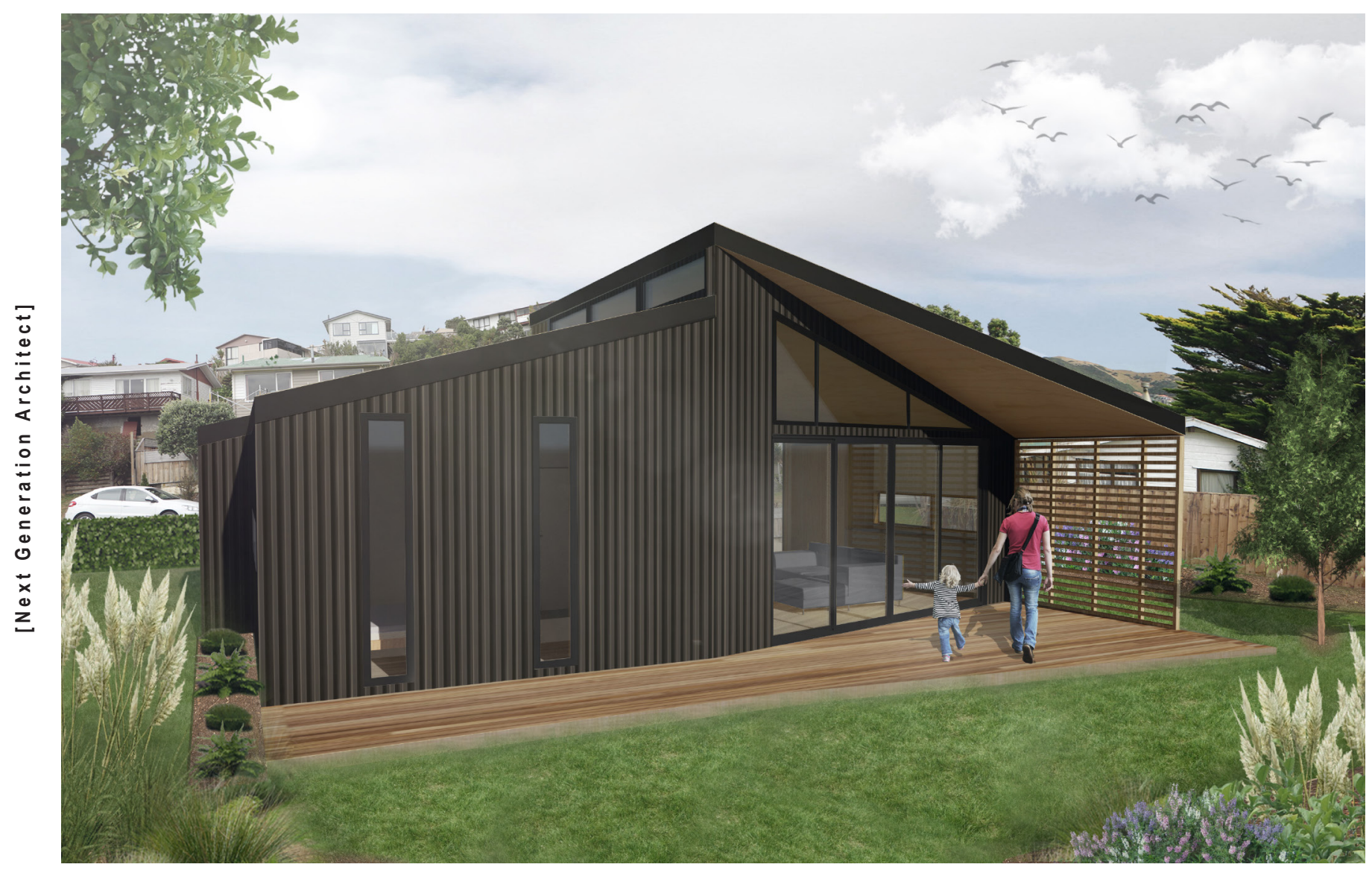

Figure 4.71 House 4.5 Exterior 


\section{House 4.5}

House 4.5 is a one storey 1 bedroom home constructed of timber framing, cladd in Coloursteel. The dwelling is designed to face north with a south facing entrance on site A. This dwelling is one of the two new designs introduced and is aimed at those looking for a smaller dwelling. The design is future proofed, with the potential to add a second bedroom. There is minimal usage of an irregular angular window on the northern face, used to achieve the desired architectural outcome.

Architectural Elements:

- Seed joinery replicated within the interior.

- Angled wall along the northern face for architectural aesthetic purposes, squared off in the bedroom for functionality.

- Minimal use of cedar on the entrance.

- A clear storey to the east allowing morning sun to enter.

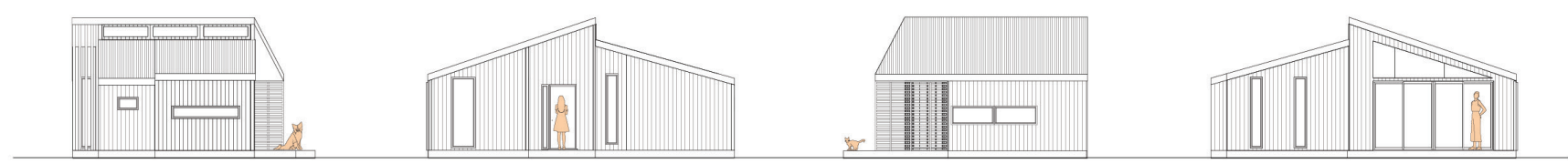

Figure 4.72 House 4.5 Elevations 
House 4.5

Plans + Sections

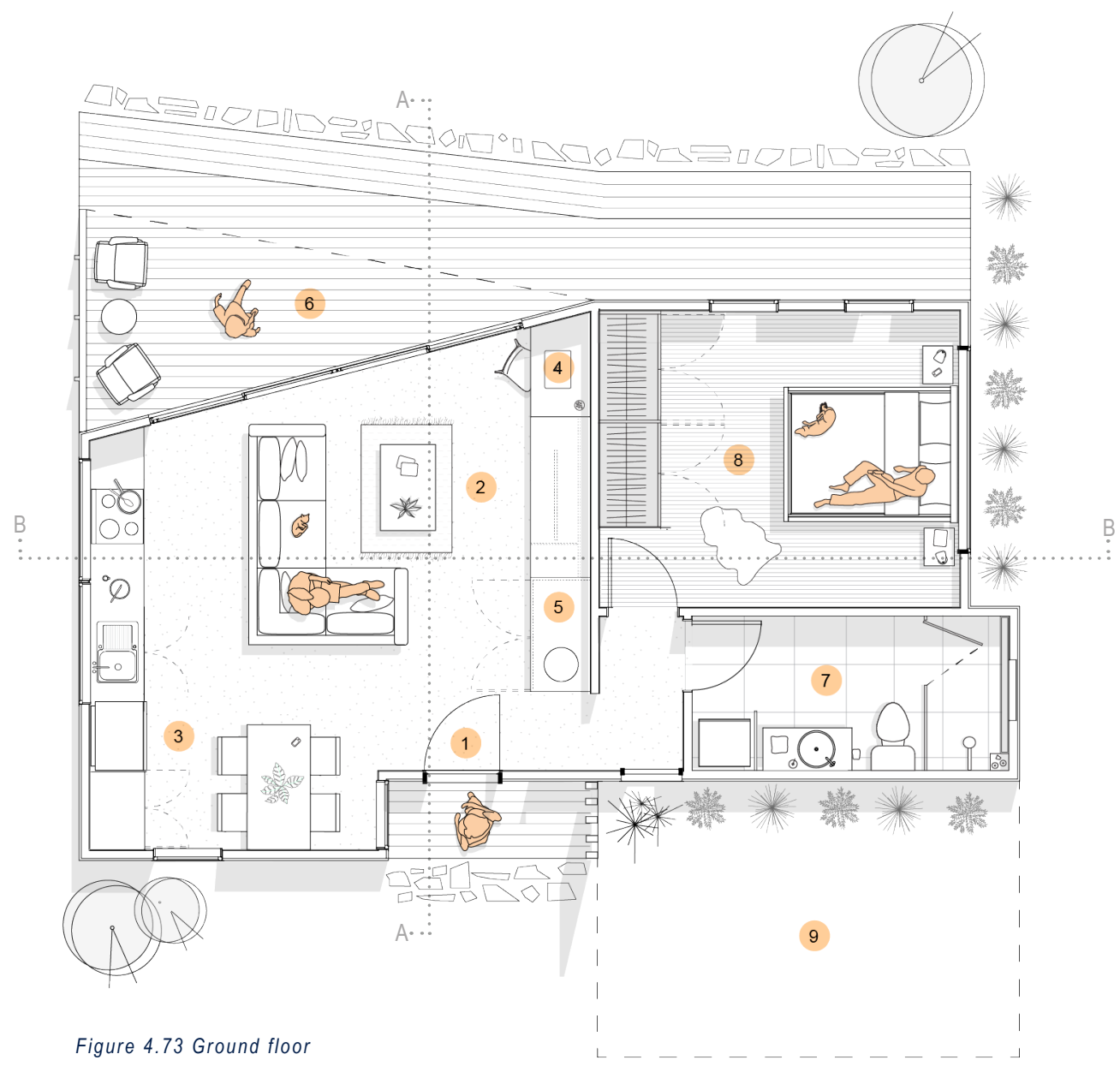




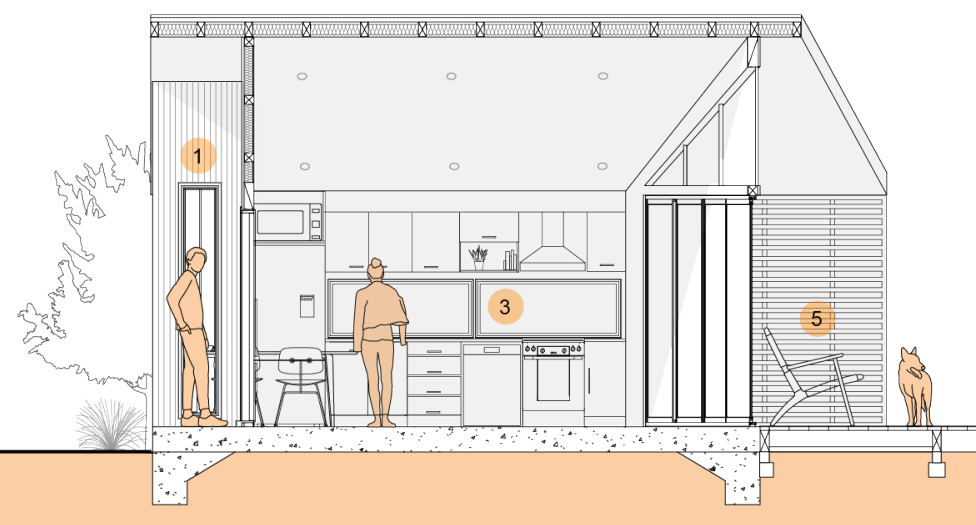

Figure 4.74 Section A-A

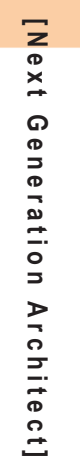


$73 m^{2}$

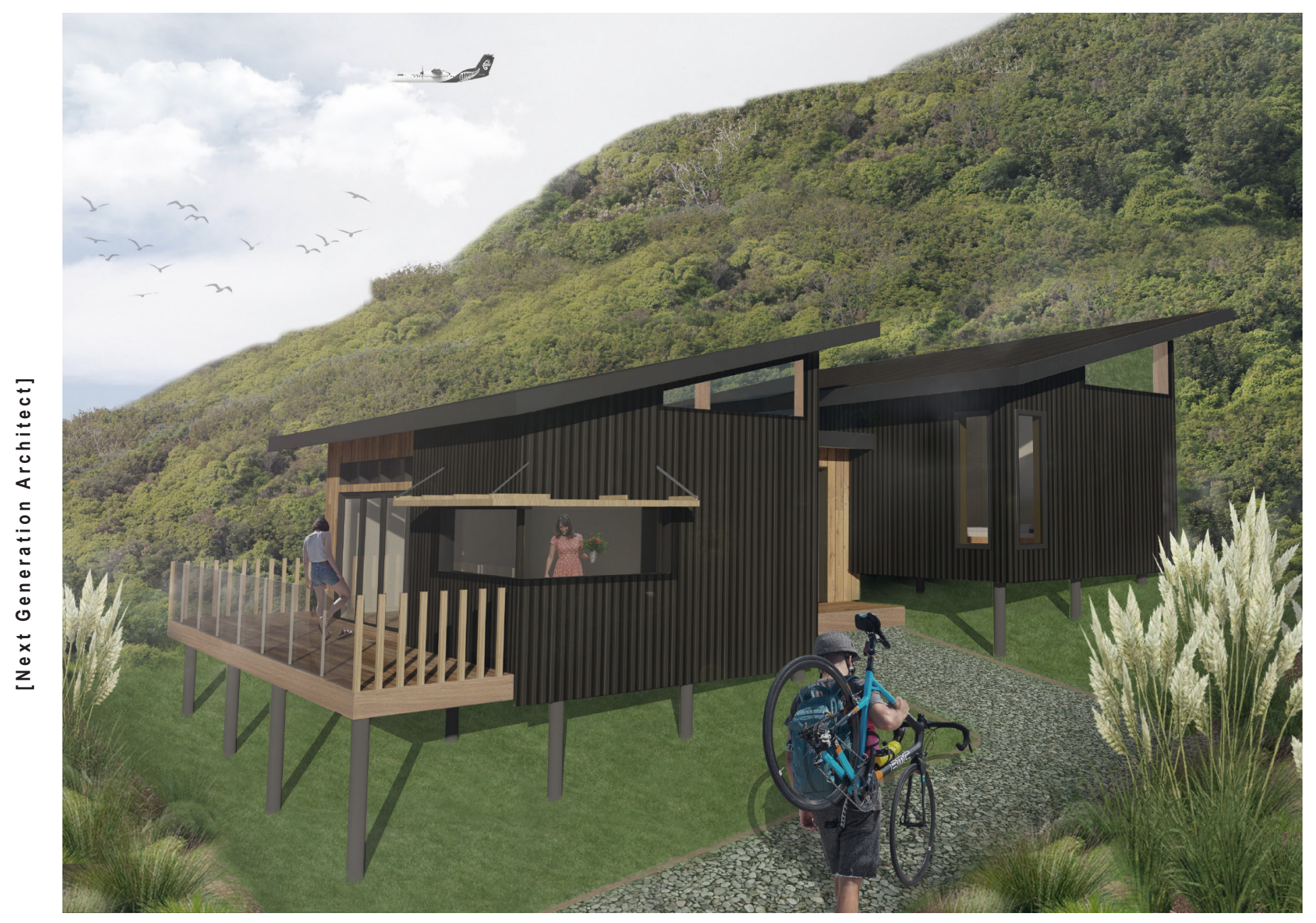

Figure 4.76 House 4.6 Exterior 


\section{House 4.6}

House 4.6 is derived from house 5 from the series of house designs exercise. Constructed of timber framing and clad with Coloursteel and cedar. It is designed to be adaptable working with a number of west sloping sites. Containing 2bedrooms and 1 bathroom, located across 3 levels that are divided into two main wings. An entrance wing, divides public and private spaces.

Architectural Elements:

- Large windows along the east face allowing morning sun to enter the dwelling.

- Roof overhang ensures spaces will not be exposed to overheating with the large glazed areas.

- Seed designed plywood joinery as storage and shelving within the interior.

- Irregular shaped windows along the north and south faces. These cost $30 \%$ more than standard windows.

- Located on timber piles for economic reasoning, reducing on site excavation.

- The mid floor roof slopes towards the entrance, eliminating the need for an uneconomical membrane roof and internal gutter.
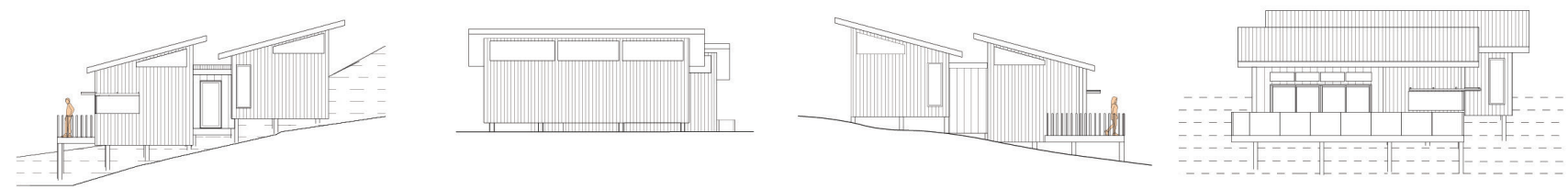
House 4.6

Plans + Sections

$\bigcirc N$

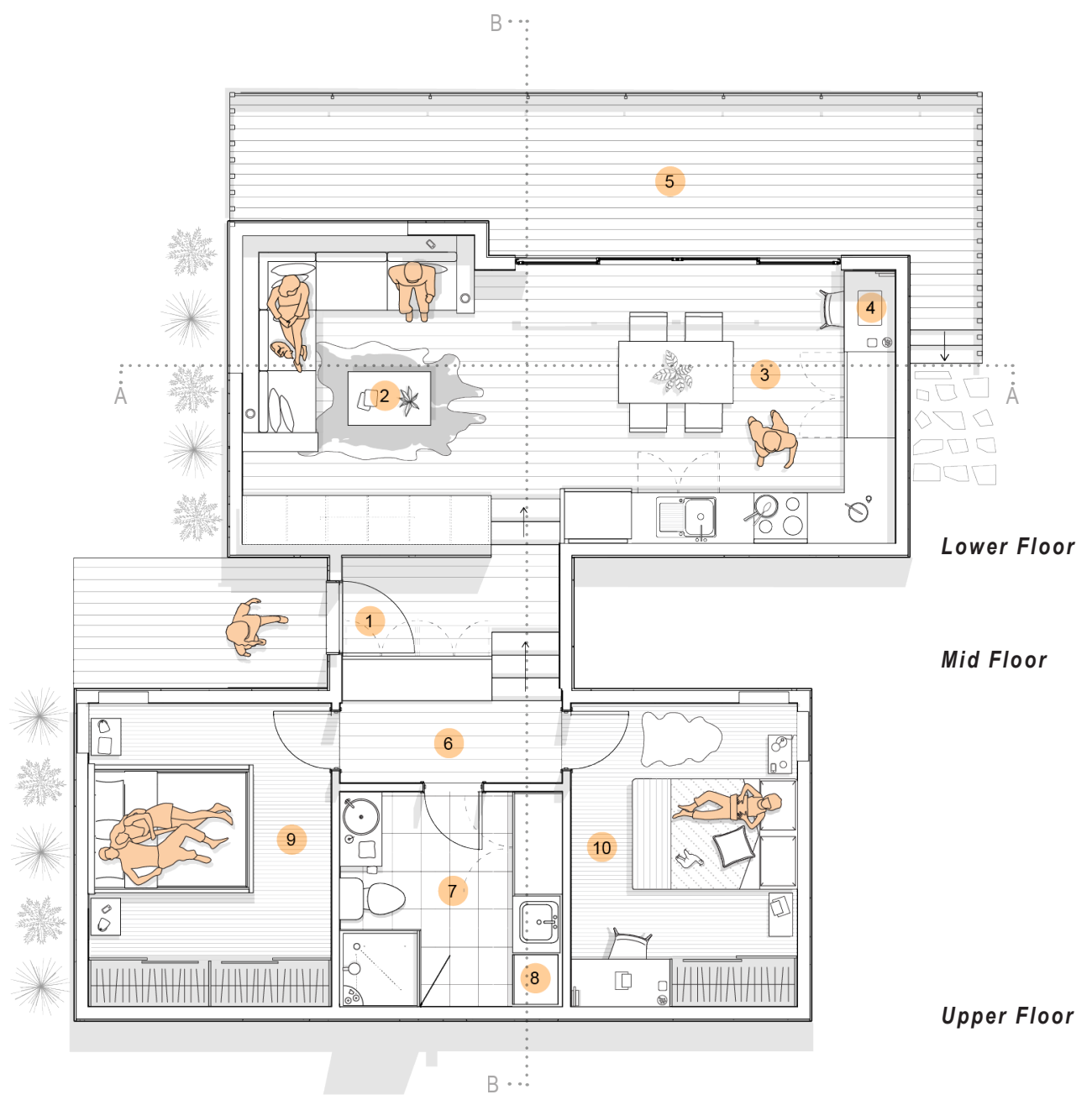

Figure 4.78 Floor plan

Key:

1. Entrance

2. Living

3. Kitchen

4. Desk

5. Outdoor Living

6. Circulation

7. Bathroom

8. Laundry

9. Master Bedrrom

10. Bedroom 1 


\section{A Selection of Interior Renders}

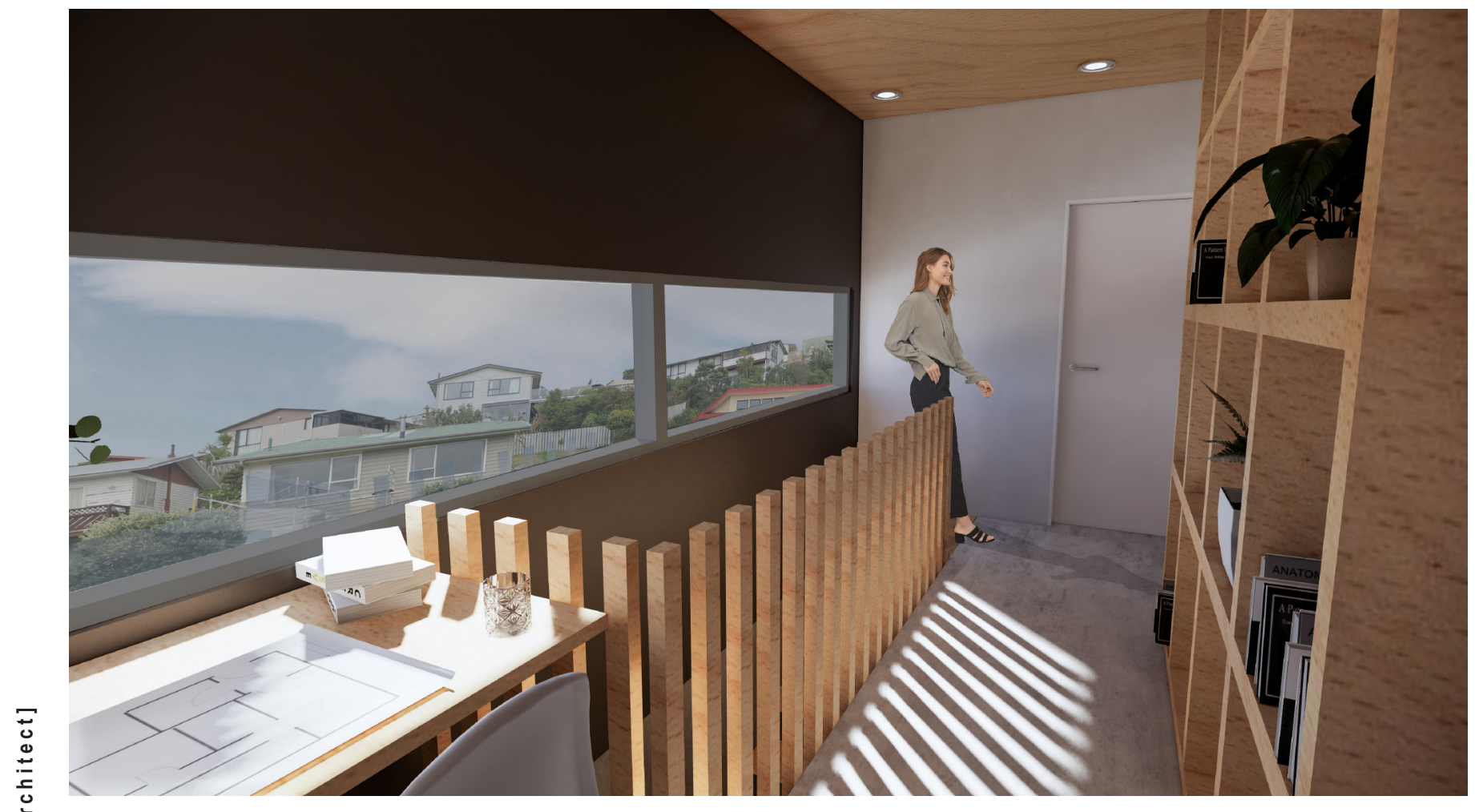

Figure 4.81 Houses $4.2 \& 4.4$ upstairs circulation and desk space.

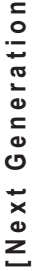

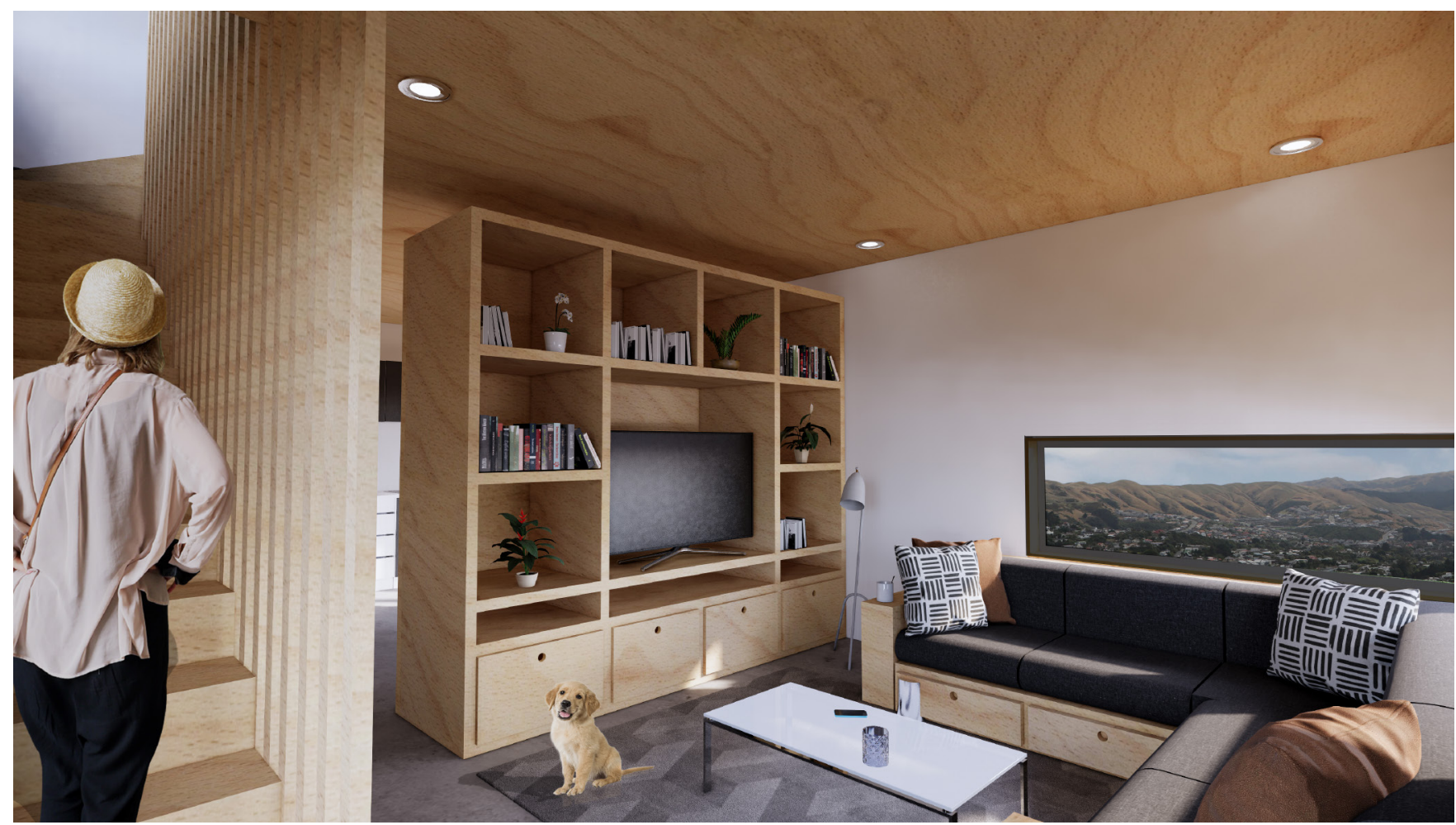

Figure 4.82 House 4.2 lounge joinery and additional built in storage. 


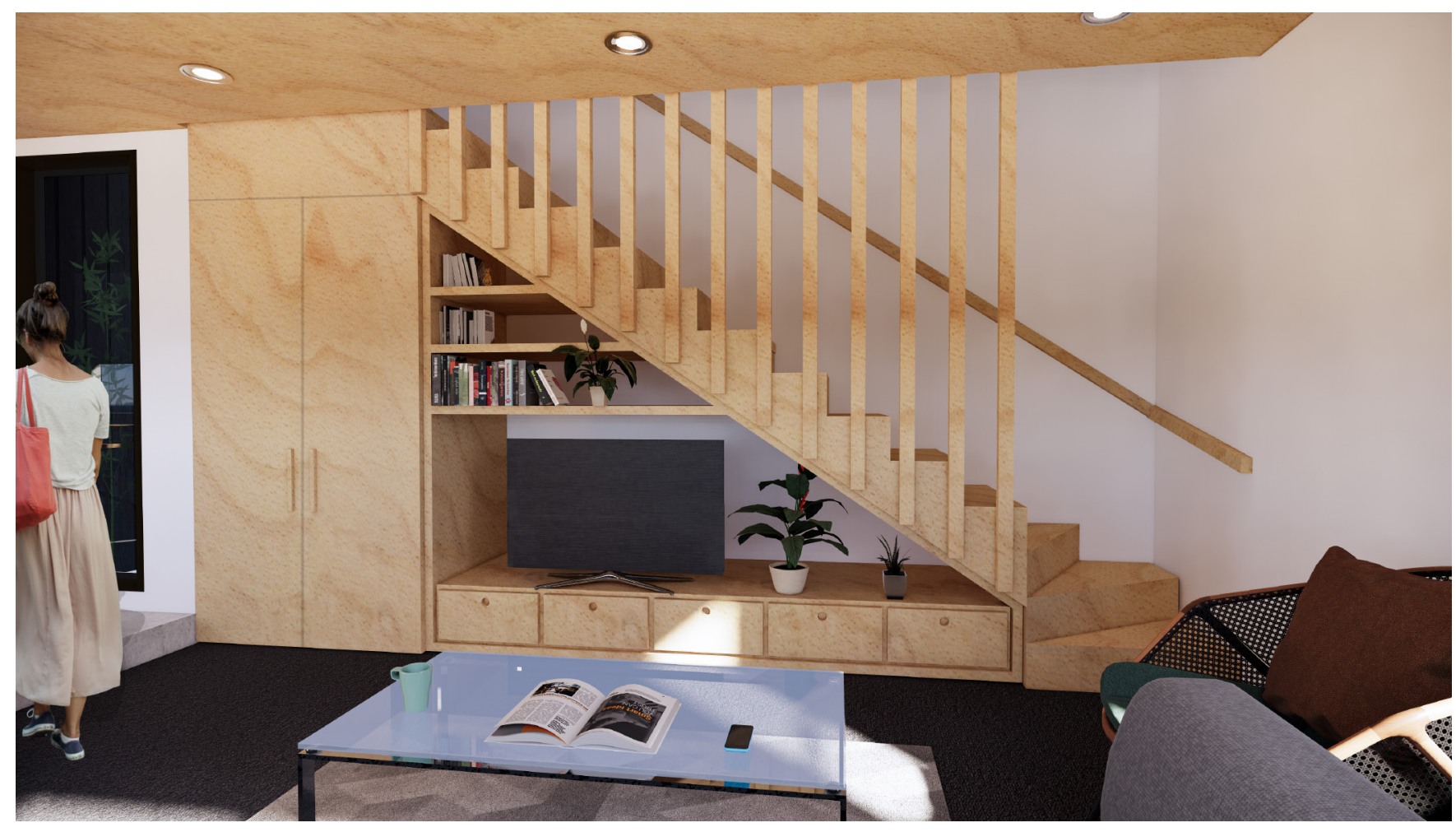

Figure 4.83 House 4.1, seed design of understair TV and storage joinery.

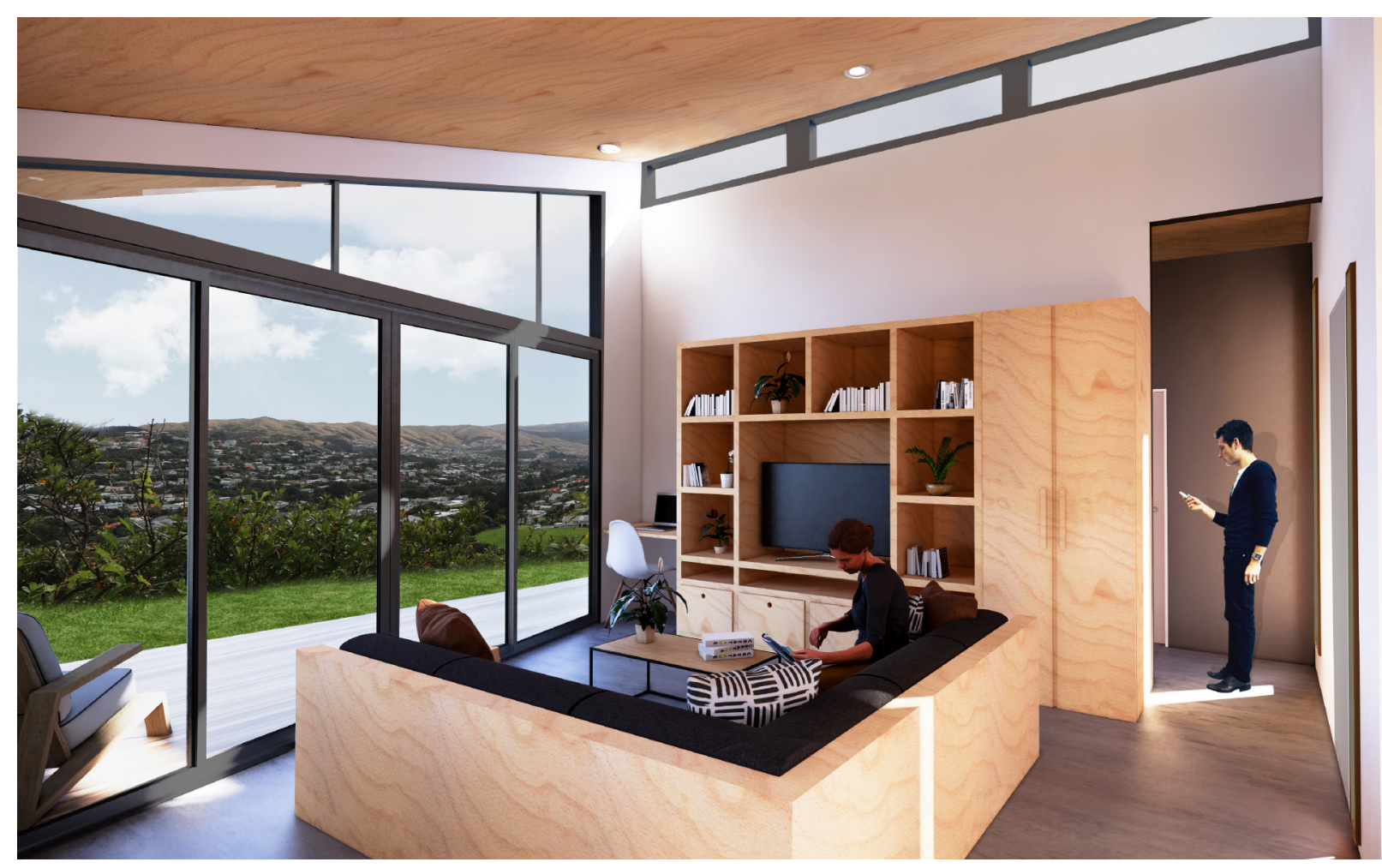

Figure 4.84 House 4.5, clear story \& irregular windows, and joinery. 


\title{
First Cost Estimates
}

\author{
Upfront and Lifecycle Costing
}

In addition to the first cost estimate of all six housing typologies designed, lifecycle costing of materials was introduced to cover a 50-year lifespan. This created an understanding into quality long lasting materials, maintenance requirements and lifecycle economics of materials. Final materials were carefully selected, considering both cost and quality over the 50-year lifespan. Costs were estimated through Revit schedules providing material quantities and cost data from QV costbuilder. It was then placed into spreadsheets that used BRANZ, clause B2 and specific manufacturers data surrounding maintenance and lifespan costs, broken down within the spreadsheets. The elements costed, include labour, joinery, cladding, roofing, flooring, painting and floor materials. It excludes inflation over the 50-year period, hardware, household appliances, plumbing, electrical, dwellings outside normal climatic conditions and presumes required maintenance is undertaken.

BIM through the use of Revit, continued to be used as a costing tool for the first cost estimate, aided by spreadsheets (house 4.1 is used as an example in figures $4.86-4.88$ ) to cost additional elements and professional fees. The first cost estimate excluded land, landscaping, additional interior fixtures, special hardware and lighting fixtures, margins and overheads, and project specific site preparation costs. Spreadsheets are located in appendix 3.

Architects must be smart with material selection, ensuring cost efficiency and value over time. The designs implement value using above code insulation on external walls, roofing and flooring. Well insulated homes provide year-round comfort and provide economic benefits surrounding heating and cooling. Thermal mass is explored through the use of concrete slabs. Typical timber framing acts as a thermal bridge as heat flows easier through timber than insulation. Thermal bridging is reduced by using stronger framing; achieved by moving a $90 \mathrm{~mm}$ wall to a $140 \mathrm{~mm}$ deep wall at wider spacings, allowing for more insulation which results in a higher thermal performance. (Smarter Homes, 2019) 


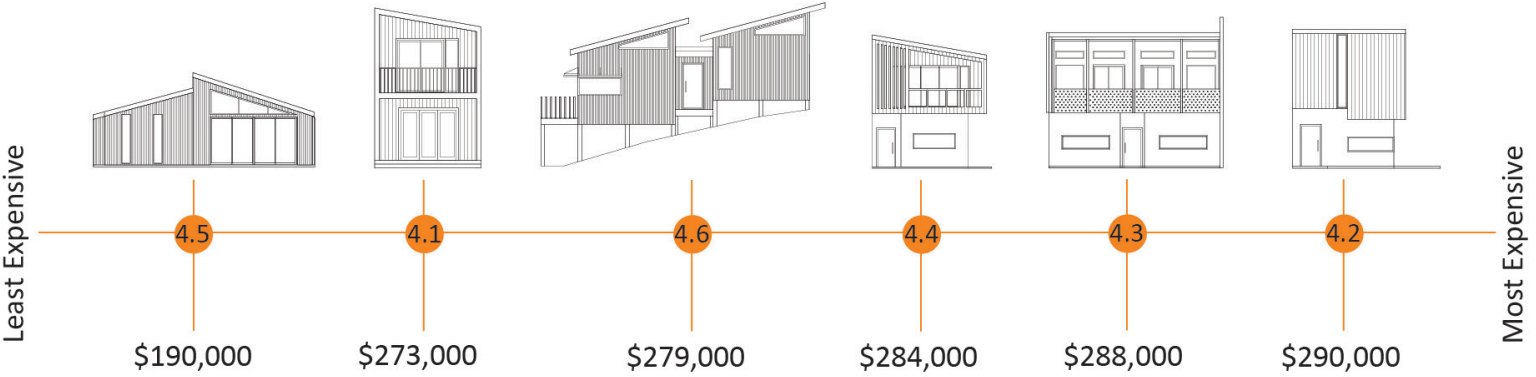

Timber framed dwellings clad in colour steel followed by Linea weatherboard contain the lowest upfront costs. These dwellings also contain the smallest floor areas. Small areas of cedar are used in a number of dwellings to maximise the budget.

Costs per $\mathrm{m}^{2}$

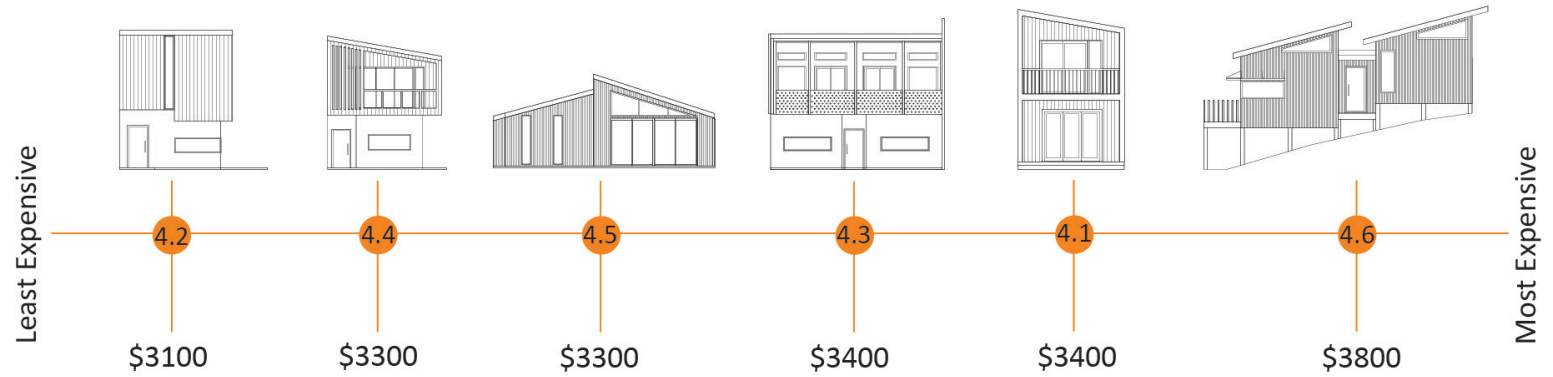

The average cost per $\mathrm{m}^{2}$ is $\$ 3400$. Houses with smaller floor areas contain higher costs per $\mathrm{m} 2$, due to the cost of essential components such as the kitchen and bathroom being spread across a smaller area. House 4.6 has a higher cost due to the larger areas of roofing and decking.
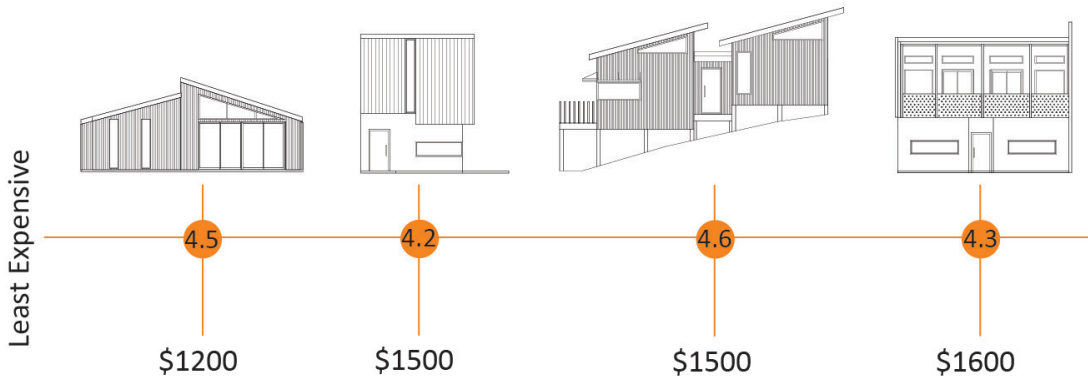

Lifecycle Costs per Year

Dwelling 4.5 holds the lowest lifecycle cost due to the small size of the dwelling. Concrete with an acid wash requires the lowest maintenance. Insulated concrete panels contain a high upfront cost but have a larger lifespan and require less maintenance. An acid wash allows the flexibility for change in the future to a paint finish.
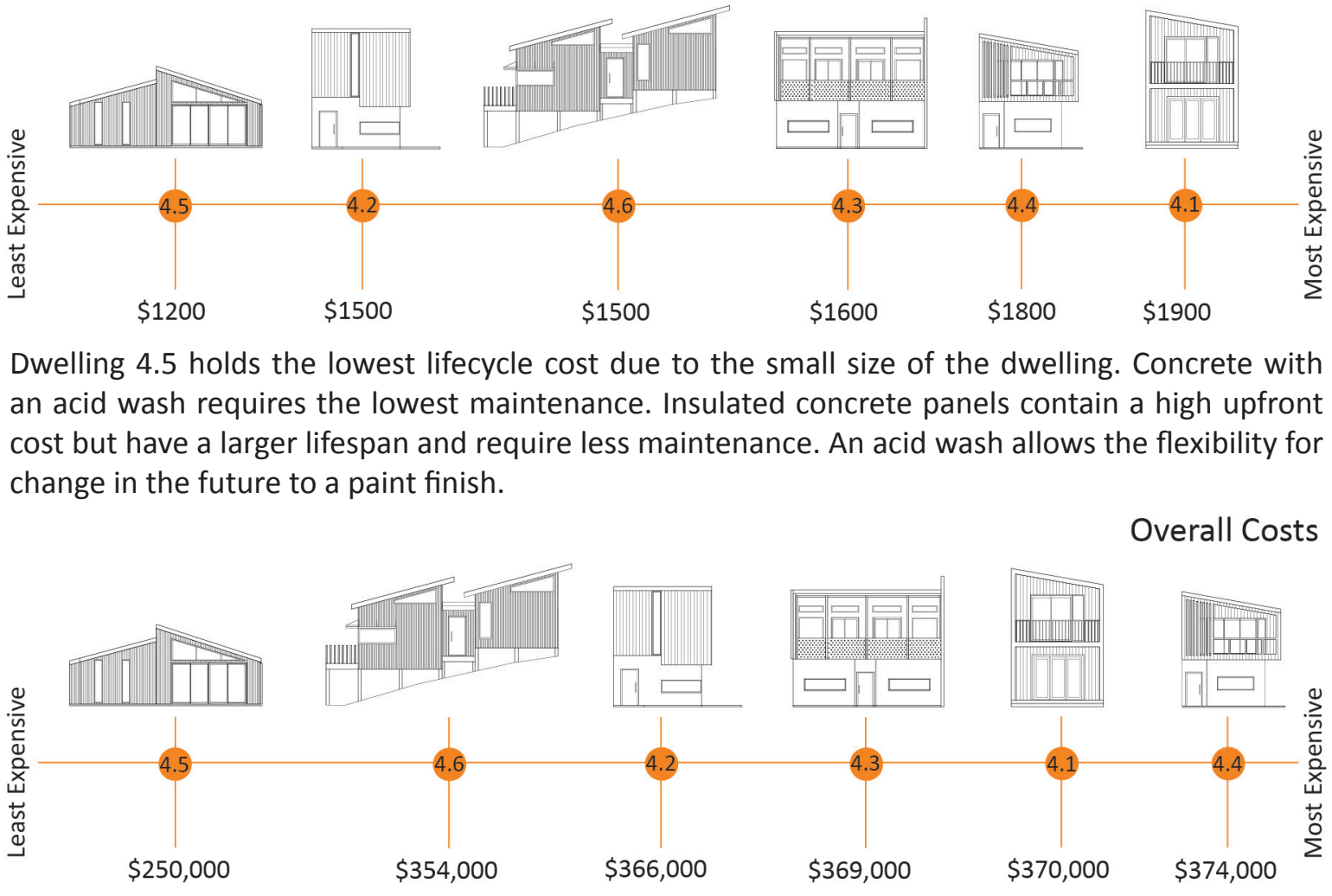

Overall timber framed homes clad predominantly in coloursteel are the most economical, followed by concrete and finally weatherboard. The hybrid combination is the most expensive overall due to the maintenance surrounding the weatherboard staining. 
Overall Costs and Lifespan

Figure 4.86 First Cost 4.1

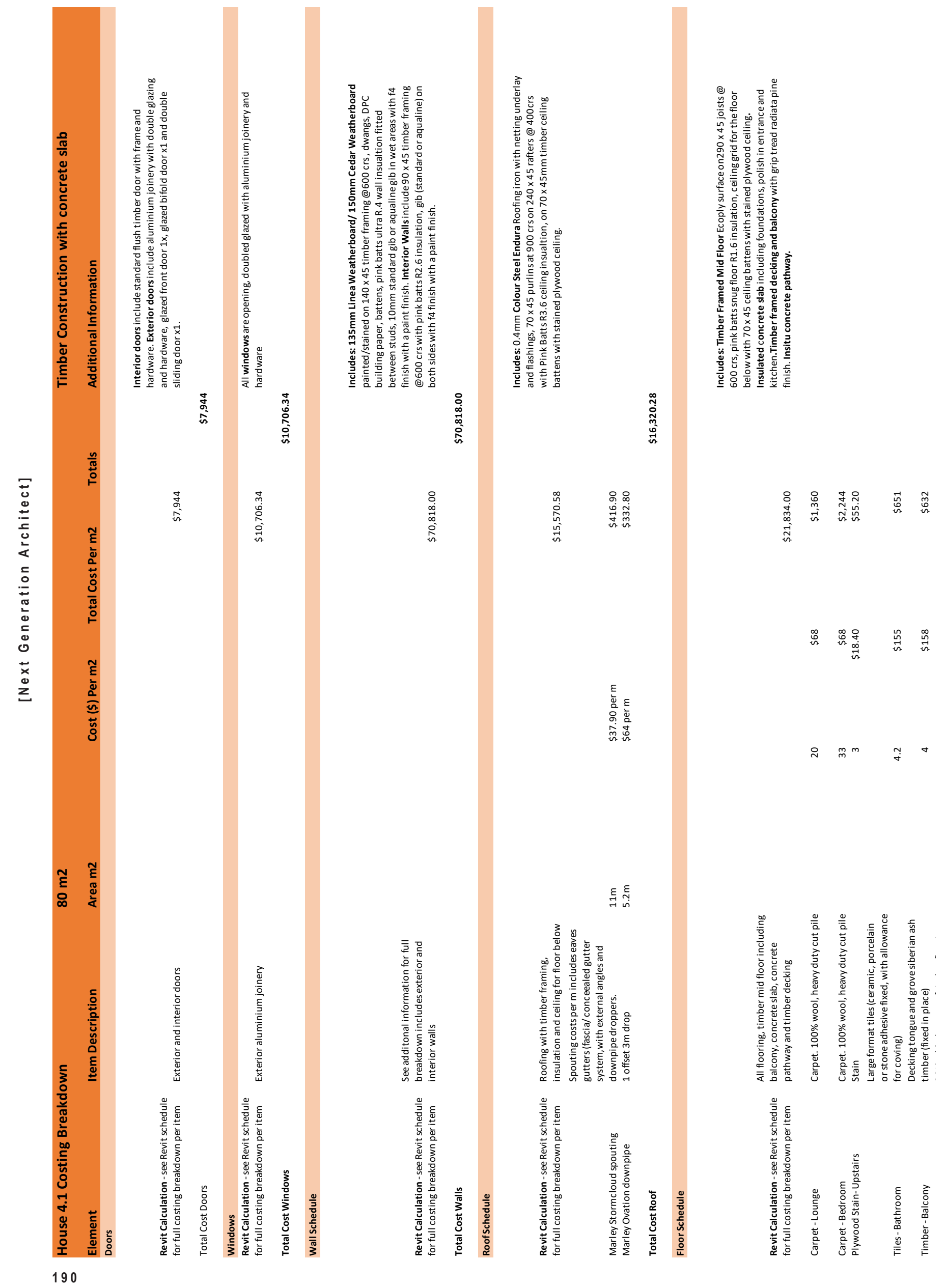




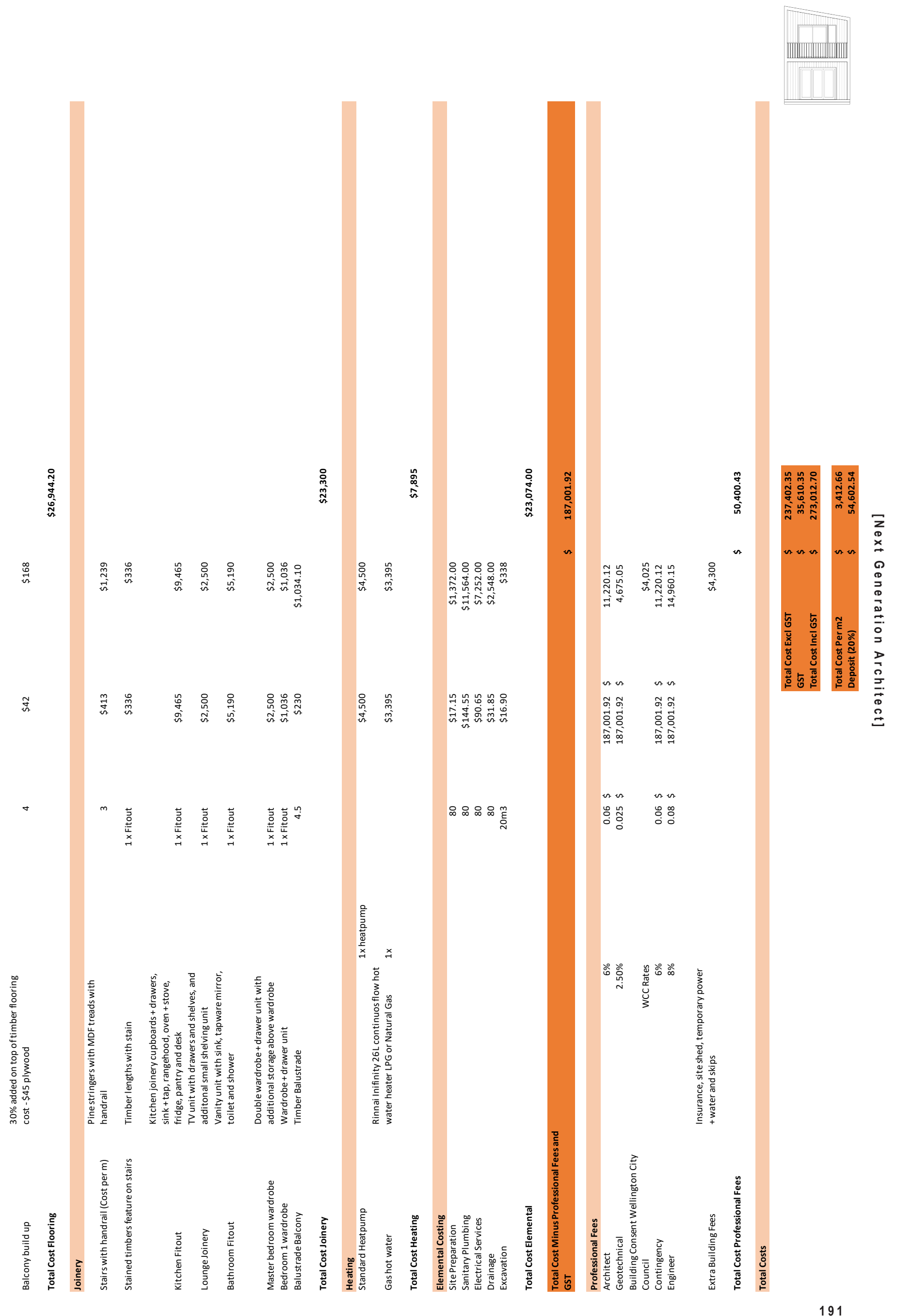


Figure 4.87 Lifecycle cost 4.1

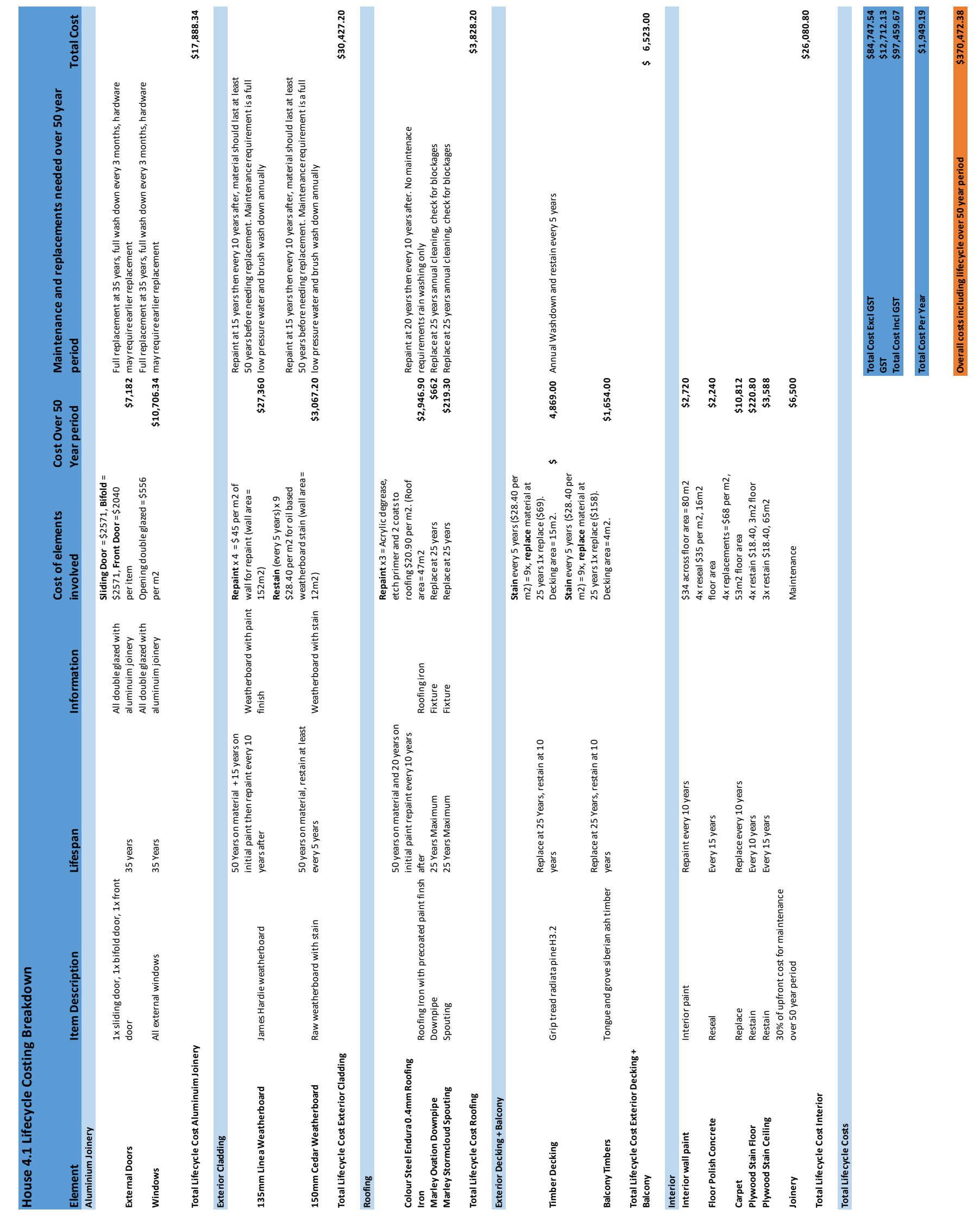




\begin{tabular}{|c|c|c|}
\hline \multicolumn{3}{|c|}{ <Door Schedule> } \\
\hline A & B & C \\
\hline Family and Type & Cost & Total Cost \\
\hline \multicolumn{3}{|c|}{ Ext Bifold3-1Lite(NZ): Bifold double glazed with Aluminium Joinery. $2100 \times 1980$} \\
\hline Ext Bifold3-1Lite(NZ): Bifold double glazed with & $\$ 2571.00$ & $\$ 2571.00$ \\
\hline \multicolumn{3}{|c|}{ Ext Single In-Timber-1Lite (NZ): Glazed Front Door with Aluminium Joinery860 x 2030} \\
\hline Ext Single In-Timber-1Lite (NZ): Glazed Front & $\$ 2040.00$ & $\$ 2040.00$ \\
\hline \multicolumn{3}{|c|}{ Exterior_Sliding_Door_3843: Double glazed sliding door with aluminium joinery } \\
\hline Exterior_Sliding_Door_3843: Double glazed sli & $\$ 2571.00$ & $\$ 2571.00$ \\
\hline \multicolumn{3}{|c|}{ Int Single-Flush (NZ): Standard flush interior door. $710 \times 1980$} \\
\hline Int Single-Flush (NZ): Standard flush interior do & $\$ 254.00$ & $\$ 254.00$ \\
\hline Int Single-Flush (NZ): Standard flush interior do & $\$ 254.00$ & $\$ 254.00$ \\
\hline Int Single-Flush (NZ): Standard flush interior do & $\$ 254.00$ & $\$ 254.00$ \\
\hline Grand total: 6 & & $\$ 7944.00$ \\
\hline
\end{tabular}

\begin{tabular}{|c|c|c|c|}
\hline \multicolumn{4}{|c|}{$<$ Wall Schedule $>$} \\
\hline A & B & c & D \\
\hline Family and Type & Area & Cost & Total Cost \\
\hline \multicolumn{4}{|c|}{ Basic Wall: $135 \mathrm{~mm}$ Linea Weatherboard full build up incl interior Gib } \\
\hline Basic Wall: $135 \mathrm{~mm}$ Linea Weatherbo & $13 \mathrm{~m}^{2}$ & $\$ 423.20$ & $\$ 5519.37$ \\
\hline Basic Wall: $135 \mathrm{~mm}$ Linea Weatherboard fu & $9 \mathrm{~m}^{2}$ & $\$ 423.20$ & $\$ 3937.82$ \\
\hline Basic Wall: $135 \mathrm{~mm}$ Linea Weatherboard fu & $6 \mathrm{~m}^{2}$ & $\$ 423.20$ & $\$ 2582.84$ \\
\hline Basic Wall: $135 \mathrm{~mm}$ Linea Weatherboard fu & $11 \mathrm{~m}^{2}$ & $\$ 423.20$ & $\$ 4785.38$ \\
\hline Basic Wall: $135 \mathrm{~mm}$ Linea Weatherboard fu & $12 \mathrm{~m}^{2}$ & $\$ 423.20$ & $\$ 5017.33$ \\
\hline Basic Wall: $135 \mathrm{~mm}$ Linea Weatherboard fu & $10 \mathrm{~m}^{2}$ & $\$ 423.20$ & $\$ 4399.22$ \\
\hline Basic Wall: $135 \mathrm{~mm}$ Linea Weatherboard fu & $2 \mathrm{~m}^{2}$ & $\$ 423.20$ & $\$ 705.78$ \\
\hline Basic Wall: $135 \mathrm{~mm}$ Linea Weatherboard fu & $1 \mathrm{~m}^{2}$ & $\$ 423.20$ & $\$ 555.87$ \\
\hline Basic Wall: $135 \mathrm{~mm}$ Linea Weatherboard fu & $1 \mathrm{~m}^{2}$ & $\$ 423.20$ & $\$ 531.33$ \\
\hline Basic Wall: $135 \mathrm{~mm}$ Linea Weatherboard fu & $2 \mathrm{~m}^{2}$ & $\$ 423.20$ & $\$ 1056.31$ \\
\hline Basic Wall: $135 \mathrm{~mm}$ Linea Weatherboard fu & $2 \mathrm{~m}^{2}$ & $\$ 423.20$ & $\$ 823.84$ \\
\hline Basic Wall: $135 \mathrm{~mm}$ Linea Weatherboard fu & $2 \mathrm{~m}^{2}$ & $\$ 423.20$ & $\$ 950.68$ \\
\hline Basic Wall: $135 \mathrm{~mm}$ Linea Weatherboard fu & $14 \mathrm{~m}^{2}$ & $\$ 423.20$ & $\$ 6088.15$ \\
\hline Basic Wall: $135 \mathrm{~mm}$ Linea Weatherboard fu & $15 \mathrm{~m}^{2}$ & $\$ 423.20$ & $\$ 6387.06$ \\
\hline Basic Wall: $135 \mathrm{~mm}$ Linea Weatherboard fu & $3 \mathrm{~m}^{2}$ & $\$ 423.20$ & $\$ 1071.01$ \\
\hline Basic Wall: $135 \mathrm{~mm}$ Linea Weatherboard fu & $2 \mathrm{~m}^{2}$ & $\$ 423.20$ & $\$ 761.13$ \\
\hline Basic Wall: $135 \mathrm{~mm}$ Linea Weatherboard fu & $15 \mathrm{~m}^{2}$ & $\$ 423.20$ & $\$ 6353.16$ \\
\hline Basic Wall: $135 \mathrm{~mm}$ Linea Weatherboard fu & $10 \mathrm{~m}^{2}$ & $\$ 423.20$ & $\$ 4056.06$ \\
\hline Basic Wall: $135 \mathrm{~mm}$ Linea Weatherboard fu & $1 \mathrm{~m}^{2}$ & $\$ 423.20$ & $\$ 485.81$ \\
\hline Basic Wall: $135 \mathrm{~mm}$ Linea Weatherboard fu & $2 \mathrm{~m}^{2}$ & $\$ 423.20$ & $\$ 841.14$ \\
\hline \multicolumn{4}{|c|}{ Basic Wall: $135 \mathrm{~mm}$ Linea Weatherboard including full build up with aqualine Gib interior } \\
\hline Basic Wall: $135 \mathrm{~mm}$ Linea Weatherboard in & $2 \mathrm{~m}^{2}$ & $\$ 432.20$ & $\$ 713.62$ \\
\hline Basic Wall: $135 \mathrm{~mm}$ Linea Weatherboard in & $2 \mathrm{~m}^{2}$ & $\$ 432.20$ & $\$ 686.16$ \\
\hline Basic Wall: $135 \mathrm{~mm}$ Linea Weatherboard in & $3 \mathrm{~m}^{2}$ & $\$ 432.20$ & $\$ 1473.45$ \\
\hline \multicolumn{4}{|c|}{ Basic Wall: $150 \mathrm{~mm}$ Cedar weatherboard with build up including standard Gib } \\
\hline Basic Wall: $150 \mathrm{~mm}$ Cedar weatherboard $\mathrm{w}$ & $6 \mathrm{~m}^{2}$ & $\$ 480.20$ & $\$ 2825.12$ \\
\hline Basic Wall: $150 \mathrm{~mm}$ Cedar weatherboard w & $6 \mathrm{~m}^{2}$ & $\$ 480.20$ & $\$ 2777.75$ \\
\hline \multicolumn{4}{|c|}{ Basic Wall: Standard $90 \times 45$ interior framed walls with gib on bothsides } \\
\hline Basic Wall: Standard $90 \times 45$ interior frame & $1 \mathrm{~m}^{2}$ & $\$ 185.50$ & $\$ 273.47$ \\
\hline Basic Wall: Standard $90 \times 45$ interior frame & $10 \mathrm{~m}^{2}$ & $\$ 185.50$ & $\$ 1817.59$ \\
\hline Basic Wall: Standard $90 \times 45$ interior frame & $2 \mathrm{~m}^{2}$ & $\$ 185.50$ & $\$ 312.45$ \\
\hline \multicolumn{4}{|l|}{ Basic Wall: Standard interior wall with Aqualine } \\
\hline Basic Wall: Standard interior wall with Aqu & $7 \mathrm{~m}^{2}$ & $\$ 198.80$ & $\$ 1378.68$ \\
\hline Basic Wall: Standard interior wall with Aqu & $5 \mathrm{~m}^{2}$ & $\$ 198.80$ & $\$ 1039.45$ \\
\hline Basic Wall: Standard interior wall with Aqu & $3 \mathrm{~m}^{2}$ & $\$ 198.80$ & $\$ 611.58$ \\
\hline Grand total: 31 & & & $\$ 70818.62$ \\
\hline
\end{tabular}

\begin{tabular}{|c|c|c|c|}
\hline \multicolumn{4}{|c|}{$<$ Floor Schedule $>$} \\
\hline A & B & C & D \\
\hline Family and Type & Area & Cost & Total Cost \\
\hline \multicolumn{4}{|c|}{ Floor: Decking, timber framed with timber topping } \\
\hline Floor: Decking, tim & $11 \mathrm{~m}^{2}$ & $\$ 168.00$ & $\$ 1779.80$ \\
\hline \multicolumn{4}{|c|}{ Floor: Generic $150 \mathrm{~mm}$} \\
\hline Floor: Generic 150 & $20 \mathrm{~m}^{2}$ & $\$ 150.00$ & $\$ 3012.24$ \\
\hline \multicolumn{4}{|l|}{ Floor: Path } \\
\hline Floor: Path & $7 \mathrm{~m}^{2}$ & $\$ 59.00$ & $\$ 388.52$ \\
\hline \multicolumn{4}{|c|}{ Floor: Polished Concrete Entry, Kitchen and Dining } \\
\hline Floor: Polished Co & $19 \mathrm{~m}^{2}$ & $\$ 270.00$ & $\$ 5008.36$ \\
\hline \multicolumn{4}{|c|}{ Floor: timber framed step with timber decking } \\
\hline Floor: timber frame & $4 \mathrm{~m}^{2}$ & $\$ 168.00$ & $\$ 711.92$ \\
\hline \multicolumn{4}{|c|}{ Floor: Timber mid floor including build up, insulation and ground floor ceiling } \\
\hline Floor: Timber mid & $137 \mathrm{~m}^{2}$ & $\$ 298.00$ & $\$ 10932.72$ \\
\hline Grand total: 6 & & & $\$ 21833.57$ \\
\hline
\end{tabular}

\begin{tabular}{|c|c|c|c|c|c|}
\hline \multicolumn{6}{|c|}{$<$ Window Schedule $>$} \\
\hline A & B & c & D & E & $\mathbf{F}$ \\
\hline Family and Type & Height & Width & Window Area & Cost & Total Cost \\
\hline \multicolumn{6}{|c|}{3 window: Standard 3 panel $600 \times 900$} \\
\hline 3 window: Standar & 1980 & 600 & 1.188 & $\$ 556.00$ & $\$ 660.53$ \\
\hline 3 window: Standar & 1980 & 600 & 1.188 & $\$ 556.00$ & $\$ 660.53$ \\
\hline 3 window: Standar & 1980 & 600 & 1.188 & $\$ 556.00$ & $\$ 660.53$ \\
\hline 3 window: Standar & 1980 & 600 & 1.188 & $\$ 556.00$ & $\$ 660.53$ \\
\hline 3 window: Standar & 1980 & 600 & 1.188 & $\$ 556.00$ & $\$ 660.53$ \\
\hline 3 window: Standar & 1980 & 600 & 1.188 & $\$ 556.00$ & $\$ 660.53$ \\
\hline 3 window: Standar & 1980 & 600 & 1.188 & $\$ 556.00$ & $\$ 660.53$ \\
\hline \multicolumn{6}{|c|}{ FL 1 Aluminum-Grooved (NZ): Balcony window master bedroom } \\
\hline FL 1 Aluminum-Gr & 2100 & 500 & 1.05 & $\$ 556.00$ & $\$ 583.80$ \\
\hline \multicolumn{6}{|c|}{ FL 1 Aluminum-Grooved (NZ): Large windows in recess } \\
\hline FL 1 Aluminum-Gr & 2200 & 800 & 1.76 & $\$ 556.00$ & $\$ 978.56$ \\
\hline \multicolumn{6}{|c|}{ FL 1 Aluminum-Grooved (NZ): Large windows in recess first floor } \\
\hline FL 1 Aluminum-Gr & 2200 & 800 & 1.76 & $\$ 556.00$ & $\$ 978.56$ \\
\hline FL 1 Aluminum-Gr & 2200 & 800 & 1.76 & $\$ 556.00$ & $\$ 978.56$ \\
\hline \multicolumn{6}{|c|}{ Multi-Panel_Awning_1958: Kitchen, dining 2 panel window } \\
\hline Multi-Panel_Awnin & 600 & 1800 & 1.08 & $\$ 556.00$ & $\$ 600.48$ \\
\hline Multi-Panel_Awnin & & 1800 & 1.08 & $\$ 556.00$ & $\$ 600.48$ \\
\hline \multicolumn{6}{|c|}{ Multi-Panel_Awning_1958: Living Room long $700 \times 3500$} \\
\hline Multi-Panel_Awnin & 700 & 3500 & 2.45 & $\$ 556.00$ & $\$ 1362.20$ \\
\hline & & & & & $\$ 10706.34$ \\
\hline
\end{tabular}

\begin{tabular}{|c|c|c|c|}
\hline \multicolumn{3}{|c|}{ <Roof Schedule> } \\
\hline A & B & C & D \\
\hline w & Area & Cost & Total Cost \\
\hline & & \\
\hline & & \\
\hline Basic Roof: Timber framed roofing with colour steel endura, insulation and ceiling below \\
\hline Basic Roof: Timber & $47 \mathrm{~m}^{2}$ & $\$ 330.30$ & $\$ 15570.58$ \\
\hline Grand total: 1 & & $\$ 15570.58$ \\
\hline
\end{tabular}




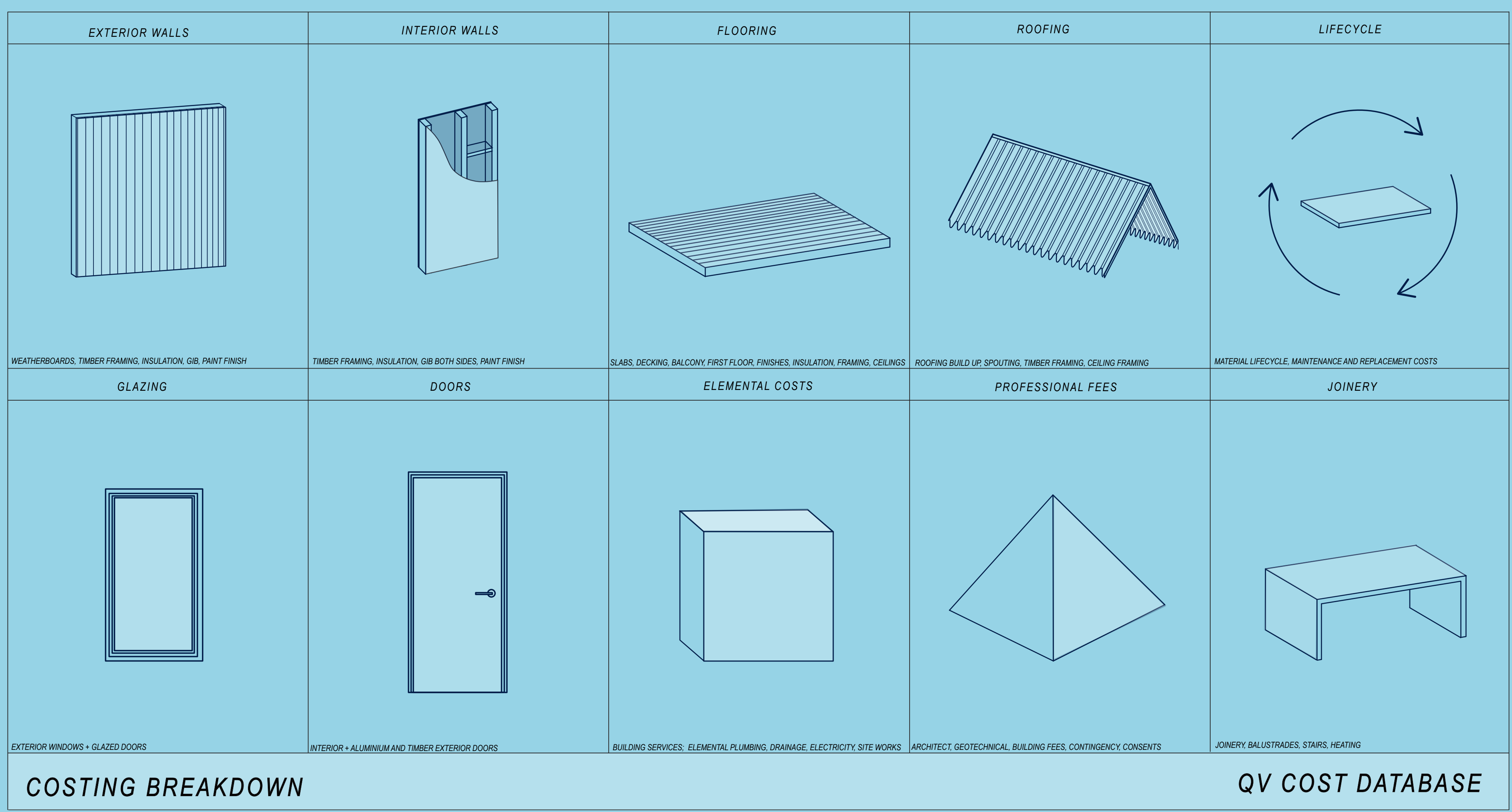


Costing Diagram Figure 4.89 Elements costed diagram 


\title{
Findings and Reflection
}

Next Generation Architect

\begin{abstract}
A Next Generation Architect will have the knowledge to advise their clients on the most economical materials and construction techniques. It is crucial that the lifespans of materials, upfront and lifecycle costs and implications of selected products is understood, when considering the overall value, ongoing costs and future resale value of a dwelling. Lifecycle costs were analysed and applied to designs, considering the upfront and maintenance costs required. The exercise undertaken on house 4.1 testing five cladding types was successful in gaining an understanding into the economics of design concepts, detail, materials, or the best way to utilise materials such as a small area of expensive materials like cedar. The concept of value in design is explored in this design phase through the use of standard detailing, allowing architects to store libraries of details to be used across future projects, saving documentation time.
\end{abstract}

Design Phase Four introduced two new housing typologies and the development of the four houses designed in Phase Three. The two new designs gave a 1 bedroom option with consideration into the future with space to add an additional bedroom. The split level portrayed a site-specific option that can be amended to suit other west sloping sites. The interiors of the dwellings are now felt as habitable spaces. This is achieved through the design of joinery, storage, furniture and material usage, illustrated through plans, sections and renders. Seed designs containing stair joinery, panelling, shelving and furniture containing storage were repeated across all dwellings as standard items. House 4.1 explored four interior fit out options and five exterior options; this gave the architectural product a number of aesthetic choices for clients to choose from. 

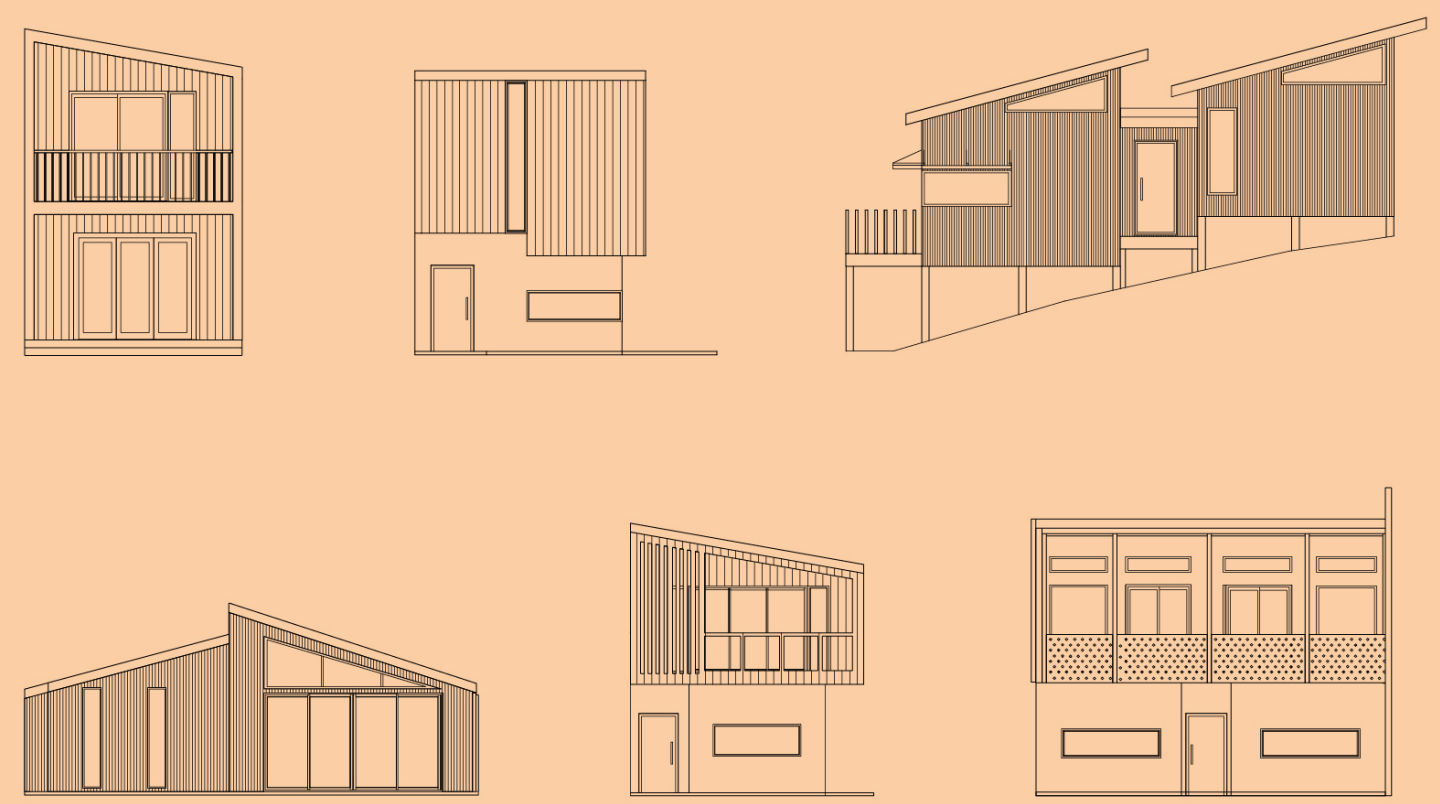

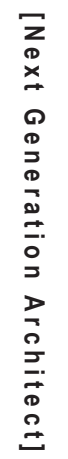




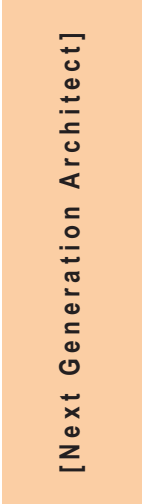




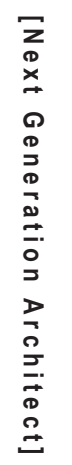

$\frac{07}{\text { Conclusion }}$ 


\section{How can architects work with value to optimise design?}

Seven conclusions are drawn from this research, drawn from each design phase. They demonstrate how an architect can work with value more accurately. They include architecture as a product, BIM, simplicity, standard detailing, lifecycle and time.

The Next Generation Architect has the role architect as a maker. Linking both the design and construction as a whole, rather than individual processes, similar to the young practice, Makers of Architecture. This allows the architect to work seamlessly alongside a builder or fabricator. By combining both processes it allows for cost implications and construction techniques to be understood and utilised from the start of a project. In a time of fragmentation of architecture services and partial architecture services, this also restores a continuity of architectural practice right through the design and build process.

An architect cannot control the cost of land, however they can control the utilisation and efficiency of its usage. Controlling the overall costs of the architectural product is achieved through material selection, including consideration of lifespan, maintenance, quality, modular design, and optimising usable floor area. Simplicity was considered through six housing typologies, designed with special elements of each house carefully selected and utilised to ensure the outcomes are both economical and architectural. The first cost estimates within each design phase explored definitions of value. By creating a cost library and understanding the up to date costing of each element of a design, it allows for design decisions to be made that work with a set budget. All housing typologies designed were costed to be affordable and under $\$ 500,000$ as a first cost estimate.

\section{Architecture as product:}

Architects can work with value by designing and documenting architecture as product. Architecture as product is illustrated through the use of the pattern book in Design Phase Two. This is a key way architects can work with value to optimise design. A number of New Zealand architects are already working with this concept of architecture as product creating cost effective dwellings, seen through the Snug Homes, Herbst architect's Te Modular and Andre Hodgkin's iPad. The pattern book created a number of housing typologies that are versatile across a number of sites. There are minimal variations to construction type, material, foundations and window placement. Repetition is key for any product, including products of architecture. Repeating designs also allows for the multi-proof consent system to be used saving clients' money and time through the speed of construction. Repetition with minimal charges around bespoke selections and material fit outs allows the architecture to remain a product where all cost implications are understood. Without turning each project into a bespoke home, professional fees and time are saved. 
BIM:

BIM through the use of computer modelling software such as Revit, or ArchiCAD, allows architects to see the implications of value from the conceptual phase through to the final design of a project. This gives architects a first cost estimate to what elements are costing before progressing the design into a developed form, which also considers both cost and design. Storing referenced cost data in libraries allows architects to access these records and apply them into BIM software, such as Revit Schedules. BIM provides accurate cost estimates through the use of a digital model; this eliminates the number of mistakes within a project when costing. Collaboration and communication across disciplines in the real world, allows for multiple professionals to work seamlessly on the same file. This is also a way that mistakes can be highlighted and eliminated before construction begins, saving rework in the design phase. This ensures confidence in the Next Generation Architect.

\section{Simplicity:}

To keep dwellings economical, architects need to consider simplicity within the design. Value is explored through the design, with the use of modular forms across all six housing typologies, including standard wall to floor heights that work with standard sheet sizes. A minimal material pallet was explored, with a maximum of two materials on the external envelope of the dwellings. This was also the case with the interiors, where a number of fit out options were explored. Floor areas provide an illusion of space while using minimal area, to ensure there is no wasted space. Within each room clever storage systems, joinery and furniture were designed to save space within each dwelling.

\section{Standard detailing:}

Standard detailing and construction processes of a dwelling allow architects to achieve an economic outcome that considers value and accuracy of the design. This is achieved through sharing libraries of details across a number of projects. This saves time and money that can be spent elsewhere within the design, and provides a clear and accurate process for builders and councils to follow. Keeping irregular details and elements to a minimum, is an economical choice that reduces the complexity of a project. Architectural homes can be achieved through the use of standard detailing. This is seen through the Eames house, that is a bespoke outcome of the case study house program. The Eames house using standard steel framing and a modular form, mixed with the use of carefully selected materials, created a successful outcome. Construction processes that have been considered throughout the six housing typologies include precast concrete, timber framing and a hybrid of the two. Posi-Struts are a standard construction process, applied to dwellings where larger spans of flooring and roofing are needed. 


\section{Lifecycle:}

Considering the lifecycle of a building is a vital way that architects can work with value, to optimise design over time. Lifecycle costings of the dwellings considered material, maintenance and replacement, upfront and whole life costing. Having an understanding of materials and their maintenance requirements, is a crucial element of value for architects to understand. Materials have a number of cost implications involved with them, including upfront costs, maintenance, warranty and replacement that affect the overall value. A Next Generation Architect will inform their client on the most economic materials that require a long lifespan and minimal maintenance with the cost implications illustrated over a 50-year period.

\section{Time:}

Time is critical when considering the value of a project. Time equals cost therefore a faster design and construction phase will provide clients with a number of savings. Time, is saved through the use of architecture as product, standard detailing and the use of BIM. Reflecting on the cost quality and time equation architects will typically consider quality within bespoke design over the other values. When designing, a Next Genertion Architect will work with the parameters of the seven findings while valuing cost, time and quality.

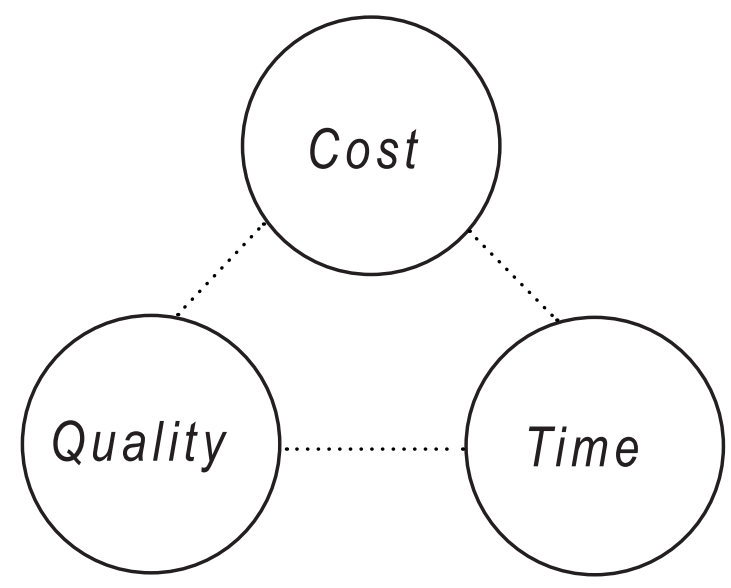

Figure 4.90 Cost, quality time diagram

The combination of these seven key aspects are key findings as to how a Next Generation Architect can work with value to optimise design. The client can have faith that the historic reputation of a stereotypical architect is refute. That their architect is competent to balance time, quality and cost, ensuring value is understood through all aspects of design.

A Next Generation Architect will be aware of cost at all times, aided by the use of smart software. Compromises within the design will not occur, as a Next Generation Architect will always be aware of the cost and the budget as they are designing. The awareness towards cost allows the trust to be restored with an architect and their services. 
Further Research

A number of questions have been generated throughout this research with possible further exploration. The following aspects could be developed further, if time permitted. These include understanding to a greater extent the effects of energy costs, passive solar design and prefabricated construction techniques.

\section{Next Generation Architect}

A Next Generation Architect will be conscious towards cost, quality and time. There will be a merge of the design and construction phases, resulting in less external consultants 'clipping the ticket', that add to overall costs. When approaching their services, there will be a choice of selecting an architectural product or a bespoke design based on the client's requirements and budget. Advice will be given surrounding economical construction techniques, design decisions and materials that best suit the client's needs and overall lifecycle of the building. This will help restore the reputation of the architectural profession as ethical, responsible and capable designers who can deliver outstanding design to meet a budget. 
Bibliography 
Abreue Lima, D. \& Isaacs, N. (2018). Max Rosenfeld: The New Zealand's Home Architect. WordPress. https://urbanjewishheritageconference.files.wordpress.com/2018/04/abreu-e-lima-and-isaacs.pdf

Beveridge, J. (2016). Disrupting the housing model. Build. 152, 84-85.

Brudson, N. (2017). Cladding costs over a lifetime. Build. 163, 82-83

Bucknell, C. (n.d.). The kitset bach. Homes to Love. https://www.homestolove.co.nz/real-homes/hometours/the-kitset-bach

Building Performance . (2016). Choosing a designer or architect. Building Performance. https://www. building.govt.nz/projects-and-consents/planning-a-successful-build/scope-and-design/choosing-theright-people-for-your-type-of-building-work/choosing-a-designer-or-architect-for-your-building-project/

Bierre, S., Howden-Chapman, P., \& Early, L. (Eds.). (2013). Homes People Can Afford: How to Improve Housing in New Zealand. Steele Roberts Aotearoa.

Chatson, D. (2019). Home loan affordability report Wellington .Interest. https://www.interest.co.nz/ property/home-loan-affordability

Chatson, D. (2019). Home loan affordability report. A monthy assessment of home loan affordability in New Zealand . Interest. https://www.interest.co.nz/property/home-loan-affordability

Church, A. (2019). The truth behind that 'dramatic drop' in home-ownership. OneRoof. https://www. oneroof.co.nz/news/the-truth-behind-that-dramatic-drop-in-home-ownership-36067

ColourSteel . (n.d.). Warranty \& maintenance. ColourSteel. https://www.colorsteel.co.nz/warranty/

Consumer NZ. (n.d.). Carpet buying guide. Consumer NZ.https://www.consumer.org.nz/articles/carpet

Cuff, D. (1992). Architecture: The Story of Practice. The MIT Press.

Deamer, P. (Ed.). (2015). The Architect as Worker: Immaterial Labor, the Creative Class, and the Politics of Design. Bloomsbury Academic.

Dejtiar, F. (2019). Case Study Houses: Lessons on Modern, Low-Budget and Easy to Build Living Spaces. Archdaily. https://www.archdaily.com/913748/case-study-houses-lessons-on-modern-lowbudget-and-easy-to-build-living-spaces

Eaqub, S., \& Eaqub, S. (2015). Generation Rent: Rethinking New Zealand's Priorities. Bridget Williams Books Limited.

Foster, C. (2015). Small House Living: Design-Conscious New Zealand Homes of 90m2 or Less. Penguin Random House New Zealand.

Foster, C. (2019). Big Ideas for Small Houses. Penguin Random House New Zealand.

Fung, J. (2010). Life cycle costs and analysis of roof cladding systems. BRANZ .

Gluckman, A. (1990). Identity and involvement: Auckland Jewry, past and present. Dunmore Press.

Hawkes, C. (2019). Cost blowouts in home building are common, but can be minimised. Stuff. https:// www.stuff.co.nz/life-style/homed/latest/115190999/cost-blowouts-in-home-building-are-common-butcan-be-minimised

Hawkes, C. (2019). Grand Designs NZ: Wedge house not your typical alpine chalet. Stuff. https://www. stuff.co.nz/life-style/homed/houses/116069557/grand-designs-nz-wedge-house-not-your-typicalalpine-chalet 
Hodgkin, A. (n.d.). iPad . Architex. http://www.ipad.net.nz

Howard, N. Burgess, J. \& Lim, C. (2007). Comparative service life assessment of window systems. Australian Government.

James Hardie . (n.d.). Linea Weatherboard . James Hardie. https://www.jameshardie.co.nz/products/ cladding/linea-weatherboard

James Hardie . (n.d.). Titan Facade Panel . James Hardie. https://www.jameshardie.co.nz/products/ cladding/titan

KiwiBuild. (2019). What types of homes are available? KiwiBuild. https://www.kiwibuild.govt.nz/buyinga-kiwibuild-home/what-types-of-homes-are-available/

Kulper, P. (2013). A World Below. Architectural Design, 83(5), 56-63. https://doi.org/10.1002/ad.1663

Levy, F., \& Ouellette, J. (2019). BIM for Design Firms (1st ed.). John Wiley \& Sons, Ltd. https://doi. org/10.1002/9781119252849

London deputy mayor Lister blames "expensive architects" for housing woes. (2013). Building Design, (2069), 3.

Manch, T. (2018). Nine million-dollar suburbs for Wellington as house values jump nearly 50 per cent. Stuff. https://www.stuff.co.nz/business/property/108353295/nine-milliondollarsuburbs-for-wellington-as-house-values-jump-nearly-50-per-cent?fbclid=IwAR3Z9yoUhbw IfAJFyn4LXAb1Bs3pHPM4SewgmJc2PDUylqYX96i7sOnNPE

Marmor,M. (1996). Back to the drawing board: The architectural manual of Sebastiano Serlio (14751554). The Yale University Library Gazette, 70(3/4), 115-125.

McCoy, E. (1977). Case Study Houses 1945-1962. Hennessey \& Ingalls, Inc.

Melbourne-Hayward, A. (2017). The act of making . ArchitectureNow. https://architecturenow.co.nz/ articles/the-act-of-making-makers-of-architecture/

Melbourne School of Design. (2015). Merchant Builders: Towards a new archive. Melbourne University.

Ministry of Business, Innovation and Employment. (2019). Acceptable Solutions and Verification Methods: For New Zealand Building Code Clause B2 Durability. New Zealand Government .

Ministry of Business, Innovation and Employment. (2016). MultiProof Consent . Building Performance. https://www.building.govt.nz/building-code-compliance/product-assurance-and-multiproof/multiproof/

NZIA. (2017). 10 Myths about Architects. New Zealand Institute of Architects Incorporated.

NZIA. (2018). NZIA Agreement for Architects Services. New Zealand Institute of Architects Incorporated.

O'Callaghan, J. \& Pickett, C. (2012). Designer Suburbs: Architects and Affordable Homes in Australia. NewSouth Publishing.

O'Callaghan, J. (2017). "Individuality" and the standardised house: The display home interiors of Australian builder Pettit \& Sevitt, 1961-1978. Interiors, 8(3), 141-158. https://doi.org/10.1080/204191 12.2017.1400815

Page, I. (2015). Cladding costs over a lifetime. Build. 147, 71-72. 
Perez, A. (2010). Eames House. ArchDaily. https://www.archdaily.com/66302/ad-classics-eameshouse-charles-and-ray-eames

Prefab NZ. (2018). Snug Home Catalogue. Prefab NZ. http://www.prefabnz.com/Projects/Detail/snugdesign-competition

Pringle, T. (2019). Exceeding the Minimum. Build. 172, 38-41.

Quotable Value Limited. (2019). QV Costbuilder. QV Costbuilder. https://www.qvcostbuilder.co.nz

Rawlinsons. (2011). NZ Construction Handbook 2011. Rawlinsons Media Limited.

Rendell, J. (2013). "A Way With Words: Feminists Writing Architectural Design Research."Design research in architecture : an overview. Ashgate Publishing Limited.

RIBA . (2018). The cost of not designing to a budget.RIBA. https://www.architecture.com/knowledgeand-resources/knowledge-landing-page/the-cost-of-not-designing-to-a-budget

Sebastian, R. (2010). Integrated Design and Engineering using Building Information Modeling: A Pilot Project of Small-Scale Housing Development in The Netherlands. Architectural Engineering and Design Management , 6(2), 103-110. https://doi-org.helicon.vuw.ac.nz/10.3763/aedm.2010.0116

Shead, O. (2015). The top 6 reasons to not use an architect. Interiors Addict. https://theinteriorsaddict. com/the-top-6-reasons-to-not-use-an-architect

Smarter Homes. (2019). Insulating your home. Smarter Homes. https://www.smarterhomes.org.nz/ smart-guides/heating-cooling-and-insulation/insulating-your-home/

Smith, C. (n.d.). These architectural community houses promise to break the poverty cycle. Homes to Love. https://www.homestolove.co.nz/inspiration/community-houses-triangle-road-strachan-group

Steele, J. (2002). Eames House: Charles and Ray Eames. Phaidon Press Limited.

Strachan Group Architects. (n.d.). Studio 19 Bach. Strachan Group Architects. https://www.sgaltd. co.nz/studio-19-

Strachan Group Architects. (n.d.). Triangle Road Community Housing, Massey, Auckland . Strachan Group Architects. https://www.sgaltd.co.nz/triangle-road

Wellington City Council. (2009). Wellington City District Plan Residential Areas. Wellington City Council. https://wellington.govt.nz/ /media/your-council/plans-policies-and-bylaws/district-plan/changes/ active-changes-variations/files/change72-decision-chap05-standards-v2.pdf?la=en

Wellington City Council. (2019). Property Search. Wellington City Council. https://wellington.govt.nz/ services/rates-and-property/property/property-search

Wheeler, T. (2015). Ken Woolley. Architecture Australia. https://architectureau.com/articles/vale-kenwoolley-1933-2015/ 


\section{Chapters $1 \& 2$}

Figure 1.02. Example of a page of the NZIA Agreement for architects' services contract. NZIA. (2018). NZIA Agreement for Architects Services. New Zealand Institute of Architects Incorporated.

Figures 1.06 - 1.11. Makers of Architecture. (2015). Warrander Studio. Makers of Architecture. http:// www.makersofarchitecture.co.nz/project/warrander-studio

Figures 1.12 - 1.14. Strachan Group Architects. (n.d.). Triangle Road Community Housing, Massey, Auckland . Strachan Group Architects. https://www.sgaltd.co.nz/triangle-road

\section{Chapter 3}

Figure 2.01 \& 2.11. Build Smart. (n.d.). Two Bedroom Transportable Homes. Build Smart. https:// www.builtsmart.co.nz/transportable-homes-floor-plans-prices/2-bedroom-house-plans

Figure 2.02, 2.11 \& 2.19. Exterior render and authors edit on plan. Lockwood Homes. (n.d.). Vacationer. Lockwood Ready Build. https://lockwoodreadybuilt.co.nz/home/vacationer/

Figure 2.03, 2.11 \& 2.12. Exterior render and authors edit on plan. Stonewood Homes. (n.d.). Avon. Stonewood Homes. https://stonewood.co.nz/home-designs/avon/

Figure 2.04, 2.11 \& 2.18. Exterior render and authors edit on plan. A1 Homes. (n.d.). Plan EH127. A1 Homes. https://www.a1homes.co.nz/plans/18/EH127

Figure 2.05 \& 2.11. Exterior render and authors edit on plan. Design Builders. (n.d.). Plan 1705. Design Builders. https://www.designbuilders.co.nz/budget/plan-17025/

Figure 2.06, 2.11, 2.14 \& 2.15. Exterior render and authors edit on plan. Design Builders. A1 Homes. (n.d.). Plan BH136. A1 Homes. https://www.a1homes.co.nz/plans/18/BH136

Figure 2.07, 2.11 \& 2.16. A1 Homes. Exterior render and authors edit on plan. Design Builders. (n.d.). Plan BH84. A1 Homes. https://www.a1homes.co.nz/plans/18/BH84

Figure 2.08, 2.11 \& 2.13. Keith Hay Homes. (n.d.). Raglan. Keith Hay Homes. https://www.keithhayhomes.co.nz/housing/coastal/raglan.html

Figure 2.09 \& 2.11. Design Builders. (n.d.). Plan 18004. Design Builders. https://www.designbuilders. co.nz/budget/plan-18004-2/

Figure 2.10 \& 2.11. Design Builders. (n.d.). Plan 1419. Design Builders. https://www.designbuilders. co.nz/budget/plan-1419/

Figure 2.17 \& 2.11. Authors edit on plan. Lockwood Homes (n.d.). Acacia. Lockwood Ready Build. https://lockwood.co.nz/home/acacia-show-home-taupo/

Figures 2.23-2.26. Studio 19 Images. Source: Strachan Group Architects. (n.d.). Studio 19 Bach. Strachan Group Architects. https://www.sgaltd.co.nz/studio-19-

Figures $2.27 \&$ 2.28. Authors edit using district plan information for site diagram. Wellington City Council. (2009). Wellington City District Plan Residential Areas. Wellington City Council. https://wellington.govt.nz/ /media/your-council/plans-policies-and-bylaws/district-plan/ changes/active-changes-variations/files/change72-decision-chap05-standards-v2.pdf?la=en 


\section{Chapter 4}

Figures 3.01 \& 3.02. State housing plans authors edit. McKay, B., Stevens, A., \& Devitt, S. (2014). Beyond the state : New Zealand state houses from modest to modern. Penguin Group NZ.

Figures 3.03-3.05. Rees Quilford. (2016). Merchant Builders: Celebrating a fifty-year legacy. The University of Melbourne. https://pursuit.unimelb.edu.au/articles/merchant-builders-celebrating-a-fifty-year-legacy

Figures 3.06 - 3.08. Modern House.(n.d.) Pettit and Sevitt. Modern House. http://www.modernhouse. co/pettit-sevitt/

Figures 3.09 - 3.12. Exterior renders and authors edit on plans. Source: Prefab NZ. (2018). Snug Home Catalogue. Prefab NZ. http://www.prefabnz.com/Projects/Detail/snug-design-competition

Figures 3.13 -3.19. Hodgkin, A. (n.d.). iPad. Architex. http://www.ipad.net.nz

\section{Chapter 5}

Figures 4.12 \& 4.13. Herbst Architects. (n.d.). Te Modular. Herbst Architects. http://herbstarchitects. co.nz/projects/te-modular

Figure 4.14. Home Magazine.(n.d.). Two compact homes squeeze into a tiny Christchurch site. Homes to Love. https://www.homestolove.co.nz/real-homes/home-tours/two-compact-homes-squeeze-intotiny-christchurch-site

Figure 4.16. Actual. (n.d.). Wedge House. Actual Architecture Co. https://www.actual.ac/project/ wedge-house/

Figure 4.17. Hawkes, C. (2019). Grand Designs NZ: Wedge house not your typical alpine chalet. Stuff. https://www. stuff.co.nz/life-style/homed/houses/116069557/grand-designs-nz-wedge-housenot-your-typical-alpine-chalet

Figure 4.18. Radermacher, D. (2019). Wanaka Wedge House. Actual Architecture Co. https://www. actual.ac/project/wanaka-wedge-house/

Figure 4.19 \& 4.20. Authors edit of construction detailing. Steele, J. (2002). Eames House: Charles and Ray Eames. Phaidon Press Limited.

Figure 4.21. AD Editorial Team. (2019). Spotlight Charles and Ray Eames. Arch Daily. https://www. archdaily.com/642966/spotlight-charles-and-ray-eames?ad_source=search\&ad_medium=search_ result_all

Figure 4.25. Authors edit of construction detail. Mitek fabricated products. (2019). Posi-Strut Design Manual. Mitek.

Figures 4.26 \& 4.27. Authors edit combining data from 2 sources. Page, I. (2015). Cladding costs over a lifetime. Build. 147, 71-72. And Brudson, N. (2017). Cladding costs over a lifetime. Build. 163, 82-83.

Figures 4.28 \& 4.29. Authors edit. Fung, J. (2010). Life cycle costs and analysis of roof cladding systems. BRANZ. 


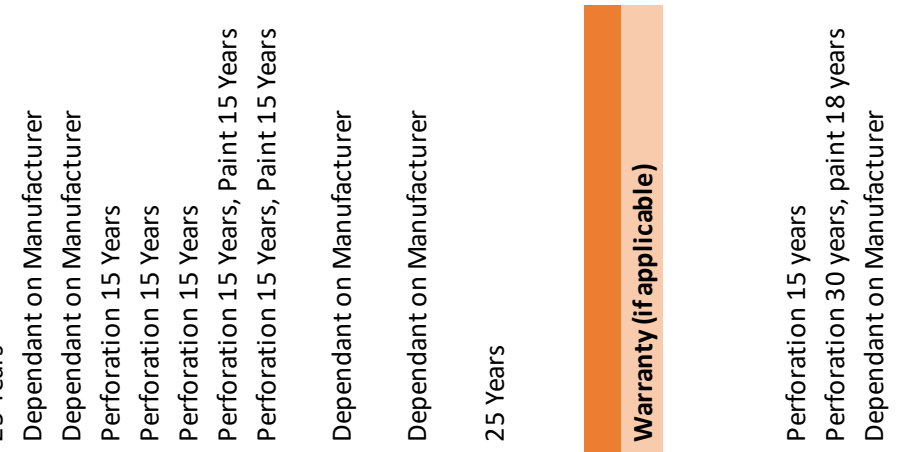

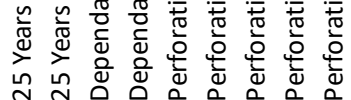

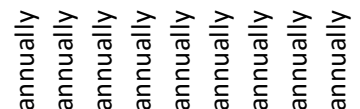

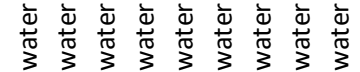

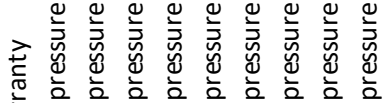

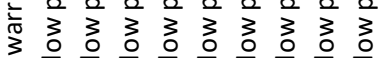

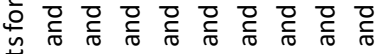

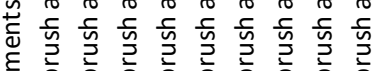

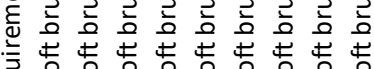

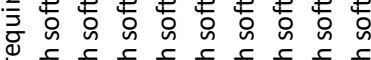

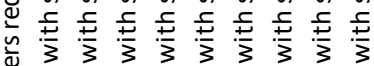

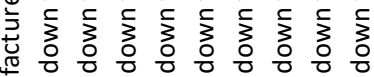

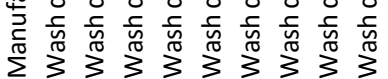

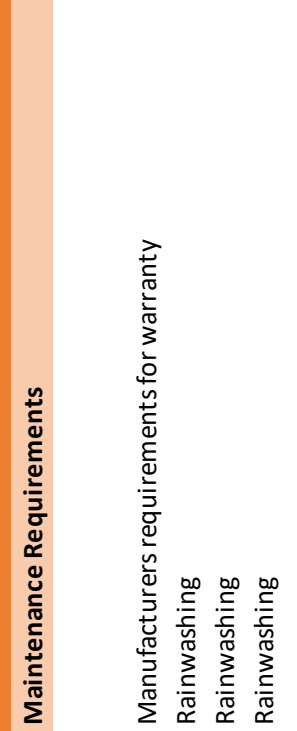

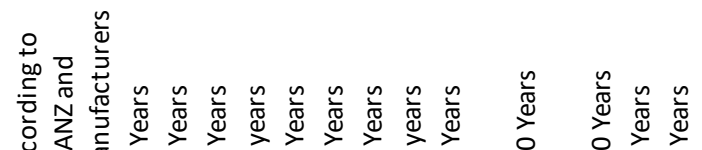

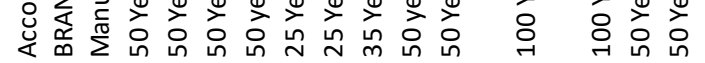

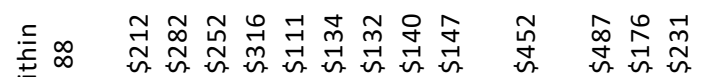
莎

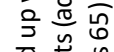

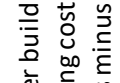

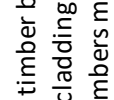

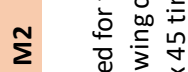

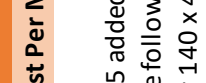

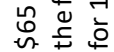

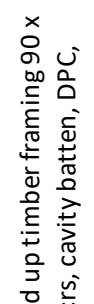
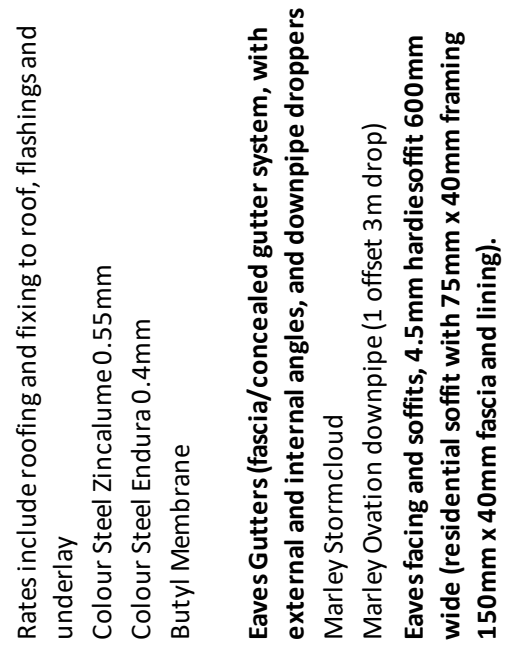


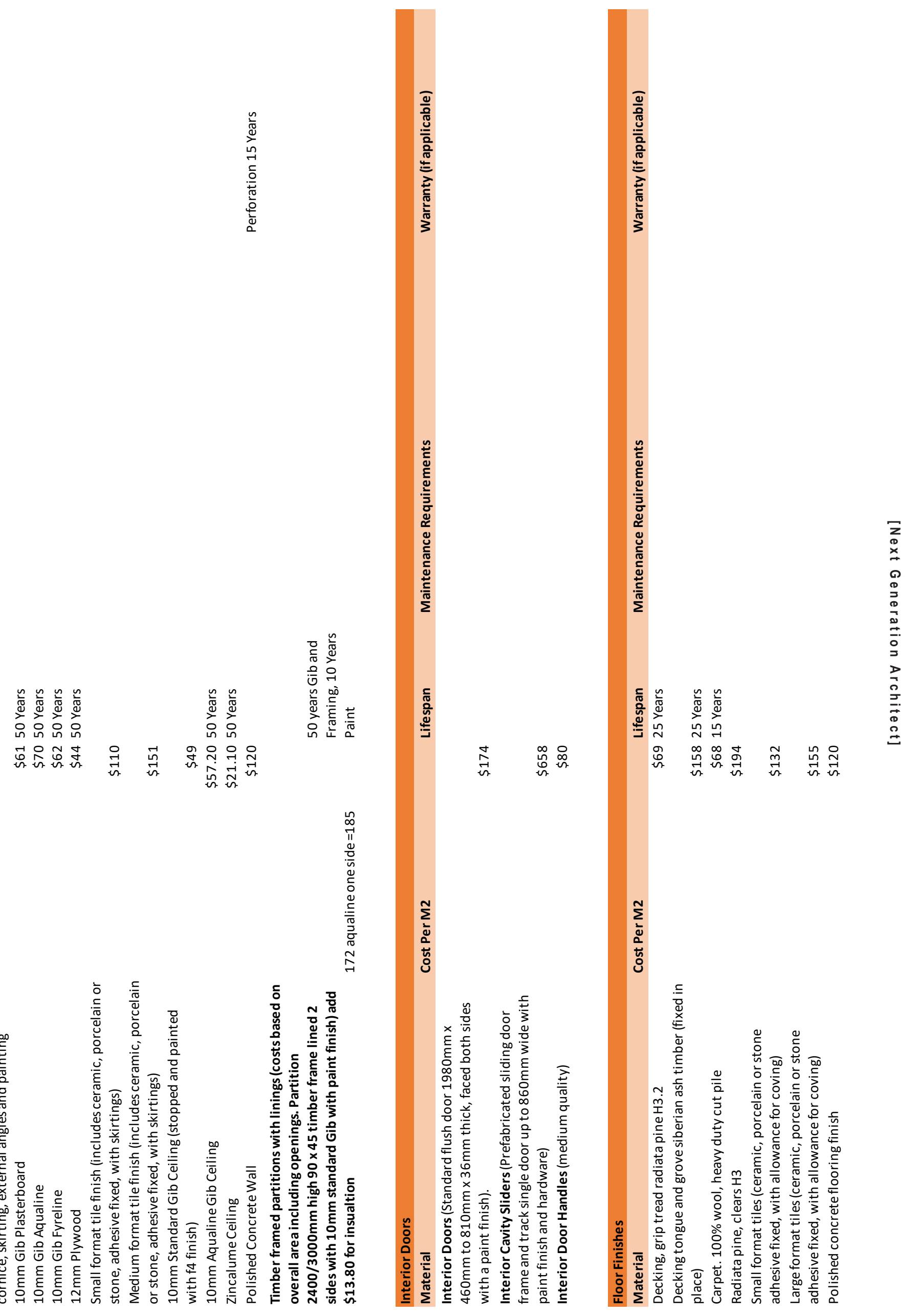




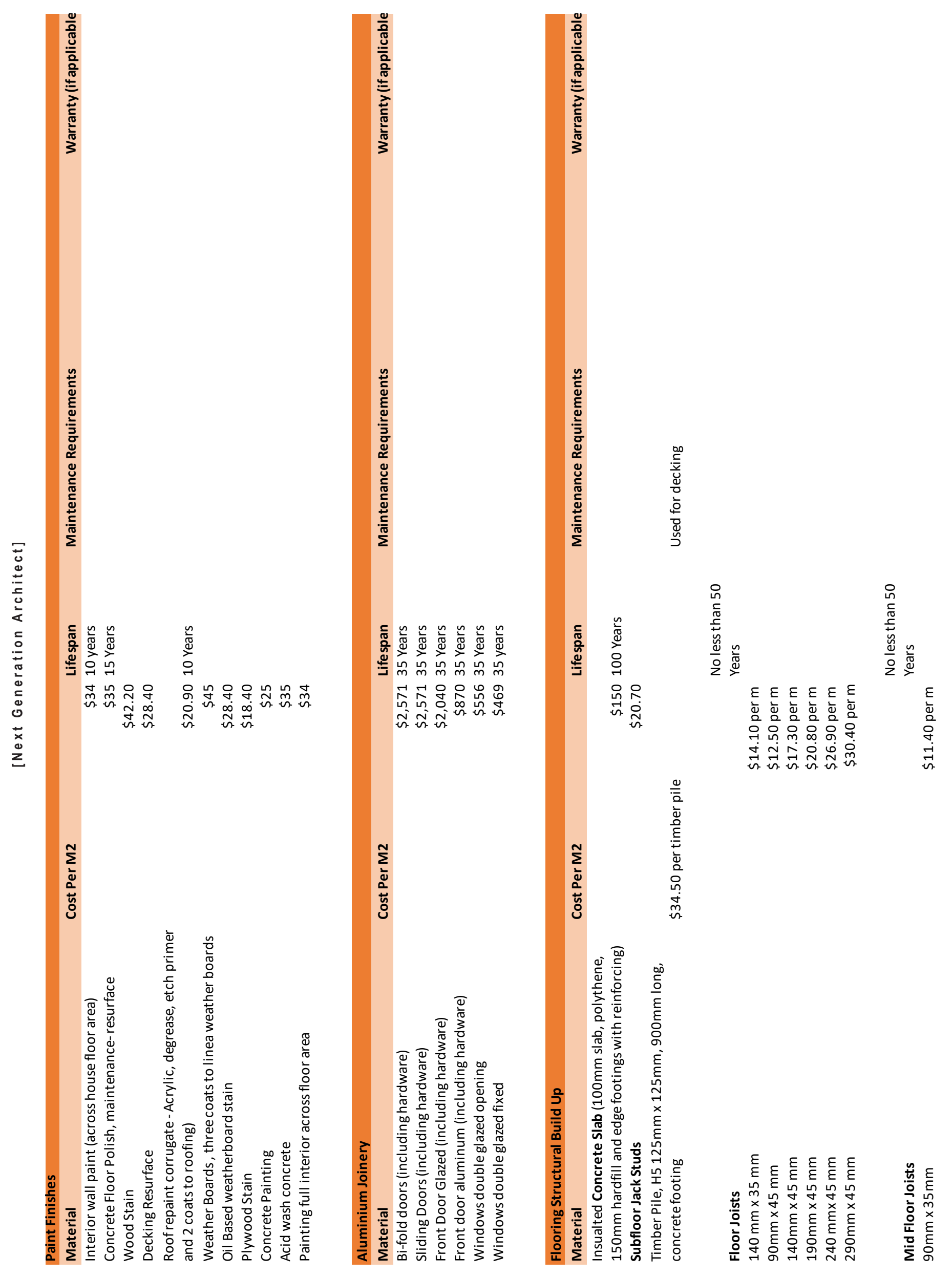




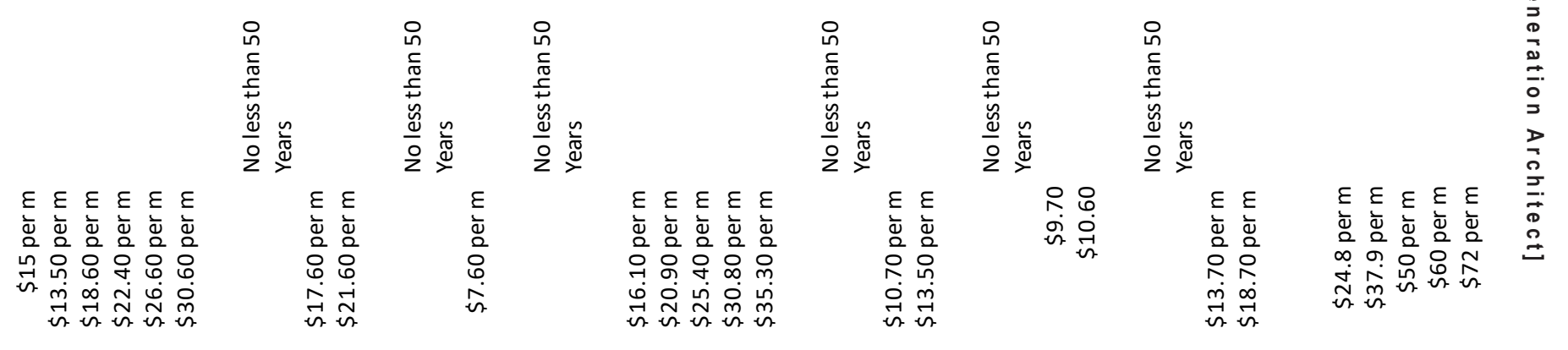

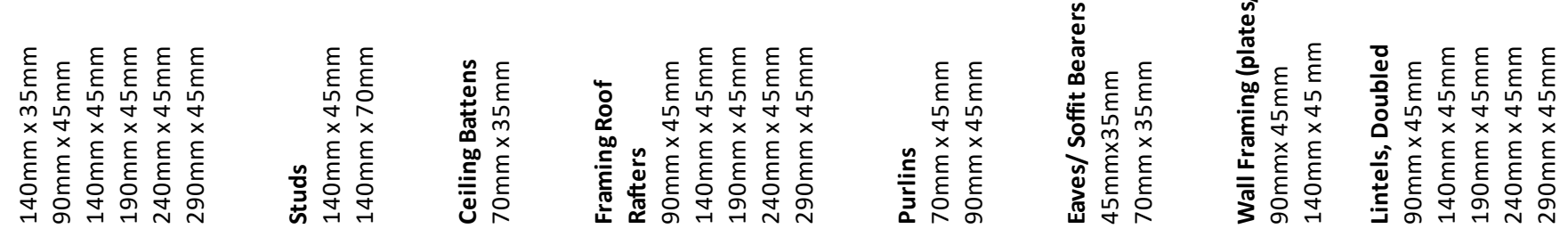



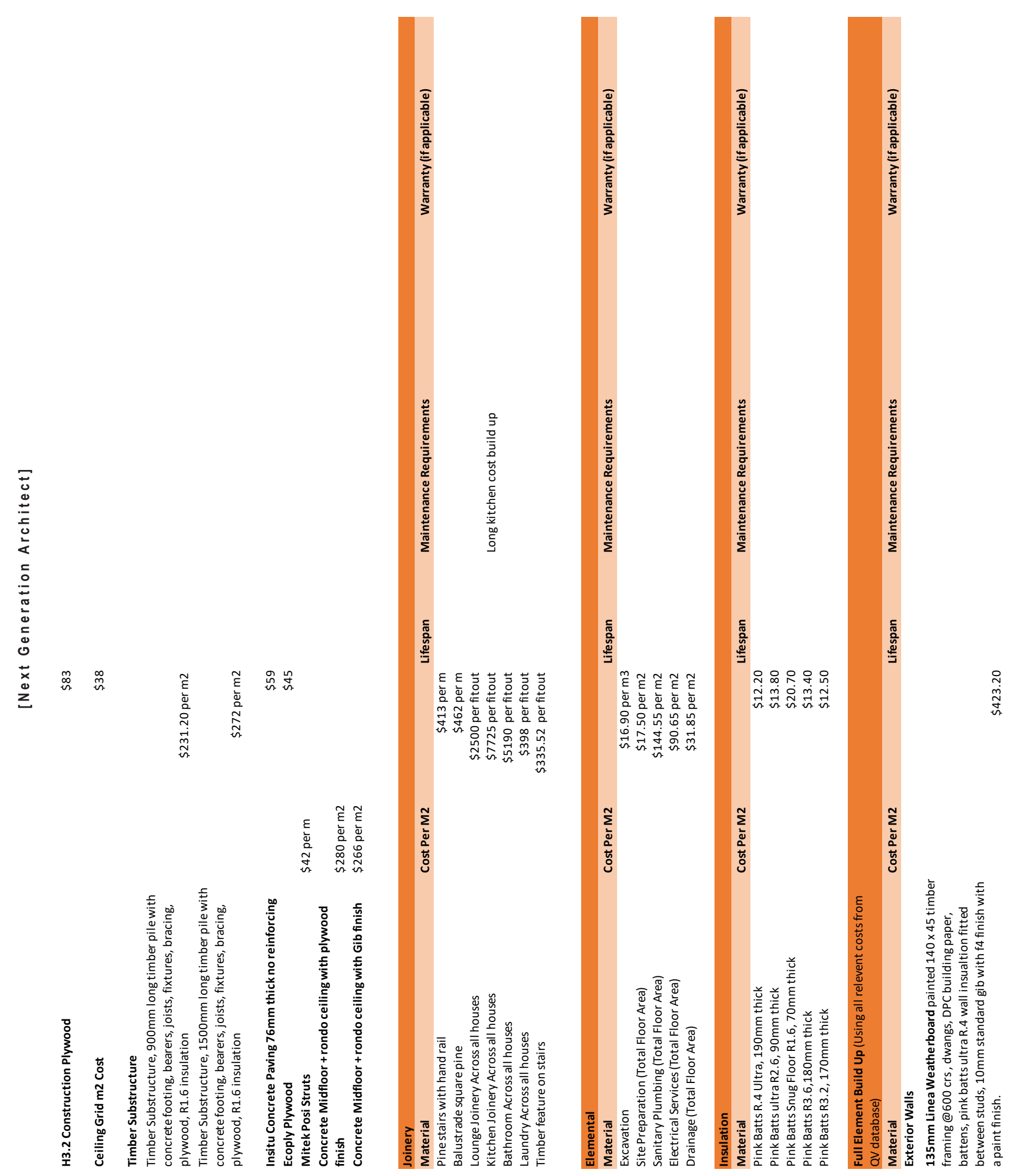

总品 


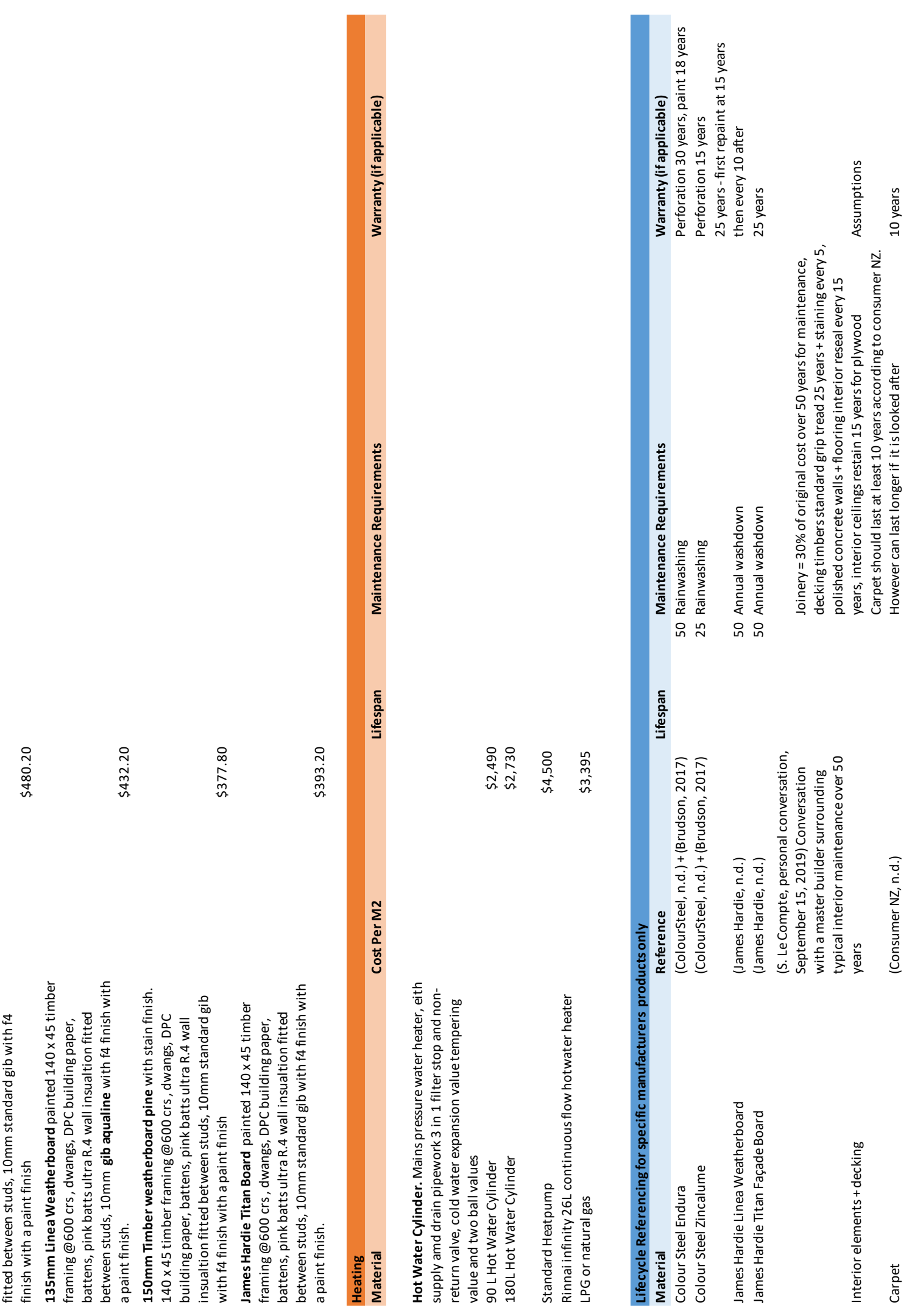




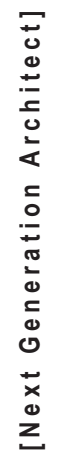




\section{Appendix 2}

Design Phase 3 Costing Breakdown 


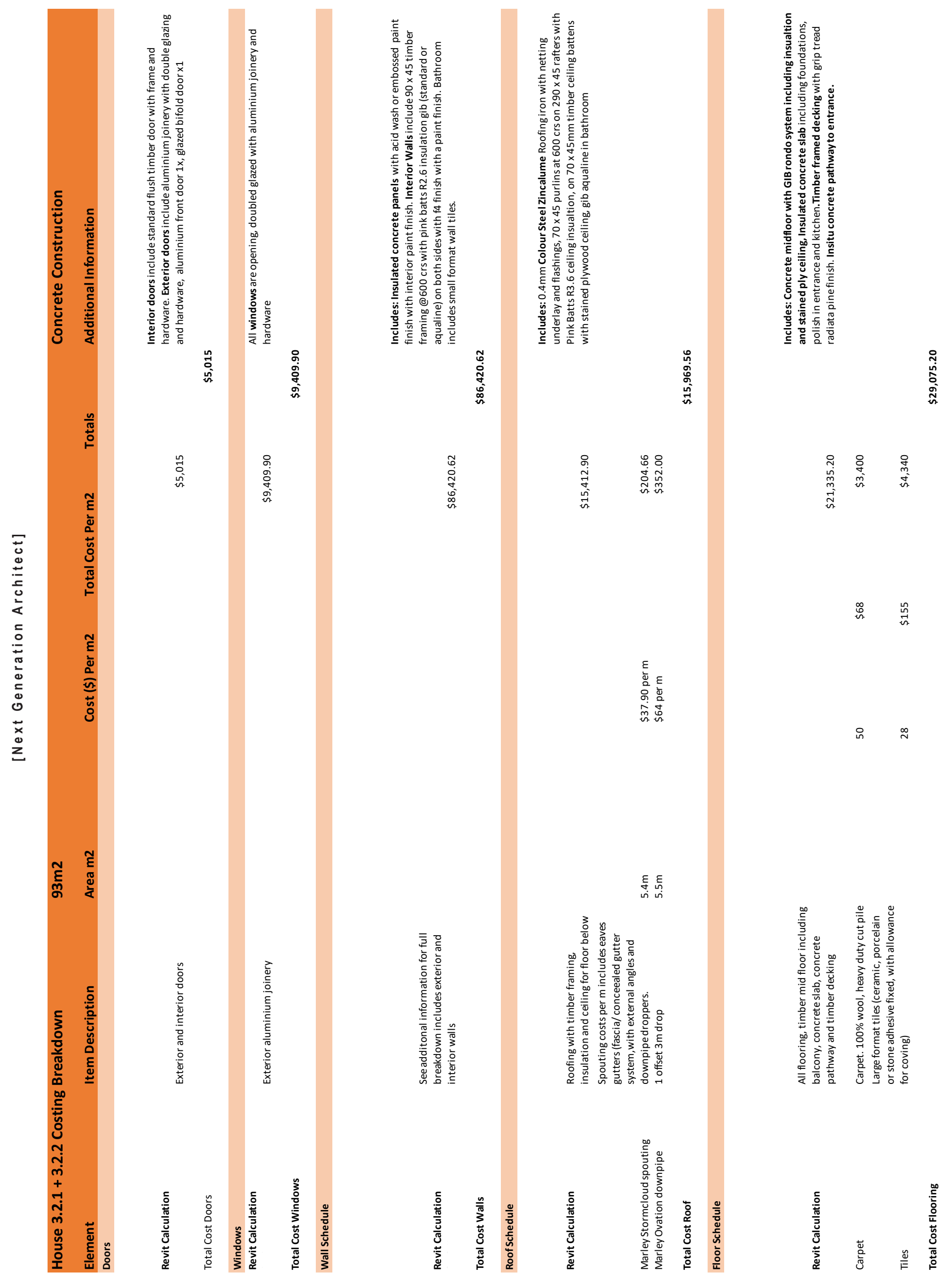



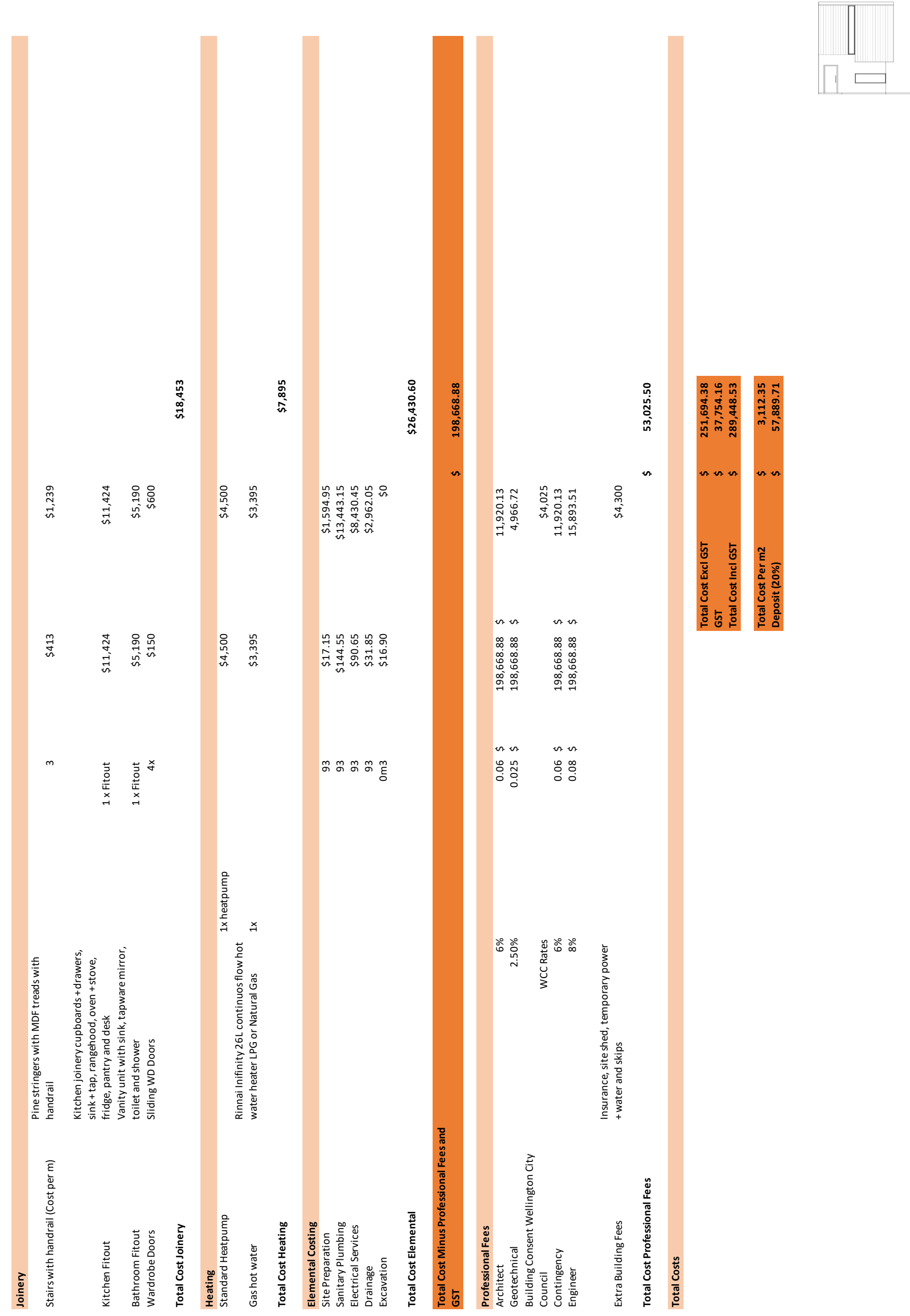
Figure 4.93 Houses 3.2.3 - 3.2.6 costing breakdown

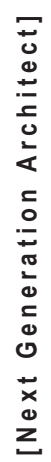
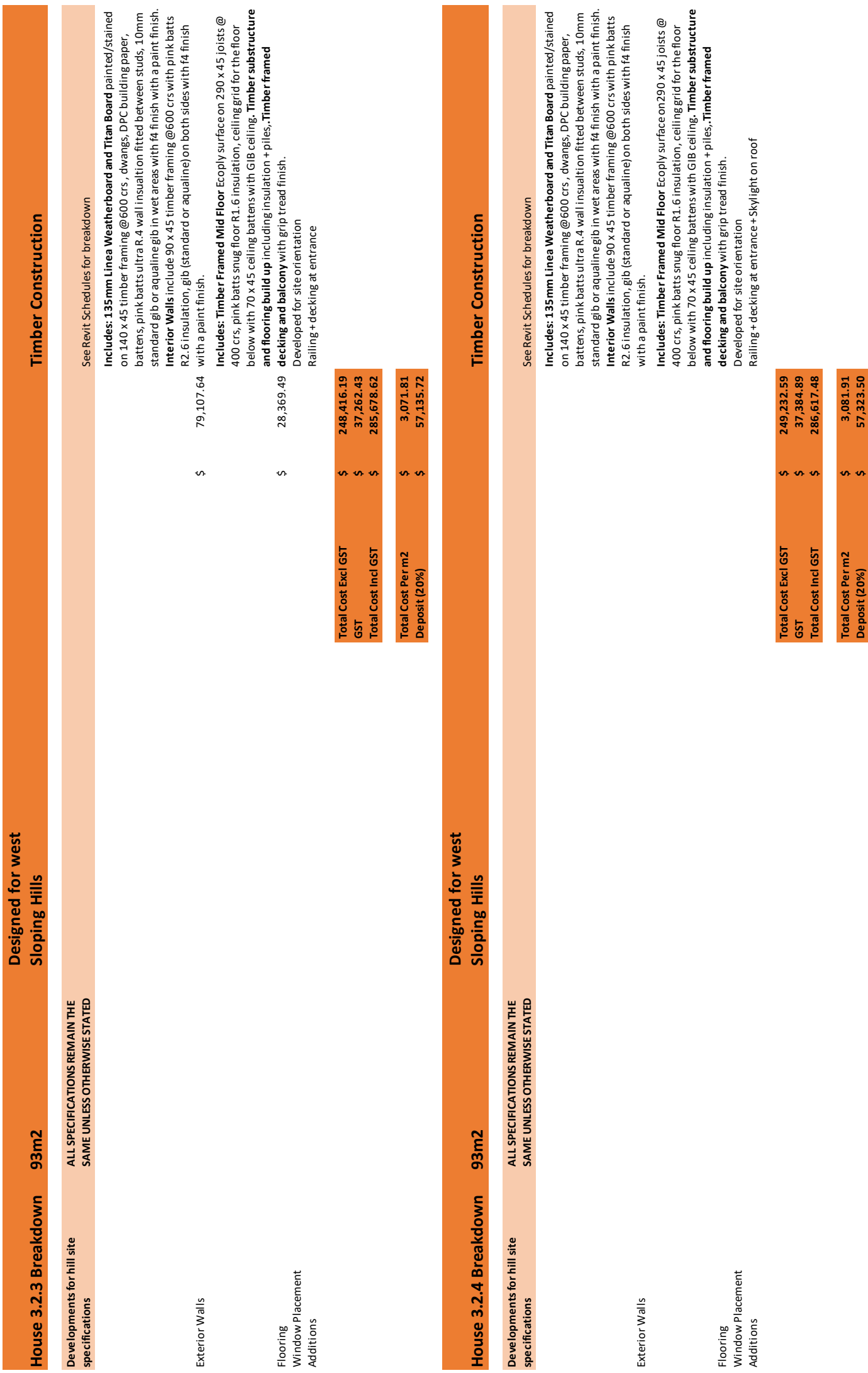

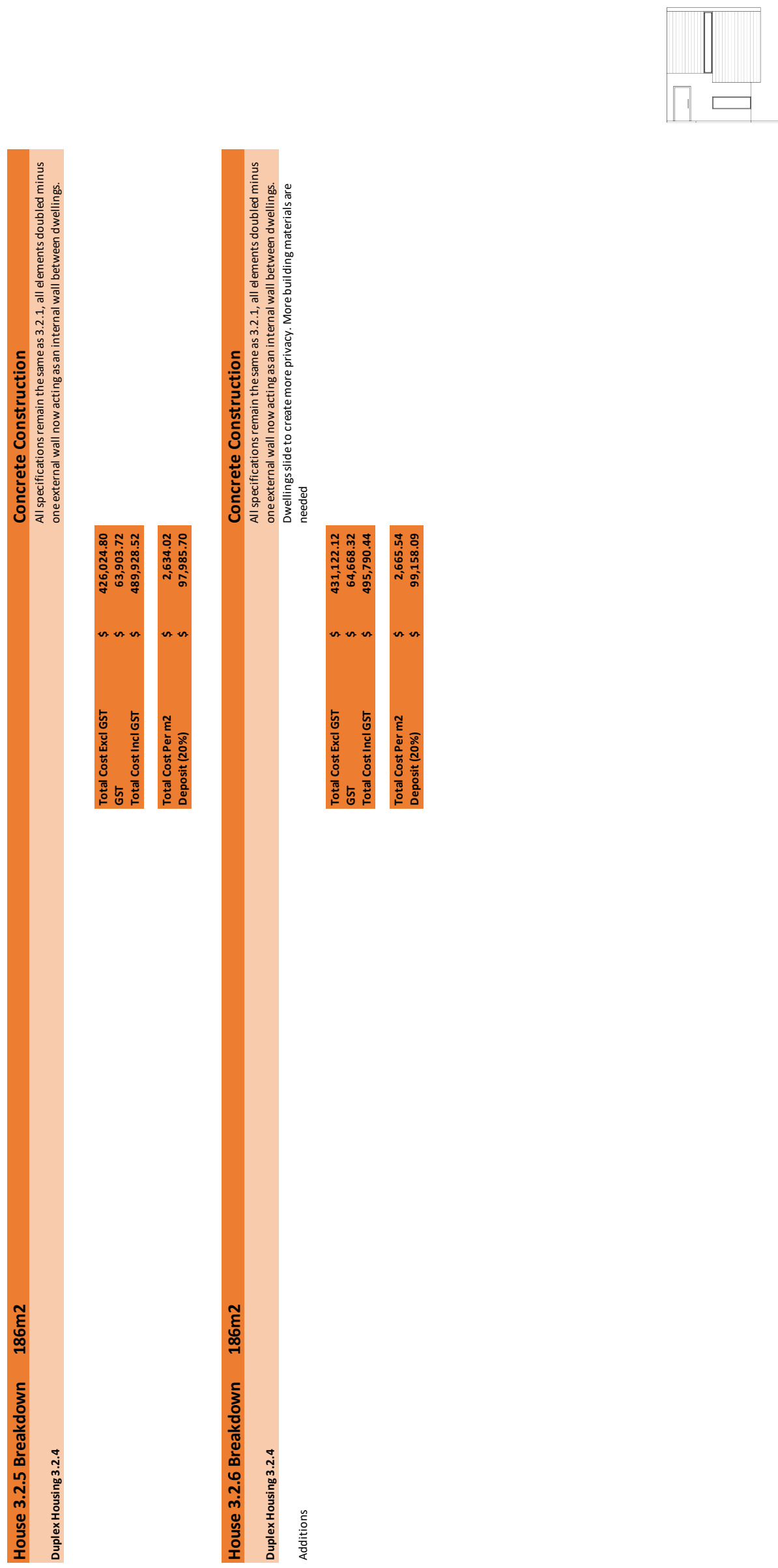

\begin{tabular}{l}
$z$ \\
0 \\
$x$ \\
0 \\
0 \\
0 \\
0 \\
0 \\
0 \\
0 \\
0 \\
0 \\
0 \\
$D$ \\
$D$ \\
0 \\
0 \\
\hline 0 \\
0 \\
0 \\
\hline
\end{tabular} 
Figure 4.94 House 3.3.1 costing breakdown

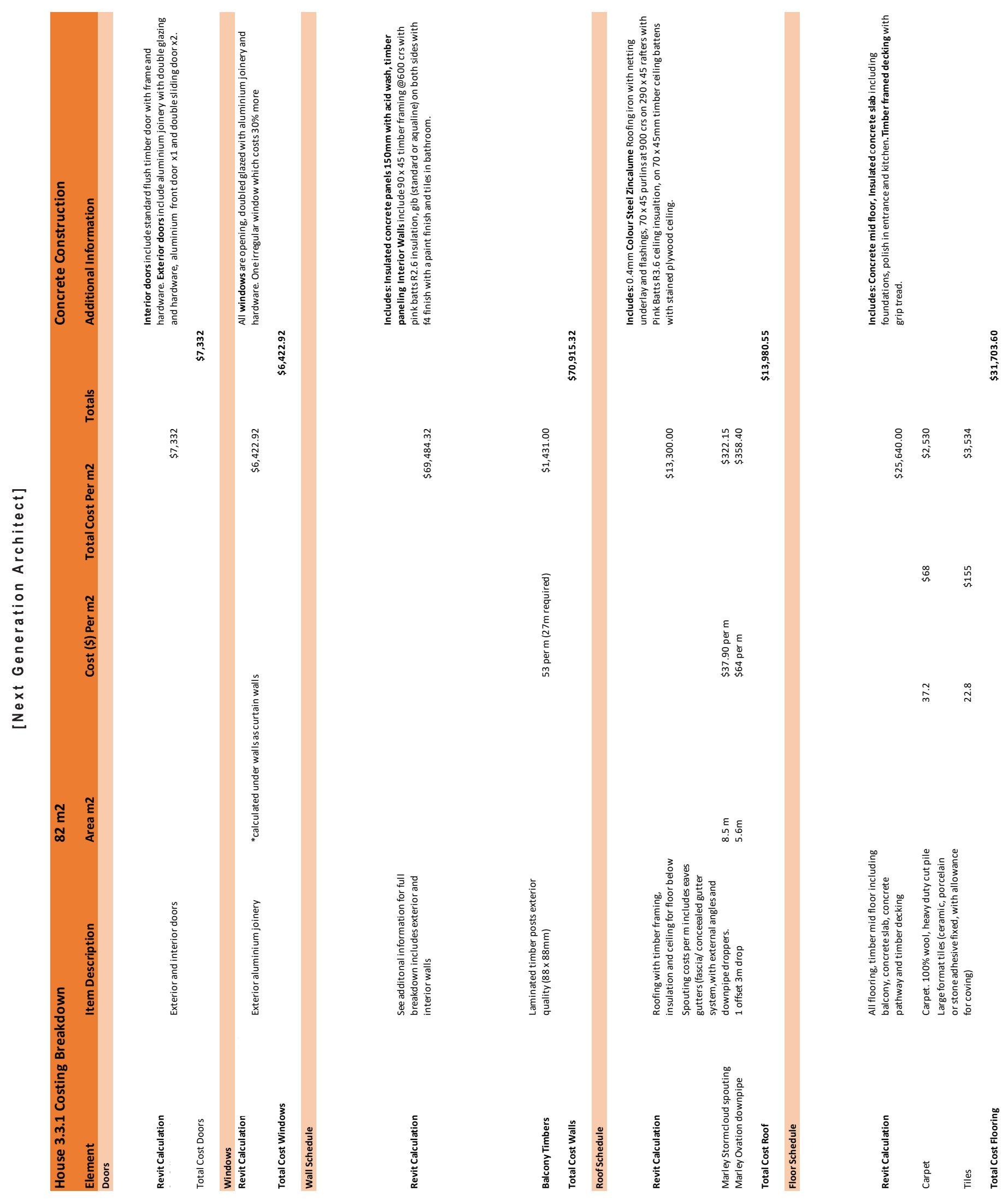



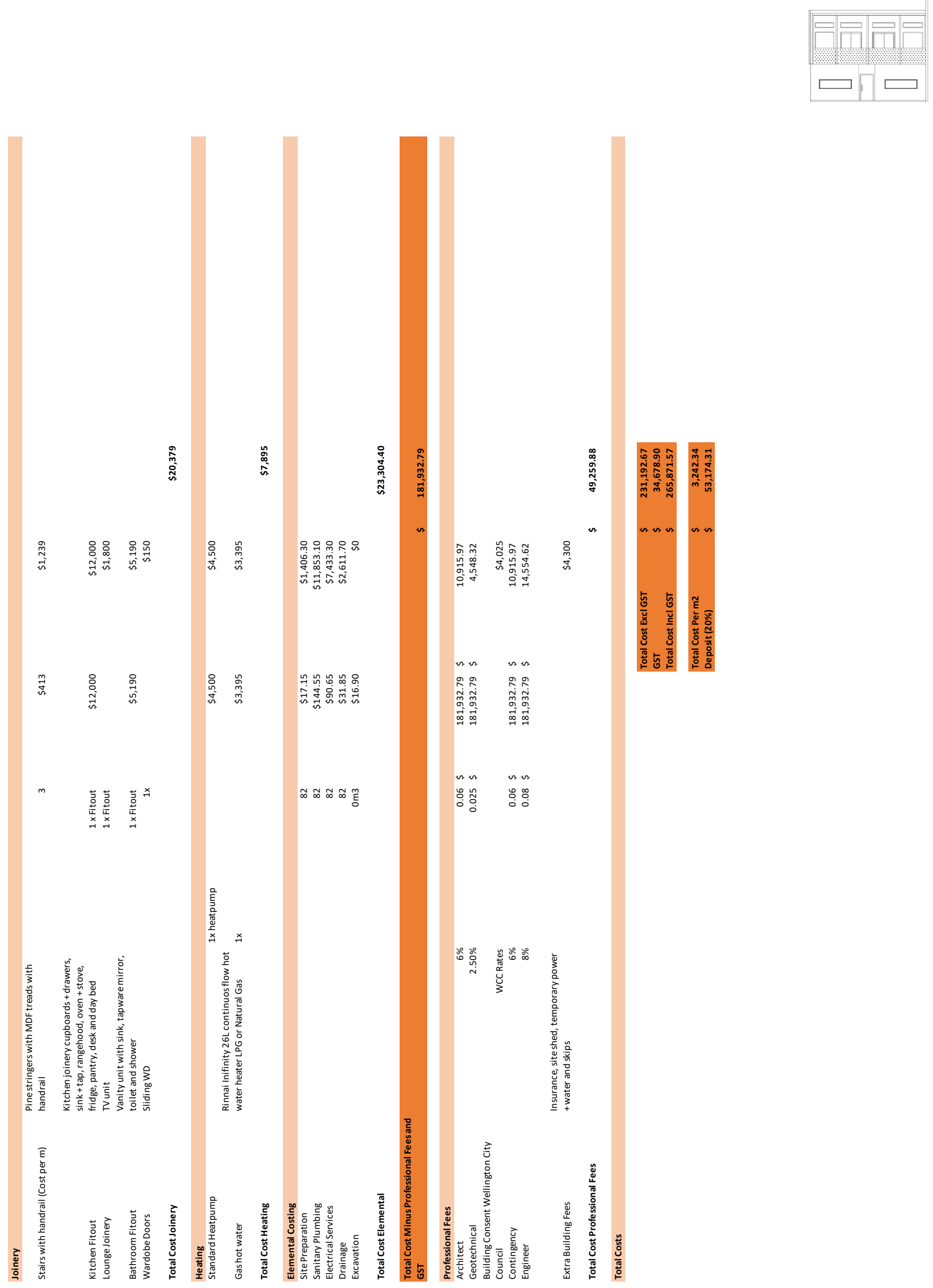

\begin{tabular}{l}
$z$ \\
0 \\
$x$ \\
0 \\
0 \\
0 \\
0 \\
0 \\
0 \\
0 \\
0 \\
0 \\
0 \\
$D$ \\
$D$ \\
0 \\
0 \\
\hline 0 \\
0 \\
0 \\
\hline
\end{tabular} 
Figure 4.95 Houses 3.3 .2 and 3.3.3 costing breakdown

$\square \square \square$

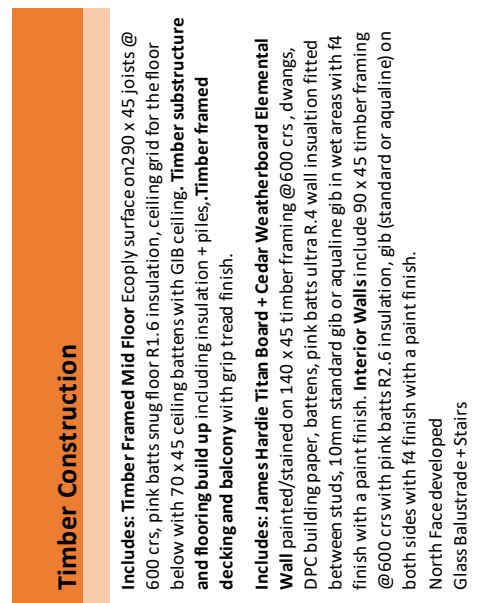

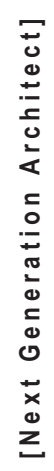
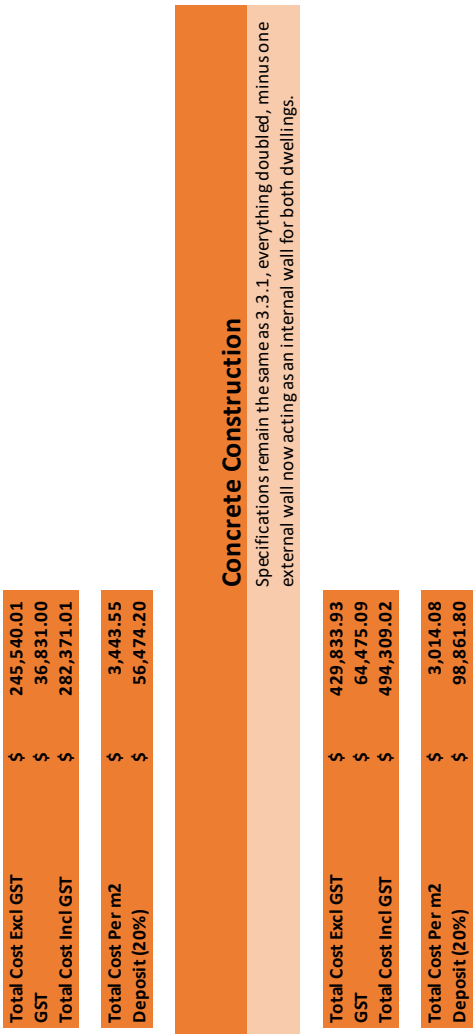

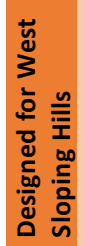
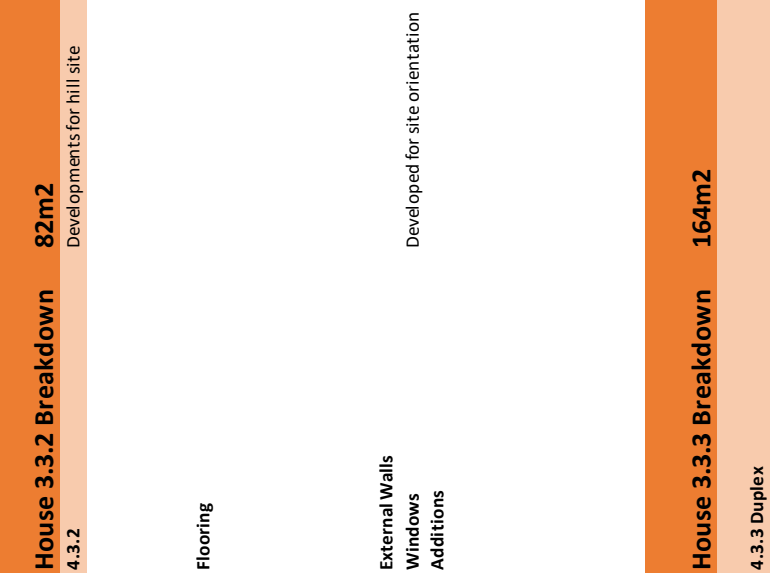


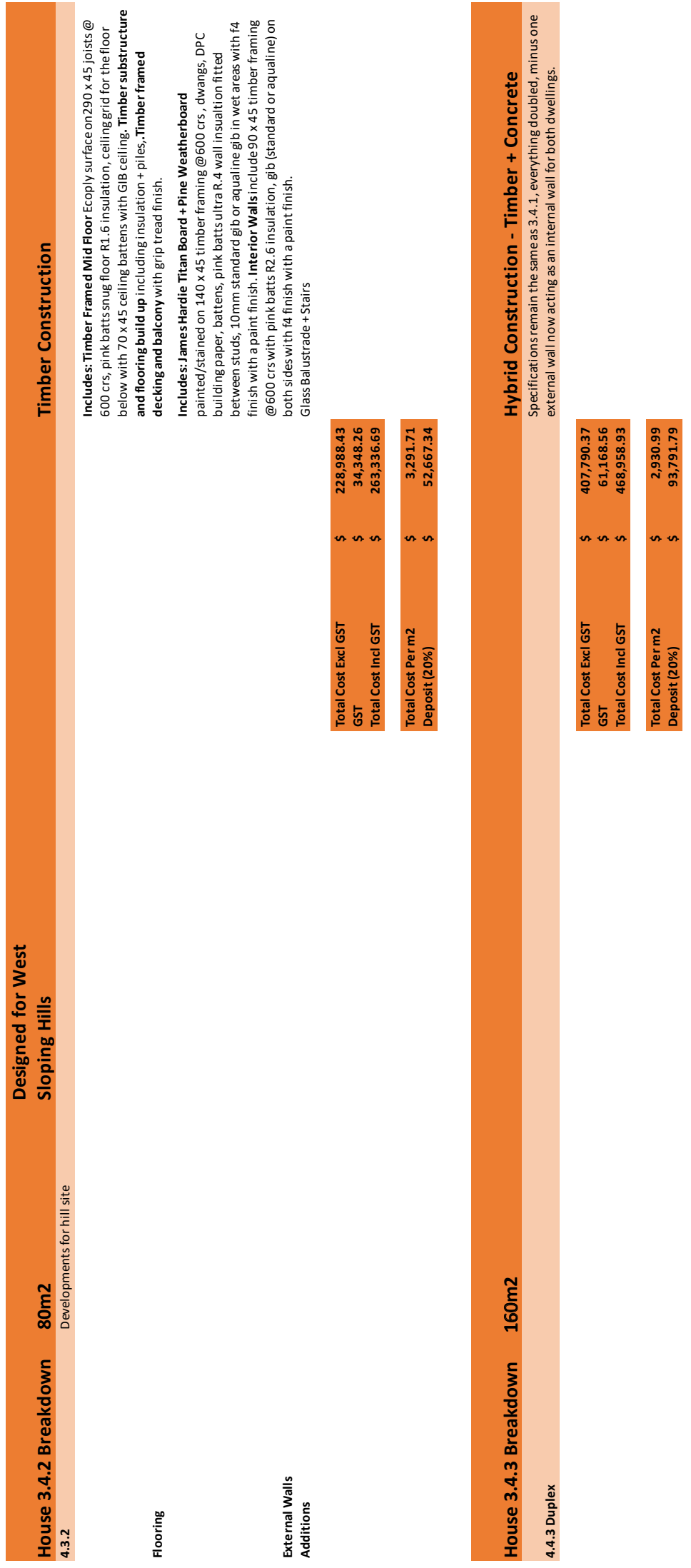




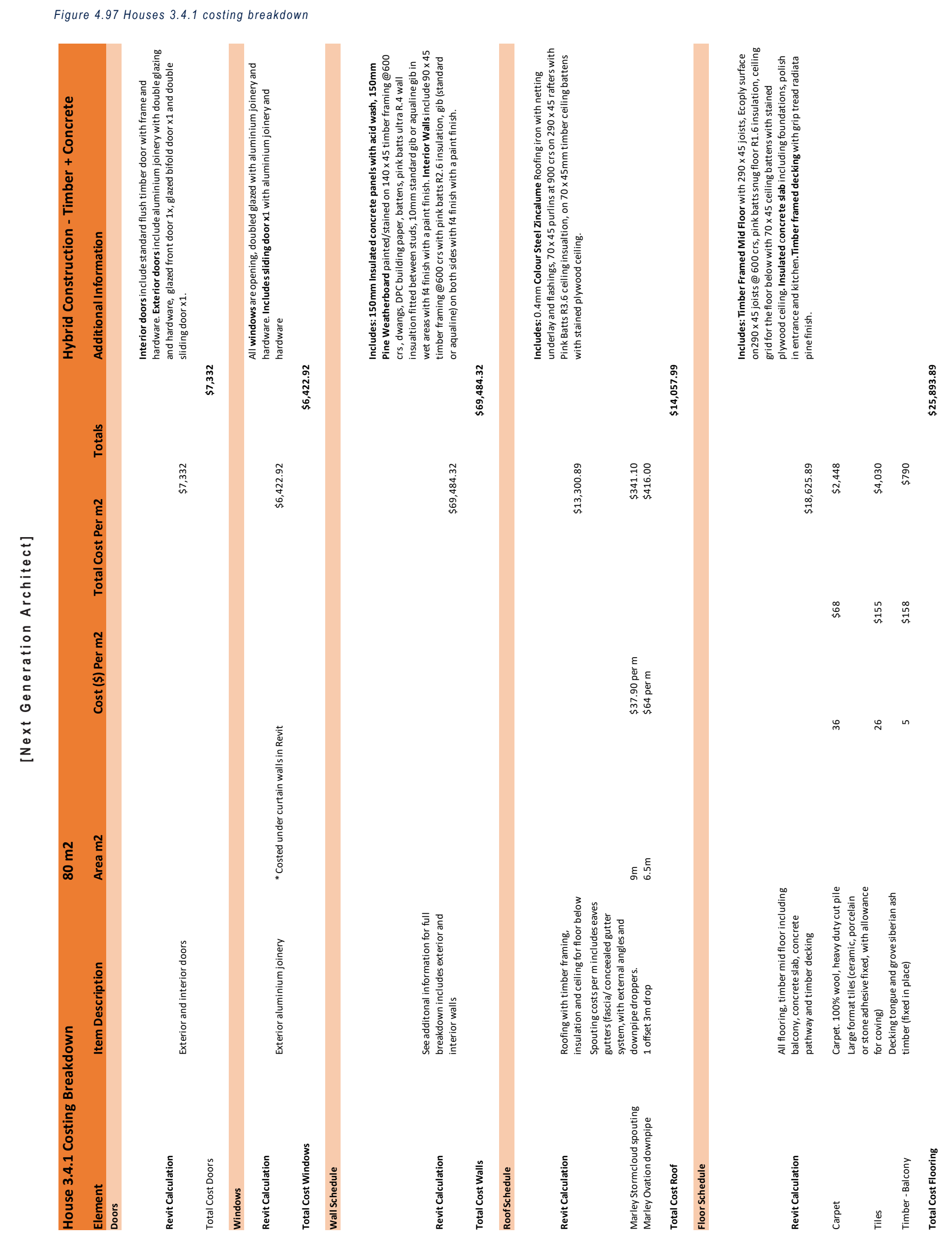




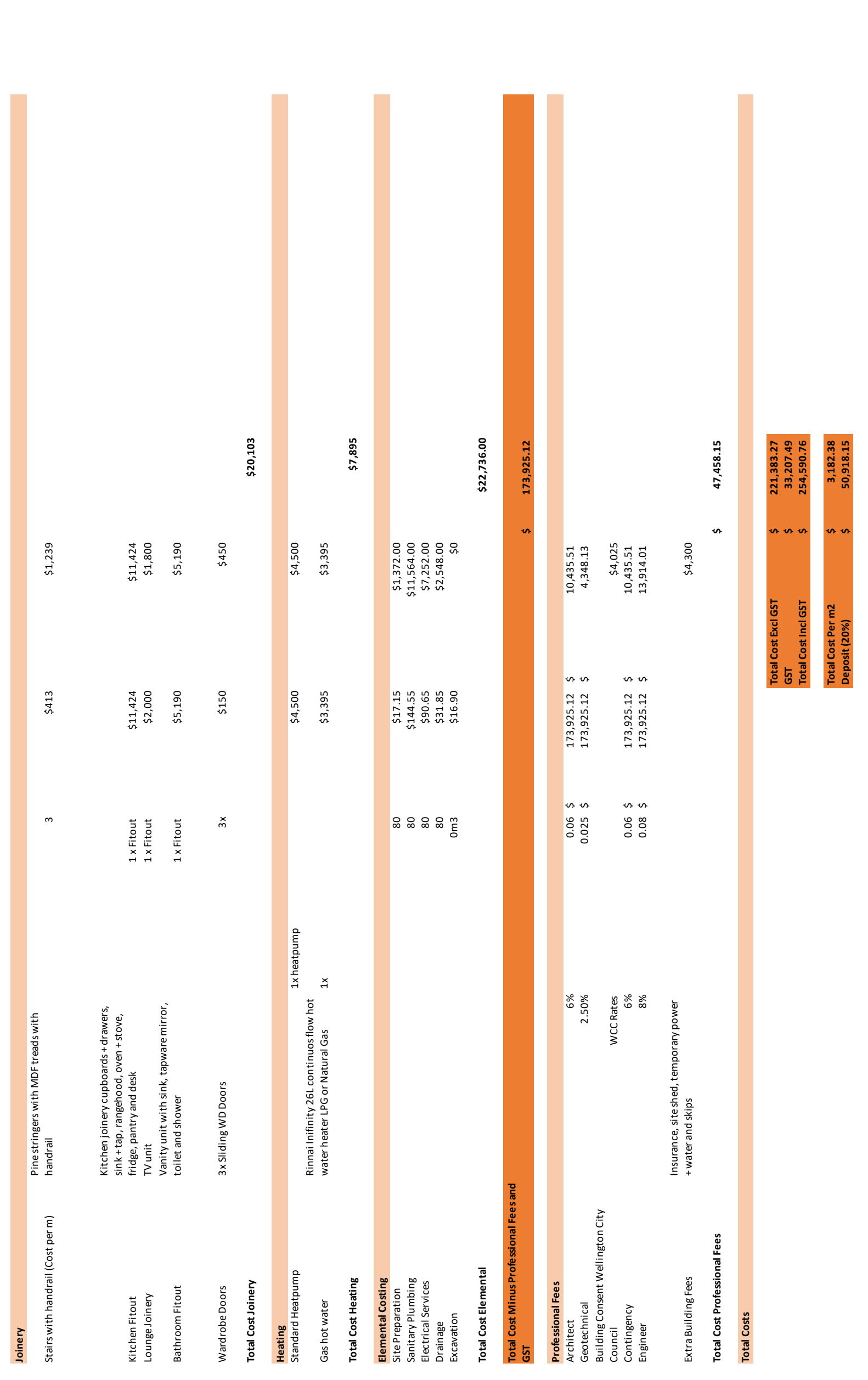

fin

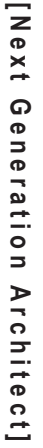


Design Phase 4 Costing Breakdown 


\begin{tabular}{|c|c|c|c|}
\hline \multicolumn{4}{|c|}{$<$ Wall Schedule $>$} \\
\hline A & B & C & D \\
\hline Family and Type & Area & Cost & Total Wall Cost \\
\hline \multicolumn{4}{|c|}{ Basic Wall: $10 \mathrm{~mm}$ Gib with paint finish both sides } \\
\hline Basic Wall: $10 \mathrm{~mm}$ & $14 \mathrm{~m}^{2}$ & $\$ 189.80$ & $\$ 2624.21$ \\
\hline Basic Wall: $10 \mathrm{~mm}$ & $10 \mathrm{~m}^{2}$ & $\$ 189.80$ & $\$ 1980.07$ \\
\hline Basic Wall: $10 \mathrm{~mm}$ & $8 \mathrm{~m}^{2}$ & $\$ 189.80$ & $\$ 1459.75$ \\
\hline \multicolumn{4}{|c|}{ Basic Wall: $10 \mathrm{~mm}$ standard Gib with one aqualine side } \\
\hline Basic Wall: 10mm & $4 \mathrm{~m}^{2}$ & $\$ 289.80$ & $\$ 1158.23$ \\
\hline Basic Wall: $10 \mathrm{~mm}$ & $6 \mathrm{~m}^{2}$ & $\$ 289.80$ & $\$ 1614.27$ \\
\hline \multicolumn{4}{|c|}{ Basic Wall: 70T_10Gb-BS } \\
\hline \multicolumn{4}{|c|}{ Basic Wall: 70T_1 $43 \mathrm{~m}^{2}$} \\
\hline \multicolumn{4}{|c|}{ Basic Wall: 150 Insualted Concrete embossed with paint finish on int and ext } \\
\hline Basic Wall: 150 In & $14 \mathrm{~m}^{2}$ & $\$ 487.00$ & $\$ 6994.68$ \\
\hline Basic Wall: 150 In & $27 \mathrm{~m}^{2}$ & $\$ 487.00$ & $\$ 13290.56$ \\
\hline Basic Wall: $150 \mathrm{In}$ & $11 \mathrm{~m}^{2}$ & $\$ 487.00$ & $\$ 5445.05$ \\
\hline Basic Wall: $150 \mathrm{In}$ & $30 \mathrm{~m}^{2}$ & $\$ 487.00$ & $\$ 14673.26$ \\
\hline Basic Wall: 150 In & $7 \mathrm{~m}^{2}$ & $\$ 487.00$ & $\$ 3367.76$ \\
\hline \multicolumn{4}{|c|}{ Basic Wall: $150 \mathrm{~mm}$ Insulated Concrete ext with acid wash and int paint finish } \\
\hline Basic Wall: $150 \mathrm{~mm}$ & $10 \mathrm{~m}^{2}$ & $\$ 452.00$ & $\$ 4340.08$ \\
\hline Basic Wall: $150 \mathrm{~mm}$ & $20 \mathrm{~m}^{2}$ & $\$ 452.00$ & $\$ 8940.25$ \\
\hline Basic Wall: $150 \mathrm{~mm}$ & $12 \mathrm{~m}^{2}$ & $\$ 452.00$ & $\$ 5375.05$ \\
\hline Basic Wall: $150 \mathrm{~mm}$ & $18 \mathrm{~m}^{2}$ & $\$ 452.00$ & $\$ 7931.82$ \\
\hline \multicolumn{4}{|c|}{ Curtain Wall: Exterior Glazing } \\
\hline Curtain Wall: Exteri & $i 2 \mathrm{~m}^{2}$ & $\$ 556.00$ & $\$ 1268.90$ \\
\hline Grand total: 16 & & & $\$ 80463.94$ \\
\hline
\end{tabular}

\begin{tabular}{|c|c|c|c|c|c|}
\hline \multicolumn{6}{|c|}{$<$ Window Schedule $>$} \\
\hline A & B & c & D & E & $\mathrm{F}$ \\
\hline Family and Type & Cost & Width & Height & Area & Total Cost \\
\hline \multicolumn{6}{|c|}{ AW 1 Aluminum-Grooved (NZ): Large } \\
\hline AW 1 Aluminum-G & & 500 & 3530 & 1.765 & 981.34 \\
\hline \multicolumn{6}{|c|}{ AW 1 Aluminum-Grooved (NZ): Large 3} \\
\hline AW 1 Aluminum-G & & 700 & 700 & 0.49 & 272.44 \\
\hline \multicolumn{6}{|c|}{ AW 1 Aluminum-Grooved (NZ): Normal } \\
\hline AW 1 Aluminum-G & & 2200 & 700 & 1.54 & 856.24 \\
\hline AW 1 Aluminum-G & & 2200 & 700 & 1.54 & 856.24 \\
\hline AW 1 Aluminum-G & & 2200 & 700 & 1.54 & 856.24 \\
\hline AW 1 Aluminum-G & & 2200 & 700 & 1.54 & 856.24 \\
\hline AW 1 Aluminum-G & & 2200 & 700 & 1.54 & 856.24 \\
\hline \multicolumn{6}{|c|}{ AW 1 Aluminum-Grooved (NZ): Square } \\
\hline AW 1 Aluminum-G & & 700 & 1200 & 0.84 & 467.04 \\
\hline AW 1 Aluminum-G & & 700 & 1200 & 0.84 & 467.04 \\
\hline \multicolumn{6}{|c|}{ AW 1 Aluminum-Grooved (NZ): Square 2} \\
\hline AW 1 Aluminum-G & & 1400 & 1800 & 2.52 & 1401.12 \\
\hline \multicolumn{6}{|c|}{ Multi-Panel_Awning_1958: long Double } \\
\hline Multi-Panel_Awnin & & 4400 & 700 & 3.08 & 1712.48 \\
\hline Grand total: 11 & & & & & 9582.66 \\
\hline
\end{tabular}

\begin{tabular}{|c|c|c|}
\hline \multicolumn{3}{|c|}{ <Door Schedule> } \\
\hline A & B & C \\
\hline Family and Type & Cost & Total Cost \\
\hline \multicolumn{3}{|c|}{ Ext Bifold3-1Lite(NZ): Bifold $2100 \times 1980$} \\
\hline \multicolumn{2}{|c|}{ Ext Bifold3-1Lite(NZ) $\$ 2571.00$} & $\$ 2571.00$ \\
\hline \multicolumn{3}{|c|}{ Int Single-Flush (NZ): Interior doors flush $710 \times 1980$} \\
\hline \multicolumn{2}{|c|}{ Int Single-Flush (NZ) $\$ 254.00$} & $\$ 254.00$ \\
\hline \multicolumn{2}{|c|}{ Int Single-Flush (NZ) $\$ 254.00$} & $\$ 254.00$ \\
\hline \multicolumn{2}{|c|}{ Int Single-Flush (NZ) $\$ 254.00$} & $\$ 254.00$ \\
\hline \multicolumn{2}{|c|}{ Int Single-Flush (NZ) $\$ 254.00$} & $\$ 254.00$ \\
\hline \multicolumn{3}{|c|}{ Single_hung_door_CR4: Aluminium Front Door } \\
\hline \multicolumn{2}{|c|}{ Single_hung_door_C $\$ 870.00$} & $\$ 870.00$ \\
\hline \multicolumn{2}{|l|}{ Grand total: 6} & $\$ 4457.00$ \\
\hline
\end{tabular}

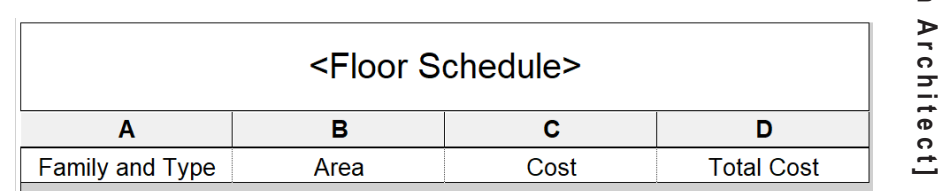




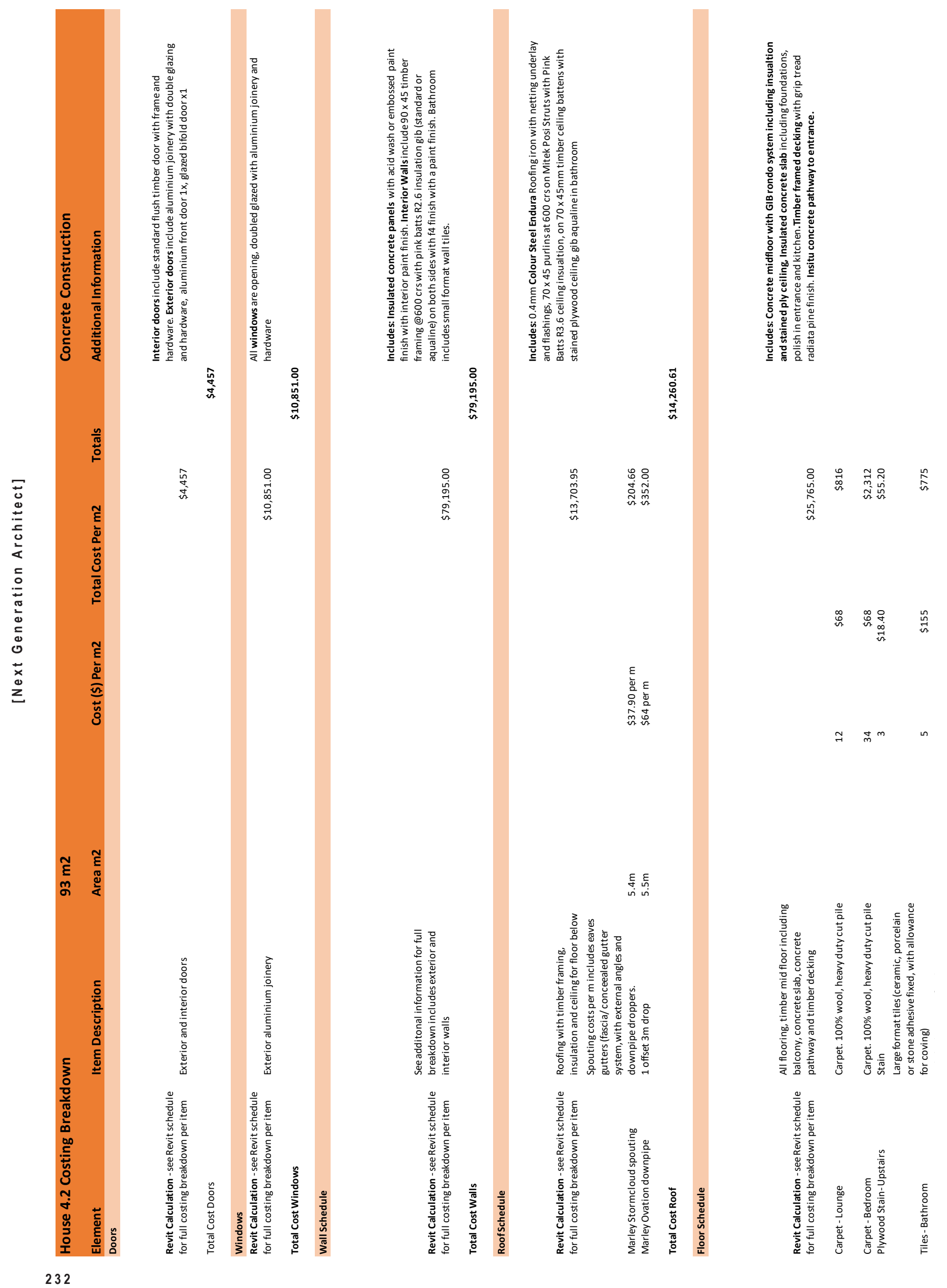



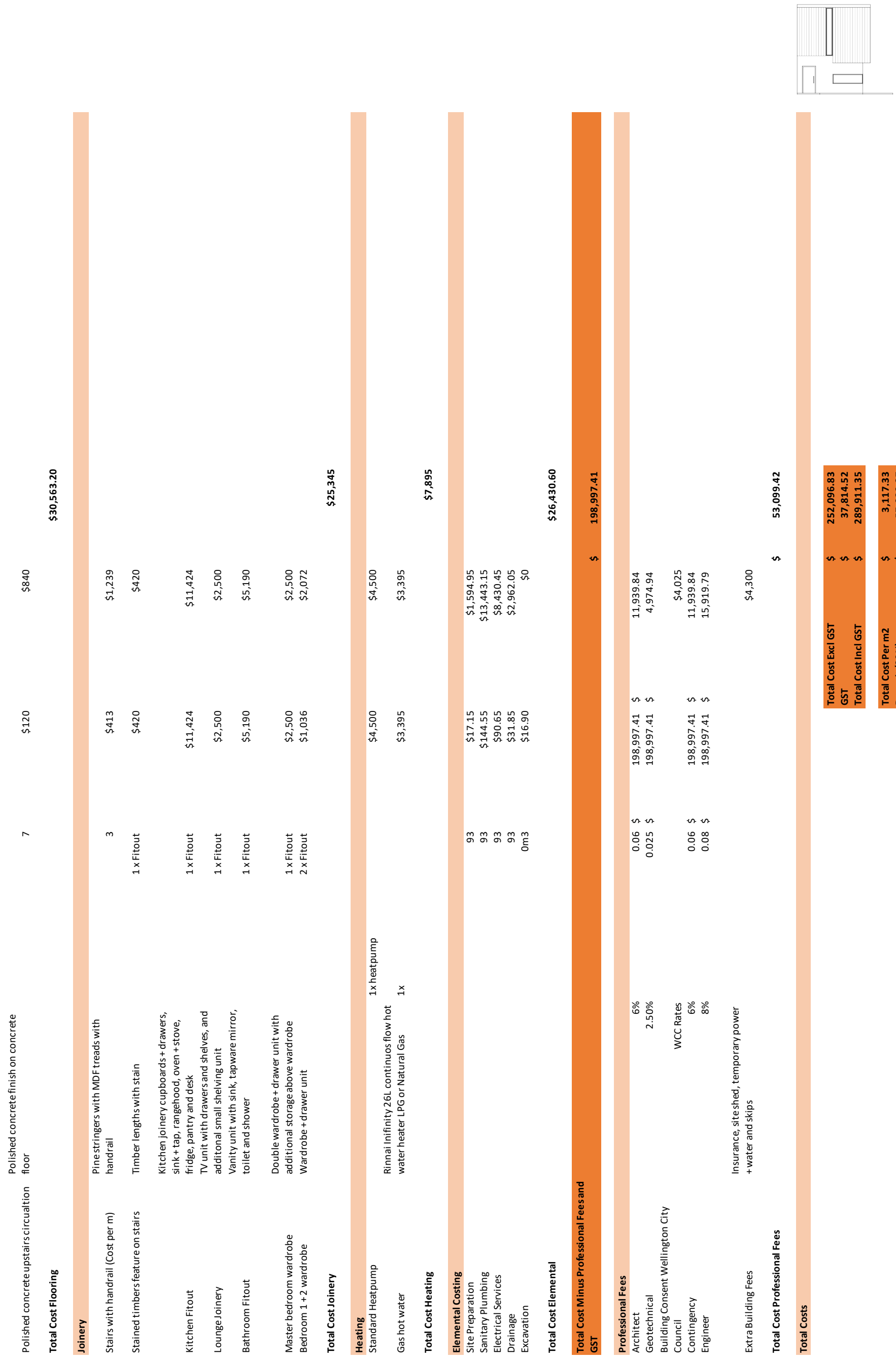
Figure 4.100 Lifecycle cost 4.2

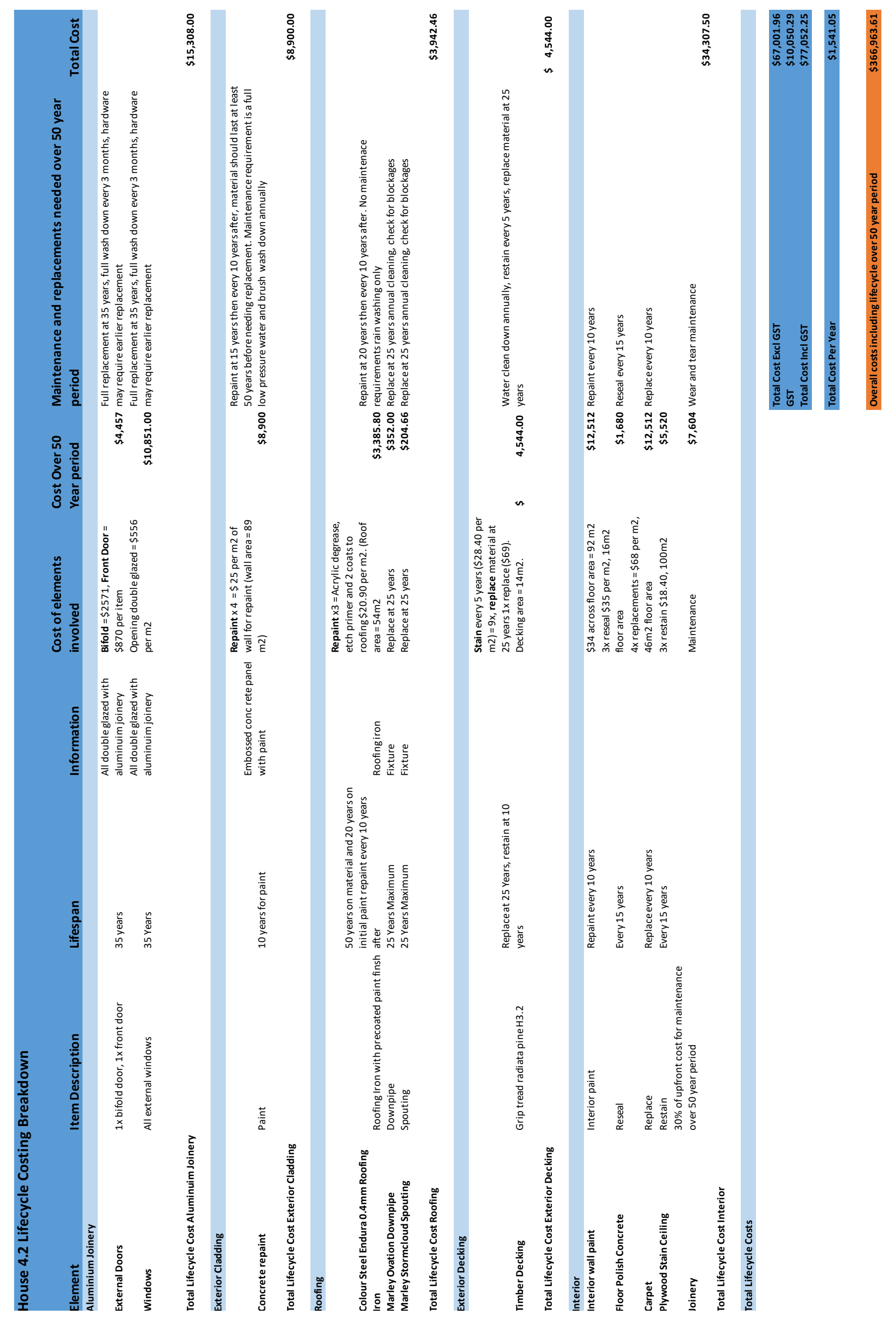




\begin{tabular}{|c|c|c|c|}
\hline \multicolumn{4}{|c|}{$<$ Wall Schedule $>$} \\
\hline A & $\mathbf{B}$ & C & D \\
\hline Family and Type & Area & Cost & Total Cost \\
\hline \multicolumn{4}{|c|}{ Basic Wall: 90T_10Gb-BS } \\
\hline Basic Wall: 90T_10 & $4 \mathrm{~m}^{2}$ & 185.80 & $\$ 651.27$ \\
\hline Basic Wall: 90T_10 & $8 \mathrm{~m}^{2}$ & 185.80 & $\$ 1399.41$ \\
\hline Basic Wall: 90T_10 & $12 \mathrm{~m}^{2}$ & 185.80 & $\$ 2163.56$ \\
\hline Basic Wall: 90T_10 & $1 \mathrm{~m}^{2}$ & 185.80 & $\$ 170.68$ \\
\hline \multicolumn{4}{|c|}{ Basic Wall: 150 Concrete polish one side raw ext 3} \\
\hline Basic Wall: 150 Co & $12 \mathrm{~m}^{2}$ & 505.00 & $\$ 6202.03$ \\
\hline \multicolumn{4}{|c|}{ Basic Wall: 150 Insulated Concrete paint finish } \\
\hline Basic Wall: 150 Ins & $25 \mathrm{~m}^{2}$ & 452.00 & $\$ 11105.64$ \\
\hline Basic Wall: 150 Ins & $8 \mathrm{~m}^{2}$ & 452.00 & $\$ 3615.56$ \\
\hline Basic Wall: 150 Ins & $2 \mathrm{~m}^{2}$ & 452.00 & $\$ 1058.17$ \\
\hline Basic Wall: 150 Ins & $3 \mathrm{~m}^{2}$ & 452.00 & $\$ 1240.83$ \\
\hline Basic Wall: 150 Ins & $2 \mathrm{~m}^{2}$ & 452.00 & $\$ 796.63$ \\
\hline Basic Wall: 150 Ins & $8 \mathrm{~m}^{2}$ & 452.00 & $\$ 3756.75$ \\
\hline Basic Wall: 150 Ins & $16 \mathrm{~m}^{2}$ & 452.00 & $\$ 7336.46$ \\
\hline Basic Wall: 150 Ins & $19 \mathrm{~m}^{2}$ & 452.00 & $\$ 8767.10$ \\
\hline Basic Wall: 150 Ins & $12 \mathrm{~m}^{2}$ & 452.00 & $\$ 5277.33$ \\
\hline \multicolumn{4}{|c|}{ Basic Wall: 150 Insulated Concrete polish one side raw ext 2} \\
\hline Basic Wall: 150 Ins & $46 \mathrm{~m}^{2}$ & 452.00 & $\$ 20807.51$ \\
\hline \multicolumn{4}{|c|}{ Basic Wall: Aqualine + tiles } \\
\hline Basic Wall: Aqualin & $4 \mathrm{~m}^{2}$ & 289.80 & $\$ 1065.93$ \\
\hline Basic Wall: Aqualin & $8 \mathrm{~m}^{2}$ & 289.80 & $\$ 2308.56$ \\
\hline \multicolumn{4}{|c|}{ Basic Wall: Perforation } \\
\hline Basic Wall: Perfora & $2 \mathrm{~m}^{2}$ & 143.00 & $\$ 242.76$ \\
\hline Basic Wall: Perfora & $2 \mathrm{~m}^{2}$ & 143.00 & $\$ 331.13$ \\
\hline Basic Wall: Perfora & $2 \mathrm{~m}^{2}$ & 143.00 & $\$ 342.97$ \\
\hline Basic Wall: Perfora & $2 \mathrm{~m}^{2}$ & 143.00 & $\$ 262.81$ \\
\hline \multicolumn{4}{|c|}{ Basic Wall: Timber Panel } \\
\hline Basic Wall: Timber & $4 \mathrm{~m}^{2}$ & 344.40 & $\$ 1269.36$ \\
\hline \multicolumn{4}{|c|}{ Curtain Wall: Exterior Glazing } \\
\hline Curtain Wall: Exteri & $1 \mathrm{~m}^{2}$ & 722.80 & $\$ 906.65$ \\
\hline Grand total: 23 & & & $\$ 81079.08$ \\
\hline
\end{tabular}

\begin{tabular}{|c|c|c|c|c|c|}
\hline \multicolumn{6}{|c|}{$<$ Window Schedule $>$} \\
\hline A & B & c & D & E & $\mathbf{F}$ \\
\hline Family and Type & Cost & Width & Height & Area & Total Cost \\
\hline \multicolumn{6}{|c|}{ AW 1 Aluminum-Grooved (NZ): front } \\
\hline AW 1 Aluminum-G & 556.00 & 2400 & 700 & 1.68 & $\$ 934.08$ \\
\hline AW 1 Aluminum-G & 556.00 & 2400 & 700 & 1.68 & $\$ 934.08$ \\
\hline \multicolumn{6}{|c|}{ AW 1 Aluminum-Grooved (NZ): front 2} \\
\hline AW 1 Aluminum-G & 556.00 & 1800 & 700 & 1.26 & $\$ 700.56$ \\
\hline \multicolumn{6}{|c|}{ FL 1 Aluminum-Grooved (NZ): Balcony 1} \\
\hline FL 1 Aluminum-Gr & 556.00 & 1500 & 500 & 0.75 & $\$ 417.00$ \\
\hline FL 1 Aluminum-Gr & 556.00 & 1500 & 500 & 0.75 & $\$ 417.00$ \\
\hline FL 1 Aluminum-Gr & 556.00 & 1500 & 500 & 0.75 & $\$ 417.00$ \\
\hline FL 1 Aluminum-Gr & 556.00 & 1500 & 500 & 0.75 & $\$ 417.00$ \\
\hline \multicolumn{6}{|c|}{ FL 1 Aluminum-Grooved (NZ): Balcony 2} \\
\hline FL 1 Aluminum-Gr & 556.00 & 1500 & 2100 & 3.15 & $\$ 1751.40$ \\
\hline FL 1 Aluminum-Gr & 556.00 & 1500 & 2100 & 3.15 & $\$ 1751.40$ \\
\hline \multicolumn{6}{|c|}{ FL 1 Aluminum-Grooved (NZ): Standard Square } \\
\hline FL 1 Aluminum-Gr & 556.00 & 1000 & 1400 & 1.4 & $\$ 778.40$ \\
\hline \multicolumn{6}{|c|}{ FL 1 Aluminum-Grooved (NZ): Standard Square Small } \\
\hline FL 1 Aluminum-Gr & 556.00 & 500 & 1200 & 0.6 & $\$ 333.60$ \\
\hline FL 1 Aluminum-Gr & 556.00 & 500 & 1200 & 0.6 & $\$ 333.60$ \\
\hline Grand total: 12 & & & & & $\$ 9185.12$ \\
\hline
\end{tabular}

\begin{tabular}{|l|c|c|c|}
\hline \multicolumn{4}{|c|}{ <Roof Schedule> } \\
\hline A & B & C & D \\
\hline Family and Type & Area & Cost & Total Cost \\
\hline \multicolumn{3}{|c|}{} & \\
\hline Basic Roof: Colour steel roofing with timber build up, including ceiling \\
\hline Basic Roof: Colour & $50 \mathrm{~m}^{2}$ & 253.00 & $\$ 12602.29$ \\
\hline Grand total: 1 & & $\$ 12602.29$ \\
\hline
\end{tabular}

\begin{tabular}{|c|c|c|c|}
\hline \multicolumn{4}{|c|}{$<$ Floor Schedule> } \\
\hline A & B & C & D \\
\hline Family and Type & Area & Cost & Total Cost \\
\hline \multicolumn{4}{|c|}{ Floor: $150 \mathrm{~mm}$ Insulated concrete slab with polished finish } \\
\hline \multicolumn{2}{|c|}{ Floor: $150 \mathrm{~mm}$ Insulated co $39 \mathrm{~m}^{2}$} & 270.00 & $\$ 10518.26$ \\
\hline \multicolumn{4}{|l|}{ Floor: Balcony } \\
\hline Floor: Balcony & $9 \mathrm{~m}^{2}$ & 296.00 & $\$ 2707.36$ \\
\hline \multicolumn{4}{|c|}{ Floor: Concrete Mid floor + ceiling build up } \\
\hline \multicolumn{2}{|c|}{ Floor: Concrete Mid floor $+33 \mathrm{~m}^{2}$} & 280.00 & $\$ 9258.78$ \\
\hline \multicolumn{4}{|l|}{ Floor: Timber Decking } \\
\hline Floor: Timber Decking & $19 \mathrm{~m}^{2}$ & 168.00 & $\$ 3155.67$ \\
\hline Grand total: 4 & & & $\$ 25640.07$ \\
\hline
\end{tabular}

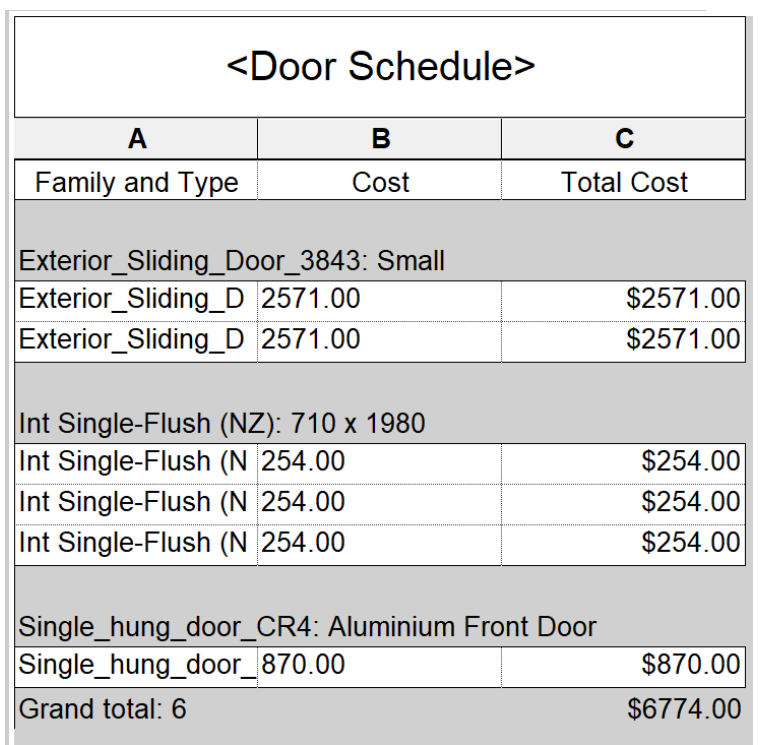




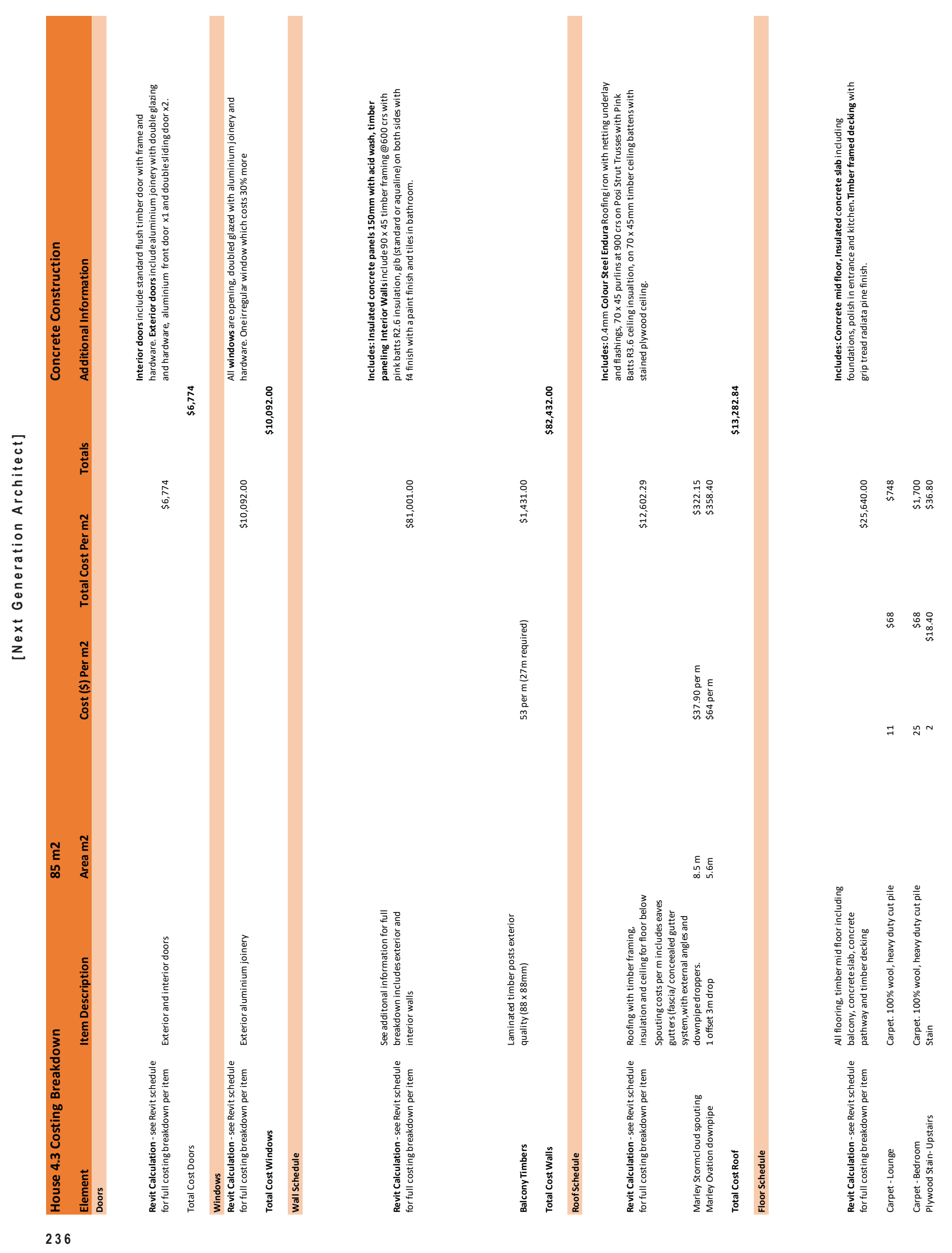



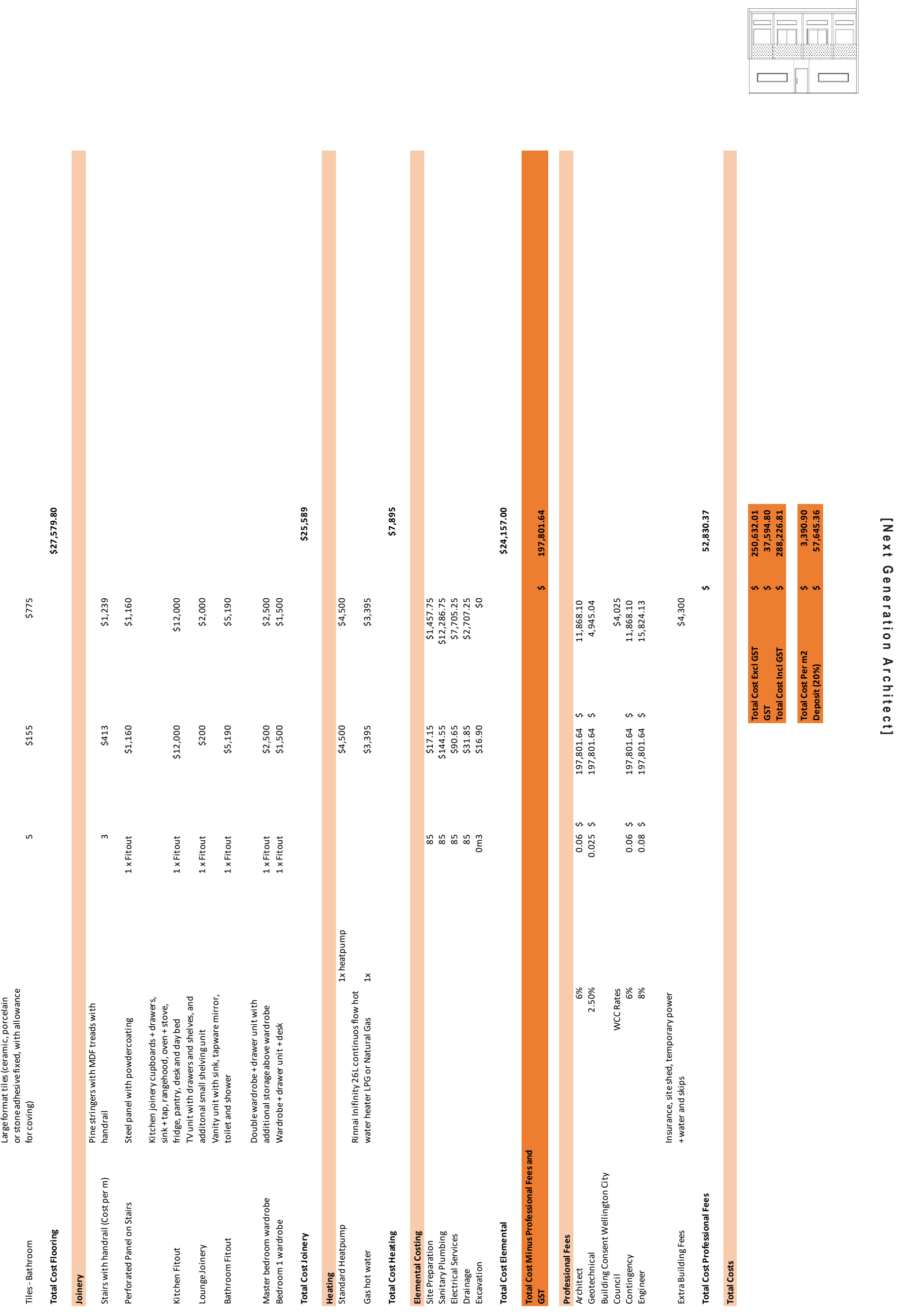


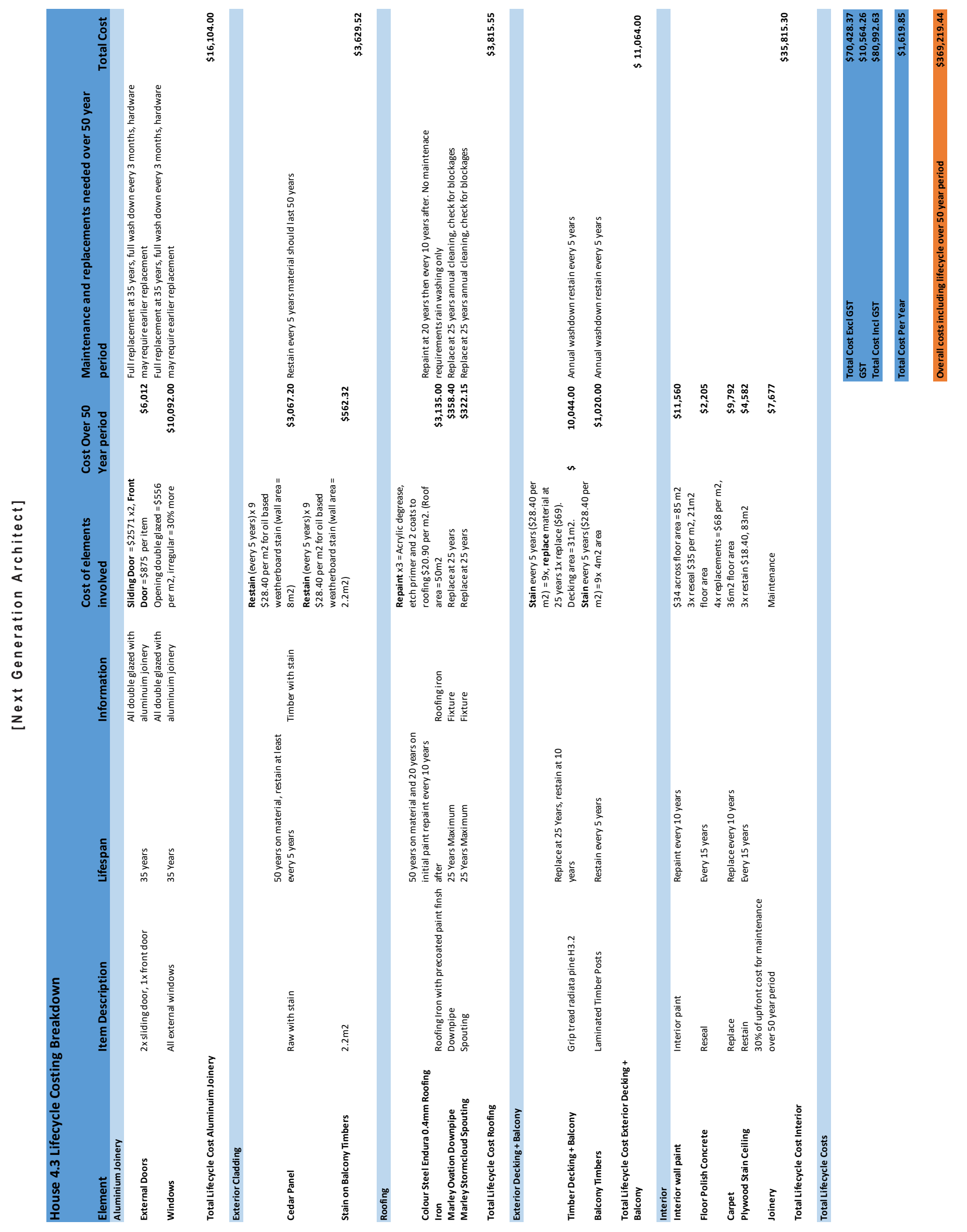


Figure 4.104 Revit schedules screenshot 4.4

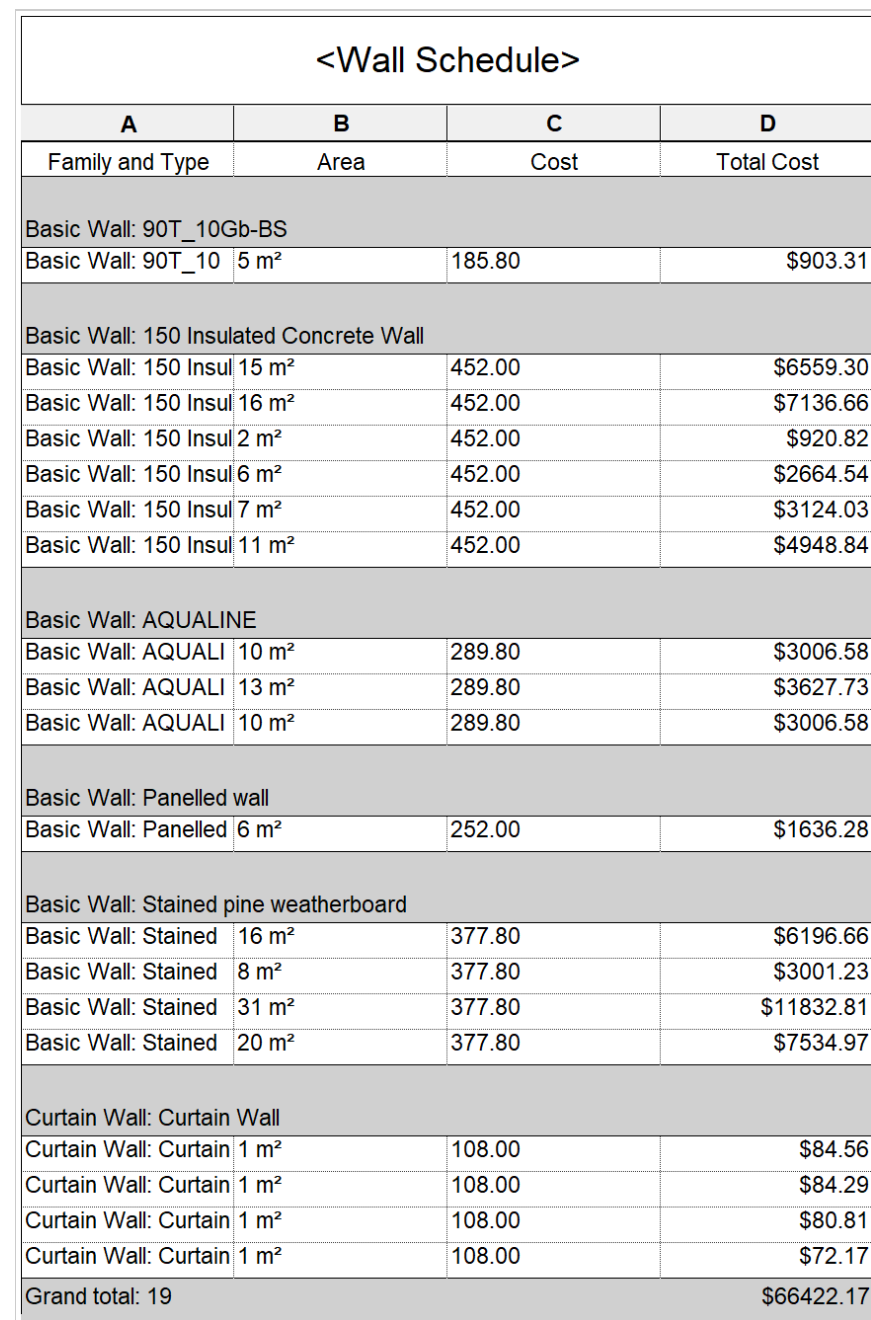

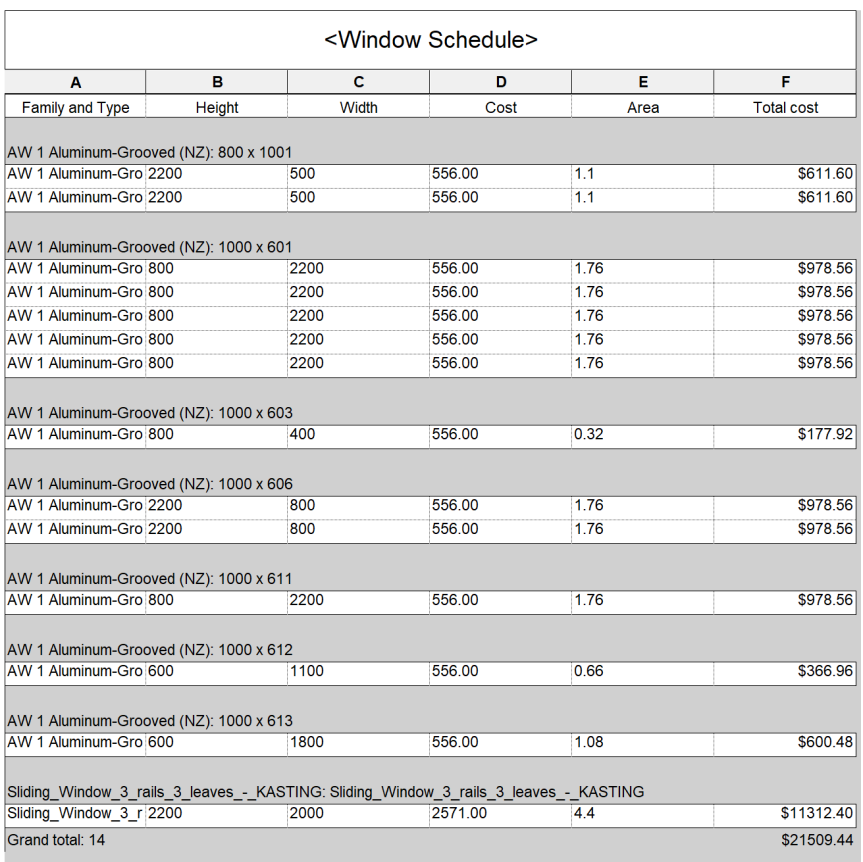

\begin{tabular}{|c|c|c|c|}
\hline \multicolumn{4}{|c|}{$<$ Floor Schedule> } \\
\hline A & B & C & D \\
\hline Family and Type & Area & Cost & Total Cost \\
\hline \multicolumn{4}{|c|}{ Floor: $150 \mathrm{~mm}$ Concrete Slab } \\
\hline Floor: $150 \mathrm{~mm}$ Con & & 270.00 & $\$ 9626.20$ \\
\hline \multicolumn{4}{|c|}{ Floor: Paved Entrance } \\
\hline Floor: Paved Entra & & 59.00 & $\$ 156.13$ \\
\hline \multicolumn{4}{|c|}{ Floor: Timber Decking } \\
\hline Floor: Timber Deck & & 168.00 & $\$ 2048.08$ \\
\hline Floor: Timber Deck & & 168.00 & $\$ 1056.56$ \\
\hline \multicolumn{4}{|c|}{ Floor: Timber Midfloor + Ceiling } \\
\hline Floor: Timber Midfl & & 290.00 & $\$ 13170.76$ \\
\hline Grand total: 5 & & & $\$ 26057.73$ \\
\hline
\end{tabular}

\begin{tabular}{|l|c|c|}
\hline \multicolumn{2}{|c|}{ <Door Schedule> } \\
\hline A & B & C \\
\hline Family and Type & Cost & Total Cost \\
\hline Ext Bifold3-1Lite(NZ): $2100 \times 1980$ & \\
\hline Ext Bifold3-1Lite(N 2571.00 & \\
\hline Int Single-Flush (NZ): $710 \times 1980$ & \\
\hline
\end{tabular}

\begin{tabular}{|l|c|c|c|}
\hline \multicolumn{4}{|c|}{ <Roof Schedule> } \\
\hline A & B & C & D \\
\hline Family and Type & Area & Cost & Total Cost \\
\hline \multicolumn{3}{|c|}{} & \\
\hline Basic Roof: Colour Steel Roofing + Timber build up + Ceiling build up \\
\hline Basic Roof: Colour $52 \mathrm{~m}^{2}$ & 300.00 & 15699.52 \\
\hline Grand total: 1 & & 15699.52 \\
\hline
\end{tabular}




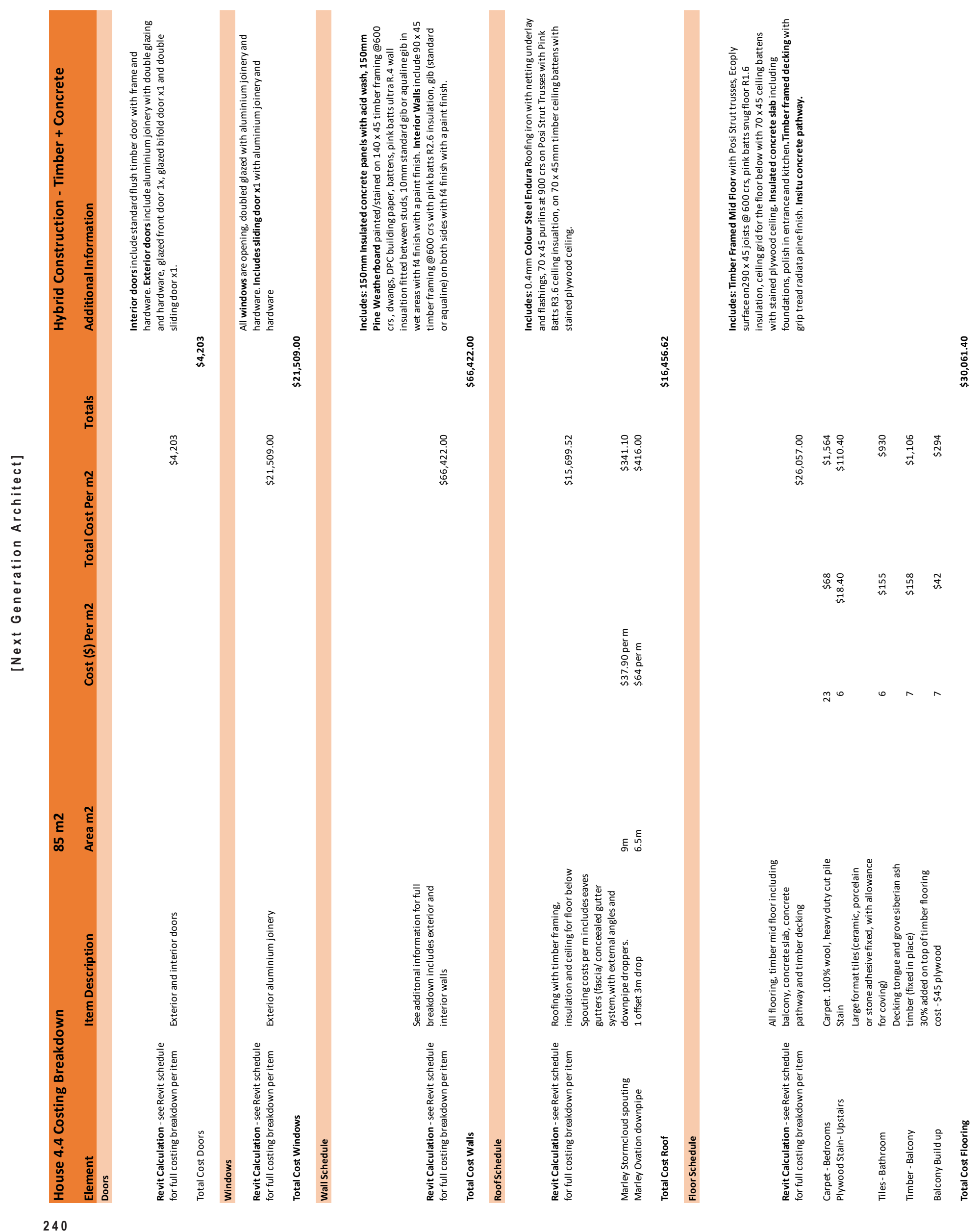




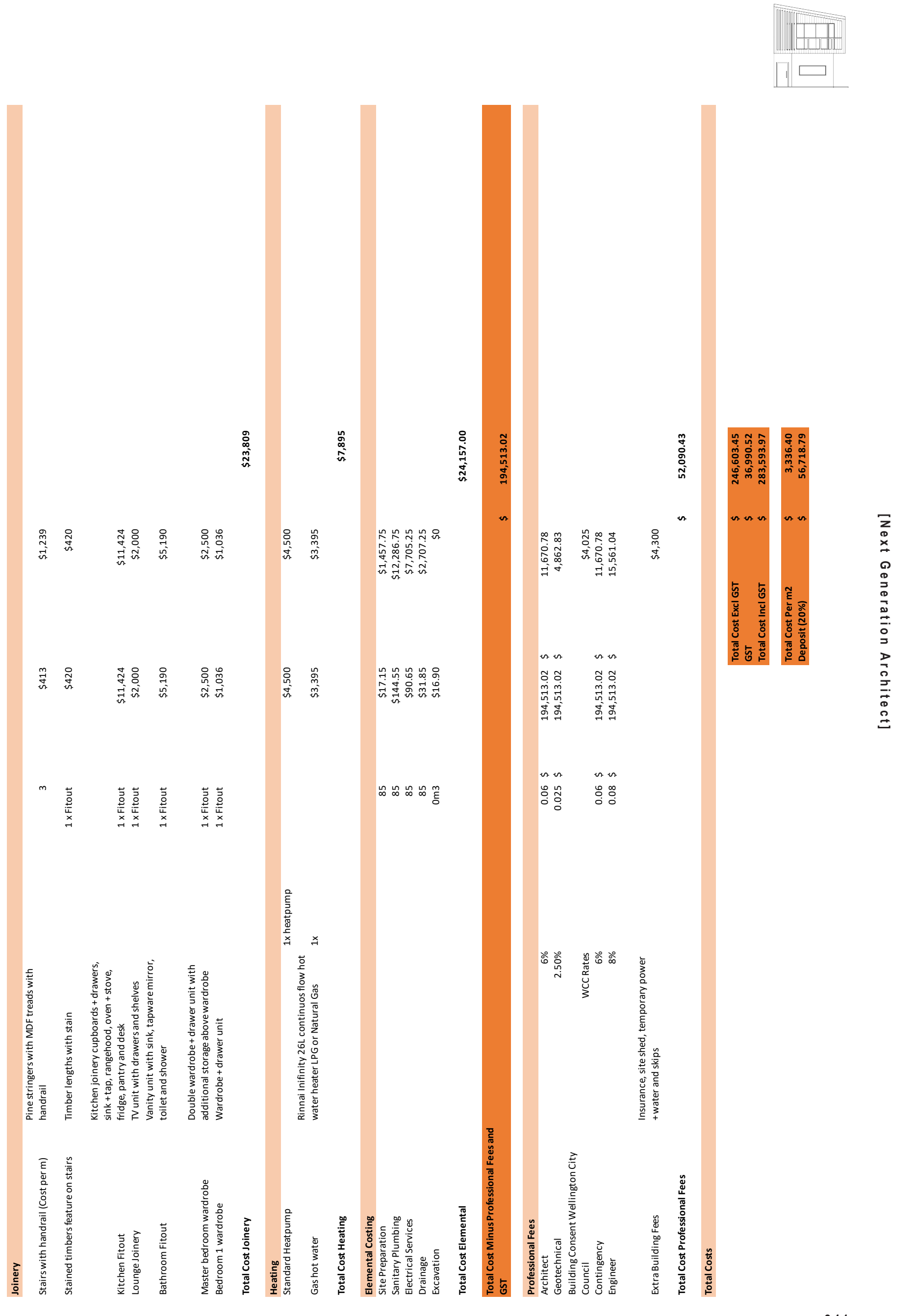


Figure 4.106 Lifecycle cost 4.4

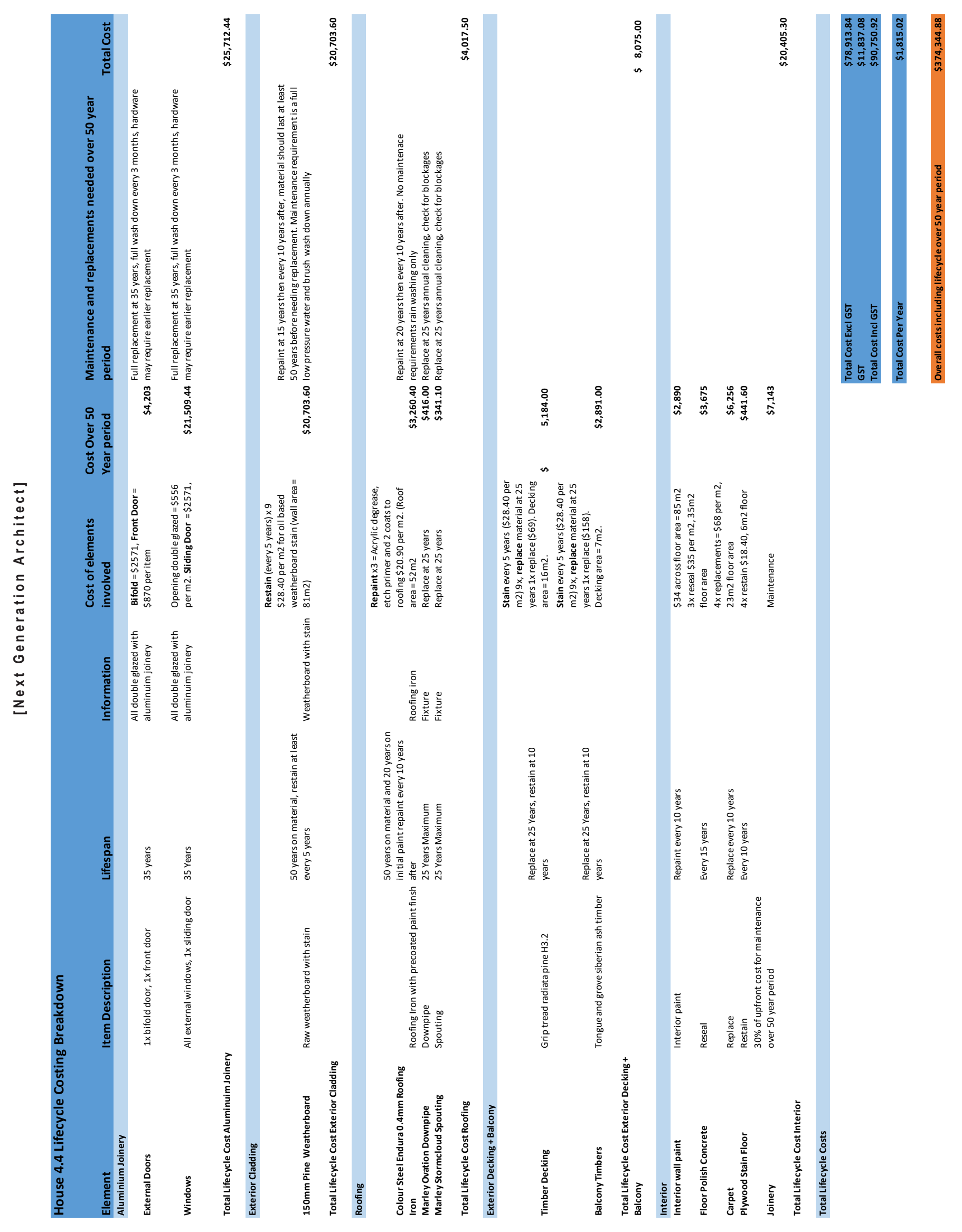


Figure 4.107 Revit schedules screenshot 4.5

\begin{tabular}{|c|c|c|c|}
\hline \multicolumn{4}{|c|}{$<$ Wall Schedule $>$} \\
\hline A & B & C & D \\
\hline Family and Type & Area & Cost & Total Cost \\
\hline \multicolumn{4}{|c|}{ Basic Wall: 90T_10Gb-BS } \\
\hline Basic Wall: 90T_10 & $2 \mathrm{~m}^{2}$ & 185.80 & $\$ 321.70$ \\
\hline Basic Wall: 90T_10 & $13 \mathrm{~m}^{2}$ & 185.80 & $\$ 2494.37$ \\
\hline \multicolumn{4}{|l|}{ Basic Wall: Cedar } \\
\hline Basic Wall: Cedar & $10 \mathrm{~m}^{2}$ & 480.20 & $\$ 4939.97$ \\
\hline Basic Wall: Cedar 2 & $2 \mathrm{~m}^{2}$ & 480.20 & $\$ 1114.70$ \\
\hline \multicolumn{4}{|c|}{ Basic Wall: Colour steel ext wall build up incl int } \\
\hline Basic Wall: Colour st & $10 \mathrm{~m}^{2}$ & 237.40 & $\$ 2406.98$ \\
\hline Basic Wall: Colour st 7 & $7 \mathrm{~m}^{2}$ & 237.40 & $\$ 1766.93$ \\
\hline Basic Wall: Colour st & $11 \mathrm{~m}^{2}$ & 237.40 & $\$ 2672.67$ \\
\hline Basic Wall: Colour st \& & $8 \mathrm{~m}^{2}$ & 237.40 & $\$ 1850.59$ \\
\hline Basic Wall: Colour st \& & $8 \mathrm{~m}^{2}$ & 237.40 & $\$ 1925.23$ \\
\hline Basic Wall: Colour st 6 & $6 \mathrm{~m}^{2}$ & 237.40 & $\$ 1340.73$ \\
\hline \multicolumn{4}{|c|}{ Basic Wall: Ext with aqualine int } \\
\hline Basic Wall: Ext with & $4 \mathrm{~m}^{2}$ & 246.40 & $\$ 1086.46$ \\
\hline Basic Wall: Ext with & $1 \mathrm{~m}^{2}$ & 246.40 & $\$ 260.35$ \\
\hline Basic Wall: Ext with & $11 \mathrm{~m}^{2}$ & 246.40 & $\$ 2592.51$ \\
\hline \multicolumn{4}{|c|}{ Basic Wall: Interior one side aqualine + tiles } \\
\hline Basic Wall: Interior o & $4 \mathrm{~m}^{2}$ & 289.80 & $\$ 1089.02$ \\
\hline Basic Wall: Interior of & $8 \mathrm{~m}^{2}$ & 289.80 & $\$ 2298.66$ \\
\hline \multicolumn{4}{|c|}{ Curtain Wall: Exterior Glazing Triangle } \\
\hline Curtain Wall: Exterio & $1 \mathrm{~m}^{2}$ & 556.00 & $\$ 302.81$ \\
\hline Curtain Wall: Exterio & $1 \mathrm{~m}^{2}$ & 556.00 & $\$ 302.81$ \\
\hline Curtain Wall: Exterio & $1 \mathrm{~m}^{2}$ & 556.00 & $\$ 302.81$ \\
\hline Curtain Wall: Exterio & $3 \mathrm{~m}^{2}$ & 556.00 & $\$ 1588.43$ \\
\hline Grand total: 19 & & & $\$ 30657.70$ \\
\hline
\end{tabular}

\begin{tabular}{|c|c|c|c|}
\hline \multicolumn{4}{|c|}{$<$ Roof Schedule $>$} \\
\hline A & B & C & D \\
\hline Family and Type & Area & Cost & Total Cost \\
\hline \multicolumn{4}{|c|}{ Basic Roof: Large Roof with Colour steel + Posi Struts + Ceiling } \\
\hline Basic Roof: Large & $45 \mathrm{~m}^{2}$ & 271.00 & $\$ 12166.63$ \\
\hline \multicolumn{4}{|c|}{ Basic Roof: Small Colour Steel Roof + timber build up + ceiling } \\
\hline Basic Roof: Small & $16 \mathrm{~m}^{2}$ & 355.30 & $\$ 5845.71$ \\
\hline Basic Roof: Small & $11 \mathrm{~m}^{2}$ & 355.30 & $\$ 3745.27$ \\
\hline \multicolumn{3}{|l|}{ Grand total: 3} & $\$ 21757.61$ \\
\hline \multicolumn{4}{|c|}{ <Door Schedule> } \\
\hline \multicolumn{2}{|c|}{ A } & B & C \\
\hline \multicolumn{2}{|c|}{ Family and Type } & Cost & Total Cost \\
\hline \multicolumn{4}{|c|}{ Ext Single In-Timber-1Lite (NZ): Aluminium Front Door } \\
\hline \multicolumn{3}{|c|}{ Ext Single In-Timber-1Lite (NZ): Alumi 870.00} & $\$ 870.00$ \\
\hline \multicolumn{4}{|c|}{ Int Single-Flush (NZ): $810 \times 1980$} \\
\hline \multicolumn{2}{|c|}{ Int Single-Flush (NZ): $810 \times 1980$} & 254.00 & $\$ 254.00$ \\
\hline \multicolumn{2}{|c|}{ Int Single-Flush (NZ): $810 \times 1980$} & 254.00 & $\$ 254.00$ \\
\hline \multicolumn{3}{|c|}{ Grand total: 3} & $\$ 1378.00$ \\
\hline \multicolumn{4}{|c|}{$<$ Floor Schedule> } \\
\hline A & B & C & D \\
\hline Family and Type & Area & Cost & Total Cost \\
\hline \multicolumn{4}{|c|}{ Floor: Concrete Slab } \\
\hline \multicolumn{2}{|c|}{ Floor: Concrete SI $58 \mathrm{~m}^{2}$} & 150.00 & $\$ 8739.91$ \\
\hline \multicolumn{4}{|c|}{ Floor: Timber Decking } \\
\hline \multicolumn{2}{|c|}{ Floor: Timber Deck $22 \mathrm{~m}^{2}$} & 168.00 & $\$ 3765.97$ \\
\hline \multicolumn{2}{|c|}{ Floor: Timber Deck $2 \mathrm{~m}^{2}$} & 168.00 & $\$ 384.57$ \\
\hline \multicolumn{3}{|l|}{ Grand total: 3} & $\$ 12890.45$ \\
\hline
\end{tabular}

\begin{tabular}{|c|c|c|c|c|c|}
\hline \multicolumn{6}{|c|}{$<$ Window Schedule $>$} \\
\hline A & B & C & D & $\mathbf{E}$ & $\mathbf{F}$ \\
\hline Family and Type & Cost & Height & Width & Area & Total Cost \\
\hline \multicolumn{6}{|c|}{ FL 1 Aluminum-Grooved (NZ): entrance } \\
\hline FL 1 Aluminum-Gr & 556.00 & 2200 & 200 & 0.44 & $\$ 244.64$ \\
\hline \multicolumn{6}{|c|}{ FL 1 Aluminum-Grooved (NZ): half } \\
\hline FL 1 Aluminum-Gr & 556.00 & 2400 & 400 & 0.96 & $\$ 533.76$ \\
\hline FL 1 Aluminum-Gr & 556.00 & 2400 & 400 & 0.96 & $\$ 533.76$ \\
\hline FL 1 Aluminum-Gr & 556.00 & 2400 & 400 & 0.96 & $\$ 533.76$ \\
\hline FL 1 Aluminum-Gr & 556.00 & 2400 & 400 & 0.96 & $\$ 533.76$ \\
\hline \multicolumn{6}{|c|}{ FL 1 Aluminum-Grooved (NZ): Longways 1} \\
\hline FL 1 Aluminum-Gr & 556.00 & 2400 & 800 & 1.92 & $\$ 1067.52$ \\
\hline \multicolumn{6}{|c|}{ FL 1 Aluminum-Grooved (NZ): Longways 3} \\
\hline FL 1 Aluminum-Gr & 556.00 & 400 & 2400 & 0.96 & $\$ 533.76$ \\
\hline \multicolumn{6}{|c|}{ FL 1 Aluminum-Grooved (NZ): Longways 4} \\
\hline FL 1 Aluminum-Gr & 556.00 & 400 & 700 & 0.28 & $\$ 155.68$ \\
\hline \multicolumn{6}{|c|}{ FL 1 Aluminum-Grooved (NZ): Slim Long } \\
\hline FL 1 Aluminum-Gr & 556.00 & 600 & 1500 & 0.9 & $\$ 500.40$ \\
\hline FL 1 Aluminum-Gr & 556.00 & 600 & 1500 & 0.9 & $\$ 500.40$ \\
\hline \multicolumn{6}{|c|}{ Sliding_Window_2_rails_4_leaves_-_KASTING: 4 Panel sliding door } \\
\hline Sliding_Window_2 & 476.00 & 2400 & 4500 & 10.8 & $\$ 5140.80$ \\
\hline Grand total: 11 & & & & & $\$ 10278.24$ \\
\hline
\end{tabular}


Figure 4.108 First Cost 4.5

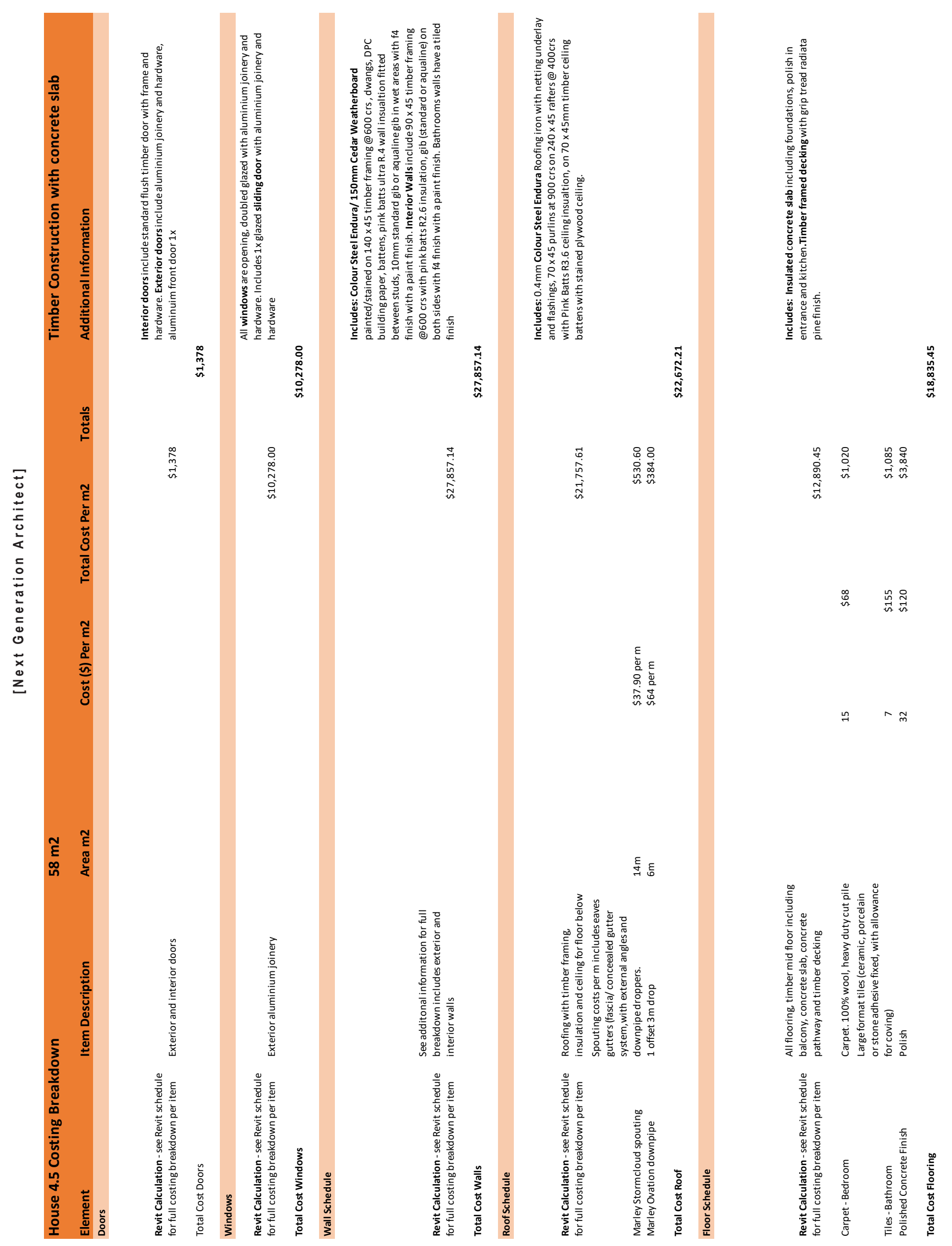




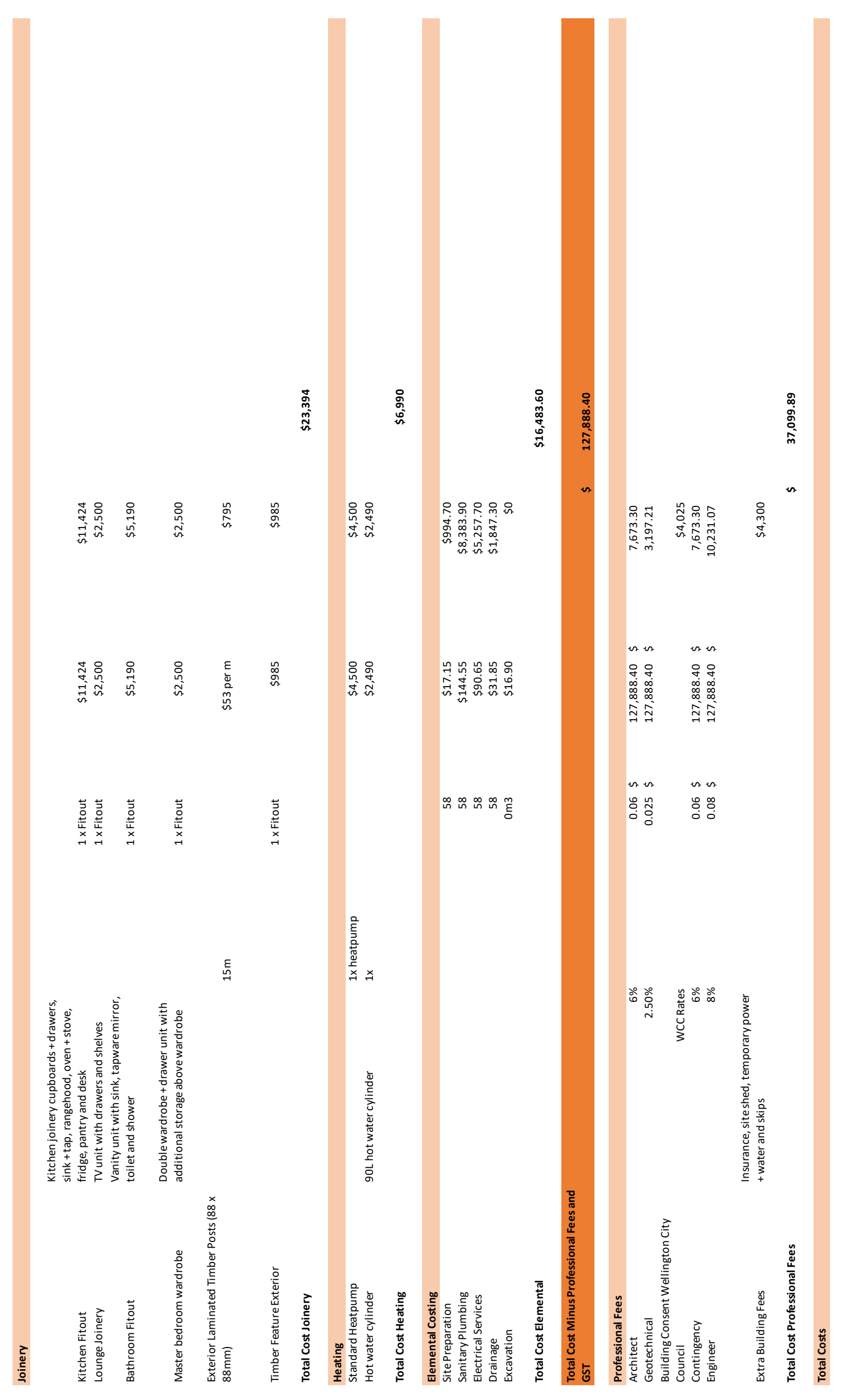

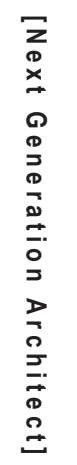


Figure 4.109 Lifecycle cost 4.5

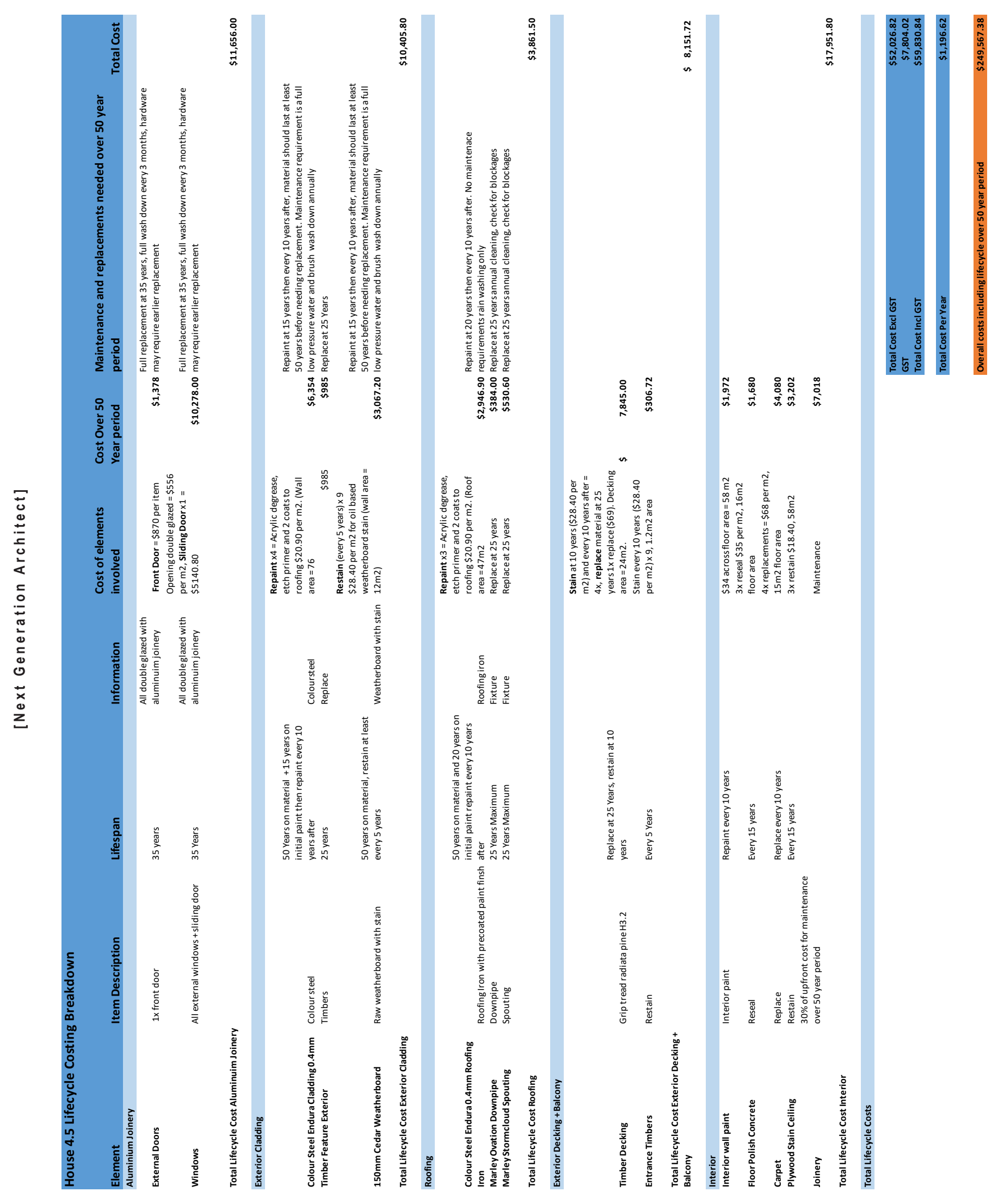




\begin{tabular}{|c|c|c|c|}
\hline \multicolumn{4}{|c|}{$<$ Wall Schedule $>$} \\
\hline A & B & C & D \\
\hline Family and Type & Cost & Area & Total Cost \\
\hline \multicolumn{4}{|l|}{ Basic Wall: Cedar } \\
\hline Basic Wall: Cedar & 480.20 & $3 \mathrm{~m}^{2}$ & $\$ 1249.66$ \\
\hline Basic Wall: Cedar & 480.20 & $4 \mathrm{~m}^{2}$ & $\$ 1893.35$ \\
\hline Basic Wall: Cedar & 480.20 & $6 \mathrm{~m}^{2}$ & $\$ 2719.61$ \\
\hline \multicolumn{4}{|c|}{ Basic Wall: Colour Steel + Interior lining + painting } \\
\hline Basic Wall: Colour & 237.40 & $13 \mathrm{~m}^{2}$ & $\$ 2980.05$ \\
\hline Basic Wall: Colour & 237.40 & $24 \mathrm{~m}^{2}$ & $\$ 5644.29$ \\
\hline Basic Wall: Colour & 237.40 & $12 \mathrm{~m}^{2}$ & $\$ 2795.96$ \\
\hline Basic Wall: Colour & 237.40 & $6 \mathrm{~m}^{2}$ & $\$ 1493.13$ \\
\hline Basic Wall: Colour & 237.40 & $9 \mathrm{~m}^{2}$ & $\$ 2152.29$ \\
\hline Basic Wall: Colour & 237.40 & $23 \mathrm{~m}^{2}$ & $\$ 5473.16$ \\
\hline Basic Wall: Colour & 237.40 & $11 \mathrm{~m}^{2}$ & $\$ 2527.61$ \\
\hline Basic Wall: Colour & 237.40 & $9 \mathrm{~m}^{2}$ & $\$ 2049.92$ \\
\hline Basic Wall: Colour & 237.40 & $7 \mathrm{~m}^{2}$ & $\$ 1661.69$ \\
\hline Basic Wall: Colour & 237.40 & $1 \mathrm{~m}^{2}$ & $\$ 154.17$ \\
\hline Basic Wall: Colour & 237.40 & $2 \mathrm{~m}^{2}$ & $\$ 429.41$ \\
\hline \multicolumn{4}{|c|}{ Basic Wall: Interior one side aqualine with tiles } \\
\hline Basic Wall: Interior & 289.80 & $9 \mathrm{~m}^{2}$ & $\$ 2707.69$ \\
\hline Basic Wall: Interior & 289.80 & $6 \mathrm{~m}^{2}$ & $\$ 1700.38$ \\
\hline Basic Wall: Interior & 289.80 & $9 \mathrm{~m}^{2}$ & $\$ 2707.69$ \\
\hline \multicolumn{4}{|c|}{ Curtain Wall: Balcony Balustrade Glazed } \\
\hline Curtain Wall: Balcon & 354.00 & $8 \mathrm{~m}^{2}$ & $\$ 2901.49$ \\
\hline \multicolumn{4}{|c|}{ Curtain Wall: Ext Glazing Irregular/structure required } \\
\hline Curtain Wall: Ext Gl & 722.80 & $2 \mathrm{~m}^{2}$ & $\$ 1252.66$ \\
\hline Curtain Wall: Ext GI & 722.80 & $2 \mathrm{~m}^{2}$ & $\$ 1468.50$ \\
\hline Curtain Wall: Ext GI & 722.80 & $2 \mathrm{~m}^{2}$ & $\$ 1387.26$ \\
\hline Curtain Wall: Ext GI & 722.80 & $1 \mathrm{~m}^{2}$ & $\$ 720.81$ \\
\hline Curtain Wall: Ext GI & 722.80 & $1 \mathrm{~m}^{2}$ & $\$ 720.54$ \\
\hline Curtain Wall: Ext GI & 722.80 & $1 \mathrm{~m}^{2}$ & $\$ 935.14$ \\
\hline Curtain Wall: Ext GI & 722.80 & $7 \mathrm{~m}^{2}$ & $\$ 5138.21$ \\
\hline Curtain Wall: Ext GI & 722.80 & $1 \mathrm{~m}^{2}$ & $\$ 883.91$ \\
\hline \multicolumn{4}{|c|}{ Curtain Wall: Exterior Glazing } \\
\hline \multicolumn{2}{|c|}{ Curtain Wall: Exterio 556.00} & $1 \mathrm{~m}^{2}$ & $\$ 755.12$ \\
\hline \multicolumn{2}{|c|}{ Curtain Wall: Exterio 556.00} & $2 \mathrm{~m}^{2}$ & $\$ 910.81$ \\
\hline \multicolumn{2}{|c|}{ Curtain Wall: Exterio 556.00} & $1 \mathrm{~m}^{2}$ & $\$ 772.13$ \\
\hline \multicolumn{3}{|l|}{ Grand total: 29} & $\$ 58186.62$ \\
\hline
\end{tabular}

\begin{tabular}{|c|c|c|c|}
\hline \multicolumn{4}{|c|}{$<$ Floor Schedule $>$} \\
\hline A & B & C & D \\
\hline Family and Type & Cost & Area & Total Cost \\
\hline \multicolumn{4}{|l|}{ Floor: Balcony } \\
\hline Floor: Balcony & 275.00 & $19 \mathrm{~m}^{2}$ & $\$ 5339.91$ \\
\hline \multicolumn{4}{|l|}{ Floor: Entrance Decking } \\
\hline Floor: Entrance Decking & 168.00 & $2 \mathrm{~m}^{2}$ & $\$ 336.00$ \\
\hline \multicolumn{4}{|c|}{ Floor: Timber Flooring + Insulation + Ply topping + subfloor framing } \\
\hline Floor: Timber Flooring + & 272.00 & $5 \mathrm{~m}^{2}$ & $\$ 1397.34$ \\
\hline Floor: Timber Flooring + & 272.00 & $29 \mathrm{~m}^{2}$ & $\$ 7868.97$ \\
\hline Floor: Timber Flooring + & 272.00 & $34 \mathrm{~m}^{2}$ & $\$ 9269.12$ \\
\hline Grand total: 5 & & & $\$ 24211.34$ \\
\hline
\end{tabular}

\begin{tabular}{|c|c|c|}
\hline \multicolumn{3}{|c|}{ <Door Schedule> } \\
\hline A & B & C \\
\hline Family and Type & Cost & Total Cost \\
\hline \multicolumn{3}{|c|}{ Ext Single Out-Aluminum-Grooved (NZ): Glazed Front Door } \\
\hline Ext Single Out-Alu & & $\$ 2040.00$ \\
\hline \multicolumn{3}{|c|}{ Int Single-Flush (NZ): $710 \times 1980$} \\
\hline Int Single-Flush (N & & $\$ 254.00$ \\
\hline Int Single-Flush (N & & $\$ 254.00$ \\
\hline Int Single-Flush (N & & $\$ 254.00$ \\
\hline Grand total: 4 & & $\$ 2802.00$ \\
\hline
\end{tabular}

\begin{tabular}{|c|c|c|c|}
\hline \multicolumn{4}{|c|}{$<$ Roof Schedule $>$} \\
\hline A & B & C & D \\
\hline Family and Type & Area & Cost & Total Cost \\
\hline \multicolumn{4}{|c|}{ Basic Roof: Module 1 Colour steel roof + posi struts + ceiling } \\
\hline Basic Roof: Modul & & 270.30 & $\$ 13395.85$ \\
\hline \multicolumn{4}{|c|}{ Basic Roof: Module 2 Colour steel roof + posi struts + ceiling } \\
\hline Basic Roof: Modul & & 282.30 & $\$ 1693.50$ \\
\hline \multicolumn{4}{|c|}{ Basic Roof: Module 3 Colour steel roof + posi struts + ceiling } \\
\hline Basic Roof: Modul & & 271.30 & $\$ 15484.44$ \\
\hline Grand total: 3 & & & $\$ 30573.80$ \\
\hline
\end{tabular}

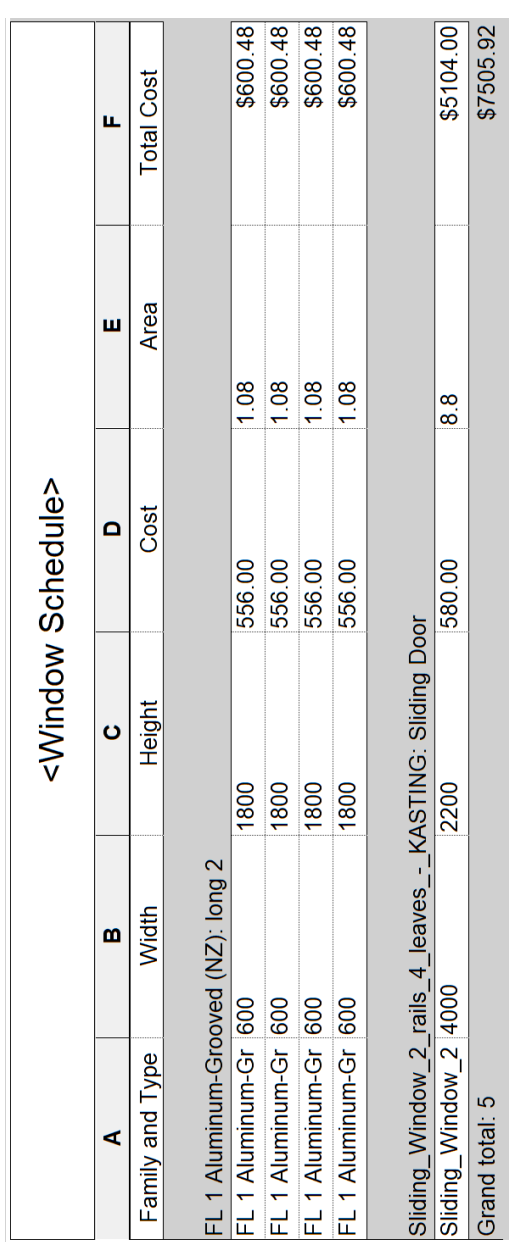



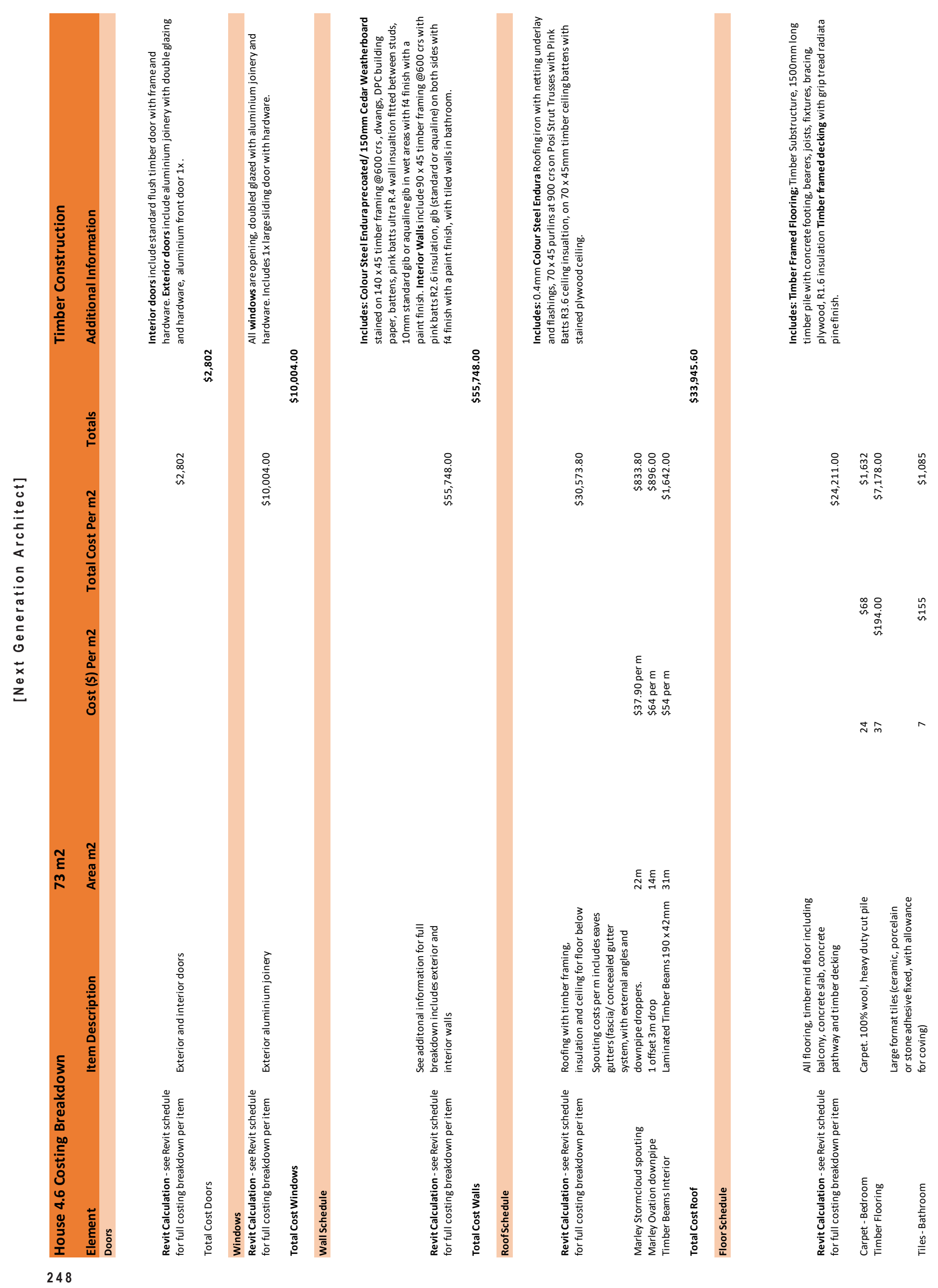

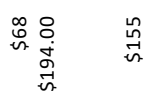
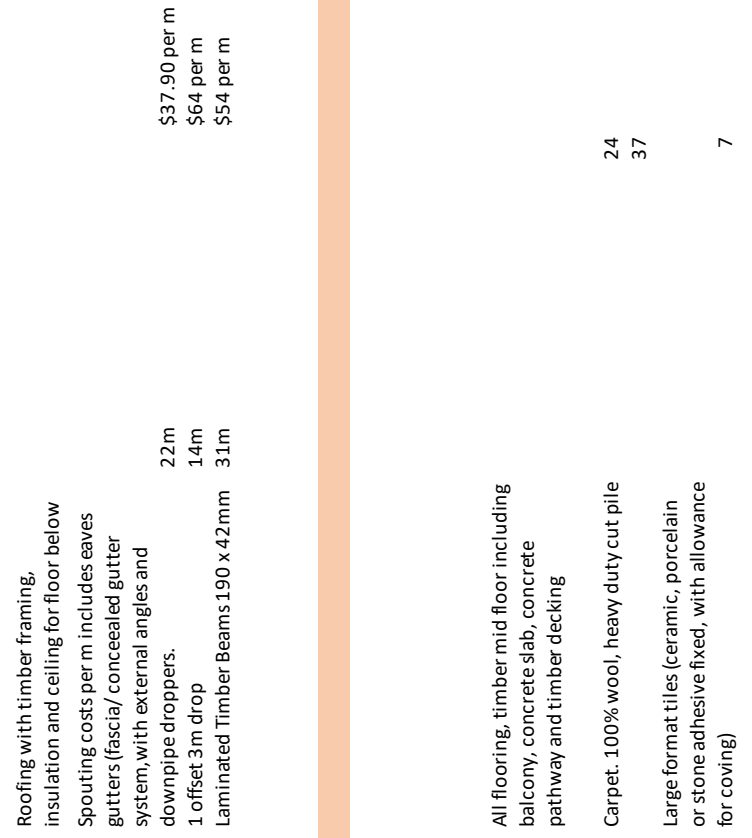

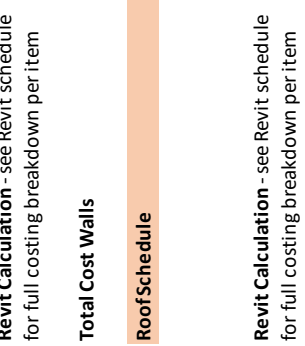
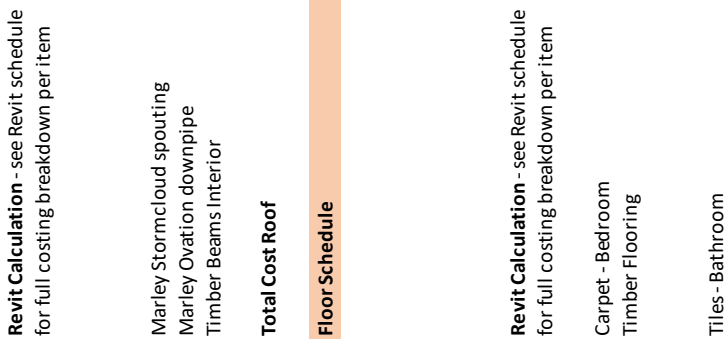

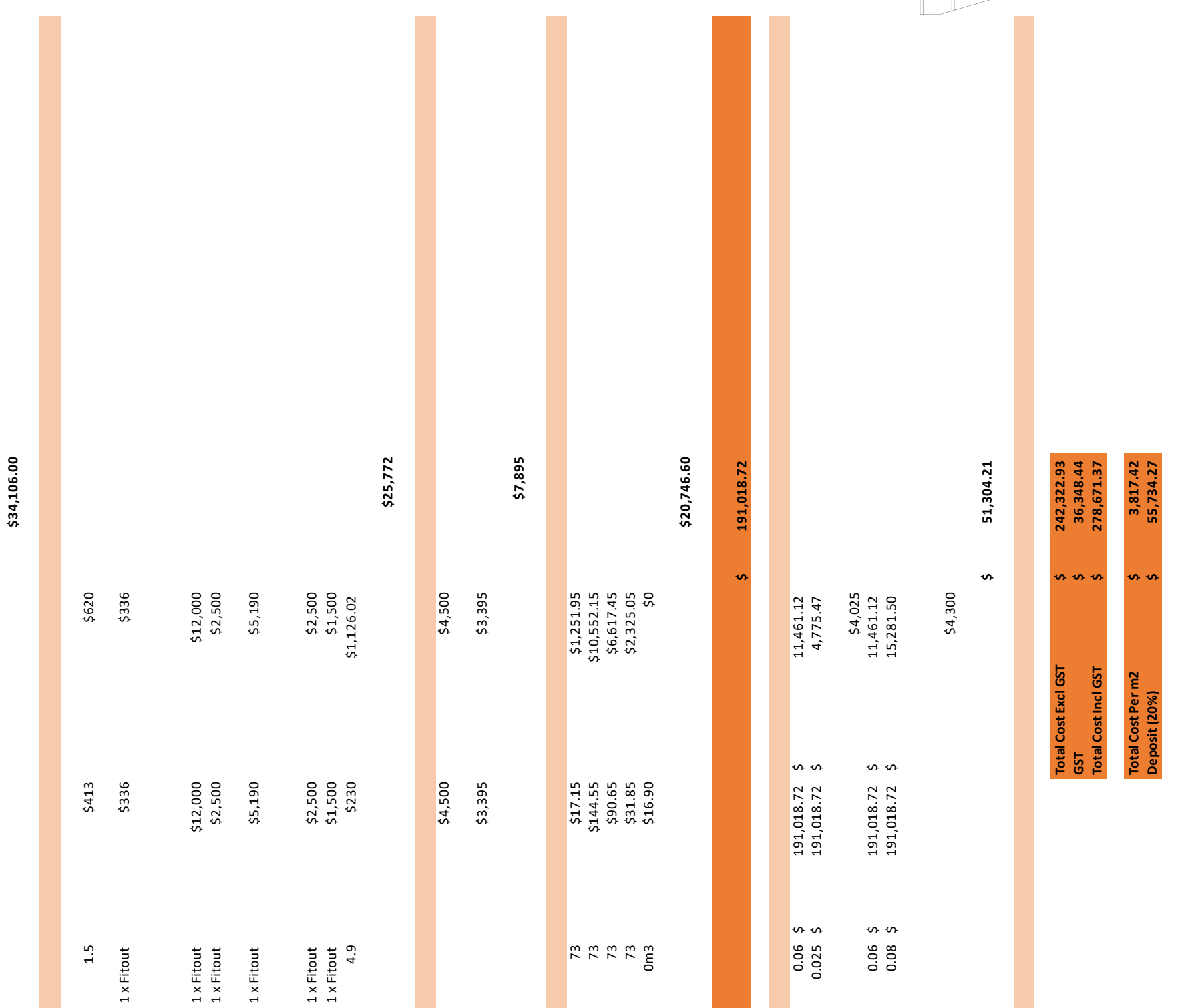

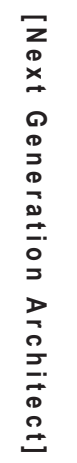

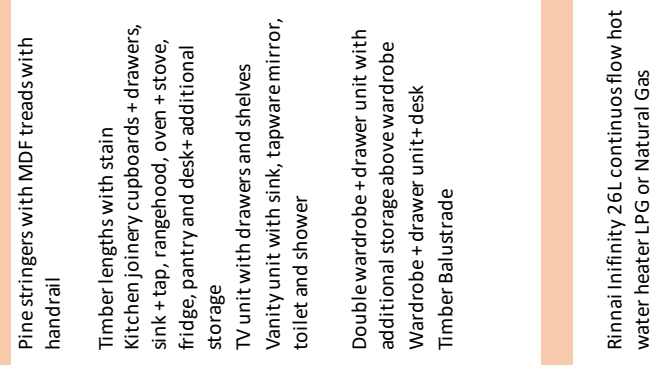

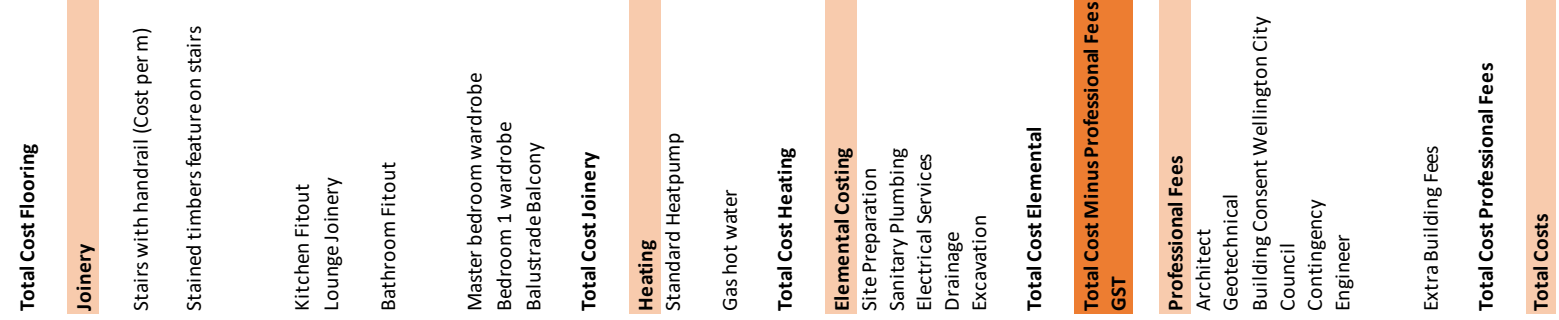




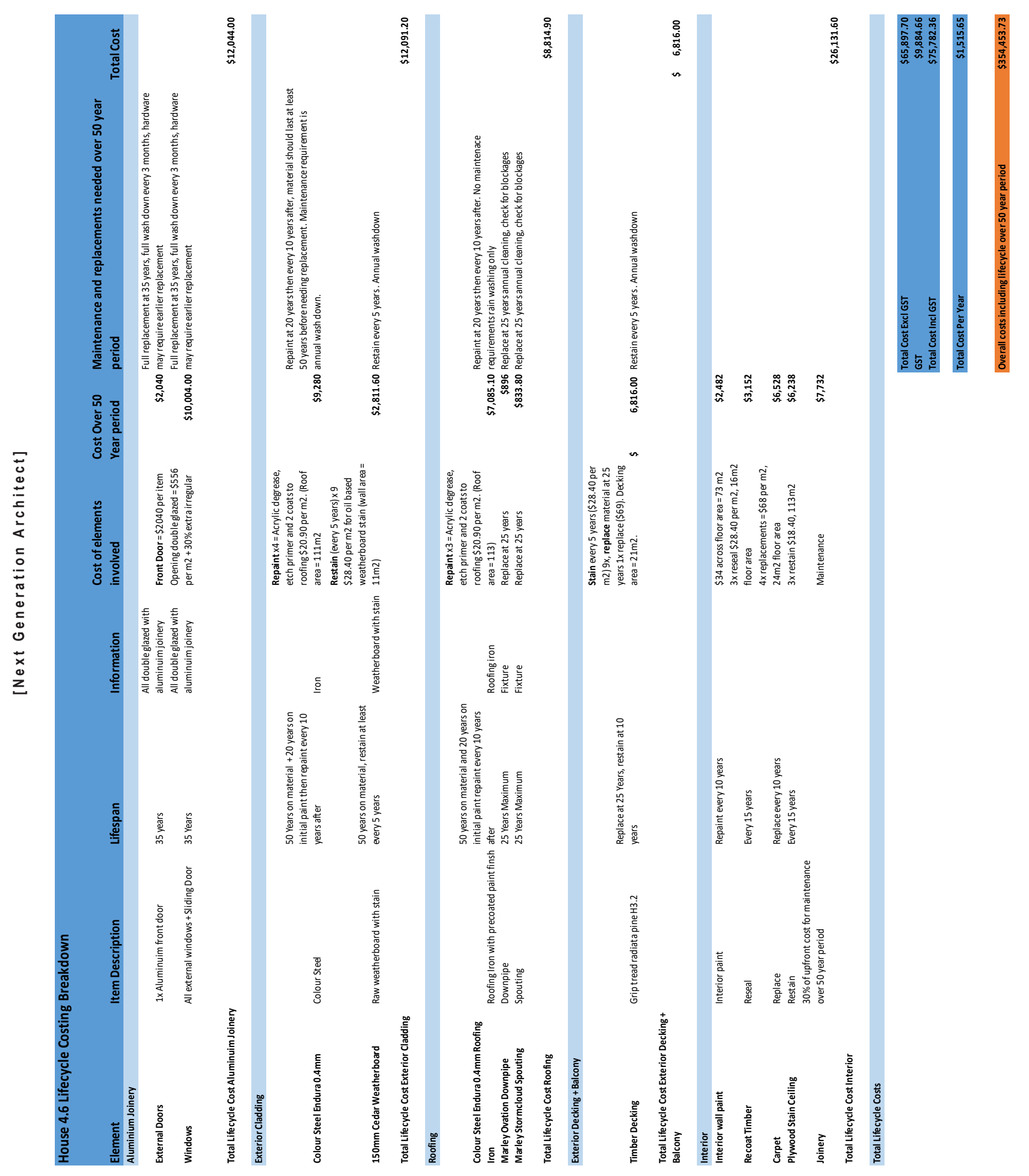




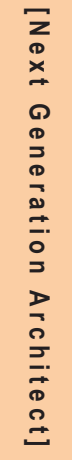

